\title{
A NOVEL REVERSE FLOW REACTOR COUPLING ENDOTHERMIC AND EXOTHERMIC REACTIONS
}

\author{
PROEFSCHRIFT
}

ter verkrijging van

de graad van doctor aan de Universiteit Twente, op gezag van de rector magnificus, prof.dr. F.A. van Vught, volgens besluit van het College voor Promoties in het openbaar te verdedigen op vrijdag 27 oktober 2000, te 16.45 uur.

door

\section{Martin van Sint Annaland}

geboren op 2 juni 1971

te Apeldoorn 
Dit proefschrift is goedgekeurd door de promotoren

prof.dr.ir. J.A.M. Kuipers

prof.dr.ir. W.P.M. van Swaaij 
aan mijn ouders 
Samenstelling promotiecommissie:

prof.dr. W.E. van der Linden, voorzitter

prof.dr.ir. J.A.M. Kuipers, promotor

prof.dr.ir. W.P.M. van Swaaij, promotor

prof.dr. M.P. Duduković

prof.dr.ir. A. Bliek

prof.dr.ir. L. Lefferts

prof.dr.ir. G.F. Versteeg

ir. M.J. van der Burgt, referent
Universiteit Twente

Universiteit Twente

Universiteit Twente

Washington University

Universiteit van Amsterdam

Universiteit Twente

Universiteit Twente

The research in this thesis was funded by the Netherlands Organization for Scientific Research (N.W.O.).

Cover by H.M.P. van Sint Annaland, M. van Sint Annaland

(C) October 2000 M. van Sint Annaland, Enschede, The Netherlands

No part of this book may be reproduced in any form by print, photoprint, microfilm or any other means without written permission from the author / publisher.

Niets uit deze uitgave mag worden verveelvoudigd en/of openbaar gemaakt door middel van druk, fotokopie, microfilm of op welke andere wijze dan ook zonder voorafgaande schriftelijke toestemming van de schrijver/ uitgever.

ISBN 90-36515009 


\section{Contents}

$\begin{array}{ll}\text { Summary } & 1\end{array}$

$\begin{array}{ll}\text { Samenvatting } & 5\end{array}$

1. General introduction 11

$\begin{array}{ll}\text { Abstract } & 12 \\ \text { I. } & 13\end{array}$

1. Introduction 13

1.1 Direct and indirect coupling of endothermic and exothermic reactions 13

1.2 Open-loop and closed-loop reverse flow processes 15

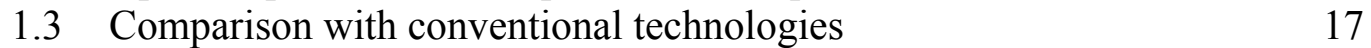

2. Reactor system 18

3. This thesis $\quad 22$

$\begin{array}{ll}\text { References } & 25\end{array}$

2. Irreversible endothermic reactions comparison of reactor configurations 29

$\begin{array}{ll}\text { Abstract } & 30\end{array}$

1. Introduction 31

2. Simulation models 34

2.1 The Dynamic Model and the High Switching Frequency Model 34

2.2 Model assumptions $\quad 35$

3. Design criteria 40

4. Sequential reactor configuration $\quad 42$

4.1 Overall energy balance $\quad 42$

4.2 Matching of Damköhler numbers 43

4.3 Zero differential creep velocity 48

5. Simultaneous reactor configuration 58

$\begin{array}{lll}5.1 \text { Co-current operation } & 59\end{array}$

$\begin{array}{lll}5.2 \text { Counter-current operation } & 61\end{array}$

5.2.1 Effect of switching of compartments 65

$\begin{array}{ll}\text { 6. Comparison of reactor configurations } & 67\end{array}$

$\begin{array}{ll}\text { 7. Summary and conclusions } & 71\end{array}$

$\begin{array}{ll}\text { Acknowledgements } & 72\end{array}$

$\begin{array}{ll}\text { Notation } & 73\end{array}$

$\begin{array}{ll}\text { References } & 75 \\ & 73\end{array}$

Appendix A - Maximum temperature in a reverse flow reactor 78 
3. Reversible endothermic reactions in the sequential reactor configuration 83

Abstract $\quad 84$

1. Introduction 85

2. Simulation model 86

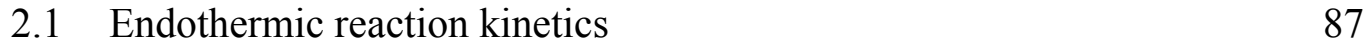

2.2 Exothermic reaction kinetics 89

3. Effect of reversible reactions 90

3.1 Effect of the inlet pressure 90

3.2 Effect of the thermodynamic equilibrium 93

4. Inactive sections 94

5. Less active sections 99

5.1 Effect of homogeneous propane combustion 105

6. Plateau temperature control 106

7. Summary and conclusions 108

Acknowledgements 109

$\begin{array}{ll}\text { Notation } & 109\end{array}$

References 113

Appendix A - Modelling of internal and external mass transfer limitations $\quad 114$

\section{Propane dehydrogenation reaction kinetics} over a monolithic platinum alumina catalyst 117

Abstract 118

1. Introduction 119

2. Experimental 126

2.1 Experimental set-up 126

2.2 Experimental procedure 132

2.2.1 Decrease of catalyst activity during a single experiment 133

2.2.2 Decrease of catalyst for repeated experiments 136

3. Experimental results 139

3.1 Propane dehydrogenation and propylene hydrogenation 140

3.2 Side-reactions during propane dehydrogenation and

3.2.1 Product selectivities $\quad 144$

$\begin{array}{lll}3.2 .1 & \text { Reaction rates } & 149\end{array}$

4. Derivation of rate equations 154

5. Discussion 159

5.1 Comparison of propane dehydrogenation reaction rate with literature 159

5.2 Hydrogen dependency 161

5.2.1 Number of free platinum surface sites $\quad 162$

5.3 Thermodynamics 165

6. Summary and conclusions 169

Acknowledgements 171

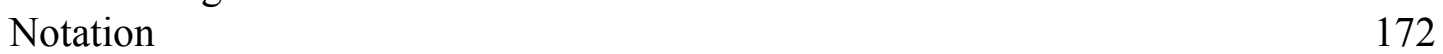

$\begin{array}{ll}\text { References } & 173\end{array}$ 
5. Reaction kinetics of coke formation during propane dehydrogenation over a monolithic platinum alumina catalyst

Abstract 178

1. Introduction 179

2. Experimental 181

2.1 Experimental set-up 181

2.2 Experimental results 184

3. Kinetic model 191

3.1 Model assumptions 191

3.2 Coke formation rate equation 195

4. Discussion 201

5. Summary and conclusions 204

Acknowledgements 205

Notation 205

References 207

Appendix A - Derivation of the coke formation rate equation 209

Appendix B - Solution of the coke formation rate equation
for short times on stream

6. Safety analysis of switching between reductive and oxidative conditions 213

Abstract 214

1. Introduction 215

2. Modelling 217

3. Simulation results 220

3.1 No premixing 220

3.2 Premixed feed 222

3.3 Premixing in the inlet section 223

4. Experimental 224

5. Experimental results 225

5.1 Premixed feed 225

5.2 Switching between pure propane and air as feed 227

$\begin{array}{ll}\text { 6. Conclusions } & 227\end{array}$

Acknowledgements 228

Notation 228

References 229

Appendix A - Validity of the one-dimensional plug flow model
with superimposed axial dispersion 232 
7. Reaction coupling reverse flow reactor - an experimental study 235

Abstract 236

1. Introduction 237

2. Experimental 239

2.1 Experimental set-up 239

2.2 Reverse flow reactor $\quad 242$

3. Experimental results and discussion 244

3.1 Propane and methane combustion in reverse flow 244

3.2 Propane dehydrogenation coupled with methane combustion
in reverse flow

3.2.1 Effect of back-conversion in a reactor entirely filled
with active catalyst

3.2.2 Effect of back-conversion in a reactor with inactive sections flanking the active catalyst 259

3.2.3 Qualitative comparison with model simulations 263

4. Summary and conclusions $\quad 265$

$\begin{array}{ll}\text { Acknowledgements } & 267\end{array}$

$\begin{array}{ll}\text { Notation } & 267\end{array}$

$\begin{array}{ll}\text { References } & 270\end{array}$

Appendix A - Estimation of heat losses in the experimental reverse flow reactor 271

Appendix B - Kinetics of the heterogeneous combustion of methane and propane over a monolithic platinum alumina catalyst 275

Appendix C - Kinetics of the combustion of carbonaceous deposits formed during propane dehydrogenation on a monolithic platinum alumina catalyst

\section{Optimisation of process conditions and} comparison with conventional processes $\quad 285$

$\begin{array}{ll}\text { Abstract } & 286\end{array}$

1. Introduction 287

2. Optimal axial temperature profiles for the propane dehydrogenation 288

2.1 Optimisation model 289

2.2 Optimisation results 293

2.2.1 Influence of time on stream 294

2.2.2 Influence of gas residence time 295

2.2.3 Influence of propane inlet mole fraction for
propane-hydrogen mixtures

$\begin{array}{ll}\text { 2.2.4 Comparison with isothermal conditions } & 297\end{array}$

$\begin{array}{ll}2.2 .5 \text { Conclusions } & 298\end{array}$

3. Comparison with conventional industrial processes 300

4. Conclusions 306

$\begin{array}{ll}\text { Acknowledgements } & 307\end{array}$

$\begin{array}{ll}\text { Notation } & 308\end{array}$

$\begin{array}{ll}\text { References } & 309\end{array}$

Dankwoord (Acknowledgements)

$\begin{array}{ll}\text { Levensloop } & 317\end{array}$ 


\section{Summary}

Highly endothermic heterogeneously catalysed gas phase reactions at high temperatures with possible rapid but reversible catalyst deactivation are an industrially important class of chemical transformations. Because of the energy supply at high temperatures and the necessary catalyst regeneration dedicated reactor technology is required. In this thesis a new reactor concept is proposed for this type of reactions, aiming for improved energy efficiency through multi-functionality. The reactor concept aims to combine the indirect coupling of energy necessary for endothermic reactions and energy released by exothermic reactions, without mixing of endothermic and exothermic reactants, with closed-loop adiabatic reverse flow operation. The periodic flow reversals while feeding the reactants without any preheating result in low temperatures at both reactor ends, while high temperatures prevail in the centre of the reactor, incorporating recuperative heat exchange inside the reactor. This reactor concept, called the 'Reaction Coupling Reverse Flow Reactor' (RCRFR), has been studied for the non-oxidative propane dehydrogenation to propylene and hydrogen over a monolithic platinum alumina catalyst, indirectly coupled with the exothermic combustion with air of coke, formed as a side-product during the dehydrogenation, and added hydrocarbon fuels for overall energy balance. In the RCRFR the propane dehydrogenation reaction, energy supply at high temperatures, catalyst regeneration by burning off the coke and recuperative heat exchange are all integrated in one apparatus. This reactor concept is particularly interesting for the propane dehydrogenation, because it allows operation at more severe reaction conditions with higher product yields in addition to savings on external heat exchange and catalyst regeneration equipment. In this thesis the reactor concept has been developed by a theoretical study focussing on how the RCRFR should be operated, by an experimental study on the kinetics of the main reactions, by testing the technical feasibility of the reactor concept in a small laboratory scale reactor aiming for a proof of principle and finally by assessing its economic potential via comparison with conventional processes for industrial propylene production by catalytic propane dehydrogenation.

Indirect coupling of reaction energies of endothermic and exothermic reactions in reverse flow can be accomplished in two basic reactor configurations, designated by the 'sequential' and 'simultaneous' reactor configuration. In the sequential reactor configuration the endothermic and exothermic reactants are fed discontinuously and sequentially to the same catalyst bed, where the bed acts as an energy repository delivering energy during the 
endothermic reaction phase and storing energy during the consecutive exothermic reaction phase, while concurrently regenerating the catalyst. In the simultaneous reactor configuration the endothermic and exothermic reactants are fed continuously and simultaneously to different catalyst beds exchanging energy, either in co-current or counter-current operation mode, and the endothermic and exothermic feed streams are periodically switched in order to counteract catalyst deactivation. The dynamic reactor behaviour has been studied via detailed numerical simulations and energy constraints to achieve an ignited cyclic steady state with maximum conversion for both the endothermic and exothermic process steps while satisfying a maximum temperature constraint have been examined for both reactor configurations. In an adiabatic reverse flow reactor the axial temperature profile results from the chosen operating conditions. It is shown that for a single first order exothermic reaction the maximum dimensionless temperature depends on a single dimensionless number and that for high throughputs the maximum temperature can only be controlled via the exothermic inlet concentration. If a maximum temperature constraint limits the production capacity, only in the sequential reactor configuration the endothermic inlet concentration can be optimised at high throughput and maximum energy efficiency without adjusting the gas velocities, by the choice of a switching scheme with inherently zero differential creep velocity and by using the ratio of the cycle times.

For reversible endothermic reactions the equilibrium can be shifted towards the reactants at the reactor outlet because of the low exit temperatures due to the reverse flow concept, resulting in significantly lower conversions. A new solution is introduced for the sequential reactor configuration to achieve both full equilibrium conversion and recuperative heat exchange while simultaneously avoiding too high temperatures. The proposed solution utilises the movement of the temperature fronts and employs less active catalyst sections installed at either end of the active catalyst bed and optionally completely inactive sections at the reactor ends, whereas simultaneous propane and methane combustion is used for energy supply and control of the plateau temperature.

To assess the potential of the RCRFR for the propane dehydrogenation, quantitative predictive reaction rate expressions were experimentally determined for the propane dehydrogenation, propylene hydrogenation and their most important side-reactions, viz. propane cracking, propane and propylene hydrogenolysis and coke formation, covering very wide concentration and temperature ranges over a partially deactivated monolithic platinum alumina catalyst, resembling the conditions occurring in a RCRFR. 
The reaction kinetics of the gas phase reactions over the monolithic platinum alumina catalyst were determined in a differentially operated reactor, where the same catalyst sample was used for many experiments consisting of reduction, (de)hydrogenation and temperature programmed oxidation (TPO), so that the measured reaction rates could be corrected for the decrease in catalytic activity caused by sintering and destruction of the most active sites or decrease in platinum dispersion. The propane dehydrogenation and propylene hydrogenation reaction rates typically decrease during the course of a single experiment due to the formation of carbonaceous deposits on the active sites and reach an asymptotic steady state after about half an hour. For the steady state reaction rates of the propane dehydrogenation and hydrogenolysis at higher temperatures, the propane cracking and propylene hydrogenolysis, reaction orders for hydrogen were observed corresponding to the reaction stoichiometry. However, the propane dehydrogenation and hydrogenolysis at lower temperatures and the propylene hydrogenation show a remarkable additional order in the hydrogen concentration. This finding was interpreted by assuming that the reactions can take place at two different surface sites: platinum and acid alumina surface sites. The reactions taking place at the platinum surface sites have a supplementary order in the hydrogen concentration, which could be explained by the influence of hydrogen on the number of free platinum surface sites not covered with carbonaceous deposits.

Coke formation reaction rates under propane dehydrogenation reaction conditions over a monolithic platinum alumina catalyst were determined separately in a thermogravimetric analyser (TGA) as a function of time on stream covering wide temperature and concentration ranges. For relatively short times on stream, especially at low temperatures and low propylene concentrations, a remarkable initial quadratic increase was observed in the coke content versus time with a high apparent propylene reaction order. After longer times on stream the coke formation rate decreases to a constant residual coke growth. The experimental data have been successfully described by a kinetic rate expression based on a mechanistic dual coke growth model.

Subsequently, the technical feasibility of the RCRFR concept was tested. Firstly, from a safety analysis on the effects of the possible formation of combustible gas mixtures of hydrocarbons and air upon switching between reductive and oxidative conditions due to mixing in the monolith channels and in the inlet sections it was concluded that intermediate 
flushing with inert gases can safely be omitted, provided that proper precautions are taken. A proof of principle of the RCRFR concept was demonstrated in a small laboratory scale reactor. Experiments coupling propane dehydrogenation with methane combustion in a reactor entirely filled with active catalyst showed the seriousness of conversion losses at the reactor end due to the low exit temperatures. Inactive sections installed at either end of the active catalyst section could effectively counteract this back-conversion, as predicted by detailed numerical simulations. The oxygen concentration during the methane combustion cycles needed to be reduced in order to avoid excessive temperatures due to local combustion of carbonaceous products in the wascoat deposited during the preceding propane dehydrogenation cycle.

On the basis of the experimentally determined reaction rates for the propane dehydrogenation, propylene hydrogenation and their most important side reactions including coke formation, optimal process conditions have been determined using Pontryagin's maximisation principle. For undiluted propane feeds at atmospheric pressure the propylene yield is optimal is at high reactor temperatures $\left(675-725^{\circ} \mathrm{C}\right)$ and short cycle times. Maximum propylene yields (50$60 \%$ ) are thus attained at high propane conversion (75-90\%) and relatively low propylene selectivity ( $\mathrm{ca} .70 \%$ ) with significant amounts of coke formed as by-product. Due to the increase of the coke formation rate as a function of time on stream the optimal axial temperature profile shifts from a strongly increasing temperature profile at the beginning of the dehydrogenation cycle to an almost uniform axial temperature profile after a few minutes on stream. The RCRFR is very well suited for these 'high intensity' operating conditions.

Finally, process characteristics of a process for propane dehydrogenation based on the new reactor concept were qualitatively compared with commercial propane dehydrogenation processes. The RCRFR process resembles the Houdry Catofin process, however, large savings on investments in expensive high-temperature heat exchange equipment in the reactor section can be achieved. Furthermore, the higher propane conversion reduces the propane recycle flow rate, decreasing compression costs (also because of higher reactor pressure) and reducing investments and operating costs in the gas separation units. Concluding, the economic potential of the RCRFR-process looks very promising, however, it still remains to be demonstrated experimentally that indeed high propane conversion and propylene (or olefin) yield can be achieved in the RCRFR with a high energy efficiency. 


\section{Samenvatting}

Sterk endotherme heterogeen gekatalyseerde gasfase reacties, die bij hoge temperatuur plaatsvinden met mogelijk snelle, maar reversibele katalystor deactivering, zijn een industrieel belangrijke klasse van chemische conversies. De energie-overdracht bij hoge temperaturen en de noodzakelijke katalysatorregeneratie vereist speciale reactortechnologie. In dit proefschrift wordt voor dit type reacties een nieuw reactorconcept voorgesteld, waarbij via multifunctionaliteit een verbeterde energie-efficiëntie wordt nagestreefd. In het reactorconcept wordt een indirecte koppeling tussen de energie die nodig is voor endotherme reacties en de energie die vrijkomt bij exotherme reacties, zonder menging van endotherme en exotherme reactanten, bewerkstelligd in een adiabatische 'omkeer'-reactor (reverse flow reactor). In een omkeer-reactor wordt periodiek de gasstroomrichting door het katalysatorbed omgekeerd, terwijl de reactanten zonder voorverwarming gevoed worden. Deze operatiewijze resulteert in lage temperaturen aan beide reactoruiteinden en hoge temperaturen in het midden van de reactor, waarmee regeneratieve warmtewisseling in de reactor geïntegreerd wordt. Dit reactorconcept, 'Reaction Coupling Reverse Flow Reactor' (RCRFR) genoemd, is bestudeerd voor de propaan dehydrogenering tot propeen en waterstof over een platina-alumina monolietkatalysator, waarbij de endotherme propaan dehydrogenering indirect gekoppeld wordt aan de exotherme verbranding van koolstofproducten, die tijdens de dehydrogenering op het katalystormateriaal worden afgezet, en extra brandstof om in de totale energiebehoefte te voorzien. In de RCRFR wordt de propaandehydrogenering, energie-overdracht bij hoge temperaturen, katalysatorregeneratie middels het afbranden van de koolstofproducten en regeneratieve warmtewisseling volledig geïntegreerd in één apparaat. Dit reactorconcept is vooral aantrekkelijk voor de katalytische propaandehydrogenering, aangezien naast besparingen op externe apparatuur voor warmtewisseling en katalysatorregeneratie de operatie extremere condities toelaat, waarbij hogere productopbrengsten gerealiseerd kunnen worden. In dit proefschrift wordt het reactorconcept ontwikkeld via een theoretische studie m.b.t. hoe de RCRFR het beste uitgevoerd en bedreven kan worden, met experimenten om de kinetiek van de belangrijkste reacties vast te stellen, middels het testen van de technische haalbaarheid van het reactorconcept in een kleine RCRFR-reactor op laboratorium-schaal teneinde het reactorprincipe aan te tonen, en tenslotte middels het evalueren van het economisch potentieel via het vergelijken met conventionele processen voor industriële propeenproductie via katalytische propaandehydrogenering. 
Indirecte koppeling van reactie-energiën van de endotherme en exotherme reacties in een omkeer-reactor kan gerealiseerd worden in twee basis reactorconfiguraties, aangegeven met de 'sequentiële' en 'simultane' reactorconfiguratie. In de sequentiële reactorconfiguratie worden de endotherme en exotherme reactanten discontinu en achtereenvolgens gevoed aan hetzelfde katalysatorbed, waarbij het katalysatormateriaal tevens dienst doet als medium voor energie-opslag, dat energie afgeeft tijdens de endotherme reactiefase en energie opslaat tijdens de daaropvolgende exotherme reactiefase, waarbij tevens het katalysatormateriaal geregenereerd wordt. In de simultane reactorconfiguratie worden de reactanten continu en tegelijkertijd gevoed aan verschillende katalysatorbedden, die energie uitwisselen, ofwel in meestroom of in tegenstroom contact. Hierbij worden periodiek de voedingsstromen omgewisseld om katalysatordeactivering ongedaan te maken. Het dynamische reactorgedrag is bestudeerd met gedetailleerde numerieke simulaties en voor beide reactorconfiguraties zijn randvoorwaarden aangaande de energiehuishouding opgesteld om een cyclisch stationaire toestand te bereiken met maximale conversie voor zowel de endotherme als de exotherme processtap, terwijl tegelijkertijd aan een maximum temperatuur randvoorwaarde voldaan wordt. In een adiabatische omkeer-reactor is het axiale temperatuurprofiel een gevolg van de gekozen operatiecondities. Er is afgeleid dat voor een enkele eerste orde exotherme reactie de maximale dimensieloze temperatuur slechts afhangt van een enkel dimensieloos kental en dat voor hoge debieten de maximum temperatuur alleen ingesteld kan worden met de exotherme ingangsconcentratie. Bij een beperkende maximum grenswaarde voor de katalysatortemperatuur kan alleen in de sequentiële reactorconfiguratie de endotherme ingangsconcentratie geoptimaliseerd worden bij hoge debieten en maximale energieefficiëntie zonder de gassnelheden aan te passen, via de keuze van een geschikt schakelschema en de verhouding van de cycletijden.

Voor reversibele endotherme reacties kan het evenwicht naar de kant van de reactanten verschoven worden aan het uiteinde van de reactor als gevolg van de lage uitgangstemperaturen in de omkeerreactor, wat in een aanzienlijk conversieverlies kan resulteren. Een nieuwe oplossing wordt geïntroduceerd voor de sequentiële reactorconfiguratie om zowel volledige evenwichtsconversie als regeneratieve warmtewisseling te realiseren, waarbij tevens te hoge temperaturen voorkomen kan worden. De voorgestelde oplossing maakt gebruik van het opschuiven van de temperatuurfronten en bestaat uit het plaatsen van minder actieve katalysatorsecties aan beide zijden van het actieve katalysatorbed en eventueel volledig inactieve secties aan beide reactoruiteinden, waarbij 
gelijktijdige verbranding van propaan en methaan gebruikt wordt om de energie te leveren en de plateau-temperatuur te regelen.

Om de mogelijkheden van de RCRFR voor propaandehydrogenering te kunnen bestuderen zijn experimenteel reactiesnelheidsvergelijkingen bepaald voor de propaandehydrogenering, propeenhydrogenering en de belangrijkste nevenreacties, zoals het kraken van propaan en de hydrogenolyse van propaan en propeen en cokesvorming, die de reactiesnelheden kwantitatief over een groot concentratie- en temperatuurbereik kunnen beschrijven voor een gedeeltelijk gedeactiveerde platina-alumina monoliet-katalysator, condities die ook in de RCRFR kunnen voorkomen.

De reactiekinetiek van de gasfase reacties is bepaald over de platina-alumina monolietkatalyator in een differentieel bedreven reactor, waarbij steeds hetzelfde katalysator-monster gebruikt werd voor vele experimenten, die uit achtereenvolgens een reductiestap, een (de)hydrogeneringsstap en een regeneratiestap (TPO) bestonden. Zodoende konden de gemeten reactiesnelheden gecorrigeerd worden voor de afname in katalytische activiteit tengevolge van sintering of beschadiging van de meest actieve plaatsen of een verlies van platina dispersie. De propaandehydrogenerings- en propeenhydrogeneringsreactiesnelheden nemen ook af gedurende een enkel experiment door de afzetting van koolstofproducten op de actieve plaatsen aan het oppervlak, maar bereiken na ongeveer een half uur een asymptotische stationaire waarde. Voor de quasi-stationaire reactiesnelheden van de propaandehydrogenering en -hydrogenolyse bij hogere temperaturen, het kraken van propaan en de hydrogenolyse van propeen, werd een reactie-orde voor waterstof gevonden overeenkomstig met de reactiestoïchiometrie. Evenwel, de propaandehydrogenering en -hydrogenolyse bij lagere temperaturen en de propeenhydrogenering vertonen een opvallende extra orde in de waterstofconcentratie. Dit werd geïnterpreteerd door aan te nemen dat de reacties op twee verschillende plaatsen aan het oppervlak kunnen plaatsvinden, te weten de platina- en de zure alumina-plaatsen, waarbij de reacties die zich op de platina-plaatsen afspelen een extra orde in de waterstofconcentratie hebben, wat verklaard kan worden door de invloed van waterstof op het aantal vrije platina-oppervlakteplaatsen, die niet met koolstofafzettingen bedekt zijn.

Vormingssnelheden van cokes onder propaandehydrogeneringscondities op een platinaalumina monoliet-katalysator werden afzonderlijk bepaald middels thermogravimetrische analyse (TGA) als een functie van de procestijd voor wederom een groot concentratie- en temperatuurbereik. Voor relatief korte procestijden, vooral bij lage temperaturen en lage 
propeenconcentraties, werd voor de cokesconcentratie een opvallende initiële kwadratische toename in de tijd waargenomen met een hoge schijnbare orde in de propeenconcentratie. Voor langere procestijden nam de cokesvormingssnelheid af tot een constante lage restsnelheid. De experimentele data kon goed beschreven worden met een kinetiekvergelijking gebaseerd op een mechanistisch model voor de cokesvorming uitgaande van twee typen cokes.

Vervolgens is de technische haalbaarheid van het RCRFR concept getoetst. Eerst is op basis van een veiligheidsanalyse over de effecten van de mogelijke vorming van explosieve gasmengsels van koolwaterstoffen in lucht, die bij het schakelen tussen reductieve en oxidatieve condities als gevolg van menging in de monolietkanaaltjes of in de inlaatsecties kunnen ontstaan, geconcludeerd dat tussentijds spoelen met inerte gassen niet is vereist, als passende maatregelen getroffen worden. Het principe van de RCRFR is gedemonstreerd in een kleine laboratorium-reactor. Experimenten waarbij de propaan-dehydrogenering gekoppeld werd aan de methaanverbranding in een reactor volledig gevuld met actief katalysatormateriaal toonden aan dat aanzienlijke conversieverliezen aan het uiteinde van de reactor optreden vanwege de lage uitgangstemperaturen. Met inactieve secties geplaatst aan beide zijden van het actieve katalystorbed kon het conversieverlies effectief tegengegaan worden, overeenkomstig de resultaten van gedetailleerde numerieke simulaties. De zuurstofconcentratie tijdens de methaanverbrandingscycli moest verlaagd worden om te hoge temperaturen te voorkomen als gevolge van de locale verbranding van koolstofproducten in de washcoat die er tijdens de voorafgaande dehydrogenering zijn afgezet.

Op basis van de experimenteel bepaalde reactiesnelheden voor de propaandehydrogenering, propeenhydrogenering en de belangrijkste nevenreacties inclusief cokesvorming, zijn optimale procescondities bepaald met behulp van Pontryagin's maximalisatie-principe. Voor een onverdunde propaanvoeding bij atmospherische druk blijkt dat de propeenopbrengst optimaal is bij hoge reactortemperaturen $\left(675-725^{\circ} \mathrm{C}\right)$ en korte cycletijden. De maximale propeenopbrengst $(50-60 \%)$ wordt aldus bereikt bij hoge propaanconversie $(75-90 \%)$ en relatief lage propeenselectiviteit (ongeveer 70\%), waarbij een significante hoeveelheid cokes gevormd wordt als bijproduct. Tengevolge van de toename in de cokesvormingssnelheid als functie van de procestijd verandert het optimale axiale temperatuurprofiel van een sterk oplopend temperatuurprofiel aan het begin van de dehydrogeneringscyclus tot een bijna 
uniform temperatuurprofiel na een paar minuten. De RCRFR is uitstekend geschikt voor deze 'hoge-intensiteit' bedrijfscondities.

Tenslotte zijn de proceskenmerken van een proces voor propaandehydrogenering gebaseerd op het nieuwe reactorconcept kwalitatief vergeleken met commerciële propaan dehydrogeneringsprocessen. Het RCRFR-proces lijkt sterk op het Houdry Catofin proces, maar voor het RCRFR-proces kunnen grote besparingen op dure hoge-temperatuur warmtewisselaars in de reactorsectie gerealiseerd worden. Vervolgens wordt door de hogere propaanconversie de recycle-stroom verkleind, wat de compressiekosten reduceert (ook tengevolge van de hogere reactordruk) en tevens de investeringskosten en bedrijfskosten van de gasscheidingssectie verlagen. De economische mogelijkheden van het RCRFR-proces lijken veelbelovend, maar eerst moet experimenteel aangetoond worden dat inderdaad hoge propaanconversies en propeenopbrengst (of olefine-opbrengst) gerealiseerd kunnen worden in de RCRFR met hoge energie-efficiëntie. 
CHAPTER 1

GENERAL INTRODUCTION 


\begin{abstract}
Highly endothermic heterogeneously catalysed gas phase reactions at high temperatures with possible rapid but reversible catalyst deactivation are an industrially important class of chemical transformations and require dedicated reactor technology because of the energy supply at high temperatures and necessary catalyst regeneration. In this thesis a new reactor concept is proposed for this type of reactions aiming for improved energy efficiency through multi-functionality. The reactor concept aims to achieve an indirect coupling of energy necessary for endothermic reactions and energy released by exothermic reactions without mixing of endothermic and exothermic reactants, in closed-loop adiabatic reverse flow operation, i.e. incorporating recuperative heat exchange inside the reactor using periodic gas flow reversals. In this chapter this new reactor concept is introduced and qualitatively compared with conventional technologies. Subsequently, it is indicated that the reactor concept is especially interesting for the non-oxidative propane dehydrogenation indirectly coupled with fuel combustion over a platinum based monolithic catalyst. Finally, the objective of the work is formulated and the outline of this thesis is presented.
\end{abstract}




\section{Introduction}

Highly endothermic heterogeneously catalysed gas phase reactions at high temperatures with possible rapid but reversible catalyst deactivation are an industrially important class of chemical transformations. Examples of large industrial processes based on this type of reactions are the dehydrogenation of lower paraffins, the dehydrogenation of ethylbenzene and the production of synthesis gas. Processes for highly endothermic reactions with catalyst deactivation require dedicated reactor technology. The reactors differ mainly in the method of energy supply for the endothermic reactions and the method of catalyst regeneration, predominantly determined by the catalyst properties and the rate of catalyst deactivation. In this work a new reactor concept is proposed for this type of reactions aiming for improved energy efficiency through multi-functionality.

\subsection{Direct and indirect coupling of endothermic and exothermic reactions}

Mixing of the endothermic reactants with exothermic reactants or other components, designated as 'direct coupling' by Kulkarni (1996a), can eliminate the need for heat exchange and it can strongly reduce or completely avoid catalyst deactivation, at the cost of strongly diluting the endothermic products and possibly decreasing the product selectivities due to side-reactions between the endothermic and exothermic reactants and products. Blanks et al. (1990) tested a reactor with direct coupling of endothermic and exothermic reactions in a pilot plant for synthesis gas production by partial oxidation of natural gas combining the highly endothermic steam reforming of natural gas with the exothermic methane combustion. Problems of coke formation were effectively eliminated in this bi-directional adiabatic synthesis gas generator. The direct coupling of the ethylbenzene dehydrogenation with hot steam added concurrently at a downstream location and the direct coupling of the $\mathrm{NO}_{x}$-SCR (selective catalytic reduction) with side-stream ammonia introduction were studied by Snyder and Subramaniam $(1994,1997)$. Also the oxidative propane dehydrogenation is a good example of the direct coupling of endothermic and exothermic reactants. The reaction enthalpies of the propane dehydrogenation and hydrogen combustion are effectively coupled, resulting in a net slightly exothermic reaction and additionally allowing surpassing thermodynamic constraints (e.g. Cavani and Trifirò, 1995). 
In this work it is assumed that strongly diluting the endothermic reactants with inert components or mixing with exothermic reactants is undesired, so that heat supply by feeding preheated gas is insufficient to maintain the reactor temperature at the desired level to obtain the specified conversion and that a separate catalyst regeneration is required.

Processes based on 'indirect coupling' that are currently being applied in industry for highly endothermic reactions with catalyst deactivation are based on interconnected fluidised bed or packed or moving bed technologies.

If the catalyst is sufficiently resistant against attrition and if inevitable catalyst losses can be tolerated, interconnected fluidised beds can be used with their excellent heat transfer characteristics, like the FCC process. Catalyst material is continuously circulated between a reactor in which the endothermic reactions take place deactivating the catalyst and a second reactor where the catalyst is regenerated and reheated. The energy needed for the endothermic reactions is supplied via catalyst circulation. The heat released during the usually exothermic regeneration can effectively be used for the endothermic process step.

Instead of a costly catalyst transport to an external regenerator, catalyst regeneration can be accomplished in situ by periodic alternation of the gas phase flowing through the catalyst. Highly endothermic reactions require either a series of adiabatic packed bed reactors with intermediate heaters or a non-adiabatic packed bed reactor. If the endothermic reactions take place at high operating temperatures expensive high temperature heat exchange equipment is required. Furthermore, because of poor heat transfer characteristics in packed beds and the relatively small driving force for heat transfer because of the high temperatures, large heat exchanging areas are required to achieve the desired heat exchange in a non-adiabatic fixed bed reactor, as e.g. in the direct-fired non-adiabatic packed bed reactor with side-wall burners.

As an alternative for using expensive high temperature external or internal heat exchange equipment, energy for the endothermic reactions can also be delivered in situ to the fixed catalyst bed during the regeneration phase. Thus the catalyst bed acts as an energy repository. During the endothermic reaction phase energy is withdrawn from the fixed catalyst bed deactivating the catalyst both 'thermally' and catalytically and during the regeneration phase the energy is restored to the bed while reactivating the catalyst.

The catalyst regeneration can be carried out either using a heat-exchanging medium heated in a separate furnace or heat exchange equipment or by carrying out exothermic reactions in the fixed catalyst bed. A well-known traditional process applied for indirect coupling of 
endothermic and exothermic reactions in the same catalyst bed is the Catofin Houdry process (e.g. Meyers, 1997). Strongly endothermic catalytic paraffin dehydrogenation is periodically alternated with a heating cycle feeding hot air. In the conventional process the hydrocarbons and air are fed at the same reactor end. Recently it has been shown, however, that higher conversions and improved energy efficiencies can be obtained with counter-current sequential feeding of the paraffins and air, due to a more favourable axial temperature profile (Ercan and Gartside, 1996). For obvious reasons, indirect coupling of endothermic and exothermic reactions is only economically interesting, if the products of the endothermic reaction phase are the products of interest.

An example of a process in which the energy for the endothermic reactions is supplied by heating the catalyst bed by a heat exchanging medium is the ethylbenzene dehydrogenation process over an iron oxide catalyst as studied by Heggs (1986a) and Heggs and Abdullah (1986b). The ethylbenzene/steam feed is periodically alternated with high temperature steam to reheat the catalyst bed. In their reactor set-up the ethylbenzene/steam feed was fed countercurrently to the hot steam. The indirect coupling of the dehydrogenation of ethylbenzene and hot steam as a regenerating medium in counter-current operation has also been modelled by Haynes et al. (1992). Kulkarni (1996a) and Kulkarni and Dudukovic (1996b, 1997) performed model simulations for the RE-GAS-process for synthesis gas production based on indirect coupling of endothermic steam reforming and exothermic hydrocarbon combustion with periodic flow reversals: the endothermic reactants were fed at one side of the reactor and the exothermic reactants at the other side.

\subsection{Open-loop and closed-loop reverse flow processes}

To minimise energy requirements the reactants are heated by cooling the products. In conventional processes this is achieved in an external heat exchanger. For fixed catalyst beds recuperative heat exchange can also be accomplished with a forced dynamic operation by periodic reversal of the gas flow direction through the catalyst bed making use of the large thermal capacity of the catalyst bed compared to the gas phase, as firstly proposed by Cottrell (1938). However, only since the seventies the application of forced unsteady-state operation by periodic gas flow reversals has been studied for exothermic reactions in large industrial processes, initiated by the pioneering work of especially Russian researchers (e.g. Boreskov et al., 1979, 1982; Boreskov and Matros, 1983). For exothermic reactions the reverse flow 
reactor allows an autothermal operation with high temperatures in the centre of the reactor while maintaining low temperatures at the reactor inlet and outlet. Integration of recuperative heat exchange in the reactor by periodic flow reversals, referred to as 'closed-loop' reverse flow operation by Matros and Bunimovich (1996), has been studied extensively for exothermic reactions. Most processes for endothermic reactions, although operated in reverse flow, do not recover the energy of the product gas for preheating the inlet gas inside the catalyst bed, but in an external heat exchanger ('open-loop' reverse flow operation). Furthermore, for optimal energy efficiency recuperative heat exchange should be achieved for both the endothermic and exothermic reaction phases. Only very recently Frauhammer et al. (1999) proposed an indirect closed-loop reverse flow reactor coupling methane steam reforming and methane combustion.

In this work the term 'closed-loop' refers to the energy efficiency of the process, i.e. a low average temperature difference between the gas inlet and outlet, in contrast to its mass transfer analogy in for example the Simulated Moving-Bed Chromatography reactor (e.g. Dünnebier et al., 1997) or the pressure swing reactor (e.g. Alpay et al., 1993). Additionally, for some processes both mass and energy efficiencies are important, as for example for the (modified) steam iron process for hydrogen production from industrial reducing waste gases, as studied by Seiler and Emig (1997) with model simulations. The steam iron process consists of consecutive cycles of exothermic reduction of an iron oxide $\left(\mathrm{Fe}_{3} \mathrm{O}_{4}\right)$ by synthesis gas and subsequent endothermic reoxidation of the reduced iron oxide $(\mathrm{FeO})$ with steam obtaining hydrogen. Furthermore, the concept of reduction-oxidation cycling in a fixed bed reactor with periodic flow reversals is also very interesting for selective catalytic oxidation processes. Firstly, in this process air can be used as an indirect oxidiser without diluting the product stream with nitrogen rendering a costly separate nitrogen-oxygen separation redundant. This could be a very interesting benefit in for example synthesis gas production via CPO (catalytic partial oxidation) of methane via reduction-oxidation cycling in a fixed bed filled with e.g. $\mathrm{Cu} / \mathrm{CuO}_{\mathrm{x}}$. Furthermore, using the lattice oxygen as the actual oxidiser the product selectivity might be enhanced, which might open up possibilities for e.g. oxidative propane dehydrogenation. 


\subsection{Comparison with conventional technologies}

A qualitative comparison of the benefits and drawbacks of a closed-loop reverse flow reactor with indirect coupling of endothermic and exothermic reactions, called the Reaction Coupling Reverse Flow Reactor (RCRFR), compared to the conventional packed bed and interconnected fluidised bed technologies for endothermic reactions is summarised in Table 1. A moderately endothermic heterogeneously catalysed reaction at relatively low temperatures with a relatively low catalyst deactivation rate is probably preferably carried out in a conventional adiabatic or non-adiabatic packed bed reactor. For highly endothermic reactions at high temperatures with very rapid reversible catalyst deactivation an interconnected fluidised bed system can be beneficial, provided that the activity and selectivity properties of

Table 1. Qualitative comparison of the 'closed-loop' reverse flow process with indirect coupling of endothermic and exothermic reactions with the conventional adiabatic packed bed and the interconnected fluidised beds processes.

\begin{tabular}{|c|c|c|c|c|}
\hline \multicolumn{2}{|c|}{ reactor selection criteria } & PBR & IFBR & RCRFR \\
\hline $\begin{array}{l}\text { reaction } \\
\text { conditions }\end{array}$ & $\begin{array}{c}\text { reaction endothermicity } \\
\text { temperature } \\
\text { attrition resistance } \\
\text { catalyst deactivation rate }\end{array}$ & $\begin{array}{l}\text { low } \\
\text { low } \\
\text { low } \\
\text { low }\end{array}$ & $\begin{array}{l}\text { moderate-very high } \\
\text { high } \\
\text { high } \\
\text { moderate-very high }\end{array}$ & $\begin{array}{c}\text { moderate- } \\
\text { high } \\
\text { high } \\
\text { low- } \\
\text { moderate }\end{array}$ \\
\hline $\begin{array}{l}\text { process } \\
\text { control } \\
\end{array}$ & $\begin{array}{c}\text { temperature control } \\
\text { solids handling }\end{array}$ & $\begin{array}{c}- \\
+/{ }^{1} \\
\end{array}$ & $\begin{array}{l}+ \\
- \\
\end{array}$ & $\begin{array}{c}+/- \\
+\end{array}$ \\
\hline $\begin{array}{l}\text { development } \\
\text { costs }\end{array}$ & $\begin{array}{l}\text { process knowledge } \\
\text { catalyst development }\end{array}$ & $\begin{array}{l}+ \\
+ \\
+\end{array}$ & $\begin{array}{l}+ \\
- \\
\end{array}$ & $\begin{array}{l}-- \\
+/-\end{array}$ \\
\hline \multirow{3}{*}{$\begin{array}{l}\text { investment } \\
\text { costs }\end{array}$} & $\begin{array}{l}\text { reactor section } \\
\text { gas back mixing } \\
\text { equipment erosion }\end{array}$ & $\begin{array}{l}+ \\
+ \\
+\end{array}$ & $\begin{array}{l}- \\
-\end{array}$ & $\begin{array}{l}+ \\
+ \\
\end{array}$ \\
\hline & $\begin{array}{l}\text { auxiliary equipment } \\
\text { heat exchange } \\
\text { gas solid separation }\end{array}$ & -- & $\begin{array}{l}- \\
-\end{array}$ & $+{ }^{2}$ \\
\hline & control equipment & + & - & - \\
\hline $\begin{array}{l}\text { operating } \\
\text { costs }\end{array}$ & $\begin{array}{c}\text { compression costs } \\
\text { (pressure drop/solids handling) } \\
\text { catalyst losses/equipment erosion } \\
\text { product losses }\end{array}$ & $\begin{array}{l}- \\
+ \\
+\end{array}$ & $\begin{array}{l}-3 \\
- \\
+\end{array}$ & $\begin{array}{l}+{ }^{4} \\
+ \\
-5\end{array}$ \\
\hline
\end{tabular}

PBR: Packed Bed Reactor; IFBR: Interconnected Fluidised Bed Reactor;

RCRFR: Reaction Coupling Reverse Flow Reactor;

${ }^{1}$ possible plugging of the catalyst bed;

2 only a start-up heater;

${ }^{3}$ large gas flows for solids transport;

${ }^{4}$ especially in case of a monolithic catalyst;

${ }^{5}$ because of flow direction and reaction phase switching; 
the catalyst do not have to be compromised in order to attain sufficiently adequate attrition resistance. A closed-loop reverse flow reactor coupling endothermic and exothermic reactions may offer large savings on investments for a separate regenerator and external high temperature heat exchange equipment and operating costs for solids transport. Especially if the high switching frequency between the endothermic and exothermic reactions can be exploited for operation at more severe process conditions or if by unsteady operation the optimal process conditions can be better approached - because of the dynamic properties of the reactor as a whole or by the dynamic response of the catalyst characteristics to changes in process conditions (e.g. Matros, 1996) - a reverse flow reactor for endothermic reactions may have significant benefits.

\section{Reaction system}

The non-oxidative propane dehydrogenation to propylene and hydrogen over a monolithic platinum based catalyst is a very interesting reaction system for operation in a reverse flow reactor, coupling the endothermic propane dehydrogenation indirectly with the exothermic combustion with air of coke, formed as a side-product during the dehydrogenation, and added hydrocarbon fuels for overall energy balance. This reaction system, schematically depicted in Figure 1, has been selected to study the reactor behaviour of the Reaction Coupling Reverse Flow Reactor.

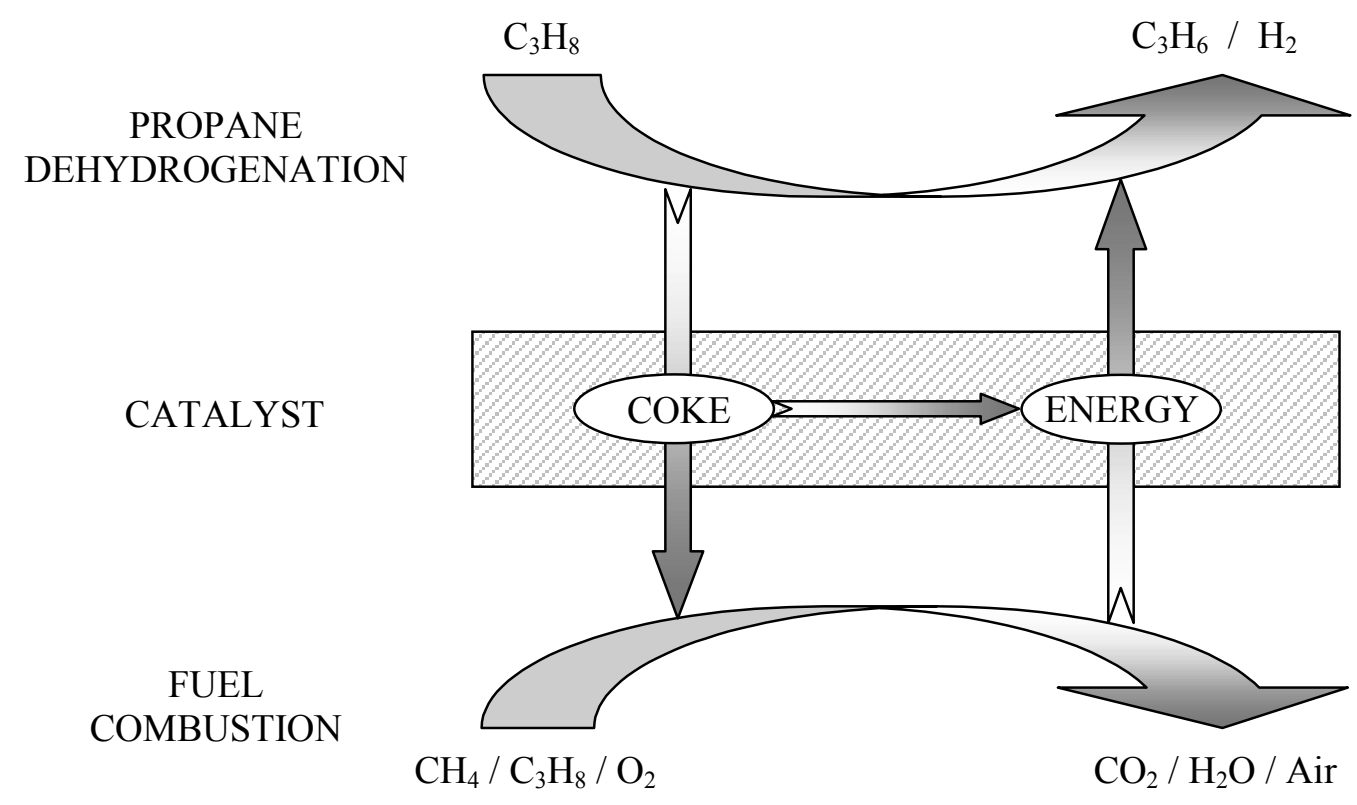

Figure 1. Schematic representation of the Reaction Coupling Reverse Flow Reactor concept for the catalytic non-oxidative propane dehydrogenation. 
The strong increase in the demand for propylene during the last decade (Taffe, 1996; Cosyns et al., 1998), especially because of the polypropylene production (Baker, 1999), has initiated the development of new alternative processes in addition to traditional petrochemical or refinery processes, where propylene is obtained as a by-product. The increased availability of lower alkanes resulting from more strict environmental legislation has made especially catalytic dehydrogenation processes economically attractive (Resasco and Haller, 1994).

The dehydrogenation of propane is highly endothermic $\left(130 \mathrm{~kJ} \cdot \mathrm{mole}^{-1}\right.$ at $\left.650{ }^{\circ} \mathrm{C}\right)$ and is carried out over a chromia or platinum based catalyst at atmospheric or slightly subatmospheric pressures and at high temperatures (typically, 550-650 ${ }^{\circ} \mathrm{C}$ ) because of thermodynamic constraints. The propane dehydrogenation is an equilibrium reaction favouring the propylene production at lower total pressures and higher temperatures (see Figure 2). Although the equilibrium is shifted towards propylene at lower system pressures, the total propylene production capacity of the reactor is also strongly reduced and additionally compression costs for the product separation are increased. The equilibrium conversion of propane to propylene is also increased with increasing temperatures, increasing from $48 \%$ at $600{ }^{\circ} \mathrm{C}$ to $81 \%$ at $700{ }^{\circ} \mathrm{C}$ for undiluted propane feed at atmospheric pressure. However, at these high temperatures carbonaceous deposits, collectively termed coke, are rapidly formed and as a consequence thereof catalyst deactivation prevails necessitating catalyst regeneration.

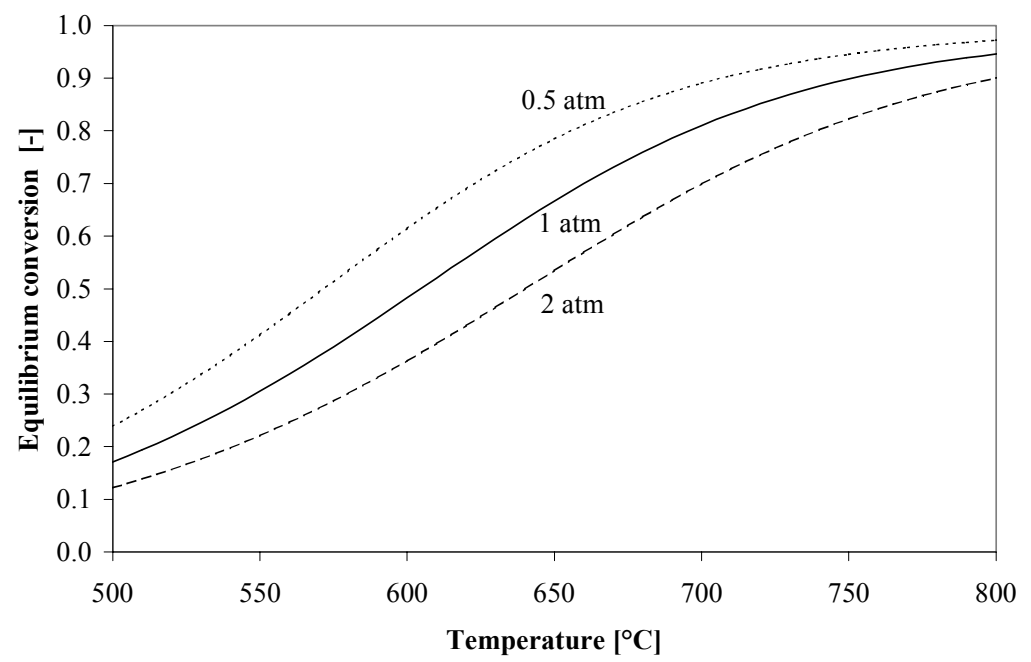

Figure 2. Equilibrium conversion for propane dehydrogenation of undiluted propane as a function of temperature for different total pressures.

Using the reverse flow concept to integrate recuperative heat exchange inside a fixed bed reactor combined with in situ energy supply by exothermic combustion reactions and in situ 
catalyst regeneration large savings on external heat exchange and catalyst regeneration equipment can be realised. Also side-reactions in high temperature external heat exchangers are avoided (Pujado and Vora, 1990). Furthermore, the regeneration of the catalyst and energy supply for the endothermic propane dehydrogenation can be effectively combined by simultaneous combustion of the coke and added hydrocarbon fuels. The heat released during the burning of the coke can be effectively recovered for the endothermic propane dehydrogenation, so that coke formation has no adverse effects on the process economics, unless the propane feedstock for the propane dehydrogenation is much more expensive than the fuel feedstock.

Moreover, in the adiabatic reverse flow reactor the endothermic and exothermic reaction phases are alternated with relatively high frequencies because of the large energy consumption during the propane dehydrogenation, inherently assuring very fast catalyst regeneration. Operation with short propane dehydrogenation and regeneration cycles has the distinct advantage of operation at a relatively low coke content at the catalyst surface with the corresponding high catalyst activity and an easy coke removal without deteriorating the catalyst properties. The short time on stream during the dehydrogenation process step assures high hydrogen to carbon ratios of the coke (Brito et al., 1996), which can be combusted completely with short regeneration times. The inherently fast catalyst regeneration therefor allows operation at higher temperatures (or lower hydrogen concentrations) with higher propylene yields.

Concluding, the adiabatic reverse flow reactor is a particularly interesting reactor concept for the non-oxidative propane dehydrogenation, because it allows operation at more severe reaction conditions with higher product yields in addition to savings on external heat exchange equipment.

The in situ catalyst regeneration in a reverse flow reactor allows the use of a catalyst containing highly active and expensive ingredients. The most active catalysts for the nonoxidative propane dehydrogenation are based on platinum as the active component with possibly tin added as promotor (a.o. Loc et al., 1991). Because of the relatively high propane dehydrogenation reaction rates internal diffusion limitations decrease the catalyst efficiency for particles larger than about $0.5-1 \mathrm{~mm}$ in diameter, especially at higher temperatures. For a fixed bed of particulates of these dimensions the maximum gas velocity (and thus the production capacity) is strongly limited by the permissible pressure drop. A monolithic catalyst maximises the catalyst utilisation with a very high specific external catalyst surface 
area per unit reactor volume with insignificant internal diffusion limitations due to the very small washcoat thickness, while maintaining a pressure drop about two orders of magnitude lower than in particulate systems (Cybulski and Moulijn, 1994). Also the absence of dispersion avoiding disadvantageous gas back-mixing, increased design flexibility and relatively easy scale-up properties (concept of parallelism) constitute considerable advantages of monolithic catalysts.

Monolithic catalysts consist of a support containing many small parallel channels, which are coated with a layer of material with a high internal surface area, usually $\gamma-\mathrm{Al}_{2} \mathrm{O}_{3}$, in which the catalytically active components are dispersed, schematically depicted in Figure 3. For the propane dehydrogenation reaction system in adiabatic reverse flow operation a ceramic monolith support of cordierite $\left(2 \mathrm{MgO} \cdot 5 \mathrm{SiO}_{2} \cdot 2 \mathrm{Al}_{2} \mathrm{O}_{3}\right)$ is better suited than a metallic support, because ceramic supports have a larger heat capacity and a better thermal shock and thermal stress resistance. For this work a commercial cordierite $\mathrm{Pt} / \gamma-\mathrm{Al}_{2} \mathrm{O}_{3}$ monolith supplied by Engelhard was selected, consisting of square channels (400 cpsi) with a hydraulic diameter of $0.96 \mathrm{~mm}$, a channel wall thickness of $0.19 \mathrm{~mm}$ and an average washcoat thickness of $37 \mu \mathrm{m}$ (11-89 $\mu \mathrm{m})$ (determined by SEM, see Figure 4), where in the washcoat $1.5 \mathrm{~g}$ Pt per liter monolith was dispersed, corresponding to about $1.1 \mathrm{wt} \%$ Pt. The BET area of a fresh monolith sample was determined at $35 \mathrm{~m}^{2} / \mathrm{g}$ monolith with an average pore diameter of about $11 \mathrm{~nm}$. In this work no attempts have been undertaken to optimise the catalyst properties, e.g. type and concentration of active components and promotors and the type of support. The catalyst activity and propylene selectivity might be enhanced by adding Sn or In to the platinum based catalyst and the coke selectivity might be decreased by reducing the acidity of the washcoat. Furthermore, the washcoat thickness and platinum content could be optimised.

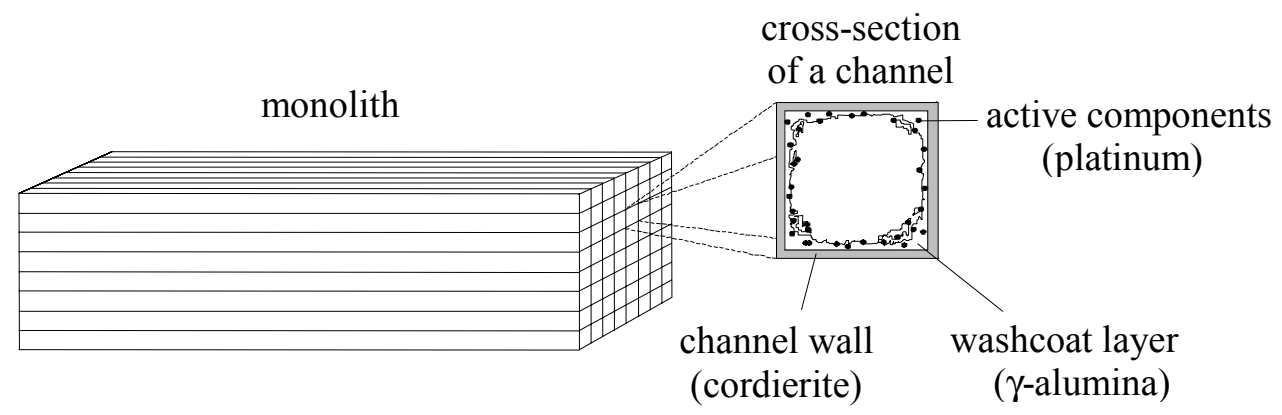

Figure 3. Schematic representation of the monolithic catalyst. 

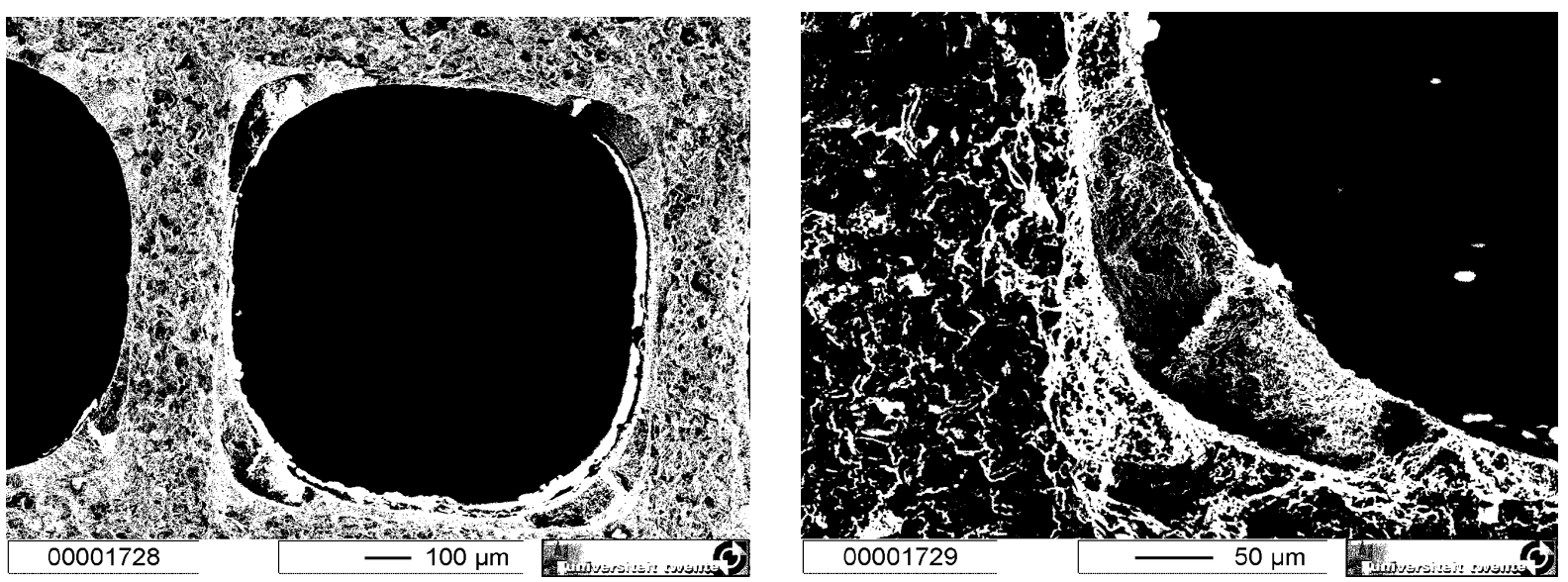

Figure 4. SEM-pictures from the monolithic catalyst showing the non-uniform washcoat distribution.

It is noted that the platinum-based monolith is a catalyst for both the endothermic propane dehydrogenation and the exothermic fuel combustion. Perhaps a catalyst could be composed of two different types of active components, where one type of active component is a catalyst for the endothermic reaction and the other for the exothermic reaction without any adverse cross influences of the active components, like undesired side-reactions. This alternative would enable further reactor optimisation through the matching of the activities of the active components for the respective reactions. However, this option is not explored further in this thesis. In this work only the more difficult case of the same active component for both the endothermic and exothermic reactions is considered.

Besides the catalytic propane dehydrogenation for example the production of synthesis gas via the endothermic decomposition of methane in coke and hydrogen coupled with the exothermic partial oxidation of the coke is also a very interesting reaction system for the Reaction Coupling Reverse Flow Reactor. Alternatively, part of the coke could be converted with steam to synthesis gas, for which case the necessary reaction energy could be supplied by combustion of part of the produced hydrogen or synthesis gas with air. However, despite the more general applicability of the reactor concept, this thesis will focus only on the above described reaction system of catalytic propane dehydrogenation. 


\section{This thesis}

The objective of the Ph.D. research described in this thesis is the development of a closedloop reverse flow reactor for highly endothermic reactions with rapid but reversible catalyst deactivation through the indirect coupling of endothermic and exothermic reactions. The reactor concept is studied for the non-oxidative propane dehydrogenation over a commercial platinum based monolithic catalyst coupled with the combustion with air of hydrocarbon fuels (methane and propane) and carbonaceous deposits formed as a side-product during the dehydrogenation.

Firstly, in Chapters 2 and 3 it is discussed on basis of detailed numerical simulations how the operating conditions of the endothermic and exothermic reaction phases should be matched in order to achieve an ignited cyclic steady state in the RCRFR and how the operating conditions can be used to indirectly control the axial temperature profile.

In Chapter 2 the simulation models to study the dynamic reactor behaviour are described and subsequently energy constraints, relating the endothermic and exothermic operating conditions, to achieve a cyclic steady state satisfying a maximum temperature constraint are discussed for two different basic reactor configurations, designated by the 'sequential' and the 'simultaneous' reactor configuration. It is shown that the production capacity or energy efficiency can be further optimised in the sequential reactor configuration compared to the simultaneous reactor configuration using the ratio of the endothermic and exothermic cycle times, provided that an appropriate switching scheme is chosen.

In Chapter 2 the propane dehydrogenation is considered as a simple first order irreversible reaction. However, like most industrially important endothermic reactions the propane dehydrogenation is an equilibrium reaction. Due to the steep temperature decline at the reactor outlet because of the reverse flow concept, the equilibrium can be shifted towards the reactants resulting in significantly lower propane conversions. In Chapter 3 the theoretical study is extended to reversible endothermic reactions for the sequential reactor configuration providing a new solution to avoid this 'back-conversion' while still achieving recuperative heat exchange and avoiding excessive temperatures and additionally controlling the plateau temperature.

Subsequently, in Chapters 4 and 5 the experimental kinetic investigations on the propane dehydrogenation, propylene hydrogenation and their most important side-reactions, viz. 
propane cracking and propane and propylene hydrogenolysis and coke formation, for wide temperature and concentration ranges over a partially deactivated monolithic platinum alumina catalyst, corresponding to conditions occurring in a RCRFR, are described.

In Chapter 4 the experimental work on the reaction kinetics of the gas phase reactions is described. It is discussed how the measured reaction rates of the gas phase reactions measured in a differentially operated reactor can be corrected for the decrease in catalytic activity caused by sintering and destruction of the most active sites or decrease in platinum dispersion by measuring kinetics over a catalyst sample used for many consecutive experiments consisting of reduction, (de)hydrogenation and TPO. Based on the experimental results for wide temperature and concentration ranges reaction rate expressions are derived describing the observed remarkable influences of temperature and composition. An explanation is presented for the observed extra order in the gas phase hydrogen concentration (additional to the order expected on the basis of reaction stoichiometry) for all reactions taking place at the platinum surface sites.

In Chapter 5 the experimental study on coke formation rates under propane dehydrogenation reaction conditions in a thermogravimetric analyser is described. A kinetic rate expression is derived based on a mechanistic dual coke growth model describing the experimentally observed striking dependencies of the coke formation rate as a function of time, temperature and composition over wide temperature and concentration ranges.

Chapter 6 deals with a safety analysis of switching between reductive and oxidative conditions on the basis of detailed numerical simulations supplemented by some qualitative experiments. The effects of the possible formation of combustible gas mixtures of hydrocarbons and air due to mixing in the monolith channels and in the inlet sections are studied in order to investigate whether intermediate flushing with inert gases could be safely omitted. In Chapter 7 the technical feasibility of the RCRFR is subsequently tested in a small laboratory scale reactor aiming for a proof of principle. Experimental results for the RCRFR for propane dehydrogenation coupled with methane combustion will be presented, focussing on the effects of back-conversion and coke formation and coke combustion.

Finally, in Chapter 8 optimal process conditions are determined on the basis of the experimentally determined reaction rates for the propane dehydrogenation, propylene hydrogenation and their most important side-reactions including coke formation using Pontryagin's maximisation principle. The effects of the propane dehydrogenation cycle time 
and the propane inlet concentration on the optimal axial temperature profiles are presented. Chapter 8 concludes with a qualitative comparison of process characteristics of a process for propane dehydrogenation based on the new reactor concept with conventional commercial propane dehydrogenation processes, showing good economic opportunities for the new RCRFR process.

\section{References}

Alpay, E., Kenney, C.N. and Scott, D.M. (1993). Simulation of rapid pressure swing adsorption and reaction processes. Chem. Engng Sci., 48, 3173-3186

Baker, J. (Ed.) (1999). Propylene. European Chemical News, July 1999, 18-19

Blanks, R.F., Wittrig, T.S. and Peterson, D.A. (1990). Bidirectional adiabatic synthesis gas generator. Chem. Engng Sci., 45, 2407-2413

Boreskov, G.K., Matros, Yu.Sh., Kiselev, O.V. (1979). Catalytic processes carried out under nonstationary conditions. Kinet. Katal., 20, 636-641

Boreskov, G.K., Bunimovic, G.A., Matros, Yu.Sh., Ivanov, A.A. (1982). Catalytic processes under non-steady state conditions, II. Switching the direction for the feed of the reaction mixture to the catalyst bed. Experimental results, Kinet. Katal., 23, 402-406

Boreskov, G.K. and Matros, Yu.Sh. (1983). Unsteady-state performance of heterogeneous catalytic reactions. Catal. Rev.-Sci. Engng, 25, 551-590

Brito, A., Arvelo, R., Villarroel, R., Garcia, F.J. and Garcia, M.T. (1996). Coke and H/C ratio profiles on a $\mathrm{Cr}_{2} \mathrm{O}_{3} / \mathrm{Al}_{2} \mathrm{O}_{3}$ catalyst during the butene-1 dehydrogenation reaction. Chem. Eng. Sci., 51, 4385-4391.

Cavani, F. and Trifirò, F. (1995). The oxidative dehydrogenation of ethane and propane as an alternative way for the production of light olefins. Catalysis Today, 24, 307-313 
Cosyns, J., Chodorge, J., Commereuc, D. and Torck, B. (1998). Maximize propylene production. Hydrocarbon Process., March 1998, 61-66

Cottrell, F.G. (1938). Purifying gases and apparatus therefor. US patent 2,121,733

Cybulski, A. and Moulijn, J.A. (1994). Monoliths in heterogeneous catalysis. Catal. Rev.Sci.Eng., 36, 179-270

Dünnebier, G., Weirich, I. and Klatt, K.-U. (1998). Computationally efficient dynamic modelling and simulation of simulated moving bed chromatographic processes with linear isotherms. Chem. Engng Sci., 53, 2537-2546

Ercan, C. and Gartside, R.J. (1996). Reactor performance and stability in an alternating reaction-reheat paraffin dehydrogenation system. Can. J. Chem. Eng., 74, 626-637

Frauhammer, J., Eigenberger, G., Hippel, L.v. and Arntz, D. (1999). A new reactor concept for endothermic high-temperature reactions. Chem. Engng Sci., 54, 3661-3670

Haynes, T.N., Georgakis, C. and Caram, H.S. (1992). The application of reverse flow reactors to endothermic reactions. Chem. Engng Sci., 47, 2927-2932

Heggs, P.J. (1986). Modelling the dynamics of regenerative catalytic reactors. Trans. Inst. M.C., $8,115-122$

Heggs, P.J. and Abdullah, N. (1986). Experimental investigation of a transient catalytic reactor for the dehydrogenation of ethylbenzene to styrene. Chem. Eng. Res. Des., 6, 258-265

Kulkarni, M.S. (1996a). Dynamics of asymmetric fixed-bed reactors: coupling of exothermic and endothermic reactions. Ph.D. Thesis, Sever Institute of Washington University, Saint Louis, USA

Kulkarni, M.S. and Dudukovic M.P. (1996b). A bidirectional fixed-bed reactor for coupling of exothermic and endothermic reactions. AIChE J., 42, 2897-2910

Kulkarni, M.S. and Dudukovic, M.P. (1997). Periodic operation of asymmetric bidirectional fixed-bed reactors: energy efficiency. Chem. Engng Sci., 52, 1777-1788 
Loc, L.C., Gaidai, N.A., Kiperman, S.L., T'huoang, H.S., Podkletnova, N.M. and Kogan, S.B. (1991). Kinetics of propane dehydrogenation on aluminoplatinum catalysts. Kinetics and Catalysis, 32, 61-66

Matros, Yu. Sh. (1996). Forced unsteady-state processes in heterogeneous catalytic reactors. Can. J. Chem. Engng, 74, 566-579

Matros, Yu.Sh. and Bunimovich, G.A. (1996). Reverse-flow operation in fixed bed catalytic reactors. Catal. Rev.-Sci. Eng., 39, 1-68

Meyers, R.A. (1997). Handbook of petroleum refining processes, second edition, McGrawHill Inc., USA

Pujado, P.R. and Vora, B.V. (1990). Make $\mathrm{C}_{3}-\mathrm{C}_{4}$ olefins selectively. Hydrocarbon Processing March, 65-70

Resasco, D.E. and Haller, G.L. (1994). Catalytic dehydrogenation of lower alkanes. J. Catal., $11,379-411$

Seiler, H. and Emig, G. (1997). Reduction-oxidation-cycling in a fixed bed reactor with periodic flow reversal. In Froment, G.F. and Waugh, K.C. (Eds). Dynamics of surfaces and reaction kinetics in heterogeneous catalysis. Elsevier, Amsterdam, The Netherlands, 479-488

Snyder, J.D. and Subramaniam, B. (1994). A novel reverse flow strategy for ethylbenzene dehydrogenation in a packed-bed reactor. Chem. Engng Sci., 49, 5585-5601

Snyder, J.D. and Subramaniam, B. (1997). Numerical simulation of a reverse-flow $\mathrm{NO}_{x}$-SCR reactor with side-stream ammonia addition. Chem. Engng Sci., 53, 727-734

Taffe, P. (1996). Propping up the propylene supply. Eur. Chem. News, 21-27 October, 27-28 
CHAPTER 2

IRREVERSIBLE ENDOTHERMIC REACTIONS COMPARISON OF REACTOR CONFIGURATIONS 


\begin{abstract}
A new reactor concept has been developed for highly endothermic heterogeneously catalysed gas phase reactions at high temperatures with rapid but reversible catalyst deactivation. The reactor concept aims to achieve an indirect coupling of energy necessary for endothermic reactions and energy released by exothermic reactions, without mixing of the endothermic and exothermic reactants, in a closed-loop reverse flow operation. Periodic gas flow reversal incorporates regenerative heat exchange inside the reactor. The reactor concept has been studied for the coupling between the non-oxidative propane dehydrogenation and methane combustion over a monolithic catalyst.
\end{abstract}

Two different reactor configurations have been considered: the sequential reactor configuration, where the endothermic and exothermic reactants are fed sequentially to the same catalyst bed acting as an energy repository and the simultaneous reactor configuration, where the endothermic and exothermic reactants are fed continuously to two different compartments directly exchanging energy. The dynamic reactor behaviour has been studied by detailed numerical simulation for both reactor configurations. Energy constraints, relating the endothermic and exothermic operating conditions, to achieve a cyclic steady state have been discussed. Furthermore, it has been indicated how the operating conditions should be matched in order to control the maximum temperature. Also, it has been shown that the maximum dimensionless temperature for a single first order reaction in reverse flow reactors depends on a single dimensionless number. Finally, both reactor configurations have been compared based on their operating conditions. It has been shown that only in the sequential reactor configuration the endothermic inlet concentration can be optimised at high throughput and maximum reaction coupling energy efficiency independently of the gas velocities, by the choice of a switching scheme with inherently zero differential creep velocity and by using the ratio of the cycle times. 


\section{Introduction}

For highly endothermic heterogeneously catalysed gas phase reactions at high temperatures with rapid but reversible catalyst deactivation a new reactor concept is developed. This reactor concept is based on the indirect coupling of energy necessary for endothermic reactions and energy released by exothermic reactions - i.e. without mixing of the endothermic and exothermic reactants avoiding undesired side-reactions - in closed-loop reverse flow operation. Under reverse flow operation the gas flow direction through a fixed catalyst bed is periodically reversed, while the reactants are fed without any preheating. The periodic gas flow reversals result in low inlet and outlet temperatures with high temperatures in the centre of the reactor, so that regenerative heat exchange is integrated inside the reactor. The reactor concept is studied for non-oxidative propane dehydrogenation coupled with the combustion of methane over a monolithic catalyst.

Indirect coupling of reaction energies of endothermic and exothermic reactions with integrated recuperative heat exchange can be accomplished in two different basic reactor configurations, termed the sequential and simultaneous reactor configuration (see Figures 1 and 2). In the sequential reactor configuration endothermic and exothermic reactants are fed discontinuously and sequentially to the same catalyst bed, where the bed acts as an energy repository delivering energy during the endothermic reaction phase and storing energy during the consecutive exothermic reaction phase while concurrently regenerating the catalyst. In the simultaneous reactor configuration the endothermic and exothermic reactants are fed continuously to different catalyst beds exchanging energy and the endothermic and exothermic feed streams are periodically switched in order to counteract catalyst deactivation. In Figure 2 the endothermic and exothermic compartments are schematically depicted as two catalyst beds. A larger heat exchanging area between the endothermic and exothermic compartments can be achieved in a shell-and-tube heat exchanger type reactor construction or a monolith where one part of the channels is fed with endothermic reactants and the remaining channels with exothermic reactants, similar to the reactor set-up described by Frauhammer et al. (1999), but without interchanging the reactants feed streams. The larger heat exchanging area is achieved, however, at the expensive of a much more complex feed supply construction. Both the sequential and simultaneous reactor configurations can be operated in different modes, as schematically indicated in Figures 1 and 2. The order in which the different operation modes are alternated is referred to as the switching scheme. 


\section{SEQUENTIAL REACTOR CONFIGURATION}

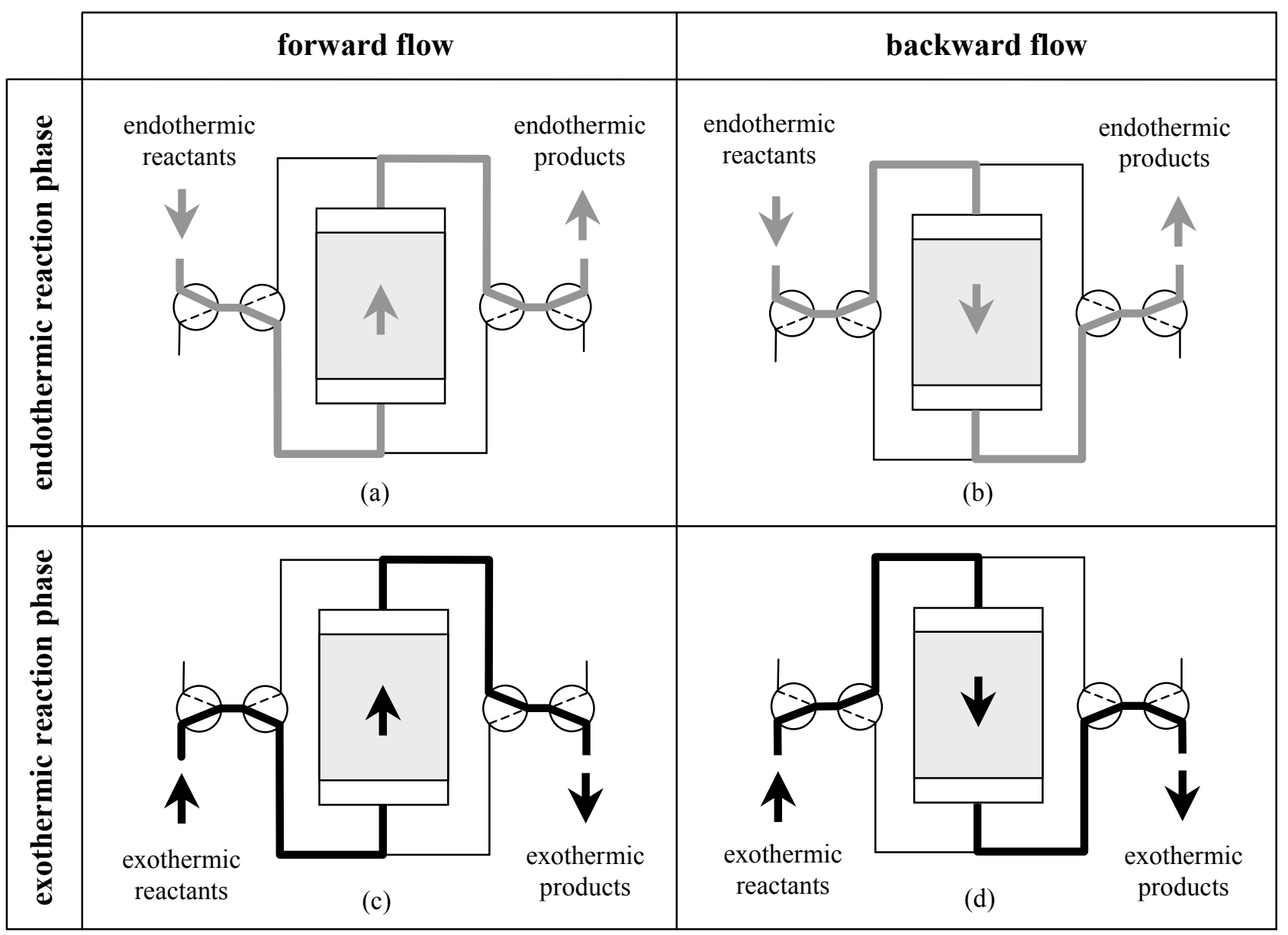

Figure 1. Schematic representation of the operation modes for the sequential reactor configuration.

In this chapter the dynamic reactor behaviour of these two reactor configurations is studied by detailed numerical simulation in order to derive energy constraints necessary to avoid extinction and to arrive at an ignited cyclic steady state. The energy constraints relate the operating conditions of the endothermic and exothermic reaction cycles, especially the reactant inlet concentrations and inlet mass fluxes. Additionally, for the sequential reactor configuration the influence of the switching scheme and the cycle times for flow direction and reaction phase switching is studied. Because the temperature in the centre of the reactor is not controlled directly in this adiabatic reactor, additional constraints are imposed on the operating conditions in order to attain the desired temperature level in the centre of the reactor. Based on the energy and temperature constraints the reactor configurations can be compared based on the operating conditions for maximum throughput and maximum reaction coupling energy efficiency in the cyclic steady state satisfying the temperature requirements. 


\section{SIMULTANEOUS REACTOR CONFIGURATION}

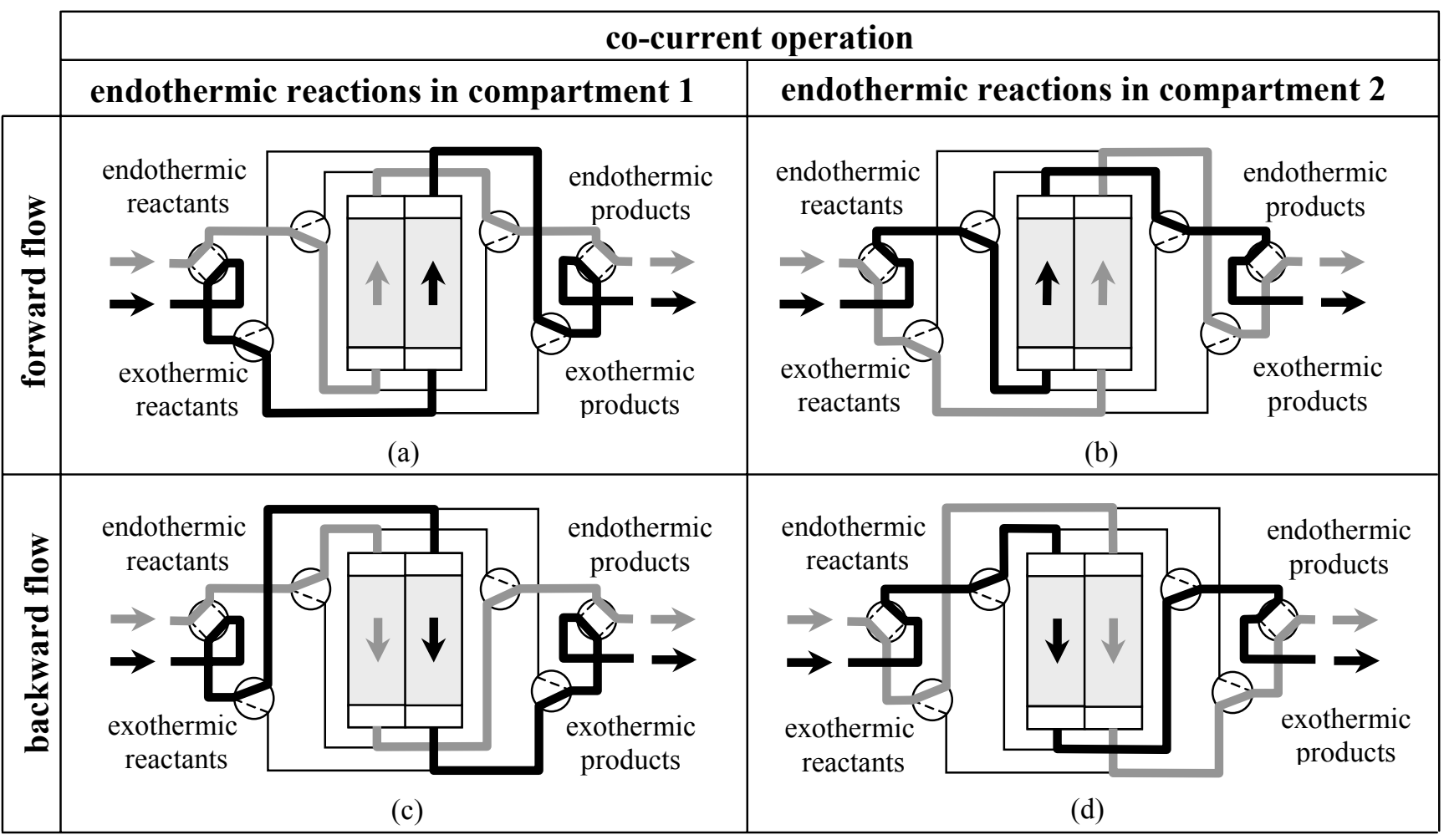

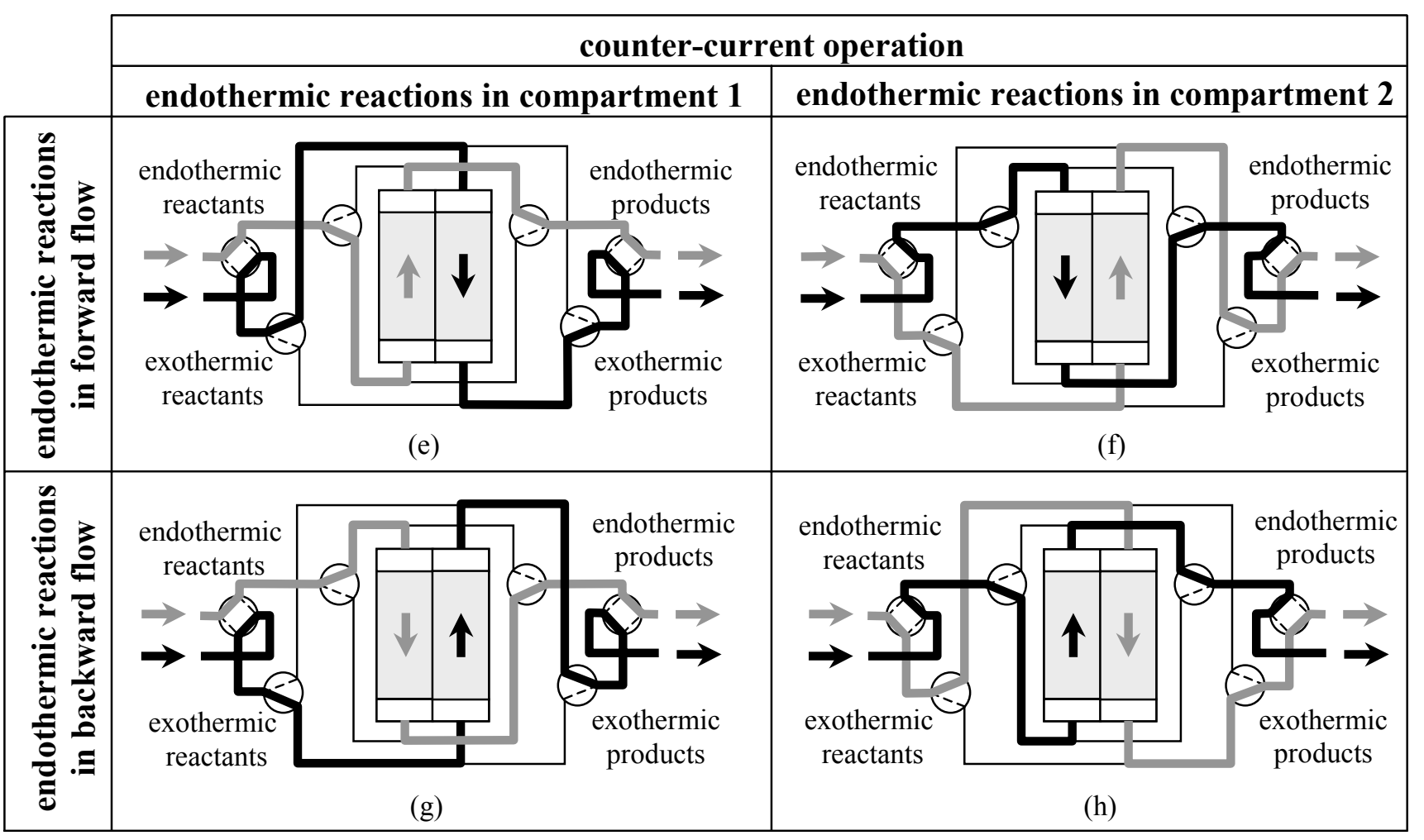

Figure 2. Schematic representation of the operation modes for the simultaneous reactor configuration. 
The dynamic reactor behaviour is studied with two different types of simulation models, differing in complexity in the description of the transient processes in the reverse flow reactor. First these models and their assumptions are described. Next, using these models energy constraints are derived for the sequential and simultaneous reactor configuration successively. Then, based on design criteria the two reactor configurations are compared based on their operating conditions. In this chapter the propane dehydrogenation is considered as an irreversible reaction. However, the propane dehydrogenation is an equilibrium reaction and the low exit temperatures resulting from the reverse flow concept entail considerable propane conversion losses. How this 'back-conversion' can be counteracted is discussed in Chapter 3 .

\section{Simulation models}

\subsection{The Dynamic Model and the High Switching Frequency Model}

For a given endothermic and exothermic reaction system in a ceramic monolithic catalyst the operating conditions are determined by the inlet composition and inlet mass flow rate for the endothermic and exothermic reaction phases. For the sequential reactor configuration, the endothermic and exothermic reaction cycle times and flow reversal cycle times and the switching scheme are additionally required. In order to determine how the operating conditions effect the cyclic steady state in a reverse flow reactor indirectly coupling endothermic and exothermic reactions, numerical models are used to simulate the transient reactor behaviour. Two different types of models are used, differing in complexity in the description of the transient processes in the reverse flow reactor, designated as Dynamic Model (DM) and High Switching Frequency Model (HSFM).

The DM constitutes of unsteady-state mass, momentum and energy balances for the gas and catalyst phase, with time-dependent boundary conditions to incorporate flow direction and reaction phase switching. The approximate HSFM is used to facilitate the study of the influence of the operating conditions on the cyclic steady state for the sequential reactor configuration. Due to the large reaction enthalpies of the propane dehydrogenation and methane combustion the reaction phase switching times are expected to be relatively short. The HSFM assumes infinitely fast switching of the gas flow direction, and can be derived from the DM by expanding the time-dependencies in Taylor-series (Haynes et al., 1995) or by recognising the counter-current reactor concept in the limit of infinitely fast switching 
(Eigenberger and Nieken, 1988). In the HSFM the movement of the temperature fronts has been excluded from the modelling due to cancellation of net effective heat convection, facilitating the comparison of the cyclic steady state under different operating conditions. Secondly, for short reaction phase and flow direction switching times the different switching schemes approach the same limit, so that also the influence of the switching scheme is excluded in the HSFM. Here it is assumed that the reactor is long enough to create two different reaction zones at either side of the reactor. In the limit of very short cycle times the catalyst temperature profile at one side of the reactor is hardly effected when reactants are fed at the other reactor end. Thus the particular order of the reaction phases and flow direction switching doesn't influence the cyclic steady state temperature profiles in case of short cycle times. However, in the HSFM it is assumed that both the endothermic and exothermic reactants are fed from both sides of the reactor, unlike the asymmetric switching scheme proposed by Kulkarni (1996a). The HSFM offers the opportunity to study the effect of operating conditions on the transient reactor behaviour of a sequential reverse flow reactor without considering the switching scheme. The results can then be refined using the DM. It should be noted that although the HSFM is conceptually simpler, it is not so numerically. Finally, simulations have confirmed the expected correspondence of the DM with very small cycle times and the HSFM, irrespective of the switching scheme.

\subsection{Model assumptions}

The intricate transient behaviour of reverse flow reactors coupling endothermic and exothermic reactions in monolithic catalysts has been studied by solving the transport equations of mass, momentum and energy for both the gas and catalyst phase, using the following general model assumptions:

\section{Symmetrical adiabatic monolithic reactor}

It is assumed that the inlet gas velocity is equal for all channels in the monolith and that heat losses to the surroundings can be neglected (justified for monoliths with a large diameter), allowing to neglect a radial temperature profile over the channels of the monolith. 


\section{Impermeable pseudo-homogeneous catalyst phase}

The monolithic channels consist of an impermeable ceramic support with a porous washcoat layer in which the active component is uniformly dispersed. Mass transfer between different channels can be left out of consideration and heat transport in the solid catalyst phase is described with effective heat transfer properties.

\section{One-dimensional plug flow with superimposed axial dispersion}

A one-dimensional plug flow model with superimposed axial dispersion for gas phase mass, momentum and energy transport sufficiently captures the most salient features of monolithic reverse flow reactors, according to the theory for generalised Taylor dispersion for reactive systems (see Chapter 6, Appendix A or Van Sint Annaland et al., 2000, Appendix A).

\section{Gas phase in pseudo-steady state}

The accumulation of energy in the gas phase can be neglected because of the negligible volumetric heat capacity of the gas phase compared to that of the solid phase. The accumulation of momentum in the gas phase can be ignored due to very small response times for small channels. It is assumed that also gas phase mass accumulation can be neglected, which is only valid if the gas phase residence time is much smaller than the cycle times for flow reversal and gas phase switching. Although the ratio of the gas residence time to the switching time was about $5 \%$ in some calculations, neglect of mass accumulation was necessary to avoid calculation of moving concentration fronts, which require intolerably large computation times. By assuming the gas phase in pseudo-steady state also the phenomena during reaction phase switching are ignored.

Finally it should be noted that the equations of change are written in the mass average reference frame. Heterogeneously catalysed gas phase reactions without mass deposition do not induce a net mass flux from the gas bulk to the catalyst surface, so that the mass and heat transfer coefficients need not be adjusted for a non-zero net mass flux (Bird et al., 1960). Should the component continuity equations be written in terms of mole fractions, fluxcorrection factors can be important in case of a non-zero net mole flux.

For the propane dehydrogenation and methane combustion reaction system the equations of change can be further simplified. Since the conversion rate of the propane dehydrogenation in a monolithic catalyst with its very small washcoat thickness is completely determined by 
intrinsic kinetics without external or internal mass transfer limitations. Moreover, only combustion with very low fuel concentrations is considered in this work, so that diffusion coupling plays no role in this reaction system and a Fickian description of mass and heat transfer can be used. This allows the substitution of the catalyst phase component mass balance in the gas phase component mass balance. Based on numerical simulations with a more general and detailed dynamic model it has been concluded for the reactor and reaction system and operating conditions under consideration that entrance effects on mass and heat transfer and radiative heat transfer can safely be ignored. Furthermore, the effects of axial dispersion of mass and heat in the gas phase are negligible for the relatively high gas flow velocities considered.

The DM and the HSFM model equations are summarised in Tables 1 and 2. A uniform initial axial catalyst temperature profile and the usual Danckwerts-type boundary conditions have been implemented, where both the inlet and outlet boundary conditions are periodically switched and the physical properties and reactions are periodically alternated upon reaction phase switching. The gas phase physical properties have been modelled following Reid et al. (1988) using pure component properties as described by Dauber and Danner (1985). The solid phase is a monolith with rectangular channels $(0.96 \mathrm{~mm}$ hydraulic diameter with a gas phase porosity of 0.69 ), where $1 \mathrm{wt} \% \mathrm{Pt}$ has been dispersed in a $\gamma-\mathrm{Al}_{2} \mathrm{O}_{3}$ washcoat on a cordierite support, whose physical properties have been taken from Hayes et al. (1996). For the simultaneous reactor configuration the temperature profile across the boundary separating the endothermic and exothermic reaction compartments has been assumed in pseudo-steady state. Because of the switching between the compartments the same volume fraction and specific catalyst area and catalyst properties have been assumed for both compartments.

In this chapter the heterogeneous propane dehydrogenation and methane combustion are considered as simple first order irreversible reactions without mass transfer limitations. The pseudo-first order heterogeneous reaction rate constant and activation energy for the propane dehydrogenation are approximated using experimental results obtained by Loc et al. (1991) $\left(k_{r, \infty}^{\text {endo }}=4.2 \mathrm{~m} \cdot \mathrm{s}^{-1}, E_{a c t}^{\text {endo }}=59 \mathrm{~kJ} \cdot \mathrm{mole}^{-1}\right)$ and for the methane combustion using the results from Trimm and Lam (1980), which show that the reaction order in methane reduces to first order for very low reactant concentrations $\left(k_{r, \infty}^{e x o}=4400 \mathrm{~m} \cdot \mathrm{s}^{-1}, E_{a c t}^{e x o}=86 \mathrm{~kJ} \cdot \mathrm{mole}^{-1}\right)$. In this chapter homogeneous combustion is ignored, as is the axial pressure drop. Also the effects of coke 
formation on the reaction rates (transient kinetics) and the energy released during catalyst regeneration have been neglected.

Table 1. Model equations for the High Switching Frequency Model (HSFM).

Catalyst energy equation:

$$
(1-\varepsilon) \rho_{c} C_{p, c} \frac{\partial T_{c}}{\partial t}=(1-\varepsilon) \frac{\partial}{\partial z}\left(\lambda_{c} \frac{\partial T_{c}}{\partial z}\right)+h \frac{a_{v}}{2}\left(T_{g, \rightarrow}-T_{c}\right)+h \frac{a_{v}}{2}\left(T_{g, \leftarrow}-T_{c}\right)+\sum_{j=1}^{n_{c}} r_{j, \rightarrow}^{h e t} \bar{h}_{j, \rightarrow} \frac{a_{v}}{2}+\sum_{j=1}^{n_{c}} r_{j, \leftarrow}^{h e t} \bar{h}_{j, \leftarrow} \frac{a_{v}}{2}
$$

\section{Forward direction:}

Gas phase overall continuity equation:

$$
v_{z, g, \rightarrow}=\frac{\Phi_{m, i n}^{\prime \prime}}{\varepsilon \rho_{g, \rightarrow}}
$$

Gas phase continuity equation for component $i$ :

$$
0=\varepsilon \frac{\partial}{\partial z}\left(\rho_{g, \rightarrow} D_{a x, \rightarrow} \frac{\partial \omega_{i, g, \rightarrow}}{\partial z}\right)-\Phi_{m, i n}^{\prime \prime} \frac{\partial \omega_{i, g, \rightarrow}}{\partial z}+r_{i, \rightarrow}^{h e t} a_{v}
$$

Gas phase energy balance:

$$
0=\varepsilon \frac{\partial}{\partial z}\left(\lambda_{g, \rightarrow} \frac{\partial T_{g, \rightarrow}}{\partial z}\right)-\Phi_{m, i n}^{\prime \prime} C_{p, g, \rightarrow} \frac{\partial T_{g, \rightarrow}}{\partial z}+\varepsilon \sum_{j=1}^{n_{c}} \rho_{g} D_{a x, j \rightarrow} \frac{\partial \omega_{j, g, \rightarrow}}{\partial z} C_{p, g, j, \rightarrow} \frac{\partial T_{g, \rightarrow}}{\partial z}-h_{\rightarrow} a_{v}\left(T_{g, \rightarrow}-T_{c}\right)
$$

\section{Backward direction:}

Gas phase overall continuity equation:

$$
v_{z, g, \leftarrow}=\frac{\Phi_{m, i n}^{\prime \prime}}{\varepsilon \rho_{g, \leftarrow}}
$$

Gas phase continuity equation for component $i$ :

$$
0=\varepsilon \frac{\partial}{\partial z}\left(\rho_{g, \leftarrow} D_{a x, \leftarrow} \frac{\partial \omega_{i, g, \leftarrow}}{\partial z}\right)-\Phi_{m, i n}^{\prime \prime} \frac{\partial \omega_{i, g, \leftarrow}}{\partial z}+r_{i, \leftarrow}^{h e t} a_{v}
$$

Gas phase energy balance:

$$
0=\varepsilon \frac{\partial}{\partial z}\left(\lambda_{g, \leftarrow} \frac{\partial T_{g, \leftarrow}}{\partial z}\right)-\Phi_{m, i n}^{\prime \prime} C_{p, g, \leftarrow} \frac{\partial T_{g, \leftarrow}}{\partial z}+\varepsilon \sum_{j=1}^{n_{c}} \rho_{g} D_{a x, j \leftarrow} \frac{\partial \omega_{j, g, \leftarrow}}{\partial z} C_{p, g, j, \leftarrow} \frac{\partial T_{g, \leftarrow}}{\partial z}-h_{\leftarrow} a_{v}\left(T_{g, \leftarrow}-T_{c}\right)
$$

The arrows $\rightarrow$ and $\leftarrow$ refer to the variables during forward or backward flow respectively. 
Table 2. Model equations for the Dynamic Model (DM) for the sequential and simultaneous reactor configuration.

\section{Sequential reactor configuration:}

Catalyst energy balance:

$$
(1-\varepsilon) \rho_{c} C_{p, c} \frac{\partial T_{c}}{\partial t}=(1-\varepsilon) \frac{\partial}{\partial z}\left(\lambda_{c} \frac{\partial T_{c}}{\partial z}\right)+h a_{v}\left(T_{g}-T_{c}\right)+\sum_{j=1}^{n_{c}} r_{j}^{\text {het }} \bar{h}_{j} a_{v}
$$

Gas phase overall continuity equation:

$$
v_{z, g}=\frac{\Phi_{m, i n}^{\prime \prime}}{\varepsilon \rho_{g}}
$$

Gas phase continuity equation for component $i$ :

Gas phase momentum balance:

$$
0=\varepsilon \frac{\partial}{\partial z}\left(\rho_{g} D_{a x} \frac{\partial \omega_{i, g}}{\partial z}\right)-\Phi_{m, i n}^{\prime \prime} \frac{\partial \omega_{i, g}}{\partial z}+r_{i}^{h e t} a_{v}+r_{i}^{h o m} \varepsilon
$$

Gas phase energy balance:

$$
\frac{\partial p}{\partial z}=-4 f \frac{1}{2} \rho_{g} v_{z, g}^{2} \frac{1}{d_{h, c}}
$$

$$
0=\varepsilon \frac{\partial}{\partial z}\left(\lambda_{g} \frac{\partial T_{g}}{\partial z}\right)-\Phi_{m, i n}^{\prime \prime} C_{p, g} \frac{\partial T_{g}}{\partial z}+\varepsilon \sum_{j=1}^{n_{c}} \rho_{g} D_{a x, j} \frac{\partial \omega_{j, g}}{\partial z} C_{p, g, j} \frac{\partial T_{g}}{\partial z}-h a_{v}\left(T_{g}-T_{c}\right)+\sum_{j=1}^{n_{c}} r_{j}^{h o m} \bar{h}_{j} \varepsilon
$$

\section{Simultaneous reactor configuration:}

For both compartments $k=1,2$ (endothermic and exothermic):

Catalyst energy balance:

$$
\begin{aligned}
(1-\varepsilon) \rho_{c, k} C_{p, c, k} \frac{\partial T_{c, k}}{\partial t}=(1-\varepsilon) \frac{\partial}{\partial z}\left(\lambda_{c, k} \frac{\partial T_{c, k}}{\partial z}\right)+h_{k} a_{v}\left(T_{g, k}-T_{c, k}\right)+\sum_{j=1}^{n_{c}} r_{j, k}^{h e t} & \bar{h}_{j, k} a_{v} \\
& \quad+\frac{\lambda_{s}}{\delta_{s}} a_{v} \sum_{l=1}^{2}\left(1-\delta_{k, l}\right)\left(T_{c, l}-T_{c, k}\right)
\end{aligned}
$$

Gas phase overall continuity equation:

Gas phase continuity equation for reactant $A$ :

$$
v_{z, g, k}=\frac{\Phi_{m, i n, k}^{\prime \prime}}{\varepsilon \rho_{g, k}}
$$

Gas phase momentum balance:

$$
0=\varepsilon \frac{\partial}{\partial z}\left(\rho_{g, k} D_{a x, k} \frac{\partial \omega_{i, g, k}}{\partial z}\right)-\Phi_{m, i n, k}^{\prime \prime} \frac{\partial \omega_{i, g, k}}{\partial z}+r_{i, k}^{h e t} a_{v}+r_{i, k}^{h o m} \varepsilon
$$

Gas phase energy balance:

$$
\frac{\partial p_{k}}{\partial z}=-4 f_{k} \frac{1}{2} \rho_{g, k} v_{z, g, k}^{2} \frac{1}{d_{h, c}}
$$

$$
\begin{aligned}
0=\varepsilon \frac{\partial}{\partial z}\left(\lambda_{g, k} \frac{\partial T_{g, k}}{\partial z}\right)-\Phi_{m, i n, k}^{\prime \prime} C_{p, g, k} \frac{\partial T_{g, k}}{\partial z}+\varepsilon \sum_{j=1}^{n_{c}} \rho_{g, k} D_{a x, j, k} \frac{\partial \omega_{j, g, k}}{\partial z} C_{p, g, j, k} \frac{\partial T_{g, k}}{\partial z} & -h_{k} a_{v}\left(T_{g, k}-T_{c, k}\right)+\sum_{j=1}^{n_{c}} r_{j, k}^{\text {hom }} \bar{h}_{j, k} \varepsilon
\end{aligned}
$$


Both the DM and the HSFM have been solved using a finite difference technique with Barton's second order scheme for the convective terms (e.g. Centrella and Wilson, 1984). From calculations it has been concluded that for the reaction and reactor system under study with at least 1000 axial grid cells per meter reactor length and a time step less than $0.1 \mathrm{~s}$ sufficiently accurate results are obtained. Generally, over a hundred complete cycles are required to completely obtain the cyclic steady state, although the main features of the temperature profiles clearly emerge after only about twenty full cycles.

With these models energy constraints to obtain a cyclic steady state are derived for both the sequential and simultaneous reactor configuration. Next, the operating conditions of the two different reactor configurations are compared. Before discussing the energy constraints and comparing the operating conditions the criteria on which this comparison is based are briefly outlined.

\section{Design criteria}

In an optimal design of a reverse flow reactor coupling endothermic and exothermic reactions a maximisation of the time averaged production of the products of the endothermic reaction phase is achieved, while minimising the energy requirement in terms of fuel consumption during the exothermic reaction phase. Also maximum conversion for both the endothermic and exothermic reaction phases is aimed for in order to minimise energy requirements for product separation and reactant recycles. This optimisation is subdued firstly by a maximum gas velocity, which depends mainly on the channel diameter and shape because of compression costs (pressure drop) or capital investments (reactor length). Secondly, a maximum allowable catalyst temperature limits the reactor optimisation. The maximum allowable temperature is mainly determined by, on the one hand, reaction kinetics and selectivities due to undesired by-product formation by cracking, hydrogenolysis or coking, or on the other hand, catalyst properties because of sintering of the washcoat or reduction in the dispersion of the active component. Thirdly, the fuel inlet concentration for the exothermic reaction phase should be below the lower explosion limit. These optimisation variables and constraints have been summarised in Table 3 . 
Table 3. Reactor optimisation variables and constraints for a given reactor and endothermic and exothermic reaction system.

\begin{tabular}{|c|c|c|}
\hline & Sequential reactor configuration & Simultaneous reactor configuration \\
\hline Operating & $\Phi_{m, i n}^{\prime \prime e n d o}, \omega_{g, i n}^{e n d o}, \Delta t^{e n d o}$ & $\Phi_{m, \text { in }}^{\prime \prime \text { endo }}, \omega_{g, \text { in }}^{\text {endo }}$ \\
\hline variables & $\Phi_{m, i n}^{\prime \prime e x o}, \omega_{g, i n}^{e x o}, \Delta t^{e x o}$ & $\Phi_{m, i n}^{\prime \prime e x o}, \omega_{g, i n}^{e x o}$ \\
\hline $\begin{array}{l}\text { Product } \\
\text { maximisation: }\end{array}$ & $M=\Phi_{m, \text { in }}^{\prime \prime \text { endo }} \omega_{g, \text { in }}^{\text {endo }} \frac{\Delta t^{\text {endo }}}{\Delta t^{\text {endo }}+\Delta t^{\text {exo }}}$ & $M=\varepsilon \rho_{g, i n}^{\text {endo }} v_{z, g, i n}^{\text {endo }} \omega_{g, \text { in }}^{\text {endo }}$ \\
\hline $\begin{array}{l}\text { Energy } \\
\text { efficiency } \\
\text { maximisation: }\end{array}$ & $\eta=\frac{\Phi_{m, \text { in }}^{\prime \prime \text { endo }} \omega_{g, \text { in }}^{\text {endo }}\left(\Delta h_{r}^{\text {endo }}\right) \zeta^{\text {endo }} \Delta t^{\text {endo }}}{\Phi_{m, \text { in }}^{\text {exo }} \omega_{g, \text { exo }}^{\text {exo }}\left(-\Delta h_{r}^{\text {exo }}\right) \zeta^{\text {exo }} \Delta t^{\text {exo }}}$ & $\eta=\frac{\Phi_{m, i n}^{\text {endo }} \omega_{g, i n}^{\text {endo }}\left(\Delta h_{r}^{\text {endo }}\right) \zeta^{\text {endo }}}{\Phi_{m, \text { in }}^{\prime \prime \text { exo }} \omega_{g, \text { in }}^{\text {exo }}\left(-\Delta h_{r}^{\text {exo }}\right) \zeta^{\text {exo }}}$ \\
\hline Constraints: & $\begin{array}{l}v_{z, g}(z, t)<v_{z, g, \max } \\
T_{c}(z, t)<T_{\max } \\
\omega_{g, \text { in }}^{\text {exo }}<\omega_{\max }\end{array}$ & $\begin{array}{l}\text { imum pressure drop; reactor length) } \\
\text { duct yield; catalyst properties) } \\
\text { er explosion limit) }\end{array}$ \\
\hline
\end{tabular}

Energy integration using the reverse flow concept results in high temperatures in the centre of the catalyst bed, while low temperatures can be maintained at the reactor ends. The temperature profile in a reverse flow reactor cannot be controlled directly, but results from the chosen operating conditions. The maximum temperature in the reactor is mainly determined by the operating conditions during the exothermic reaction phase. The reactor configuration, flow direction or reaction phase switching scheme and cycling times and the endothermic reaction conditions have only marginal influence on the maximum temperature in the cyclic steady state. In Appendix A it is shown that the dimensionless maximum temperature, $\theta_{c, \max }$, in a reverse flow reactor with a single exothermic reaction depends on the operating conditions via a single dimensionless number $\Theta$, referred to as the maximum-temperaturenumber, defined as

$\Theta=\frac{\left(-\Delta h_{r}\right) \Phi_{m, i n}^{\prime \prime 2} \omega_{g, \text { in }}}{2 \lambda_{\text {eff }} k_{r, \infty} a_{v} \rho_{g, i n} T_{g, \text { in }}}=\frac{1}{2} \frac{\Delta \theta_{a d}}{\theta_{g, \text { in }}} \frac{P e_{h}}{D a_{\infty}}$

according to a monotonously increasing function given by 
$\theta_{c, \text { max }} \exp \left(-\frac{1}{\theta_{c, \text { max }}}\right)\left[1-\theta_{c, \text { max }} \frac{1-2 \theta_{c, \text { max }}}{1-5 \theta_{c, \text { max }}^{2}}\right]=\Theta$

In order to avoid extinction and to achieve a cyclic steady state in a reverse flow reactor coupling endothermic and exothermic reactions, the operating conditions of the endothermic reaction phase need to be adjusted to the exothermic reaction phase. For a given reaction system and endothermic and exothermic reactions the variables available for tuning are the inlet reactant concentrations, inlet mass fluxes and - for the sequential reactor configuration the switching scheme and the flow direction and reaction phase cycle times. Due to the different reactor behaviour of the sequential and simultaneous reactor configuration the energy constraints will be discussed separately.

\section{Sequential reactor configuration}

Starting with a simple overall energy balance the dynamic reactor behaviour is studied in increasing detail, from the HSFM to the DM, leading to new energy constraints for a cyclic steady state.

\subsection{Overall energy balance}

Firstly, a cyclic steady state can only be achieved, if the total energy production during the exothermic reaction phase cycle exceeds the total energy consumption during the consecutive endothermic reaction phase cycle, because of energy losses by convective gas transport at the reactor outlet (heat losses through the reactor wall are neglected). Considering the reactor as a black-box, the overall energy balance reads

$$
\begin{aligned}
& 0=\frac{1}{\Delta t^{\text {endo }}+\Delta t^{e x o}} \int_{0}^{\Delta t^{\text {exo }}}\left[\Phi_{m, \text { in }}^{\prime \text { exo }} \omega_{g, \text { in }}^{\text {exo }}\left(-\Delta h_{r}^{\text {exo }}\right) \zeta^{\text {exo }}-\Phi_{m, \text { in }}^{\text {exo }}\left(C_{p, g, \text { out }}^{\text {exo }} T_{g, \text { out }}-C_{p, g, \text { in }}^{\text {exo }} T_{g, \text { in }}\right)\right] d t \\
& +\frac{1}{\Delta t^{\text {endo }}+\Delta t^{\text {exo }}} \int_{0}^{\Delta t^{\text {endo }}}\left[-\Phi_{m, i n}^{\text {endo }} \omega_{g, \text { in }}^{\text {endo }}\left(\Delta h_{r}^{\text {endo }}\right) \zeta^{\text {endo }}-\Phi_{m, i n}^{\text {endo }}\left(C_{p, g, \text { out }}^{\text {endo }} T_{g, \text { out }}-C_{p, g, \text { in }}^{\text {endo }} T_{g, \text { in }}\right)\right] d t
\end{aligned}
$$


which after rearanging yields

$$
\frac{\Phi_{m, \text { in }}^{\prime \text { endo }}}{\Phi_{m, \text { in }}^{\text {exo }}} \frac{\omega_{g, \text { in }}^{\text {endo }}}{\omega_{g, \text { in }}^{\text {exo }}} \frac{\Delta t^{\text {endo }}}{\Delta t^{\text {exo }}}=\frac{\left(-\Delta h_{r}^{\text {exo }}\right) \zeta^{\text {exo }}-\frac{\Delta\left(C_{p, g} T_{g}\right)^{\text {exo }}}{\omega_{g, \text { in }}^{\text {exo }}}}{\left(\Delta h_{r}^{\text {endo }}\right) \zeta^{\text {endo }}+\frac{\Delta\left(C_{p, g} T_{g}\right)^{\text {endo }}}{\omega_{g, \text { in }}^{\text {endo }}}} \leq \frac{\left(-\Delta h_{r}^{\text {exo }}\right)}{\left(\Delta h_{r}^{\text {endo }}\right)}
$$

stating that the multiplication of the ratios of inlet mass fluxes, inlet reactant mass fractions and cycle times of the endothermic reaction phase compared to the exothermic reaction phase is bounded by the ratio of the reaction enthalpy of the exothermic reaction and the endothermic reaction.

\subsection{Matching of Damköhler numbers}

While still satisfying the overall energy balance, different sets of operating conditions can be selected. In Figure 3 the influence of different sets of operating conditions, all satisfying the overall energy balance, on the axial profiles in the cyclic steady state for the sequential reactor configuration obtained from the HSFM are shown. In these calculations the operating conditions of the endothermic reaction phase have been kept the same in order to keep the total energy demand for the endothermic conversions constant. The endothermic inlet mass fraction has been set to unity, the endothermic inlet interstitial gas velocity to $0.25 \mathrm{~m} \cdot \mathrm{s}^{-1}$ and the endothermic reaction phase cycle time has been kept at $30 \mathrm{~s}$. The reactor length has been chosen long enough to avoid overlapping reaction zones. Also the total amount of energy which can be produced during the exothermic reaction phase is kept constant in these calculations and somewhat larger than necessary for the endothermic process step to account for convective heat losses avoiding extinction of the reactor. Figure 3 clearly shows that the cyclic steady state axial temperature and mass fraction profiles strongly depend on the choice of operating conditions. The operating conditions influence firstly the axial position of the reaction zones in the reactor, and secondly the relative position of the endothermic and exothermic reaction zones. 

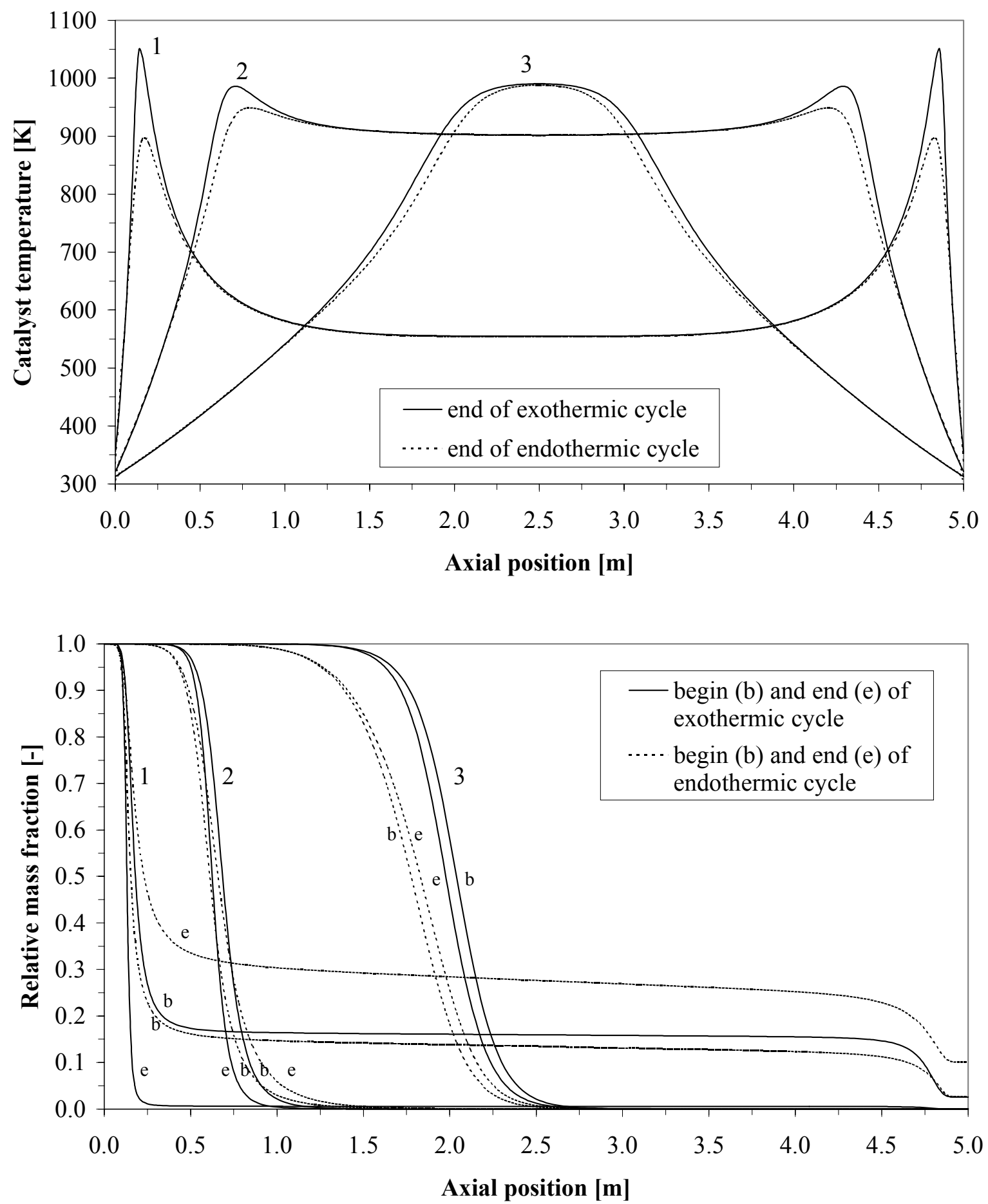

Figure 3.a Influence of the exothermic reaction phase operating conditions on the axial profiles of the catalyst temperature (top) and the gas phase mass fraction at forward gas flow normalised with the inlet mass fraction (bottom), for the sequential reactor configuration using the HSFM. Endothermic operating conditions are kept constant $\left(\omega_{g, \text { in }}^{\text {endo }}=1\right.$, $\left.v_{z, g, \text { in }}^{\text {endo }}=0.25 \mathrm{~m} \cdot \mathrm{s}^{-1}, \Delta t^{e n d o}=30 \mathrm{~s}\right)$. Variation of $v_{z, g, \text { in }}^{e x o}$ and $\omega_{g, \text { in }}^{e x o}\left(\right.$ keeping $\left.\Delta t^{e x o}=30 \mathrm{~s}\right)$ :

1. $v_{z, g, \text { in }}^{\text {exo }}=5 \mathrm{~m} \cdot \mathrm{s}^{-1}, \quad \omega_{g, \text { in }}^{\text {exo }}=0.0060$

2. $v_{z, g, i n}^{\text {exo }}=10 \mathrm{~m} \cdot \mathrm{s}^{-1}, \omega_{g, \text { in }}^{\text {exo }}=0.0030$

3. $v_{z, g, \text { in }}^{\text {exo }}=20 \mathrm{~m} \cdot \mathrm{s}^{-1}, \omega_{g, \text { in }}^{\text {exo }}=0.0015$ 

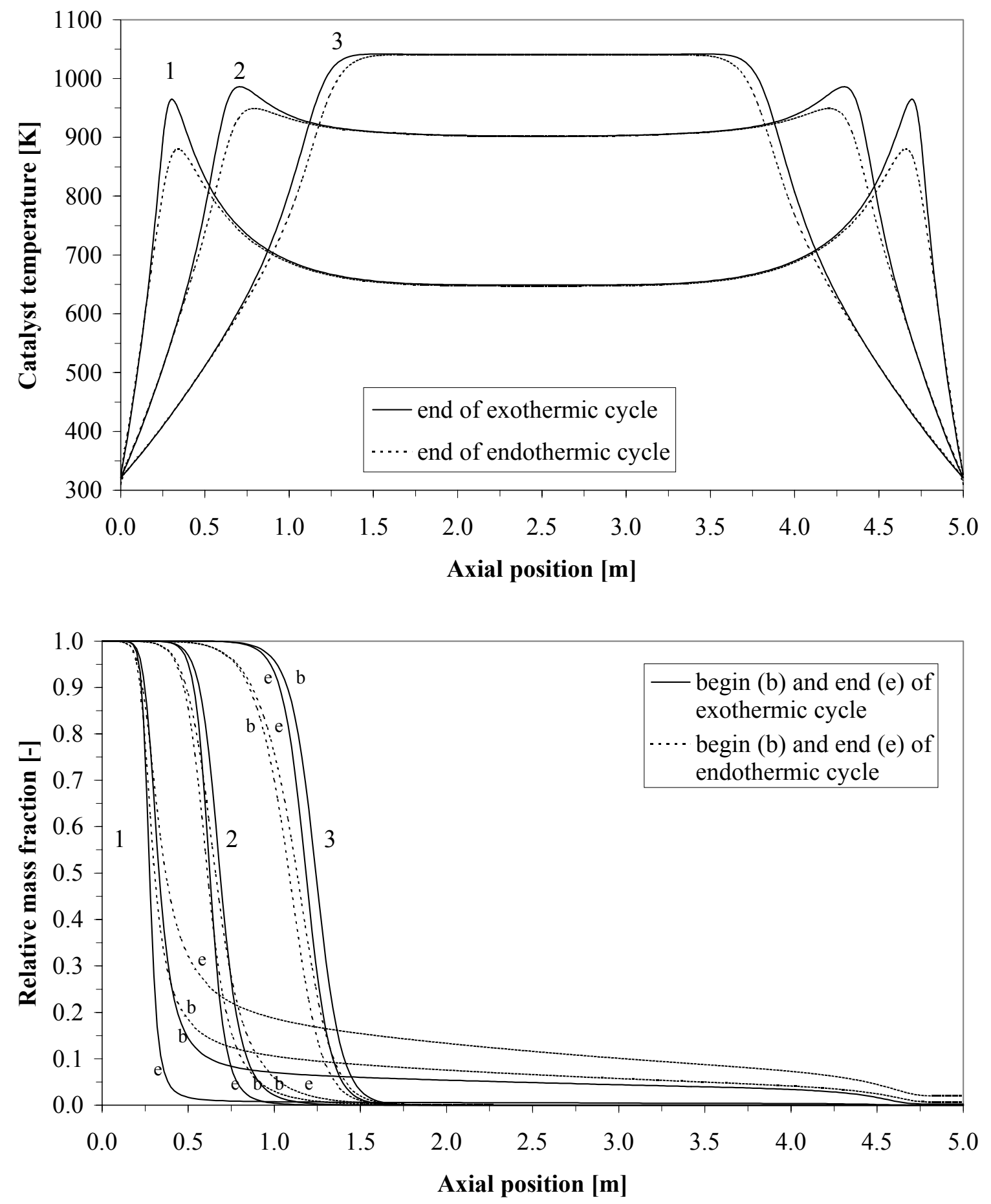

Figure 3.b Influence of the exothermic reaction phase operating conditions on the axial profiles of the catalyst temperature (top) and gas phase mass fraction at forward gas flow normalised with the inlet mass fraction (bottom), for the sequential reactor configuration using the HSFM. Endothermic operating conditions are kept constant $\left(\omega_{g, \text { in }}^{\text {endo }}=1, v_{z, g, \text { in }}^{\text {endo }}=\right.$ $0.25 \mathrm{~m} \cdot \mathrm{s}^{-1}, \Delta t^{\text {endo }}=30 \mathrm{~s}$ ). Variation of $v_{z, g, \text {,in }}^{\text {exo }}$ and $\Delta t^{\text {exo }}$ (keeping $\omega_{g, \text { in }}^{\text {exo }}=0.003$ ):
1. $v_{z, g, \text { in }}^{\text {exo }}=5 \mathrm{~m} \cdot \mathrm{s}^{-1}, \Delta t^{\text {exo }}=60 \mathrm{~s}$
2. $v_{z, g, \text { in }}^{\text {exo }}=10 \mathrm{~m} \cdot \mathrm{s}^{-1}, \Delta t^{\text {exo }}=30 \mathrm{~s}$
3. $v_{z, g, \text { in }}^{\text {exo }}=20 \mathrm{~m} \cdot \mathrm{s}^{-1}, \Delta t^{\text {exo }}=15 \mathrm{~s}$ 

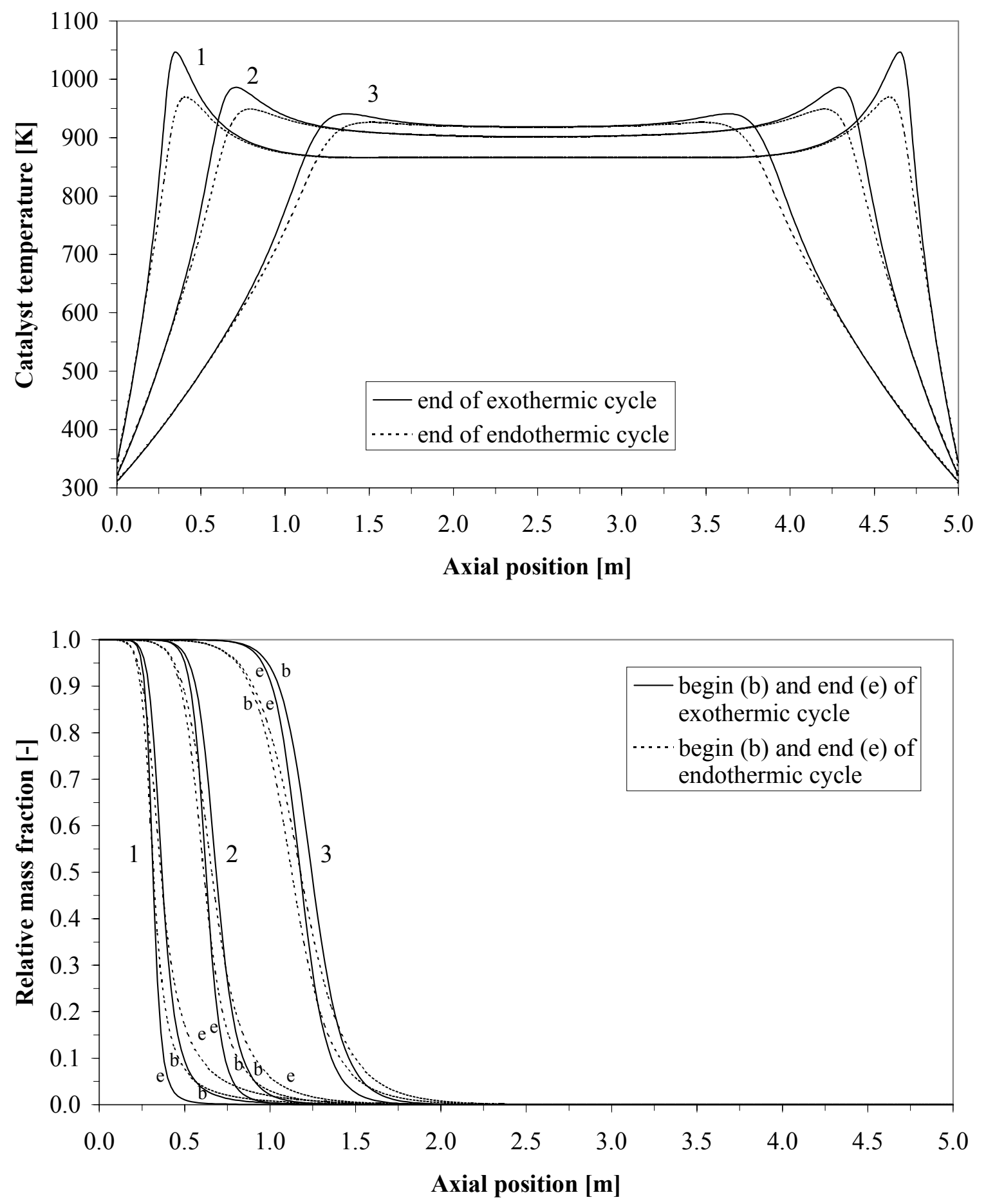

Figure 3.c Influence of the exothermic reaction phase operating conditions on the axial profiles of the catalyst temperature (top) and the gas phase mass fraction at forward gas flow normalised with the inlet mass fraction (bottom), for the sequential reactor configuration using the HSFM. Endothermic operating conditions are kept constant $\left(\omega_{g, \text { in }}^{\text {endo }}=1, v_{z, g, \text { in }}^{\text {endo }}=\right.$ $\left.0.25 \mathrm{~m} \cdot \mathrm{s}^{-1}, \Delta t^{e n d o}=30 \mathrm{~s}\right)$. Variation of $\omega_{g, \text { in }}^{\text {exo }}$ and $\Delta t^{\text {exo }}$ (keeping $v_{z, g, \text { in }}^{\text {exo }}=10 \mathrm{~m} \cdot \mathrm{s}^{-1}$ ):

1. $\omega_{g, \text { in }}^{\text {exo }}=0.0060, \Delta t^{\text {exo }}=15 \mathrm{~s}$

2. $\omega_{g, \text { in }}^{\text {exo }}=0.0030, \Delta t^{\text {exo }}=30 \mathrm{~s}$

3. $\omega_{g, \text { in }}^{\text {exo }}=0.0015, \Delta t^{\text {exo }}=60 \mathrm{~s}$ 
The position of the reaction zones is determined by the inlet temperature gradient and the ignition temperature of the exothermic reaction. Using the HSFM, it has been found that the inlet temperature gradient increases linearly with increasing exothermic reactant inlet mass fractions and decreases linearly with increasing inlet gas velocities in case the effective axial heat transport is completely dominated by gas convection (see Appendix A). At higher inlet reactant mass fractions and lower inlet gas velocities the temperature gradient is larger and the exothermic reaction reaches its ignition temperature at an axial position closer to the feed inlet.

Furthermore, the relative position of the endothermic and exothermic reaction zones determines whether a constant temperature plateau at the maximum temperature is formed at the centre of the monolith, or whether temperature maxima are created near the inlet and outlet with a low temperature plateau while the maximum temperature varies with time. The first situation arises when the exothermic reaction zone is located more inward compared to the endothermic reaction zone, and the latter when the opposite is true, as can be clearly seen from Figures 3.a and b. Moreover, in case the endothermic reaction zone is located more inward than the exothermic reaction zone, full conversion is not reached during both the endothermic and exothermic reaction phase due to the resulting unfavourable temperature profile, despite the fact that sufficient energy has been introduced during the exothermic reaction phase. The endothermic reaction has consumed all possible energy at the centre of the reactor, rendering the centre of the reactor ineffective for both the endothermic and exothermic reactions. Besides, it should be noted that at the temperature plateau no conversion takes place, allowing a reduction of the reactor length.

In order to achieve maximum conversion during the endothermic and exothermic reaction phases maximising the overall energy efficiency and to obtain an advantageous temperature profile with a constant temperature plateau at the maximum design temperature, not only the total amount of energy transferred from the exothermic to the endothermic reaction phase needs to tuned, also the axial position relative to the heat front where the exothermic reaction delivers energy and where the endothermic reaction consumes energy needs to be adjusted. This matching of the reaction zones, or Damköhler numbers, can only be achieved by adjusting the exothermic inlet gas velocity to the endothermic inlet gas velocity according to at least the inverse of the ratio of their reaction constants. Generally, the exothermic fuel combustion reaction rate is much larger than the endothermic dehydrogenation reaction rate, 
so that Damköhler-matching results in much higher gas velocities during the exothermic reaction phase compared to the endothermic reaction phase.

\subsection{Zero differential creep velocity}

An ignited cyclic steady state can only be achieved, if the distance the heat fronts cover are equal in both flow directions, presuming that the reactor length exceeds this distance by far. This is referred to as 'zero differential creep velocity' by Kulkarni (1996a). The heat front velocity during an exothermic reaction phase is always lower than during an endothermic reaction phase with the same operating conditions due to the heat released by the exothermic reactions. During the endothermic reaction phase the heat front seems to move with two different velocities, one below and one above the endothermic 'ignition' temperature. Using a homogeneous model and neglecting dispersion terms and assuming constant physical properties, it can be easily derived that the heat front velocity (for exothermic reactions) can be well approximated by (Froment, 1990)

$$
w=v_{z, g, \text { in }} \frac{\varepsilon \rho_{g, i n} C_{p, g}}{(1-\varepsilon) \rho_{c} C_{p, c}+\varepsilon \rho_{g} C_{p, g}}\left(1-\frac{\Delta T_{a d}}{T_{c, \max }-T_{g, \text { in }}}\right)
$$

If a switching scheme were selected where the endothermic reactants are always fed from one side of the reactor and the exothermic reactants always from the opposite side, the gas velocity or reaction cycle time of the endothermic or exothermic reaction phase needs to be adjusted in order to achieve zero differential creep velocity. The relevant expression is given by

$$
\frac{v_{z, g, \text { in }}^{e x o}}{v_{z, g, \text { in }}^{\text {exdo }}} \frac{\Delta t^{e x o}}{\Delta t^{\text {endo }}}=\frac{\rho_{g, \text { in }}^{\text {endo }} C_{p, g}^{\text {endo }}}{\rho_{g, \text { in }}^{e x o} C_{p, g}^{e x o}} \frac{1}{1-\frac{\Delta T_{a d}^{e x o}}{T_{c, \text { max }}-T_{g, \text { in }}}}
$$

How to adjust the exothermic and endothermic reaction phase cycle times to achieve a cyclic steady state was extensively studied by Kulkarni (1996a) and Kulkarni and Dudukovic 
(1996b, 1997). In this way the energy requirement of zero differential creep velocity limits the operational window of the reverse flow reactor.

However, if the endothermic and exothermic reactants are both fed at both reactor ends with equal operating conditions when feeding from either side, zero differential creep velocity is inherently attained, without any additional requirements on the gas velocities and reaction cycle times. Switching schemes, represented by a sequence of process steps, with inherently zero differential creep velocity can be classified in three categories:

I. Higher reaction phase switching frequency than flow direction switching frequency

a. The exothermic reaction phase first

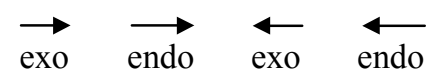

b. The endothermic reaction phase first

$$
\overrightarrow{\text { endo }} \underset{\text { exo }}{\longrightarrow} \stackrel{\leftarrow}{\leftarrow \text { endo }}
$$

II. Equal reaction phase and flow direction switching frequencies

$$
\overrightarrow{\text { exo }} \underset{\text { endo }}{\longleftarrow} \stackrel{\leftarrow}{\longleftarrow}
$$

III. Higher flow direction switching frequency than reaction phase switching frequency

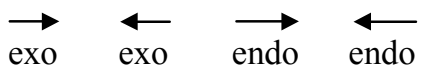

When counting the number of reaction phase or flow direction switches, it should be noted that there is an additional reaction phase or flow direction switch at the end of the switching scheme. For the operating conditions listed in Table 4 the influence of the switching scheme on the cyclic steady state axial temperature and concentration profiles is presented in Figure 4. The temperature profiles show some striking features, which will be discussed below. Here, only a complete cycle consisting of four process steps is considered. Similar temperature and concentration profiles are obtained for switching schemes with inherently zero differential creep velocity consisting of more process steps. 
Table 4. Operating conditions used to study the influence of the switching scheme for the DM (reactor length has been set to $2 \mathrm{~m}$ ).

\begin{tabular}{ccc}
\hline & Endothermic reaction phase & Exothermic reaction phase \\
\hline Inlet reactant mass fraction $\omega_{g, \text { in }}[-]$ & 1.0 & 0.0030 \\
Inlet gas velocity $v_{z, g, \text {, } n}\left[\mathrm{~m} \cdot \mathrm{s}^{-1}\right]$ & 0.05 & 2.0 \\
Reaction cycle time $\Delta t[\mathrm{~s}]$ & 180 & 180 \\
\hline
\end{tabular}

In Figure 4.a axial profiles in the cyclic steady state for switching scheme I.a are shown. The axial profiles of the catalyst temperature are shown at the end of every process step and the axial profiles of the gas phase mass fraction (normalised with the inlet mass fraction) are presented at the beginning and end of each process step. For switching scheme I.a the complete cycle starts with the last axial temperature profile from the previous cycle (indicated by the dashed line and $\overleftarrow{\text { endo }}$ ). Feeding exothermic reactants from the left side creates a temperature peak while shifting the temperature fronts to the right. During the subsequent feeding of endothermic reactants at the same inlet position, the energy stored during the exothermic phase is completely withdrawn. The distance the heat fronts cover during the endothermic phase is smaller than the distance during the exothermic phase due to the much longer exothermic cycle time chosen. Subsequently the flow direction is reversed and the same reaction sequence is carried out, finally resulting in a symmetrical axial temperature profile in the cyclic steady state with a temperature plateau in the centre of the reactor. As discussed before, the height of the temperature plateau strongly depends on the matching of the endothermic and exothermic Damköhler numbers.

When the order of the reaction phases is reversed, similar symmetrical temperature profiles are obtained (see Figure 4.b). Interestingly the temperature plateau is somewhat higher for switching scheme I.b (979 K) compared to switching scheme I.a (913 K). As can be clearly seen in the mass fraction profiles, the exothermic reaction zone is located more inward and the endothermic reaction zone more outward for switching scheme I.b as opposed to switching scheme I.a, causing a better energy accumulation. 

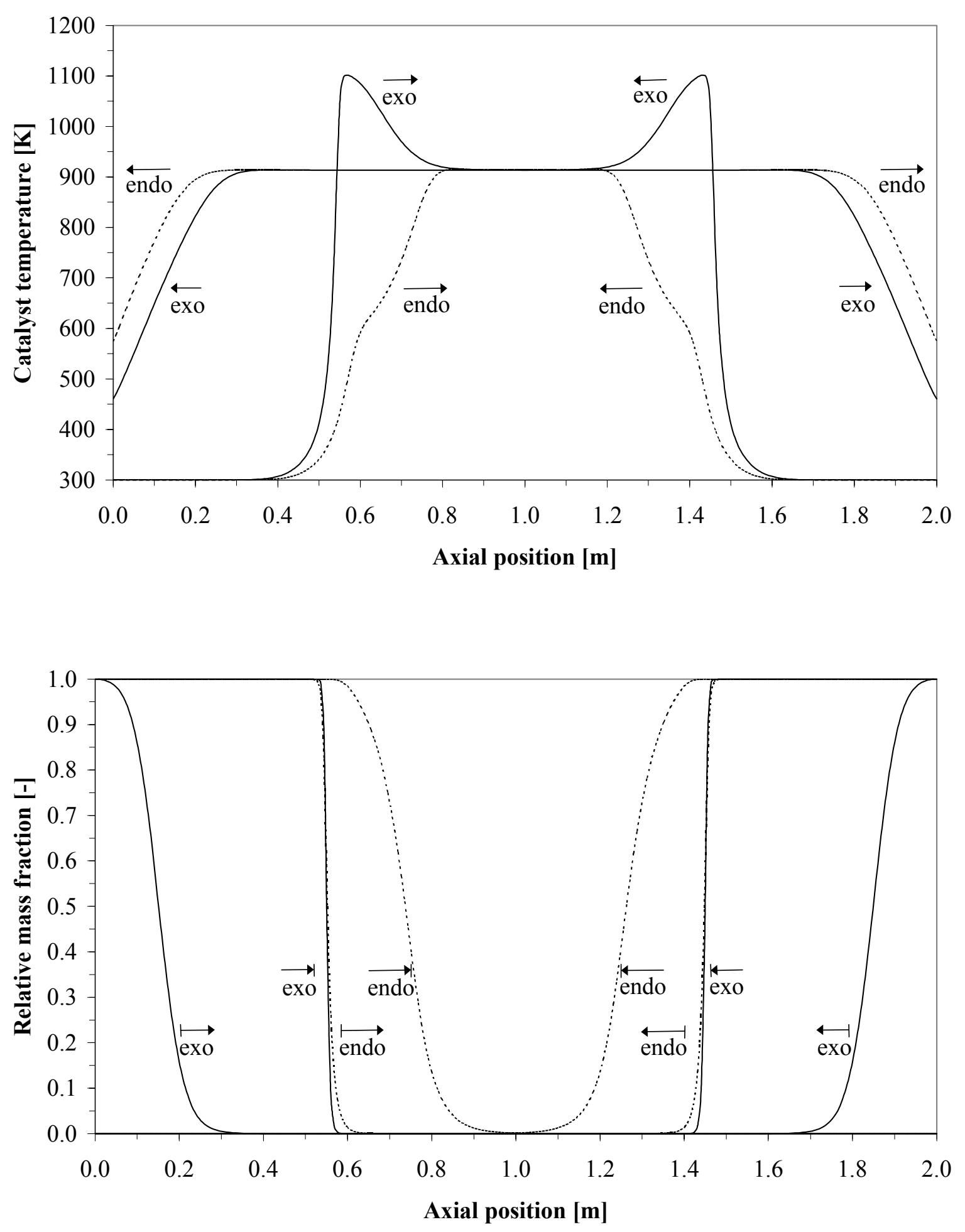

Figure 4.a Influence of the switching scheme with zero differential creep velocity on the axial profiles of the catalyst temperature (top) and gas phase mass fraction normalised with the inlet mass fraction (bottom) for the sequential reactor configuration using the DM $(\longmapsto \longrightarrow \longmapsto$ indicate the beginning and end of the forward and the beginning and end of the backward cycle respectively). Operating conditions are listed in Table 4.

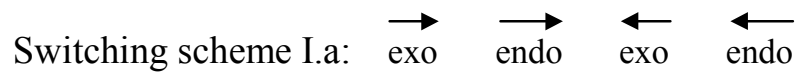



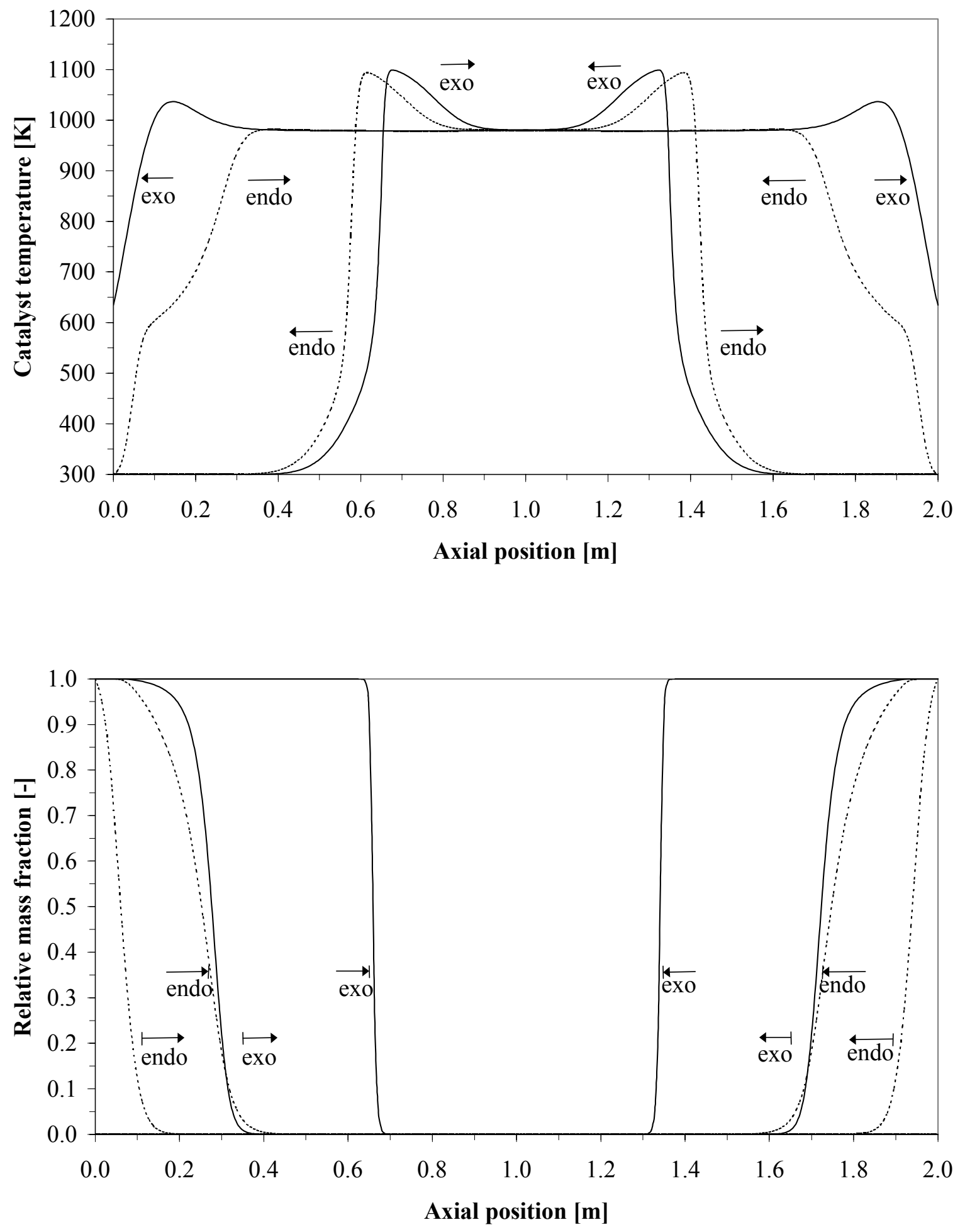

Figure 4.b Influence of the switching scheme with zero differential creep velocity on the axial profiles of the catalyst temperature (top) and gas phase mass fraction normalised with the inlet mass fraction (bottom) for the sequential reactor configuration using the DM $(\longmapsto \longrightarrow \longmapsto$ indicate the beginning and end of the forward and the beginning and end of the backward cycle respectively). Operating conditions are listed in Table 4.

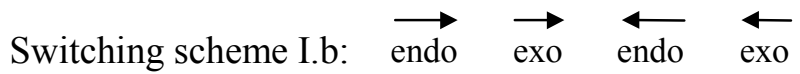



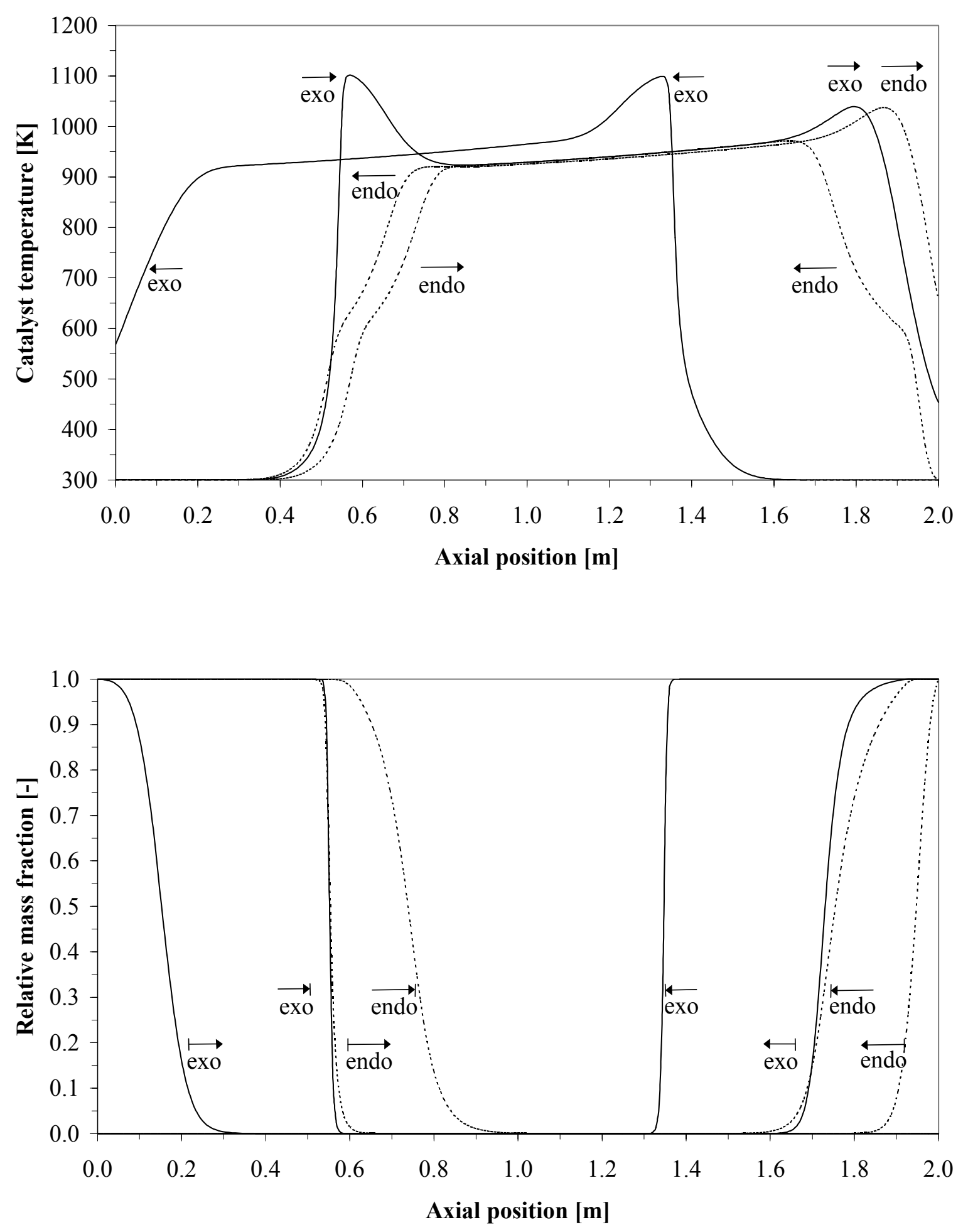

Figure 4.c Influence of the switching scheme with zero differential creep velocity on the axial profiles of the catalyst temperature (top) and gas phase mass fraction normalised with the inlet mass fraction (bottom) for the sequential reactor configuration using the DM $(\longmapsto \longleftrightarrow \longmapsto$ indicate the beginning and end of the forward and the beginning and end of the backward cycle respectively). Operating conditions are listed in Table 4.

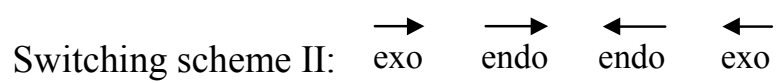



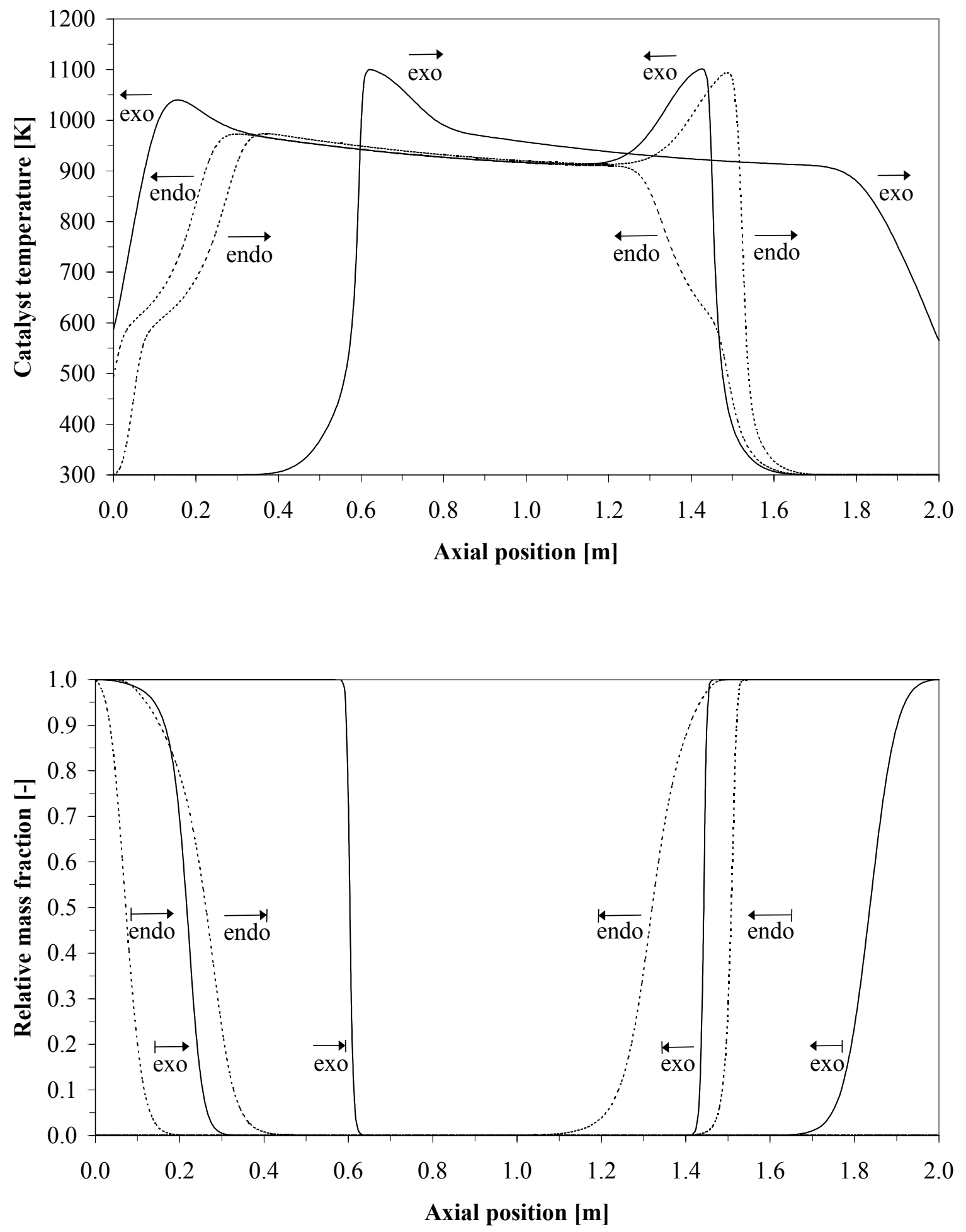

Figure 4.d Influence of the switching scheme with zero differential creep velocity on the axial profiles of the catalyst temperature (top) and gas phase mass fraction normalised with the inlet mass fraction (bottom) for the sequential reactor configuration using the DM $(\longmapsto \longrightarrow \longmapsto$ indicate the beginning and end of the forward and the beginning and end of the backward cycle respectively). Operating conditions are listed in Table 4.

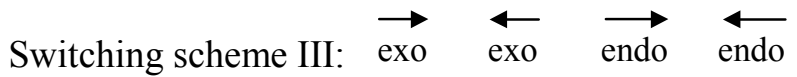


In switching scheme II switching of the gas flow direction and reaction phase is asynchronous, resulting in an asymmetric switching scheme, i.e. differing reaction phase sequence in forward and backward direction, also reflected in a striking asymmetric cyclic steady state temperature profile (Figure 4.c). The positive slope in the temperature 'plateau' is explained by the difference in the relative positions of the endothermic and exothermic reaction zones for both reactor ends. At the left side the endothermic reaction zone is positioned more inward, while at the right side the exothermic reaction zone is located further inside the reactor, so that the left side of the temperature profiles matches with those of switching scheme I.a and the right side with those of switching scheme I.b.

Remarkably also for switching scheme III, where the flow direction is reversed more often than the reaction phase, the cyclic steady state temperature profiles are asymmetric, although the switching scheme is symmetric. The negative slope in the temperature 'plateau' is again explained by the difference in the relative positions of the endothermic and exothermic reaction zones (see Figure 4.d), caused by different operating conditions during the endothermic and exothermic reaction phases. When reactants are fed from one side of the reactor the temperature front at the opposite reactor end is spread due to axial heat transport, which is dominated by convective transport. Due to the much higher gas velocity this spreading is much more pronounced during the exothermic reaction phase. Due to the flattening of the temperature profile and the temperature increase close to the reactor end, the reaction zone of the subsequent cycle is somewhat shifted towards the reactor end. In switching scheme III the difference in effective axial heat dispersion has shifted the endothermic reaction zone more outward at the left side of the reactor and the exothermic reaction zone more outward at the right side of the reactor, explaining the negative slope of the temperature plateau.

Concluding, for the sequential reactor configuration similar temperature profiles are obtained for the different switching schemes with inherently zero differential creep velocity, only differing in the location of the temperature maximums and the height and slope of the temperature plateau. The maximum temperature is the same for all switching schemes ( $c a$. $1100 \mathrm{~K}$ ), as expected, since the exothermic operating conditions have been kept the same. The analytical approximation for the maximum temperature for the exothermic reaction conditions under consideration is $1103 \mathrm{~K}\left(\Theta \approx 8.21 \cdot 10^{-6}\right)$, where the physical properties have been calculated at the maximum temperature. 
In these calculations the outlet gas temperature is relatively high due to the relatively high exothermic inlet fraction chosen for these calculations. In the cyclic steady state the timeaveraged gas outlet temperature equals the net difference between the energy consumed during the endothermic reaction phase and the energy produced during the exothermic reaction phase. Decreasing the exothermic inlet fraction results in a decrease of gas outlet temperature, until extinction occurs when the energy production during the exothermic reaction phase has become insufficient to deliver the energy required for the endothermic conversions and to account for convective heat losses. The minimum exothermic inlet mass fraction where extinction is still prevented is a measure for the energy efficiency of the reactor and the switching scheme. The reaction coupling energy efficiency is defined as the ratio of the theoretical minimum exothermic inlet mass fraction without heat losses and the minimum exothermic inlet mass fraction still avoiding extinction. To determine the most energy efficient switching scheme the minimum exothermic inlet mass fractions have been calculated using the DM (see Table 5).

Table 5. Minimum exothermic inlet mass fraction still preventing blow out $\left(\omega_{g, \text { in }}^{\text {exo }}\right)_{\text {min }}$ for different switching schemes with zero differential creep velocity in the sequential reactor configuration with the operating conditions in Table 4. The theoretical minimum exothermic inlet mass fraction neglecting convective heat losses is 0.00221 .

\begin{tabular}{|c|c|c|c|c|c|}
\hline \multicolumn{5}{|c|}{ Switching scheme } & $\left(\omega_{g, \text { in }}^{\text {exo }}\right)_{\min }$ \\
\hline I.a & $\overrightarrow{\mathrm{exo}}$ & $\overrightarrow{\text { endo }}$ & $\underset{\text { exo }}{\longleftarrow}$ & $\stackrel{\longleftarrow}{\text { endo }}$ & 0.00228 \\
\hline I.b & $\overrightarrow{\text { endo }}$ & $\overrightarrow{\text { exo }}$ & $\overleftarrow{\text { endo }}$ & $\stackrel{\leftarrow}{\text { exo }}$ & 0.00226 \\
\hline II. & $\overrightarrow{\text { exo }}$ & $\overrightarrow{\text { endo }}$ & $\stackrel{\longleftarrow}{\text { endo }}$ & $\stackrel{\leftarrow}{\text { exo }}$ & 0.00227 \\
\hline III. & $\overrightarrow{\text { exo }}$ & $\stackrel{\leftarrow}{\leftarrow \text { exo }}$ & $\overrightarrow{\text { endo }}$ & $\overleftarrow{\text { endo }}$ & 0.00230 \\
\hline
\end{tabular}

Switching scheme I.b, where the exothermic reaction zone is positioned the most inward, has the highest reaction coupling energy efficiency. The HSFM-switching scheme, resembled by switching scheme III in the limit of many flow direction switches before alternating the reaction phase, is the least energy efficient switching scheme, having the exothermic reaction zone located most outwardly. The differences in reaction coupling energy efficiencies for the 

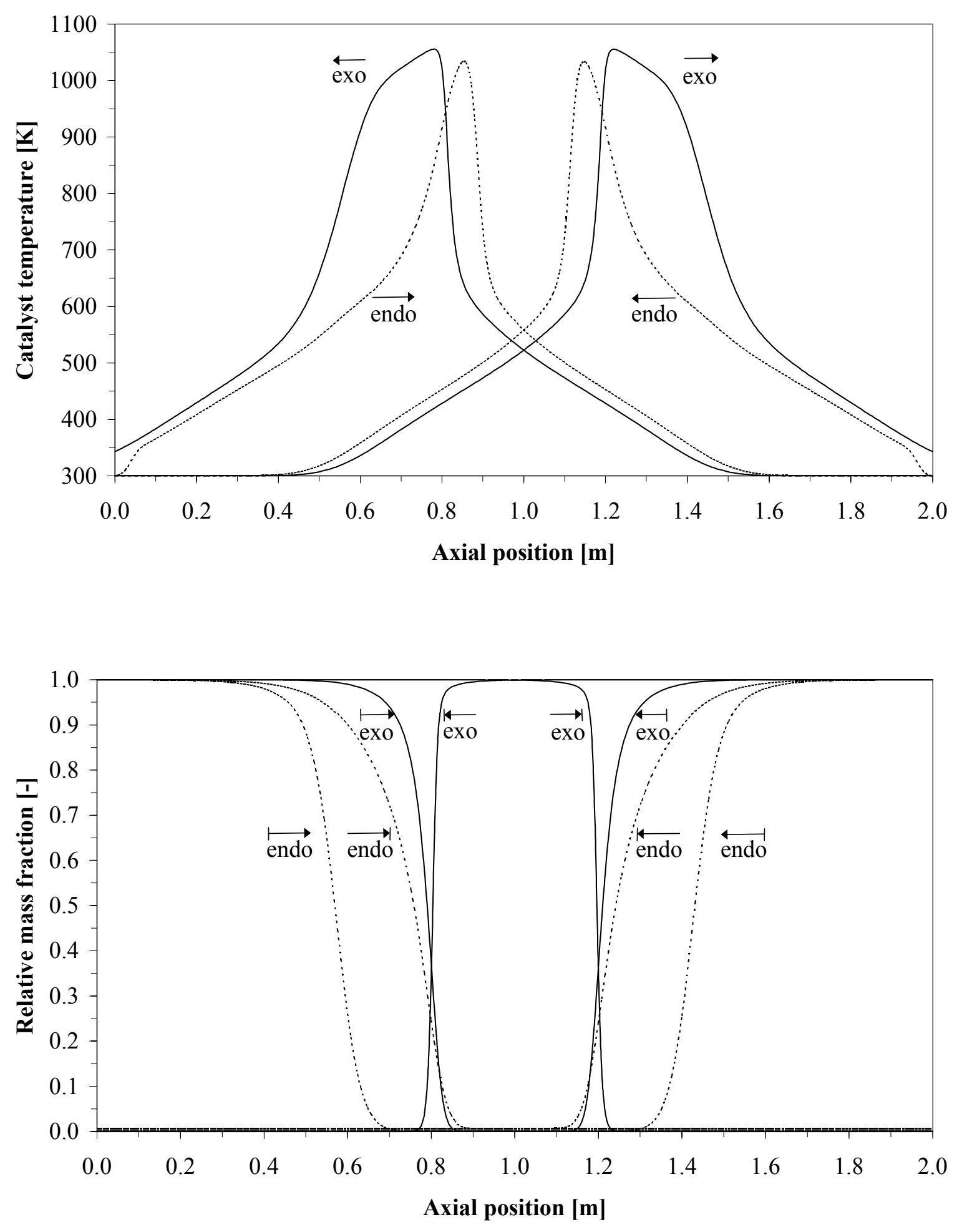

Figure 5. The axial profiles of the catalyst temperature (top) and gas phase mass fraction normalised with the inlet mass fraction (bottom) for the most energy efficient switching scheme (I.b) at the minimum exothermic inlet mass fraction just preventing extinction, for the sequential reactor configuration using the DM. 
different switching schemes are however marginal. For all switching schemes reaction coupling energy efficiencies over $96 \%$ have been found. In Figure 5 the cyclic steady state profiles are shown for switching scheme I.b. at the minimum exothermic inlet concentration. Note the overlapping reaction zones for both reaction phases. The energy efficiency of switching schemes with more reaction phase switches before alternating the flow direction is only marginally higher, although a longer reactor is needed.

It should be realised that the reaction coupling energy efficiency strongly depends on the reactor length chosen. At lower exothermic inlet mass fractions the initial temperature gradient is much lower and the ignition temperature is reached further inside the reactor. The economically optimal energy efficiency results from a compromise between investment costs (reactor length) and operating costs (fuel consumption).

\section{Simultaneous reactor configuration}

In the simultaneous reactor configuration the endothermic and exothermic reactants are fed continuously and simultaneously to two different compartments. The reactants can be fed at the same reactor end or at opposite reactor ends, referred to as co-current and counter-current operation respectively.

The reactor behaviour of the co-currently-operated simultaneous reactor configuration is very similar to the reactor behaviour of the sequential reactor configuration, especially for small reaction cycle times. It is assumed that the inlet and outlet positions for both the endothermic and exothermic reaction phases are switched concurrently, for there is no obvious reason to switch asynchronously. Furthermore, switching of the endothermic and exothermic compartments has no effect on the dynamic reactor behaviour, when energy effects during catalyst regeneration can be ignored.

The simultaneous reactor in counter-current operation is actually not a reverse flow reactor, since the flow direction is not alternated and a real steady state is obtained, in contrast to the sequential reactor configuration and the co-currently operated simultaneous reactor configuration. However, the reactor behaviour is similar to asymmetric reverse flow reactors, also allowing recuperative heat exchange inside the reactor (Kulkarni, 1996a; Frauhammer et al., 1999). 
The overall energy balance for the simultaneous reactor configuration in both operation modes is identical to the overall energy balance for the sequentially operated reactor configuration for equal reaction cycle times,

$$
\frac{\Phi_{m, \text { in }}^{\prime \prime \text { endo }}}{\Phi_{m, \text { in }}^{\text {exo }}} \frac{\omega_{g, \text { in }}^{\text {endo }}}{\omega_{g, \text { in }}^{\text {exo }}}=\frac{\left(-\Delta h_{r}^{\text {exo }}\right) \zeta^{\text {exo }}-\frac{\Delta\left(C_{p, g} T_{g}\right)^{\text {exo }}}{\omega_{g, \text { in }}^{\text {exo }}}}{\left(\Delta h_{r}^{\text {endo }}\right) \zeta^{\text {endo }}+\frac{\Delta\left(C_{p, g} T_{g}\right)^{\text {endo }}}{\omega_{g, \text { in }}^{\text {endo }}}} \leq \frac{\left(-\Delta h_{r}^{\text {exo }}\right)}{\left(\Delta h_{r}^{\text {endo }}\right)}
$$

\subsection{Co-current operation}

Firstly, zero differential creep velocity is trivial if the cycle times for flow direction switching are chosen equal. Furthermore, as for the sequential reactor configuration, also for the cocurrently operated simultaneous reactor configuration the reaction zones of the endothermic and exothermic reactions need to be tuned in order to form a temperature plateau at high temperatures at the centre of the reactor in the cyclic steady state and to achieve maximum conversion for both reaction phases.

In Figure 6 it is shown that this can be achieved by choosing the Damköhler number of the exothermic reaction phase smaller than the Damköhler number of the endothermic reaction phase. Furthermore, the maximum catalyst temperature for the co-currently operated simultaneous reactor configuration is somewhat lower than for the maximum catalyst temperature for the sequential reactor configuration, due to the immediate heat transfer from the exothermic to the endothermic compartment. In Figure 6 infinitely fast heat transfer between the endothermic and exothermic compartments has been assumed, as is the case for the very thin channel walls of a monolithic catalyst, where the endothermic and exothermic reactions are carried out in adjoining channels in chessboard-like arrangement. Remarkably, the maximum temperature doesn't necessarily increase in case of less efficient heat transfer between the compartments. Due to obstruction of heat transfer from the exothermic reaction phase to the endothermic reaction phase, less efficient heat transfer actually leads to a better matching of the exothermic and endothermic reaction zones in this case, resulting in somewhat lower maximum temperatures (see Figure 7). 

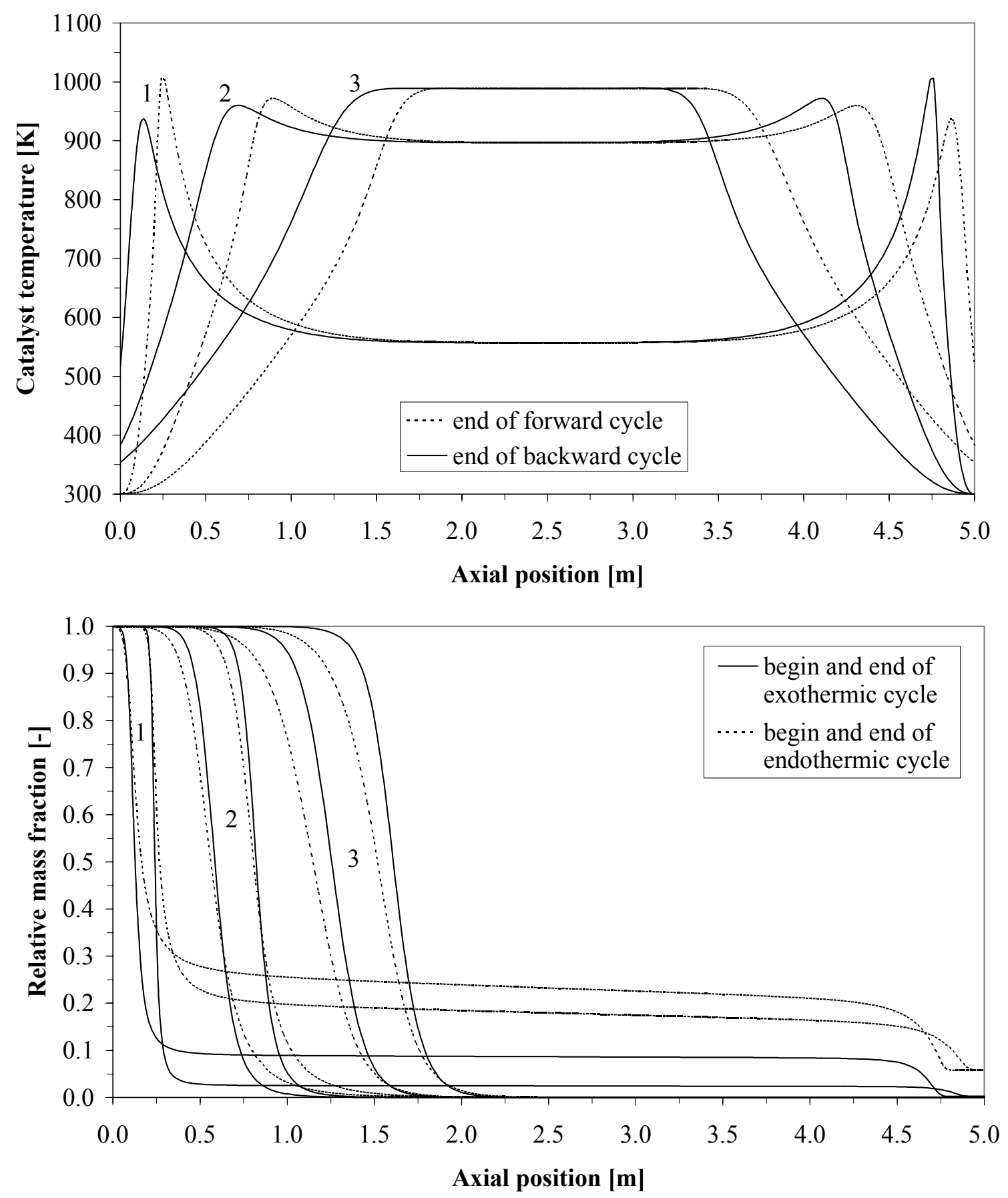

Figure 6. Influence of the exothermic reaction phase operating conditions on the axial profiles of the catalyst temperature (top) and gas phase mass fraction at forward gas flow normalised with the inlet mass fraction (bottom) for the co-currently operated simultaneous reactor configuration with constant endothermic operating conditions: $\omega_{g, \text { in }}^{\text {endo }}=1, v_{z, g, \text { in }}^{\text {endo }}=0.25$ $\mathrm{m} \cdot \mathrm{s}^{-1}$. The flow direction is reversed every $30 \mathrm{~s}$ and infinite heat transfer rate between the endothermic and exothermic compartments $\left(\lambda_{s} / \delta_{s} \rightarrow \infty\right)$ has been assumed. Selected values for $v_{z, g, \text { in }}^{\text {exo }}$ and $\omega_{g, \text { in }}^{\text {exo }}$ :

1. $v_{z, g, \text { in }}^{\text {exo }}=5 \mathrm{~m} \cdot \mathrm{s}^{-1}, \quad \omega_{g, \text { in }}^{\text {exo }}=0.006$

2. $v_{z, g, \text { in }}^{\text {exo }}=10 \mathrm{~m} \cdot \mathrm{s}^{-1}, \omega_{g, \text { in }}^{\text {exo }}=0.003$

3. $v_{z, g, \text { in }}^{\text {exo }}=15 \mathrm{~m} \cdot \mathrm{s}^{-1}, \omega_{g, \text { in }}^{\text {exo }}=0.002$ 


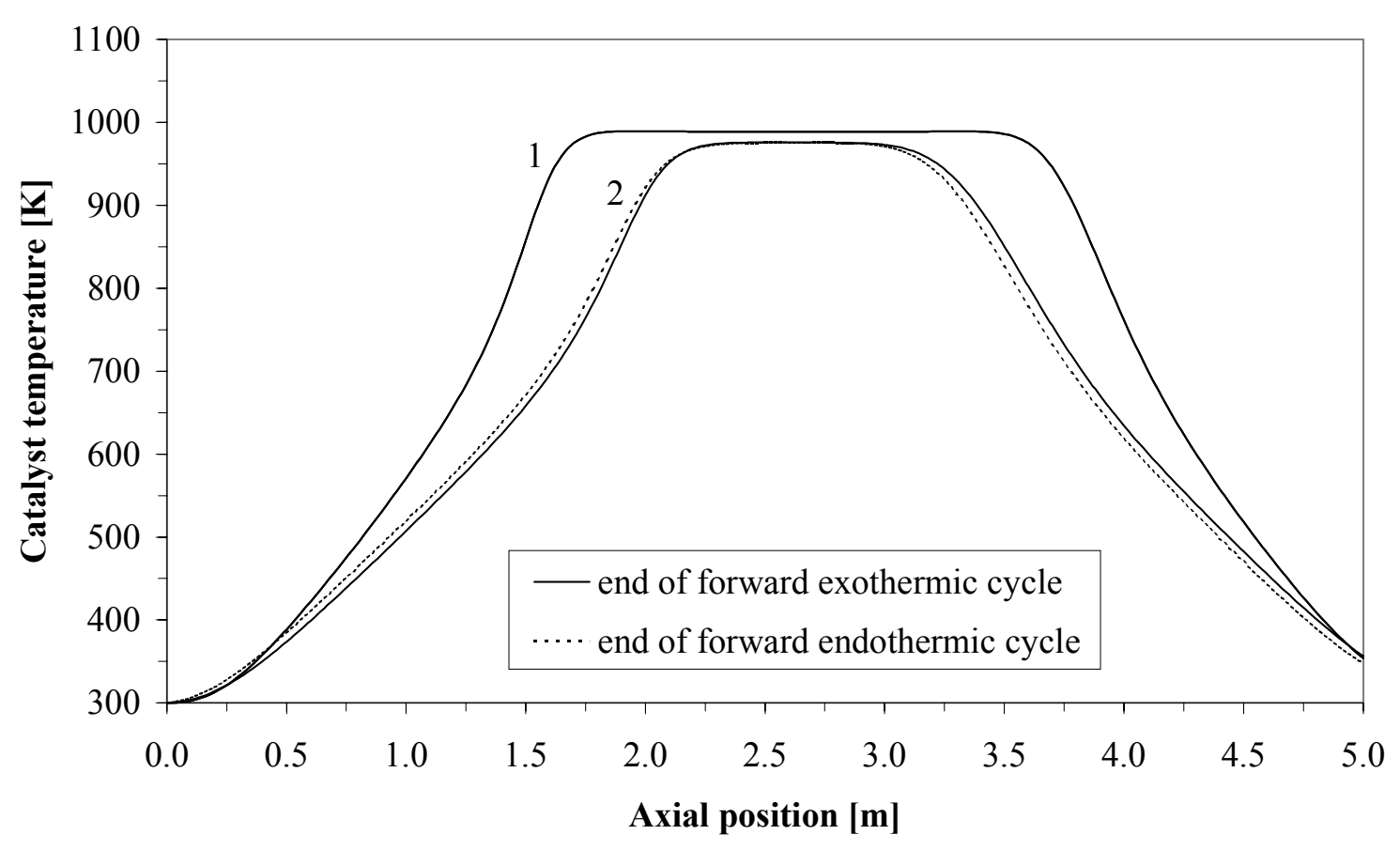

Figure 7. Influence of the heat transfer rate between the endothermic and exothermic compartments $\left(\lambda_{s} / \delta_{s}\right)$ on the axial catalyst temperature profile for the co-currently operated simultaneous reactor configuration, for the following operating conditions: $\omega_{g, \text { in }}^{\text {endo }}=1, v_{z, g, \text { in }}^{\text {endo }}=0.25 \mathrm{~m} \cdot \mathrm{s}^{-1}$, $v_{z, g, \text { in }}^{\text {exo }}=10 \mathrm{~m} \cdot \mathrm{s}^{-1}, \omega_{g, \text { in }}^{\text {exo }}=0.003$. The flow direction is reversed every $30 \mathrm{~s}$.

1. $\lambda_{s} / \delta_{s}=4000 \mathrm{~W} \cdot \mathrm{m}^{-2} \cdot \mathrm{K}^{-1}$

2. $\lambda_{s} / \delta_{s}=40 \mathrm{~W} \cdot \mathrm{m}^{-2} \cdot \mathrm{K}^{-1}$

Finally, comparably high reaction coupling energy efficiencies can be accomplished in the co-currently operated simultaneous reactor configuration as in the sequential reactor configuration $\left(\omega_{g, i n, \min }^{\text {exo }}=0.00229\right)$.

\subsection{Counter-current operation}

For the counter-currently operated simultaneous reactor configuration firstly the steady state is studied when endothermic and exothermic reactants are continuously fed to the same compartment. Thereafter the dynamic response to switching of compartments - necessary for catalyst regeneration - is reported. 
In contrast to the earlier configurations described, in counter-current operation the endothermic and exothermic reaction zones are located at opposite reactor ends and do not overlap for sufficiently long reactors. Assuming that the operating conditions have been set such that the overall energy balance is satisfied, a steady state can only be attained if the gas velocities of both reaction phases are tuned according to their heat front velocities. This result can easily be derived using a partial energy balance for either reaction zone. The partial energy balance over the exothermic reaction zone states that the energy produced by the exothermic reactions equals the difference in energy required for heating the exothermic reactants and the energy gained by cooling the endothermic products,

$0=\Phi_{m, \text { in }}^{\prime \prime \text { exo }} \omega_{g, \text { in }}^{\text {exo }}\left(-\Delta h_{r}^{\text {exo }}\right) \zeta^{\text {exo }}-\Phi_{m, \text { in }}^{\text {"exo }}\left(C_{p, g, \text { max }}^{\text {exo }} T_{c, \text { max }}-C_{p, g, \text { in }}^{\text {exo }} T_{g, \text { in }}\right)+\Phi_{m, \text { in }}^{\text {endo }}\left(C_{p, g, \max }^{\text {endo }} T_{c, \text { max }}-C_{p, g, \text { out }}^{\text {endo }} T_{g, \text { out }}^{\text {endo }}\right)$

Assuming constant heat capacities this can be rearranged into

$\frac{\Phi_{m, \text { in }}^{\prime \prime \text { endo }}}{\Phi_{m, \text { in }}^{\prime \text { exo }}}=\frac{C_{p, g}^{\text {exo }}}{C_{p, g}^{\text {endo }}} \frac{\left(T_{c, \max }-T_{g, \text { in }}\right)-\Delta T_{a d}^{\text {exo }} \zeta^{\text {exo }}}{\left(T_{c, \max }-T_{g, \text { out }}^{\text {endo }}\right)}$

Substitution of the heat front velocities during the exothermic and endothermic reaction phases, $w^{\text {exo }}$ and $w^{\text {endo }}$ respectively, results in

$\frac{w^{\text {exo }}}{w^{\text {endo }}}=1-\frac{T_{g, \text { out }}^{\text {endo }}-T_{g, \text { in }}}{T_{c, \max }-T_{g, \text { in }}}$

where the front velocities during the exothermic and endothermic reaction phases are respectively given by

$$
\begin{aligned}
& w^{\text {exo }} \approx \frac{\Phi_{m, \text { in }}^{\text {"exo }} C_{p, g}^{\text {exo }}}{(1-\varepsilon) \rho_{c} C_{p, c}}\left[1-\frac{\Delta T_{a d}^{\text {exo }} \zeta^{\text {exo }}}{T_{c, \text { max }}-T_{g, \text { in }}}\right] \\
& w^{\text {endo }} \approx \frac{\Phi_{m, \text { in }}^{\text {"endo }} C_{p, g}^{\text {endo }}}{(1-\varepsilon) \rho_{c} C_{p, c}}
\end{aligned}
$$


The partial energy balance thus states that the heat front velocity of the endothermic and exothermic reaction phases needs to be equal to obtain a steady state, neglecting convective heat losses. It should be noted that because of this partial energy balance the ratio of gas velocities is fixed and only a small lasting deviation in this ratio can be allowed due to the convective heat losses (see Figure 8). If the heat front velocity in the exothermic compartment exceeds the heat front velocity in the endothermic compartment, a temperature peak will move through the catalyst bed from the exothermic feed inlet towards the endothermic feed inlet and in time the reactor will extinguish. In the reverse case, when the exothermic heat front velocity is lower than the endothermic heat front velocity, a steady state can be attained at the cost of a much lower conversion in the endothermic compartment. However, the dynamic response of the axial catalyst temperature profile to variations in the gas velocities is extremely slow.

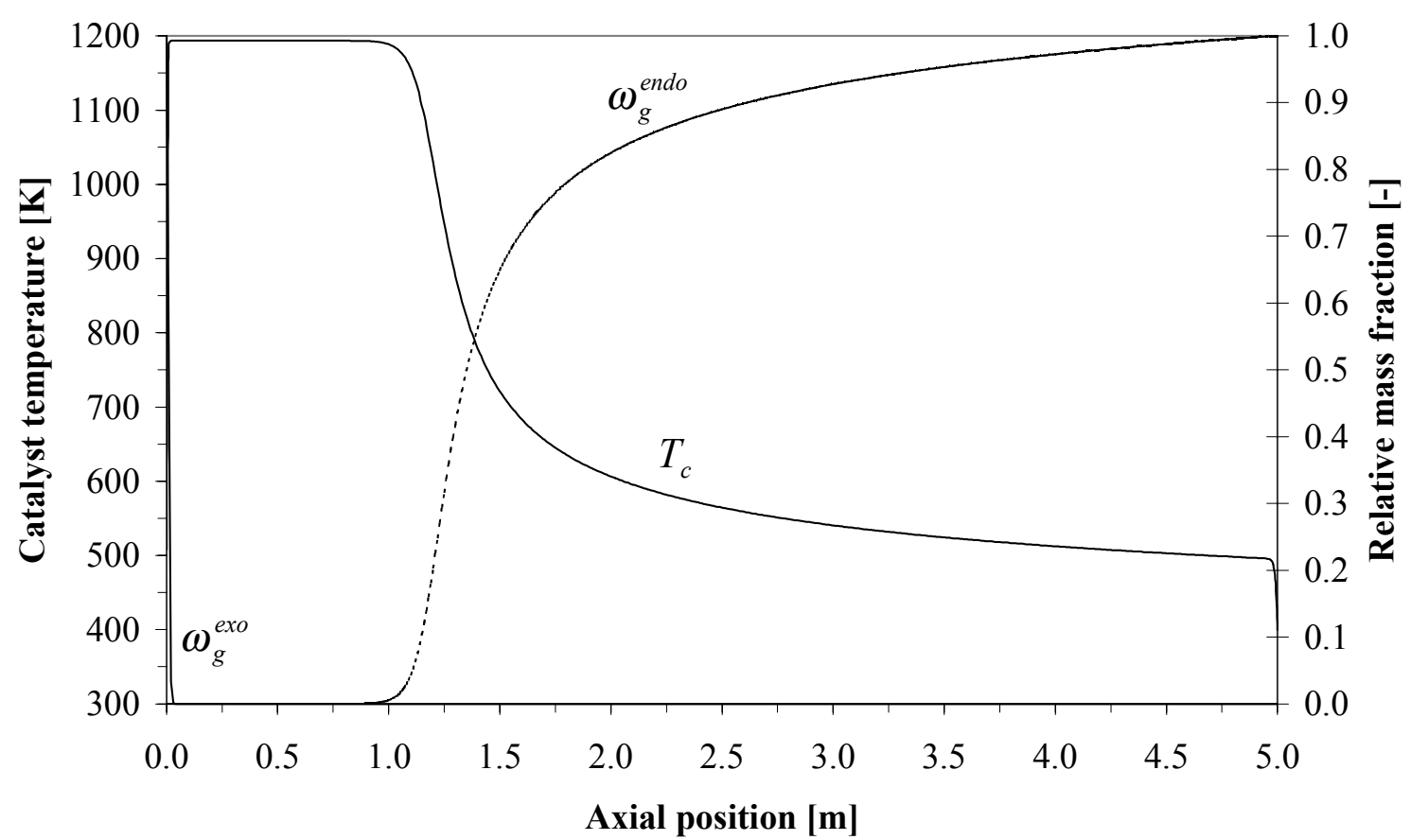

Figure 8.a The axial profiles of the catalyst temperature and gas phase mass fraction normalised with the inlet mass fraction for the counter-currently operated simultaneous reactor configuration. The heat front velocity during the exothermic reaction phase is approximately equal to the heat front velocity during the endothermic reaction phase $\left(w^{\text {exo }} \approx w^{\text {endo }}\right)$

(Operating conditions: $\omega_{g, \text { in }}^{\text {endo }}=1, v_{z, g, \text { in }}^{\text {endo }}=0.25 \mathrm{~m} \cdot \mathrm{s}^{-1}, \omega_{g, \text { in }}^{\text {exo }}=0.01, v_{z, g, \text { in }}^{\text {exo }}=2.6 \mathrm{~m} \cdot \mathrm{s}^{-1}$ ). 


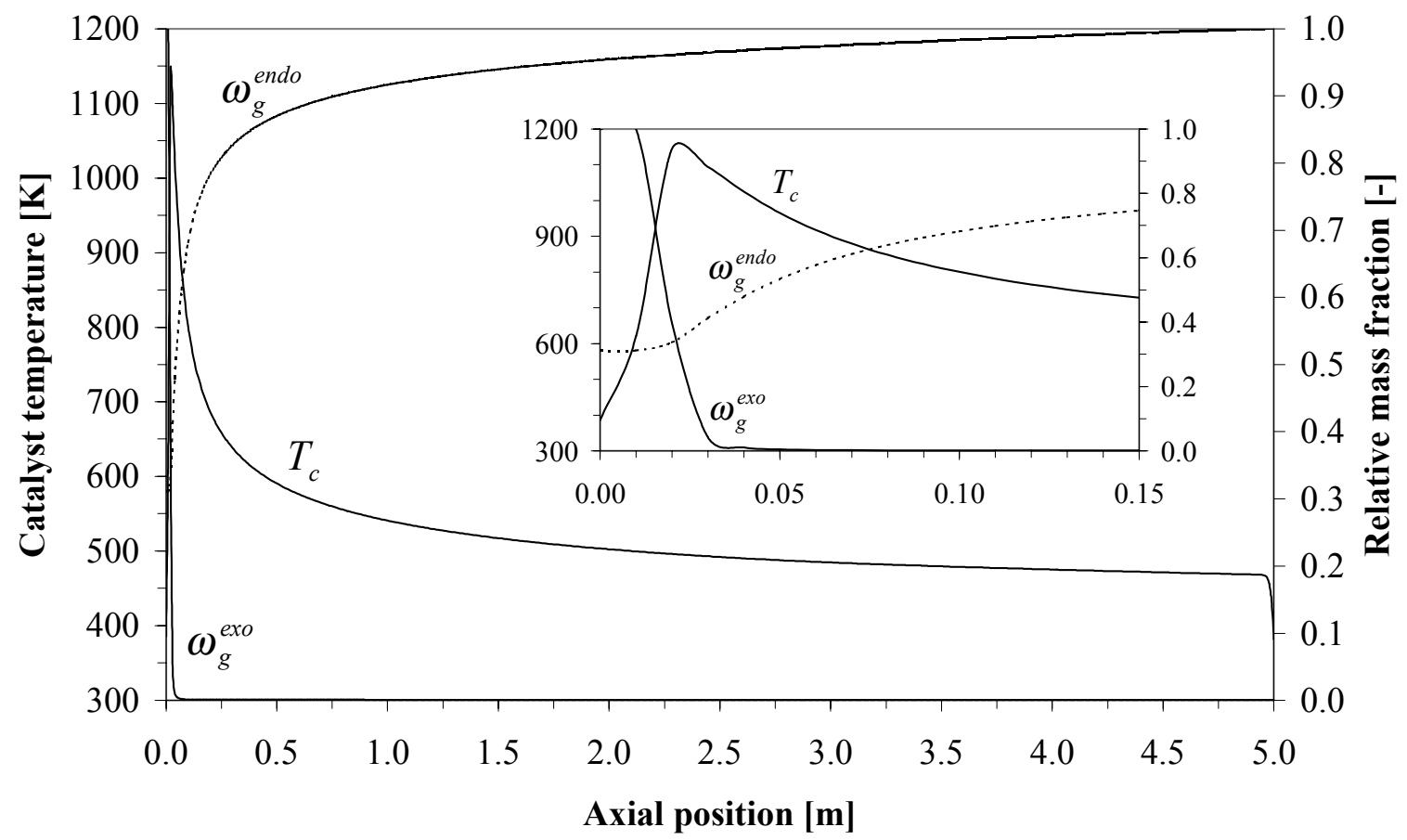

Figure 8.b The axial profiles of the catalyst temperature and gas phase mass fraction normalised with the inlet mass fraction for the counter-currently operated simultaneous reactor configuration. The heat front velocity during the exothermic reaction phase is smaller than the heat front velocity during the endothermic reaction phase $\left(w^{\text {exo }}<w^{\text {endo }}\right)$

(Operating conditions: $\omega_{g, i n}^{\text {endo }}=1, v_{z, g, \text { in }}^{\text {endo }}=0.25 \mathrm{~m} \cdot \mathrm{s}^{-1}, \omega_{g, i n}^{\text {exo }}=0.01, v_{z, g, \text { in }}^{\text {exo }}=2.0 \mathrm{~m} \cdot \mathrm{s}^{-1}$ ).

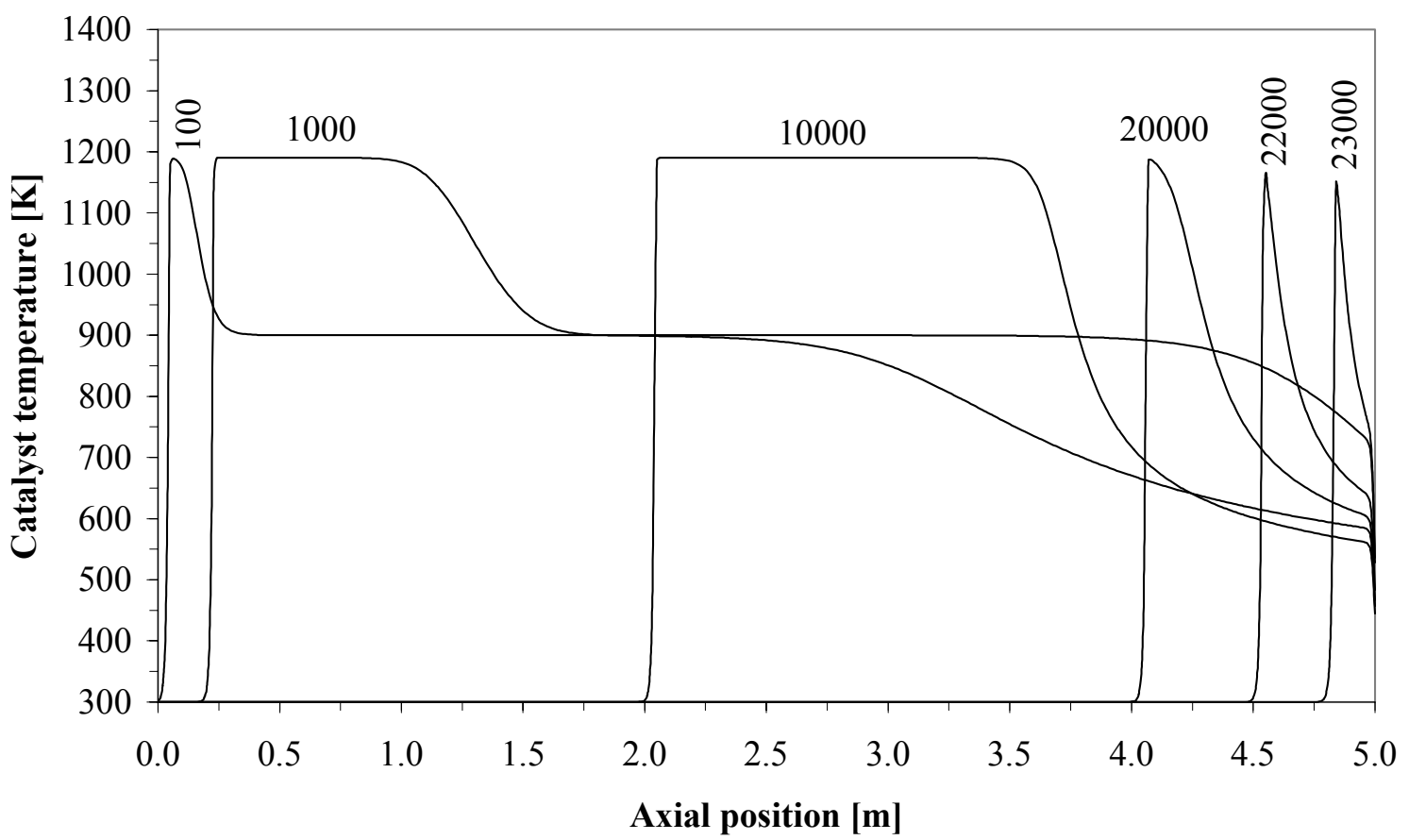

Figure 8.c Evolution of the axial profile of the catalyst temperature for the counter-currently operated simultaneous reactor configuration. The heat front velocity during the exothermic reaction phase is larger than the heat front velocity during the endothermic reaction phase $\left(w^{\text {exo }}>w^{\text {endo }}\right)$ (Time in s).

(Operating conditions: $\omega_{g, \text { in }}^{\text {endo }}=1, v_{z, g, \text { in }}^{\text {endo }}=0.25 \mathrm{~m} \cdot \mathrm{s}^{-1}, \omega_{g, \text { in }}^{\text {exo }}=0.01, v_{z, g, \text { in }}^{\text {exo }}=3.0 \mathrm{~m} \cdot \mathrm{s}^{-1}$.) 
Because the exothermic reaction zone is located very close to the exothermic feed inlet, the convective heat losses are relatively large, resulting in much lower reaction coupling energy efficiencies for the counter-current operation ( $c a$. 70\%) compared to the other reactor configurations described. Frauhammer et al. (1999) used inactive sections to shift the exothermic reaction zone further away from the inlet, thereby increasing the reaction coupling energy efficiency. However, inactive sections strongly increase the maximum temperature.

\subsubsection{Effect of switching of compartments}

Switching of compartments in a counter-currently operated simultaneous reactor configuration can be carried out with and without simultaneous switching of the inlet and outlet positions (switching form operation mode (e) to (f) or from (e) to (h) in Figure 1 respectively). Only in case the inlet and outlet positions are fixed and only the reactant feed streams are exchanged, a transient response of the temperature profiles is induced by the switching of the compartments, again neglecting energy effects during catalyst regeneration.

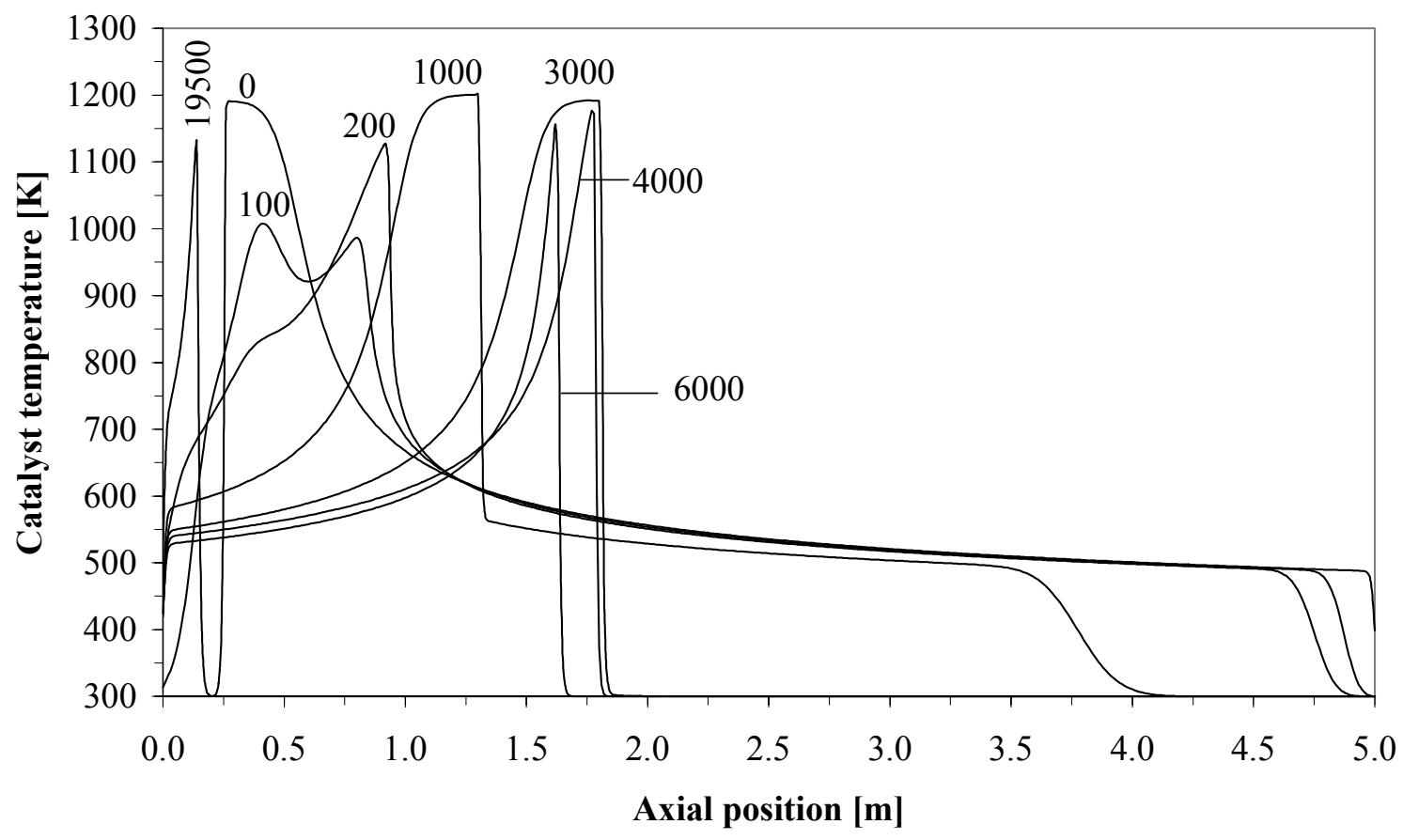

Figure 9. Dynamic response of the axial catalyst temperature profile for the counter-currently operated simultaneous reactor configuration to switching of the compartments after $11800 \mathrm{~s}$, while fixing the inlet and outlet positions. (Operating conditions: $\omega_{g, \text { in }}^{\text {endo }}=1$, $\left.v_{z, g, i n}^{\text {endo }}=0.25 \mathrm{~m} \cdot \mathrm{s}^{-1}, \omega_{g, \text { in }}^{\text {exo }}=0.01, v_{z, g, \text { in }}^{\text {exo }}=2.5 \mathrm{~m} \cdot \mathrm{s}^{-1}\right)$. (Time in $\mathrm{s}$ ). 
In Figure 9 the development of the catalyst temperature profile is shown when the feed streams to the compartments are switched after $3 \mathrm{~h}$ from start-up. Upon switching, the existing temperature peak is consumed while a new temperature peak is created on the side of the existing temperature peak. This temperature peak then moves towards the other reactor end. However, before a new steady state can be reached, this temperature peak is pushed back out of the reactor and unfortunately the reactor extinguishes after a very long time.

Remarkably, if the compartments are switched every 15 min. extinction can be avoided (see Figure 10). In this new cyclic steady state a new temperature peak is created close to the exothermic feed inlet, because of higher remaining temperatures as a result from faster compartment switching.

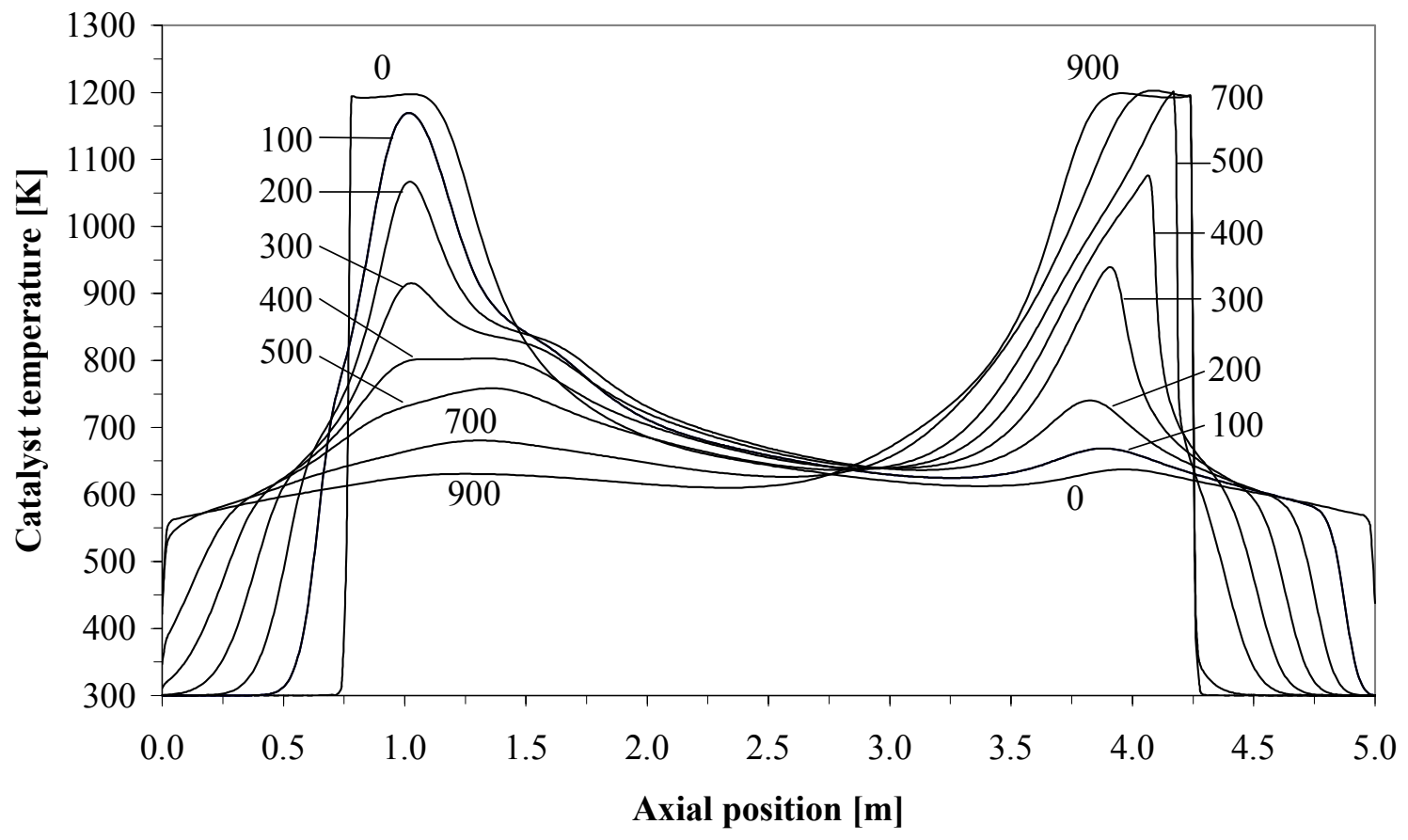

Figure 10. Dynamic response of the axial catalyst temperature profile for the counter-currently operated simultaneous reactor configuration to switching of the compartments every $900 \mathrm{~s}$, while fixing the inlet and outlet positions. (Operating conditions: $\omega_{g, \text { in }}^{\text {endo }}=1, v_{z, g, \text { in }}^{\text {endo }}=$ $\left.0.25 \mathrm{~m} \cdot \mathrm{s}^{-1}, \omega_{g, \text { in }}^{e x o}=0.01, v_{z, g, \text { in }}^{\text {exo }}=2.5 \mathrm{~m} \cdot \mathrm{s}^{-1}\right)$. (Time in $\mathrm{s}$ ). 


\section{Comparison of reactor configurations}

It has been shown that indirect coupling of endothermic and exothermic reactions can be effectively integrated with recuperative heat exchange in both reactor configurations for the propane dehydrogenation and methane combustion. Especially for the sequential reactor configuration and the co-currently operated simultaneous reactor configuration very high reaction coupling energy efficiencies can be achieved ( $\geq 96 \%)$. The reaction coupling energy efficiency for the counter-current simultaneous reactor configuration is $c a$. $70 \%$ for the same endothermic production capacity.

In the sequential reactor configuration catalyst regeneration is achieved during the exothermic reaction phase. In the simultaneous reactor configuration catalyst regeneration requires compartment switching, which effects the reactor behaviour only for the counter-current operation mode with fixed inlet and outlet positions. For this operation mode, compartment switching induces a cyclic steady state for appropriate switching times.

Table 6. Energy constraints for the different reactor configurations.

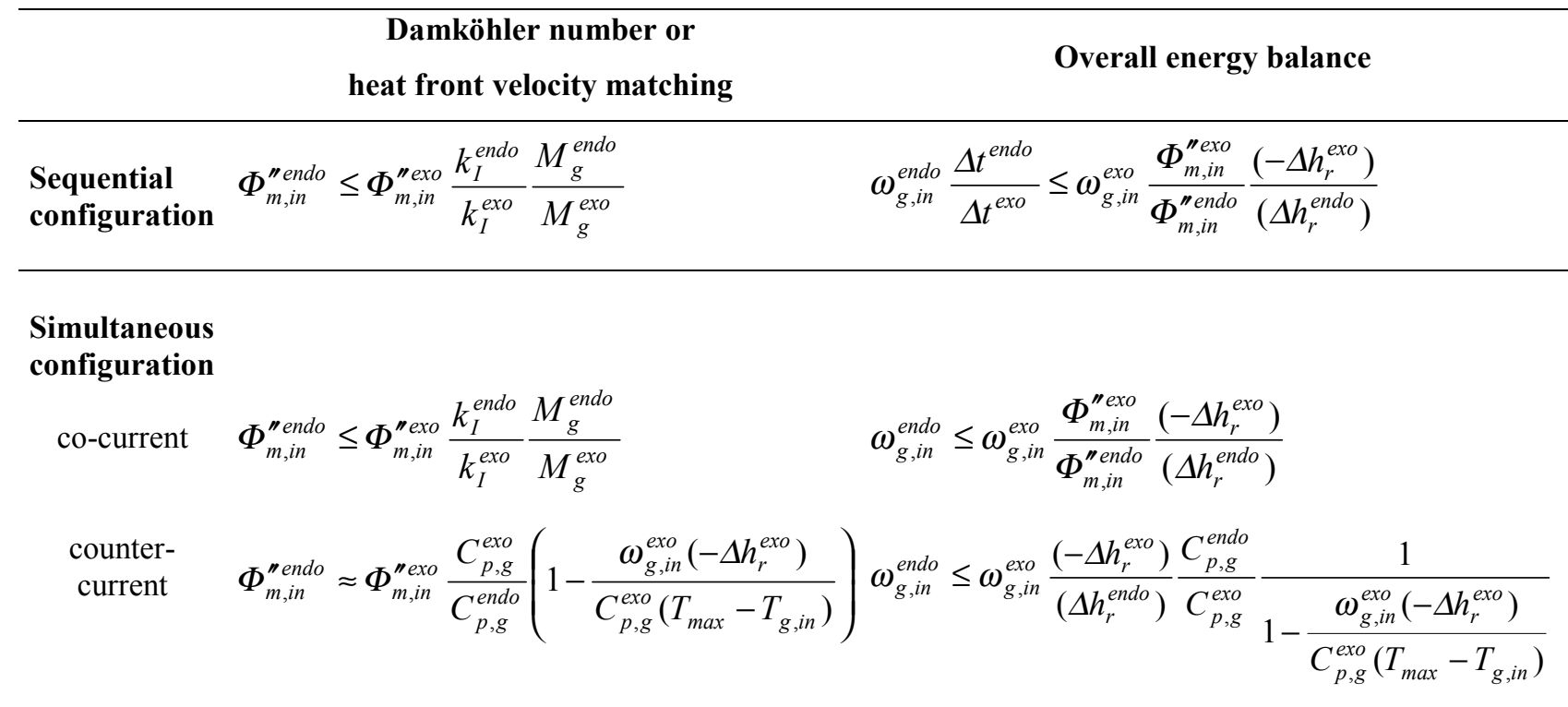

When optimising the operating conditions for a sequential or simultaneous reverse flow reactor coupling the endothermic propane dehydrogenation and exothermic methane combustion, the energy constraints discussed above (summarised in Table 6) have to be satisfied in order to effectuate an ignited cyclic steady state with maximum conversion during 
both reaction phases. Furthermore, additional constraints on the operating conditions need to be taken into account, of which a maximum catalyst temperature, maximum gas velocity and maximum exothermic inlet mass fraction are the most important. Firstly, it is very important to note that the axial catalyst temperature profile results from the dynamic reactor behaviour and can only be controlled indirectly by adjusting the exothermic inlet conditions. For the sequential reactor configuration the maximum catalyst temperature is almost solely dependent on the exothermic inlet mass fraction and the inlet gas velocity with negligible influence of the switching scheme, cycle times and endothermic operating conditions. Also for the counter-current simultaneous reactor the maximum temperature is completely determined by the exothermic inlet conditions. Inactive sections flanking the catalyst bed have been proposed to control the maximum temperature (e.g. Eigenberger and Nieken, 1988; Frauhammer et al., 1999). However, inert sections increase the maximum catalyst temperature. Due to immediate heat transfer between the endothermic and exothermic reaction zones in the co-currently operated simultaneous reactor configuration the endothermic reaction conditions can influence the maximum catalyst temperature to some extent. Nevertheless, the maximum temperature constraint restricts the possible inlet conditions for the exothermic reaction phase.

Secondly, the ratio of the gas velocities need to be matched; for the sequential configuration and the co-currently operated simultaneous reactor configuration according to the ratio of the Damköhler numbers and for the counter-currently operated simultaneous reactor according to the ratio of the heat front velocities. Since on the one hand combustion reactions are much faster than dehydrogenation reactions, and on the other hand the heat front velocity during the exothermic phase is lower than during the endothermic reaction phase, generally, the exothermic gas velocity has to be chosen higher than the endothermic gas velocity for all reactor configurations.

Maximum throughput during the endothermic reaction phase can thus be achieved by setting the exothermic gas velocity to the maximum allowable value,

$\Phi_{m, i n}^{\prime \prime e x o}=\varepsilon \rho_{g, i n}^{e x o} v_{z, g, \max }$ 
At high gas velocities the maximum temperature can only be controlled by the exothermic inlet mass fraction,

$\omega_{g, \text { in }}^{\text {exo }} \approx \frac{2 k_{r, \infty}^{e x o} \rho_{g, \text { in }}^{e x o} T_{g, \text { in }}\left(C_{p, g}^{e x o}\right)^{2}}{\left(-\Delta h_{r}^{e x o}\right) h^{e x o}} \Theta_{\max }$

with

$\Theta_{\max }=\theta_{c, \max } \exp \left(-\frac{1}{\theta_{c, \max }}\right)\left[1-\theta_{c, \max } \frac{1-2 \theta_{c, \max }}{1-5 \theta_{c, \text { max }}^{2}}\right]$

For the reaction system under consideration the exothermic inlet concentrations are well below the lower explosion limit and are low enough to assure wrong way behaviour.

Having specified the exothermic inlet mass fraction $\omega_{g, i n}^{e x o}$, exothermic inlet gas velocity $v_{z, g, i n}^{e x o}$ and the endothermic inlet gas velocity $v_{z, g, i n}^{\text {endo }}$, the endothermic inlet mass fraction, multiplied with the ratio of the endothermic reaction cycle time to the exothermic reaction cycle time in case of the sequential reactor configuration, $\omega_{g, i n}^{\text {endo }} \frac{\Delta t^{\text {endo }}}{\Delta t^{\text {exo }}}$ need to be set according to the overall energy balance.

For the co-currently operated simultaneous reactor configuration the minimum endothermic inlet mass fraction is about $75 \%$ when the Damköhler numbers are matched (see Figure 11). It should be realised that Damköhler matching impose only an approximate minimum ratio of the exothermic to endothermic gas velocities. Higher endothermic mass fractions can be chosen, if the gas velocity ratio is increased accordingly following the overall energy balance. Furthermore, for the sequential reactor configuration the ratio of the reaction cycle times gives an extra opportunity to optimise the endothermic inlet mass fraction for optimal product yield independently of the gas velocity ratio, however, at constant time-averaged production capacity. It is emphasised that the optimisation of the endothermic inlet mass fraction and gas velocity is only possible if a switching scheme is selected with inherent zero differential creep velocity. 


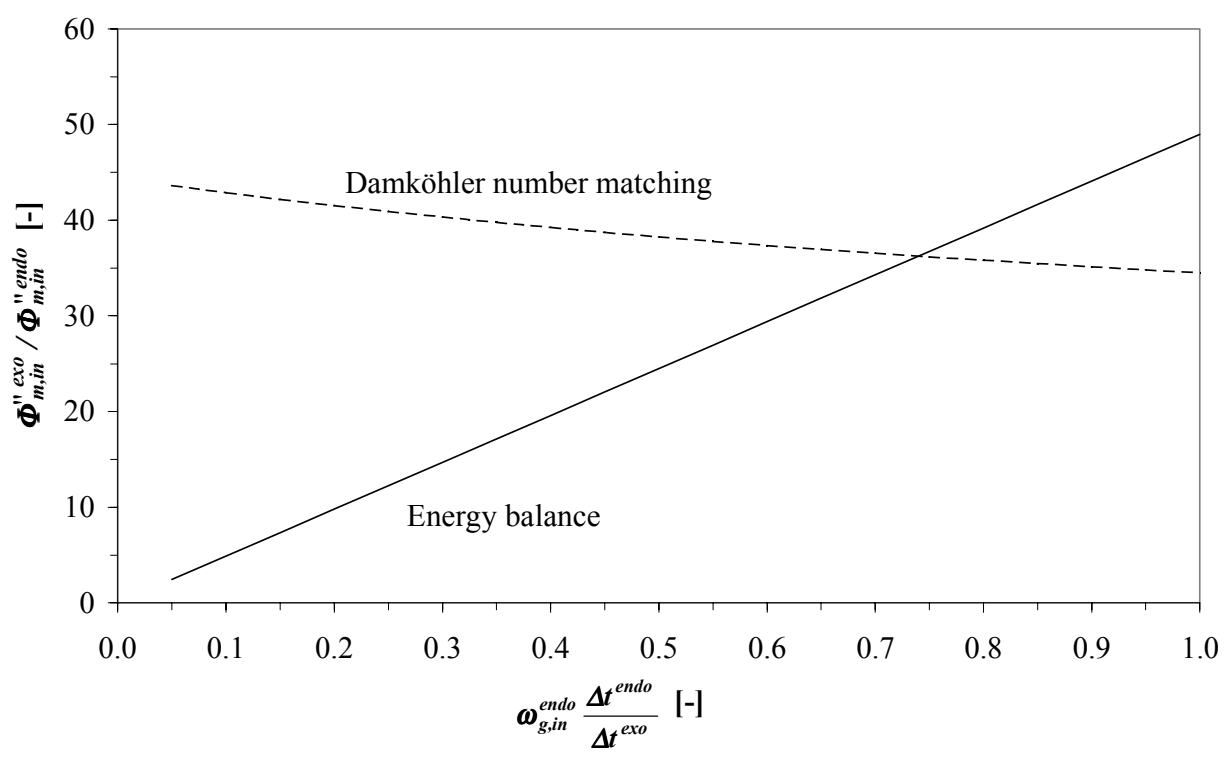

Figure 11. Operation window for the sequential reactor configuration and the simultaneous reactor configuration in co-current operation (setting the ratio of reaction phase cycle times to one).

For the counter-currently operated simultaneous reactor configuration the ratio of the gas velocities is fixed tightly according to the heat front velocities and the maximum ratio of the endothermic and exothermic inlet mass fractions according to the overall energy balance. At high gas velocities the maximum temperature can only be controlled by the exothermic inlet mass fraction. Thereby also the endothermic inlet mass fraction is set, unfortunately to a very low mass fraction of only $c a .2 .5 \%$ for the coupling of propane dehydrogenation and methane combustion (see Figure 12). It is very questionable whether a reverse reactor with reaction coupling is interesting for such small inlet concentrations of endothermic reactants. At lower gas velocities the maximum temperature can also be controlled with the exothermic gas velocity, allowing an increase of the endothermic mass fraction, however, at the expense of much lower throughputs. Selecting a pure propane feed for the dehydrogenation, only an inlet gas velocity of $0.015 \mathrm{~m} \cdot \mathrm{s}^{-1}$ can be tolerated for the endothermic reaction phase for the countercurrent simultaneous reactor, while an endothermic inlet gas velocity of $0.13 \mathrm{~m} \cdot \mathrm{s}^{-1}$ can be selected for the sequential and co-currently operated simultaneous reactor configuration, assuming $10 \mathrm{~m} \cdot \mathrm{s}^{-1}$ as a maximum inlet gas velocity. Maximum temperature control in a counter-current operation can only be accomplished with the unfavourable combination of relatively high throughput but small inlet concentrations, or high inlet concentrations but small throughput. 


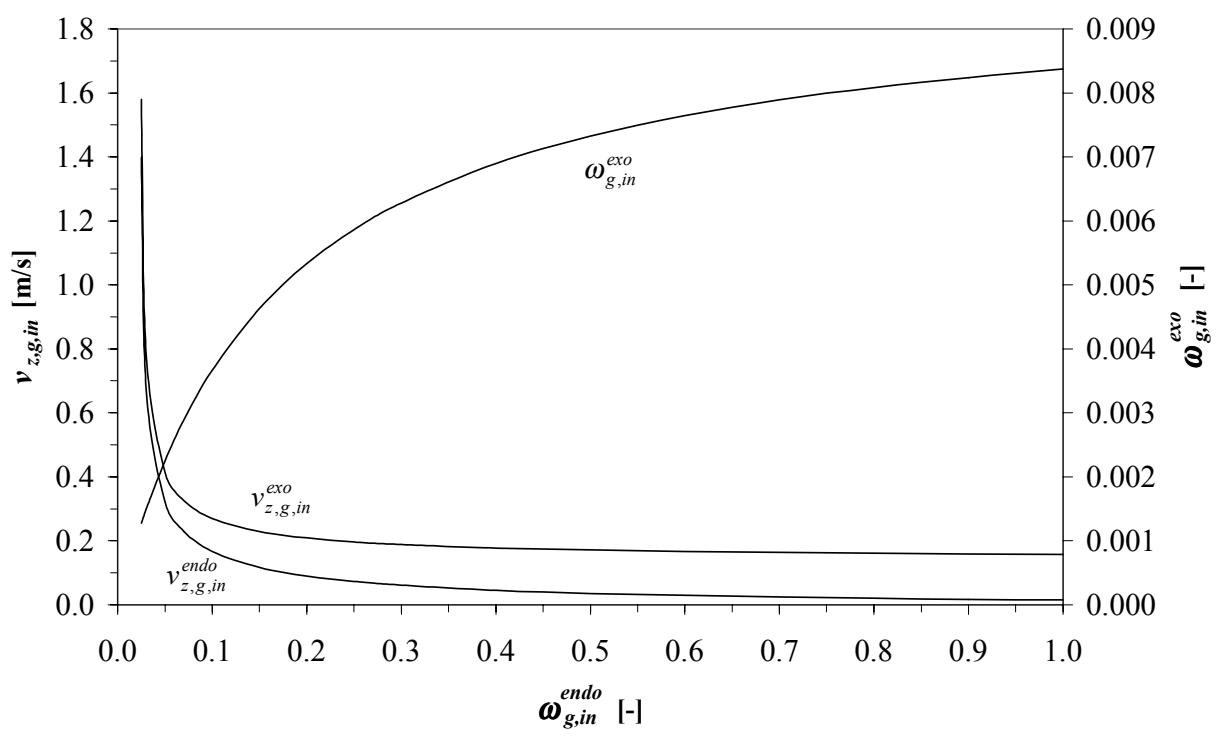

Figure 12. Operation window for the simultaneous reactor configuration in counter-current operation.

\section{Summary and conclusions}

A new reactor concept for highly endothermic reactions at high temperatures with possible rapid but reversible catalyst deactivation based on the indirect coupling between endothermic and exothermic reactions and the reverse flow concept has been studied. Two different reactor configurations have been considered, the sequential reactor configuration and the simultaneous reactor configuration in co-current and counter-current operation mode. In the sequential reactor configuration the endothermic and exothermic reactants are fed discontinuously and sequentially to the same catalyst bed acting as an energy repository. In the simultaneous reactor configuration the endothermic and exothermic reactants are fed continuously to two different compartments exchanging energy. Their reactor behaviour has been investigated via detailed numerical simulations.

Energy constraints to achieve an ignited cyclic steady state with maximum conversion for both the endothermic and exothermic reaction phases have been discussed. For the sequential reactor configuration and the co-currently operated simultaneous reactor configuration, not only the total amount of energy transferred from the exothermic to the endothermic reaction phase needs to be tuned, but also the axial position relative to the heat front where the energy is released during the exothermic reaction phase and consumed during the endothermic reaction phase needs to be adjusted via matching of the Damköhler numbers. Furthermore, 
zero differential creep velocity - trivial for the co-currently operated simultaneous reactor configuration - can be achieved in the sequential reactor configuration without additional constraints on the operating conditions by choosing an appropriate switching scheme. To avoid extinction in the counter-currently operated simultaneous reactor configuration the endothermic and exothermic gas velocities need to be set to attain equal heat front velocities.

For the coupling of propane dehydrogenation and methane combustion over a monolithic platinum-based catalyst the maximum temperature constraint limits the operating conditions during the exothermic reaction zone and thus the total production capacity. It has been shown that the maximum temperature depends on a single dimensionless number. At high gas velocities this maximum-temperature-number depends only on the exothermic inlet mass fraction, so that control of the maximum temperature can only be achieved via the exothermic inlet concentration at high throughputs. Since the ratio of the endothermic and exothermic inlet mass fractions is fixed in the counter-currently operated simultaneous reactor configuration, a limiting maximum temperature constraint entails the unfavourable combination of a relatively high throughput with small inlet concentrations, or high inlet concentrations with a small throughput. Moreover, relatively low reaction coupling energy efficiencies (ca. $70 \%$ ) are obtained with the counter-currently operated simultaneous reactor configuration.

With the sequential reactor configuration or the co-currently operated simultaneous reactor configuration much higher capacity for the production of the endothermic products can be achieved with very high reaction coupling energy efficiencies ( $\geq 96 \%)$. Due to the choice of a switching scheme with inherent zero differential creep velocity, only in the sequential reactor configuration the endothermic inlet concentration can be optimised without adjusting the gas velocities, using the ratio of the endothermic to exothermic reaction cycle times.

\section{Acknowledgements}

The author wishes to thank H.A. Bottenberg and H.A.R. Scholts for their contributions. Furthermore, the financial support by the Netherlands Organization for Scientific Research (N.W.O.) is gratefully acknowledged. 


\section{Notation}

$a_{v} \quad$ specific external catalyst surface area $\left[\mathrm{m}^{2} \cdot \mathrm{m}^{-3}\right]$

$C_{p} \quad$ heat capacity $\left[\mathrm{J} \cdot \mathrm{kg}^{-1} \cdot \mathrm{K}^{-1}\right]$

$d_{h, c} \quad$ hydraulic channel diameter [m]

$D \quad$ diffusivity $\left[\mathrm{m}^{2} \cdot \mathrm{s}^{-1}\right]$

$D_{a x, j} \quad$ axial dispersion coefficient for component $j\left[\mathrm{~m}^{2} \cdot \mathrm{s}^{-1}\right]$

$f \quad$ friction coefficient [-]

$h \quad$ external heat transfer coefficient $\left[\mathrm{J} \cdot \mathrm{m}^{-2} \cdot \mathrm{K}^{-1} \cdot \mathrm{s}^{-1}\right]$

$\bar{h}_{j} \quad$ partial molar enthalpy of component $j\left[\mathrm{~J} \cdot \mathrm{kg}^{-1}\right]$

$\Delta h_{r} \quad$ reaction enthalpy $\left[\mathrm{J} \cdot \mathrm{kg}^{-1}\right]$

$E_{\text {act }} \quad$ activation energy $\left[\mathrm{J} \cdot \mathrm{mole}^{-1}\right]$

$k_{r, \infty} \quad$ pre-exponential first order heterogeneous reaction rate constant $\left[\mathrm{m} \cdot \mathrm{s}^{-1}\right]$

$k_{x} \quad$ external mass transfer coefficient $\left[\mathrm{m} \cdot \mathrm{s}^{-1}\right]$

$L \quad$ reactor length [m]

$M \quad$ (time-averaged) production capacity $\left[\mathrm{kg} \cdot \mathrm{m}^{-2} \cdot \mathrm{s}^{-1}\right]$

$n_{c} \quad$ total number of components

$p \quad$ pressure $[\mathrm{Pa}]$

$r_{j}^{\text {het }} \quad$ production rate of component $j$ by heterogeneous reactions $\left[\mathrm{kg} \cdot \mathrm{m}^{-2} \cdot \mathrm{s}^{-1}\right]$

$r_{j}^{\text {hom }} \quad$ production rate of component $j$ by homogeneous reactions $\left[\mathrm{kg} \cdot \mathrm{m}^{-3} \cdot \mathrm{s}^{-1}\right]$

$R \quad$ gas constant $\left[\mathrm{J} \cdot \mathrm{mole}^{-1} \cdot \mathrm{K}^{-1}\right]$

$t \quad$ time [s]

$\Delta t \quad$ reaction cycle time $[\mathrm{s}]$

$T$ temperature $[\mathrm{K}]$

$\Delta T_{a d} \quad$ adiabatic temperature difference $[\mathrm{K}]$

$v_{z, g} \quad$ axial interstitial gas velocity $\left[\mathrm{m} \cdot \mathrm{s}^{-1}\right]$

$w \quad$ heat front velocity $\left[\mathrm{m} \cdot \mathrm{s}^{-1}\right]$

$z \quad$ axial position $[\mathrm{m}]$

\section{Greek letters}

$\delta_{s} \quad$ thickness of support separating endothermic and exothermic compartments [m]

$\delta_{i, j} \quad$ Kronecker delta $(=1$, if $i=j ;=0$, if $i \neq j)$ 


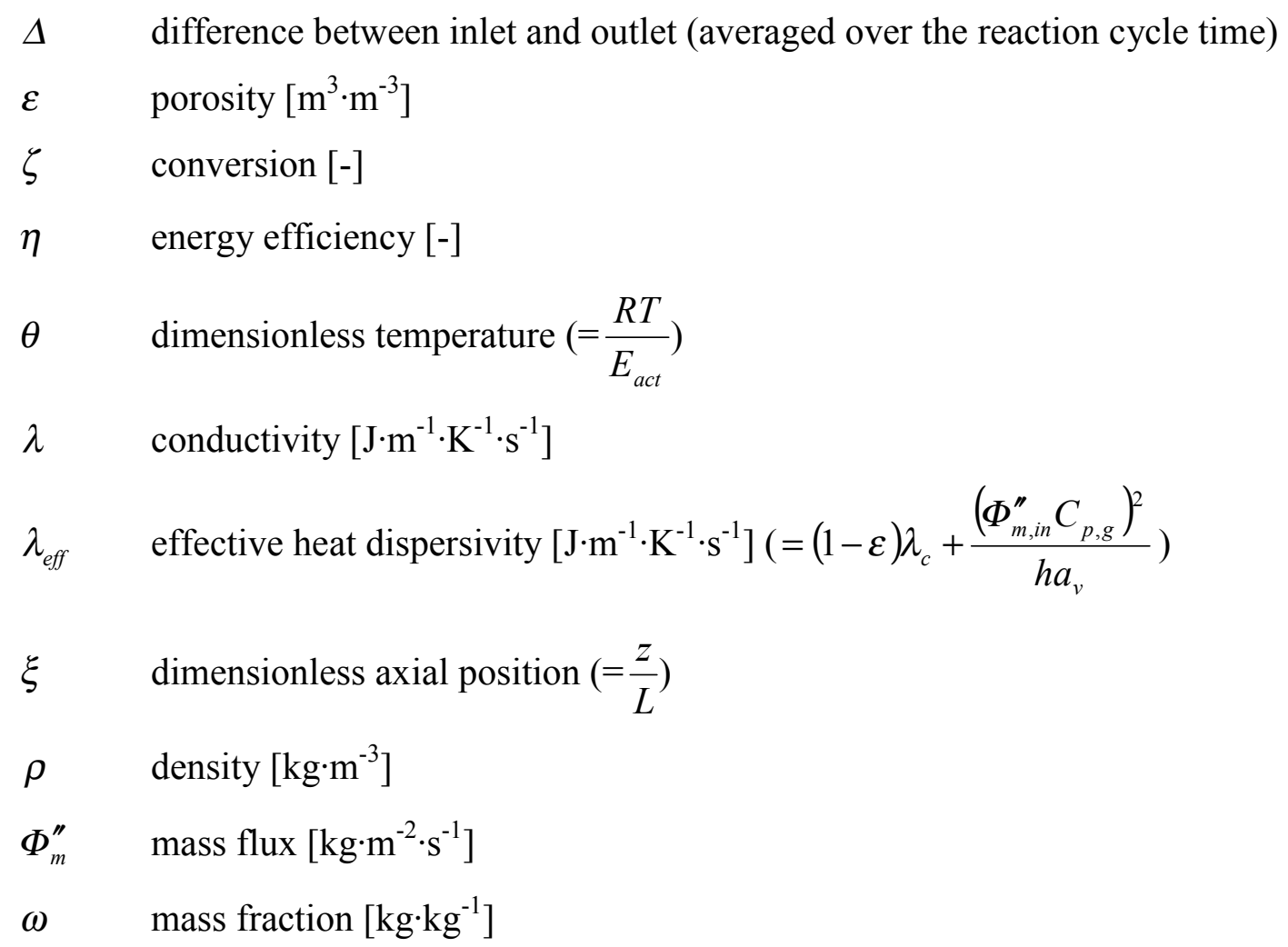

\section{Subscripts}

avg average

c catalyst phase

$g \quad$ gas phase

in at the inlet

$i, j \quad$ component $i, j$

$k, l \quad$ compartment $k, l$

$\max$ maximum

$\min \quad$ minimum

out at the outlet

$s \quad$ support separating endothermic and exothermic compartments

\section{Superscripts}

endo endothermic reaction phase

exo exothermic reaction phase

het heterogeneous reactions

hom homogeneous reactions 


\section{Dimensionless numbers}

$D a_{\infty} \quad$ Damköhler number $\left(=\frac{k_{r, \infty} a_{v} \rho_{g, i n} L}{\Phi_{m, i n}^{\prime \prime}}\right)$

$P e_{h} \quad$ Peclet number for heat transport $\left(=\frac{\Phi_{m, i n}^{\prime \prime} C_{p, g} L}{\lambda_{e f f}}\right)$

$\Delta \theta_{a d} \quad$ dimensionless adiabatic temperature $\left(=\frac{R \Delta T_{a d}}{E_{a c t}}=\frac{R}{E_{a c t}} \frac{\left(-\Delta h_{r}\right) \omega_{g, \text { in }}}{C_{p, g}}\right)$

$\left.\frac{d \theta_{c}}{d \xi}\right|_{\xi=0}$ Dimensionless initial temperature gradient $\left(=\frac{1}{2} \Delta \theta_{a d} P e_{h}=\frac{\Phi_{m, i n}^{\prime \prime} \omega_{g, i n}\left(-\Delta h_{r}\right) R L}{2 \lambda_{\text {eff }} E_{a c t}}\right)$

$\Theta \quad$ Maximum temperature number $\left(=\frac{\left.\frac{d \theta_{c}}{d \xi}\right|_{\xi=0}}{\theta_{g, i n} D a_{\infty}}=\frac{1}{2} \frac{\Delta \theta_{a d}}{\theta_{g, i n}} \frac{P e_{h}}{D a_{\infty}}=\frac{\left(-\Delta h_{r}\right) \Phi_{m, i n}^{\prime \prime 2} \omega_{g, i n}}{2 \lambda_{e f f} k_{r, \infty} a_{v} \rho_{g, i n} T_{g, i n}}\right)$

\section{Symbols}

$\rightarrow \quad$ forward flow

$\leftarrow \quad$ backward flow

$\mapsto \quad$ forward flow, at the beginning of the cycle

$\rightarrow \quad$ forward flow, at the end of the cycle

$\leftarrow \quad$ backward flow, at the beginning of the cycle

$\leftrightarrow \quad$ backward flow, at the end of the cycle

\section{References}

Agrawal, R.K. and Sivasubramanian, M.S. (1987). Integral approximations for nonisothermal kinetics. AIChE J., 33, 1212-1214

Bird, R.B. Stewart, W.E. and Lightfoot, E.N. (1960). Transport phenomena. John Wiley \& sons, New York, USA 
Centrella, J. and Wilson, J. (1984). Planar numerical cosmology. II. The difference equations and numerical tests, Astrophysical J. Suppl. Ser., 54, 229-249

Dauber, T.E. and Danner, R.P. (1985). Data compilation tables of properties of pure compounds, AIChE, New York, USA

Eigenberger, G. and Nieken, U. (1988). Catalytic combustion with periodic flow reversal. Chem. Engng Sci., 43, 2109-2115

Frauhammer, J., Eigenberger, G., Hippel, L.v. and Arntz, D. (1999). A new reactor concept for endothermic high-temperature reactions. Chem. Engng Sci., 54, 3661-3670

Froment, G.F. (1990). Reversed flow operation of fixed bed catalytic reactors. In Matros, Yu. Sh. (Ed.) Unsteady state processes in catalysis, VSP, Utrecht, The Netherlands, 57-89

Hayes, R.E., Kolaczkowski, S.T., Thomas, W.J. and Titiloye, J. (1996). Transient experiments and modeling of the catalytic combustion of methane in a monolith reactor. Ind. Eng. Chem. Res., 35, 406-414

Haynes, T.N., Georgakis, C. and Caram, H.S. (1995). The design of reverse flow reactors for catalytic combustion systems. Chem. Engng Sci., 50, 401-416

Kulkarni, M.S. (1996a). Dynamics of asymmetric fixed-bed reactors: coupling of exothermic and endothermic reactions. Ph.D. Thesis, Sever Institute of Washington University, Saint Louis, USA

Kulkarni, M.S. and Dudukovic M.P. (1996b). A bidirectional fixed-bed reactor for coupling of exothermic and endothermic reactions. AIChE J., 42, 2897-2910

Kulkarni, M.S. and Dudukovic, M.P. (1997). Periodic operation of asymmetric bidirectional fixed-bed reactors: energy efficiency. Chem. Engng Sci., 52, 1777-1788 
Loc, L.C., Gaidai, N.A., Kiperman, S.L., T’huoang, H.S., Podkletnova, N.M. and Kogan, S.B. (1991). Kinetics of propane dehydrogenation on aluminoplatinum catalysts. Kinetics and Catalysis, 32, 61-66

Matros, Yu. Sh. (1990). Performance of catalytic processes under unsteady-state conditions. In Matros, Yu. Sh. (Ed.) Unsteady state processes in catalysis, VSP, Utrecht, The Netherlands, 131-163

Matros, Yu. Sh. and Bunimovich, G.A. (1997). Unsteady-state reactor operation. In Ertl, G., Knötzinger, H. and Weitkamp, J. (Eds.) Handbook of heterogeneous catalysis, Wiley-VCH, Weinheim, 1464-1479

Nieken, U., Kolios, G., and Eigenberger G. (1995). Limiting cases and approximate solutions for fixed-bed reactors with periodic flow reversal. AIChE J., 41, 1915-1925

Reid, R.C., Prausnitz, J.M. and Poling, B.E. (1988). The properties of gases and liquids. McGraw-Hill Book Company, New York, USA

Trimm, D.L. and Lam, C.-W. (1980). The combustion of methane on platinum-alumina fibre catalysts - I. Kinetics and mechanism. Chem. Engng Sci., 35, 1405-1413

Van Sint Annaland, M., Kuipers, J.A.M. and van Swaaij, W.P.M. (2000). Safety analysis of switching between reductive and oxidative conditions in a Reaction Coupling Reverse Flow Reactor. Accepted for publication in Chem. Engng Sci. (presented at ISCRE 16, Cracow, Poland). 


\section{Appendix A - Maximum temperature in a reverse flow reactor}

Based on a pseudo-homogeneous HSFM, an approximate analytical expression can be obtained for the maximum temperature in a reverse flow reactor for a single exothermic reaction with first order reaction kinetics in case of non-overlapping reaction zones according to (Nieken et al., 1995)

$$
\int_{T_{g, i n}+\Delta T_{a d}}^{T_{c, \text { max }}} \frac{\rho_{g}}{k_{x} \frac{4 \varepsilon}{d_{h, c}}+\frac{1}{k_{r, \infty} a_{v} \exp \left(-\frac{E_{a c t}}{R T_{c}}\right)}} d T_{c}=\frac{\left(-\Delta h_{r}\right)\left(\Phi_{m, i n}^{\prime \prime}\right)^{2} \omega_{g, \text { in }}}{2 \lambda_{e f f}}
$$

with an effective axial heat dispersion consisting of axial conduction in the solid phase and a contribution by convective heat transport in the gas phase,

$\lambda_{\text {eff }}=(1-\varepsilon) \lambda_{c}+\frac{\left(\Phi_{m, i n}^{\prime \prime} C_{p, g}\right)^{2}}{h a_{v}}$

In case of negligible mass transfer limitations, the maximum temperature can be well approximated for ideal gases by the following transcendental equation in the dimensionless maximum catalyst temperature $\theta_{c, \max }$, using the integral approximation given by Agrawal and Sivasubramanian (1987),

$F\left(\theta_{c, \max }\right)-F\left(\theta_{g, \text { in }}+\Delta \theta_{a d}\right)=\Theta$

with $\quad F(x)=x \exp \left(-\frac{1}{x}\right)\left[1-x \frac{1-2 x}{1-5 x^{2}}\right]=\Theta$

where the following dimensionless temperatures have been defined:

$\theta_{c, \max }=\frac{R T_{c, \max }}{E_{a c t}}, \quad \theta_{g, \text { in }}=\frac{R T_{g, \text { in }}}{E_{a c t}}, \quad \Delta \theta_{a d}=\frac{R \Delta T_{a d}}{E_{a c t}}=\frac{R}{E_{a c t}} \frac{\left(-\Delta h_{r}\right) \omega_{g, \text { in }}}{C_{p, g}}$ 
Assuming that the inlet gas temperature is much lower than the ignition temperature, as usual in closed-loop reverse flow reactors, the equation reduces to

$$
\theta_{c, \max } \exp \left(-\frac{1}{\theta_{c, \max }}\right)\left[1-\theta_{c, \max } \frac{1-2 \theta_{c, \max }}{1-5 \theta_{c, \max }^{2}}\right]=\Theta
$$

The dimensionless maximum temperature is a unique function of a single parameter, $\Theta$, referred to as the maximum-temperature-number, which is defined as

$$
\Theta=\frac{\left(-\Delta h_{r}\right) \Phi_{m, i n}^{\prime \prime 2} \omega_{g, i n}}{2 \lambda_{e f f} k_{r, \infty} a_{v} \rho_{g, i n} T_{g, i n}}=\frac{1}{2} \frac{\Delta \theta_{a d}}{\theta_{g, i n}} \frac{P e_{h}}{D a_{\infty}}
$$

introducing the following dimensionless numbers

$$
P e_{h}=\frac{\Phi_{m, i n}^{\prime \prime} C_{p, g} L}{\lambda_{e f f}}, \quad D a_{\infty}=\frac{k_{r, \infty} a_{v} \rho_{g, i n} L}{\Phi_{m, i n}^{\prime \prime}}
$$

The maximum temperature is a monotonously increasing function of the maximumtemperature-number (see Figure A.1).

Using the approximate HSFM-expression for the temperature gradient at the inlet and outlet of reverse flow reactors (Nieken et al., 1995),

$$
\left.\frac{d T_{c}}{d z}\right|_{z=0}=\frac{\Phi_{m, i n}^{\prime \prime} \omega_{g, i n}\left(-\Delta h_{r}\right)}{2 \lambda_{e f f}}
$$

or alternatively in terms of dimensionless numbers

$$
\left.\frac{d \theta_{c}}{d \xi}\right|_{\xi=0}=\frac{1}{2} \Delta \theta_{a d} P e_{h}
$$

the maximum-temperature-number can be written as the ratio of the dimensionless inlet temperature gradient and the Damköhler number, 
$\Theta=\frac{\left(-\Delta h_{r}\right) \Phi_{m, i n}^{\prime \prime 2} \omega_{g, i n}}{2 \lambda_{e f f} k_{r, \infty} a_{v} \rho_{g, \text { in }} T_{g, \text { in }}}=\frac{1}{2} \frac{\Delta \theta_{a d}}{\theta_{g, \text { in }}} \frac{P e_{h}}{D a_{\infty}}=\frac{\left.\frac{d \theta_{c}}{d \xi}\right|_{\xi=0}}{\theta_{g, i n} D a_{\infty}}$

The famous wrong way behaviour of reverse flow reactors, i.e. lower maximum temperatures for faster reactions, is clearly visible through the inverse proportionality of the maximumtemperature-number to the Damköhler number. Furthermore, the maximum-temperaturenumber is independent of the inlet gas temperature because of the reciprocal dependency of the inlet gas density on the inlet gas temperature.

For high gas velocities the effective axial heat dispersion is dominated by the gas convection term, so that the maximum-temperature-number (and thus the maximum temperature) becomes independent of the gas mass flux and linearly dependent on the inlet reactant mass fraction,

$\Theta \approx \frac{\left(-\Delta h_{r}\right) h}{2 k_{r, \infty} \rho_{g, i n} T_{g, i n} C_{p, g}^{2}} \omega_{g, \text { in }} \quad$ (for high gas velocities)

For high gas velocities the temperature gradient increases linearly with increasing inlet mass fraction and decreasing mass flux,

$\left.\frac{d T_{c}}{d z}\right|_{z=0} \approx \frac{\left(-\Delta h_{r}\right) h a_{v}}{C_{p, g}^{2}} \frac{\omega_{g, \text { in }}}{\Phi_{m, \text { in }}^{\prime \prime}} \quad$ (for high gas velocities) 


\section{A.1 Comparison with literature and simulations}

The above described equation to predict the maximum temperature in a reverse flow reactor has been derived using the HSFM, where a reactor of finite length is considered with infinitely high flow reversal frequency, causing the temperature fronts to be stationary at the inlet and outlet. In addition to the above-derived maximum temperature equation, referred to as the HSFM-prediction, an expression to approximate the maximum temperature has been derived considering a moving heat front with constant velocity in an infinitely long reactor without flow reversal (Matros, 1990; Matros and Bunimovich, 1997). The equation given by Matros (1990) reduces to the equation given by Matros and Bunimovich (1997), if the reference temperature is set to the maximum temperature (which is necessary to obtain reasonable results). Interestingly, also their maximum temperature equation, referred to as the MHF-prediction (Moving Heat Front), can be rewritten in terms of the dimensionless maximum-temperature-number. Neglecting mass transfer limitations and assuming full conversion their maximum temperature relation can be converted to the following expression (using the symbols defined in this work)

$\theta_{c, \max } \exp \left(-\frac{1}{\theta_{c, \max }}\right) \frac{1}{2}\left[1-\frac{\Delta \theta_{a d}}{\theta_{c, \max }-\theta_{g, \text { in }}} \frac{\left(\Phi_{m, i n}^{\prime \prime} C_{p, g}\right)^{2}}{h a_{v} \lambda_{e f f}}\right]\left[1-\exp \left(-\frac{\theta_{c, \max }-\theta_{g, \text { in }}-\Delta \theta_{a d}}{\theta_{c, \max }^{2}}\right)\right]=\Theta$

In a reverse flow reactor the maximum temperature usually considerably exceeds the sum of the inlet temperature and the adiabatic temperature rise, resulting in a large Zeldovich number, so that the last term in squared brackets approaches one. Furthermore, at high gas velocities the contribution of axial energy dispersion by gas convection largely exceeds that of energy conduction through the catalyst channel walls. Then the equation reduces to

$\theta_{c, \max } \exp \left(-\frac{1}{\theta_{c, \max }}\right) \frac{1}{2}\left[1-\frac{\Delta \theta_{a d}}{\theta_{c, \max }-\theta_{g, \text { in }}}\right]=\Theta \quad$ (for high gas velocities) 


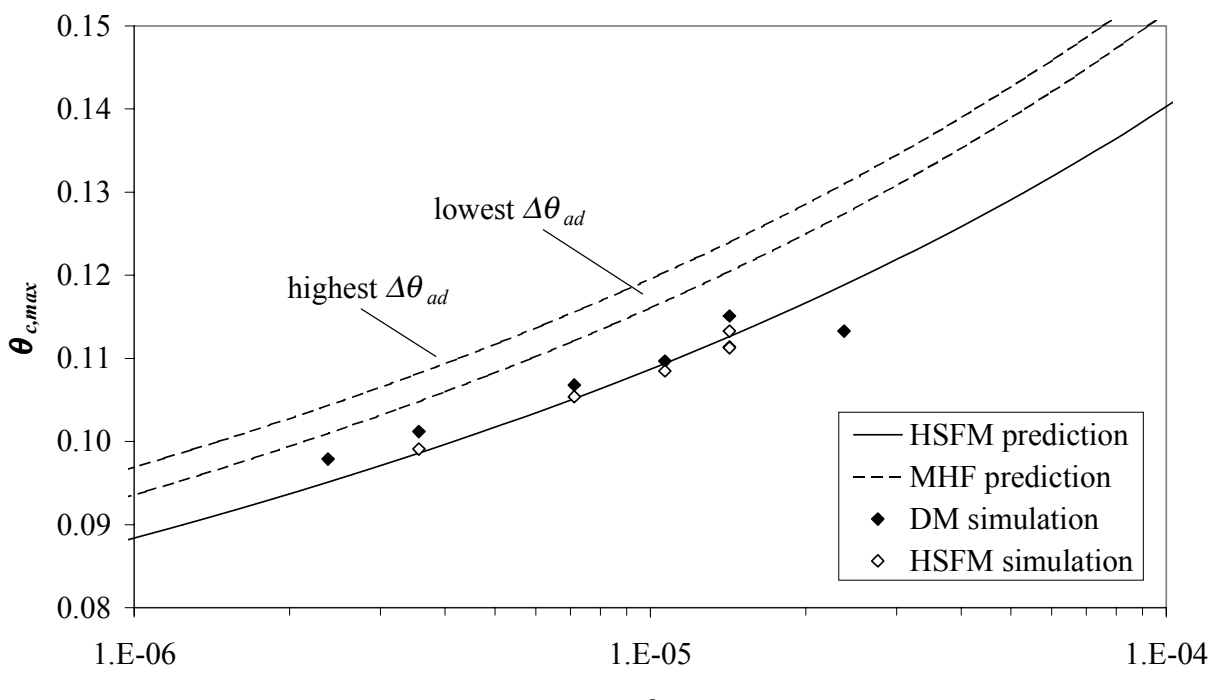

$\Theta$

Figure A.1 The dimensionless maximum catalyst temperature $\theta_{c, \max }$ as a function of the maximumtemperature-number $\Theta$, comparing the HSFM- and MHF-predictions with the HSFMand DM-simulations for methane combustion. (The inlet methane mass fraction was varied in the simulations between 0.001 and 0.006 .)

In Figure A.1 the HSFM and the MHF predictions for the maximum temperature are compared with several methane combustion simulations using the HSFM and the DM, for different values of the maximum temperature number by varying different parameters and operating conditions. The figure clearly shows that the HSFM-prediction gives a good correspondence with the simulation results and improves the MHF-prediction. Small deviations between the HSFM-predictions and the HSFM-simulations result from the temperature dependency of several physical properties and transport parameters not taken into account in the maximum temperature prediction. 
CHAPTER 3

REVERSIBLE ENDOTHERMIC REACTIONS IN THE SEQUENTIAL REACTOR CONFIGURATION 


\section{Abstract}

The new reactor concept for highly endothermic reactions at elevated temperatures with possible rapid catalyst deactivation based on the indirect coupling of endothermic and exothermic reactions in reverse flow, developed for irreversible reactions in chapter 2, has been extended to reversible endothermic reactions for the sequential reactor configuration. In the sequential reactor configuration the endothermic and exothermic reactants are fed discontinuously and sequentially to the same catalyst bed, which acts as an energy repository delivering energy during the endothermic reaction phase and storing energy during the consecutive exothermic reaction phase. The periodic flow reversals to incorporate recuperative heat exchange result in low temperatures at both reactor ends, while high temperatures prevail in the centre of the reactor. For reversible endothermic reactions these low exit temperatures can shift the equilibrium back towards the reactants side, causing 'back-conversion' at the reactor outlet.

The extent of back-conversion has been investigated for the propane dehydrogenation / methane combustion reaction system, considering a worst case scenario for the kinetics by assuming that the propylene hydrogenation reaction rate at low temperatures is only limited by mass transfer. It has been shown for this reaction system that full equilibrium conversion of the endothermic reactants cannot be combined with recuperative heat exchange, if the reactor is filled entirely with active catalyst. Inactive sections installed at the reactor ends can reduce this back-conversion, but cannot completely prevent it. Furthermore, undesired high temperature peaks can be formed at the transition point between the inactive and active sections, exceeding the maximum allowable temperature (at least for the relatively fast combustion reactions).

A new solution is introduced to achieve both full equilibrium conversion and recuperative heat exchange while simultaneously avoiding too high temperatures, even for the worst case scenario of very fast propylene hydrogenation and fuel combustion reaction rates. The proposed solution utilises the movement of the temperature fronts in the sequential reactor configuration and employs less active sections installed at either end of the active catalyst bed and completely inactive sections at the reactor ends, whereas propane combustion is used for energy supply. Finally, it is shown that the plateau temperature can be effectively controlled by simultaneous combustion of propane and methane during the exothermic reaction phase. 


\section{Introduction}

A new reactor concept for highly endothermic reactions at elevated temperatures with possible catalyst deactivation is developed based on the indirect coupling of endothermic and exothermic reactions in reverse flow. The indirect coupling of the endothermic and exothermic reactions can be accomplished in two different basic reactor configurations, referred to as the sequential and simultaneous reactor configuration. In the sequential reactor configuration the endothermic and exothermic reactants are fed discontinuously and sequentially to the same catalyst bed, as opposed to the simultaneous reactor configuration, where the endothermic and exothermic reactants are fed continuously and simultaneously to two different compartments exchanging energy through the separating walls. In chapter 2 it has been discussed for both reactor configurations how the operating conditions of both reaction phases should be set in order to achieve an optimal cyclic steady state. It has been shown that only in the sequential reactor configuration the inlet concentration can be optimised independently of the gas velocities at maximum throughput and maximum reaction coupling energy efficiency where at the same time control of the maximum temperature can be achieved. In chapter 2 the reactor concept has been studied for the indirect coupling between the propane dehydrogenation and methane combustion considering both reactions as first order irreversible reactions. However, the propane dehydrogenation is an equilibrium reaction and due to the low exit temperatures resulting from the reverse flow concept, the equilibrium can be shifted back towards the reactant side at the reactor outlet. We now extend the theoretical study of the reactor behaviour of the sequential reactor configuration for the propane dehydrogenation/fuel combustion reaction system on a $\mathrm{Pt} / \gamma-\mathrm{Al}_{2} \mathrm{O}_{3}$ monolithic catalyst to include thermodynamic equilibrium effects and to discuss possible counteractions to avoid this 'back-conversion'.

For the unusual case where a catalyst with two different types of active components could be used (and fabricated), where one type of active component is a catalyst for the endothermic reaction and the other component the exothermic reaction without any undesired influences of the active components on the other reaction (like side-reactions), back-conversion could simply be prevented by optimising the axial concentration profiles of the active components. However, for this reaction system the platinum-based monolith is a catalyst for both the endothermic dehydrogenation and the fuel combustion.

Although this work focuses on the propane dehydrogenation equilibrium reaction, a general solution to avoid back-conversion is proposed. It is important to study the reactor behaviour 
of this 'Reaction Coupling Reverse Flow Reactor' for reversible reactions, since most industrially interesting endothermic reactions are equilibrium reactions. Moreover, a catalyst for the forward reaction is also a catalyst for the reverse reaction, since the catalyst accelerates the process towards equilibrium from both sides. Hence, back-conversion is a serious problem for many endothermic equilibrium reactions.

Before discussing the simulation results including the thermodynamic propane dehydrogenation equilibrium, some remarks are made on the incorporation of more complex kinetics in the simulation model.

\section{Simulation model}

The simulation model has been described in detail in Chapter 2. In this part the gas phase axial momentum balance has been taken into account, anticipating a considerable pressure drop during the fuel combustion reaction phase due to the desired large gas velocities. Furthermore, both heterogeneous and homogeneous reactions have been included in the model. The reaction rate equations are summarised in Tables 2-4 and are briefly discussed below. The kinetic data for the heterogeneously catalysed reactions are taken from literature and adjusted for a $1 \mathrm{wt} \% \mathrm{Pt} / \gamma-\mathrm{Al}_{2} \mathrm{O}_{3}$ monolithic catalyst, with properties listed in Table 1 , assuming that the platinum dispersion remains independent of the platinum loading. The rate equations are expressed in terms of the external specific catalyst surface area. The somewhat high average pore diameter has been estimated from the effective diffusion coefficient in the washcoat given by Leung et al. (1996) for propane combustion. Dynamic effects caused by sorption or coke formation or coke combustion have been neglected, although it is assumed that periodic catalyst regeneration is a necessity.

Table 1. Monolith specification

\begin{tabular}{cccc}
\hline$d_{h, c}[\mathrm{~m}]$ & $956 \cdot 10^{-6}$ & $\delta_{w c}[\mathrm{~m}]$ & $37 \cdot 10^{-6}$ \\
$a_{v}\left[\mathrm{~m}^{2} \cdot \mathrm{m}^{-3}\right]$ & 2917 & $\delta_{w c, \min }[\mathrm{m}]$ & $11 \cdot 10^{-6}$ \\
$\varepsilon\left[\mathrm{m}^{3} \cdot \mathrm{m}^{-3}\right]$ & 0.697 & $\delta_{w c, \max }[\mathrm{m}]$ & $89 \cdot 10^{-6}$ \\
$\varepsilon_{w c} / \tau_{w c}[-]$ & 0.1 & $d_{p o r, w c}[\mathrm{~nm}]$ & 100 \\
\hline
\end{tabular}


Table 2. Propane dehydrogenation and propylene hydrogenation reaction kinetics

$$
\begin{aligned}
& \mathrm{C}_{3} \mathrm{H}_{8}(\mathrm{~A}) \rightleftarrows \mathrm{C}_{3} \mathrm{H}_{6}(\mathrm{~B})+\mathrm{H}_{2}(\mathrm{C}) \\
& r_{A, P D}^{\text {het }}=-k_{P D, 1}^{\text {het }} \psi_{P t} \rho_{g} \omega_{A, c}\left(1-\frac{1}{K_{p, P D}} \frac{\rho_{g} M_{A}}{M_{B} M_{C}} \frac{\omega_{B, c} \omega_{C, c}}{\omega_{A, c}}\right) \quad k_{P D, 1}^{h e t}=k_{P D, 1, \infty}^{\text {het }} \exp \left(-\frac{E_{P D, 1}^{h e t}}{R T_{c}}\right) \\
& \omega_{A, c}=p-\sqrt{p^{2}-q} \quad \omega_{B, c}=\omega_{B, g, i n}+\frac{M_{B}}{M_{A}}\left(\omega_{A, g, i n}-\omega_{A, c}\right) \quad \omega_{C, c}=\omega_{C, g, i n}+\frac{M_{C}}{M_{A}}\left(\omega_{A, g, i n}-\omega_{A, c}\right) \\
& p=\omega_{A, g, i n}+\frac{1}{2}\left[K_{p} \frac{M_{A}}{\rho_{g}}\left(1+\frac{k_{x}}{k_{P D, 1}^{h e t}}\right)+\frac{M_{A}}{M_{B}} \omega_{B, g, i n}+\frac{M_{A}}{M_{C}} \omega_{C, g, i n}\right] \\
& q=K_{p} \frac{M_{A}}{\rho_{g}} \frac{k_{x}}{k_{P D, 1}^{h e t}} \omega_{A, g, i n}+\left(\frac{M_{A}}{M_{B}} \omega_{B, g, i n}+\omega_{A, g, i n}\right)\left(\frac{M_{A}}{M_{C}} \omega_{C, g, i n}+\omega_{A, g, i n}\right) \\
& \frac{k_{P D, 1, \infty}^{h e t}\left[\mathrm{~m} \cdot \mathrm{s}^{-1}\right]}{K_{p, P D}(T)=\exp \left(-\frac{\Delta G_{r, P D}}{R T}\right) \approx \exp \left(16.858-\frac{15934}{T}+\frac{148728}{T^{2}}\right) \mathrm{atm}}
\end{aligned}
$$

\subsection{Endothermic reaction kinetics}

The endothermic reaction kinetics have been extended to incorporate the thermodynamic equilibrium, by assuming that the ratio of the propane dehydrogenation reaction rate constant and the propylene hydrogenation reaction rate constant is equal to the equilibrium constant. The heterogeneous propane dehydrogenation reaction rate is adapted from Loc et al. (1991), however Langmuir-Hinshelwood type propylene and hydrogen sorption effects are ignored in order to avoid additional complexities in the interpretation of the results. However, more complex reaction kinetics can easily be implemented in the model. The apparent activation energy for the propane dehydrogenation rate fitted by Loc et al. at $c a .600{ }^{\circ} \mathrm{C}\left(59 \mathrm{~kJ} \cdot \mathrm{mole}^{-1}\right)$ is much lower than the reaction enthalpy of about $130 \mathrm{~kJ} \cdot \mathrm{mole}^{-1}$. This results in extremely large reaction rates for the propylene hydrogenation at low temperatures, so that the propylene hydrogenation reaction rate becomes limited by mass transfer at low temperatures. Therefore, external mass transfer limitation has been included in the propane dehydrogenation/propylene hydrogenation conversion rate. However, the apparent overall activation energy for the 
propane dehydrogenation at lower temperatures is probably much higher than measured by Loc et al. at $600{ }^{\circ} \mathrm{C}$, so that the propylene hydrogenation reaction rates are amply overestimated at low temperatures. With these kinetics a worst case situation with maximum back-conversion is studied.

Table 3. Methane combustion reaction kinetics

$\mathrm{CH}_{4}(\mathrm{~A})+2 \mathrm{O}_{2}(\mathrm{~B}) \longrightarrow \mathrm{CO}_{2}+2 \mathrm{H}_{2} \mathrm{O}$

\section{Heterogeneous reaction rate:}

$$
\begin{aligned}
& r_{A, M C}^{\text {het }}=R_{A, M C, k i n}^{\text {het }} \psi_{P t} \eta_{o v} a_{v} M_{A} \\
& R_{A, M C, k i n}^{\text {het }}= \begin{cases}-\left(\frac{k_{M C, 1}^{\text {het }} C_{A, g} C_{B, g}^{\frac{1}{2}}}{1+k_{M C, 2}^{\text {het }} C_{B, g}^{\frac{1}{2}}}+\frac{k_{M C, 4}^{\text {het }} C_{A, g} C_{B, g}}{1+k_{M C, 3}^{\text {het }} C_{B, g}}\right) \exp \left(-\frac{E_{M C, 1}^{\text {het }}}{R T_{c}}\right) & T_{c} \leq T_{1} \\
\left(R_{A, M C, k i n}^{\text {het }}\left(T_{1}\right)+\frac{R_{A, M C, k i n}^{\text {het }}\left(T_{2}\right)-R_{A, M C, k i n}^{\text {het }}\left(T_{1}\right)}{T_{2}-T_{1}}\left(T-T_{2}\right)\right) & T_{1}<T_{c}<T_{2} \\
-\left(\frac{k_{M C, 5}^{\text {het }} C_{A, g} C_{B, g}}{\left(1+k_{M C, 6}^{\text {het }} C_{A, g}+k_{M C, 7}^{\text {het }} C_{B, g}\right)^{2}}+\frac{k_{M C, 8}^{\text {het }} C_{A, g} C_{B, g}^{\frac{1}{2}}}{1+k_{M C, 6}^{\text {het }} C_{A, g}+k_{M C, 7}^{\text {het }} C_{B, g}}\right) \exp \left(-\frac{E_{M C, 2}^{\text {het }}}{R T_{c}}\right) & T_{c} \geq T_{2}\end{cases}
\end{aligned}
$$

\section{Homogeneous reaction rate:}

$$
r_{A, M C}^{\text {hom }}=-k_{M C, 1, \infty}^{\text {hom }} \exp \left(-\frac{E_{M C, 1}^{\text {hom }}}{R T_{g}}\right) \frac{C_{A, g}^{0.7} C_{B, g}^{1.3}}{C_{A, g}^{1.0}+k_{M C, 2}^{h o m}} \varepsilon M_{A}
$$

\begin{tabular}{cccc}
\hline$k_{M C, 1}^{\text {het }}\left[\mathrm{mole}^{-0.5} \cdot \mathrm{m}^{2.5} \cdot \mathrm{s}^{-1}\right]$ & $2.02 \cdot 10^{9}$ & $E_{M C, 1}^{\text {het }}\left[\mathrm{kJ} \cdot \mathrm{mole}^{-1}\right]$ & 187 \\
$k_{M C, 2}^{\text {het }}\left[\mathrm{mole}^{-0.5} \cdot \mathrm{m}^{1.5}\right]$ & $1.87 \cdot 10^{-3}$ & $E_{M C, 2}^{\text {het }}\left[\mathrm{kJ} \cdot \mathrm{mole}^{-1}\right]$ & 86 \\
$k_{M C, 3}^{\text {het }}\left[\mathrm{mole}^{-1} \cdot \mathrm{m}^{3}\right]$ & $1.13 \cdot 10^{-3}$ & $T_{1}[\mathrm{~K}]$ & 793 \\
$k_{M C, 4}^{\text {het }}\left[\mathrm{mole}^{-1} \cdot \mathrm{m}^{4} \cdot \mathrm{s}^{-1}\right]$ & $1.28 \cdot 10^{9}$ & $T_{2}[\mathrm{~K}]$ & 830 \\
$k_{M C, 5}^{\text {het }}\left[\mathrm{mole}^{-1} \cdot \mathrm{m}^{4} \cdot \mathrm{s}^{-1}\right]$ & $1.21 \cdot 10^{3}$ & & \\
$k_{M C, 6}^{\text {het }}\left[\mathrm{mole}^{-1} \cdot \mathrm{m}^{3}\right]$ & $4.54 \cdot 10^{-1}$ & $k_{M C, 1, \infty}^{h o m}\left[\mathrm{~s}^{-1}\right]$ & $8.3 \cdot 10^{5}$ \\
$k_{M C, 7}^{h e t}\left[\mathrm{~mole}^{-1} \cdot \mathrm{m}^{3}\right]$ & $2.96 \cdot 10^{-4}$ & $E_{M C, 1}^{h o m}\left[\mathrm{~kJ} \cdot \mathrm{mole}^{-1}\right]$ & 125.541 \\
$k_{M C, 8}^{h e t}\left[\mathrm{~mole}^{-0.5} \cdot \mathrm{m}^{2.5} \cdot \mathrm{s}^{-1}\right]$ & $3.91 \cdot 10^{2}$ & $k_{M C, 2}^{h o m}\left[\mathrm{~mole} \cdot \mathrm{m}^{-3}\right]$ & $10^{-3}$ \\
\hline
\end{tabular}




\subsection{Exothermic reaction kinetics}

In this work combustion of methane and propane is considered. The heterogeneous methane combustion reaction kinetics have been taken from Trimm and Lam (1980) and slightly adjusted to include an overall temperature dependency. The heterogeneous propane combustion reaction kinetics has been approximated from Hiam et al. (1968). It should be noted that the maximum temperatures in the simulations considerably exceed the temperatures for which the reaction rate equations were experimentally derived, especially for the heterogeneous propane combustion reaction rate. Internal and external mass transfer limitations for the heterogeneous combustion reactions are included using an average effectiveness factor. The usually radially non-uniform washcoat thickness distribution is taken into account via an approximate averaging procedure for the effectiveness factor, shortly outlined in appendix A.

Furthermore, also homogeneous methane and propane combustion reactions are included using simple one step kinetic rate equations, adapted from Westbrook and Dryer (1981). Due to the overall negative reaction order for methane in the homogeneous methane combustion reaction rate infinite reaction rates are extrapolated for small methane concentrations. These computational problems have been overcome by adjusting the homogeneous methane combustion reaction rate equation so that for low methane concentrations the methane reaction order approaches the positive methane reaction order derived for the two step kinetic model by Dryer and Glassman (1973). It should be realised that the one step homogeneous combustion models overestimate the overall homogeneous combustion rate for the small fuel concentrations considered in this work.

Finally, it is emphasised here that the kinetic data as described above constitute a worst case scenario, since both the propylene hydrogenation reaction rate and the homogeneous and heterogeneous fuel combustion reaction rates are considerably overestimated. The qualitative effects of the operating conditions on the reactor behaviour of a reverse flow reactor coupling fuel combustion reactions with reversible endothermic reactions are investigated using these worst case kinetic data, in order to challenge a general solution to avoid back-conversion even for endothermic equilibrium reactions with a very fast reaction rate of the reverse reaction. 
Table 4. Propane combustion reaction kinetics

$\mathrm{C}_{3} \mathrm{H}_{8}(\mathrm{~A})+5 \mathrm{O}_{2}(\mathrm{~B}) \longrightarrow 3 \mathrm{CO}_{2}+4 \mathrm{H}_{2} \mathrm{O}$

\section{Heterogeneous reaction rate:}

$r_{A, P C}^{h e t}=R_{A, P C, k i n}^{h e t} \psi_{P t} \eta_{o v} a_{v} M_{A}$

$R_{A, P C, k i n}^{\text {het }}=-k_{P C, 1, \infty}^{\text {het }} \exp \left(-\frac{E_{P C, 1}^{\text {het }}}{R T_{c}}\right) C_{A}$

Homogeneous reaction rate:

$$
\begin{array}{rlll}
r_{A, P C}^{\text {hom }}=-k_{P C, 1, \infty}^{\text {hom }} \exp \left(-\frac{E_{P C, 1}^{\text {hom }}}{R T_{g}}\right) C_{A, g}^{0.1} C_{B, g}^{1.65} \varepsilon M_{A} & & \\
\hline k_{P C, 1, \infty}^{\text {het }}\left[\mathrm{m} \cdot \mathrm{s}^{-1}\right] & 1.1 \cdot 10^{5} & E_{P C, 1}^{\text {het }}\left[\mathrm{kJ} \cdot \mathrm{mole}^{-1}\right] & 71.13 \\
k_{P C, 1, \infty}^{\text {hom }}\left[\mathrm{mole}^{-0.75} \cdot \mathrm{m}^{2.25} \cdot \mathrm{s}^{-1}\right] & 2.7 \cdot 10^{7} & E_{P C, 1}^{\text {hom }}\left[\mathrm{kJ} \cdot \mathrm{mole}^{-1}\right] & 125.54
\end{array}
$$

\section{Effect of reversible reactions}

The extent of the conversion losses at the end of the reactor due to the thermodynamic equilibrium has been investigated for the propane dehydrogenation/methane combustion reaction system. In these calculations the axial gas phase momentum balance has been taken into account to allow for a pressure drop over the monolith caused by the high gas velocities during the fuel combustion reaction phase. The required inlet pressure affects the specification of the operating conditions. Before discussing the simulation results, this will be outlined in more detail subsequently.

\subsection{Effect of the inlet pressure}

A higher inlet pressure during the exothermic reaction phase has a twofold effect on the specification of the operating conditions. Firstly, to achieve the same amount of energy release during the exothermic reaction phase, the exothermic inlet mass fraction or inlet gas velocity or cycle time should be decreased corresponding to the increase in the inlet pressure. 
Secondly, the inlet pressure effects the maximum temperature through its influence on the overall reaction rate. For methane combustion at $1000 \mathrm{~K}$ over a $1 \mathrm{wt} \% \mathrm{Pt} / \gamma-\mathrm{Al}_{2} \mathrm{O}_{3}$ monolithic catalyst (with properties listed in Table 1) the methane combustion rate is mainly determined by kinetics (the overall efficiency factor accounting for internal and external mass transfer limitations is approximately $75 \%$ assuming the kinetics as given in Table 3). For small methane concentrations the heterogeneous methane combustion obeys an overall second order kinetics, first order in the methane and first order in the oxygen concentration (Trimm and Lam, 1980). At these small methane concentrations the oxygen concentration is approximately constant, so that the methane combustion can essentially be considered as a pseudo-first order reaction with a pseudo-first order reaction rate constant linearly dependent on the total pressure. Thus, for methane combustion at high gas velocities the maximumtemperature number $\Theta$, defined in Chapter 2, decreases by about a factor four if the inlet pressure is doubled,

$\Theta \approx \frac{\left(-\Delta h_{r}^{e x o}\right) h^{e x o} R \omega_{g, \text { in }}^{e x o}}{2\left(C_{p, g}^{e x o}\right)^{2} k_{r, I, \infty}^{e x o} p_{i n} M_{g, i n}} \approx \frac{\left(-\Delta h_{r}^{e x o}\right) h^{e x o} R^{2} T_{g, i n} \omega_{g, C H_{4}, \text { in }}^{\text {exo }} M_{O_{2}}}{2\left(C_{p, g}^{e x o}\right)^{2} \eta_{o v} k_{r, I I, \infty}^{e x o} p_{i n}^{2} M_{g, i n}^{2} \omega_{g, O_{2}, \text { in }}^{\text {exo }}}$

If the maximum time-averaged production capacity of the endothermic products is restricted by a maximum temperature constraint an increase in the inlet pressure during the exothermic reaction phase has an adventitious beneficial effect on the time-averaged production capacity. The maximum temperature constraint specifies a maximum value for the maximumtemperature number. A higher inlet pressure therefore allows an increase of the exothermic inlet mass fraction and thus a reduction of the exothermic cycle time, while still complying with the maximum temperature constraint. However, a higher inlet pressure during the exothermic reaction phase increases the combustion reaction rate, so that the matching of the endothermic and exothermic Damköhler numbers requires a reduction of the endothermic gas velocity relative to the exothermic gas velocity and as a consequence thereof the production capacity is reduced. Hence, an optimum in the production capacity is expected as a function of the inlet pressure. Furthermore, the increase in the inlet pressure and corresponding increase in the exothermic inlet mass fraction is restricted by the lower explosion limit or by the condition of a positive heat front velocity to assure recuperative heat exchange. Using a homogeneous model assuming negligible temperature differences between the gas bulk and the catalyst surface, the heat front velocity can be approximated by (e.g. Froment, 1990), 
$w=v_{z, g, \text { in }} \frac{\varepsilon \rho_{g, \text { in }} C_{p, g}}{(1-\varepsilon) \rho_{c} C_{p, c}+\varepsilon \rho_{g} C_{p, g}}\left(1-\frac{\Delta T_{a d}}{T_{c, \text { max }}-T_{g, \text { in }}}\right)$

stating that a positive heat front velocity is assured, if the adiabatic temperature rise is smaller than the maximum temperature rise. Thus, the exothermic inlet mass fraction is subjected to the following condition

$\omega_{g, \text { in }}^{\text {exo }}<\min \left(\omega_{\max }, \frac{C_{p, g}^{e x o}}{\left(-\Delta h_{r}^{\text {exo }}\right)}\left(T_{c, \max }-T_{g, \text { in }}\right)\right)$

For a fuel combustion reaction system with a maximum temperature constraint of about $1000 \mathrm{~K}$ the exothermic inlet mass fractions ensuring wrong way behaviour are below the lower explosion limits. Finally, it is noted that at higher adiabatic temperature rises the equation for the heat front velocity may become less accurate, because the temperature difference between the gas and the catalyst is proportional to the adiabatic temperature rise in the fully developed laminar flow regime.

Taking the inlet pressure effects into account, the endothermic and exothermic operating conditions have been specified following the design rules derived in Chapter 2. An overview of the selected input parameters is given in Table 5 .

Table 5. Operating conditions used for the propane dehydrogenation/methane combustion reaction system.

Endothermic reaction phase Exothermic reaction phase

Propane dehydrogenation

Methane combustion

\begin{tabular}{ccc} 
Inlet reactant mass fraction $\omega_{g, \text { in }}[-]$ & 1.0 & 0.0060 \\
Inlet gas velocity $v_{z, g, \text { in }}\left[\mathrm{m} \cdot \mathrm{s}^{-1}\right]$ & 0.20 & 10.0 \\
Inlet pressure $p_{\text {in }}[\mathrm{atm}]$ & 1.0 & 3.0 \\
Reaction cycle time $\Delta t[\mathrm{~s}]$ & 90 & 12 \\
\hline Total reactor length $[\mathrm{m}]$ & $\underset{\text { exo }}{\longrightarrow} \underset{\text { endo }}{\longrightarrow} \underset{\text { exo }}{\leftarrow} \underset{\text { endo }}{\text { Switching scheme }}$
\end{tabular}




\subsection{Effect of the thermodynamic equilibrium}

In Figure 1 the cyclic steady state axial profiles for the catalyst temperature (always at the end of a reaction cycle) and gas phase mass fraction profiles are plotted for the propane dehydrogenation/methane combustion reaction system for the operating conditions listed in Table 5. For clarity only the axial profiles of the process steps with the gas flowing in the forward direction are shown, since the chosen switching scheme (scheme I.a: $\overrightarrow{\text { exo }} \underset{\text { endo }}{\leftarrow} \leftarrow \stackrel{\leftarrow}{\leftarrow \text { endo }}$, see Chapter 2) will result in symmetrical profiles.
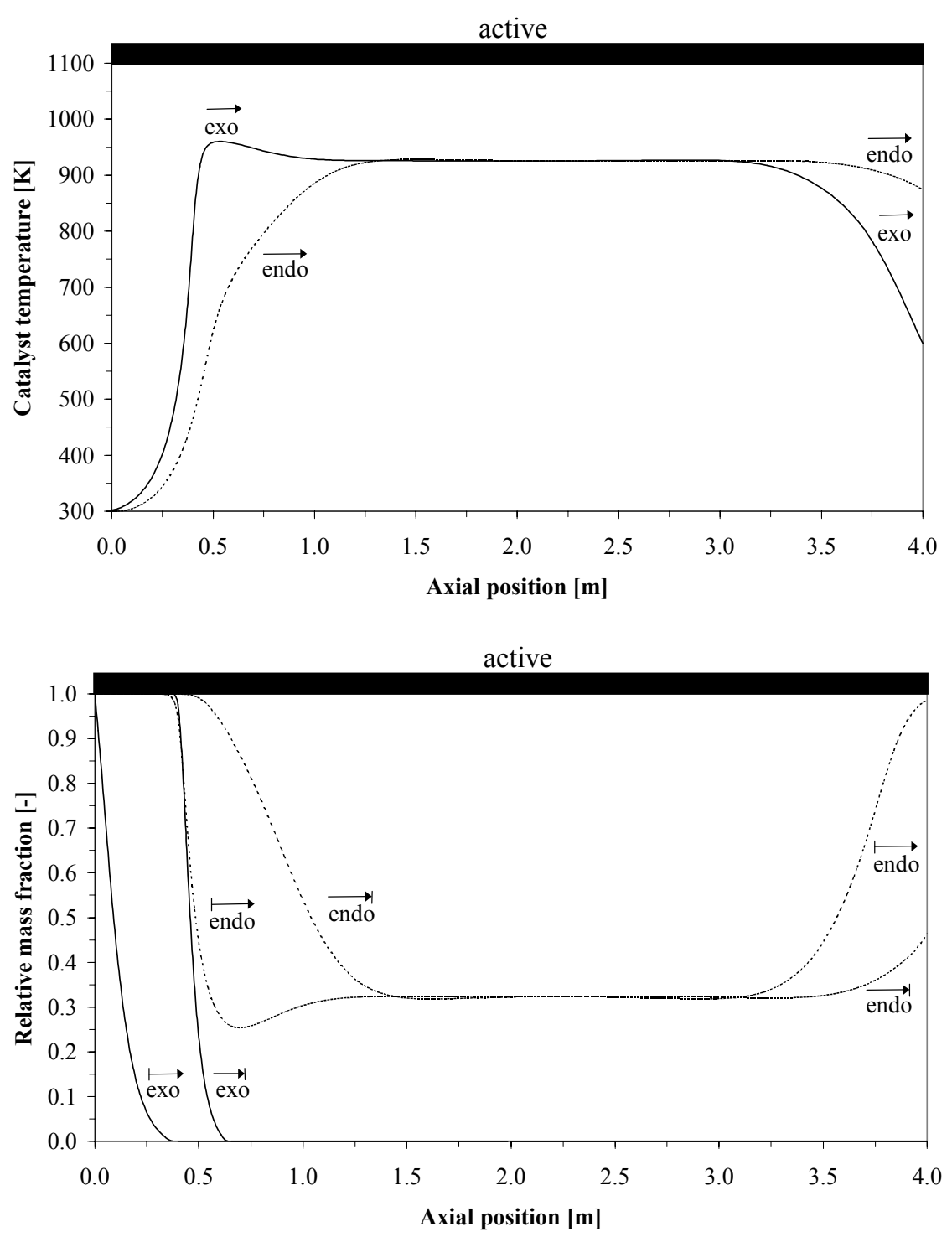

Figure 1. Effect of the propane dehydrogenation thermodynamic equilibrium on the cyclic steady state axial profiles of the catalyst temperature (top) and the gas phase mass fraction normalised with the inlet mass fraction (bottom) at the beginning $(\longmapsto)$ and end $(\longrightarrow)$ of the forward endothermic and exothermic cycle (operating conditions listed in Table 5). 
From Figure 1 the enormous influence of the propane dehydrogenation thermodynamic equilibrium is clear. The low temperatures at the reactor outlet at the beginning of the endothermic propane dehydrogenation cycle cause an almost complete back-conversion of propylene to propane. Due to the exothermicity of the propylene hydrogenation reaction the outlet temperature strongly increases, however, inducing a considerable reduction of the backconversion at the end of the propane dehydrogenation cycle. The back-conversion thwarts itself. High overall propane conversions are accompanied by high outlet temperatures and low outlet temperatures involve low overall propane conversions. For the sake of completeness it is remarked here that the back-conversion is even complete during the entire endothermic reaction cycle for a switching scheme where the order of feeding endothermic and exothermic

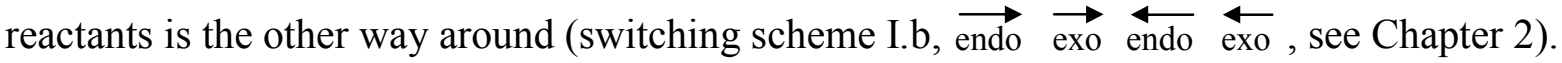
Since the endothermic reaction phase is carried out first when switching the flow direction, the back end temperature front is located more inside the catalyst at a greater distance from the back end of the reactor during the endothermic reaction phase. The longer residence time at lower temperatures results in much higher conversion losses for this switching scheme. Thus, full conversion and recuperative heat exchange cannot be combined together for a reversible endothermic reaction in a reactor set-up filled completely with active catalyst. In the subsequent sections a solution is proposed enabling full conversion and recuperative heat exchange simultaneously.

\section{Inactive sections}

In order to suppress back-conversion or large energy losses inactive monoliths could be placed at both ends of the reactor flanking an active catalyst section in the middle. If the reverse reaction becomes important only at relatively low temperatures and the exothermic reaction ignites at much higher temperatures, inactive sections can prevent back-conversion completely without any influence on the temperature profiles for the exothermic reaction cycle. The axial temperature and concentration profiles then coincide with those discussed in Chapter 2, where the endothermic reaction was considered irreversible. However, this is a very hypothetical case. In virtually all, relevant reaction systems the reverse reaction already becomes important at temperatures well above the ignition temperatures of combustion reactions. 
Nevertheless, if the temperature front at the back end (in relation to gas flow direction) of the temperature profile could be located inside the inactive section at the rear end of the reactor during the complete endothermic reaction cycle, back-conversion and thus large energy losses could be prevented. In this case, the composition of the product gases can be 'frozen' at the equilibrium composition corresponding to the conditions of high temperatures in the active catalyst section when the product gases are cooled in the inactive section. In order to move the back end temperature front inside the inactive section the endothermic reaction phase should be carried out after the exothermic reaction phase in the same gas flow direction, so that switching scheme I.a should be selected.
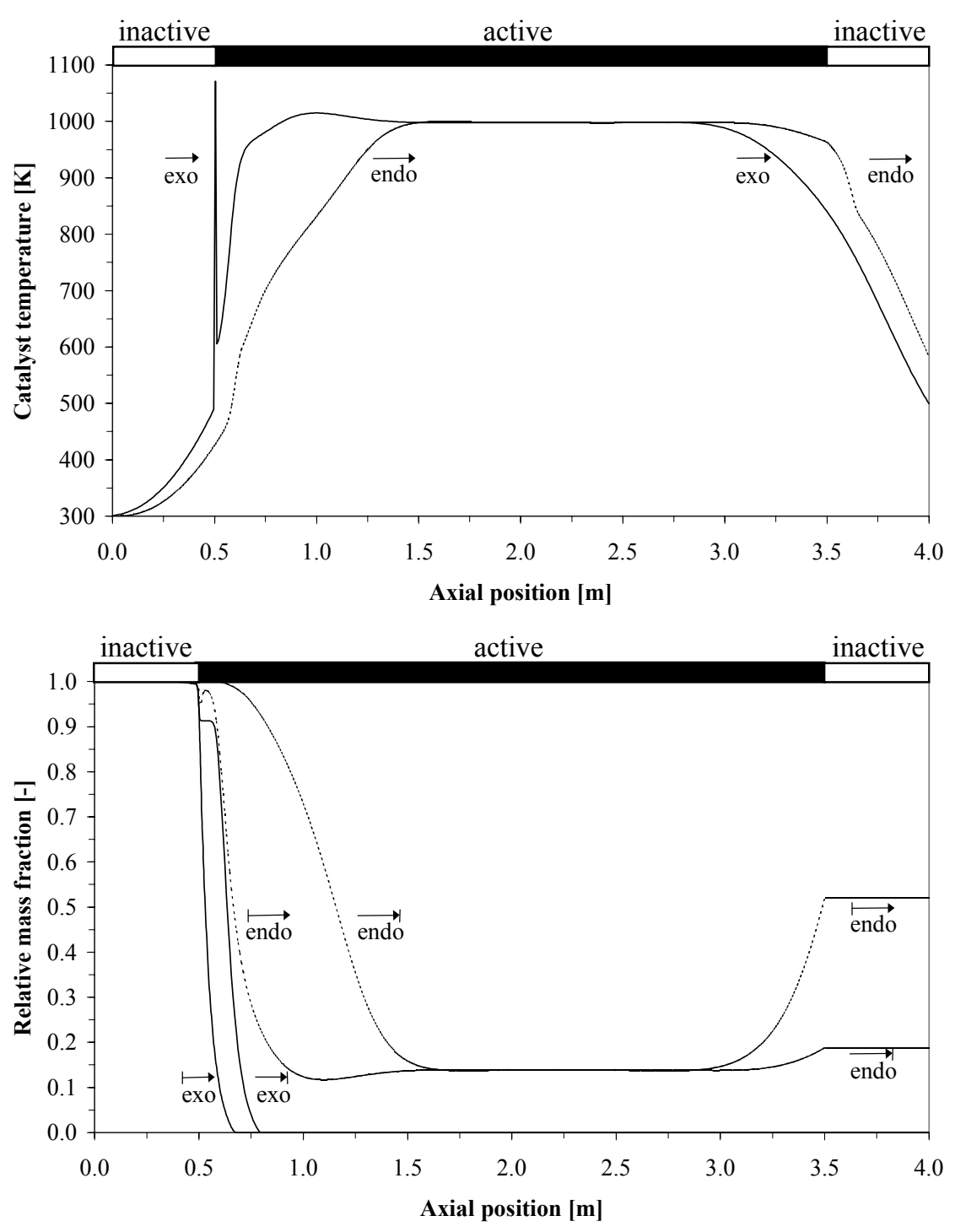

Figure 2. Effect of inactive sections of $0.5 \mathrm{~m}$ length flanking the catalyst bed at both sides on the cyclic steady state axial profiles of the catalyst temperature (top) and the gas phase mass fraction normalised with the inlet mass fraction (bottom) at the beginning $(\longmapsto)$ and end $(\longrightarrow)$ of the forward endothermic and exothermic cycle (operating conditions listed in Table 5). 
Figure 2 shows axial profiles in the cyclic steady state of the catalyst temperature and gas phase mass fraction for the forward process steps, for the case where the active section is shortened and two inactive sections of $0.5 \mathrm{~m}$ length are positioned at both reactor ends (keeping the total reactor length the same), again for the propane dehydrogenation/methane combustion reaction system and the operating conditions listed in Table 5.

Firstly, by comparing the axial profiles of Figures 1 and 2 it is clear that the inactive sections are effective in reducing the back-conversion and convective energy losses. However, the back-conversion cannot be completely avoided. Especially at the beginning of endothermic reaction cycle the back end temperature front of the axial temperature profile is not completely situated in the inactive section. The temperature at the transition from the active to the inactive section at the back end of the reactor is about $840 \mathrm{~K}$ at the beginning of the endothermic cycle, which is well below the plateau temperature in the centre of the reactor (ca. $1000 \mathrm{~K}$ ). Due to this temperature gradient in the active catalyst section still considerable conversion losses occur during the first stages of the endothermic reaction cycle. Due to the movement of the temperature fronts towards the back end of the reactor during the forward endothermic reaction cycle and the energy production by the reverse reaction the temperature at the transition from the active to the inactive section increases, causing a further reduction of the back-conversion. The temperature decrease at the back end of the active catalyst section is caused by the order of the reaction phases in the switching scheme. Although it is necessary to carry out the endothermic reaction phase after the exothermic reaction phase in the same gas flow direction in order to move the back end temperature gradient inside the inactive section, the front temperature gradient is strongly decreased during the endothermic reaction phase. This results in a large endothermic reaction zone at the end of the endothermic reaction phase and furthermore lower temperatures at the transition between the active and inactive sections when the endothermic reactants are fed from the opposite side. The conversion losses could be reduced somewhat by decreasing the endothermic inlet gas velocity relative to the exothermic gas velocity (better matching of reaction zones), however, at the expense of a lower overall production capacity.

Secondly, high temperature peaks are formed at the transition from the inactive to the active section. In the first half of the exothermic cycle the temperature peak is formed and then the maximum temperature diminishes when the temperature front moves into the active catalyst bed (see Figure 3.a). The high temperature peaks directly result from the requirement to locate 
the back end temperature front in the inactive section at the rear end of the reactor during the entire forward flow endothermic reaction cycle. When switching to the exothermic reaction phase in backward flow, the exothermic reactants are heated to high temperatures in the inactive section. The exothermic reactants then enter the active catalyst bed at high temperatures, as a result of which the fuel is combusted in a very small first part of the active catalyst section at the transition from the inactive to the active catalyst section, causing locally very high temperature peaks. Obviously, the temperature peaks would be considerably less pronounced, if the heterogeneous reaction rate or the adiabatic temperature rise of the exothermic reaction phase were smaller.

The effect of the length of the inactive sections flanking the active catalyst bed at both reactor ends keeping the total reactor length constant is presented in Figure 3. This figure clearly shows that large inactive sections are effective in reducing the back-conversion (Figure 3.b) and large convective energy losses (Figure 3.c), however, at the expense of the formation of temperature peaks exceeding the maximum allowable temperature (Figure 3.a). Moreover, conversion losses could not be completely avoided, because the back end of the active catalyst section could not be maintained at the plateau temperature. The extent to which backconversion occurs in this set-up with entirely inactive sections flanking the active catalyst bed is mainly determined by the reaction rate of the reverse reaction at high temperatures. Consequently, entirely inactive sections cannot be used to completely suppress backconversion for fast equilibrating reversible endothermic reactions.

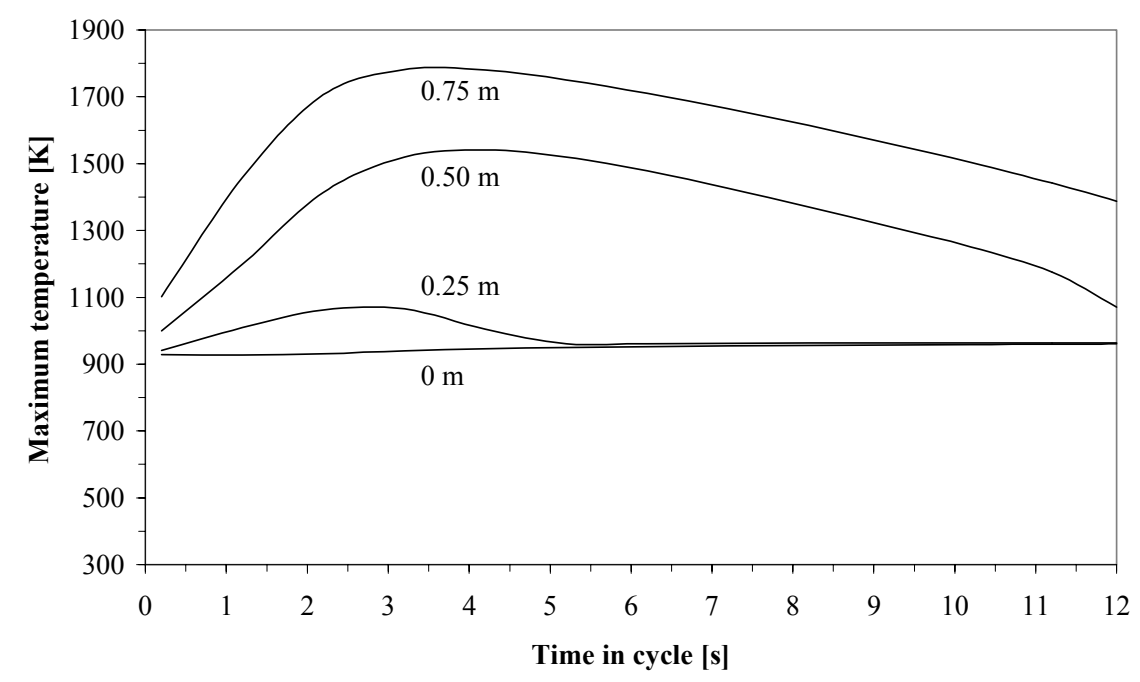

Figure 3.a Effect of the length of the inactive sections flanking the catalyst bed at both sides on the evolution of the maximum temperature during the exothermic cycle in the cyclic steady state (operating conditions listed in Table 5). 


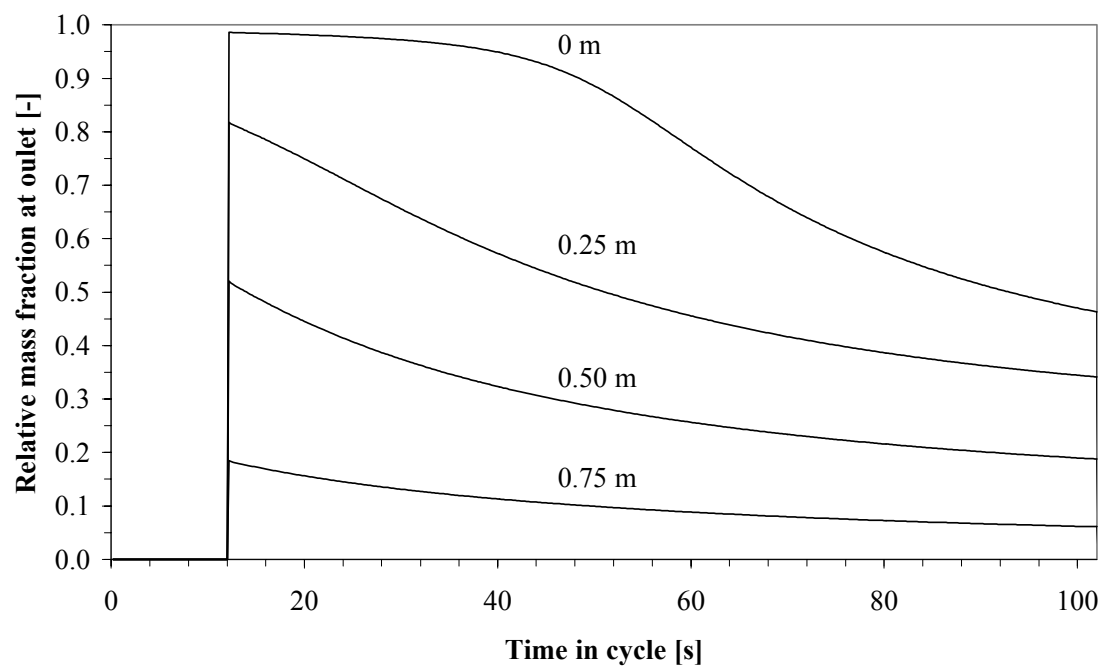

Figure 3.b Effect of the length of the inactive sections flanking the catalyst bed at both sides on the evolution of the gas phase mass fraction normalised with the inlet mass fraction at the reactor outlet during one exothermic and endothermic reaction cycle in the cyclic steady state (operating conditions listed in Table 5).

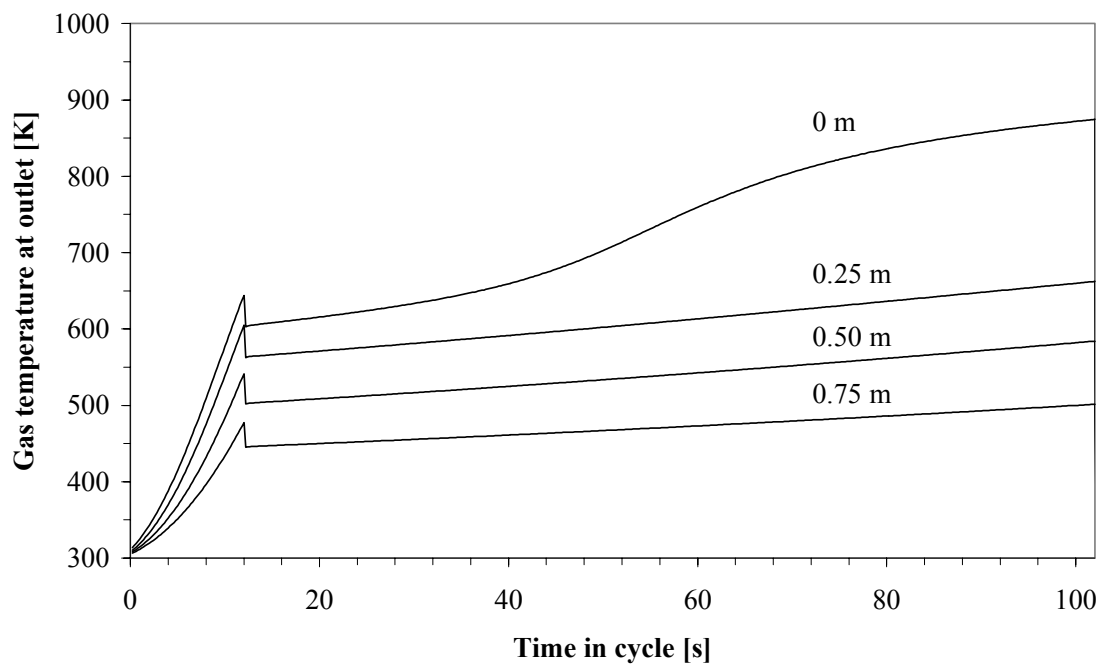

Figure 3.c Effect of the length of the inactive sections flanking the catalyst bed at both sides on the evolution of the outlet gas phase temperature during one exothermic and endothermic reaction cycle in the cyclic steady state (operating conditions listed in Table 5). 


\section{Less active sections}

Although the reverse reaction is completely inhibited in an entirely inactive section, it might also be sufficiently retarded in a much less active catalyst section. If the exothermic reactants do react in this much less active section, while the reactions during the endothermic reaction cycle take place predominantly in the active catalyst section, the back-end temperature gradient can be kept inside the less active sections during the endothermic reaction cycles and back-conversion can be prevented. This requires a much higher exothermic conversion rate compared to the endothermic conversion rate, which is generally the case and also applies for the propane dehydrogenation/fuel combustion reaction system.

However, despite the desired spatial separation of the reaction zones obtained by using different catalyst activities, the energy released at the exothermic reaction zone should be transferred to the endothermic reaction zone. Only in the sequential reactor configuration effective use can be made of the movement of the temperature fronts, so that the reaction zones are spatially separated, but not relative to the temperature front and the energy release and consumption. Starting by feeding exothermic reactants energy is stored at the front temperature front in the less active section. During the exothermic reaction phase this temperature front moves towards the active catalyst bed. When the temperature front reaches the transition between the less active and active catalyst sections endothermic reactants are fed in the same flow direction. The energy stored by the exothermic reaction in the less active section is now consumed by the endothermic reaction in the active catalyst bed. At the moment of switching from the exothermic to the endothermic reactants the back-end temperature front has moved into the less active section, so that the backward reaction rate is strongly reduced preventing conversion losses.

To carry out the exothermic reaction in a much less active section propane combustion is proposed in stead of methane combustion. Since the heterogeneous propane combustion reaction rate is roughly 250 times larger than the heterogeneous methane combustion reaction rate at $700 \mathrm{~K}$ (Ma et al., 1996), a 250 times less active section compared to the active catalyst bed can be used under further comparable operating conditions as before for the methane combustion. In this work it has been assumed that the reduction in catalytic activity is achieved by reducing the overall platinum loading. A lower activity can also be achieved differently, e.g. by using a catalyst with a much smaller internal catalyst surface area or 
washcoat thickness or by selecting a catalyst with a different active component. The operating conditions used to study the effect of the less active sections for the propane dehydrogenation/propane combustion reaction system are given in Table 6 . The reactor length has been increased to $5 \mathrm{~m}$ to avoid overlapping reaction zones, necessitating a corresponding increase in the inlet pressure during the exothermic reaction cycle to $4 \mathrm{~atm}$.

Table 6. Operating conditions used for the propane dehydrogenation/propane combustion reaction system.

\section{Endothermic reaction phase Exothermic reaction phase}

Propane dehydrogenation

Propane combustion

\begin{tabular}{|c|c|c|c|c|}
\hline Inlet reactant mass fraction $\omega_{g, \text { in }}[-]$ & 1.0 & & & 0.0030 \\
\hline Inlet gas velocity $v_{z, g, \text { in }}\left[\mathrm{m} \cdot \mathrm{s}^{-1}\right]$ & 0.20 & & & 10.0 \\
\hline Inlet pressure $p_{\text {in }}[\mathrm{atm}]$ & 1.0 & & & 4.0 \\
\hline Reaction cycle time $\Delta t[\mathrm{~s}]$ & 45 & & & 15 \\
\hline Total reactor length [m] & \multicolumn{3}{|c|}{5.0} & \\
\hline Switching scheme & $\overrightarrow{\text { exo }}$ & $\overrightarrow{\text { endo }}$ & $\leftarrow$ & $\overleftarrow{\text { endo }}$ \\
\hline
\end{tabular}

Simulation results for the case using two $1.5 \mathrm{~m}$ length, 250 times less active sections flanking the catalyst bed at both ends are presented in Figure 4. In this calculation homogeneous propane combustion has been ignored. The influence of the homogeneous propane combustion is discussed below. The axial mass fraction profile clearly shows the spatial separation of the exothermic and endothermic reaction zones, while the energy released by the exothermic reaction is effectively transferred to the endothermic reactants, shown by the axial temperature profile. At the transition between the less active and active sections a small temperature peak is created during the exothermic reaction phase. However, the maximum temperature increases only to some extent and the maximum allowable temperature is not exceeded (see Figure 5). 

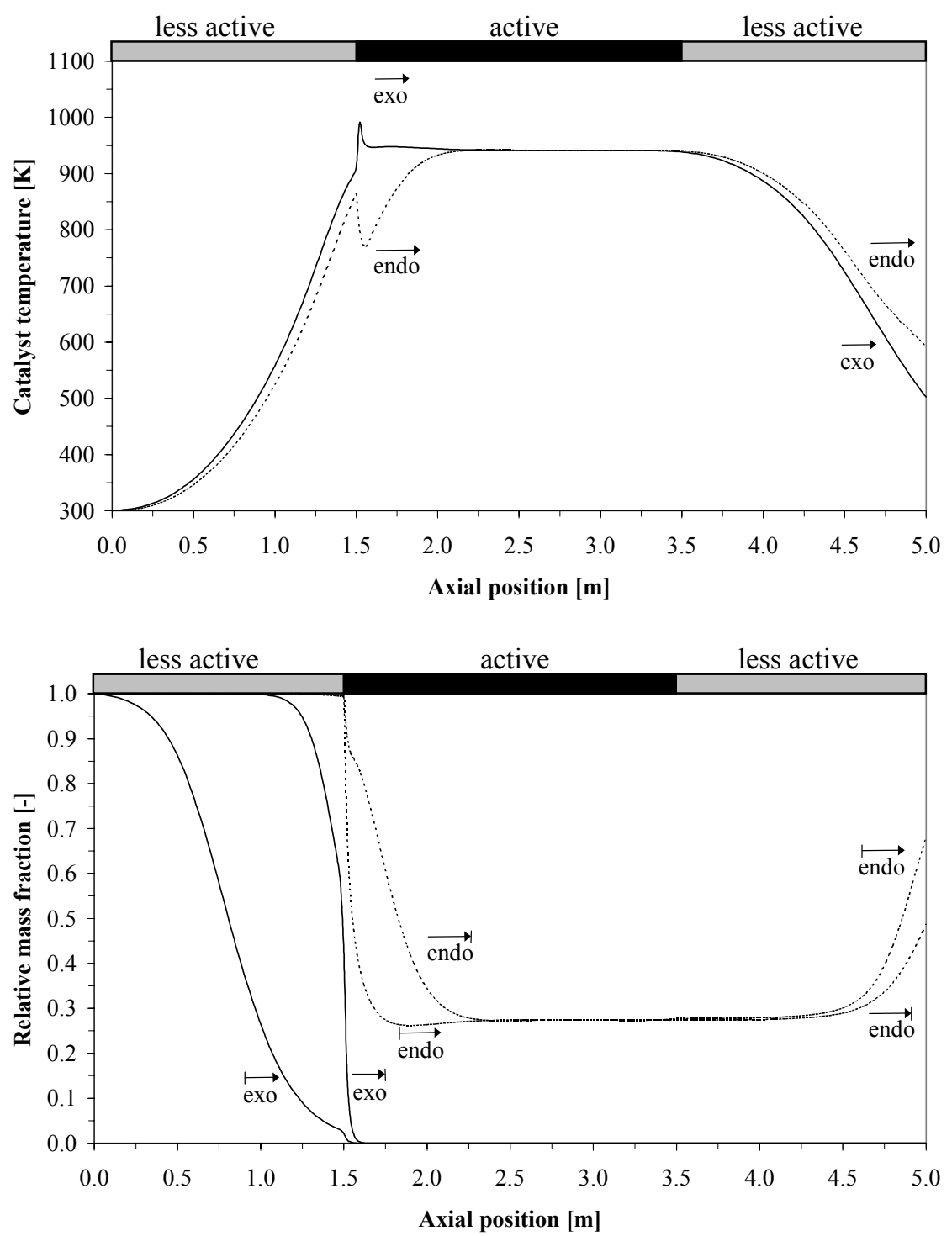

Figure 4. Effect of $1.5 \mathrm{~m}$ length, 250 times less active sections flanking the catalyst bed at both sides on the cyclic steady state axial profiles of the catalyst temperature (top) and the gas phase mass fraction normalised with the inlet mass fraction (bottom) at the beginning $(\longmapsto)$ and end $(\longrightarrow)$ ) of the forward endothermic and exothermic cycle (operating conditions listed in Table 6 and homogeneous propane combustion neglected).

Fortunately, the influence of the length of the less active sections on the axial temperature profile at the same operating conditions is relatively small, as can be seen in Figure 6. For smaller less active sections the reaction zones are shifted somewhat towards the reactor ends, but the maximum temperature is hardly effected. Due to the very high gas velocities during the exothermic reaction phase the back-end temperature profile (opposite to where the reactants are fed) is levelled out, rendering the matching of the reaction zones less critical. 


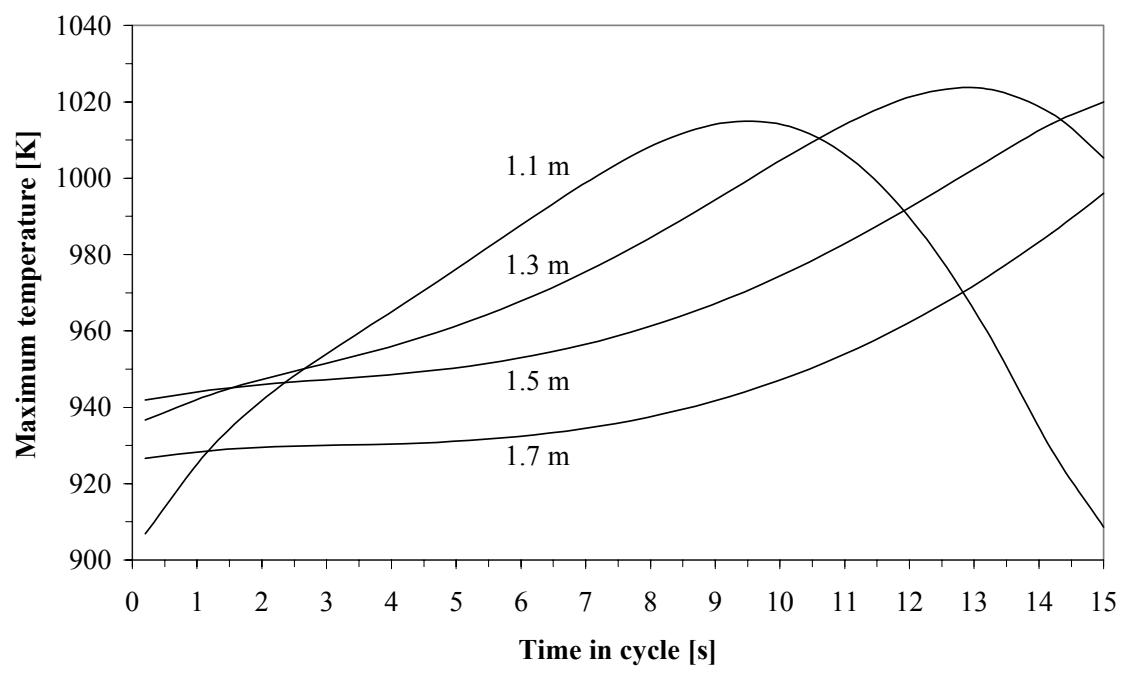

Figure 5. Effect of the length of the 250 times less active sections flanking the catalyst bed at both sides on the evolution of the maximum temperature during the exothermic cycle in the cyclic steady state (operating conditions listed in Table 6 and homogeneous propane combustion neglected).

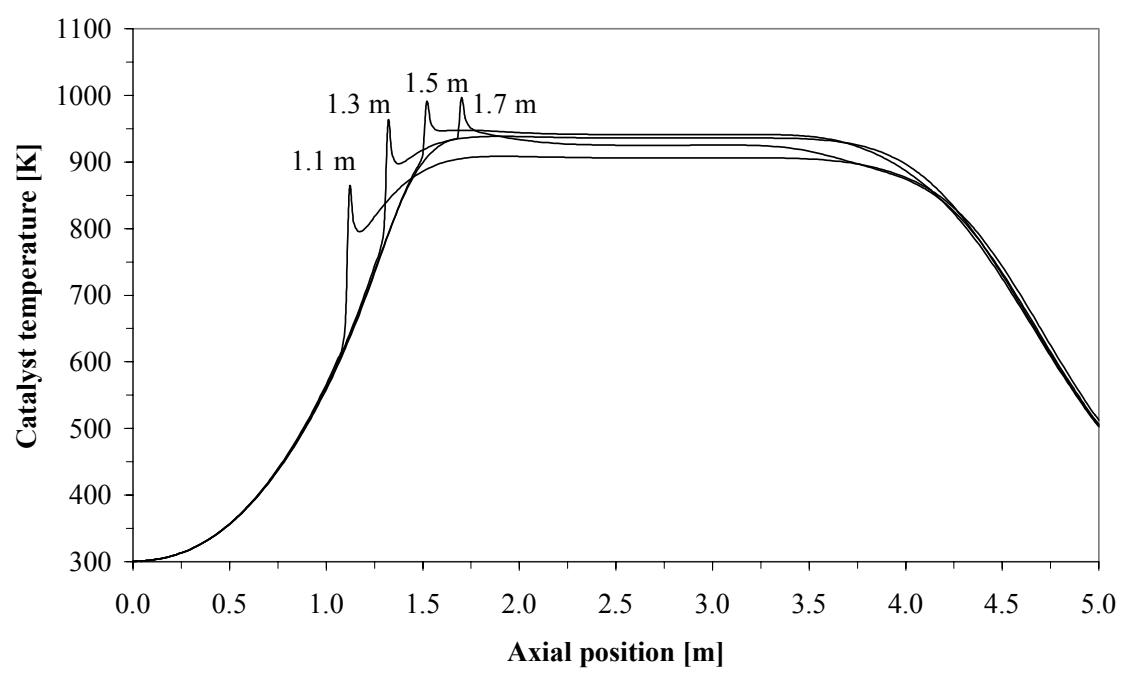

Figure 6. Effect of the length of the 250 times less active sections flanking the catalyst bed at both sides on the cyclic steady state axial catalyst temperature at the end of the forward exothermic cycle (operating conditions listed in Table 6 and homogeneous propane combustion neglected).

Furthermore, the back-end temperature profile is indeed located in the less active sections at the reactor ends. However, at the very end of the reactor in the less active section (at $c a .4 .5-$ $5.0 \mathrm{~m}$ axial position for the forward flow cycle, see Figure 4) the backward reaction still takes place even on a 250 times less active catalyst bed. This back-conversion is mostly caused by the extremely large overestimation of the backward reaction rate at low temperatures. However, considering the worst case scenario, the $1.5 \mathrm{~m}$ less active sections at both reactor 
ends could be replaced by $1.0 \mathrm{~m}$ less active sections flanking the catalyst bed and $0.5 \mathrm{~m}$ completely inactive sections at the reactor ends. In this set-up the back-conversion can be almost completely eliminated during the entire endothermic reaction phase, further minimising convective energy losses (see Figure 7).
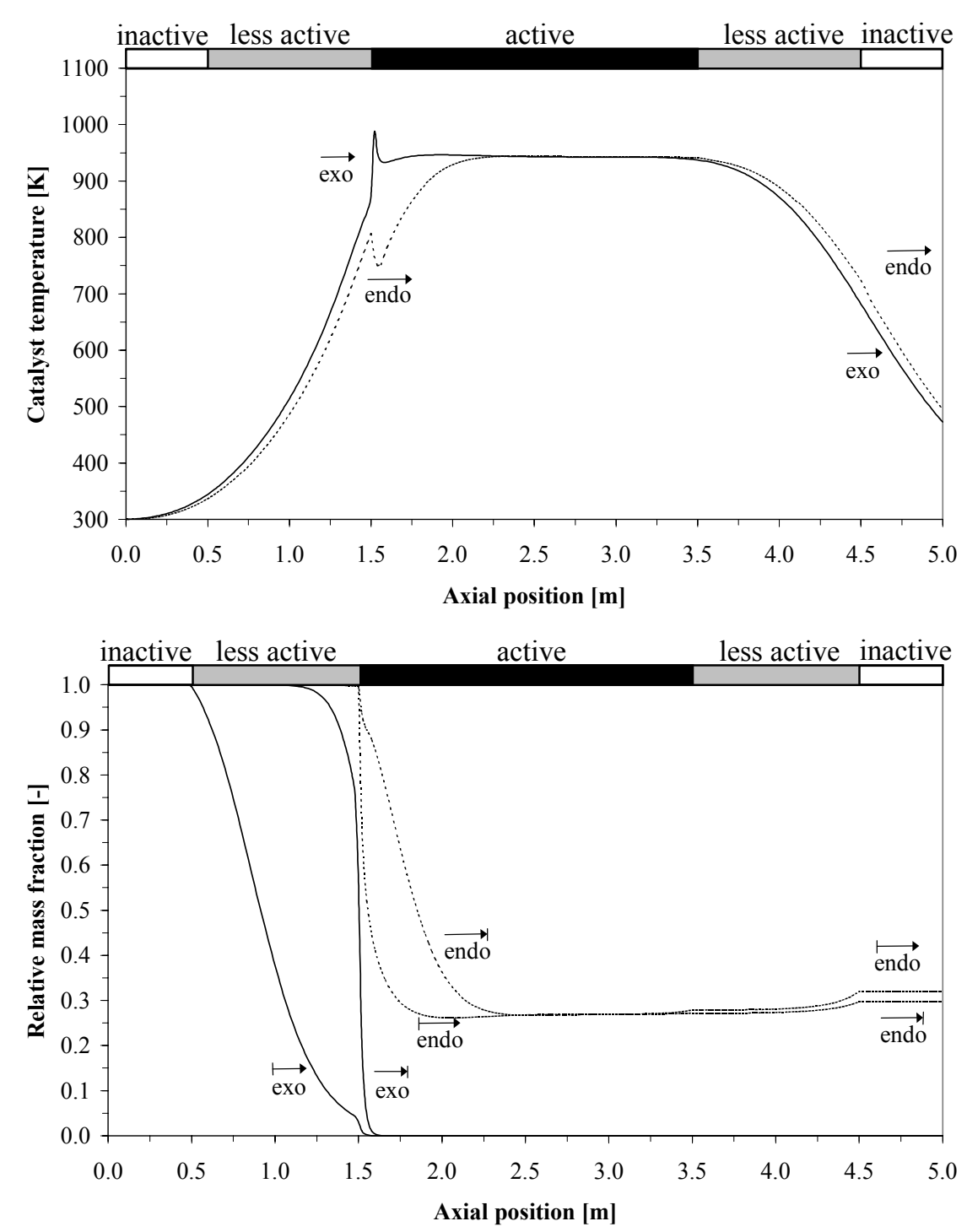

Figure 7. Effect of $1.0 \mathrm{~m}$ length, 250 times less active sections flanking the catalyst bed at both sides and $0.5 \mathrm{~m}$ completely inactive sections at the reactor ends on the cyclic steady state axial profiles of the catalyst temperature (top) and the gas phase mass fraction normalised with the inlet mass fraction (bottom) at the beginning $(\longmapsto)$ and end $(\longrightarrow)$ of the forward endothermic and exothermic cycle (operating conditions listed in Table 6 and homogeneous propane combustion neglected).

Finally, use of less active and inactive sections at the reactor inlet and outlet not only avoids back-conversion, it also saves on catalyst costs. Furthermore, the less active and inactive 
sections protect the much more expensive active catalyst bed, because the large temperature gradients at the reactor inlet and outlet are completely located in these less active or inactive sections. Obviously, one should take special care during start-up of the reactor to avoid too high temperatures in the active catalyst bed.
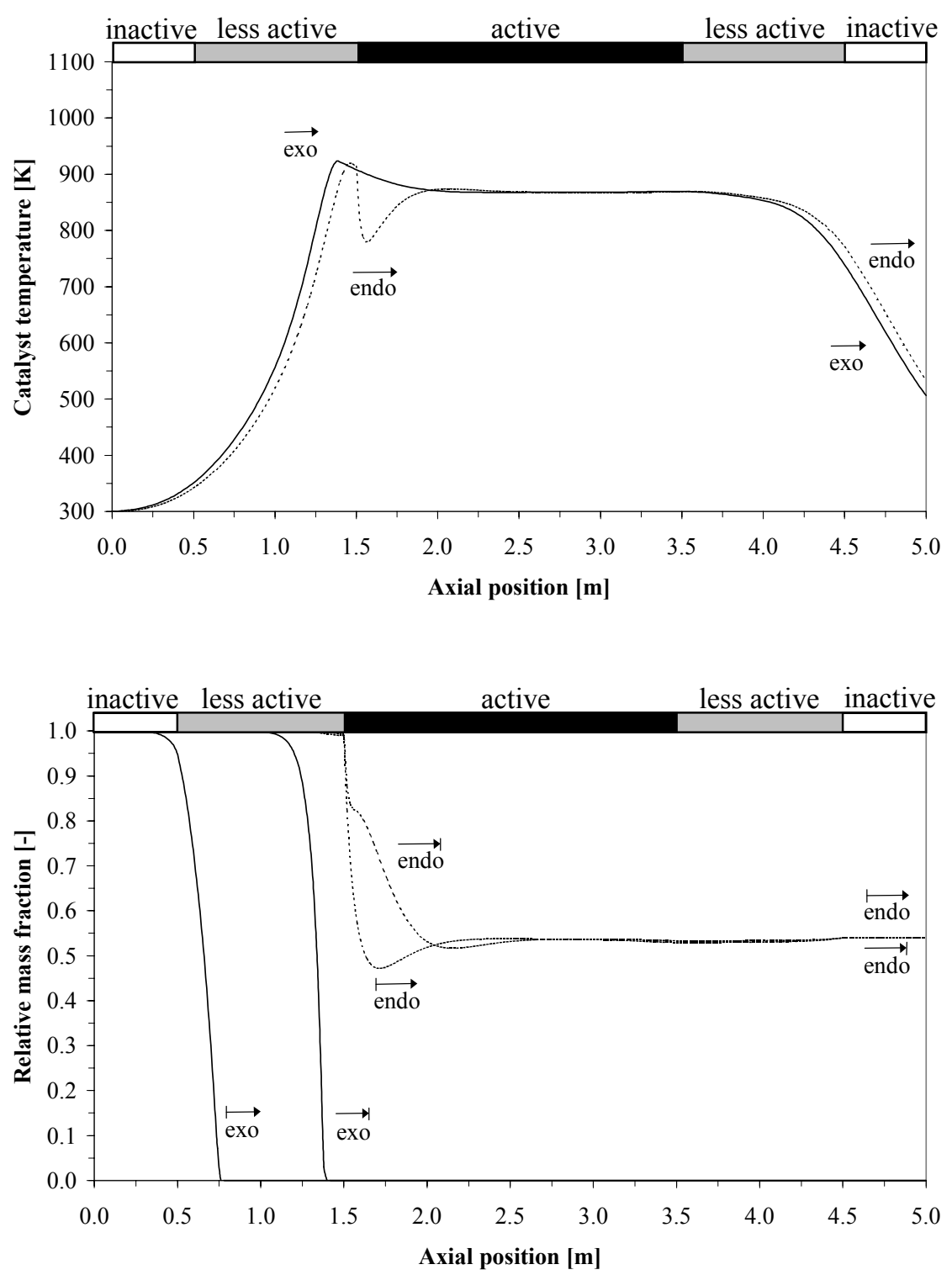

Figure 8. Effect of homogeneous propane combustion for the case of $1.0 \mathrm{~m}$ length 250 times less active sections flanking the catalyst bed at both sides and $0.5 \mathrm{~m}$ completely inactive sections at the reactor ends on the cyclic steady state axial profiles of the catalyst temperature (top) and the gas phase mass fraction normalised with the inlet mass fraction (bottom) at the beginning $(\longmapsto)$ and end $(\longrightarrow)$ of the forward endothermic and exothermic cycle (operating conditions listed in Table 6). 


\subsection{Effect of homogeneous propane combustion}

In the discussion above homogeneous propane combustion has been neglected. In Figure 8 the simulation results are shown including the homogenous propane combustion for the case of $1.0 \mathrm{~m}$ length, 250 times less active sections flanking the catalyst bed and $0.5 \mathrm{~m}$ completely inactive sections at the reactor ends for the operating conditions listed in Table 6.

Taking the homogeneous propane combustion into account the overall propane reaction rate has increased considerably (see Figure 9). This causes firstly a decrease in the maximum temperature and secondly a decrease in the plateau temperature, because the exothermic reaction zone is shifted somewhat towards the reactor end relative to the endothermic reaction zone. Due to the decrease of the plateau temperature the propane conversion is strongly reduced, because the equilibrium conversion is a strong function of the temperature between 800 and $1000 \mathrm{~K}$ for pure propane feed at atmospheric pressure.

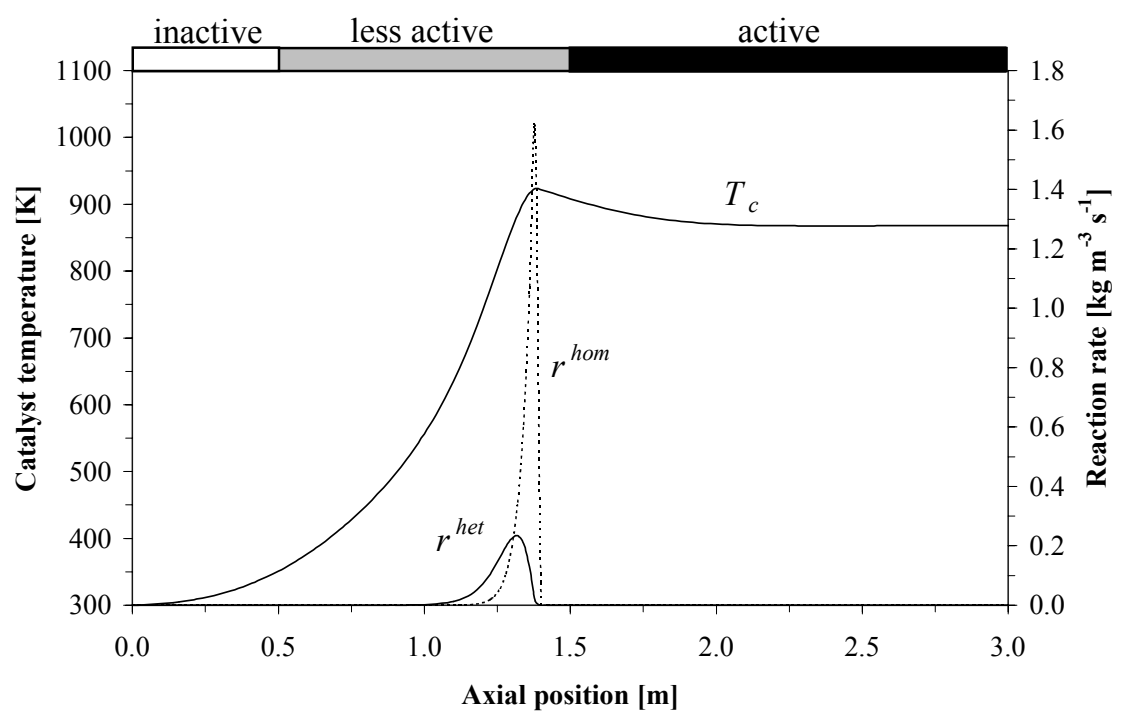

Figure 9. Comparison of the heterogeneous and homogeneous propane combustion reaction rates for the case of $1.0 \mathrm{~m}$ length, 250 times less active sections flanking the catalyst bed at both sides and $0.5 \mathrm{~m}$ completely inactive sections at the reactor ends at the end of the forward exothermic cycle in the cyclic steady state (operating conditions listed in Table 6). 


\section{Plateau temperature control}

Since the plateau temperature determines the equilibrium conversion, it is necessary to control this temperature. However, the plateau temperature is directly controlled, but is a resultant of the relative positions of the endothermic and exothermic reaction zones. In an adiabatic reverse flow reactor the plateau temperature can be increased by shifting the relative position of the exothermic reaction zone relative to the temperature front more inwards compared to the endothermic reaction zone (see Chapter 2). This can be achieved by decreasing the ratio of the endothermic to exothermic gas velocities, which reduces the time averaged production capacity. If the operating conditions are selected so that the exothermic reaction zone is located much more inward relative to the temperature front compared to the endothermic reaction zone, the plateau temperature will equal the maximum temperature. The maximum temperature is mostly determined by the exothermic operating conditions. In this case the plateau temperature can be indirectly set via the specification of the exothermic operating conditions.

However, a new method to directly control the plateau temperature is proposed, making use of the differences in catalytic activity along the axial position in the reactor. When adding methane to the propane/air mixture during the exothermic reaction phase, the propane combustion takes place in the less active section, but most of the methane will be combusted in the active section because of the much lower methane combustion rate compared to the propane combustion rate. Thus, the methane combustion stores energy far inwards relative to the temperature front, thereby strongly increasing the plateau temperature. In Figure 10 simulation results are presented using simultaneous combustion of methane and propane during the exothermic reaction cycle. It is shown that the plateau temperature increases almost $150 \mathrm{~K}$ from $868 \mathrm{~K}$ to $1012 \mathrm{~K}$ using an addition of only $0.10 \mathrm{wt} \%$ methane to the propane/air mixture, which represents an additional adiabatic temperature rise of only $44 \mathrm{~K}$. Figure 11 shows that the plateau temperature and thus the minimum endothermic outlet mass fraction can be directly controlled with the inlet methane mass fraction.

The ratio of the inlet concentrations of methane and propane for the exothermic combustion reaction phase and the platinum content of the less active and active sections can be used to control the maximum temperature and the plateau temperature and to optimise the time- 
averaged production capacity at the desired (equilibrium) conversion and the reaction coupling energy efficiency.
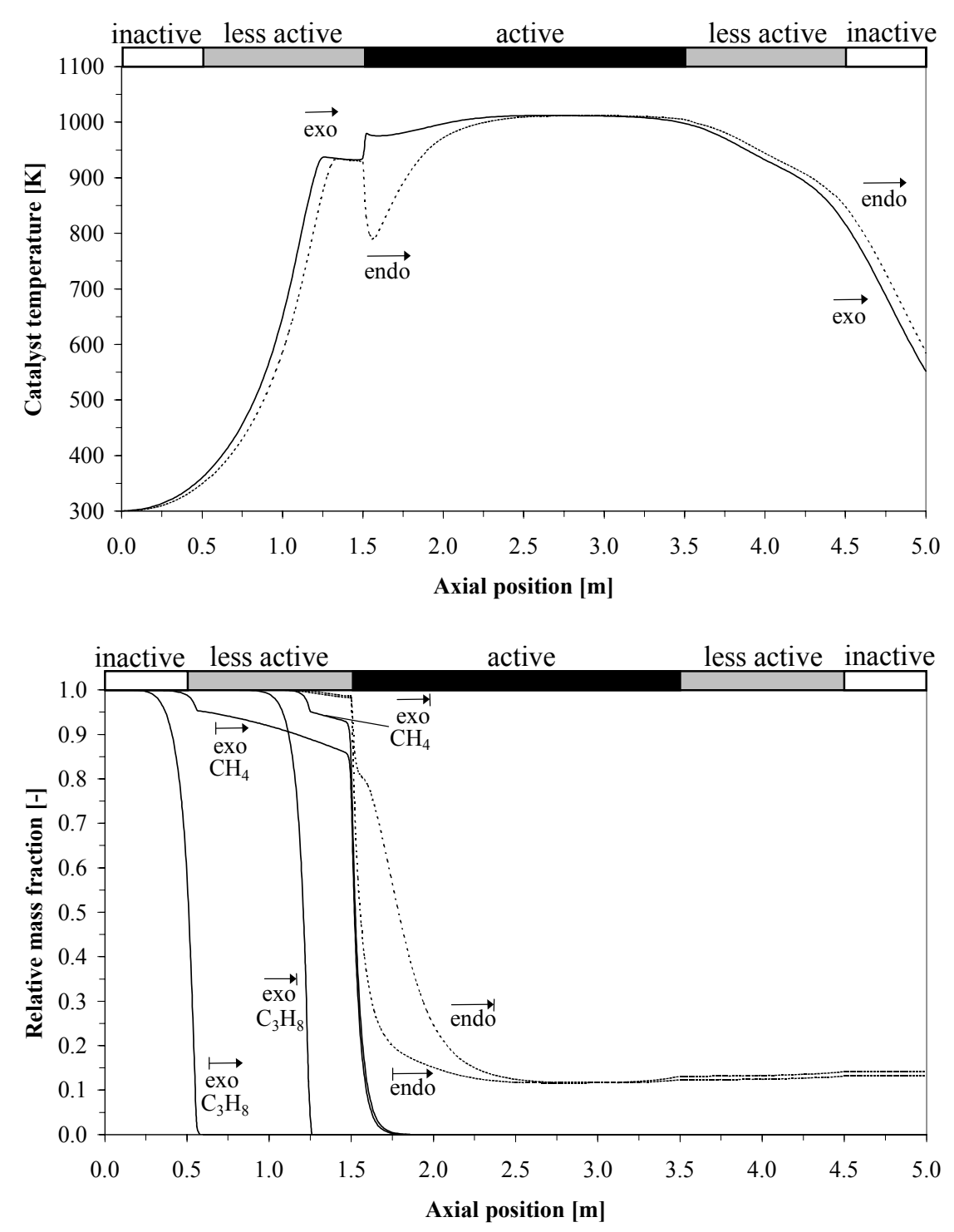

Figure 10. Increase of the plateau temperature by simultaneous combustion of methane and propane for the case of $1.0 \mathrm{~m}$ length, 250 times less active sections flanking the catalyst bed at both sides and $0.5 \mathrm{~m}$ completely inactive sections at the reactor ends on the cyclic steady state axial profiles of the catalyst temperature (top) and gas phase mass fraction normalised with the inlet mass fraction (bottom) at the beginning $(\longmapsto)$ and end $(\longrightarrow)$ of the forward endothermic and exothermic cycle (operating conditions listed in Table 6 , methane inlet mass fraction during the exothermic cycle was set to 0.0010 ). 


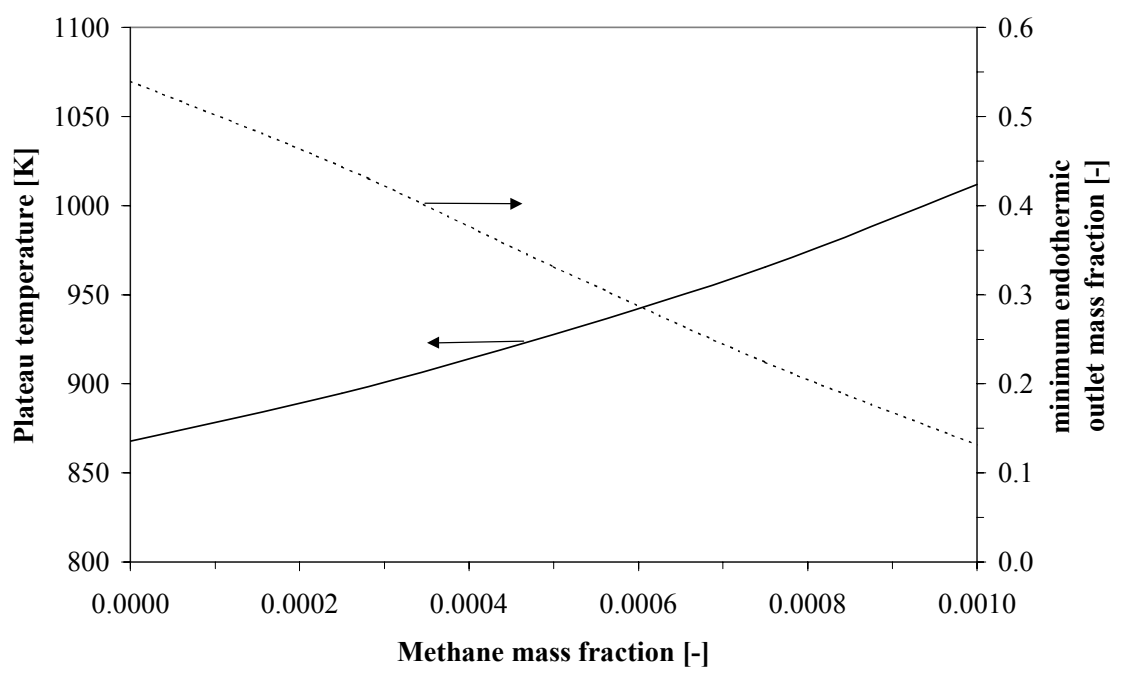

Figure 11. Effect of the methane inlet mass fraction on the cyclic steady state plateau temperature and minimum endothermic outlet mass fraction using simultaneous combustion of methane and propane during the exothermic reaction phase for the case of $1.0 \mathrm{~m}$ length, 250 times less active sections flanking the catalyst bed at both sides and $0.5 \mathrm{~m}$ completely inactive sections at the reactor ends (operating conditions listed in Table 6).

\section{Summary and conclusions}

The novel reactor concept for highly endothermic reactions at elevated temperatures with possible rapid catalyst deactivation, based on the indirect coupling of endothermic and exothermic reactions in reverse flow in the sequential reactor configuration, has been extended for reversible endothermic reactions. Using a detailed simulation model it has been shown that for the propane dehydrogenation/methane combustion reaction system in a platinum-based monolithic catalyst, considering a worst case scenario for the kinetics, most of the propane conversion is lost at the end of the reactor due to low exit temperatures resulting from the reverse flow concept. Due to the exothermicity of the propylene hydrogenation the temperatures at the reactor outlet could increase, reducing this 'back-conversion', but increasing convective energy losses. Full conversion and recuperative heat exchange cannot be combined for reversible reactions in a reactor filled entirely with active catalyst.

It has been demonstrated that positioning inactive sections flanking the catalyst bed at both reactor ends can reduce this back-conversion or convective energy losses. However, the backconversion cannot be avoided completely. Furthermore, at the transition between the inactive and active sections large temperature peaks are formed, largely exceeding the maximum allowable temperature, at least for relatively fast combustion reactions. 
For the sequential reactor configuration effective use can be made of the movement of the temperature fronts enabling one to separate the exothermic and endothermic reaction zones spatially, but not relative to the temperature front. Due to the movement of the temperature front the energy released by the exothermic reactions can be efficiently transferred to the endothermic reactants although the reaction zones are at different axial positions. The solution proposed to achieve full equilibrium conversion and recuperative heat exchange simultaneously and avoiding too high temperatures is to place less active sections flanking the active catalyst bed and small completely inactive sections at the reactor ends and to use propane combustion for energy supply. In the less active sections the propane combustion can take place and the propylene hydrogenation can be sufficiently retarded. Small completely inactive sections can be placed at the reactor ends to avoid back-conversion where the temperature decreases to very low temperatures, if the propylene hydrogenation reaction rate might become significant even on a much less active catalyst section. Furthermore, the temperature gradients are located completely in the less active or inactive sections, protecting the active catalyst bed. Finally, adding methane to the propane/air feed during the exothermic reaction cycle allows direct control of the plateau temperature and thus the propane conversion during the endothermic reaction cycle.

\section{Acknowledgements}

The author wishes to thank H.A.R. Scholts for his valuable contribution to the modelling work. The financial support by the Netherlands Organization for Scientific Research (N.W.O.) is gratefully acknowledged.

\section{Notation}

$a_{v} \quad$ specific external catalyst surface area $\left[\mathrm{m}^{2} \cdot \mathrm{m}^{-3}\right]$

$C_{p} \quad$ heat capacity $\left[\mathrm{J} \cdot \mathrm{kg}^{-1} \cdot \mathrm{K}^{-1}\right]$

$C_{A, g} \quad$ gas phase concentration of component $A\left(=\frac{\rho_{g} \omega_{A, g}}{M_{A}}\right)$

$d_{\text {pore,wc }}$ average pore diameter in the washcoat [m]

$D_{e f f} \quad$ effective diffusion coefficient $\left[\mathrm{m}^{2} \cdot \mathrm{s}^{-1}\right]$ 
$D_{i j} \quad$ binary diffusion coefficient $\left[\mathrm{m}^{2} \cdot \mathrm{s}^{-1}\right]$

$D_{K} \quad$ Knudsen diffusion coefficient $\left[\mathrm{m}^{2} \cdot \mathrm{s}^{-1}\right]$

$f_{c} \quad$ fraction of the washcoat distributed in the channel corners [-]

$\Delta G_{r} \quad$ reaction free enthalpy $\left[\mathrm{J}^{\mathrm{kg}} \mathrm{kg}^{-1}\right]$

$h \quad$ external heat transfer coefficient $\left[\mathrm{J} \cdot \mathrm{m}^{-2} \cdot \mathrm{K}^{-1} \cdot \mathrm{s}^{-1}\right]$

$\Delta h_{r} \quad$ reaction enthalpy $\left[\mathrm{J} \cdot \mathrm{kg}^{-1}\right]$

$E_{\text {act }} \quad$ activation energy $\left[\mathrm{J} \cdot \mathrm{mole}^{-1}\right]$

$k \quad$ reaction rate constant

$k_{I} \quad$ pseudo first order reaction rate constant $\left[\mathrm{s}^{-1}\right]$

$k_{r, \infty} \quad$ pre-exponential reaction rate constant $\left[\mathrm{m} \cdot \mathrm{s}^{-1}\right]$

$k_{r, I, \infty} \quad$ pre-exponential pseudo first order heterogeneous reaction rate constant $\left[\mathrm{m} \cdot \mathrm{s}^{-1}\right]$

$k_{r, I I, \infty} \quad$ pre-exponential pseudo second order heterogeneous reaction rate constant $\left[\mathrm{m}^{4} \cdot \mathrm{mole}^{-1} \cdot \mathrm{s}^{-1}\right]$

$k_{x} \quad$ external mass transfer coefficient $\left[\mathrm{m} \cdot \mathrm{s}^{-1}\right]$

$K_{p} \quad$ thermodynamic equilibrium constant [atm]

$M \quad$ molar mass $\left[\mathrm{kg} \cdot \mathrm{mole}^{-1}\right]$

$n_{c} \quad$ total number of components [-]

$p \quad$ pressure $[\mathrm{Pa}]$

$p \quad$ parameter in the calculation of the propane dehydrogenation reaction rate

$q \quad$ parameter in the calculation of the propane dehydrogenation reaction rate

$R_{A, k i n} \quad$ reaction rate of component $A$ without mass transfer limitations $\left[\mathrm{mole} \cdot \mathrm{m}^{-2} \cdot \mathrm{s}^{-1}\right.$ ]

$r_{A}^{\text {het }} \quad$ production rate of component $A$ by heterogeneous reactions $\left[\mathrm{kg} \cdot \mathrm{m}^{-2} \cdot \mathrm{s}^{-1}\right]$

$r_{A}^{\text {hom }} \quad$ production rate of component $A$ by homogeneous reactions $\left[\mathrm{kg} \cdot \mathrm{m}^{-3} \cdot \mathrm{s}^{-1}\right.$ ]

$R \quad$ gas constant $\left[\mathrm{J} \cdot \mathrm{mole}^{-1} \cdot \mathrm{K}^{-1}\right]$

$S_{B E T} \quad$ total internal and external specific catalyst surface area $\left[\mathrm{m}^{2} \cdot \mathrm{kg}^{-1}\right]$

$\Delta t \quad$ cycle time $[\mathrm{s}]$

$T \quad$ temperature $[\mathrm{K}]$

$\Delta T_{a d} \quad$ adiabatic temperature difference $[\mathrm{K}]$

$v_{z, g} \quad$ axial interstitial gas velocity $\left[\mathrm{m} \cdot \mathrm{s}^{-1}\right]$

$w \quad$ heat front velocity $\left[\mathrm{m} \cdot \mathrm{s}^{-1}\right]$

$x \quad$ mole fraction $\left[\right.$ mole $\cdot \mathrm{mole}^{-1}$ ] 


\section{Greek letters}

$\delta_{w c} \quad$ washcoat thickness [m]

$\varepsilon \quad$ monolith porosity $\left[\mathrm{m}^{3} \cdot \mathrm{m}^{-3}\right]$

$\varepsilon_{w c} \quad$ washcoat porosity $\left[\mathrm{m}^{3} \cdot \mathrm{m}^{-3}\right]$

$\eta \quad$ catalyst efficiency [-]

$\lambda \quad$ conductivity $\left[\mathrm{J} \cdot \mathrm{m}^{-1} \cdot \mathrm{K}^{-1} \cdot \mathrm{s}^{-1}\right]$

$\lambda_{\text {eff }} \quad$ effective heat dispersivity $\left[\mathrm{J} \cdot \mathrm{m}^{-1} \cdot \mathrm{K}^{-1} \cdot \mathrm{s}^{-1}\right]\left(=(1-\varepsilon) \lambda_{c}+\frac{\left(\Phi_{m, i n}^{\prime \prime} C_{p, g}\right)^{2}}{h a_{v}}\right)$

$\rho \quad$ density $\left[\mathrm{kg} \cdot \mathrm{m}^{-3}\right]$

$\tau_{w c} \quad$ washcoat tortuosity [-]

$\Phi_{m}^{\prime \prime} \quad$ mass flux $\left[\mathrm{kg} \cdot \mathrm{m}^{-2} \cdot \mathrm{s}^{-1}\right]$

$\psi_{P t} \quad$ platinum loading in the washcoat [\%]

$\omega \quad$ mass fraction $\left[\mathrm{kg} \cdot \mathrm{kg}^{-1}\right]$

\section{Subscripts}

$A, B, C$ component $A, B, C$

avg average

c catalyst phase

$g$ gas phase

$i \quad$ component $i$

in at the inlet

$\max$ maximum

MC methane combustion

min minimum

ov overall

$P C \quad$ propane combustion

$P D$ propane dehydrogenation

wc washcoat 


\section{Superscripts}

endo endothermic reaction phase

exo exothermic reaction phase

het heterogeneous reactions

hom homogeneous reactions

\section{Dimensionless numbers}

$\Theta \quad$ Maximum temperature number $\left(=\frac{\left(-\Delta h_{r}\right) \Phi_{m, \text { in }}^{\prime \prime 2} \omega_{g, \text { in }}}{2 \lambda_{\text {eff }} k_{r, \infty} a_{v} \rho_{g, \text { in }} T_{g, \text { in }}}\right)$

$B i_{x} \quad$ Biot number for mass transport $\left(=\frac{k_{x} \delta_{w c}}{D_{e f f, w c}}\right)$

$\Phi_{w c} \quad$ washcoat Thiele modulus $\left(=\delta_{w c} \sqrt{\frac{k_{I}}{D_{e f f, w c}}}\right)$

\section{Symbols}

$\rightarrow \quad$ forward flow

$\leftarrow \quad$ backward flow

$\mapsto \quad$ forward flow, at the beginning of the cycle

$\rightarrow \quad$ forward flow, at the end of the cycle

$\leftarrow \quad$ backward flow, at the beginning of the cycle

$\leftrightarrow \quad$ backward flow, at the end of the cycle 


\section{References}

Dryer, F.L. and Glassman, I. (1973). High Temperature oxidation of CO and CH4. 14th Symposium (international) on combustion, 987

Froment, G.F. (1990). Reversed flow operation of fixed bed catalytic reactors. In Matros, Yu. Sh. (Ed.) Unsteady state processes in catalysis, VSP, Utrecht, The Netherlands, 57-89

Hayes, R.E., Kolaczkowski, S.T. (1997). Introduction to catalytic combustion. Gordon and Breach Science Publishers, Singapore

Hiam, L., Wise, H. and Chaikin, S. (1968). Catalytic oxidation of hydrocarbons on platinum. J. Catalysis, 9-10, 272-276

Leung, D., Hayes, R.E., and Kolaczkowski, S.T. (1996). Diffusion limitation effects in the washcoat of a catalytic monolith reactor, Can. J. Chem. Engng, 74, 94-103

Loc, L.C., Gaidai, N.A., Kiperman, S.L., T'huoang, H.S., Podkletnova, N.M. and Kogan, S.B. (1991). Kinetics of propane dehydrogenation on aluminoplatinum catalysts. Kinetics and Catalysis, 32, 61-66

Ma, L., Trimm, D.L. and Jiang, C. (1996). The design and testing of an autothermal reator for the conversion of light hydrocarbons to hydrogen: I. The kinetics of the catalytic oxidation of light hydrocarbons. Applied Catalysis A: General, 138, 275-283

Reid, R.C., Prausnitz, J.M. and Poling, B.E. (1988). The properties of gases and liquids. McGraw-Hill Book Company, New York, USA

Trimm, D.L.and Lam, C.-W. (1980). The combustion of methane on platinum-alumina fibre catalysts - I Kinetics and mechanism. Chem. Engng Sci., 35, 1405-1413

Westbrook, C.K. and Dryer, F.L. (1981). Simplified reaction mechanisms for the oxidation of hydrocarbon fuels in flames. Combustion Science and Technology, 27, 31-43 


\section{Appendix A - Modelling of internal and external mass transfer limitations}

The overall reaction efficiency factor for a pseudo-first order heterogeneous reaction including internal and external mass transfer limitations is given by

$\frac{1}{\eta_{o v}}=\frac{1}{\eta_{w c}}+\frac{\Phi_{w c}^{2}}{B i_{x}}$

in which the washcoat Thiele modulus $\Phi_{w c}$ and the dimensionless mass Biot number $B i_{x}$ are defined as

$$
\begin{aligned}
B i_{x} & =\frac{k_{x} \delta_{w c}}{D_{e f f, w c}} \\
\Phi_{w c} & =\delta_{w c} \sqrt{\frac{k_{I}}{D_{e f f, w c}}}
\end{aligned}
$$

The pseudo-first order reaction rate constant is approximated by

$$
k_{I}=\frac{r_{A, k i n}^{h e t}}{\rho_{g} \omega_{A, g}}
$$

The effective diffusion coefficient in the pores of the washcoat $D_{\text {eff,wc }}$ is approximated using an effective bulk diffusion coefficient $D_{\text {eff }}$ and the Knudsen diffusion coefficient $D_{K}$

$$
D_{e f f, w c}=\frac{\varepsilon_{w c}}{\tau_{w c}}\left(\frac{1}{D_{e f f}}+\frac{1}{D_{K}}\right)^{-1}
$$

The effective reactant-gas mixture binary diffusion coefficient is estimated via Blanc's law using the binary diffusion coefficients $D_{i j}$ (calculated from Fuller's equation) and the molar fractions $x_{i}$ (Reid et al., 1988): 
$D_{\text {eff }}=\left[\sum_{\substack{j=1 \\ i \neq j}}^{n_{c}} \frac{x_{i}}{D_{i j}}\right]^{-1}$

Assuming a narrow pore size distribution and straight pores the Knudsen diffusion coefficient can be estimated from (Hayes and Kolaczkowski, 1997)

$D_{K}=3.067\left(\frac{2 \varepsilon_{w c}}{S_{B E T, w c} \rho_{w c}}\right) \sqrt{\frac{T}{M_{g}}}=1.533 d_{p o r e, w c} \sqrt{\frac{T}{M_{g}}} \mathrm{~m} \cdot \mathrm{s}^{-2}$

Considering the washcoat as an isothermal flat slab, the internal washcoat efficiency $\eta_{w c}$ can be approximated by

$\eta_{w c} \approx \frac{\tanh \left(\Phi_{w c}\right)}{\Phi_{w c}}$

In a square monolith channel the washcoat is not equally distributed along the perimeter of the channel. The washcoat thickness in the corners of a square channel can be almost an order of magnitude larger than the washcoat thickness along the sides of the channel. To correctly account for the unequal washcoat distribution two-dimensional calculations over the crosssection of the washcoat should be carried out (see e.g. Leung et al., 1996). However, this level of complexity is avoided in this work. In stead, an approximate average efficiency factor is used to roughly account for this unequal washcoat distribution.

\section{A.1 Average internal washcoat efficiency for square monolithic channels}

In order to derive a reasonable approximation for the average internal washcoat efficiency taking the radially non-uniform washcoat distribution into account, information about the average $\left(\delta_{w c}\right)$, minimum $\left(\delta_{w c, \text { min }}\right)$ and maximum $\left(\delta_{w c, \max }\right)$ washcoat thickness is assumed, e.g. obtained by SEM.

The washcoat distribution is assumed to be distributed in four equal parts along the sides of the square, having a washcoat thickness equal to the minimum washcoat thickness, and four 
equal parts in the four corners with a linearly washcoat thickness varying between the minimum and maximum washcoat thickness, as depicted in Figure A.1.
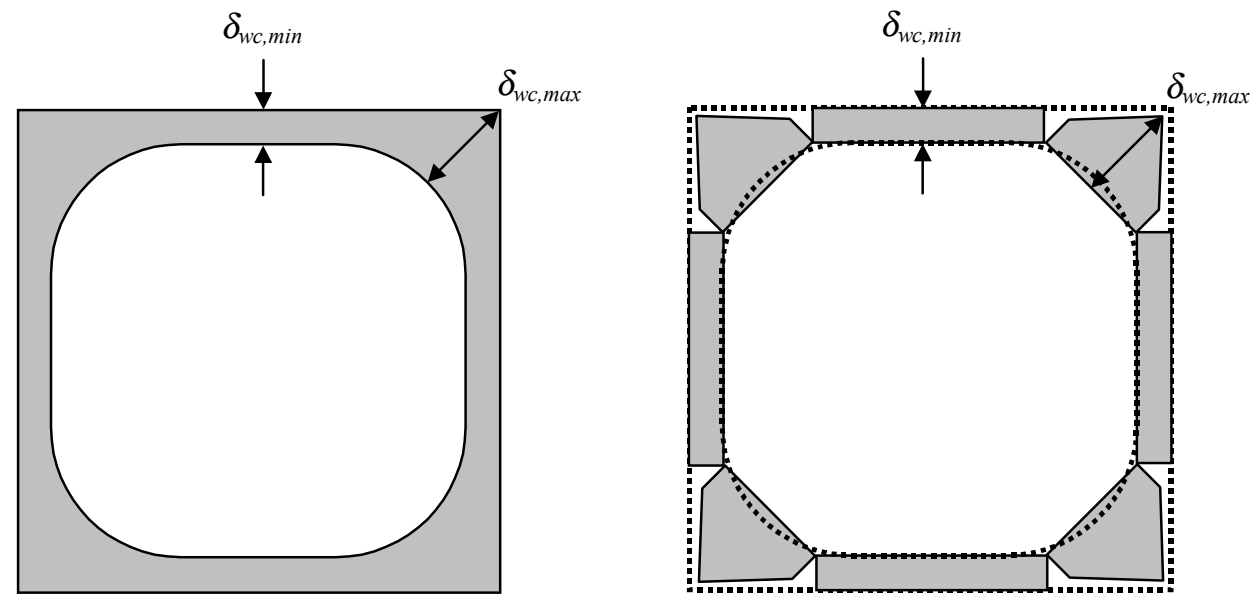

Figure A.1 Schematic representation of the washcoat distribution over the cross-section of a square monolith channel and the approximation proposed.

The fraction of the washcoat distributed in the corners $f_{c}$ is approximated by:

$$
f_{c}=\frac{\delta_{w c}-\delta_{w c, \min }}{\left(\frac{\delta_{w c, \max }+\delta_{w c, \min }}{2}\right)-\delta_{w c, \min }}
$$

Since the washcoat efficiency decreases with an exponential-like function with increasing washcoat thickness, the average washcoat efficiency of the corners is approximated with a logarithmic mean of the minimum and maximum washcoat thickness. Thus, the average washcoat efficiency is approximated by:

$$
\eta_{w c, a v g}=\left(1-f_{c}\right) \eta_{w c}\left(\delta_{w c, \min }\right)+f_{c} \frac{\eta_{w c}\left(\delta_{w c, \min }\right)-\eta_{w c}\left(\delta_{w c, \max }\right)}{\ln \left(\frac{\eta_{w c}\left(\delta_{w c, \min }\right)}{\eta_{w c}\left(\delta_{w c, \max }\right)}\right)}
$$


CHAPTER 4

\author{
PROPANE DEHYDROGENATION \\ REACTION KINETICS \\ OVER A MONOLITHIC \\ PLATINUM ALUMINA CATALYST
}




\section{Abstract}

The propane dehydrogenation and propylene hydrogenation reaction kinetics on a monolithic $\mathrm{Pt} / \gamma-\mathrm{Al}_{2} \mathrm{O}_{3}$ catalyst have been experimentally investigated in a differentially operated reactor. The same catalyst sample was used for many experiments consisting of reduction, (de)hydrogenation and TPO, in order to simulate the reaction conditions in a Reaction Coupling Reverse Flow Reactor and to correct the measured reaction rates for the decrease in catalytic activity caused by sintering and destruction of the most active sites or decrease in platinum dispersion, via interpolation of the catalytic activity of standard experiments. The propane dehydrogenation and propylene hydrogenation reaction rates typically decrease during the course of an experiment, due to the formation of carbonaceous deposits on the active sites. Although the extent of and the rate at which the catalytic activity decreases depends on the operating conditions prior to and during the experiments, the reaction rates reached an asymptotic steady state value after about half an hour. These pseudo steady state reaction rates of the propane dehydrogenation and propylene hydrogenation have been determined as a function of temperature and composition over wide temperature and concentration ranges. From the selectivity data information about the kinetics of the most important gas phase side reactions, viz. propane cracking and propane and propylene hydrogenolysis, was extracted.

For the reaction rates of the propane dehydrogenation and hydrogenolysis at higher temperatures, the propane cracking and the propylene hydrogenolysis reaction orders for hydrogen were observed corresponding to the reaction stoichiometry. However, the propane dehydrogenation and hydrogenolysis at lower temperatures and the propylene hydrogenation show a remarkable additional order in the hydrogen concentration. This was interpreted by assuming that the reactions can take place at two different surface sites, platinum surface sites and acid alumina surface sites, where the reactions taking place at the platinum surface sites have a supplementary order in the hydrogen concentration. It has been shown that the additional hydrogen order can be explained by the influence of hydrogen on the number of free surface sites not covered with carbonaceous deposits.

Reaction rate expressions based on the above assumption were capable of describing the experimentally observed remarkable influences of temperature and composition on the pseudo-steady state reaction rates for reaction mixtures whose composition strongly deviates from the equilibrium composition. However, a necessary adjustment has been included to predict the thermodynamic equilibrium correctly. 


\section{Introduction}

The highly endothermic non-oxidative heterogeneously catalysed propane dehydrogenation is carried out at high temperatures $\left(550-650{ }^{\circ} \mathrm{C}\right)$ because of thermodynamic constraints. However, at high temperatures carbonaceous site-products, collectively termed coke, are formed at the catalyst surface, necessitating catalyst regeneration. A new multifunctional reactor is developed, where the propane dehydrogenation reaction, energy supply at high temperatures, catalyst regeneration and recuperative heat exchange are all integrated in one apparatus. In this 'Reaction Coupling Reverse Flow Reactor' (RCRFR) endothermic propane dehydrogenation reaction phases are alternated by fuel combustion reaction phases, where the fixed catalyst is used as an energy store, indirectly coupling the reaction enthalpies of the endothermic and exothermic reactions. During the endothermic propane dehydrogenation reaction phase energy is withdrawn from the catalyst cooling down the catalyst and simultaneously coke is deposited on the catalyst surface. During a consecutive exothermic fuel combustion process step the catalyst is reheated and concurrently regenerated by burning off the coke. Furthermore, by periodically alternating the gas flow direction through the catalyst material the reactants can be fed to the reactor without any pre-heating, while still high temperatures prevail in the centre of the reactor. Via the reverse flow concept recuperative heat exchange is integrated in the reactor.

In the RCRFR the catalyst is regenerated in situ, which allows the application of a catalyst with highly active (and expensive) components. For the non-oxidative propane dehydrogenation the highest reaction rates have been reported for a catalyst with platinum as the active component and possibly tin added as promotor (a.o. Loc et al., 1991a). In our study a monolithic catalyst was selected, mainly because of the very high specific external catalyst surface area per unit reactor volume (maximising catalyst efficiency especially for the desired high temperatures) while maintaining a pressure drop of about two orders of magnitude lower than for a bed of particles (Cybulski and Moulijn, 1994). Using a monolithic catalyst, very high gas velocities can be applied during the combustion process step. This is necessary to maximise the propylene production capacity, while matching the Damköhler numbers of the endothermic and exothermic reaction phases which is necessary to utilise the entire catalyst efficiently (see Chapter 2). Furthermore, the absence of dispersion in the monolithic channels combined with low temperatures at the reactor inlet and outlet resulting from the reverse flow 
concept allows switching between the propane dehydrogenation reaction phase and the combustion reaction phase without intermediate flushing with nitrogen (see Chapter 6).

Due to the large reaction enthalpies of the propane dehydrogenation step and fuel combustion step the cycle times for reaction phase switching are relatively short, assuring fast catalyst regeneration. Subsequently, fast catalyst regeneration allows operation of the endothermic propane dehydrogenation reaction phase at more severe reaction conditions, because the shorter the time on stream, the smaller the amount of coke deposited and the larger the hydrogen to carbon ratio of the coke (Brito et al., 1996), either facilitating the burning of the coke. Thus, the fast catalyst regeneration allows operation at higher temperatures and lower hydrogen concentrations with higher equilibrium conversions. This makes the RCRFR a particularly interesting reactor concept for the propane dehydrogenation reaction, next to possible large savings on investments for heat exchange equipment thanks to the reverse flow concept.

However, the allowed increase in the temperature and decrease in the hydrogen concentration to maximise the propylene production rate (i.e. benefit of fast regeneration), strongly depend on the reaction rate of the propane dehydrogenation and its side-reactions. The following issues have to be considered in this respect:

1. The decrease of coke deposition during the endothermic propane dehydrogenation process step due to the smaller cycle times compared to the increase in coke deposition at higher temperatures and lower hydrogen concentrations;

2. The extent of the increase in the time-averaged propane dehydrogenation reaction rate (averaged over an entire propane dehydrogenation reaction cycle) due to operation with a catalyst, which has just been regenerated, i.e. the time-dependency of the propane dehydrogenation reaction rate due to coke formation;

3. The extent of the decrease in the propylene selectivity at higher temperatures and the extent of the increase in the propylene selectivity for lower hydrogen concentrations, i.e. the extent of the increase in the reaction rates of the propane dehydrogenation compared to the gas phase side-reactions, especially propane cracking, and propane and propylene hydrogenolysis. Since the energy released by the combustion of the coke can be effectively used for the propane dehydrogenation, the coke selectivity is only important, if the propane feedstock for the propane dehydrogenation is much more expensive than the fuel 
feedstock. Furthermore, also the total olefin selectivity is important, since ethylene is a very valuable side-product.

It should be realised that a relatively large increase in the equilibrium conversion can be achieved with a relatively small temperature increase, because the equilibrium conversion is strongly temperature dependent in the temperature range of 600 to $700{ }^{\circ} \mathrm{C}$. For undiluted propane feed the equilibrium conversion of propane to propylene increases from about $50 \%$ at $600{ }^{\circ} \mathrm{C}$ to $80 \%$ at $700{ }^{\circ} \mathrm{C}$. Furthermore, the propylene production rate is optimised through operation at low hydrogen concentrations, because dilution with hydrogen decreases the reactor capacity (propane flow rate), equilibrium propane conversion and gas phase propylene and olefin selectivity, provided that stable operation is possible due to the fast catalyst regeneration. Moreover, it has been shown that the retardation of the coke formation by hydrogen strongly decreases at higher temperatures (see Chapter 5).

To determine optimal process conditions information about the reaction rates of the propane dehydrogenation and propylene hydrogenation and their most important side-reactions, viz. propane cracking, propane and propylene hydrogenolysis and coke formation, as a function of temperature and composition and as a function of time on stream, is indispensable.

Furthermore, because of the reverse flow concept a trapezoid axial temperature profile is established in the cyclic steady state with low temperatures at the reactor inlet and outlet and high temperatures in the centre of the reactor. The temperature fronts at the reactor inlet and outlet wander back and forth during the different process steps. Thus, large temperature and concentration gradients prevail in the RCRFR, so that information about the reaction kinetics is required over wide temperature and concentration ranges.

Moreover, the propane dehydrogenation is an endothermic equilibrium reaction and due the low exit temperatures the equilibrium can be shifted towards the reactant side at the reactor outlet. How this 'back-conversion' can be counteracted by positioning less active and possibly also inactive catalyst material at the reactor inlet and outlet has been discussed in Chapter 3. To investigate the extent of the back-conversion and the optimal catalyst concentration profile also information about the propylene hydrogenation rate as a function of temperature and composition over wide temperature and concentration ranges is required. 
Despite the increased interest in propane dehydrogenation processes in the last decade (Resasco and Haller, 1994) no complete reaction rate equation for the propane dehydrogenation over a platinum based alumina catalyst valid for wide temperature and concentration ranges is available in the literature. The main reason for the deficiency of knowledge on the propane dehydrogenation reaction kinetics (and mechanism) is the very complex coke formation process taking place simultaneously at the catalyst surface and influencing the propane dehydrogenation reaction kinetics. The complex interplay of the coke formation and propane dehydrogenation processes obfuscates information on the reaction mechanism and kinetics. The research published in the literature has mainly focussed on the optimisation of catalyst properties for the propane dehydrogenation. Especially the effect of the addition of tin and indium to platinum catalysts on the catalyst stability and the propane dehydrogenation reaction rate has been investigated (a.o. Loc et al., 1991a; Bariås, 1993; Bariås et al., 1994, Larsson and Andersson, 1994; Bariås et al., 1995; Bariås et al., 1996; Larsson, 1997). No kinetic studies on the propane dehydrogenation over monolithic catalysts have been reported.

The most important contribution on the influence of reaction conditions on the dehydrogenation of propane, n-butane and isobutane and their mixtures on platinum and platinum-tin catalysts has been reported by Loc et al. (1986, 1988, 1990, 1991a, 1993a, 1993b, 1993c, 1995, 1996). They investigated the influences of the propane, propylene and hydrogen concentration on the propane dehydrogenation reaction rate over a platinum alumina catalyst and derived a Langmuir-Hinshelwood type reaction rate equation (Loc et al., 1991a)

$$
R_{P D}=\frac{k p_{\mathrm{C}_{3} \mathrm{H}_{8}}}{p_{\mathrm{H}_{2}}^{0.5}+K_{a d s, \mathrm{C}_{3} \mathrm{H}_{6}} p_{\mathrm{C}_{3} \mathrm{H}_{6}}}\left(1-\frac{1}{K_{p}} \frac{p_{\mathrm{C}_{3} \mathrm{H}_{6}} p_{\mathrm{H}_{2}}}{p_{\mathrm{C}_{3} \mathrm{H}_{8}}}\right)
$$

They assured that the experiments were carried out in the kinetic regime, which required a particle diameter smaller than $2 \mathrm{~mm}$, and that the degree to which the system approximated equilibrium under the experimental conditions was not too high (0.21-0.90). However, the presented reaction rate equation is only valid for a relatively small temperature range of $570-620^{\circ} \mathrm{C}$ and for propane feeds strongly diluted with hydrogen (at least $c a .30 \%$ hydrogen). Extrapolation of their presented reaction rate equations to lower temperatures or 
lower hydrogen concentrations gives erroneous results. Firstly, the propane dehydrogenation reaction rate equation tends to infinity when the hydrogen concentration approaches zero (the term 1 has been omitted in the denominator of the Langmuir-Hinshelwood term). Secondly, because Loc et al. fitted an activation energy of $59 \mathrm{~kJ} \cdot \mathrm{mole}^{-1}$ for the propane dehydrogenation reaction at $600{ }^{\circ} \mathrm{C}$, which is much smaller than the propane dehydrogenation reaction enthalpy of $130 \mathrm{~kJ} \cdot \mathrm{mole}^{-1}$ at $600{ }^{\circ} \mathrm{C}$, the propylene hydrogenation reaction rate is enormously overestimated at low temperatures (say below $300{ }^{\circ} \mathrm{C}$ ). If the ratio of the reaction rate constants for the propane dehydrogenation $\left(k_{f}\right)$ and propylene hydrogenation $\left(k_{b}\right)$ is related by the equilibrium constant $\left(K_{p}\right)$ (valid at equilibrium, provided that the reaction orders correspond with the reaction stoichiometry), the temperature dependency of the propylene hydrogenation reaction rate constant is given by

$\frac{\partial k_{b}}{\partial T}=-\frac{k_{f, \infty}}{R T^{2}}\left(\Delta H_{r}-E_{f}\right) e^{-\frac{\Delta G_{r}-E_{f}}{R T}}$

This equation shows that the propylene hydrogenation reaction rate constant strongly increases at lower temperatures, if the activation energy for the propane dehydrogenation $\left(E_{f}\right)$ is smaller than the propane dehydrogenation reaction enthalpy $\left(\Delta H_{r}\right)$. Loc et al. (1991b) also experimentally investigated the kinetics of the propylene hydrogenation reaction at $500-570^{\circ} \mathrm{C}$. They derived a similar Langmuir-Hinshelwood reaction rate equation and fitted an activation energy for the propylene hydrogenation reaction rate constant of $-86 \mathrm{~kJ} \cdot \mathrm{mole}^{-1}$, which corresponds reasonably to the reaction enthalpy and the measured activation energy for the propane dehydrogenation reaction rate constant at $570{ }^{\circ} \mathrm{C}$, but again too high propylene hydrogenation reaction rates are extrapolated for low temperatures. In both papers Loc et al. also explicitly acknowledged that the experimental data could not be fitted with an Arrhenius plot, although they presented fitted activation energies nevertheless.

Biloen et al. (1977) investigated the reaction kinetics of the propane dehydrogenation over pure $\mathrm{Pt}$ and powderlike Pt-Au alloy catalysts at low temperatures of $350-400{ }^{\circ} \mathrm{C}$ and very high hydrogen mole fractions (hydrogen to propane mole ratio of 50) in order to reduce the influence of sintering and coke formation. They found propane and hydrogen reaction orders of $1.00 \pm 0.02$ and $-1.1 \pm 0.1$ and activation energy of $128 \pm 8 \mathrm{~kJ} \cdot \mathrm{mole}^{-1}$. Although care was taken that the kinetic results were not influenced by diffusional resistances, the observed 
reaction orders and activation energy very likely suggest that the reaction rate was limited by equilibrium. Note that for a propane/hydrogen feed with a propane mole fraction of 0.02 at $400{ }^{\circ} \mathrm{C}$ the equilibrium conversion is only $0.16 \%$. For small conversions the apparent activation energy can be determined by

$$
E_{\text {act,apparent }}=-R \frac{\partial(\ln (\zeta))}{\partial\left(\frac{1}{T}\right)}
$$

If the experimentally determined conversion approaches the equilibrium conversion, the apparent activation energy can be obtained from

$$
E_{\text {act,apparent }} \approx-R \frac{\partial\left(\ln \left(\zeta^{e q}\right)\right)}{\partial\left(\frac{1}{T}\right)}=-R \frac{\partial\left(\ln \left(\zeta^{e q}\right)\right)}{\partial\left(\ln \left(K_{p}\right)\right)} \frac{\partial\left(\ln \left(K_{p}\right)\right)}{\partial\left(\frac{1}{T}\right)}
$$

After substitution of Van het Hoff's equation (neglecting the temperature dependency of the reaction enthalpy) (see e.g. Atkins, 1990) this reduces to

$$
E_{\text {act,apparent }} \approx \frac{\partial\left(\ln \left(\zeta^{e q}\right)\right)}{\partial\left(\ln \left(K_{p}\right)\right)} \Delta H_{r}
$$

Realising that for strongly diluted feeds the equilibrium conversion equals the equilibrium constant, it can be shown that the apparent activation energy approaches the reaction enthalpy, as observed by Biloen et al. Hence, in order to correctly determine the reaction rate kinetics of an equilibrium reaction it is important that the extent to which the system approaches equilibrium under the experimental conditions is small.

Bariås (1993) measured the propane dehydrogenation kinetics over a $\mathrm{Pt}-\mathrm{Sn} / \gamma-\mathrm{Al}_{2} \mathrm{O}_{3}$ catalyst and found reaction orders in propane and hydrogen of 0.93 and -0.67 , respectively, which reasonably corresponds to the findings of Loc et al. (1991a). He did not investigate the influence of propylene on the reaction rate. Furthermore, he fitted an activation energy of about $100 \mathrm{~kJ} \cdot \mathrm{mole}^{-1}$ for the propane dehydrogenation. However, this fit is based on only two experiments at 427 and $519^{\circ} \mathrm{C}$ and secondly, the measured conversions were relatively close to the equilibrium conversions. 
An experimental study has been carried out to determine the reaction kinetics of the propane dehydrogenation and propylene hydrogenation and the most important gas phase sidereactions over a platinum alumina monolithic catalyst as a function of temperature and composition over wide temperature and concentration ranges. Although coke selectivities have been measured, the coke formation rates as a function of temperature and composition and as a function of the time on stream have been investigated in more detail in a separate study using thermogravimetric analysis (see Chapter 5).

In order to restrict this kinetic investigation on the propane dehydrogenation the following aspects were left out of consideration:

\section{Detailed reaction mechanism;}

The purpose of this research is the derivation of kinetic reaction rate expressions. Although from the experimental observations some conclusions can be drawn on the reaction mechanism, this is not the main focus of this work. Extensive additional kinetic research including transient kinetic investigations (e.g. with isotopes, expanding the work by Bariås, 1993), are necessary to completely elucidate the propane dehydrogenation reaction mechanism, taking account of effects of coke formation.

\section{Catalyst optimisation;}

Catalyst optimisation (e.g. type and concentration of active components and promotors, type of support, etc.) has been completely ignored. A commercial $\mathrm{Pt} / \gamma-\mathrm{Al}_{2} \mathrm{O}_{3}$ monolithic catalyst was selected (supplied by Engelhard) and no attempts to improve the catalyst activity or selectivity have been undertaken. The propylene selectivity might be increased by adding Sn or In to the platinum based catalyst. The coke selectivity could be reduced by modifying the washcoat acidity. Finally, the platinum content could be optimised.

\section{Long term catalyst properties;}

The long term durability (i.e. weeks-months) of the catalyst material for repeated rapid changes in reaction conditions, namely temperature (because of large reaction enthalpies) and composition (rapid recurrent alternations between reductive and oxidative conditions), and for frequent coke formation and coke combustion cycles on the activity and selectivity of the propane dehydrogenation, has not been considered. However, the effect of alternating reaction conditions has been investigated up to almost 70 repeated cycles of propane dehydrogenation (ca. $30 \mathrm{~min}$. per cycle) and combustion ( $c a .1 \mathrm{hr}$ ). 
Obviously, especially these last two issues need to be addressed when investigating the economic potential of this new propane dehydrogenation process compared to conventional processes.

Before presenting and discussing experimental results, first the experimental set-up and the experimental procedure used to determine the reaction kinetics are described in the next section.

\section{Experimental}

In the RCRFR the catalyst changes often and rapidly from reductive to oxidative reaction conditions because of the rapid switching between the propane dehydrogenation and fuel combustion reaction phases. In order to investigate the reaction kinetics under comparable reaction conditions a reactor has been designed to determine reaction kinetics over a monolithic catalyst, which has endured several (de)hydrogenation and combustion cycles. In almost all other kinetic research published in the literature a fresh sample of catalyst is used for each experiment. By using the same monolith piece for many different experiments the effects of sintering and destruction of the most active sites can be excluded from the effects of coke formation, as explained below. Due to the open structure of monolithic catalysts with a large frontal surface area for the gas flow (large gas phase porosity) problems of catalyst plugging resulting from coke formation do not occur in monoliths, unlike in packed bed reactors, where plugging can be a serious problem.

First the kinetics-reactor and the experimental set-up are described. Then the experimental procedure used to determine the reaction kinetics is discussed with special attention for the time-dependency of the catalyst activity during the propane dehydrogenation because of sintering and coke formation.

\subsection{Experimental set-up}

A special reactor was constructed to carry out propane dehydrogenation and propylene hydrogenation kinetic experiments on a monolithic catalyst in differential operation, i.e. at low reactant conversion $(<10 \%)$, so that the influence of axial concentration gradients or 
back-mixing can be neglected. In Figure 1 a picture and a detailed schematic of the reactor is shown. The reactor consisted of a tray with a cover made of high temperature stainless steel, insulated with ceramic wool in a brick housing. In the tray a thin squared piece of a monolithic catalyst with a cross-sectional area of $55 \mathrm{~mm}$ x $55 \mathrm{~mm}$ and a length of $7.5 \mathrm{~mm}$ was positioned on top of a layer of ceramic wool functioning as gas distributor. A metal gas distribution plate showed excessive coke formation and eventually even caused plugging of the distribution plate. The monolith was not crushed, but left in one piece in order to avoid possible influences of the support. Except for the outer two rows of channels of the monolith, about $1 \mathrm{~mm}$ of the top and the bottom of the monolith was removed and replaced by ceramic plates. Thus gas could flow only through the outer two rows of channels of the monolith and thus temperature profiles in the monolith due to the relatively high reaction enthalpy are avoided. At ten different positions in the monolith the temperatures were continuously measured using K-type thermocouples and stored using a PC equipped with a data-acquisition card. The temperature of the reactor was controlled by using four $200 \mathrm{~W}$ cylindrical heaters installed in the metal tray and by flowing cold nitrogen gas though many tiny holes drilled in the metal tray.
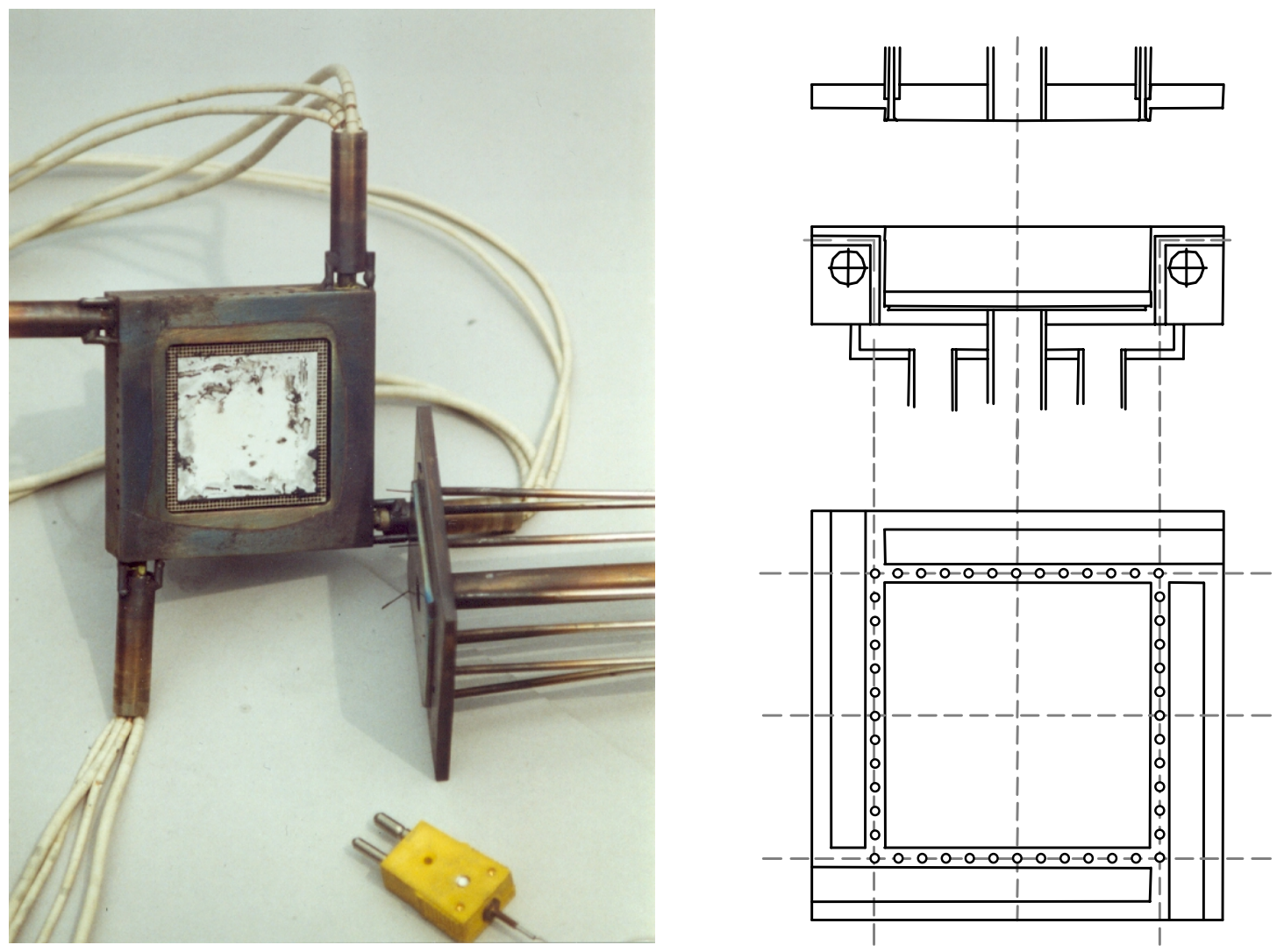

Figure 1. Picture and detailed schematic of the kinetics-reactor. 
With mass flow controllers the total flow rate and the composition of the reaction mixture consisting of propane, propylene, hydrogen and nitrogen (all chemical grades about 3.0) was set (see Figure 2). The reactants were fed to the reactor pre-heated using tape-heaters wrapped around the feed conduit over a short distance to avoid side-reactions. During the propane dehydrogenation or propylene hydrogenation experiments gas samples from the reactor effluent were taken automatically by switching a 16-port-valve controlled via a PLC (Programmable Logic Computer) (see Figure 3), storing the gas samples in small loops of $100 \mu \mathrm{l}$. It has been verified that representative gas samples could be taken with this system even as fast as every second. Moreover, with this sampling system the dead time of the whole set-up was determined at about $50 \mathrm{~s}$.

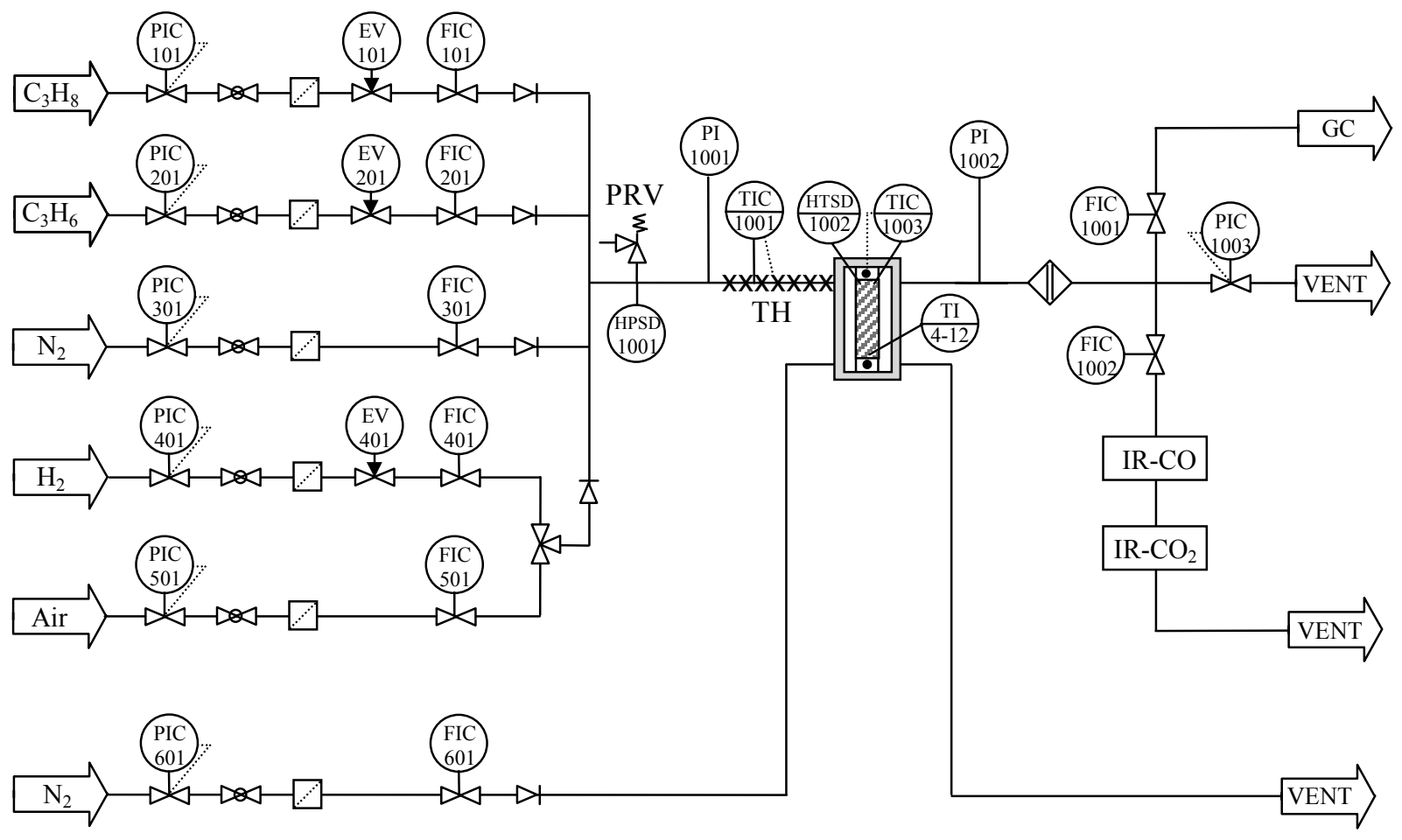

\begin{tabular}{ll}
\hline Abbreviation & Description \\
\hline EV & Emergency valve \\
FIC & Flow rate indicator and controller \\
GC & GC analysis section \\
HPSD & High pressure shut down \\
HTSD & High temperature shut down \\
PI & Pressure indicator \\
PIC & Pressure indicator and controller \\
PRV & Pressure relieve valve \\
TH & Tape heaters \\
TI & Temperature indicator \\
TIC & Temperature indicator and controller \\
VENT & Gas ventilation system \\
\hline
\end{tabular}

Figure 2. Flowsheet of the experimental set-up. 
The samples were analysed on a GC-TCD (Gas Chromatograph with a Thermal Conductivity Detector) using helium (5.0) as carrier gas (see Figure 3). With two columns, a Chrompack PoraPLOT column (a $50 \mathrm{~m}$ fused silica capillary column with a $10 \mu \mathrm{m} \mathrm{Al}_{2} \mathrm{O}_{3} / \mathrm{Na}_{2} \mathrm{SO}_{4}$ washcoat) and a Molsieve packed column (5A 80-100 Mesh, $2 \mathrm{~m} * 1 / 8$ inch * $2 \mathrm{~mm} \mathrm{SS}$ ), the relative concentrations of nitrogen, propane, propylene, ethane, ethylene and methane could be quantitatively determined in about 25 minutes. With the PLC the analysis of the samples was carried out automatically over night. Samples with very high propane and very low propylene concentrations and vice versa could be analysed quantitatively. Due to the very low conversions and low selectivities the concentrations of ethane, ethylene and methane were very small (e.g. 1\% conversion of a feed consisting of $10 \%$ propane in nitrogen and a product selectivity of $5 \%$ results in a product concentrations of about $50 \mathrm{ppm}$, strongly diluted in propane and nitrogen). The concentrations of ethane and ethylene could still be determined with good accuracy, but in some cases the quantitative determination of methane suffered from larger experimental errors. From the relative concentrations the propane conversion and product selectivities were calculated. The hydrogen concentration was not measured, but calculated from overall hydrogen and carbon atom balances over the reactor, taking account of changes in the gas velocity due to the chemical reactions. For verification the hydrogen concentration in the effluent was determined with TCD for some experiments, where the TCD-signal was corrected for the influence of propane and propylene. The calculated hydrogen concentrations corresponded well with the corrected measured hydrogen concentrations.

In order to regenerate the catalyst and to determine the amount of coke deposited on the monolith during the (de)hydrogenation, the set-up was flushed with nitrogen for a few minutes and subsequently air was introduced into the reactor to burn off the coke. The concentrations of the formed carbon monoxide and carbon dioxide were determined continuously by routing part of the reactor effluent to IR-analysers and the data was recorded automatically on a PC using a data-acquisition card. To avoid too high temperatures at the catalyst surface, possibly deteriorating the catalyst properties, and too high carbon monoxide and dioxide concentrations (i.e. above the maximum concentration detectable by the IRanalysers) during the coke combustion, the reactor was first cooled to about $300{ }^{\circ} \mathrm{C}$ before air was introduced. Under a constant air flow the temperature was increased to about $650{ }^{\circ} \mathrm{C}$. Air was fed to the reactor until the carbon monoxide and dioxide concentrations approached zero. 
Via integration of the sum of the carbon monoxide and carbon dioxide concentrations with time (using Simpson's rule) and multiplication with the air flow through the reactor the amount of coke (carbon) deposited was determined.

The experiments were carried out on a Pt $\gamma-\mathrm{Al}_{2} \mathrm{O}_{3}$ cordierite monolith (supplied by Engelhard) with $1.5 \mathrm{~g} / 1 \mathrm{Pt}$ dispersed in the washcoat, corresponding to about $1.1 \mathrm{wt} \% \mathrm{Pt}$ in the washcoat, under steady state operating conditions at temperatures up to a maximum of about $700{ }^{\circ} \mathrm{C}$ and at pressure slightly above the atmospheric pressure (1.2 bar absolute). The monolith consisted of squared channels with a hydraulic channel diameter of $0.96 \mathrm{~mm}$, a channel wall thickness of $0.19 \mathrm{~mm}$ and an average washcoat thickness of $37 \mu \mathrm{m}(11-89 \mu \mathrm{m})($ determined by SEM). The gas residence time was kept constant for all the experiments and equal to $0.074 \mathrm{~s}$, corresponding to a gas velocity through the monolithic channels of $0.10 \mathrm{~m} \cdot \mathrm{s}^{-1}$ and a GHSV of $45000 \mathrm{~h}^{-1}$. For experiments at different temperatures the total gas flow $\left(c a .30 \mathrm{l} \cdot \mathrm{h}^{-1}\right)$ was adjusted to achieve the same gas residence time. A GHSV of $45000 \mathrm{~h}^{-1}$ can be considered very large in comparison with other kinetic research reported in literature for the nonoxidative propane dehydrogenation; e.g. Loc et al. (1991a) used a GHSV of 400-8000 h-1, Babenkova et al. (1994) $2000 \mathrm{~h}^{-1}$ and Bariås et al. (1996) only 3-10 $\mathrm{h}^{-1}$. The high GHSV assured, firstly, that the reactor was operated under differential operating conditions (conversion always smaller than $10 \%$, except for propylene hydrogenation at lower temperatures). Secondly, the small residence time ensured that the experimentally observed conversion was always much smaller than the equilibrium conversion (except for propane dehydrogenation at temperatures below $450{ }^{\circ} \mathrm{C}$ ).

Finally, using the maximum observed reaction rate it has been verified by calculations that concentration and temperature differences between the gas bulk and catalyst phase are negligibly small, so that influences of mass and heat transfer limitations can be excluded. Calculated overall mass transfer efficiency factors were well above $99 \%$, as expected, because of the very small washcoat thickness. Furthermore, also based on the experimentally observed very strong increase in the reaction rates at high temperatures (described in the next section) influences of mass transfer limitations can be excluded.

Moreover, the temperature measurements confirmed that the experiments were performed isothermally (no significant temperature differences between temperatures measured in the outermost channel and the channel next to it, nor at different axial positions. 


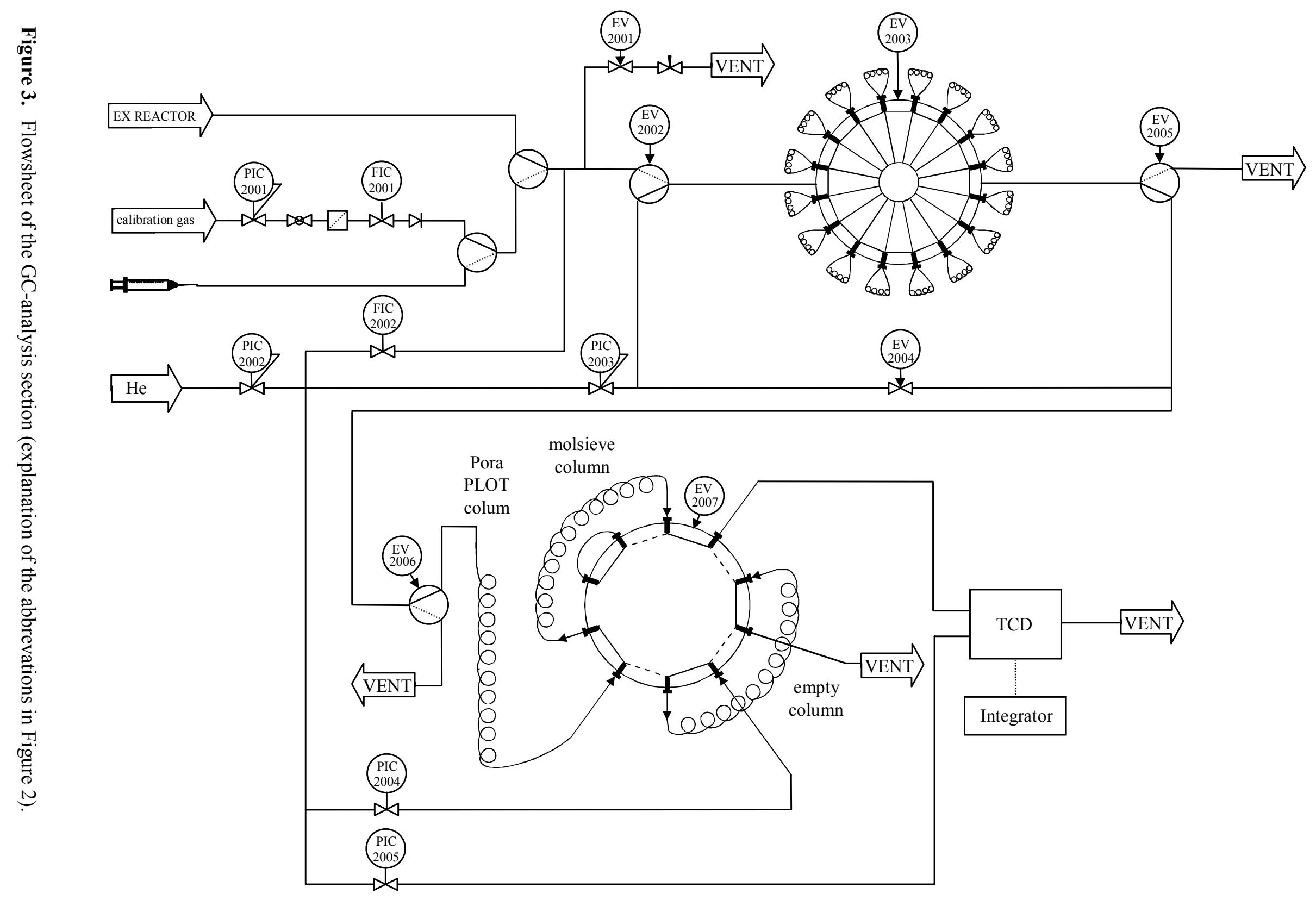




\subsection{Experimental procedure}

A propane dehydrogenation experiment typically consisted of 30 minutes of propane dehydrogenation, followed by 10 minutes of flushing with nitrogen and about 45 minutes of TPO (Temperature Programmed Oxidation) to regenerate the catalyst and concluded with 30 minutes of reduction under pure hydrogen at the reaction temperature (reduction conditions following Babenkova et al., 1994, and Loc et al., 1993a). In Figure 4 results of repeated propane dehydrogenation experiments under the same reaction conditions are plotted as a
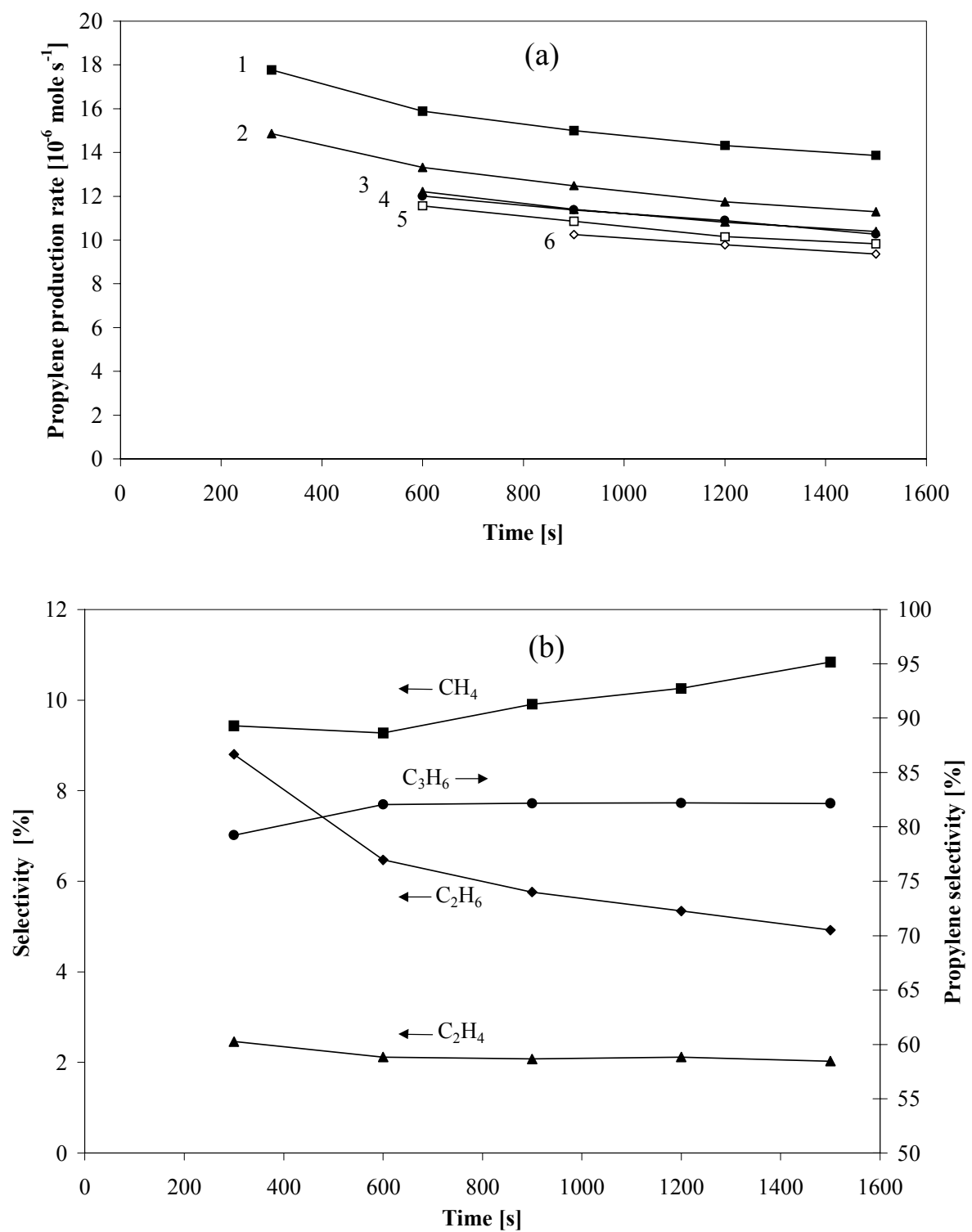

Figure 4. Propylene production rate (a) and gas phase product selectivities (b) as a function of the time during the propane dehydrogenation for repeated experiments (1-6) under the same operating conditions $\left(50 \%\right.$ propane and $50 \%$ hydrogen feed at $600{ }^{\circ} \mathrm{C}$ for $25 \mathrm{~min}$.), starting with a fresh monolith sample. 
function of time during the propane dehydrogenation (total dehydrogenation time for these runs was 25 minutes), starting with a fresh monolith. Figure 4 shows firstly that the catalyst activity decreases during a propane dehydrogenation experiment and secondly that after regeneration and reduction of the catalyst the initial catalyst activity cannot be restored completely.

\subsubsection{Decrease of catalyst activity during a single experiment}

The decrease in the catalyst activity during a single propane dehydrogenation experiment is attributed to the formation of coke. In Figure 5 the results of TPO are shown for propane dehydrogenation experiments under the same process conditions but for different times on stream. From Figure 5 two different types of peaks can be discerned, relatively sharp peaks at approximately $400{ }^{\circ} \mathrm{C}$ and $460-470{ }^{\circ} \mathrm{C}$ and a broad peak with a maximum between 500 $600{ }^{\circ} \mathrm{C}$, shifting to higher temperatures for longer times on stream. These results compare well with the findings of Larsson et al. (1996), who investigated the coke formation processes during the propane dehydrogenation on a $\mathrm{Sn}-\mathrm{Pt} / \gamma-\mathrm{Al}_{2} \mathrm{O}_{3}$ catalyst. Via TPO they also distinguished two types of coke, where the metallic coke was combusted at a temperature of $460{ }^{\circ} \mathrm{C}$ and the coke on the support combusted at temperatures around $550{ }^{\circ} \mathrm{C}$.

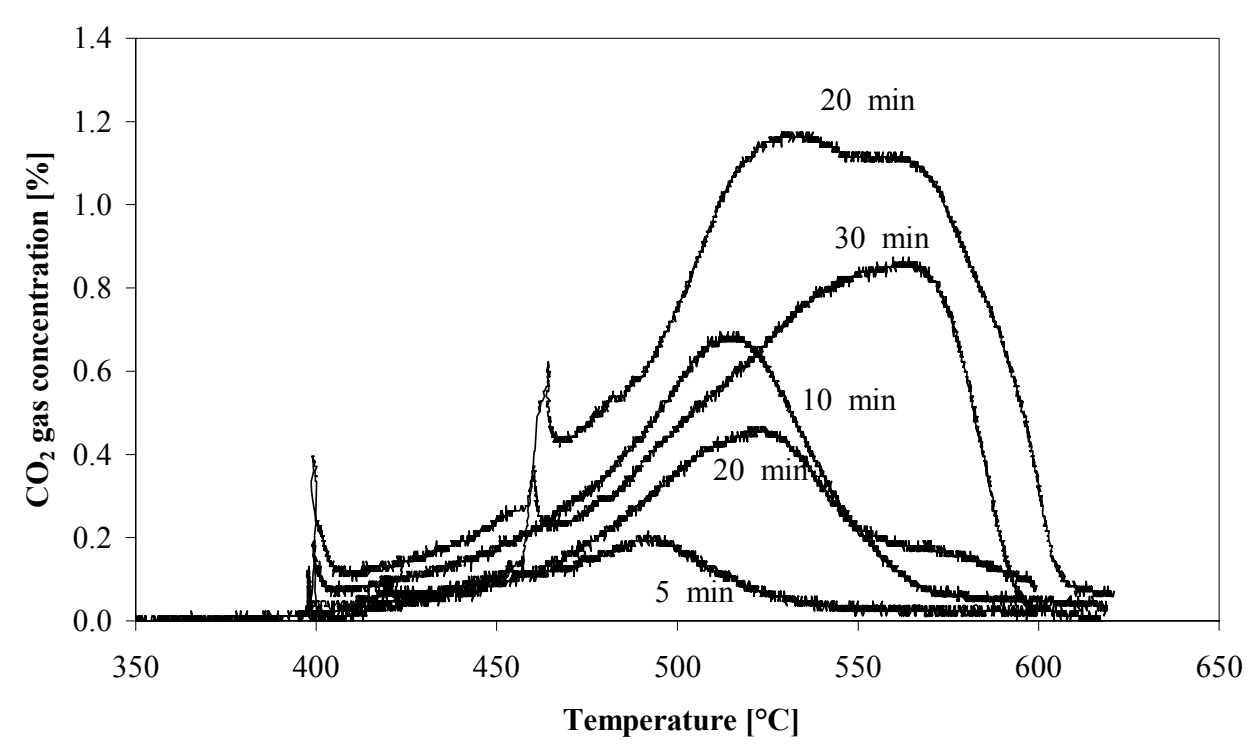

Figure 5. TPO of a coked sample for different times on stream for the propane dehydrogenation with $50 \%$ propane and $50 \%$ hydrogen in the feed at $600{ }^{\circ} \mathrm{C}\left(\mathrm{CO}_{2}\right.$ gas concentration in the reactor effluent as a function of the reactor temperature with a temperature ramp rate of $0.10 \mathrm{~K} \cdot \mathrm{s}^{-1}$ and an air flow of $103.9 \mathrm{Nl} \cdot \mathrm{h}^{-1}$ ). 
Attributing the sharp peaks at the lower temperatures to metallic coke and the high temperature broad peak to coke on the support, it can be concluded that the amount of coke on the support is much larger than the amount of metallic coke (which is also the conclusion from the TGA-study discussed in chapter 5). Furthermore, also the general trend that the amount of metallic coke and coke on the support increases with time during the propane dehydrogenation experiments can be observed in Figure 5.

It was found that not only the extent of, but also the rate at which the catalyst activity decreases depends on both the operating conditions during the propane dehydrogenation experiment and - remarkably - the (reduction) conditions prior to the experiment. However, for all experiments the catalyst activity reached a practically stationary asymptotic value after about half an hour, i.e. the catalyst activity did not change significantly in the next few hours. Only for very long times on stream some further gradual decline in the catalyst activity was observed. Also Webb and Matheson (1994) observed that the propane dehydrogenation reaction rate over a $0.66 \mathrm{wt} \% \mathrm{Pt} / \gamma-\mathrm{Al}_{2} \mathrm{O}_{3}$ catalyst at $600{ }^{\circ} \mathrm{C}$ approached a steady state value after about 30 minutes of time on stream.

For a propane-hydrogen feed with relatively high hydrogen concentrations the catalyst activity reached its steady state value in about 30 minutes, but for propane-nitrogen mixtures the steady state was already reached within about 10 minutes. These findings might be explained by the strong decrease in the formation rate of metallic coke on the active sites for higher hydrogen concentrations at $600{ }^{\circ} \mathrm{C}$.

Furthermore, also the conditions just prior to the experiment have an important influence on the rate at which the catalyst activity decreases. Figure 6 shows that flushing with nitrogen after reducing the catalyst under pure hydrogen at the reaction temperature increases the rate at which the catalyst activity decreases for experiments with the same reaction conditions, however, eventually the same asymptotic value is approached. This is in agreement with the findings of Bariås (1993), that evacuation of hydrogen by Ar-purge of $\mathrm{Sn}-\mathrm{Pt} / \gamma-\mathrm{Al}_{2} \mathrm{O}_{3}$ catalysts prior to the experiments retarded the propane dehydrogenation reaction rate, even the initial reaction rate. Also Somorjai (1977) found that although the initial reaction rates can differ, eventually the same reaction rates are found. Despite the difference in catalyst activity the gas phase product selectivities were almost identical, showing that the propane dehydrogenation reaction rate and its most important side reactions were effected similarly. From the influence of the conditions prior to the propane dehydrogenation experiments it can be concluded that 

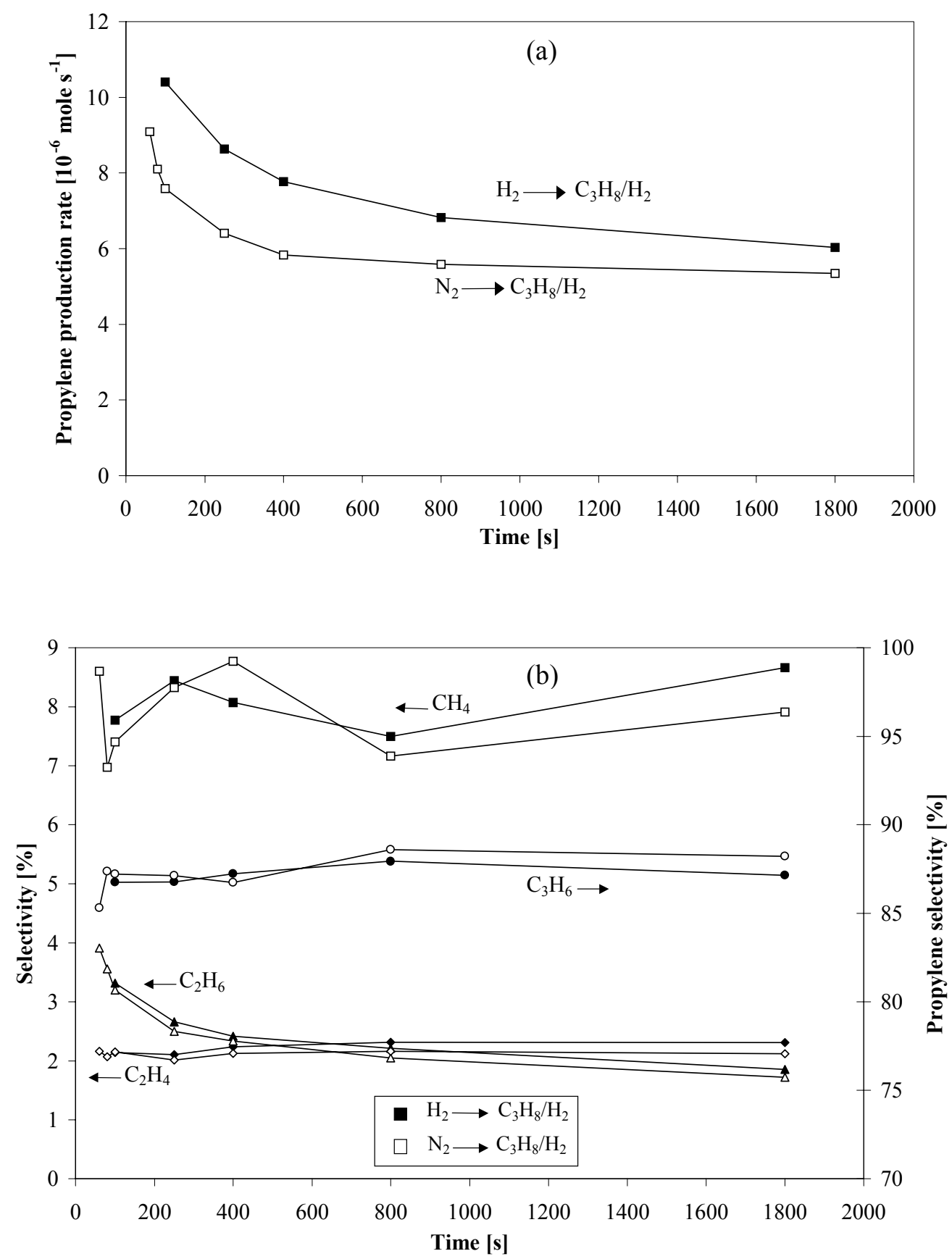

Figure 6. Comparison of the propylene production rate (a) and gas phase product selectivity (b) as a function of time during a propane dehydrogenation experiment with $50 \%$ propane and $50 \%$ hydrogen in the feed at $600{ }^{\circ} \mathrm{C}$ for 30 minutes with different reduction conditions prior to the experiment:

I) Reduction in pure hydrogen at $600{ }^{\circ} \mathrm{C}$ for 30 minutes and then switching to the experimental conditions (indicated with closed squares);

II) Reduction in pure hydrogen at $600{ }^{\circ} \mathrm{C}$ for 30 minutes, followed by flushing with nitrogen for 30 minutes and then switching to the experimental conditions (indicated with open squares); 
also the amount of hydrogen adsorbed at the active sites and the rate of hydrogen adsorption and desorption (probably chemisorption) or reduction of the active platinum surface sites is determinative for the rate at which the catalyst activity decreases. The hydrogen at the active sites can reduce the formation of metallic coke, e.g. by decreasing the amount of propylene adsorbed at the active sites from which probably coke precursors are formed or by reducing already formed coke precursors. The total amount of coke formed in the experiment without flushing with nitrogen was about $10 \%$ less compared with the experiment with nitrogen flushing (0.00114 and 0.00127 mole carbon, respectively).

Because of the influence of the reduction conditions great care should be taken when studying initial reaction rates, which is common in many kinetic investigations. This work has been focussed on determining the influence of the reaction conditions during the propane dehydrogenation and propylene hydrogenation on the asymptotic virtually steady state values, so that the influence of reduction conditions are of no importance.

\subsubsection{Decrease of catalyst activity for repeated experiments}

Furthermore, the loss of initial catalytic activity after regeneration and reduction (see Figure 4) is attributed to sintering and destruction of the most active sites or decrease in platinum dispersion, confirmed by comparing the BET area and the average pore diameter of a fresh and used monolith sample. The BET area and the average pore diameter of the used monolith sample were determined for the sealed inner part, which only experienced temperature changes, and the outer two rows of channels, who where also exposed to the reaction mixtures.

Table 1. Specific catalyst surface area (BET area per weight of the monolith) and the average pore-diameter of a fresh monolithic sample and a used monolithic sample, both for the sealed inner part and the outer two rows of channels.

\begin{tabular}{lcc}
\hline & BET area $\left[\mathbf{m}^{2} \cdot \mathbf{g}^{-1}\right.$ monolith $]$ & Average pore diameter $[\AA]$ \\
\hline Fresh sample & 35.3 & 112 \\
Used sample, inner part & 16.4 & 167 \\
Used sample, outer two rows & 15.3 & 151 \\
\hline
\end{tabular}


Since the BET area and the average pore diameter of the used monolith for both the inner part and the outer two rows were comparable, it is concluded that repeated coke formation and coke combustion did not effect the catalyst activity.
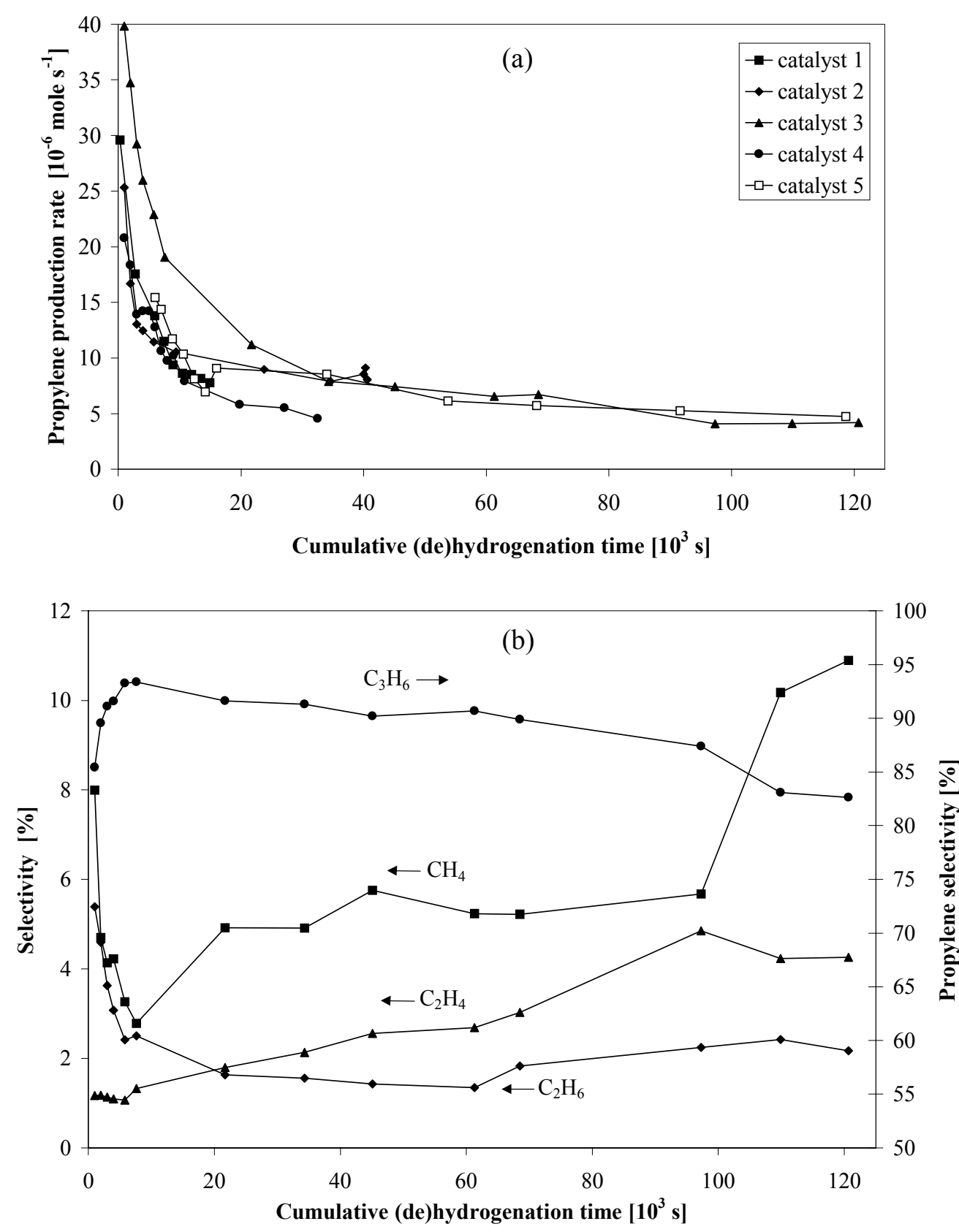

Figure 7. Propylene production rate (a) and gas phase product selectivities (b) for repeated standard experiments $\left(30 \mathrm{~min}\right.$ of propane dehydrogenation at $600{ }^{\circ} \mathrm{C}$ with a feed of $50 \%$ propane and $50 \%$ hydrogen) as a function of the cumulative propane dehydrogenation time (Between the standard experiments after about $20 \cdot 10^{3}$ s cumulative dehydrogenation time the kinetic experiments were carried out). 
In order to exclude the influence of sintering and destruction of the most active sites on the reaction rates a standard propane dehydrogenation experiment was defined as 30 minutes of propane dehydrogenation with a $50 \%$ propane and $50 \%$ hydrogen feed at $600{ }^{\circ} \mathrm{C}$. By repeatedly carrying out this standard experiment after a few experiments at different operating conditions the loss of catalytic activity could be monitored.

In Figure 7 the propylene production rates determined for the standard experiments are plotted as a function of the total dehydrogenation time, ignoring that an experiment also consisted of flushing with nitrogen, TPO and reduction (which was about the same for all the experiments). Moreover, to assure the removal of all carbonaceous deposits the reactor with the monolith sample was usually kept under air at about $400{ }^{\circ} \mathrm{C}$ over night. Figure 7 clearly shows, that the catalyst activity reduces strongly in the first few hours of cumulative dehydrogenation time, even up to a factor of 5 to 10 . Since the decrease in catalytic activity is a factor of 5 to 10 , but the decrease in the BET area is about a factor of 2 , it is concluded that also the destruction of the most active sites or the decrease in the platinum dispersion reduces the catalyst activity. However, the rate at which the catalyst activity decreases reduces strongly after 5 to 6 hours of cumulative dehydrogenation time. The kinetic experiments were carried out on this partly deactivated monolith sample with a relatively small further decrease in catalyst activity. Via linear interpolation between the standard experiments the reaction rates determined under different operating conditions were corrected for the loss in activity and scaled to a reference value. A reference value $\left(6.03 \cdot 10^{-6}\right.$ mole $\left.\cdot \mathrm{s}^{-1}\right)$ has been chosen, corresponding to the catalyst activity for long cumulative dehydrogenation times. Using this method of interpolation between standard experiments the reaction rates were compensated for the decrease in catalytic activity due to sintering and destruction of the most active sites or decrease in platinum dispersion, which also allowed easier comparison of experiments, carried out on different catalyst samples.

Finally Figure 7.b shows that for large cumulative dehydrogenation times the selectivity towards propylene decreases somewhat (from about 90 to $85 \%$ ) and the selectivity towards ethylene and methane increases considerably, while the selectivity towards ethane increases only mildly. Apparently the contribution of cracking of propane giving ethylene and methane increases for longer times on stream compared to the propane dehydrogenation, suggesting that the cracking of propane does not (primarily) occur at the same surface sites, but either at different surface sites or in the gas phase. 


\section{Experimental results}

In order to investigate the influences of the temperature and the concentrations of propane, propylene, hydrogen and nitrogen on the propane dehydrogenation and propylene hydrogenation asymptotic 'steady state' reaction rates several series of experiments have been carried out, of which an overview is given in Table 2 . The very small reactant conversions assured that the reactor was operated differentially and that the observed conversion was much smaller than the equilibrium conversion. However, owing to the small conversions it was not possible to accurately determine the amount of propylene formed in propane dehydrogenation experiments where propylene was added to the feed purposely, and similarly for the amount of propane formed in propylene hydrogenation experiments with propane added to the feed.

Table 2. Overview of experimental series

\begin{tabular}{|c|c|c|c|c|c|c|}
\hline & \multirow[t]{2}{*}{ Series } & \multirow[t]{2}{*}{$\mathrm{T}\left[{ }^{\circ} \mathrm{C}\right]$} & \multicolumn{4}{|c|}{ Gas composition (inlet mole percentage) } \\
\hline & & & Propane & Propylene & Hydrogen & Nitrogen \\
\hline \multirow{6}{*}{ 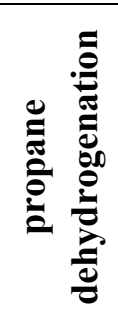 } & 1 & 600 & $0-100$ & 0 & 0 & $0-100$ \\
\hline & 2 & 600 & $0-100$ & 0 & $0-100$ & 0 \\
\hline & 3 & 600 & $0-70$ & 0 & 30 & $0-30$ \\
\hline & 4 & 600 & 50 & 0 & $0-50$ & $0-50$ \\
\hline & 5 & $425-675$ & 50 & 0 & 50 & 0 \\
\hline & 6 & $500-650$ & 50 & 0 & 0 & 50 \\
\hline \multirow{7}{*}{ 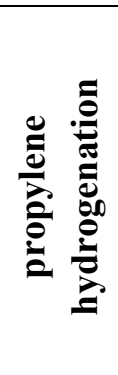 } & 1 & 450 & 0 & $0-70$ & 30 & $0-70$ \\
\hline & 2 & 450 & 0 & 30 & $0-70$ & $0-70$ \\
\hline & 3 & 600 & 0 & $0-70$ & 30 & $0-70$ \\
\hline & 4 & 600 & 0 & 30 & $0-70$ & $0-70$ \\
\hline & 5 & 450 & 0 & $15-50$ & $15-50$ & $0-70$ \\
\hline & 6 & $120-600$ & 0 & 25 & 25 & 50 \\
\hline & 7 & $300-625$ & 0 & 50 & 50 & 0 \\
\hline
\end{tabular}

First the experimental results for the asymptotic 'steady state' propane dehydrogenation and propylene hydrogenation reaction rates are shortly described. Subsequently, from the selectivity data information on the kinetics of the most important side-reactions is extracted. 


\subsection{Propane dehydrogenation and propylene hydrogenation}

In Figures 8-12 the 'steady state' propylene production rates during propane dehydrogenation experiments and in Figures 13-18 the 'steady state' propane production rates during propylene hydrogenation experiments are given as a function of composition and temperature. In these figures also the results of the kinetic rate expressions derived in the next paragraph are shown.

The following important observations can be discerned from the experimental results:

\section{Propane dehydrogenation:}

1. For propane-nitrogen mixtures the propane dehydrogenation reaction rate increases linearly with the propane inlet concentration, at least up to propane inlet concentrations of about 90\% (Figure 8).

2. For propane-hydrogen mixtures the propane dehydrogenation reaction rate shows a weak optimum between propane inlet concentrations of about 40-60\% (Figure 9).

3. Experiments with pure propane in the feed exhibit a somewhat higher propane dehydrogenation reaction rate than extrapolated from other experiments (Figures 8 and 9).

4. For propane-hydrogen-nitrogen mixtures with a constant propane inlet concentration the propane dehydrogenation reaction rate increases linearly with the hydrogen inlet concentration, which is quite unexpected (Figure 10).

5. For propane-nitrogen mixtures the propane dehydrogenation reaction rate shows a typical exponential increase as a function of temperature. However for propane-hydrogen mixtures a remarkably different temperature dependency was found. Between $500{ }^{\circ} \mathrm{C}$ and $600{ }^{\circ} \mathrm{C}$ a plateau in the propane dehydrogenation reaction rate was observed, where the propane dehydrogenation reaction rate hardly increased with increasing temperature. For temperatures below $500{ }^{\circ} \mathrm{C}$ the reaction rate decreased exponentially and also for temperatures above $600{ }^{\circ} \mathrm{C}$ the reaction rate increased exponentially (Figure 12).

6. On a monolith sample without platinum dispersed in the washcoat comparable propane dehydrogenation reaction rates were found as for a monolith sample with platinum dispersed in the washcoat for a $50 \%$ propane $-50 \%$ hydrogen mixture, both at $600{ }^{\circ} \mathrm{C}$ and $675^{\circ} \mathrm{C}$. 


\section{PROPANE DEHYDROGENATION}

$\mathrm{C}_{3} \mathrm{H}_{8}$

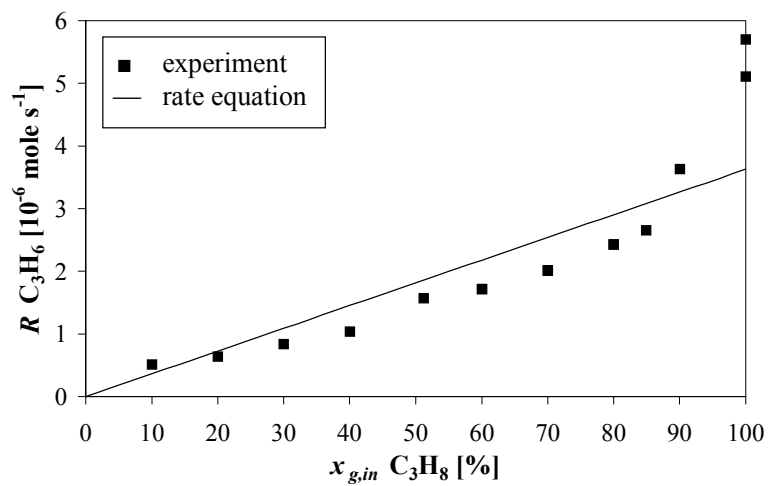

Figure 8. Propylene production rate as a function of the propane inlet concentration for propane-nitrogen mixtures at $600{ }^{\circ} \mathrm{C}$.

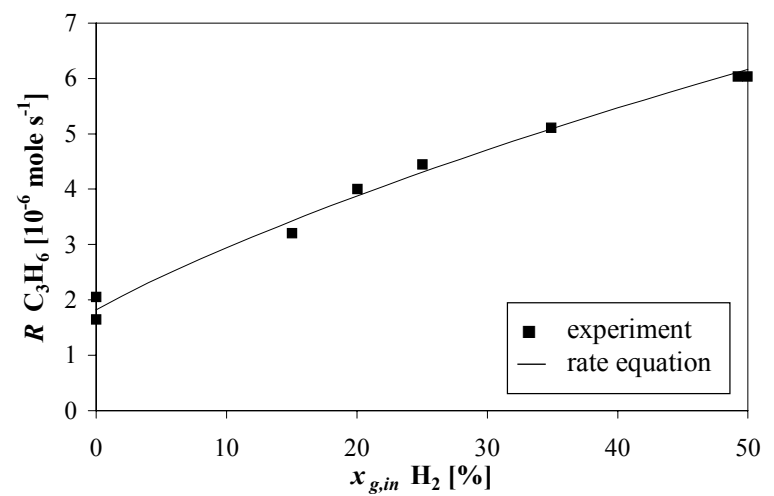

Figure 10. Propylene production rate as a function of the hydrogen inlet concentration for propane-hydrogen-nitrogen mixtures at $600{ }^{\circ} \mathrm{C}$, where the propane inlet concentration was kept constant at $50 \%$.

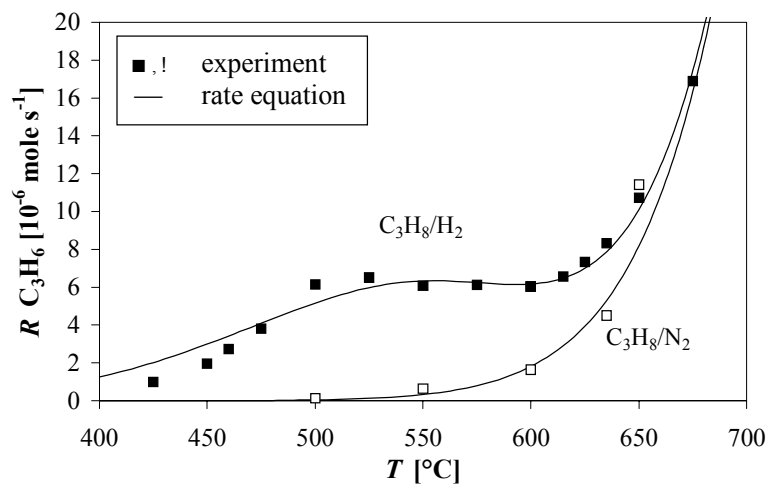

Figure 12. Propylene production rate as a function of the temperature for two different feeds:

(a) $50 \%$ propane, $50 \%$ hydrogen;

(b) $50 \%$ propane, $50 \%$ nitrogen;

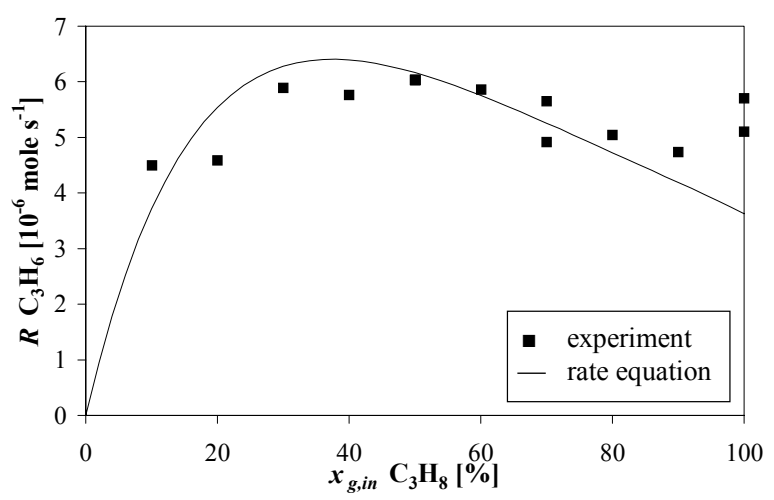

Figure 9. Propylene production rate as a function of the propane inlet concentration for propane-hydrogen mixtures at $600{ }^{\circ} \mathrm{C}$.

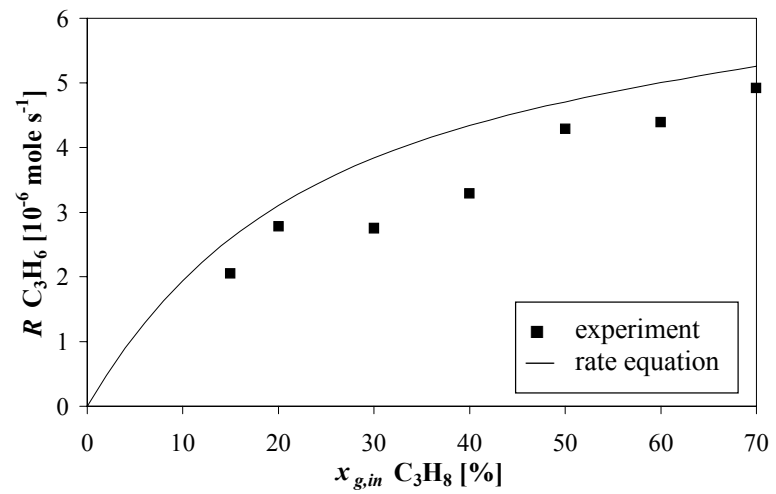

Figure 11. Propylene production rate as a function of the propane inlet concentration for propane-hydrogen-nitrogen mixtures at $600{ }^{\circ} \mathrm{C}$, where the hydrogen inlet concentration was kept constant at $30 \%$. 


\section{Propylene hydrogenation:}

1. The propylene hydrogenation reaction rate for propylene-hydrogen-nitrogen mixtures with constant hydrogen inlet concentration hardly increases with increasing propylene inlet concentration above about $20 \%$ at $450{ }^{\circ} \mathrm{C}$ and increases less than proportional at $600{ }^{\circ} \mathrm{C}$ (Figures 13 and 15).

2. For a propylene-hydrogen-nitrogen feed with constant propylene concentration the propylene hydrogenation reaction rate increases peculiarly with the square of the hydrogen inlet concentration (Figures 14 and 16).

3. The propylene hydrogenation reaction rate increases at lower temperatures and shows a remarkable optimum as a function of temperature (at about $200{ }^{\circ} \mathrm{C}$ for a mixture with $25 \%$ propylene, $25 \%$ hydrogen and 50\% nitrogen). Furthermore, note that the propylene hydrogenation reaction rates at $200{ }^{\circ} \mathrm{C}$ are very much larger than the propane dehydrogenation reaction rates at $650{ }^{\circ} \mathrm{C}$ (Figure 18). 


\section{PROPYLENE HYDROGENATION}

$$
\mathrm{C}_{3} \mathrm{H}_{6}+\mathrm{H}_{2} \longrightarrow \mathrm{C}_{3} \mathrm{H}_{8}
$$

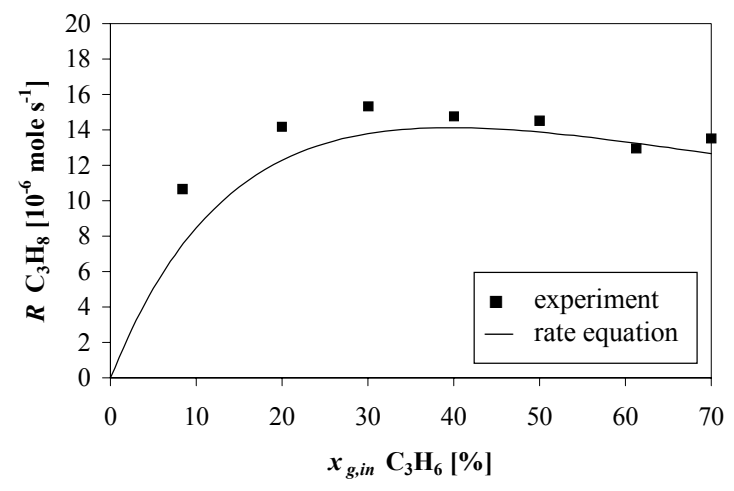

Figure 13. Propane production rate as a function of the propylene inlet concentration for propylene-hydrogen-nitrogen mixtures at $450{ }^{\circ} \mathrm{C}$ at a constant hydrogen concentration of $30 \%$.

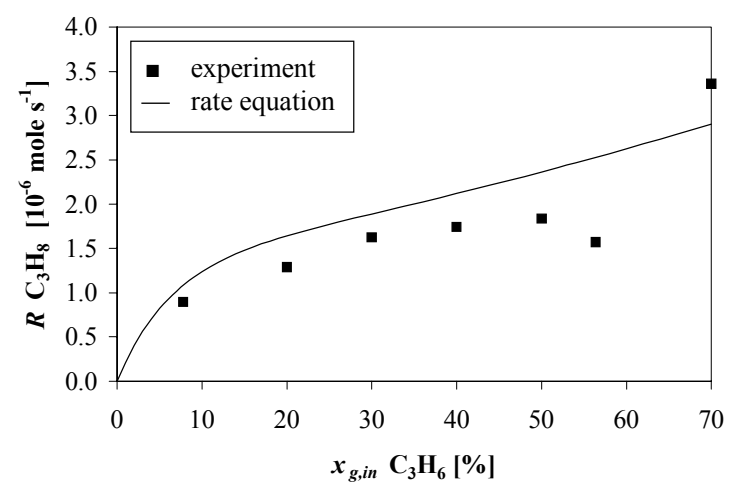

Figure 15. Propane production rate as a function of the propylene inlet concentration for propylene-hydrogen-nitrogen mixtures at $600{ }^{\circ} \mathrm{C}$ at a constant hydrogen concentration of $30 \%$.

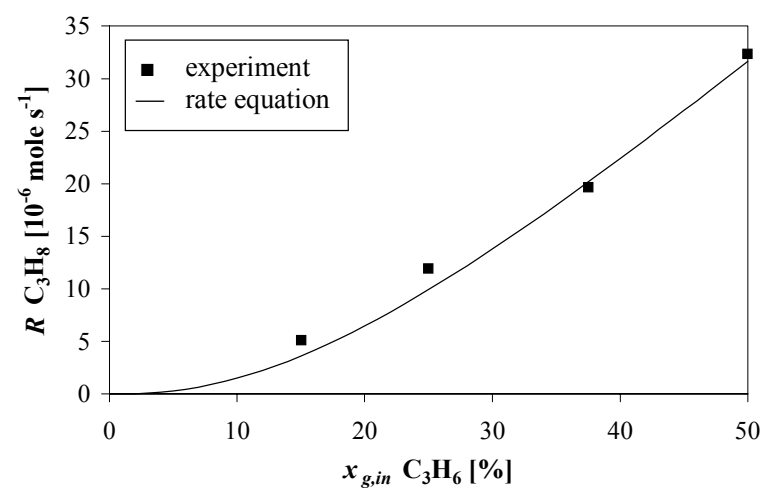

Figure 17. Propane production rate as a function of the propylene inlet concentration for propylene-hydrogen-nitrogen mixtures at $450{ }^{\circ} \mathrm{C}$ at a constant propylene-hydrogen concentration ratio of 1 .

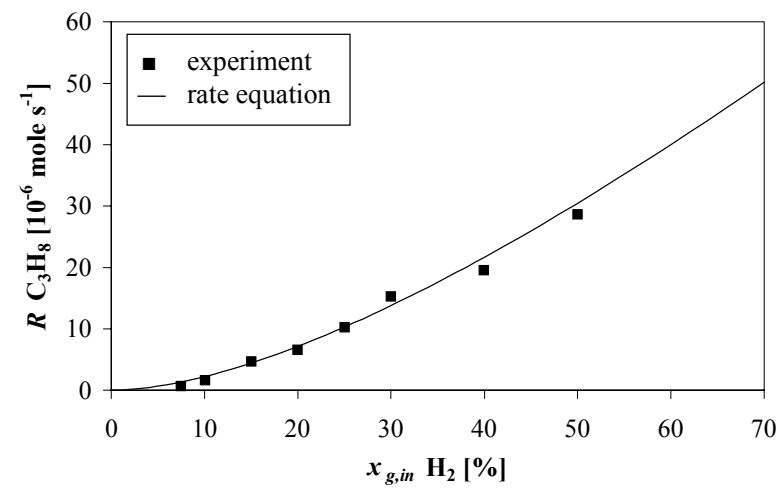

Figure 14. Propane production rate as a function of the hydrogen inlet concentration for propylene-hydrogen-nitrogen mixtures at $450{ }^{\circ} \mathrm{C}$ at a constant propylene concentration of $30 \%$.

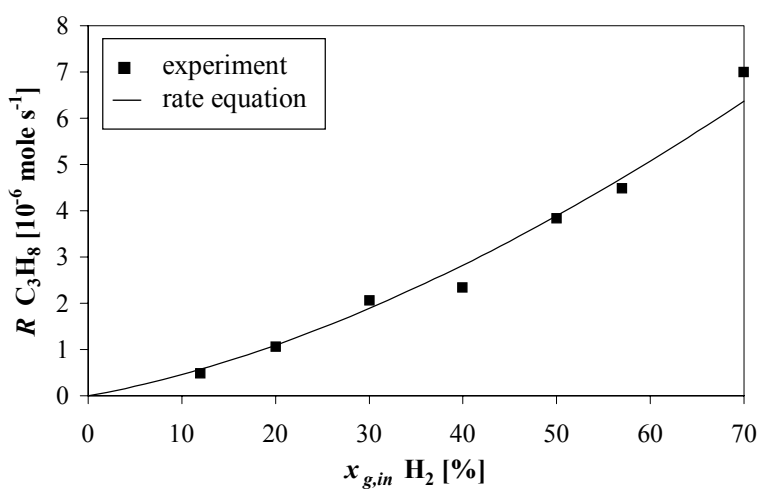

Figure 16. Propane production rate as a function of the hydrogen inlet concentration for propylene-hydrogen-nitrogen mixtures at $600{ }^{\circ} \mathrm{C}$ at a constant propylene concentration of $30 \%$.

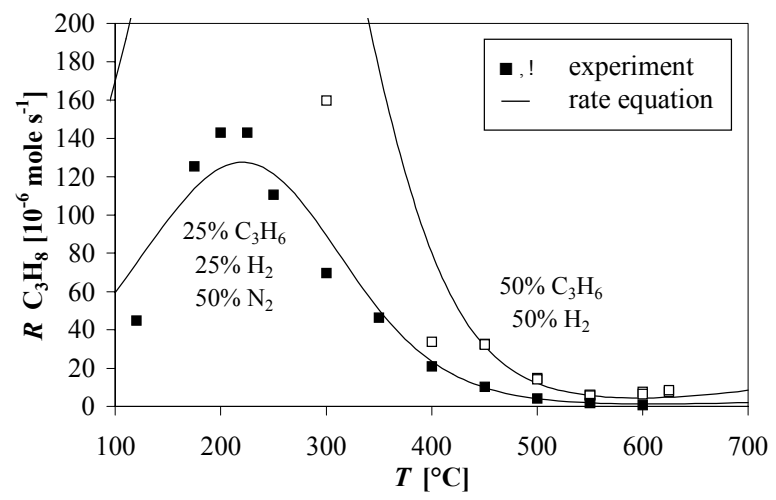

Figure 18. Propane production rate as a function of the temperature for two different feeds: (a) $50 \%$ propylene, $50 \%$ hydrogen; (b) $25 \%$ propylene, $25 \%$ hydrogen, $50 \%$ nitrogen 


\subsection{Side-reactions during propane dehydrogenation and propylene hydrogenation}

Only ethylene, ethane and methane were detected in the gas phase reactor effluent next to propane, propylene and hydrogen during propane dehydrogenation and propylene hydrogenation experiments. The concentration of methane could not always be detected accurately, causing some scatter in the methane selectivity data. The methane selectivity data have not been used in the determination of the reaction rates of the side-reactions. With TPO the total amount of the carbonaceous deposits, collectively termed coke, has been determined. The selectivities of propane and propylene towards coke have been estimated by assuming a constant coke formation rate during an experiment. This coke selectivity thus represents a time-averaged value. Since the coke selectivities were very low in all the experiments, this assumption does hardly effect the gas phase product selectivities. Finally, it should be kept in mind, that the propylene selectivity decreases and the methane and ethylene selectivities increase somewhat with ageing of the catalyst (see Figure 7). The ageing of the catalyst might effect the selectivity data to some extent. The reaction rates for the side-reactions have been corrected for the decrease in catalytic activity similar to the propane dehydrogenation and propylene hydrogenation reaction rates.

First the experimentally observed carbon selectivities during the propane dehydrogenation and propylene hydrogenation experiments are described. Then the data is presented in the form of reaction rates towards ethylene and ethane.

\subsubsection{Product selectivities}

For propane dehydrogenation experiments at $600{ }^{\circ} \mathrm{C}$ the selectivity towards propylene is about $85-95 \%$, decreasing with higher propane and higher hydrogen concentrations (see Figures 19 and 20). For propane-nitrogen mixtures the most important side-products were ethylene and methane. Only for high propane inlet concentrations some ethane was detected, however the ethane concentration was an order of magnitude lower than the ethylene concentration. The methane selectivity was somewhat higher than half of the sum of the ethane and ethylene selectivities, which is expected if propane cracking and propane hydrogenolysis are the main side reactions (see next section). 


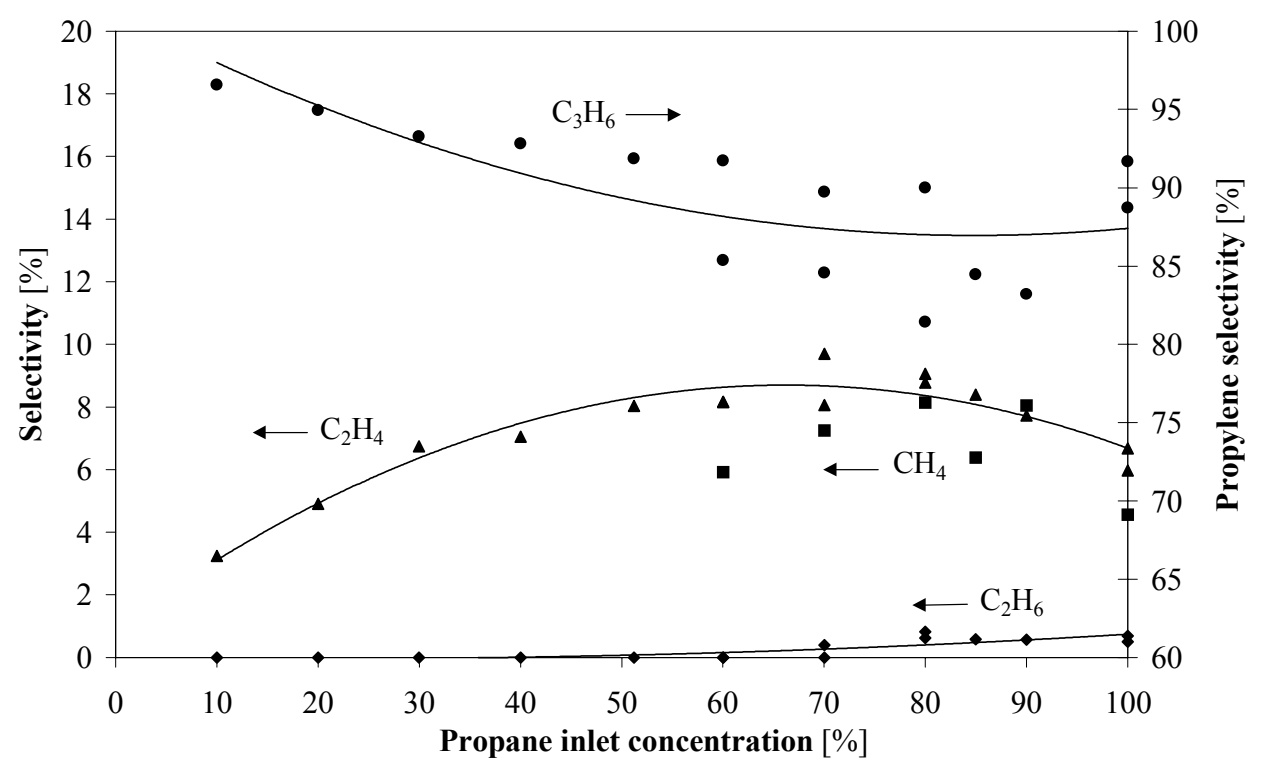

Figure 19. Gas phase product selectivities for the propane dehydrogenation of propane/nitrogen mixtures at $600{ }^{\circ} \mathrm{C}$ as a function of the propane inlet concentration.

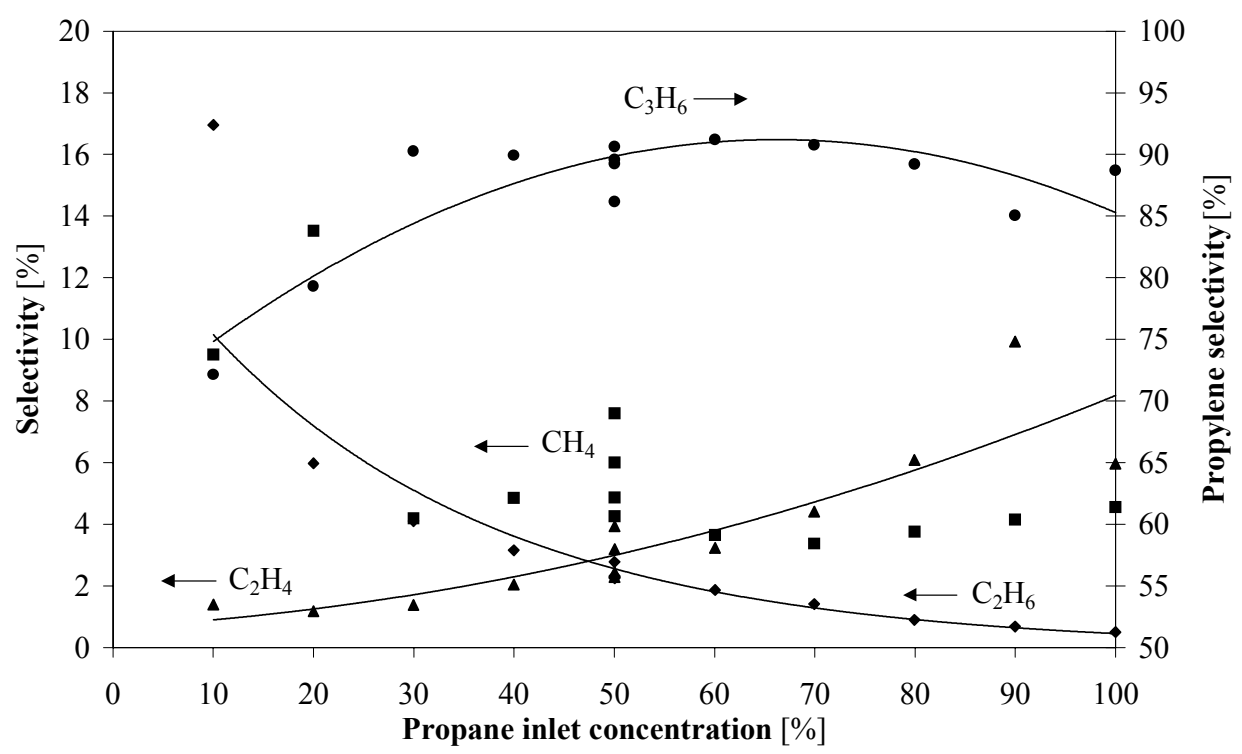

Figure 20. Gas phase product selectivities for the propane dehydrogenation of propane/hydrogen mixtures at $600^{\circ} \mathrm{C}$ as a function of the propane inlet concentration.

For propane-hydrogen mixtures with an equal molar amount of propane and hydrogen the selectivities towards ethane and ethylene were almost equal. For higher propane and lower hydrogen concentrations the selectivity towards ethylene strongly increases and the selectivity towards ethane strongly decreases (for a $90 \%$ propane / 10\% hydrogen mixture the ethylene selectivity is almost a factor 10 higher than the ethane selectivity). Vice versa, for lower propane and higher hydrogen concentrations the selectivity towards ethane strongly increases, 
while the selectivity towards ethane strongly decreases (for a 10\% propane / $90 \%$ hydrogen mixture the ethane selectivity is almost a factor 10 higher than the ethylene selectivity). For high propane concentrations and low hydrogen concentrations the methane selectivity is again slightly higher than half of the ethylene selectivity. However, for low propane concentrations and high hydrogen concentrations the methane selectivity is about similar to the ethane selectivity. The higher methane selectivity is probably due to ethane hydrogenolysis to methane for high hydrogen concentrations. Only at high temperatures also hydrogenation of carbonaceous products at the catalyst surface could contribute to the relatively high methane selectivities.

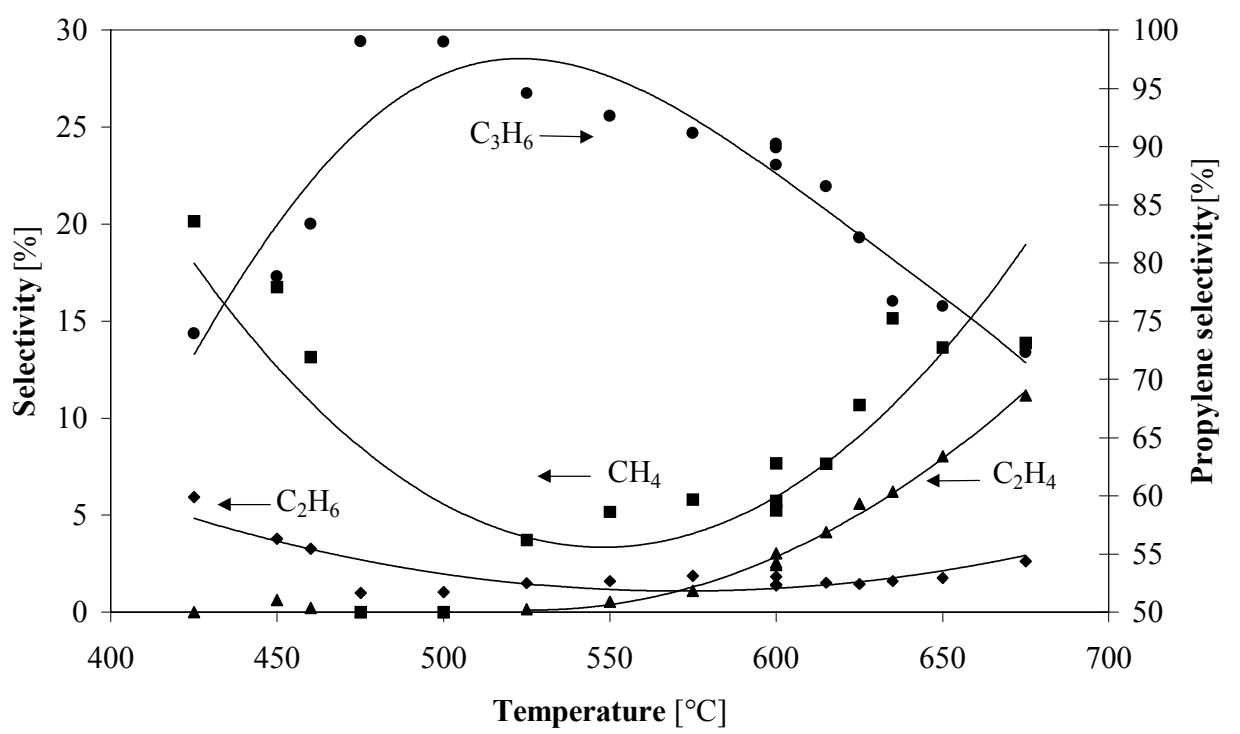

Figure 21. Gas phase product selectivities for the propane dehydrogenation of $50 \%$ propane / $50 \%$ hydrogen feed as a function of temperature.

In Figure 21 it is shown that for a 50\% propane / 50\% hydrogen feed the propylene selectivity strongly decreases from virtually $100 \%$ at $500{ }^{\circ} \mathrm{C}$ to less than $75 \%$ at $675{ }^{\circ} \mathrm{C}$. At $500{ }^{\circ} \mathrm{C}$ the ethylene selectivity is zero but increases strongly with increasing temperatures to almost $10 \%$ at $675^{\circ} \mathrm{C}$, while the ethane selectivity remains almost constant at about $1.5-2.5 \%$ over this temperature range. Also for temperatures below $500{ }^{\circ} \mathrm{C}$ the propylene selectivity strongly decreases with decreasing temperatures, while the ethane and methane selectivities strongly increase. The lower propylene selectivity for lower temperatures is due to the approach of the thermodynamic equilibrium at low temperatures (see Table 3), which reduces the propane dehydrogenation reaction rate compared to the reaction rate of side-reactions. 
The main side-products for the propylene hydrogenation experiments were methane and ethylene. For propylene-hydrogen-nitrogen mixtures with low hydrogen concentrations the ethane selectivity was negligibly small, even at $600{ }^{\circ} \mathrm{C}$. For temperatures below $450{ }^{\circ} \mathrm{C}$ the propylene selectivity was virtually $100 \%$. For propylene-hydrogen mixtures with equimolar concentrations of propylene and hydrogen the propylene selectivity strongly decreases to less than $70 \%$ at $625{ }^{\circ} \mathrm{C}$, while the methane and ethylene selectivities increase to 19 and $9 \%$ respectively, and the ethane selectivity increases to only $2.4 \%$, as can be observed in Figure 22. Again the high methane selectivity could be explained by hydrogenolysis of ethane.

Table 3. Experimentally observed conversions of propane to propylene compared with calculated equilibrium conversions for a $50 \%$ propane - $50 \%$ hydrogen mixture at different temperatures.

\begin{tabular}{cccc}
\hline $\boldsymbol{T}\left[^{\circ} \mathbf{C}\right]$ & $\boldsymbol{\zeta}^{\text {exp }}[\mathbf{\%}]$ & $\boldsymbol{\zeta}^{\text {eq }}[\mathbf{\%}]$ & $\boldsymbol{\zeta}^{\text {exp }} / \zeta^{\text {eq }}[\mathbf{\%}]$ \\
\hline 425 & 0.46 & 0.57 & 80 \\
450 & 0.96 & 1.23 & 78 \\
460 & 1.30 & 1.64 & 79 \\
475 & 1.97 & 2.47 & 78 \\
500 & 3.47 & 4.68 & 74 \\
525 & 3.76 & 8.33 & 45 \\
550 & 3.59 & 13.8 & 26 \\
575 & 3.70 & 21.4 & 17 \\
600 & 3.70 & 30.9 & 12 \\
625 & 4.16 & 41.5 & 10 \\
650 & 6.23 & 52.5 & 12 \\
675 & 9.86 & 62.7 & 16 \\
\hline
\end{tabular}

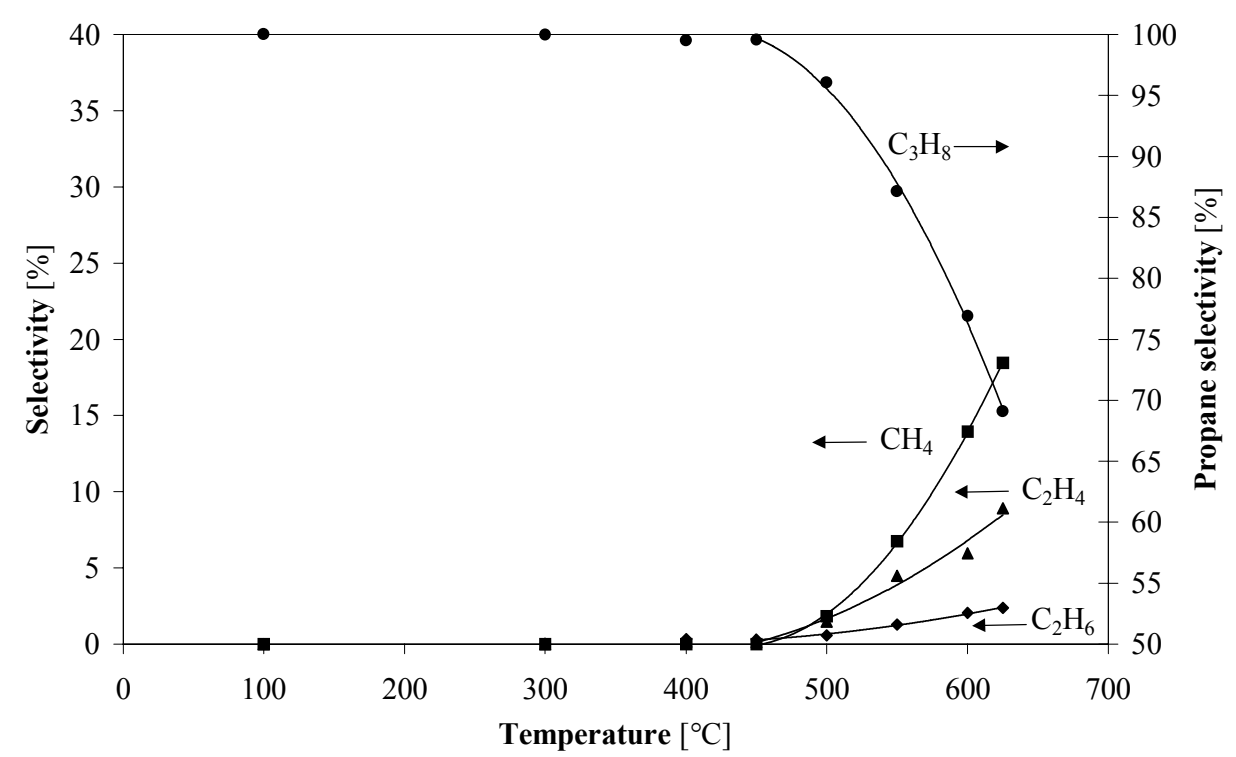

Figure 22. Gas phase product selectivities for the propylene hydrogenation of $50 \%$ propylene $50 \%$ hydrogen feed as a function of temperature. 
The coke selectivities were very small for all the propane dehydrogenation experiments. For propane dehydrogenation experiments at $600{ }^{\circ} \mathrm{C}$ with a propane-nitrogen feed the coke selectivity was only about $0.15-0.2 \%$ (independent of the propane inlet concentration). For propane-hydrogen mixtures with a hydrogen inlet concentration above $20 \%$ the coke selectivity was even an order of magnitude lower (0-0.02\%), showing somewhat higher coke selectivities for higher propane concentrations and lower hydrogen concentrations. Only when the hydrogen inlet concentration approached zero, the coke selectivity increased to $0.2 \%$. The coke selectivity during propylene hydrogenation experiments was an order of magnitude higher. Especially for high propylene concentrations and low hydrogen concentrations the coke selectivity could reach values up to $4 \%$ even at $600{ }^{\circ} \mathrm{C}$. As expected, the coke selectivities strongly increase with temperature, as shown in Figure 23.

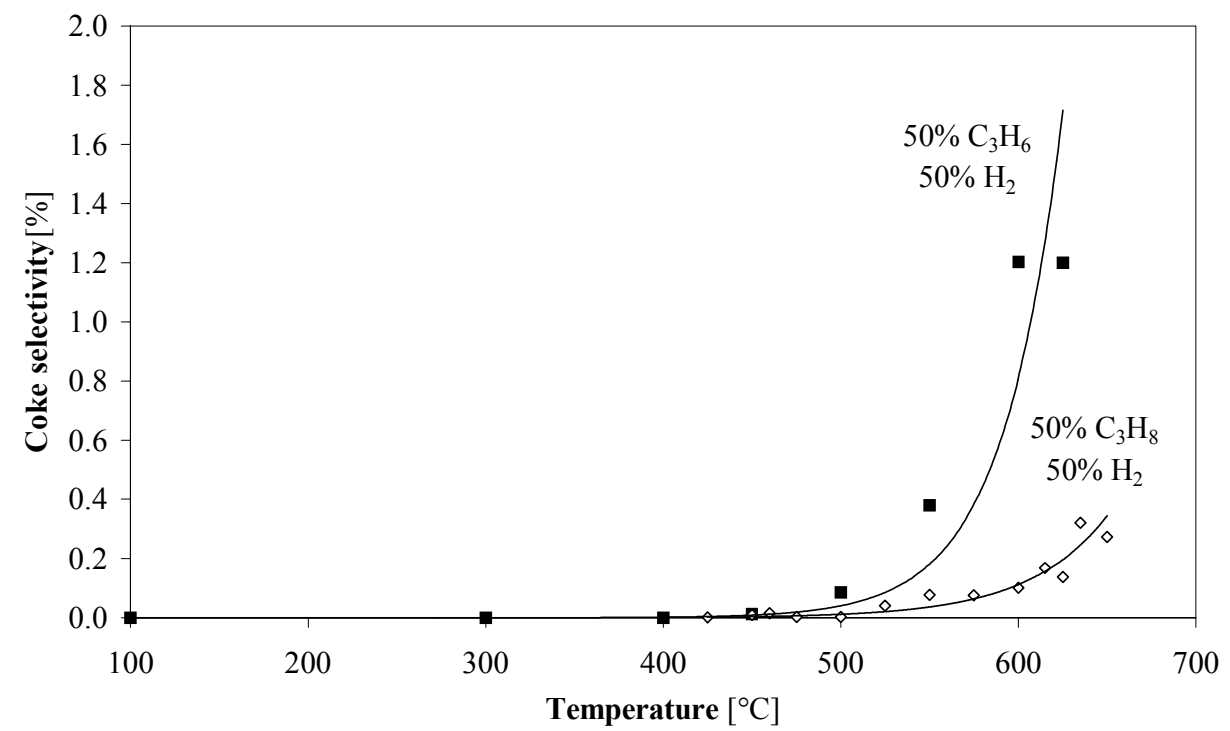

Figure 23. Coke selectivities for the propane dehydrogenation (50\% propane and $50 \%$ hydrogen feed) and for the propylene hydrogenation (50\% propylene and 50\% hydrogen feed) as a function of temperature (assuming a constant coke formation rate).

Finally, with TPO only the total amount of coke at the end of an experiment is determined, so that only time-averaged coke formation rates can be determined via the indirect method of coke combustion. From literature it is clear that the coke formation rate changes in time. Furthermore, even small concentration gradients of propylene and hydrogen can considerably influence coke formation rates, especially at the investigated temperature range $\left(550-650{ }^{\circ} \mathrm{C}\right)$. Therefor coke formation rates were determined directly via TGA (Thermogravimetric analysis) as a function of time at constant uniform operating conditions, which is discussed in Chapter 5. 


\subsubsection{Reaction rates}

From the selectivity data information about the kinetics of the most important side-reactions except coke formation can be deduced. The most important side reactions under propane dehydrogenation and propylene hydrogenation reaction conditions are the cracking of propane and the hydrogenolysis of propane and propylene (a.o. Bariås, 1993):

1. Propane cracking

2. Propane hydrogenolysis

3. Propylene hydrogenolysis
$\mathrm{C}_{3} \mathrm{H}_{8}$

$\rightleftarrows \mathrm{C}_{2} \mathrm{H}_{4}+\mathrm{CH}_{4}$

$\mathrm{C}_{3} \mathrm{H}_{8}+\mathrm{H}_{2} \rightleftarrows \mathrm{C}_{2} \mathrm{H}_{6}+\mathrm{CH}_{4}$

$\mathrm{C}_{3} \mathrm{H}_{6}+\mathrm{H}_{2}$

\section{$\mathrm{C}_{2} \mathrm{H}_{4}+\mathrm{CH}_{4}$}

From our experiments no distinction could be made between hydrogenolysis of propane on the one side and cracking of propane and subsequent hydrogenation of ethylene to ethane on the other side. Similarly the hydrogenolysis of propylene can also be considered as hydrogenation of propylene and subsequent cracking of propane. However, it is not necessary to discriminate between these reactions, since the main interest in this work is the kinetics of the formation of the side-products and not the precise mechanism. Furthermore, although these side-reactions might be reversible, the equilibrium conversions of these reactions above about $800 \mathrm{~K}$ are well above $95 \%$. The equilibria of these side-reactions were never reached in the experiments and are also generally not reached in propane dehydrogenation reactors, consequently for all practical purposes these side-reactions can be considered as irreversible. It is now assumed that under propane dehydrogenation conditions all the ethylene was formed by cracking of propane and that all the ethane was formed by hydrogenolysis of propane. Analogously, it is assumed that the ethylene formation under propylene hydrogenation conditions was due to hydrogenolysis of propylene. Consecutive reactions of ethylene and ethane, like cracking, hydrogenolysis and (de)hydrogenation have been neglected in this work, which focuses on the propane dehydrogenation / propylene hydrogenation equilibrium. The dehydrogenation rate of ethane to ethylene is relatively small for temperatures below $600{ }^{\circ} \mathrm{C}$, since the equilibrium conversion for the dehydrogenation of ethane is only about $18 \%$ for a pure ethane feed at $600{ }^{\circ} \mathrm{C}$ at atmospheric pressure. However, hydrogenation of ethylene could take place at these temperatures. 
From the selectivity data the following important observations can be discerned for the 'steady state' reaction rates of the side-reactions.

\section{Propane cracking}

1. The ethylene production rate during the propane dehydrogenation increases linearly with the propane inlet concentration (Figure 24).

2. The reaction rate of propane cracking is independent of the hydrogen inlet concentration (Figures 25 and 26).

3. The propane cracking reaction rate increases exponentially with temperature (Figures 28 and 29).

\section{Propane hydrogenolysis}

1. The ethane production rate is negligible if no hydrogen is present in the gas phase (as concluded from propane dehydrogenation experiments with propane-nitrogen feeds).

2. For propane-hydrogen mixtures the propane hydrogenolysis reaction shows a very remarkable almost linear decrease for increasing propane inlet concentrations (Figure 30).

3. The propane hydrogenolysis reaction rate increases less than proportional with increasing propane inlet concentration for propane-hydrogen-nitrogen mixtures with a constant hydrogen concentration at $600{ }^{\circ} \mathrm{C}$ (Figure 31$)$.

4. The propane hydrogenolysis reaction rate follows a striking second order dependency on the hydrogen gas phase concentration (Figure 32).

5. For low temperatures the propane hydrogenolysis reaction rate is almost independent of temperature, but at temperatures above $600{ }^{\circ} \mathrm{C}$ the reaction rate increases exponentially. (Figures 33 and 34).

\section{Propylene hydrogenolysis}

1. The ethylene production rate in propylene hydrogenation experiments is almost independent of the propylene inlet concentration at $450{ }^{\circ} \mathrm{C}$ and increases less than linear at $600{ }^{\circ} \mathrm{C}$ (Figure 35).

2. The propylene hydrogenolysis reaction rate follows an approximately linear dependency on the hydrogen gas phase concentration at both 450 and $600{ }^{\circ} \mathrm{C}$ (Figure 36).

3. The propylene hydrogenolysis reaction rate increases exponentially with temperature (Figures 37 and 38). 


\section{PROPANE CRACKING}

$$
\mathrm{C}_{3} \mathrm{H}_{8} \longrightarrow \mathrm{C}_{2} \mathrm{H}_{4}+\mathrm{CH}_{4}
$$

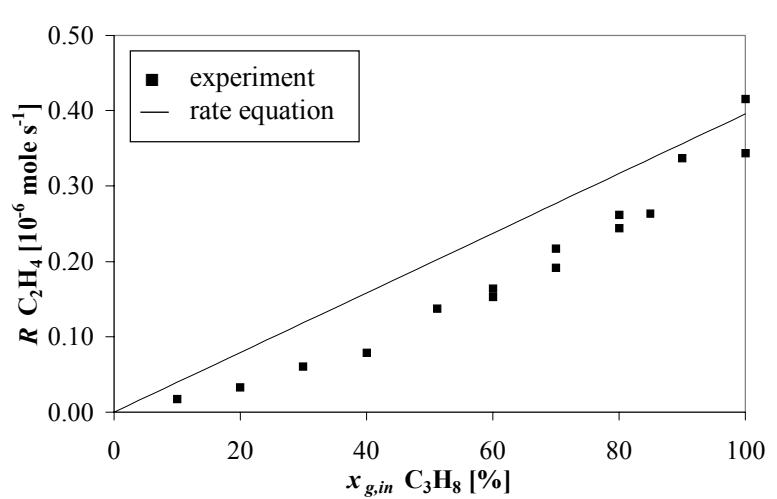

Figure 24. Ethylene production rate during the propane dehydrogenation for propanenitrogen mixtures at $600{ }^{\circ} \mathrm{C}$.

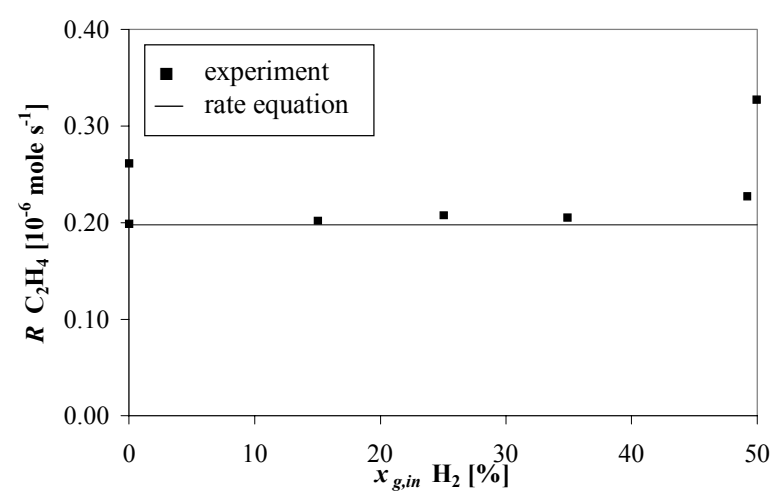

Figure 26. Ethylene production rate during the propane dehydrogenation for propanehydrogen-nitrogen mixtures with constant propane mole fraction of $50 \%$ at $600{ }^{\circ} \mathrm{C}$.

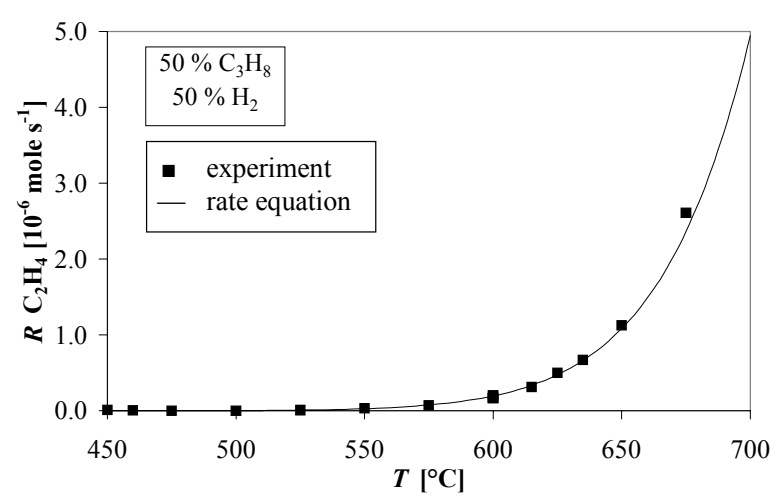

Figure 28. Ethylene production rate during the propane dehydrogenation for $50 \%$ propane $-50 \%$ hydrogen mixture.

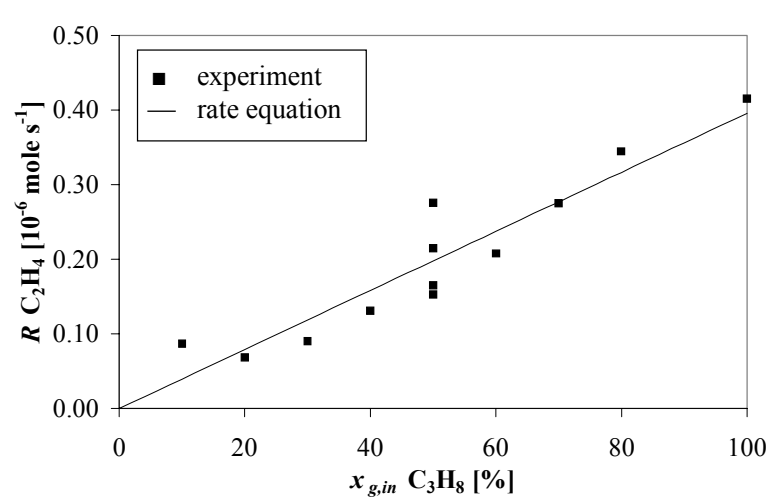

Figure 25. Ethylene production rate during the propane dehydrogenation for propanehydrogen mixtures at $600{ }^{\circ} \mathrm{C}$.

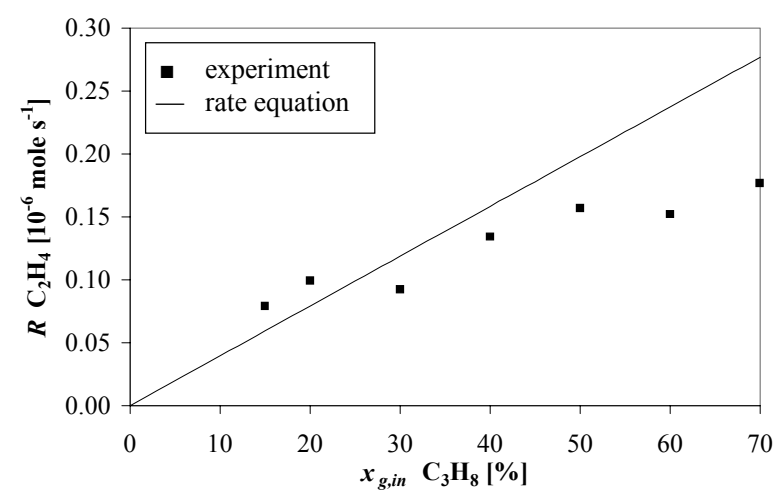

Figure 27. Ethylene production rate during the propane dehydrogenation for propanehydrogen-nitrogen mixtures with constant hydrogen mole fraction of $30 \%$ at $600{ }^{\circ} \mathrm{C}$.

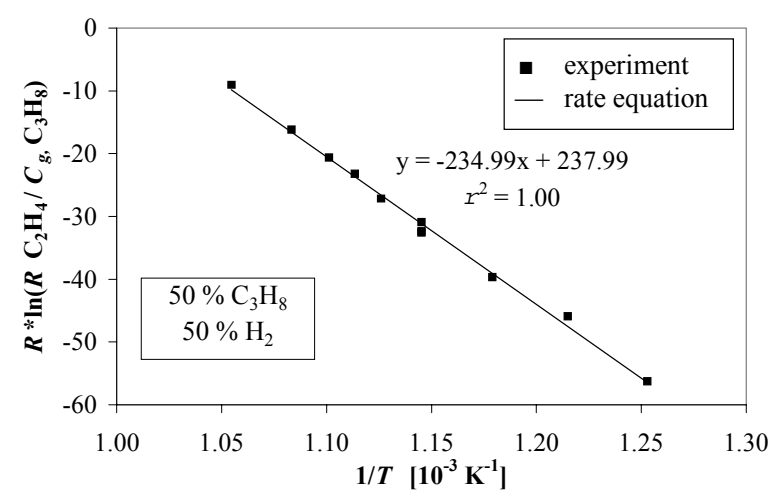

Figure 29. Arrhenius-plot for the ethylene production rate during the propane dehydrogenation for $50 \%$ propane - $50 \%$ hydrogen mixture. 


\section{PROPANE HYDROGENOLYSIS}

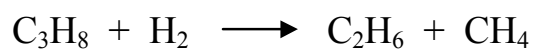

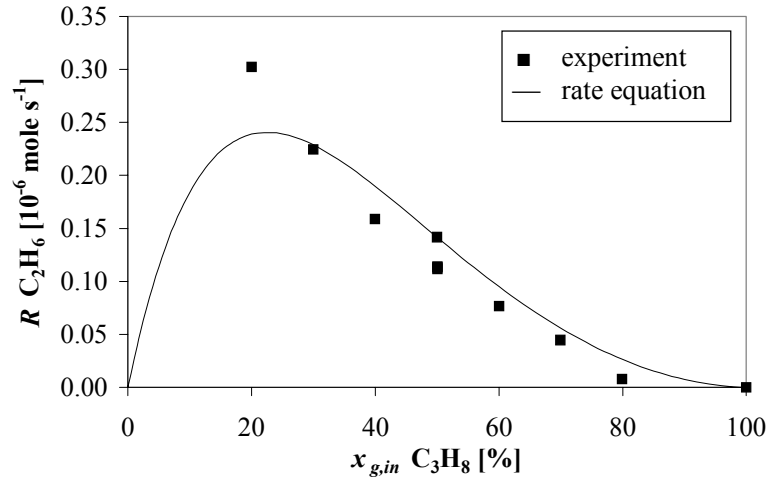

Figure 30. Ethane production rate during the propane dehydrogenation for propanehydrogen mixtures at $600{ }^{\circ} \mathrm{C}$.

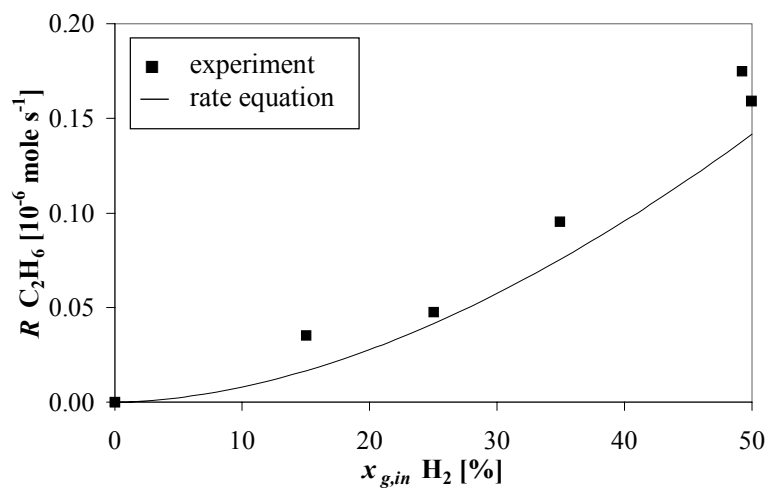

Figure 32. Ethane production rate during the propane dehydrogenation for propanehydrogen-nitrogen mixtures with constant propane mole fraction of $50 \%$ at $600{ }^{\circ} \mathrm{C}$.

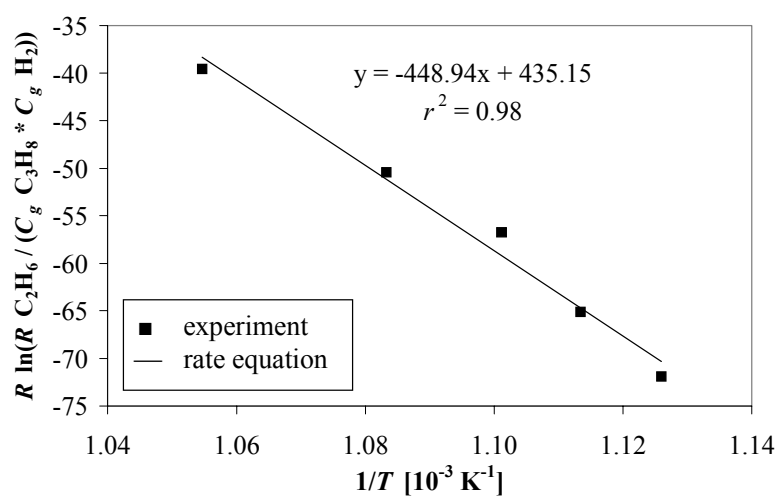

Figure 34. Arrhenius-plot for the ethane production rate during the propane dehydrogenation for a $50 \%$ propane - $50 \%$ hydrogen mixture at high temperatures (615$\left.675{ }^{\circ} \mathrm{C}\right)$.

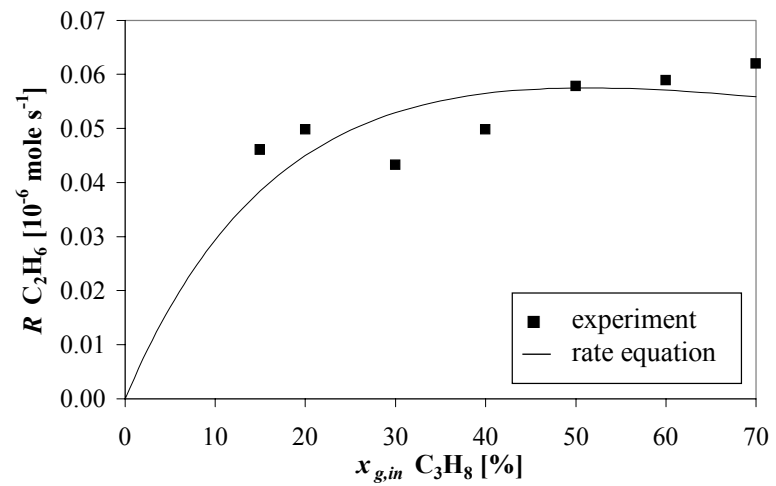

Figure 31. Ethane production rate during the propane dehydrogenation for propanehydrogen-nitrogen mixtures with constant hydrogen mole fraction of $30 \%$ at $600{ }^{\circ} \mathrm{C}$.

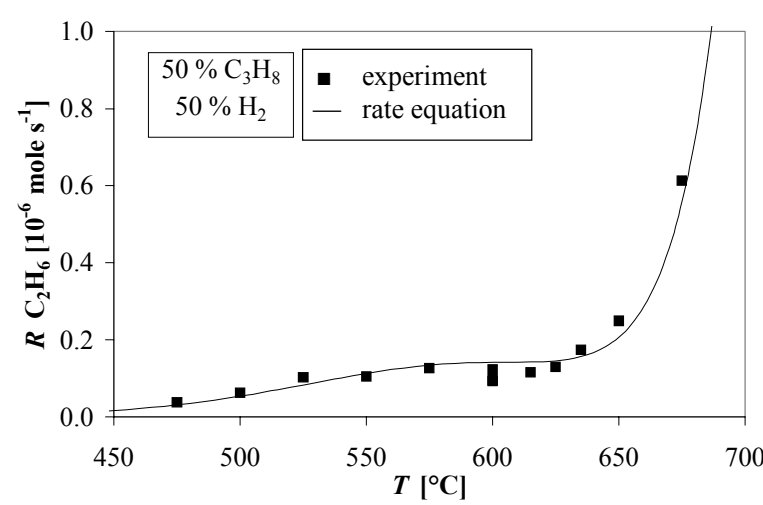

Figure 33. Ethane production rate during the propane dehydrogenation as a function of the temperature for a $50 \%$ propane - $50 \%$ hydrogen mixture. 


\section{PROPYLENE HYDROGENOLYSIS}

$$
\mathrm{C}_{3} \mathrm{H}_{6}+\mathrm{H}_{2} \longrightarrow \mathrm{C}_{2} \mathrm{H}_{4}+\mathrm{CH}_{4}
$$

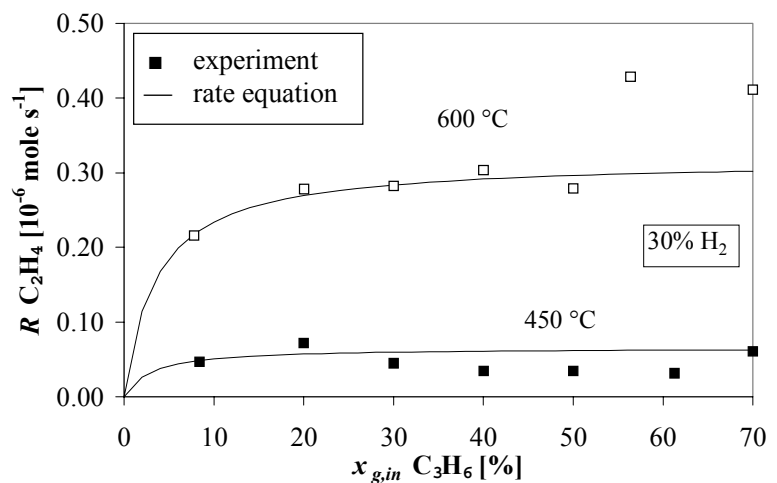

Figure 35. Ethylene production rate during propylene hydrogenation for propanehydrogen-nitrogen mixtures with constant hydrogen mole fraction of $30 \%$ at 450 and $600{ }^{\circ} \mathrm{C}$.

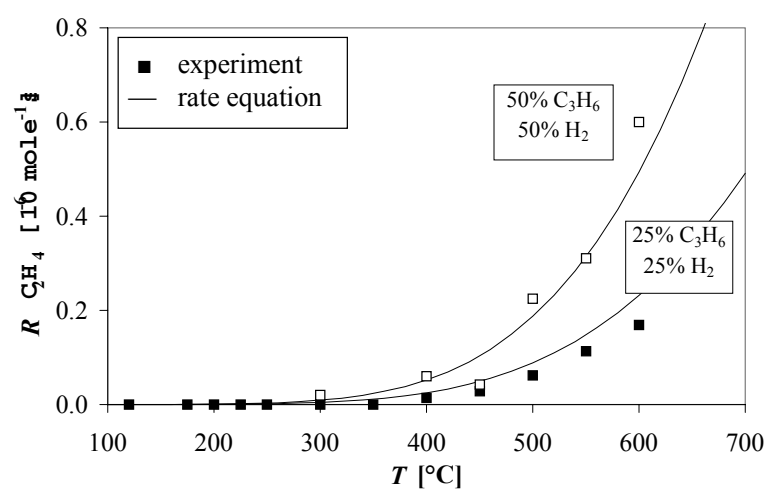

Figure 37. Ethylene production rate as a function of temperature during propylene hydrogenation for two different mixtures:

(a) $50 \%$ propane, $50 \%$ hydrogen;

(b) $25 \%$ propane, $25 \%$ hydrogen, $50 \%$ nitrogen;

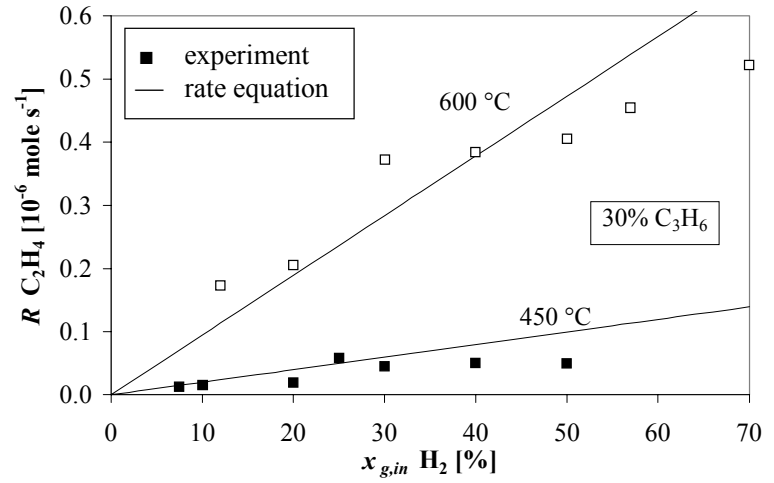

Figure 36. Ethylene production rate during propylene hydrogenation for propanehydrogen-nitrogen mixtures with constant propylene mole fraction of $30 \%$ at 450 and $600{ }^{\circ} \mathrm{C}$.

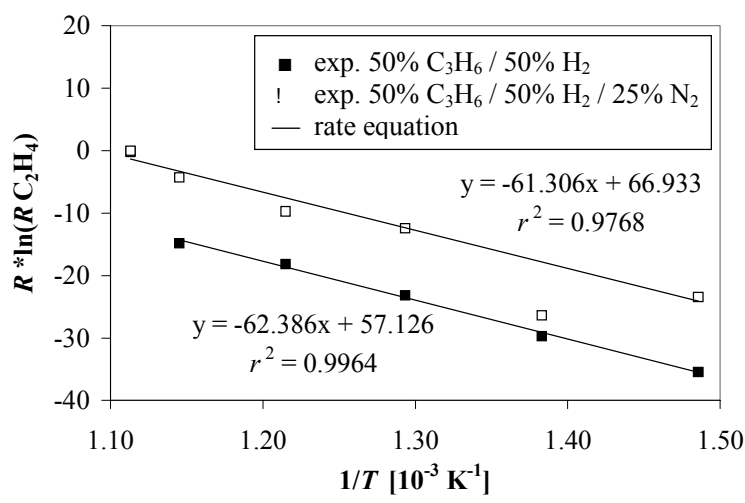

Figure 38. Arrhenius-plot for the ethylene production rate during propylene hydrogenation for two different mixtures:

(a) $50 \%$ propane, $50 \%$ hydrogen;

(b) $25 \%$ propane, $25 \%$ hydrogen, $50 \%$ nitrogen; 


\section{Derivation of rate equations}

The objective of this work is the derivation of 'steady state' reaction rate equations for the propane dehydrogenation, propylene hydrogenation and their most important side-reactions, which can describe all the experimental observations reported in the previous section as a function of temperature and composition over wide temperature and concentration ranges. The main conclusions obtained from the experimental results for the concentration dependency of the reaction rates are summarised below.

The propane dehydrogenation reaction rate consists of two contributions. The first contribution is proportional with the propane concentration, since the reaction rate is proportional with the propane concentration for propane-nitrogen mixtures. The second contribution is proportional with both the propane and the hydrogen concentration, because, firstly the propane dehydrogenation rate increases linearly with increasing hydrogen concentrations for propane-hydrogen-nitrogen mixtures with constant propane concentration, and secondly, the propane dehydrogenation shows for propane-hydrogen mixtures an optimum for propane concentrations of about $50 \%$. The second contribution is dominant at lower temperatures (below $600{ }^{\circ} \mathrm{C}$ ), but the first contribution becomes important and dominant at higher temperatures (above $c a .650{ }^{\circ} \mathrm{C}$ ). The deviation for the reaction rates of pure propane at $600{ }^{\circ} \mathrm{C}$ is attributed to the production of hydrogen during the propane dehydrogenation. Even small amounts of hydrogen produced can considerably increase the propane dehydrogenation reaction rate (i.e. non-differential operating conditions for experiments with pure propane feed, because of an axial hydrogen concentration profile). Secondly the reaction rates for pure propane feed had not yet completely reached the 'steady state'.

The propylene hydrogenation reaction rate shows a Langmuir-Hinshelwood type dependency on the propylene concentration and a second order dependency on the hydrogen concentration.

For the reaction rates of the side-reactions it can be concluded that the cracking of propane is proportional with the propane concentration and independent of the hydrogen concentration. Furthermore, the cracking of propane becomes only important at higher temperatures (above $\left.600{ }^{\circ} \mathrm{C}\right)$. The hydrogenolysis of propane consists of two contributions, which has been 
inferred from the very strong increase in the reaction rate at about $650{ }^{\circ} \mathrm{C}$. For lower temperatures the propane hydrogenolysis depends on the propane concentration according to a Langmuir-Hinshelwood type dependency and on the square of the hydrogen concentration. The reaction orders for the propane hydrogenolysis at high temperatures were not determined. It is assumed that the high temperature contribution to the propane hydrogenolysis increases linearly with both the propane and the hydrogen concentration, following the reaction stoichiometry and satisfying the experimental observation that no ethane was produced without hydrogen present in the gas mixture. Finally the propylene hydrogenolysis is proportional to the hydrogen concentration and depends on the propylene concentration according to a Langmuir-Hinshelwood type dependency.

Especially remarkable is the influence of the hydrogen concentration on the propylene hydrogenation reaction rate and the low temperature contributions of the propane dehydrogenation and propane hydrogenolysis reaction rates. All these reaction rates show a reaction order in the hydrogen concentration one higher than expected according to the reaction stoichiometry. On the other hand, the propane cracking, propylene hydrogenolysis and the high temperature contributions to the propane dehydrogenation and propane hydrogenolysis reactions have reaction orders following the reaction stoichiometry without an additional influence of the hydrogen concentration. This experimental observation can be interpreted by assuming that the reactions take place at two different surface sites, platinum surface sites and acid alumina surface sites, where propane dehydrogenation and propane hydrogenolysis reactions can take place at both sites, while propane cracking and propylene hydrogenolysis occur only at the acid surface sites and propylene hydrogenation mainly at the platinum surface sites.

The propane cracking, propylene hydrogenolysis and the high temperature contributions to the propane dehydrogenation and propane hydrogenolysis reactions are assumed to take place at the acid surface sites because the reaction orders of these reactions correspond to the reaction stoichiometry and because of the relatively high apparent activation energies. It is important to emphasise that from the experiments conducted in this work it is difficult to discriminate whether the reactions take place at the acid surface sites or in the gas phase or both. The experimentally observed linear dependency on the propane concentration for these reactions can be well explained by either assuming gas phase reactions or by assuming Henrytype adsorption of propane. However, since the reactions already take place at temperatures 
below $500{ }^{\circ} \mathrm{C}$ and because the reaction rates of the side-reactions show a good correlation with the decrease in catalytic activity, it is tentatively proposed that the side-reactions take place mainly at the alumina washcoat surface at the investigated temperature range. Furthermore, at these temperatures a higher propane concentration per unit volume might be realised at the catalyst surface compared to the gas phase. However, at higher temperatures the adsorption of propane decreases and probably at temperatures above $650-700{ }^{\circ} \mathrm{C}$ thermally activated propane dehydrogenation, cracking and hydrogenolysis become important.

With additional experiments on a monolith sample with a different channel diameter - but the same other catalyst properties - it might be possible to conclude whether the reactions take place at the acid surface sites or in the gas phase. For a monolith with a larger channel diameter the catalyst specific surface area is much smaller (less washcoat) and the gas phase porosity is higher. If the reaction rate of the side-reactions decrease for this monolith sample, it can be concluded that the reactions indeed occur at the surface sites. By comparing reaction rates on monolith samples with different channel diameters for different temperatures it is possible to investigate whether at lower temperatures the most important contribution is by reactions at the acid surface sites and at higher temperatures the gas phase reactions are dominant. However, the derived kinetics in this work is at least valid for monoliths with a channel diameter of $1.0 \mathrm{~mm}$.

The propylene hydrogenation and the low temperature contributions of the propane dehydrogenation and propane hydrogenolysis are assumed to take place at the platinum surface sites, because these reactions show a remarkably additional order in the hydrogen concentration on top of the hydrogen dependency according to the reaction stoichiometry. Propane and propylene seem to adsorb according to a Langmuir-Hinshelwood type adsorption isotherm. However, it should be realised that many other mechanisms give similar types of concentration dependencies. Moreover, it is generally assumed that hydrogen chemisorbs dissociatively at the platinum sites (a.o. Loc et al., 1991a; Bariås, 1993). For dissociative hydrogen chemisorption the surface fraction of hydrogen is proportional to the square root of the gas phase hydrogen concentration, at least for mixtures strongly diluted with inert components like nitrogen. In order to correctly describe the peculiar temperature dependency of the propane dehydrogenation and propane hydrogenolysis reaction rates it is necessary to assume that the additional reaction order in the hydrogen concentration results from the square of the dissociatively chemisorbed hydrogen surface fraction. 
The experimental results for all the 'steady state' reaction rates could be well described with reaction rate equations derived on the basis of the above assumption that the reactions take place at two different places, and that the rates of the reactions taking place at the platinum surface sites have a supplementary second order in the surface fraction of dissociatively chemisorbed hydrogen, additional to the reaction stoichiometry. Furthermore, it has been assumed that adsorption equilibria are established instantaneously, which can be justified for the 'steady state' reaction rates after about half an hour of experimentation. The reaction rate equations are summed in Table 4.

Table 4. Reaction rate equations for the propane dehydrogenation and propylene hydrogenation $\left(R_{P D}\right)$, propane cracking $\left(R_{P C}\right)$, propane hydrogenolysis $\left(R_{P H}\right)$ and propylene hydrogenolysis $\left(R_{P y H}\right)$.

$$
\begin{aligned}
\mathrm{C}_{3} \mathrm{H}_{8} \stackrel{R_{P D}}{\longleftrightarrow} \mathrm{C}_{3} \mathrm{H}_{6}+\mathrm{H}_{2} & \begin{aligned}
R_{P D} & =k_{P D, 1} \theta_{\mathrm{C}_{3} \mathrm{H}_{8}} \theta_{\mathrm{H}}^{2}-k_{P D,-1} \theta_{\mathrm{C}_{3} \mathrm{H}_{6}} C_{g, \mathrm{H}_{2}} \theta_{\mathrm{H}}^{2} \\
& +k_{P D, 2} C_{g, \mathrm{C}_{3} \mathrm{H}_{8}}-k_{P D,-2} C_{g, \mathrm{C}_{3} \mathrm{H}_{6}} C_{g, \mathrm{H}_{2}}
\end{aligned} \\
\mathrm{C}_{3} \mathrm{H}_{8} \stackrel{R_{P C}}{\longrightarrow} \mathrm{C}_{2} \mathrm{H}_{4}+\mathrm{CH}_{4} & R_{P C}=k_{P C} C_{g, \mathrm{C}_{3} \mathrm{H}_{8}} \\
\mathrm{C}_{3} \mathrm{H}_{8}+\mathrm{H}_{2} \stackrel{R_{P H}}{\longrightarrow} \mathrm{C}_{2} \mathrm{H}_{6}+\mathrm{CH}_{4} & R_{P H}=k_{P H, 1} \theta_{\mathrm{C}_{3} \mathrm{H}_{8}} C_{g, \mathrm{H}_{2}} \theta_{\mathrm{H}}^{2}+k_{P H, 2} C_{g, \mathrm{C}_{3} \mathrm{H}_{8}} C_{g, \mathrm{H}_{2}} \\
\mathrm{C}_{3} \mathrm{H}_{6}+\mathrm{H}_{2} \stackrel{R_{P y H}}{\longrightarrow} \mathrm{C}_{2} \mathrm{H}_{4}+\mathrm{CH}_{4} & R_{P y H}
\end{aligned}
$$

where

$$
\begin{aligned}
& \theta_{\mathrm{C}_{3} \mathrm{H}_{8}}=\frac{K_{\mathrm{C}_{3} \mathrm{H}_{8}} C_{g, \mathrm{C}_{3} \mathrm{H}_{8}}}{1+K_{\mathrm{C}_{3} \mathrm{H}_{8}} C_{g, \mathrm{C}_{3} \mathrm{H}_{8}}+K_{\mathrm{C}_{3} \mathrm{H}_{6}} C_{g, \mathrm{C}_{3} \mathrm{H}_{6}}+K_{\mathrm{H}} C_{g, \mathrm{H}_{2}}^{\frac{1}{2}}} \\
& \theta_{\mathrm{C}_{3} \mathrm{H}_{6}}=\frac{K_{\mathrm{C}_{3} \mathrm{H}_{6}} C_{g, \mathrm{C}_{3} \mathrm{H}_{6}}}{1+K_{\mathrm{C}_{3} \mathrm{H}_{8}} C_{g, \mathrm{C}_{3} \mathrm{H}_{8}}+K_{\mathrm{C}_{3} \mathrm{H}_{6}} C_{g, \mathrm{C}_{3} \mathrm{H}_{6}}+K_{\mathrm{H}} C_{g, \mathrm{H}_{2}}^{\frac{1}{2}}} \\
& \theta_{\mathrm{H}}=\frac{K_{\mathrm{H}} C_{g, \mathrm{H}_{2}}^{\frac{1}{2}}}{1+K_{\mathrm{C}_{3} \mathrm{H}_{8}} C_{g, \mathrm{C}_{3} \mathrm{H}_{8}}+K_{\mathrm{C}_{3} \mathrm{H}_{6}} C_{g, \mathrm{C}_{3} \mathrm{H}_{6}}+K_{\mathrm{H}} C_{g, \mathrm{H}_{2}}^{\frac{1}{2}}} \\
& \theta_{\mathrm{C}_{3} \mathrm{H}_{6}}^{s}=\frac{K_{\mathrm{C}_{3} \mathrm{H}_{6}}^{s} C_{g, \mathrm{C}_{3} \mathrm{H}_{6}}}{1+K_{\mathrm{C}_{3} \mathrm{H}_{6}}^{s} C_{g, \mathrm{C}_{3} \mathrm{H}_{6}}}
\end{aligned}
$$


For the propylene hydrogenation a second contribution has been included in the reaction rate equation in order to describe the propane dehydrogenation/propylene hydrogenation equilibrium at higher temperatures somewhat better. For the reactions involving hydrogen as a reactant, an Eley-Rideal mechanism has been assumed.

For the rate constants and 'sorption' coefficients an Arrhenius-type temperature dependency was assumed. The rate constants, sorption coefficients and activation energies have been fitted using the Levenberg-Marquardt method and the results are listed in Table 5. The results of these rate equations have been presented in the figures showing the experimental results (Figures 8-18 and 24-38). With the derived kinetic model the reaction rates could be described within typically $10-25 \%$ accuracy. Finally, it is again emphasised that no details about the precise mechanism can be deduced from the experiments described in this work. The reaction rate constants should be considered as overall lumped reaction rate constants, taking into account the combined effects of possibly several elementary reaction steps.

Table 5. Reaction rate constants (pre-exponential constants and activation energies) for the propane dehydrogenation and propylene hydrogenation $\left(R_{P D}\right)$, propane cracking $\left(R_{P C}\right)$, propane hydrogenolysis $\left(R_{P H}\right)$ and propylene hydrogenolysis $\left(R_{P y H}\right)$. The experiments were carried out on $2.0 \mathrm{~g}$ of monolithic catalyst with $1.1 \mathrm{wt} \% \mathrm{Pt}$ dispersed in the $\gamma-\mathrm{Al}_{2} \mathrm{O}_{3}$ washcoat. A BET area of $15.3 \mathrm{~m}^{2} \cdot \mathrm{g}^{-1}$ monolith has been taken as reference, determined for a catalyst after long times on stream (see Table 1). The reaction rates are expressed per unit internal catalyst surface area.

\begin{tabular}{|c|c|c|c|c|c|c|}
\hline \multirow{7}{*}{ PD } & $K_{\mathrm{C}_{3} \mathrm{H}_{8}, \infty}$ & {$\left[\mathrm{m}^{3} \cdot \mathrm{mole}^{-1}\right]$} & $5.09 \cdot 10^{5}$ & $E_{\mathrm{C}_{3} \mathrm{H}_{8}}$ & {$\left[\mathrm{~kJ} \cdot \mathrm{mole}^{-1}\right]$} & 114 \\
\hline & $K_{\mathrm{C}_{3} \mathrm{H}_{6}, \infty}$ & {$\left[\mathrm{m}^{3} \cdot \mathrm{mole}^{-1}\right]$} & $1.07 \cdot 10^{1}$ & $E_{\mathrm{C}_{3} \mathrm{H}_{6}}$ & {$\left[\mathrm{~kJ} \cdot \mathrm{mole}^{-1}\right]$} & 28.0 \\
\hline & $K_{\mathrm{H}, \infty}$ & {$\left[\mathrm{m}^{1.5} \cdot \mathrm{mole}^{-0.5}\right]$} & $1.54 \cdot 10^{-3}$ & $E_{\mathrm{H}}$ & {$\left[\mathrm{kJ} \cdot \mathrm{mole}^{-1}\right]$} & -30.5 \\
\hline & $k_{P D, 1, \infty}$ & {$\left[\right.$ mole $\left.\cdot \mathrm{m}^{-2} \cdot \mathrm{s}^{-1}\right]$} & $1.78 \cdot 10^{-6}$ & $E_{P D, 1}$ & {$\left[\mathrm{~kJ} \cdot \mathrm{mole}^{-1}\right]$} & -17.0 \\
\hline & $k_{P D,-1, \infty}$ & {$\left[\mathrm{m} \cdot \mathrm{s}^{-1}\right]$} & $6.12 \cdot 10^{-9}$ & $E_{P D,-1}$ & {$\left[\mathrm{~kJ} \cdot \mathrm{mole}^{-1}\right]$} & -38.4 \\
\hline & $k_{P D, 2, \infty}$ & {$\left[\mathrm{m} \cdot \mathrm{s}^{-1}\right]$} & $2.35 \cdot 10^{4}$ & $E_{P D, 2}$ & {$\left[\mathrm{~kJ} \cdot \mathrm{mole}^{-1}\right]$} & 209 \\
\hline & $k_{P D,-2, \infty}$ & {$\left[\mathrm{m}^{4} \cdot \mathrm{mole}^{-1} \cdot \mathrm{s}^{-1}\right]$} & $2.62 \cdot 10^{-4}$ & $E_{P D,-2}$ & {$\left[\mathrm{~kJ} \cdot \mathrm{mole}^{-1}\right]$} & 88.3 \\
\hline $\mathbf{P C}$ & $k_{P C, \infty}$ & {$\left[\mathrm{m} \cdot \mathrm{s}^{-1}\right]$} & $8.84 \cdot 10^{4}$ & $E_{P C}$ & {$\left[\mathrm{~kJ} \cdot \mathrm{mole}^{-1}\right]$} & 235 \\
\hline \multirow{2}{*}{ PH } & $k_{P H, 1, \infty}$ & {$\left[\mathrm{m} \cdot \mathrm{s}^{-1}\right]$} & $5.51 \cdot 10^{-5}$ & $E_{P H, 1}$ & {$\left[\mathrm{~kJ} \cdot \mathrm{mole}^{-1}\right]$} & 48.5 \\
\hline & $k_{P H, 2, \infty}$ & {$\left[\mathrm{m}^{4} \cdot \mathrm{mole}^{-1} \cdot \mathrm{s}^{-1}\right]$} & $1.44 \cdot 10^{15}$ & $E_{P H, 2}$ & {$\left[\mathrm{~kJ} \cdot \mathrm{mole}^{-1}\right]$} & 449 \\
\hline \multirow{2}{*}{ РyH } & $k_{P y H, \infty}$ & {$\left[\right.$ mole $\left.\cdot \mathrm{m}^{-2} \cdot \mathrm{s}^{-1}\right]$} & $1.03 \cdot 10^{-5}$ & $E_{P y H}$ & {$\left[\mathrm{~kJ} \cdot \mathrm{mole}^{-1}\right]$} & 61.8 \\
\hline & $K_{\mathrm{C}_{3} \mathrm{H}_{6}, \infty}^{s}$ & {$\left[\mathrm{~m}^{3} \cdot \mathrm{mole}^{-1}\right]$} & 1.68 & $E_{\mathrm{C}_{3} \mathrm{H}_{6}}^{s}$ & {$\left[\mathrm{~kJ} \cdot \mathrm{mole}^{-1}\right]$} & 0 \\
\hline
\end{tabular}




\section{Discussion}

In this section the experimental results for the 'steady state' reaction rates are discussed. The discussion is restricted to the following topics. Firstly, the experimentally determined reaction rates for the propane dehydrogenation are compared with some literature values. Then, an explanation is proposed for the peculiar additional hydrogen dependency of the reactions taking place at the platinum surface sites. Finally, the derived 'steady state' reaction rate equations are valid for reaction mixtures with a composition largely deviating from the equilibrium composition. It is shortly discussed how the derived reaction rate equations can be tentatively adjusted so that the reaction rates coincide with thermodynamic data when the system approaches equilibrium.

\subsection{Comparison of propane dehydrogenation reaction rate with literature}

The experimentally determined 'steady state' propane dehydrogenation reaction rate is compared with reaction data given by Loc et al. (1991a) and Bariås (1993). For a 50\% propane and $50 \%$ hydrogen mixture the propane dehydrogenation reaction rate was practically independent of the temperature at temperatures between 500 and $600{ }^{\circ} \mathrm{C}$ (at 1.2 bara) and was about $3.0 \mu \mathrm{mole} \cdot \mathrm{g}^{-1} \cdot \mathrm{s}^{-1}$ for a $1.1 \mathrm{wt} \% \mathrm{Pt} / \gamma-\mathrm{Al}_{2} \mathrm{O}_{3}$ monolith sample for large cumulative experimentation times. From the reaction rate equation given by Loc et al. an initial propane dehydrogenation reaction rate of $48 \mu \mathrm{mole} \cdot \mathrm{g}^{-1} \cdot \mathrm{s}^{-1}$ is calculated for a $50 \%$ propane, $50 \%$ hydrogen mixture over a $0.6 \mathrm{wt} \% \mathrm{Pt} / \gamma-\mathrm{Al}_{2} \mathrm{O}_{3}$ at $600{ }^{\circ} \mathrm{C}$. The reaction rate equation given by Bariås for propane dehydrogenation over a $\mathrm{Sn}-\mathrm{Pt} / \gamma-\mathrm{Al}_{2} \mathrm{O}_{3}$ catalyst, with also about $0.6 \mathrm{wt} \%$ $\mathrm{Pt}$, gives an initial propane dehydrogenation reaction of $46 \mu \mathrm{mole} \cdot \mathrm{g}^{-1} \cdot \mathrm{s}^{-1}$ for a reaction mixture with the same composition at $500{ }^{\circ} \mathrm{C}$. Bariås showed that the initial reaction rates of the propane dehydrogenation over $\mathrm{Pt} / \boldsymbol{\gamma}-\mathrm{Al}_{2} \mathrm{O}_{3}$ and $\mathrm{Sn}-\mathrm{Pt} / \boldsymbol{\gamma}-\mathrm{Al}_{2} \mathrm{O}_{3}$ catalysts are comparable (in strong contrast to longer times on stream).

Before comparing these values, the reaction rates need to be corrected for the platinum loading and the specific catalyst surface area. At these relatively low platinum concentrations the platinum dispersion can approximately be considered constant (cf. Biloen et al., 1977). Subsequently, the specific catalyst surface area of a used monolith sample was determined at 
$15.3 \mathrm{~m}^{2} \cdot \mathrm{g}^{-1}$, while Bariås used a catalyst with a catalyst surface area of $150-180 \mathrm{~m}^{2} \cdot \mathrm{g}^{-1}$. Unfortunately Loc et al. did not mention the specific catalyst surface area of their catalysts. The specific surface area of the monolith is roughly a factor of 10 lower, corresponding to the weight fraction of the washcoat in the monolith (estimated at about $8 \mathrm{wt} \%$ ). Correcting the reaction rate by Bariås for a $1 \mathrm{wt} \% \mathrm{Pt}$ catalyst a propane dehydrogenation reaction rate of $c a$. $0.7 \mu$ mole $\cdot \mathrm{m}^{-2} \cdot \mathrm{s}^{-1}$ is obtained, compared to $0.2 \mu \mathrm{mole} \cdot \mathrm{m}^{-2} \cdot \mathrm{s}^{-1}$ for the monolith in this work.

Next, the reaction rates given by Loc et al. and Bariås are extrapolated to $t=0$, while in this work the 'steady state' reaction rates reached after roughly 30 minutes of operation are reported. Compared with the initial reaction rates the 'steady state' reaction rate has decreased about a factor of two because of the deposition of carbonaceous products for a equimolar propane-hydrogen mixture at $600{ }^{\circ} \mathrm{C}$ (see Figure 6). Finally, it is noted that Bariås measured the propane dehydrogenation reaction rate on a fresh catalyst. The catalytic activity of the monolith sample strongly decreases with times on stream because of sintering $\left(35 \mathrm{~m}^{2} \cdot \mathrm{g}^{-1}\right.$ to $15.3 \mathrm{~m}^{2} \cdot \mathrm{g}^{-1}$ for a fresh and used monolith sample, see Table 1 ), which is corrected for, but also additionally because of the destruction of the most active sites or decrease in platinum dispersion. The catalytic activity on a used catalyst has decreased more than a factor of 5 (see Figure 7.a). Concluding, the order of magnitude of the experimentally observed propane dehydrogenation reaction rates corresponds well to the literature values.

Furthermore, Bariås (1993) observed a relatively high apparent activation energy of $100 \mathrm{~kJ} \cdot \mathrm{mole}^{-1}$ between 427 and $519^{\circ} \mathrm{C}$, while Loc et al. (1991a) determined an activation energy of $59 \mathrm{~kJ} \cdot \mathrm{mole}^{-1}$ at temperatures between 570 and $620^{\circ} \mathrm{C}$, although they indicated that they did not obtain a straight line in their Arrhenius plot. These apparent activation energies correspond very well with the experimental results obtained in this work, see Figure 39. Note, that for low temperatures the activation energy approaches the reaction enthalpy, because the experimentally determined conversions approach the equilibrium conversions, as discussed before.

In this work a positive influence of the hydrogen concentration on the propane dehydrogenation reaction rate was observed. Neither Loc et al. (1991a) or Bariås (1993) found a positive influence of the hydrogen concentration (hydrogen reaction orders were -0.5 and -0.67 , respectively). An explanation for the discrepancy in the influence of the hydrogen concentration is given in the next section. 


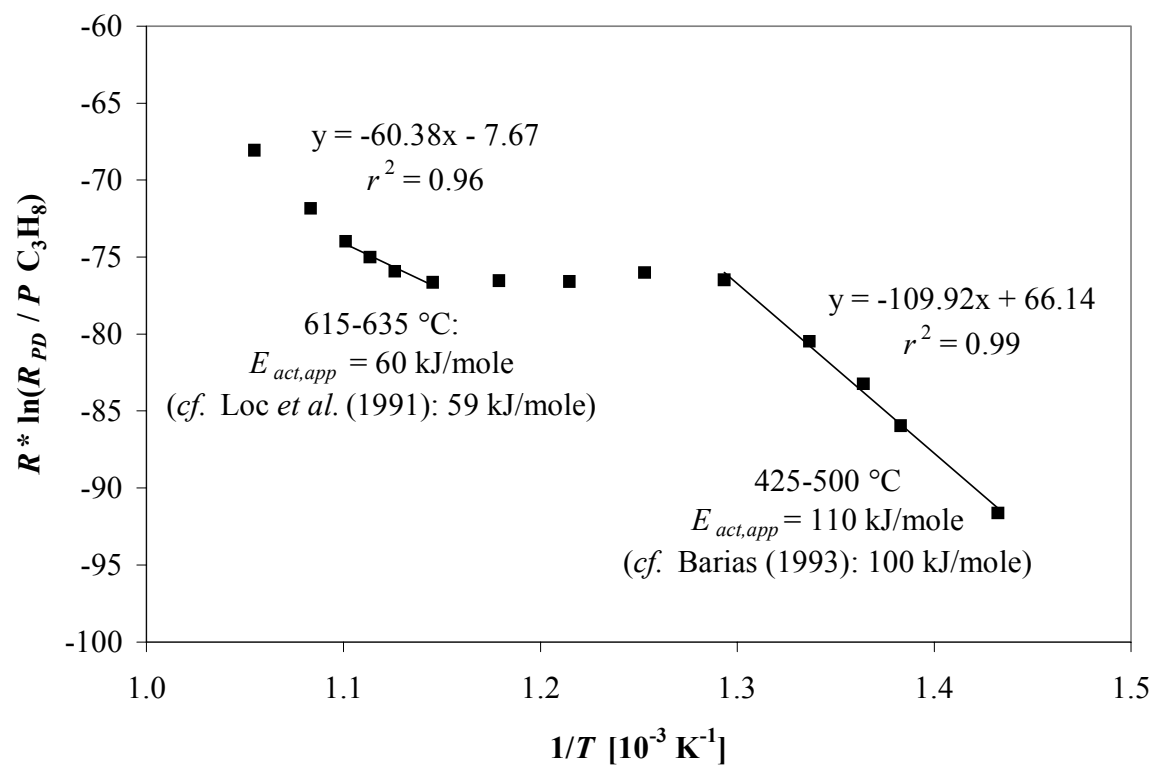

Figure 39. Comparison of apparent activation energies for the propane dehydrogenation obtained in this work with values reported by Loc et al. (1991a) and Bariås (1993).

\subsection{Hydrogen dependency}

At the end of the seventies different mechanisms have been proposed for the propane dehydrogenation. Suzuki and Kaneko (1977) and later Gorriz et al. (1989) proposed a mechanism for the propane dehydrogenation over $\mathrm{Cr}_{2} \mathrm{O}_{3}\left(-\mathrm{K}_{2} \mathrm{O}\right) / \mathrm{Al}_{2} \mathrm{O}_{3}$ catalyst based on the molecular adsorption of propane at an active surface site followed by the sequential cleavage of two $\mathrm{C}-\mathrm{H}$ bonds and concluded with the recombination of the two adsorbed hydrogen atoms to a gas phase hydrogen molecule and the desorption of propylene. This mechanism is sometimes referred to as the Horiuti-Polanyi mechanism, the generally accepted mechanism for alkane dehydrogenation and alkene hydrogenation. Also Loc et al. (1991a) described their experimental results with a reaction rate expression based on this mechanism.

Biloen et al. (1977) proposed that the propane dehydrogenation over Pt and Pt-Au catalysts for propane-hydrogen mixtures with a large hydrogen concentration follows an Eley-Rideal mechanism. Their model was based on the experimental result that the propane dehydrogenation occurs at only one platinum site. In their model the platinum sites are first activated by hydrogen. The propane molecule is then dissociatively chemisorbed on this hydrogen-activated platinum site, releasing a hydrogen molecule to the gas phase. After cleavage of the second $\mathrm{C}-\mathrm{H}$ bond the formed propylene desorbs. 
Finally, Somorjai (1977) proposed a dynamic restructuring surface model. In their model the platinum surface is covered by a near monolayer amount of carbonaceous deposits. The cleavage of the two $\mathrm{C}-\mathrm{H}$ bonds is proposed to take place on top of this overlayer and the recombination of the hydrogen atoms takes place at the platinum surface.

Only the mechanism proposed by Biloen et al. (1977) can explain a positive influence of hydrogen on the propane dehydrogenation reaction rate. However, this mechanism fails to explain the experimentally observed second order dependency on the gas phase hydrogen concentration of the propylene hydrogenation and propane hydrogenolysis reaction rates. It is proposed that the experimentally observed additional order in the gas phase hydrogen concentration for all the reactions taking place at the platinum surface sites does not result from the influence of hydrogen on the elementary reaction steps, but results from the influence of hydrogen on the number of free active platinum surface sites which are not covered by carbonaceous deposits. The positive influence of the hydrogen concentration on the reaction rates for all the reactions taking place at the platinum sites is thus explained by the retardation by hydrogen of the formation of carbonaceous products which cover platinum surface sites and withhold these sites to participate in other reactions.

\subsubsection{Number of free platinum surface sites}

It was observed in the experiments that the propane dehydrogenation and propylene hydrogenation reaction rates over $\mathrm{Pt} / \gamma-\mathrm{Al}_{2} \mathrm{O}_{3}$ catalysts at $c a .600{ }^{\circ} \mathrm{C}$ became practically constant after 10-30 minutes. The decrease in the catalyst activity can be explained by the deposition of carbonaceous products on the active platinum sites. After about half an hour the number of platinum sites covered with coke seem to have stabilised, explaining the virtually constant reaction rate. However, the total coke content on the monolith sample still increases with time at these reaction conditions (see Chapter 5) because of coke formation at the acid surface sites of the washcoat. The steady state in the number of free active sites is tentatively explained by a dynamic equilibrium between the formation of carbonaceous products on the platinum sites and the regeneration of these sites by reduction of the carbonaceous products with hydrogen or by removal of the coke precursors via transport from the platinum sites to different places at the surface. Recent research explains the improved stability of 
$\mathrm{Sn}-\mathrm{Pt} / \gamma-\mathrm{Al}_{2} \mathrm{O}_{3}$ catalysts over $\mathrm{Pt} / \gamma-\mathrm{Al}_{2} \mathrm{O}_{3}$ catalysts by the enhanced transport of carbonaceous products from the platinum sites to the support by the addition of tin (e.g. Bariås, 1993).

Larsson (1997) described the catalyst deactivation by a model - kept as simple as possible based on the assumption that two types of coke were formed on the platinum sites, one type reversible and the other irreversible. The reversible type of coke is formed out of coke precursors mainly originating from adsorbed propylene. The reversible type of coke can be removed by hydrogen or can be converted into the irreversible type of coke. The propane dehydrogenation reaction rate could be described by

$r=r_{0}\left(1-\theta_{\text {rev }}-\theta_{i r r}\right)$

where $r_{0}$ represents the reaction rate on a fresh catalyst without any coke deposits and $\theta_{\text {rev }}$ and $\theta_{i r r}$ represent the fraction of platinum surface sites covered by reversible and irreversible coke, respectively. The reversible and irreversible coke surface fractions as a function of time were described by

$$
\frac{d \theta_{r e v}}{d t}=k_{1} \frac{p_{\mathrm{C}_{3} \mathrm{H}_{6}}}{p_{\mathrm{H}_{2}}}\left(1-\theta_{\text {rev }}-\theta_{\text {irr }}\right)-k_{2} p_{\mathrm{H}_{2}} \theta_{r e v}-k_{3} \theta_{r e v}
$$

$$
\frac{d \theta_{i r r}}{d t}=k_{3} \theta_{r e v}
$$

For the relative short dehydrogenation times of about 30 minutes used in this work, compared with dehydrogenation times of many hours in the work of Larsson (1997), it is assumed that the amount of irreversible coke and the rate at which irreversible coke is formed is negligible $\left(\theta_{i r r}<<\theta_{r e v}\right.$, and $\left.k_{3}<<k_{2} p_{\mathrm{H}_{2}}\right)$. This explains the virtually constant propane dehydrogenation reaction rate after 30 minutes of experimentation.

For the pseudo-steady state for relatively short times on stream equation 15 can be simplified to 
$\theta_{\text {rev }} \approx \frac{k_{1} \frac{p_{\mathrm{C}_{3} \mathrm{H}_{6}}}{p_{\mathrm{H}_{2}}}}{k_{1} \frac{p_{\mathrm{C}_{3} \mathrm{H}_{6}}}{p_{\mathrm{H}_{2}}}+k_{2} p_{\mathrm{H}_{2}}}$

The pseudo-steady state reaction rate relative to the initial reaction rate on a surface without coke deposits equals the fraction of free platinum surface sites and is then given by

$$
\frac{r}{r_{0}} \approx 1-\theta_{\text {rev }} \approx \frac{p_{\mathrm{H}_{2}}}{\frac{k_{1}}{k_{2}} \frac{p_{\mathrm{C}_{3} \mathrm{H}_{6}}}{p_{\mathrm{H}_{2}}}+p_{\mathrm{H}_{2}}}
$$

Since the reaction rates have decreased about a factor of 2 to 3 in the pseudo-steady state compared to the initial reaction rates, the formation rate of reversible coke is of the same order of magnitude as the rate of removal of reversible coke via hydrogenation.

Note that the expression used by Larsson for the formation of reversible coke is only valid for reaction mixtures with relatively high hydrogen concentrations and for high conversions of propane to propylene. Assuming that the formation rate of reversible coke is proportional to propylene and propane surface concentrations, yielding the term in equation 15 in the limit of high hydrogen concentrations and high propane conversions, equation 18 can be represented in a more general form by

$\frac{r}{r_{0}} \approx \frac{p_{\mathrm{H}_{2}}}{\left(\frac{k_{1, \mathrm{C}_{3} \mathrm{H}_{6}}}{k_{2}} \theta_{\mathrm{C}_{3} \mathrm{H}_{6}, 0}+\frac{k_{1, \mathrm{C}_{3} \mathrm{H}_{8}}}{k_{2}} \theta_{\mathrm{C}_{3} \mathrm{H}_{8}, 0}\right)+p_{\mathrm{H}_{2}}}$

which shows the additional order in the hydrogen concentration for the reactions taking place at the platinum sites, if the term between the brackets in the denominator of equation 19 is larger than the hydrogen pressure. Larsson (1997) assumed that the hydrogenation of reversible coke occurs via hydrogen from the gas phase. However, further research about the details of the kinetics of the coke formation processes at the platinum surface sites is necessary to discriminate whether reversible type coke is removed by gas phase hydrogen or by molecularly or dissociatively adsorbed hydrogen. 
Finally, it is emphasised that the above described coke formation processes at the platinum sites should be considered as an example, showing how coke formation at the platinum sites can be responsible for additional order in the hydrogen concentration for the pseudo-steady state reaction rates at the platinum sites. No details on the coke formation processes at the platinum sites can be discerned from this work. Furthermore, it should be clear that the fitted reaction rate and adsorption constants in the fitted reaction rate equations (Table 4 and 5) should be considered as lumped constants, also taking into account effects of formation and hydrogenation of reversible coke at the platinum sites.

\subsection{Thermodynamics}

If the rate equations are implemented in a model describing concentration and temperature profiles in propane dehydrogenation reactors, it is necessary that the reaction rate equation is capable of predicting the thermodynamic equilibrium accurately. In Figure 40 the equilibrium conversion calculated with the derived reaction rate equation (i.e. when the propane dehydrogenation reaction rate equals the propylene hydrogenation reaction rate) is compared with the equilibrium conversion calculated from thermodynamics for different reaction mixtures at $600{ }^{\circ} \mathrm{C}$. The equilibrium conversion based on the reaction rate equation is generally a little overestimated.
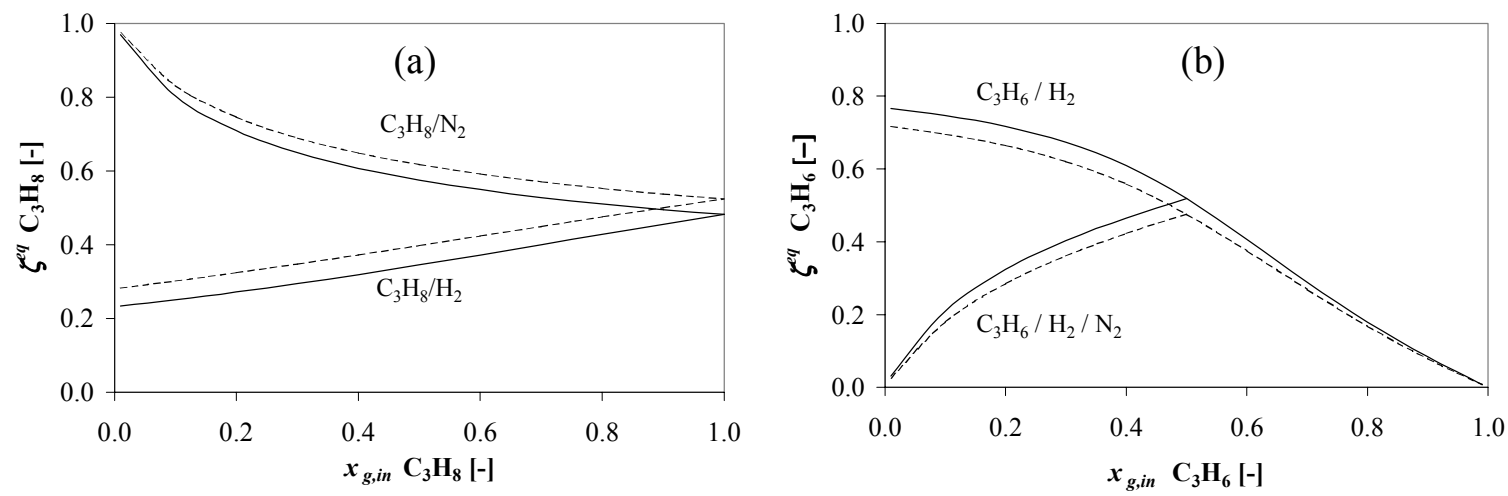

Figure 40. Comparison of the equilibrium conversion calculated on the basis of the experimentally derived reaction rate equation (dashed lines) with the equilibrium conversion calculated from thermodynamics (solid lines).

(a) Propane equilibrium conversion as a function of the propane gas phase inlet mole fraction for propane/hydrogen and propane/nitrogen mixtures at $600{ }^{\circ} \mathrm{C}$ and $1 \mathrm{~atm}$;

(b) Propylene equilibrium conversion as a function of the propylene gas phase inlet mole fraction for propylene/hydrogen and propylene/hydrogen/nitrogen mixtures with equal concentrations of propylene and hydrogen at $600{ }^{\circ} \mathrm{C}$ and $1 \mathrm{~atm}$; 
The differences between the equilibrium conversions calculated from kinetics and thermodynamics increase at lower temperatures, because in this case the propane dehydrogenation reaction rate is still relatively large, but the equilibrium conversion is very small.

Since the rate equation is based on experiments with either propane or propylene in the feed, the fitted reaction rate equation for the propane dehydrogenation/propylene hydrogenation reaction (Table 4 and 5) is only valid for reaction mixtures whose composition strongly deviates from the equilibrium composition, explaining the discrepancies between the equilibrium conversions calculated based on kinetics or thermodynamics. More detailed knowledge of the propane dehydrogenation and propylene hydrogenation reaction mechanism and kinetics, especially closer to the equilibrium, is necessary to arrive at better rate equations.

Knowledge on the thermodynamic equilibrium has not been incorporated explicitly in the reaction rate equation derived in this work. Loc et al. (1991a) included the thermodynamic equilibrium explicitly in their reaction rate expression (equation 1) by assuming that the backward reaction rate constant equals the forward reaction rate constant divided by the equilibrium constant. However, this method can only be applied for a single reaction where the reaction orders correspond to the reaction stoichiometry (at least relatively). It has been tried to set both backward reaction rate constants equal to their respective forward reaction rate constants divided by the equilibrium constant

$k_{P D,-1}=\frac{k_{P D, 1}}{K_{p}} \quad$ and $\quad k_{P D,-2}=\frac{k_{P D, 2}}{K_{p}}$

However, this failed to produce a reasonable fit to the experiments. Especially the observed peculiar temperature dependencies of the propane dehydrogenation and propylene hydrogenation reaction rates could not be captured.

A palliative is proposed to overcome this inadequacy of the derived reaction rate equation. It is proposed that in case of net propane dehydrogenation the reaction rate of the propylene hydrogenation is adjusted in such a way that the reaction rates are equal at the equilibrium 
composition as calculated by thermodynamics. In case of net propylene hydrogenation the propane dehydrogenation reaction rate is adjusted analogously. The reaction rates should be left unaltered for a reaction mixture with a composition largely deviating from the equilibrium composition, since for these conditions the reaction rates were measured. The proposed equations to adjust the reaction rate expression are given in Table 6 and the calculation strategy is briefly indicated in Figure 41. In Figure 42 the results of the adjustment of the net propane dehydrogenation reaction rate is shown as a function of the degree of propane conversion for a pure propane feed at $600{ }^{\circ} \mathrm{C}$.

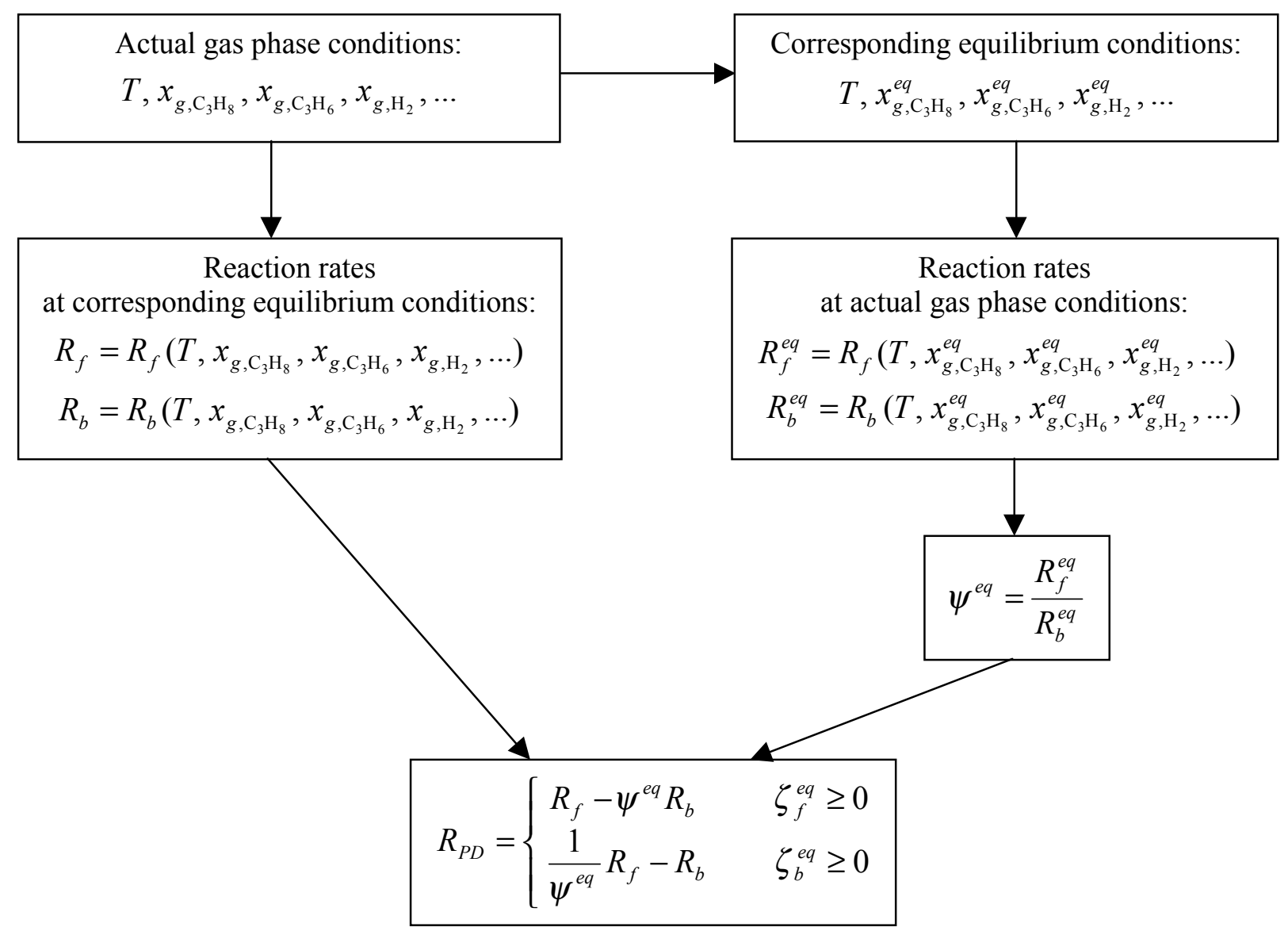

Figure 41. Calculation-strategy to adjust the derived kinetic rate equation for the propane dehydrogenation / propylene hydrogenation equilibrium reaction. 
Table 6. Equations to adjust the propane dehydrogenation - propylene hydrogen reaction rate equation to impose the thermodynamic equilibrium (see Table 4 for the definition of the constants).

$R_{P D}= \begin{cases}R_{f}-\psi^{e q} R_{b} & \zeta_{f}^{e q} \geq 0 \\ \frac{1}{\psi^{e q}} R_{f}-R_{b} & \zeta_{b}^{e q} \geq 0\end{cases}$

$\psi^{e q}=\frac{R_{f}^{e q}}{R_{b}^{e q}}$

$R_{f}=k_{P D, 1} \theta_{\mathrm{C}_{3} \mathrm{H}_{8}} \theta_{\mathrm{H}}^{2}+k_{P D, 2} C_{g, \mathrm{C}_{3} \mathrm{H}_{8}}$

$R_{b}=k_{P D,-1} \theta_{\mathrm{C}_{3} \mathrm{H}_{6}} C_{g, \mathrm{H}_{2}} \theta_{\mathrm{H}}^{2}+k_{P D,-2} C_{g, \mathrm{C}_{3} \mathrm{H}_{6}} C_{g, \mathrm{H}_{2}}$

Calculation of equilibrium composition:

\section{Propane dehydrogenation}

$$
\begin{array}{ll}
\zeta_{f}^{e q}=\frac{-B_{f}+\sqrt{B_{f}^{2}-4 A_{f} C_{f}}}{2 A_{f}} & \zeta_{b}^{e q}=\frac{-B_{b}+\sqrt{B_{b}^{2}-4 A_{b} C_{b}}}{2 A_{b}} \\
A_{f}=x_{g, \mathrm{C}_{3} \mathrm{H}_{8}}^{2}\left(1+\frac{K_{p}}{P}\right) & A_{b}=-x_{g, \mathrm{C}_{3} \mathrm{H}_{6}}^{2}\left(1+\frac{P}{K_{p}}\right) \\
B_{f}=x_{g, \mathrm{C}_{3} \mathrm{H}_{8}}\left[\left(x_{g, \mathrm{C}_{3} \mathrm{H}_{6}}+x_{g, \mathrm{H}_{2}}\right)+\frac{K_{p}}{P}\left(1-x_{g, \mathrm{C}_{3} \mathrm{H}_{8}}\right)\right] & B_{b}=x_{g, \mathrm{C}_{3} \mathrm{H}_{6}}\left[\left(1-x_{g, \mathrm{C}_{3} \mathrm{H}_{8}}\right)+\frac{P}{K_{p}}\left(x_{g, \mathrm{C}_{3} \mathrm{H}_{6}}+x_{g, \mathrm{H}_{2}}\right)\right] \\
C_{f}=x_{g, \mathrm{C}_{3} \mathrm{H}_{6}} x_{g, \mathrm{H}_{2}}-\frac{K_{p}}{P} x_{g, \mathrm{C}_{3} \mathrm{H}_{8}} & C_{b}=x_{g, \mathrm{C}_{3} \mathrm{H}_{8}}-\frac{P}{K_{p}} x_{g, \mathrm{C}_{3} \mathrm{H}_{6}} x_{g, \mathrm{H}_{2}} \\
x_{g, \mathrm{C}_{3} \mathrm{H}_{8}, f}^{e q}=\frac{x_{g, \mathrm{C}_{3} \mathrm{H}_{8}}\left(1-\zeta_{f}^{e q}\right)}{\left(1+x_{g, \mathrm{C}_{3} \mathrm{H}_{8}} \zeta_{f}^{e q}\right)} & x_{g, \mathrm{C}_{3} \mathrm{H}_{8}, b}^{e q}=\frac{x_{g, \mathrm{C}_{3} \mathrm{H}_{8}}+x_{g, \mathrm{C}_{3} \mathrm{H}_{6}} \zeta_{b}^{e q}}{\left(1-x_{g, \mathrm{C}_{3} \mathrm{H}_{6}} \zeta_{b}^{e q}\right)} \\
x_{g, \mathrm{C}_{3} \mathrm{H}_{6}, f}^{e q}=\frac{x_{g, \mathrm{C}_{3} \mathrm{H}_{6}}+x_{g, \mathrm{C}_{3} \mathrm{H}_{8}} \zeta_{f}^{e q}}{\left(1+x_{g, \mathrm{C}_{3} \mathrm{H}_{8}} \zeta_{f}^{e q}\right)} & x_{g, \mathrm{C}_{3} \mathrm{H}_{6}, b}^{e q}=\frac{x_{g, \mathrm{C}_{3} \mathrm{H}_{6}}\left(1-\zeta_{b}^{e q}\right)}{\left(1-x_{g, \mathrm{C}_{3} \mathrm{H}_{6}} \zeta_{b}^{e q}\right)} \\
x_{g, \mathrm{H}_{2}, f}^{e q}=\frac{x_{g, \mathrm{H}_{2}}+x_{g, \mathrm{C}_{3} \mathrm{H}_{8}}^{e q} \zeta_{f}^{e q}}{\left(1+x_{g, \mathrm{C}_{3} \mathrm{H}_{8}} \zeta_{f}^{e q}\right)} & x_{g, \mathrm{H}_{2}, b}^{e q}=\frac{x_{g, \mathrm{H}_{2}}-x_{g, \mathrm{C}_{3} \mathrm{H}_{6}} \zeta_{b}^{e q}}{\left(1-x_{g, \mathrm{C}_{3} \mathrm{H}_{6}} \zeta_{b}^{e q}\right)}
\end{array}
$$

\section{Propylene hydrogenation}

$$
K_{p}=\exp \left(-\frac{\sum_{i=1}^{n} v_{i} g_{i}(T)}{R T}\right) \approx \exp \left(16.858-\frac{15934}{T}+\frac{148728}{T^{2}}\right) \mathrm{atm}
$$




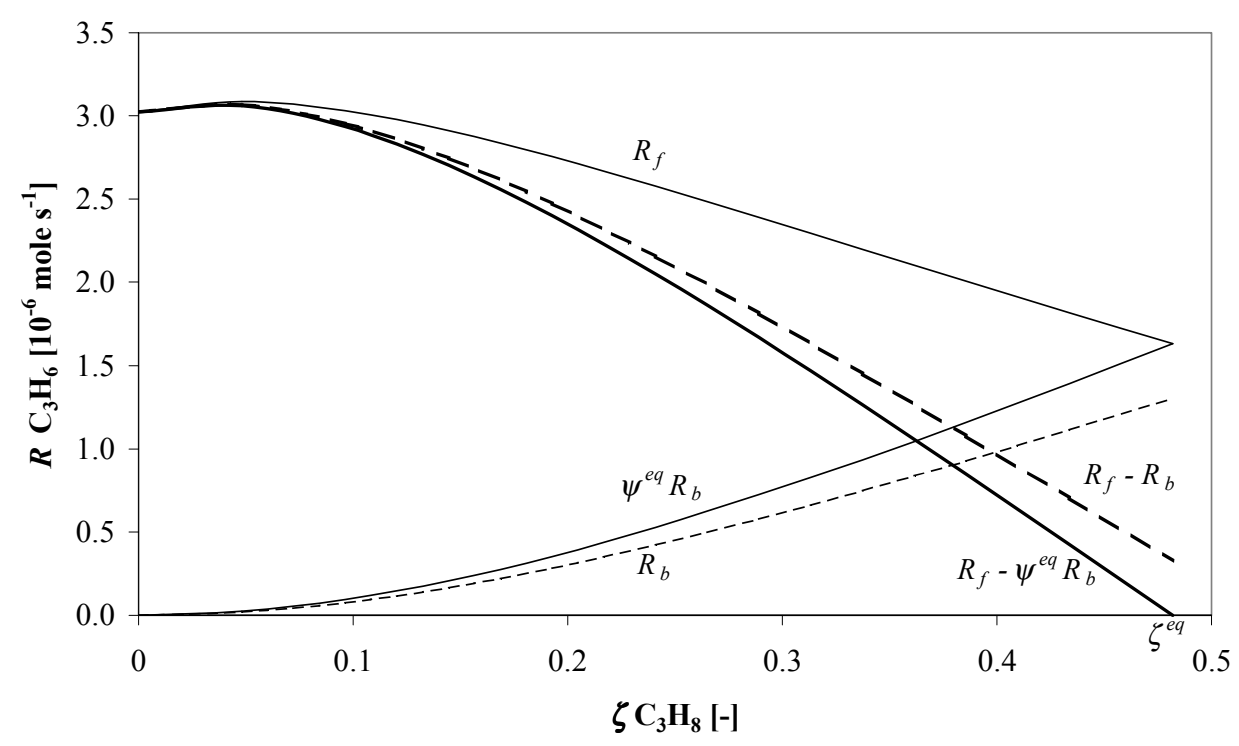

Figure 42. 'Thermodynamically' adjusted propylene production rate as a function of the propane conversion towards the equilibrium conversion starting with a pure propane feed at $600{ }^{\circ} \mathrm{C}$ and $1 \mathrm{~atm}$. The uncorrected forward reaction rate $\left(R_{f}\right)$, the uncorrected backward $\left(R_{b}\right)$ and overall reaction rates $\left(R_{f}-R_{b}\right)$ (both indicated with dashed lines) and the corrected backward $\left(\psi^{e q} R_{b}\right)$ and overall reaction rates $\left(R_{f}-\psi^{e q} R_{b}\right)$ (indicated with solid lines) are shown.

\section{Summary and conclusions}

To assess the potential of the Reaction Coupling Reverse Flow Reactor for the propane dehydrogenation, a quantitative predictive reaction rate expression is required for the propane dehydrogenation and propylene hydrogenation - and their side-reactions - valid over very wide concentration and temperature ranges. The reaction rate equations published in the literature are generally only valid for small temperature ranges and strong hydrogen dilution.

Propane dehydrogenation and propylene hydrogenation reaction rates were measured over a cordierite $\mathrm{Pt} / \gamma-\mathrm{Al}_{2} \mathrm{O}_{3}$ monolithic catalyst (1.1 wt\% $\mathrm{Pt}$ in the washcoat) in a differentially operated reactor. To better resemble the RCRFR reaction conditions the same catalyst sample was used for many experiments consisting of reduction, (de)hydrogenation and TPO. In the kinetic investigations published in literature generally each experiment is carried out over a fresh catalyst. However, by using the same catalyst sample the actually measured reaction rates can be corrected for the loss in catalytic activity because of sintering and of destruction of the most active sites or decrease in platinum dispersion via interpolation of the catalytic activity of standard experiments. During an experiment the propane dehydrogenation and 
propylene hydrogenation reaction rates also decrease as a function of time, which is attributed to the formation of carbonaceous deposits on the active sites. Although the extent of and the rate at which the catalytic activity decreases depends on the operating conditions prior to and during the experiments, the reaction rates reached a virtually asymptotic steady state value after about half an hour. For both the propane dehydrogenation and propylene hydrogenation these pseudo steady state reaction rates were determined for a wide variation of temperature and composition. The observed reaction rates and activation energies for the propane dehydrogenation correspond reasonably to values reported in the literature. From the selectivity data information about the kinetics of the most important gas phase side reactions was extracted. Only propane cracking, propane hydrogenolysis and propylene hydrogenolysis were considered as side reactions.

From the experiments it was concluded that the propane dehydrogenation and propane hydrogenolysis reaction rates consist of two contributions, one dominant at lower temperatures (below $600{ }^{\circ} \mathrm{C}$ ) and one dominant at higher temperatures (above $650{ }^{\circ} \mathrm{C}$ ). The low temperature contributions of the propane dehydrogenation and propane hydrogenolysis reaction rates, but also the propylene hydrogenation reaction rate show a remarkable additional reaction order in the hydrogen concentration, one higher than expected according to the reaction stoichiometry. On the other hand, propane cracking, propylene hydrogenolysis and the high temperature contributions of the propane dehydrogenation and propane hydrogenolysis have reaction orders corresponding to the reaction stoichiometry without additional influence of the hydrogen concentration.

These experimental observations were interpreted by assuming that the reactions can take place at two different surface sites: platinum surface sites and acid alumina surface sites. It is assumed that the propane dehydrogenation, propylene hydrogenation and propane hydrogenolysis reactions can take place at both sites, while propane cracking and propylene hydrogenolysis occur only at the acid surface sites. The reaction orders for the reactions taking place at the acid surface sites correspond to the reaction stoichiometry, but the reactions taking place at the platinum surface sites show a supplementary second order in the surface fraction of dissociatively chemisorbed hydrogen, additional to the reaction stoichiometry. The observed influences of composition and temperature on the propane dehydrogenation, propylene hydrogenation, propane cracking and propane and propylene hydrogenolysis pseudo-steady state reaction rates could be well described with rate equations 
based on the above assumption (see Tables 4 and 5). It has been shown that the additional order in the gas phase hydrogen concentration for all the reactions taking place at the platinum surface sites can be explained by the influence of hydrogen on the number of free surface sites not covered with carbonaceous products.

Finally, it has been shown that the derived kinetic rate expression for the propane dehydrogenation and propylene hydrogenation overestimate the equilibrium conversion as calculated by thermodynamics. The rate expression has been based on experiments for mixtures with a composition largely deviating from the equilibrium composition. Furthermore, no knowledge of the thermodynamic equilibrium has been included in the rate expression. A palliative has been proposed to overcome the discrepancies between equilibrium conversions calculated by thermodynamics and the derived kinetic rate expression. Obviously, the kinetic investigation should be continued by carrying out experiments for propane, propylene, hydrogen and nitrogen mixtures with a composition closer to the equilibrium conversion. Moreover, if by extensive additional kinetic research (a.o. transient kinetic investigations) more knowledge about the propane dehydrogenation / propylene hydrogenation reaction mechanism can be obtained, a better rate equation might be formulated making the thermodynamic adjustment unnecessary. However, the derived rate expressions for the propane dehydrogenation / propylene hydrogenation equilibrium reaction and their most important side reactions provide valuable information for the optimisation of the process conditions - especially the temperature and hydrogen concentration - in propane dehydrogenation reactors, and for the design, development and optimisation of the RCRFR in particular.

\section{Acknowledgements}

The author wishes to thank W. Vos and R.G.S. de Boer for their valuable contribution to the experimental work and H.J. Moed for the construction and maintenance of the kinetics reactor and the experimental set-up. Also the help by B.G.J. Kamp for the GC-analysis section is greatly appreciated. Furthermore, the financial support by the Netherlands Organization for Scientific Research (N.W.O.) is gratefully acknowledged. 


\section{Notation}

A,B,C constants for calculation of equilibrium composition

$C_{g} \quad$ gas phase concentration $\left[\mathrm{mole} \cdot \mathrm{m}^{-3}\right.$ ]

$E \quad$ activation energy $\left[\mathrm{kJ} \cdot \mathrm{mole}^{-1}\right]$

$\Delta H_{r} \quad$ reaction enthalpy $\left[\mathrm{kJ} \cdot \mathrm{mole}^{-1}\right]$

$\Delta G_{r} \quad$ reaction Gibbs free enthalpy $\left[\mathrm{kJ} \cdot \mathrm{mole}^{-1}\right]$

$k \quad$ reaction rate constant

$K \quad$ adsorption constant

$K_{p} \quad$ thermodynamic equilibrium constant [atm]

$p_{i} \quad$ partial pressure of component $i[\mathrm{~Pa}]$

$r^{2} \quad$ linear regression coefficient [-]

$R \quad$ gas constant $(=8.314)\left[\mathrm{J} \cdot \mathrm{mole}^{-1} \cdot \mathrm{K}^{-1}\right]$

$R_{i} \quad$ reaction rate of component $i\left[\right.$ mole $\left.\cdot \mathrm{s}^{-1}\right]$ or $\left[\right.$ mole $\left.\cdot \mathrm{m}^{-2} \cdot \mathrm{s}^{-1}\right]$

$t$ time [s]

$T$ temperature $[\mathrm{K}]$ or $\left[{ }^{\circ} \mathrm{C}\right]$

$x_{g} \quad$ gas phase molar fraction $\left[\right.$ mole $\left.\cdot \mathrm{mole}^{-1}\right]$

Greek symbols

$\zeta \quad$ conversion [-]

$\theta_{i} \quad$ surface fraction of component $i[-]$

$\theta_{i r r} \quad$ surface fraction of irreversible type coke [-]

$\theta_{\text {rev }} \quad$ surface fraction of reversible type coke [-]

$\psi^{e q} \quad$ correction factor to include thermodynamic equilibrium [-]

\section{Subscripts}

$\begin{array}{ll}\text { act } & \text { activation } \\ \text { ads } & \text { adsorbed } \\ \text { app } & \text { apparent } \\ b & \text { backward (i.e. proylene hydrogenation) } \\ f & \text { forward (i.e. propane dehydrogenation) } \\ g & \text { gas phase } \\ \text { in } & \text { inlet }\end{array}$




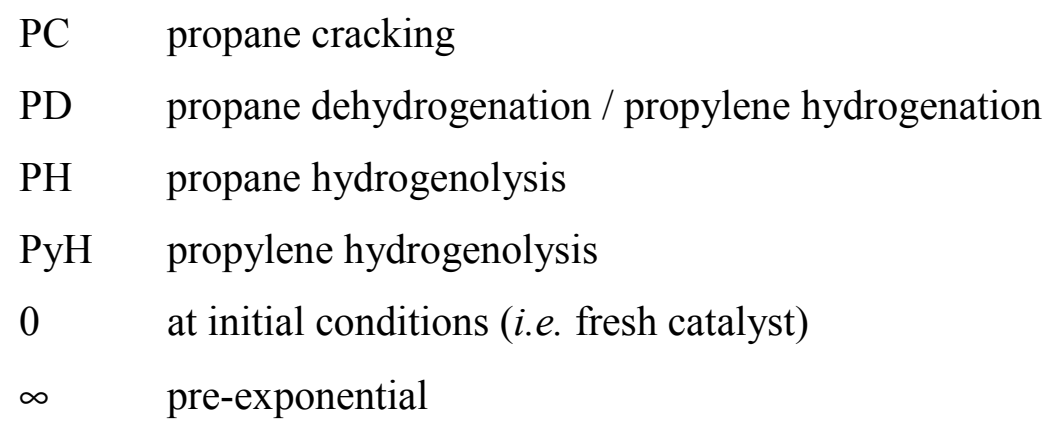

\section{Superscripts}

eq at thermodynamic equilibrium

exp experimentally determined

$s \quad$ adsorbed at the support (i.e. $\gamma-\mathrm{Al}_{2} \mathrm{O}_{3}$ washcoat)

\section{References}

Atkins, P.W. (1990). Physical Chemistry. Fourth Edition, Oxford University Press, Oxford, 219

Babenkova, L.V., Szabó, S., Naidina, I.N. and Kulievskaya, Yu. G. (1994). Correlation between hydrogen chemisorption, state of metals, and the activity of Pt/Al2O3 and Pt-SnA12O3 catalysis in propane dehydrogenation, Models in chemistry: an international forum for all aspects of chemistry-related models and modelling, ISSN 1217-8969, 131(1), 113

Bariås, O.A. (1993). Transient kinetic investigation of the catalytic dehydrogenation of propane. Ph.D. Thesis, Department of Industrial Chemistry, Norwegian Institute of Technology, University of Trondheim, Norway.

Bariås, O.A., Holmen, A. and Blekkan, E.A. (1994). Propane dehydrogenation over supported platinum catalysts: the influence of tin on the coking properties. Stud. Surf. Sci. Catal., 88, $519-524$.

Bariås, O.A., Holmen, A. and Blekkan, E.A. (1995). Propane dehydrogenation over supported platinum catalysts: effect of tin as a promotor. Catalysis Today, 24, 361-364 
Bariås, O.A., Holmen, A. and Blekkan, E.A. (1996). Propane dehydrogenation over supported $\mathrm{Pt}$ and Pt-Sn catalysts: catalyst preparation, characterization, and activity measurements, $J$. Catal., 158, 1-12

Biloen, P., Dautzenberg, F.M. and Sachtler, W.M.H. (1977). Catalytic dehydrogenation of propane to propene over platinum and platinum-gold alloys. J.Catal., 50, 77-86

Brito, A., Arvelo, R., Villarroel, R., Garcia, F.J. and Garcia, M.T. (1996). Coke and H/C ratio profiles on a $\mathrm{Cr}_{2} \mathrm{O}_{3} / \mathrm{Al}_{2} \mathrm{O}_{3}$ catalyst during the butene-1 dehydrogenation reaction. Chem. Eng. Sci., 51, 4385-4391.

Cybulski, A. and Moulijn, J.A. (1994). Monoliths in heterogeneous catalysis. Catal. Rev.Sci.Eng., 36, 179-270.

Gorriz, O.F., Cadus, L.E. and Rivarola, J.B. (1989). Catalytic dehydrogenation of propane: deactivation by coke formation. Latin American Applied Research, 19, 31-40

Larsson, M. and Andersson, B. (1994). The use of the H2-D2 equilibration reaction as a probe reaction to study the deactivation on $\mathrm{Pt}-\mathrm{A} 12 \mathrm{O} 3$ and $\mathrm{Pt}-\mathrm{Sn}-\mathrm{A} 12 \mathrm{O} 3$ catalysts during propane dehydrogenation. Catal. Deact., 88, 233-241

Larsson, M., Hultén, M., Blekkan, E.A. and Andersson, B. (1996). The effect of reaction conditions and time on stream on the coke formed during propane dehydrogenation, J. Catal., $164,44-53$

Larsson, M. (1997). Coke on supported palladium and platinum catalysts. Ph.D. Thesis. Department of Chemical Reaction Engineering, Chalmers University of Technology, Göteborg, Sweden.

Loc, L.C., Gaidai, N.A., Gudkov, B.S., Kiperman, S.L. and Kogan, S.B. (1986). Investigation of the kinetics and mechanism of the dehydrogenation of isobutane on platinum-tin catalysts. Kinet. Catal., 27, 1184-1189 
Loc, L.C., Gaidai, N.A. and Kiperman, S.L. (1988). Promotion effects in platinum-alumina catalysts for isobutane dehydrogenation. Proc. $9^{\text {th }}$ Intern. Congress on Catalysis, Calgary, Vol. 3, 1262-1267

Loc, L.C., Gaidai, N.A., Kiperman, S.L. and Kogan, S.B. (1990). Kinetics of dehydrogenation of n-butane on platinum catalysts. Kinet. Catal., 31, 421-424

Loc, L.C., Gaidai, N.A., Kiperman, S.L. and T'huoang, H.S., Podkletnova, N.M. and Kogan, S.B. (1991a). Kinetics of propane dehydrogenation on aluminoplatinum catalysts. Kinet. Catal., 34, 61-64

Loc, L.C., Gaidai, N.A., Kiperman, S.L., T’huoang, H.S. and Kogan, S.B. (1991b). Kinetics and mechanism of propylene hydrogenation on platinum catalysts, Kinet. Catal., 32, 12561261

Loc, L.C., Gaidai, N.A., Kiperman, S.L. and Thoang, H.S. (1993a). Kinetics of the dehydrogenation of n-butane and its mixtures with propane over platinum catalysts. Kinet. Catal., 34, 505-509

Loc, L.C. and Thoang, H.S. (1993b). Kinetic effects in conversion of propane, isobutane and propane-isobutane mixtures on K-Pt-gamma-A12O3 catalysts, modified by $\mathrm{Sn}$ and In, New frontiers in catalysis, 2277-2279

Loc, L.C., Gaidai, N.A., Kiperman, S.L. and Thoang, H.S., Podkletnova, N.M., Kogan, S.B. and Georgievskii, V.Yu. (1993c). Kinetics of dehydrogenation of isobutane and isobutanepropane mixtures on platinum catalysts. Kinet. Catal., 34, 604-607

Loc, L.C., Gaidai, N.A., Kiperman, S.L., Thoang, H.S., Podkletnova, N.M. and Gerogievskii, V.Yu. (1995). Kinetics of isobutane dehydrogenation over platinum-alumina catalysts in the presence of water vapour. Kinet. Catal., 36, 517-523

Loc, L.C., Gaidai, N.A., Kiperman, S.L. and Thoang, H.S. (1996). Kinetics of propane and n-butane dehydrogenation over platinum-alumina catalysts in the presence of hydrogen and water vapour. Kinet. Catal., 37, 790-796 
Resasco, D.E. and Haller, G.L. (1994). Catalytic dehydrogenation of lower alkanes. J. Catal., $11,379-411$

Somorjai, G.A. (1977). Active sites in heterogeneous catalysis. Advances in Catalysis, Vol. 26, Eds. Eley, D.D., Pines, H. and Weisz, P.B., Academic Press, New York, 1-68

Suzuki, I. and Kaneko, Y. (1977). Dehydrogenation of propane over chromia-aluminapotassiumoxide catalyst, J. Catal., 47, 239-248

Webb, G. and Matheson, I.M. (1994). An isotope labeling study of the deactivation of a Pt alumina catalyst used for propane dehydrogenation, Catal. Deact., 88, 297-304 
CHAPTER 5

REACTION KINETICS OF COKE FORMATION DURING PROPANE DEHYDROGENATION

OVER A MONOLITHIC PLATINUM ALUMINA CATALYST 


\begin{abstract}
Coke formation rates under propane dehydrogenation reaction conditions on a used monolithic $\mathrm{Pt} / \gamma-\mathrm{Al}_{2} \mathrm{O}_{3}$ catalyst have been experimentally determined in a thermogravimetric analyser (TGA) as a function of time on stream covering wide temperature and concentration ranges. For relatively short times on stream, especially at low temperatures and low propylene concentrations, a remarkable initial quadratic increase has been observed in the coke formation content versus time with a high apparent propylene reaction order. After longer times on stream the coke formation rate decreases to a constant residual coke growth above approximately $12 \mathrm{wt} \%$ coke content. The experimental data have been successfully described by a kinetic rate expression based on a mechanistic dual coke growth model. In this model it has been assumed that initially coke precursor is formed via a propylene oligomerisation process, explaining the observed auto-catalysis for short times on stream.
\end{abstract}




\section{Introduction}

The strong increase in the demand for lower olefins during the last decade (Taffe, 1996; Cosyns et al., 1998) has initiated the development of new alternative processes in addition to traditional petrochemical or refinery processes, where lower olefins are obtained as byproducts. The increased availability of lower alkanes resulting from more strict environmental legislation has made especially catalytic dehydrogenation processes economically attractive (Resasco and Haller, 1994). Dehydrogenation reactions of lower alkanes are highly endothermic and are carried out at high temperatures because of thermodynamic constraints. At these high temperatures carbonaceous deposits, collectively termed coke, are rapidly formed and as a consequence thereof catalyst deactivation prevails necessitating catalyst regeneration. These difficult process features require dedicated reactor technology.

A novel multifunctional reactor is developed for the non-oxidative propane dehydrogenation. Using a fixed monolithic catalyst as an energy repository, an indirect coupling is achieved between energy necessary for the endothermic propane dehydrogenation and energy released by the combustion with air of the formed coke and added hydrocarbons for overall thermal balance. During the endothermic propane dehydrogenation energy is withdrawn from the catalyst cooling down the catalyst. Simultaneously coke is deposited on the catalyst surface. During a consecutive exothermic fuel combustion reaction phase the catalyst is reheated and concurrently regenerated by burning off the coke. Secondly, recuperative heat exchange is integrated inside the reactor using the concept of reverse flow, i.e. periodic change of the gas flow direction while feeding the reactants without any preheating. In this 'Reaction Coupling Reverse Flow Reactor' (RCRFR), the propane dehydrogenation reaction, energy supply at high temperatures, catalyst regeneration and recuperative heat exchange are all integrated in one apparatus.

The optimal operating conditions in the RCRFR, e.g. the optimal temperature (profile), inlet composition, gas residence time and cycle times for reaction phase and flow direction switching, strongly depend on the amount of coke deposited during the dehydrogenation step of the overall process. In the literature strong effects of time-on-stream (auto-deactivation), temperature and composition (particularly the hydrogen concentration) on the coke formation rates during dehydrogenation reactions have been reported. Due to the large temperature and concentration gradients in a reverse flow reactor, continuously moving back and forth, 
information on the time-dependent rate of coke formation as a function of temperature and composition is indispensable for operation and optimisation of the RCRFR.

Catalyst deactivation during propane dehydrogenation over platinum alumina catalysts has received considerable attention in the past few years (e.g. Peña et al., 1993; Larsson et al., 1996; Bariås et al., 1996). However, the research has mainly focussed on the effect of tin addition to platinum catalysts, especially on the extent of reduction of intrinsic catalytic activity caused by the coke deposits. From temperature programmed oxidation studies (TPO) of coked Pt-Sn/ $\mathrm{Al}_{2} \mathrm{O}_{3}$ during propane dehydrogenation Larsson et al. (1996) concluded that there are three different types of coke: coke on and in the vicinity of the metal, coke on the carrier and graphitic coke on the carrier. Only a small part of the first two types of coke seems to be responsible for the observed strong decrease in catalytic activity. They correlated the decrease in intrinsic catalytic dehydrogenation activity to only a small part of the first two types of coke, in contrast to the total amount of all types of carbonaceous products produced, as before (Dumez and Froment, 1976). Also Peña et al. (1993) correlated the decrease in catalytic activity to only part of the total amount of coke. In this work, however, the focus is on the determination of the total amount of coke deposited on the catalyst surface as a function of time at given operating conditions. Although the effects of operating conditions have been identified qualitatively, no complete quantitatively predictive time-dependent coke formation rate equation has been published, to the authors' knowledge, for the propane dehydrogenation over platinum alumina catalysts as a function of temperature and composition over wide concentration and temperature ranges.

For the 1-butene dehydrogenation to 1,3-butadiene over a $\mathrm{Cr}_{2} \mathrm{O}_{3}-\mathrm{Al}_{2} \mathrm{O}_{3}$ catalyst, however, extensive models have been developed describing the time-dependent coke formation rate as a function of the operating conditions. Marin et al. (1986) extended the models by Beeckman and Froment $(1979,1980)$ describing the coke formation rates measured by Dumez and Froment (1976), assuming that the coke formation follows two stages. In a first stage sites are covered by coke precursor, originating from both 1-butene and 1,3-butadiene, which is accompanied by an instantaneous growth up to an intermediate size. The second stage corresponds to a further growth of the coke at a finite rate. In their model blockage of the smallest pores by coke deposits is taken into account, causing some $15 \%$ reduction of available catalyst surface area. However, they concluded that the pore blockage of the smallest pores occurs within a few seconds, so that only a negligible amount of coke is 
deposited in these pores. Peña et al. (1993) fitted the coking rates during 1-butene dehydrogenation on a $\mathrm{Cr}_{2} \mathrm{O}_{3} / \mathrm{Al}_{2} \mathrm{O}_{3}$ catalyst using the monolayer-multilayer coke growth model (MMCGM) (Nam and Kittrell, 1984), which considers simultaneous coke deposition directly on the catalyst surface (monolayer coke) and on coke previously deposited (multilayer coke). In the MMCGM the internal structure of the catalyst is left out of consideration, neglecting pore blocking.

The aim of this work is to derive a kinetic rate expression to qualitatively and quantitatively describe the total amount of coke deposits in time on a used platinum alumina monolithic catalyst during propane dehydrogenation reaction conditions using a differentially operated thermogravimetric unit. The rate equation is based on a mechanistic model adopted from Peña et al. (1993), extended with considerations put forward in the model proposed by Marin et al. (1986) and furthermore adjusted using experimental observations.

\section{Experimental}

\subsection{Experimental set-up}

Experiments were carried out in a thermogravimetric analyser (TGA) operated under differential isothermal reactor conditions at atmospheric pressure (see Figure 1). In a quartz tubular reactor (inner diameter $15 \mathrm{~mm}$ ) a small sample (ca. $6 \times 6 \times 3 \mathrm{~mm}$, approximately $80 \mathrm{mg}$ ) of a commercial $\mathrm{Pt} / \gamma-\mathrm{Al}_{2} \mathrm{O}_{3}$ monolithic cordierite catalyst, supplied by Engelhard, was connected with a platinum wire connected to the balance. Using SEM analysis the average channel diameter was determined at $956 \mu \mathrm{m}$, the support thickness at $189 \mu \mathrm{m}$ and the average washcoat thickness at $37 \mu \mathrm{m}(11-89 \mu \mathrm{m})$. In the washcoat $1.5 \mathrm{~g} \mathrm{Pt} / 1$ monolith was dispersed. The temperature was measured just below the catalyst sample. The tubular reactor was enwrapped with resistance wire and covered with insulation material allowing temperature control.

The electronic balance was continuously purged with a nitrogen flow ( $\left.c a .1 \mathrm{Ncm}^{3} / \mathrm{s}\right)$ to avoid coke depositions on the balance. It was checked that the nitrogen purge flow rate had no influence on the experimental results and that negligible coke formation occurred on the platinum wire. 


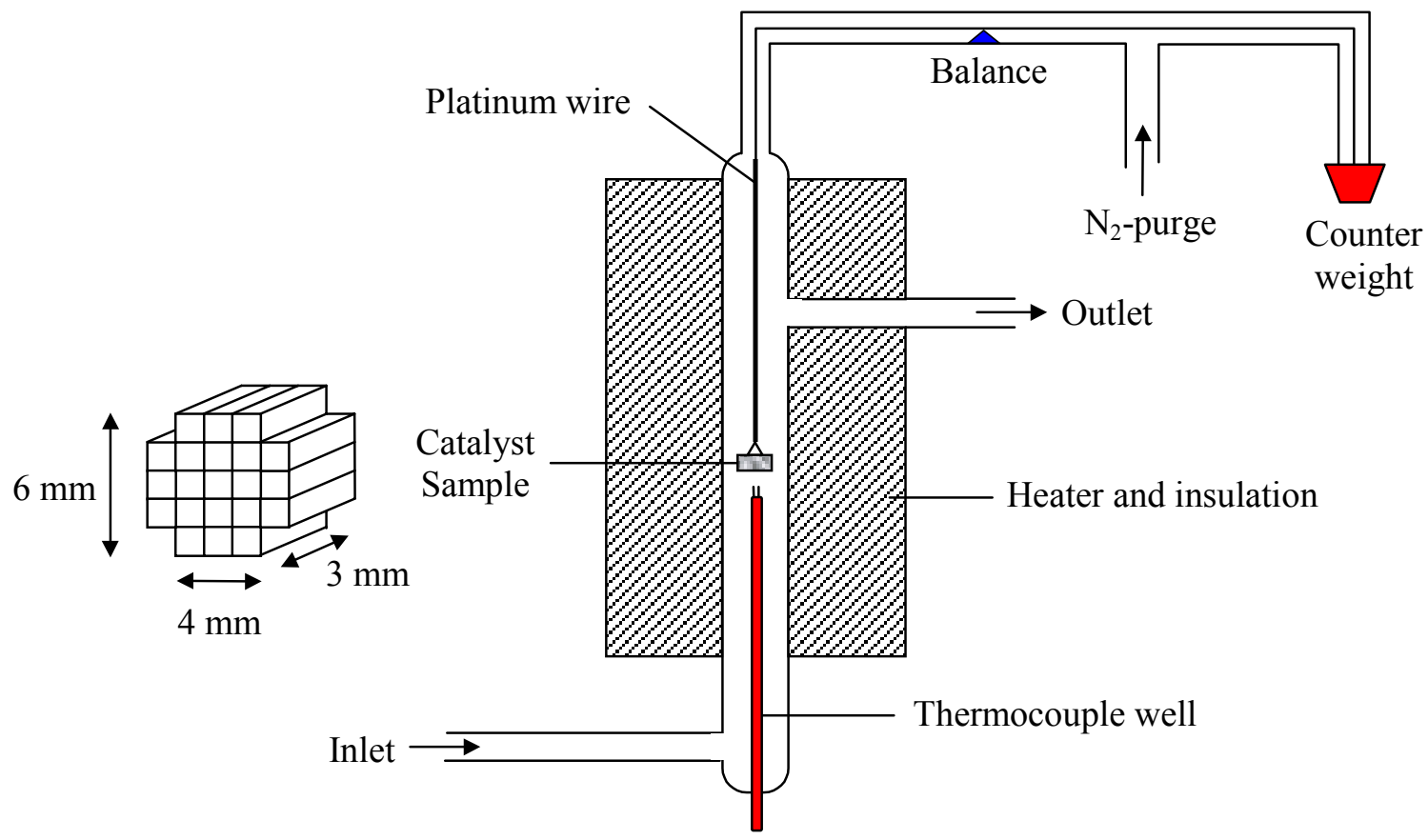

Figure 1. Schematic representation of the TGA experimental set-up.

In each experiment the catalyst sample was heated to the desired reaction temperature $\left(600-800^{\circ} \mathrm{C}\right)$ under a nitrogen flow. Using a four-way valve a propylene-hydrogen-nitrogen gas mixture was introduced, whose composition and total flow rate $\left(1-10 \mathrm{Ncm}^{3} / \mathrm{s}\right)$ was set using mass flow controllers (Brooks). The sample weight was collected automatically by a personal computer. GC analysis of the exit gases confirmed insignificant conversion of the reactants. After a certain time on stream the four-way valve was switched back to purge the reactor and subsequently air was introduced to regenerate the catalyst sample by combusting the coke deposits. By these repeated alternations between dehydrogenation and combustion reaction conditions coke formation rates were determined on the monolithic sample under reaction conditions analogous to those in a RCRFR. Furthermore, use of the same catalyst sample enables direct comparison of different experiments. Figure 2 demonstrates the good reproducibility of the experiments except for an experiment employing a fresh sample. This is probably caused by sintering or permanent destruction of the most active sites or pores by coke deposits during the first experiment on a fresh sample, confirmed by the decrease in BET area (35 to $16 \mathrm{~m}^{2} / \mathrm{g}$ monolith) and increase in average pore diameter (11.2 to $16.7 \mathrm{~nm}$ ). The figure confirms absence of further deactivation for coke formation after only a few experiments. 


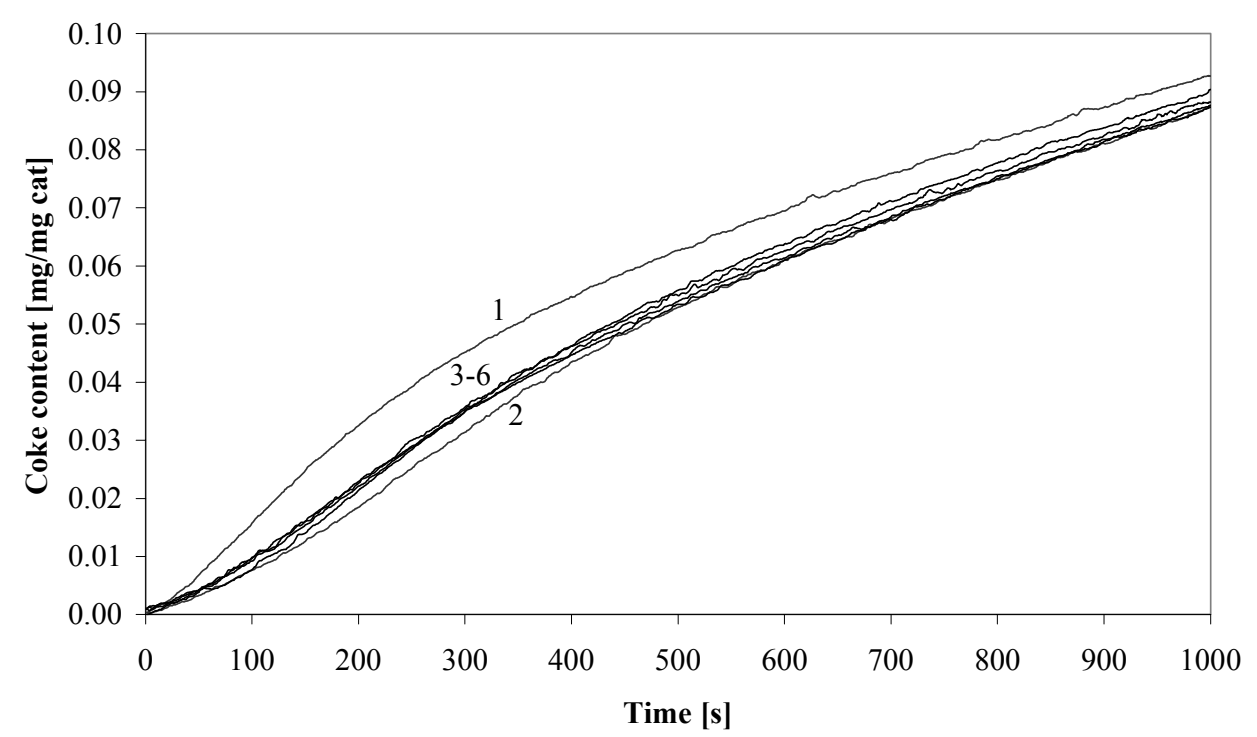

Figure 2. Coke content versus time on the same monolithic sample with platinum dispersed in the washcoat under a pure propylene atmosphere at $650{ }^{\circ} \mathrm{C}$ for six consecutive experiments (starting with a fresh sample), indicating absence of further catalyst deactivation for coking after a few experiments.

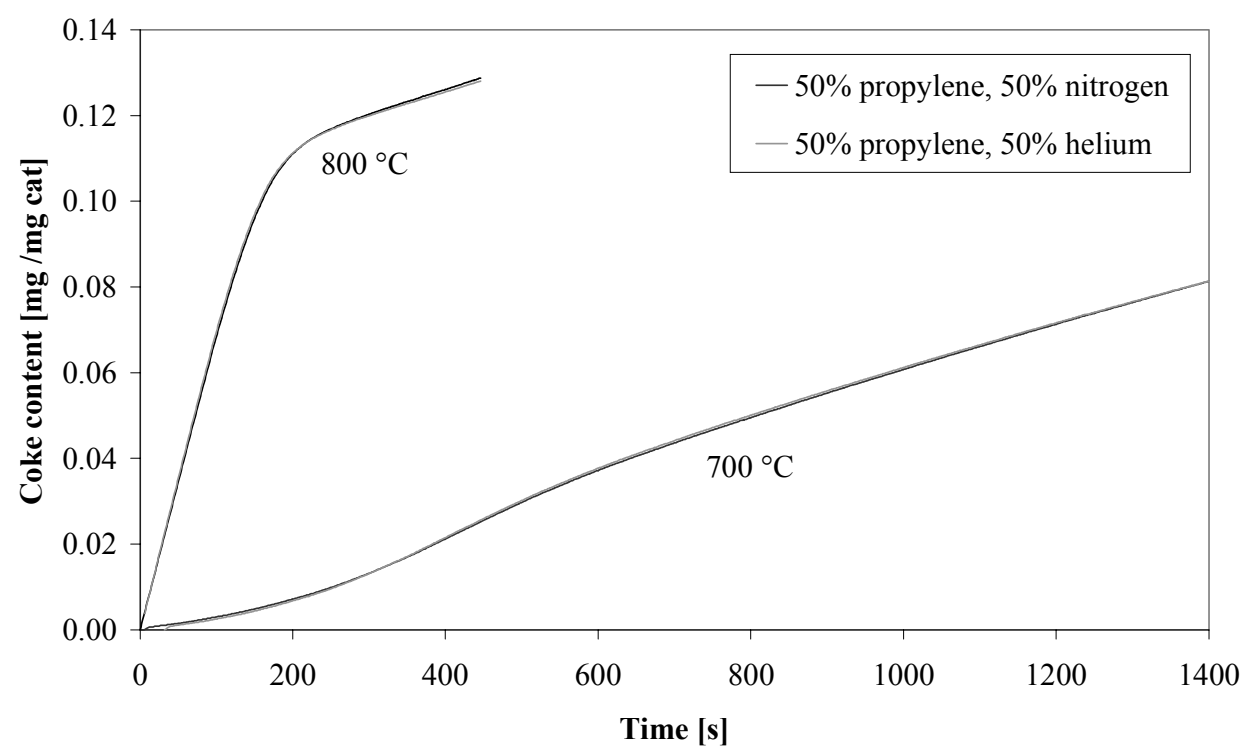

Figure 3. Comparison of coke formation rates for a $50 \%$ propylene $-50 \%$ nitrogen gas mixture and a $50 \%$ propylene $-50 \%$ helium gas mixture at 700 and $800{ }^{\circ} \mathrm{C}$, showing the absence of any mass transfer limitations.

Absence of mass transfer limitations was verified by comparing coke formation rates on the same used monolithic sample for propylene-nitrogen and propylene-helium gas mixtures with equal propylene concentration at high temperatures. Since both internal and external mass transfer strongly depend on the diffusion coefficient and the propylene-helium diffusion 
coefficient is approximately three times as large the propylene-nitrogen diffusion coefficient, according to Fuller's equation (Reid et al., 1988), mass transfer limitations could safely be excluded, since nearly identical coking rates were obtained for propylene-nitrogen and propylene-helium gas mixtures (see Figure 3).

\subsection{Experimental results}

Firstly, it has been investigated whether coke deposits during propane dehydrogenation originate from propylene only, or also from propane. In Figure 4 coke formation rates are compared for pure propylene and propane gas feeds at $650{ }^{\circ} \mathrm{C}$ on two different monolith samples, one with and one without platinum dispersed in the washcoat. The figure clearly shows the much higher coke formation rates under propylene atmosphere compared to propane atmosphere. Comparable coke formation rates are obtained under pure propylene atmosphere on both monolith samples, suggesting that most of the carbonaceous products is formed on acid sites of the $\gamma-\mathrm{Al}_{2} \mathrm{O}_{3}$ washcoat. Only for short times on stream possibly a contribution of coke initially formed at the metal surface sites and subsequently migrated to the support (e.g. Bariås et al., 1996) can be observed in the somewhat higher coke formation rates under pure propylene atmosphere on the sample with platinum dispersed in the washcoat compared to the sample without platinum. This corresponds to the findings of Barbier et al.

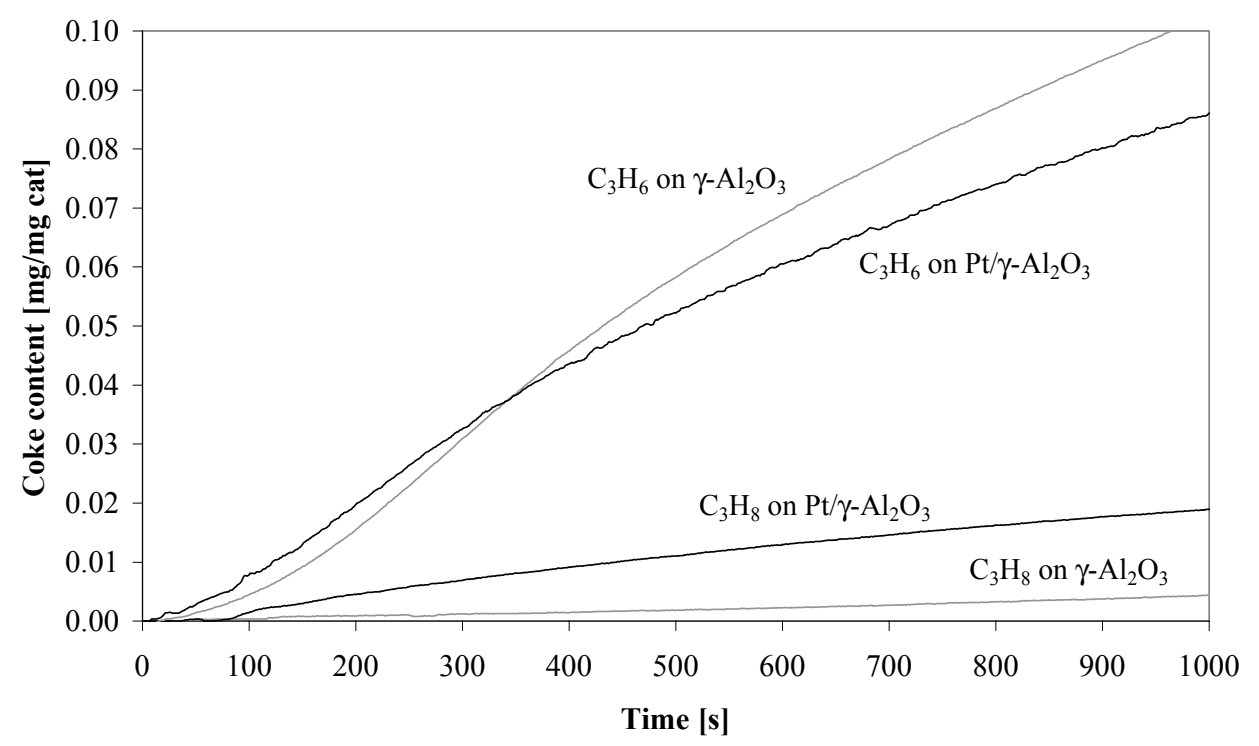

Figure 4. Comparison of coke formation rates for pure propane or propylene on monolithic samples with and without platinum dispersed in the washcoat at $650^{\circ} \mathrm{C}$. 
(1985), who found that in the first few minutes the platinum sites are covered with an amount of coke which remains constant, while the support accumulates high levels of carbonaceous deposits. The somewhat higher coke formation rate for pure propylene on the sample without platinum dispersed in the washcoat for longer times on stream is attributed to a somewhat larger specific surface area of this catalyst sample (different fabrication batch). The coke formation rates under propane atmosphere show an opposite trend. The coke formation rate under pure propane on the sample with platinum is larger than on the sample without platinum, which is probably caused by a small conversion of propane to propylene at the platinum surface sites.

Coke formation rates have been determined for different propylene-nitrogen and propylenehydrogen gas mixtures at different temperatures on monolithic samples with platinum dispersed in the washcoat. Some illustrative experimental results of the complex coke formation process are shown in Figures 5-10 and are shortly described below. It is noted here that larger experimental errors in the coke formation rates have been observed for very short times on stream, especially at high propylene concentrations.

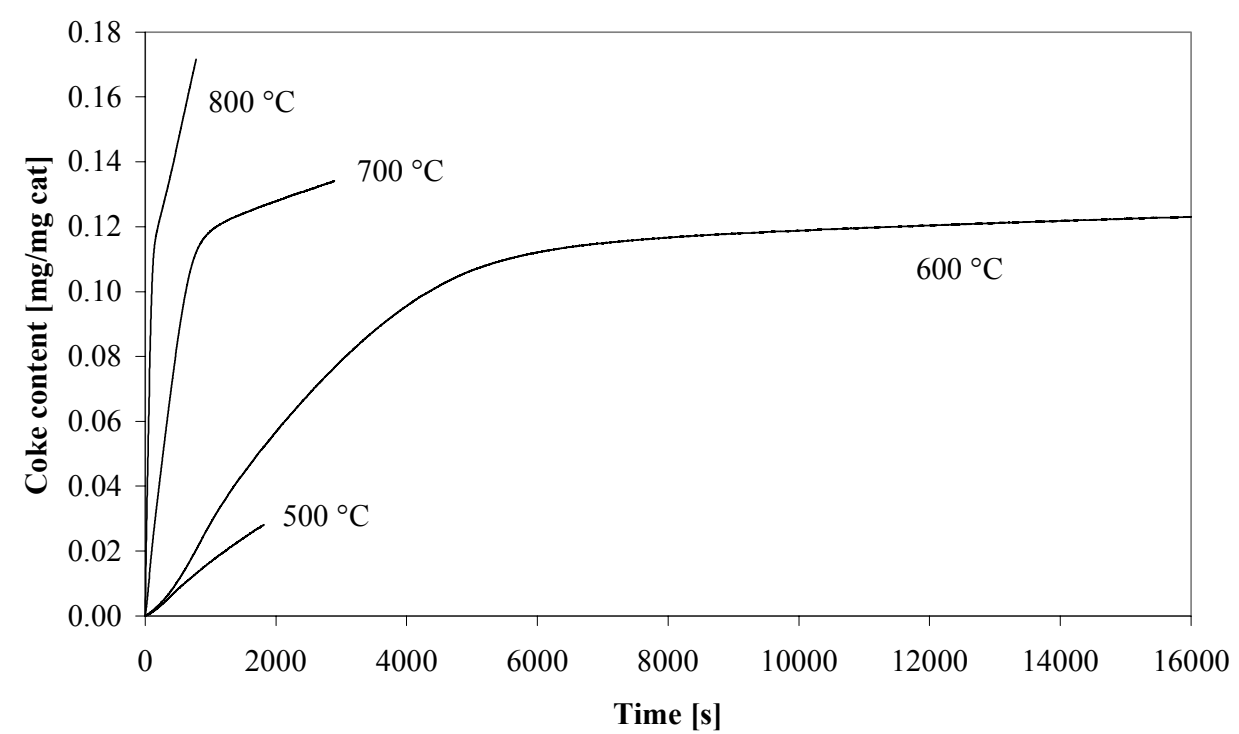

Figure 5. Coke content versus time for pure propylene feeds at different reactor temperatures.

The change of coke content in time on the monolithic sample under pure propylene atmosphere for different temperatures ranging between $500-800{ }^{\circ} \mathrm{C}$ is represented in Figure 5, showing a very strong influence of the reaction temperature. Clearly visible is the marked 
abrupt decrease in the coking rates when the coke content reaches about $12 \mathrm{wt} \%$ of the total weight of the monolithic sample, independent of the reaction temperature. Apparently, the coke formation reaction retards itself when the catalyst surface becomes coked after longer times on stream, but a residual coking activity remains. This has also been observed by Dumez and Froment (1976) and Peña et al. (1993) in their studies on coke formation rates from 1-butene over a $\mathrm{Cr}_{2} \mathrm{O}_{3} / \gamma-\mathrm{Al}_{2} \mathrm{O}_{3}$ catalyst, however, with a more gradual transition when the coke concentration reached about $5 \mathrm{wt} \%$. The coke concentration at which the coking rate changes markedly depends on the internal texture of the catalyst. For relatively long times on stream the coke formation rate has become constant (coke content increases linearly with time) and first order in the propylene gas phase concentration, as shown in Figure 6. The hydrogen concentration did not influence the residual coking activity, as also observed by Peña et al.

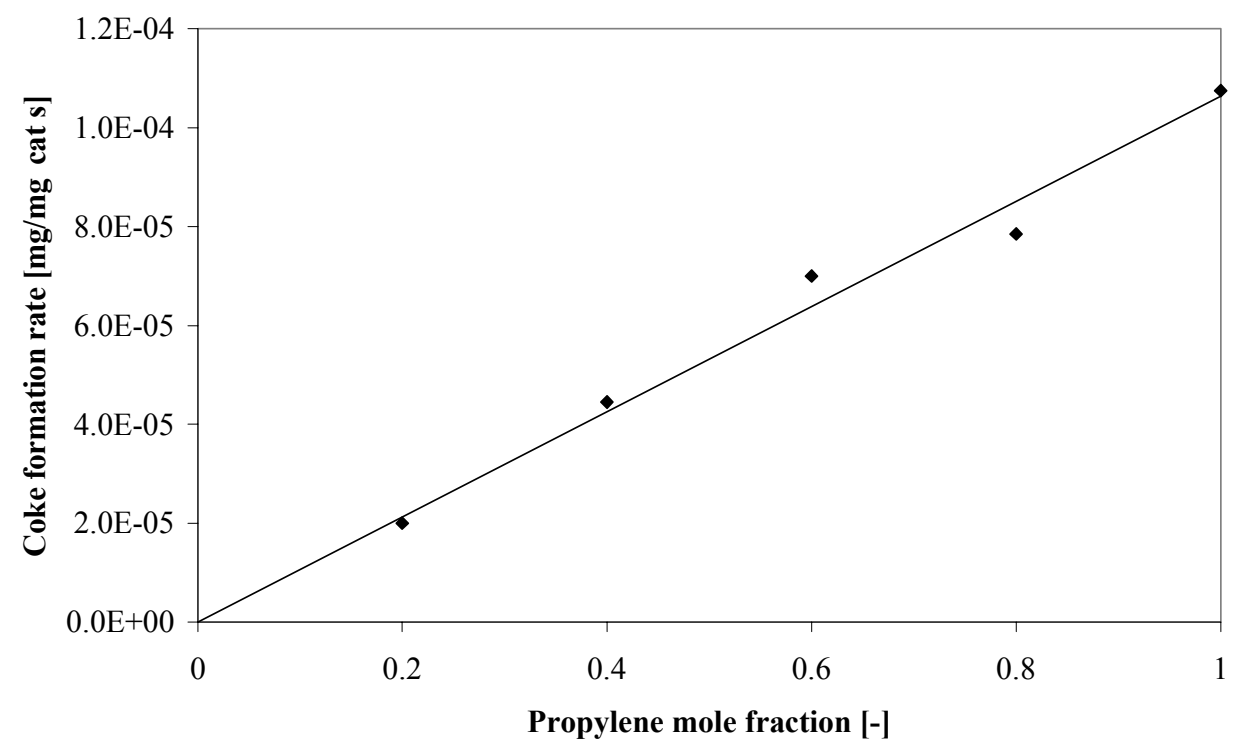

Figure 6. Coke formation rates at relatively long times on stream (multilayer coke growth) as a function of the propylene gas phase mole fraction at $800{ }^{\circ} \mathrm{C}$.

In Figure 7 the influence of the propylene concentration in propylene-nitrogen and propylenehydrogen gas mixtures on the coke formation rates at $600{ }^{\circ} \mathrm{C}$ is shown. A remarkable increase in the coke formation rates in time can be observed from the increasing slope of the coke content versus time curve, for both propylene-nitrogen and propylene-hydrogen gas mixtures and especially at lower propylene concentrations. The coke content initially increases quadratically versus time (see the excellent linear regression fit in Figure 8). 

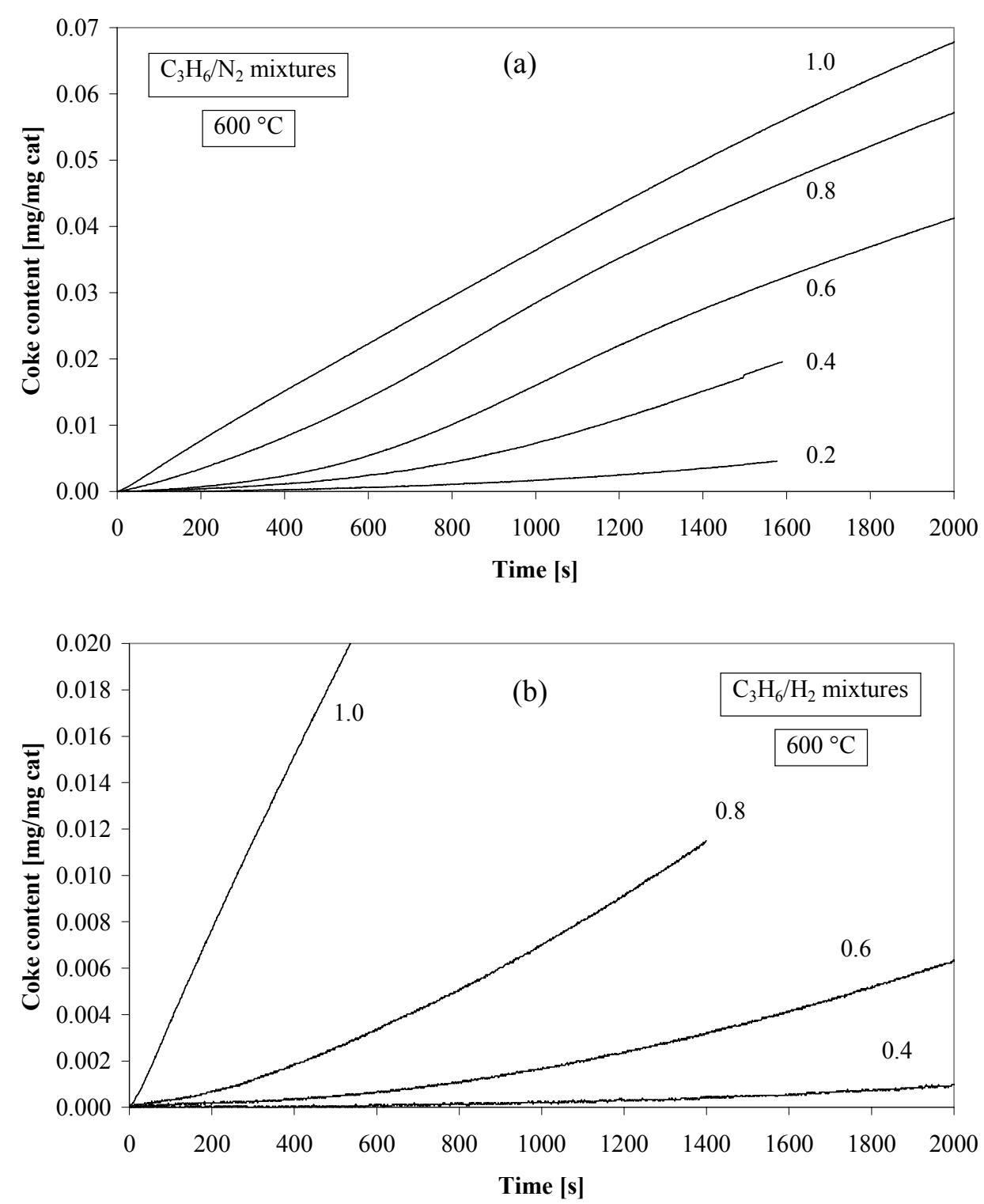

Figure 7. Coke content in time for propylene-nitrogen (a) and propylene-hydrogen (b) gas mixtures at $600{ }^{\circ} \mathrm{C}$ for different propylene gas phase mole fractions.

The increase in the coking rates evidently suggests auto-catalysis of the coke formation process at relatively short times on stream. Auto-deactivation occurs after longer times on stream, when the catalyst surface becomes covered by carbonaceous products.

The apparent reaction order of the coking process with respect to the propylene concentration is strikingly high, especially for propylene-hydrogen gas mixtures at relatively short times on stream at lower temperatures. However, the apparent reaction order in the propylene concentration decreases for longer times on stream or with increasing temperature, which corresponds to a higher coking extent of the catalyst surface, which can be discerned from 
Figure 9. For propylene-hydrogen mixtures the apparent reaction order in the propylene concentration decreases from as high as 6 at $500 \mathrm{~s}$ at $600{ }^{\circ} \mathrm{C}$, to 4 at $100 \mathrm{~s}$ at $700{ }^{\circ} \mathrm{C}$, to 1 at $500 \mathrm{~s}$ at $700{ }^{\circ} \mathrm{C}$ or $50 \mathrm{~s}$ at $800{ }^{\circ} \mathrm{C}$. Lower apparent reaction orders were found for for propylene-nitrogen mixtures, decreasing from 2 at $500 \mathrm{~s}$ at $600{ }^{\circ} \mathrm{C}$, to 1 at $50 \mathrm{~s}$ and 0.7 at 100 s at $600{ }^{\circ} \mathrm{C}$, to 0.6 at $50 \mathrm{~s}$ at $800^{\circ} \mathrm{C}$.

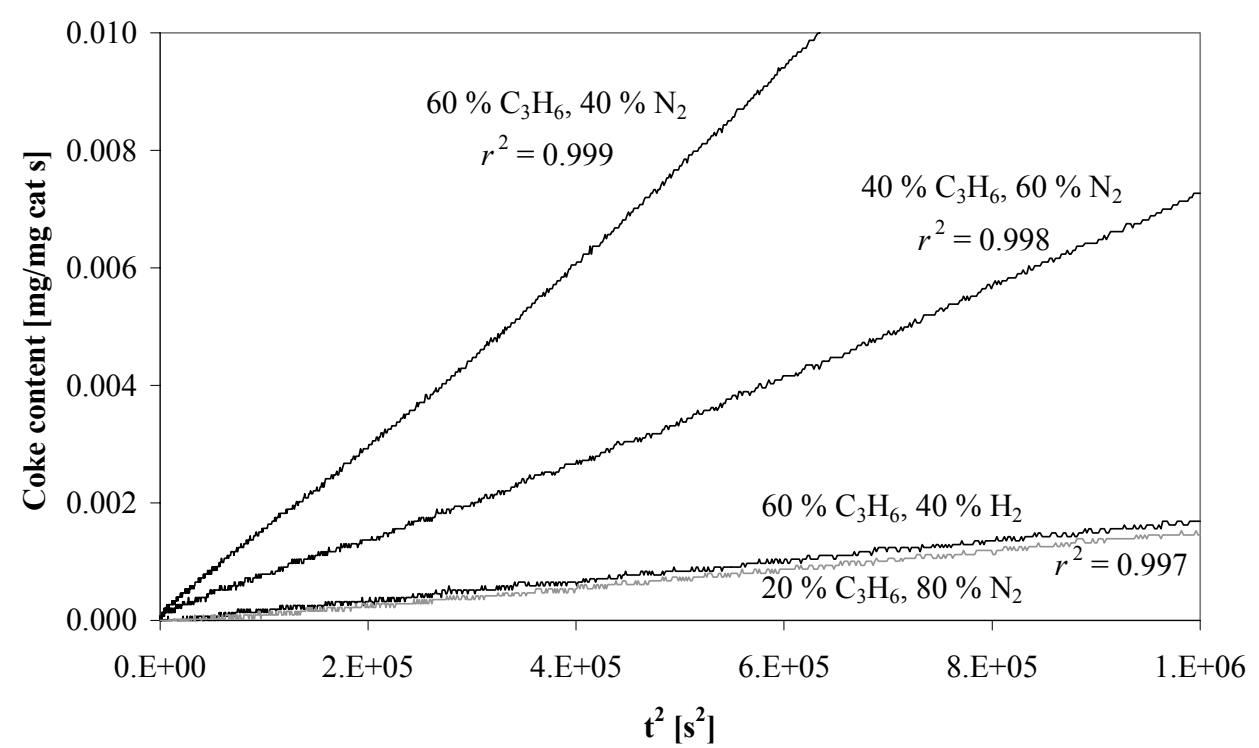

Figure 8. Coke content as a function of the time squared for different propylene-hydrogen-nitrogen gas mixtures at $600{ }^{\circ} \mathrm{C}$, showing the quadratic increase of the coke content in time.

Furthermore, Figure 7 also clearly shows the very strong influence of the hydrogen concentration on the coking rates. For example, for a $60 \%$ propylene $-40 \%$ nitrogen mixture a coke content of $1.6 \mathrm{wt} \%$ was obtained after $1000 \mathrm{~s}$ at $600{ }^{\circ} \mathrm{C}$, while for a $60 \%$ propylene $40 \%$ hydrogen mixture the coke content reached only $0.16 \mathrm{wt} \%$ after $1000 \mathrm{~s}$ at $600{ }^{\circ} \mathrm{C}$, which is one order of magnitude lower. Also, even small concentrations of hydrogen can suppress the coke formation rates enormously. However, the influence of the hydrogen decreases considerably at higher reaction temperatures as evident from Figure 10, where the maximum observed coking rates are plotted as a function of the propylene concentration for both propylene-nitrogen and propylene-hydrogen gas mixtures at different temperatures. Despite the large differences in coking with and without hydrogen at lower temperatures, the maximum coking rates of propylene-hydrogen gas mixtures approach those of propylenenitrogen at $800{ }^{\circ} \mathrm{C}$. 

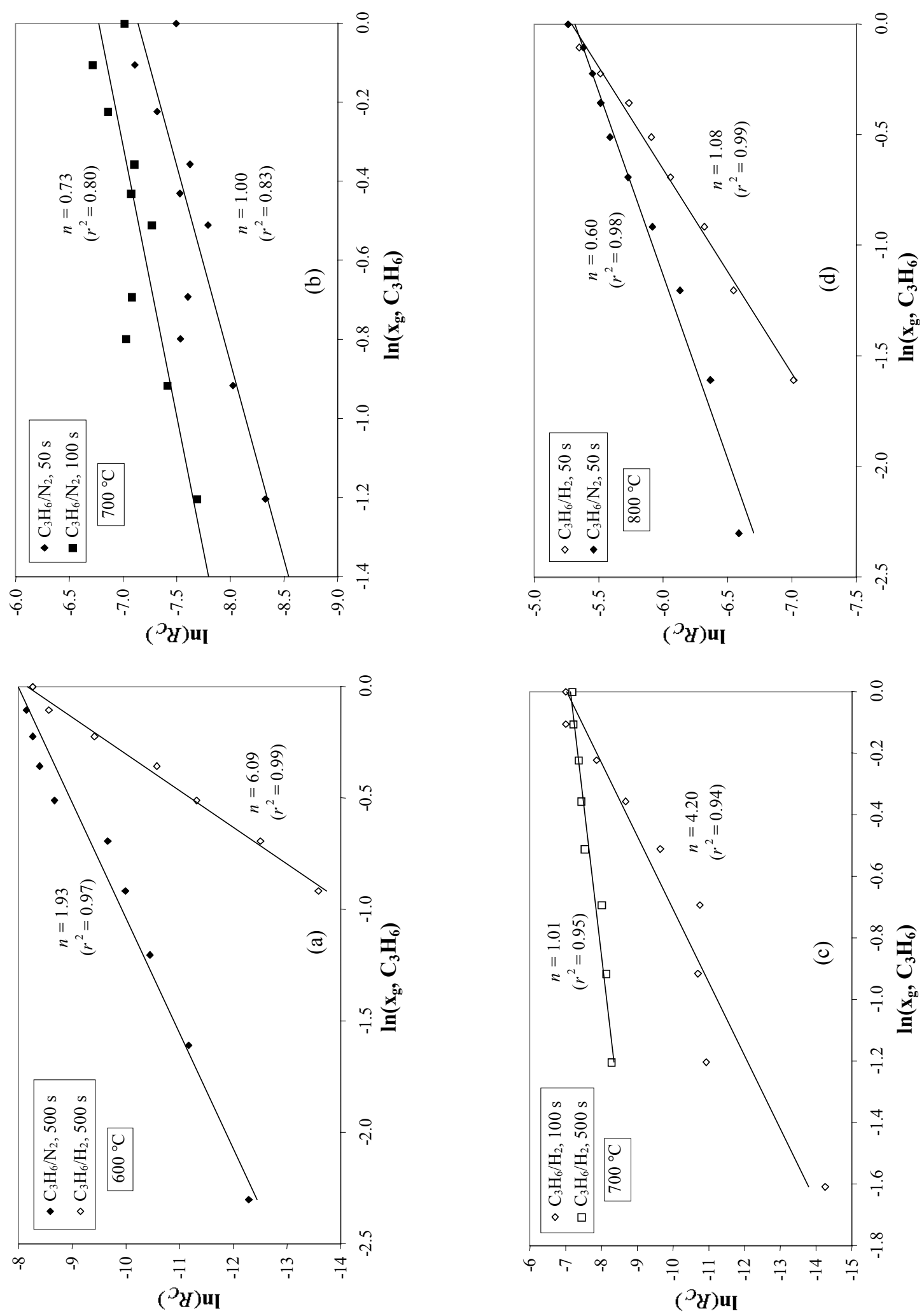

Figure 9. The logarithm of the coke formation rate versus the logarithm of the gas phase propylene mole fraction for propylene-nitrogen (closed marks) and propylene-hydrogen (open marks) gas mixtures at different temperatures, showing the apparent reaction order in the propylene concentration $n$ and the $r^{2}$ linear regression parameter in parenthesis.

(a) $\mathrm{C}_{3} \mathrm{H}_{6} / \mathrm{N}_{2}$ and $\mathrm{C}_{3} \mathrm{H}_{6} / \mathrm{H}_{2}$ mixtures at $500 \mathrm{~s}$ at $600{ }^{\circ} \mathrm{C}$;

(b) $\mathrm{C}_{3} \mathrm{H}_{6} / \mathrm{N}_{2}$ mixtures at 50 and $100 \mathrm{~s}$ at $700{ }^{\circ} \mathrm{C}$;

(c) $\mathrm{C}_{3} \mathrm{H}_{6} / \mathrm{H}_{2}$ mixtures at 100 and $500 \mathrm{~s}$ at $700{ }^{\circ} \mathrm{C}$;

(d) $\mathrm{C}_{3} \mathrm{H}_{6} / \mathrm{N}_{2}$ and $\mathrm{C}_{3} \mathrm{H}_{6} / \mathrm{H}_{2}$ mixtures at $50 \mathrm{~s}$ at $800{ }^{\circ} \mathrm{C}$; 

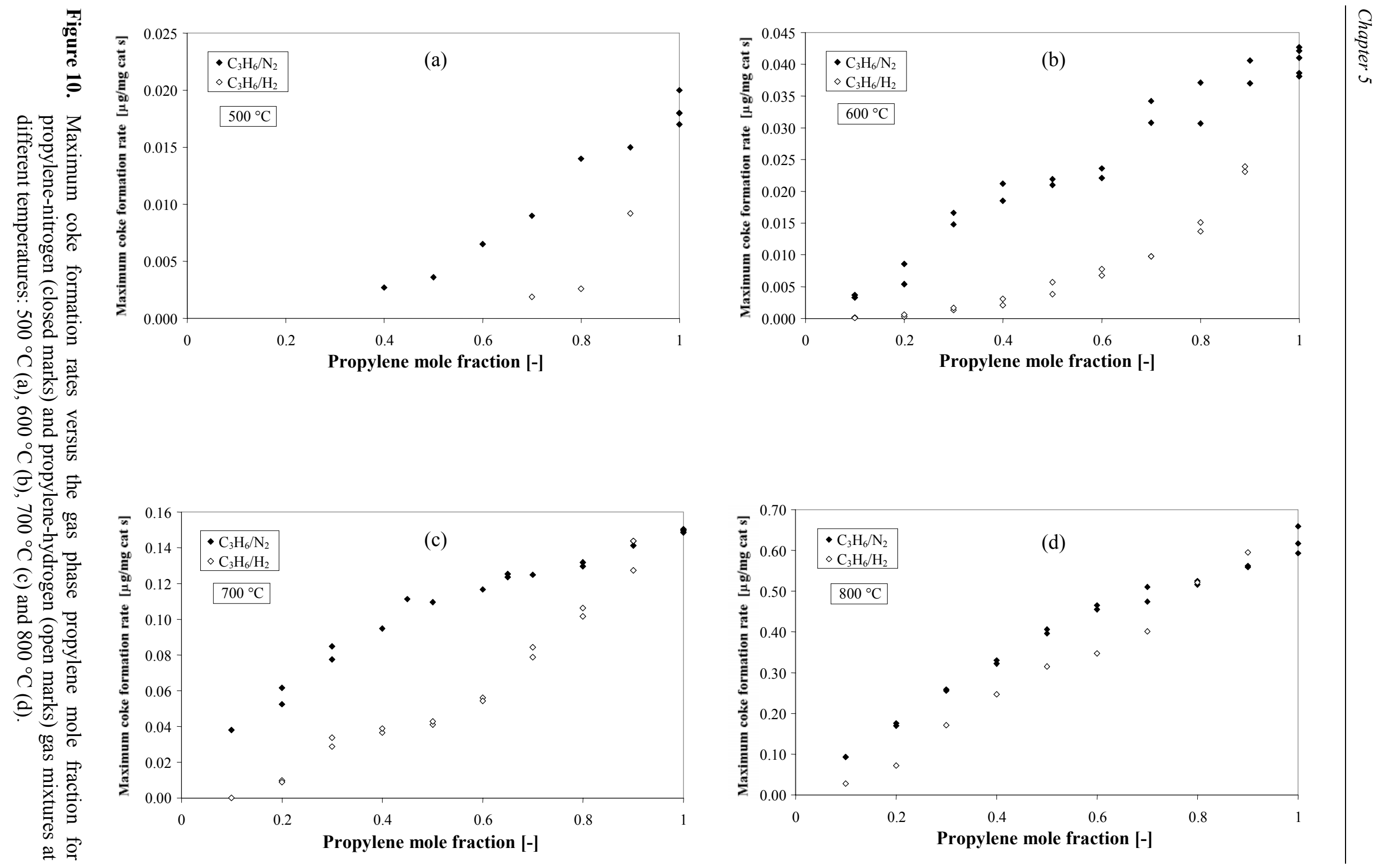
Finally, it is has been tried to regenerate the catalyst by hydrogen treatment. It was not possible to decrease the coke content under a hydrogen atmosphere, not even at $800{ }^{\circ} \mathrm{C}$. This is in accordance with findings of Larsson et al. (1996), who also reported a minor effect of exposing deactivated catalyst samples to hydrogen on the free metal surface area. However, if the coke deposits were subsequently combusted in air after the hydrogen treatment, their coke combustion rate was strongly increased. This possibly indicates that the hydrogen treatment increased the hydrogen/carbon ratio via e.g. hydrogenation of the carbonaceous compounds at the catalyst surface facilitating its combustion, but not it's desorption.

\section{Kinetic model}

\subsection{Model assumptions}

A kinetic rate expression is developed based on a, as simple as possible, mechanistic model but able to quantitatively describe the above mentioned experimental observations. The basic assumptions are as follows:

1. All coke deposits originate from propylene. Coke formation from propane can be neglected.

2. Since similar coke formation rates have been determined on monolithic samples with and without platinum dispersed in the washcoat, it is concluded that most of the coke deposits are formed at acid $\gamma-\mathrm{Al}_{2} \mathrm{O}_{3}$ surface sites. Therefore, to describe the total amount of carbonaceous compounds as a function of time no distinction is necessary in coke formed at different surface sites, like Bariås et al. (1996) assumed in their explanation of the role of tin on the coke formation rates.

3. Furthermore, the internal structure of the catalyst is not taken into account assuming that the conclusion drawn by Marin et al. (1986) for their $\mathrm{Cr}_{2} \mathrm{O}_{3} / \gamma-\mathrm{Al}_{2} \mathrm{O}_{3}$ catalyst also holds for the monolithic catalyst used in this work. The important assumption here is that the smallest pores are blocked during the very early stages of the coke formation process resulting in negligible coke amount of coke deposits in these smallest pores. The usefulness of this assumption has also been demonstrated by Peña et al. (1993), who were 
able to quantitatively describe coke formation rates up to $8 \mathrm{wt} \%$ coke content while neglecting pore blocking.

4. Following Peña et al. (1993) and Marin et al. (1986) the marked sudden decrease in the coke formation rate when the coke concentration reaches $c a .12 \mathrm{wt} \%$ is attributed to two different stages in the coke formation process. In the first stage carbonaceous compounds are formed at the catalyst surface from a coke precursor (CP), which originates from propylene adsorbed at the catalyst surface. These coke deposits are termed monolayer coke, since it is formed directly on the catalyst surface. The second stage of this dual coke growth model consists of growth of these monolayer coke deposits, which is termed multilayer coke formation, since it is formed on coke previously deposited. The terminology of monolayer and multilayer coke, denoted by $\mathrm{C}_{\mathrm{m}}$ and $\mathrm{C}_{\mathrm{M}}$ respectively, does not necessarily stand for coke growth in layers. The principal difference in these coke formation stages is merely the assumption that monolayer coke is formed through reaction of coke precursor with adsorbed propylene, while multilayer coke is formed via reaction of monolayer coke with propylene directly from the gas phase.

5. Following Marin et al. (1986) it is assumed that the formation of coke precursor is the rate determining step in the coke formation process and the coke precursor grows instantaneously to monolayer coke with adsorbed propylene molecules. Peña et al. (1993) calculated an average molecular mass of monolayer coke originating from 1-butene on a $\mathrm{Cr}_{2} \mathrm{O}_{3} / \mathrm{Al}_{2} \mathrm{O}_{3}$ catalyst of $1.2 \cdot 10^{4} \mathrm{~kg}$ coke/kmole, using results reported by Marin et al. and their own results. This would correspond to a monolayer coke consisting of almost 300 propylene molecules. However, as indicated by Marin et al., only the product of the average molecular mass of monolayer coke and the total surface site concentration is necessary to describe the coke content in time if pore blocking is ignored.

6. The auto-catalytic behaviour of the coke formation process for short times on stream, reflected by the quadratic increase in the coke content as function of time, is attributed to the formation of an intermediary product in the formation of coke precursor. Because the concentration of this intermediary product increases initially, also the coke precursor concentration and thus the coke formation rate increases initially. 
7. Because of the high apparent reaction order in the propylene concentration observed for the coke formation rate for relatively short times on stream, it is tentatively proposed that coke deposits are formed through an oligomerisation process, as proposed by Hamid and Cerouane (1994). From dimerisation of adsorbed propylene an intermediary product is formed, possibly hexene or an even further dehydrogenated or aromatised product. From the reaction of this propylene dimer, denoted by PD, with another adsorbed propylene molecule a coke precursor is formed. From the initial quadratic increase in the coke content versus time it can be concluded that there is only one rate-determining intermediary product in the coke precursor formation. Every additional rate-determining intermediary product would have raised the order of the time dependency of the coke content by the same number of additional intermediates.

It is assumed that coke precursors can also be formed from the reaction of monolayer coke with adsorbed propylene or propylene dimer. This last assumption is necessary to describe the very sudden marked transition from initially primarily monolayer coke formation to only multilayer coke formation for longer times on stream when the catalyst becomes coked, as observed in the experiments.

8. Finally, the decreased influence of the hydrogen concentration at higher temperatures is explained by a decreased hydrogen chemisorption at the catalyst surface sites. It is assumed that propylene and hydrogen adsorb competitively at the same surface sites and that hydrogen chemisorbs dissociatively at these surface sites. Furthermore, it is assumed that the adsorption equilibria are established instantaneously. Again following Dumez and Froment (1976) and Peña et al. (1993) it is assumed that the deactivation reaction involves two surface sites, so that it is assumed that coke precursor and monolayer coke occupy two surface sites.

9. Since hydrogen treatment does not decrease the coke content of a coked catalyst sample, the reaction of coke with hydrogen to form methane is omitted in this model, in contrast to Resasco and Haller (1994). However, all coke deposits can be dehydrogenated or hydrogenated and can also undergo further processes like cyclisation, aromatisation or graphitisation. Its possible influence on the overall coke formation rate is ignored in this model. 
The above outlined coke formation model, obviously a tentatively proposed simplification of the complex coke formation process, is summarised in Table 1. It is emphasised here that the proposed mechanism aims only at giving information about the reaction rate of the rate determining steps. No details about the precise structure of the species involved and the actual chemical transformations taking place at the catalyst surface are included in this model. All the species involved could undergo further reactions, like cracking, dehydrogenation or cyclisation. Even about the order, in which these reactions can take place (first dimerisation, then dehydrogenation or the other way around), the proposed mechanism does not give specifics. The only assumption in the proposed kinetic model is that the effects of these additional reactions can be lumped in 'overall' reaction rate constants of the rate determining steps. For instance, 'adsorbed propylene' should only be considered as a species originating from the adsorption of propylene from the gas phase.

Table 1. Proposed coke formation mechanism to describe the coke content as a function of time.

Adsorption equilibria:

$$
\begin{array}{lll}
1 / 2 \mathrm{H}_{2}(\mathrm{~g})+\mathrm{S} & \stackrel{K_{H}}{\rightleftarrows} \mathrm{H}(\mathrm{s}) \\
\mathrm{C}_{3} \mathrm{H}_{6}(\mathrm{~g})+\mathrm{S} \stackrel{K_{C}}{\rightleftarrows} \mathrm{C}_{3} \mathrm{H}_{6}(\mathrm{~s})
\end{array}
$$

Dimerisation:

$$
\mathrm{C}_{3} \mathrm{H}_{6}(\mathrm{~s})+\mathrm{C}_{3} \mathrm{H}_{6}(\mathrm{~s}) \stackrel{k_{R}}{\longrightarrow} \mathrm{PD}
$$

Coke precursor formation:

$$
\begin{aligned}
\mathrm{PD}+\mathrm{C}_{3} \mathrm{H}_{6}(\mathrm{~s}) & \stackrel{k_{C P}}{\longrightarrow} \mathrm{CP}+\mathrm{S} \\
\mathrm{C}_{\mathrm{m}}+\mathrm{C}_{3} \mathrm{H}_{6}(\mathrm{~s}) & \stackrel{k_{C P, 1}}{\longrightarrow} \mathrm{C}_{\mathrm{m}}+\mathrm{CP} \\
\mathrm{C}_{\mathrm{m}}+\mathrm{PD} & \stackrel{k_{C P, 2}}{\longrightarrow} \mathrm{C}_{\mathrm{m}}+\mathrm{CP}
\end{aligned}
$$

Monolayer coke formation:

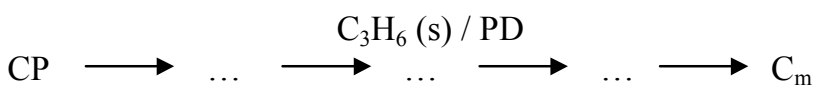

Multilayer coke formation:

$$
\begin{aligned}
& \mathrm{C}_{\mathrm{m}}+\mathrm{C}_{3} \mathrm{H}_{6}(\mathrm{~g}) \stackrel{k_{C M}}{\longrightarrow} \mathrm{C}_{\mathrm{M}} \\
& \mathrm{C}_{\mathrm{M}}+\mathrm{C}_{3} \mathrm{H}_{6}(\mathrm{~g}) \stackrel{k_{C M}}{\longrightarrow} \mathrm{C}_{\mathrm{M}}
\end{aligned}
$$




\subsection{Coke formation rate equation}

The derivation of the kinetic rate expression to describe the coke content in time based on the model described above is given in Appendix A. The results are summarised below.

The increase in coke content, $M_{\mathrm{C}}$, in time is given by the sum of the monolayer and multilayer coke production rates, thus:

$\frac{d M_{\mathrm{C}}}{d t}=\frac{d M_{\mathrm{Cm}}}{d t}+\frac{d M_{\mathrm{CM}}}{d t}=w \frac{d \theta_{\mathrm{Cm}}}{d t}+k_{C M} C_{g, \mathrm{C}_{3} \mathrm{H}_{6}} \theta_{\mathrm{Cm}}$

introducing $w$ as the maximum monolayer coke concentration. The fraction of the total surface sites occupied by propylene dimer, $\theta_{\mathrm{PD}}$, and monolayer coke, $\theta_{\mathrm{Cm}}$, are described by the following balances,

$$
\begin{aligned}
& \frac{d \theta_{\mathrm{PD}}}{d t}=k_{R} \theta_{\mathrm{C}_{3} \mathrm{H}_{6}}^{2}-k_{C P} \theta_{\mathrm{C}_{3} \mathrm{H}_{6}} \theta_{\mathrm{PD}}-k_{C P, 2} \theta_{\mathrm{PD}} \theta_{\mathrm{Cm}} \\
& \frac{d \theta_{\mathrm{Cm}}}{d t}=\frac{d \theta_{\mathrm{CP}}}{d t}=k_{C P} \theta_{\mathrm{C}_{3} \mathrm{H}_{6}} \theta_{\mathrm{PD}}+k_{C P, 1} \theta_{\mathrm{C}_{3} \mathrm{H}_{6}} \theta_{\mathrm{Cm}}+k_{C P, 2} \theta_{\mathrm{PD}} \theta_{\mathrm{Cm}}
\end{aligned}
$$

Note that the formation rate of monolayer coke equals the formation rate of coke precursor, because of the assumption of instantaneous growth of coke precursor to monolayer coke as soon as coke precursor is formed. The surface fractions of the free surface sites, $\theta_{\mathrm{S}}$, dissociatively chemisorbed hydrogen, $\theta_{\mathrm{H}}$, and propylene, $\theta_{\mathrm{C}_{3} \mathrm{H}_{6}}$, are given by the following algebraic equations respectively:

$$
\begin{gathered}
\theta_{\mathrm{S}}=\frac{\left(1-\theta_{\mathrm{PD}}-\theta_{\mathrm{Cm}}\right)}{1+K_{H} C_{g, \mathrm{H}_{2}}^{\frac{1}{2}}+K_{C} C_{g, \mathrm{C}_{3} \mathrm{H}_{6}}} \\
\theta_{\mathrm{H}}=\frac{K_{H} C_{g, \mathrm{H}_{2}}^{\frac{1}{2}}\left(1-\theta_{\mathrm{PD}}-\theta_{\mathrm{Cm}}\right)}{1+K_{H} C_{g, \mathrm{H}_{2}}^{\frac{1}{2}}+K_{C} C_{g, \mathrm{C}_{3} \mathrm{H}_{6}}}
\end{gathered}
$$


$\theta_{\mathrm{C}_{3} \mathrm{H}_{6}}=\frac{K_{C} C_{g, \mathrm{C}_{\mathrm{H}} \mathrm{H}_{6}}\left(1-\theta_{\mathrm{PD}}-\theta_{\mathrm{Cm}}\right)}{1+K_{H} C_{g, \mathrm{H}_{2}}^{\frac{1}{2}}+K_{C} C_{g, \mathrm{C}_{3} \mathrm{H}_{6}}}$

Intially, the catalyst surface is free of any coke components, thus the initial conditions are given by:

$t=0: \quad \theta_{\mathrm{PD}}=\theta_{\mathrm{Cm}}=0 \quad$ and $\quad M_{\mathrm{C}}=M_{\mathrm{Cm}}=M_{\mathrm{CM}}=0$

For the adsorption and reaction rate constants an Arrhenius-type temperature dependency has been assumed.

For relatively short times on stream the kinetic rate expression for the coke formation rate can be simplified and solved analytically (see Appendix B), giving the following for the coke content as a function of time:

$M_{\mathrm{C}}(t)=w \theta_{\mathrm{Cm}}=w\left[\frac{k_{R} \theta_{\mathrm{C}_{3} \mathrm{H}_{6}, 0}^{2} t}{1+k_{R} \theta_{\mathrm{C}_{3} \mathrm{H}_{6}, 0}^{2}}-\frac{1-\left(1+k_{R} \theta_{\mathrm{C}_{3} \mathrm{H}_{6}, 0}^{2} t\right)\left(\frac{k_{C P}}{k_{R} \theta_{\mathrm{C}_{3}, 0}}-1\right)}{\left(1+k_{R} \theta_{\mathrm{C}_{3} \mathrm{H}_{6}, 0}^{2} t\right)\left(\frac{k_{C P}}{k_{R} \theta_{\mathrm{C}_{3} \mathrm{H}_{6}, 0}}-1\right)}\right]$

where $\theta_{\mathrm{C}_{3} \mathrm{H}_{6}, 0}$ denotes the initial propylene surface fraction. A Taylor series expansion of the coke content as a function of time around $t=0$ results in

$M_{\mathrm{C}}(t) \approx \frac{1}{2} w k_{R} k_{C P} \theta_{\mathrm{C}_{3} \mathrm{H}_{6}, 0}^{3} t^{2}\left(1-\frac{1}{3} \theta_{\mathrm{C}_{3} \mathrm{H}_{6}, 0}\left(4 k_{R} \theta_{\mathrm{C}_{3} \mathrm{H}_{6}, 0}+k_{C P}\right) t+O\left(t^{2}\right)\right)$

which shows the experimentally observed second order time dependency of the coke content and the observed high apparent reaction order in the propylene concentration, as long as

$t<\frac{3}{\theta_{\mathrm{C}_{3} \mathrm{H}_{6}, 0}\left(4 k_{R} \theta_{\mathrm{C}_{3} \mathrm{H}_{6}, 0}+k_{C P}\right)}$ 
The time at which the coke formation rate does no longer increase quadratically, decreases with increasing propylene surface concentration, i.e. increasing propylene and decreasing hydrogen gas phase concentrations, and increasing temperatures, because of the increase in the reaction rate constants. This also corresponds very well with the experimental observations.

The experimentally determined coke formation rates as a function of time for different propylene-nitrogen and propylene-hydrogen mixtures at different temperatures have been used to fit the adsorption and reaction rate constants in the coke formation model described by equation 1-7. The complete set of experimentally determined coke formation rates - not the coke content in order to avoid cumulative errors - at different times on stream and different temperatures has been fitted simultaneously using the multivariable Levenberg-Marquardt algorithm. The maximum monolayer coke concentratrion has been fixed at $12 \mathrm{wt} \%$ and the pre-exponential multilayer coke formation rate constant $k_{C M, \infty}$ and the multilayer coke formation activation energy $E_{C M}$ have been directly obtained from an Arrhenius plot, using the slope of the coke content versus time curve at large times on stream after the sudden marked decrease in coke formation rate, i.e. for $\mathrm{w}>12 \mathrm{wt} \%$. The regression results are presented in Table 2. In Figures 11, 12 and 13 the fitted and experimentally determined coke formation rates are plotted as a function of the propylene gas phase mole fraction at 600,700 and $800^{\circ} \mathrm{C}$, respectively.

Table 2. Results of the Levenberg-Marquardt regression for the adsorption and reaction rate constants for the coke formation model from Table 1, using equation 1-7.

\begin{tabular}{|c|c|c|c|c|c|}
\hline \multicolumn{3}{|c|}{ Pre-exponential constant } & \multicolumn{3}{|c|}{ Activation energy } \\
\hline$\overline{K_{C, \infty}}$ & $1.24 \cdot 10^{-1}$ & {$\left[\mathrm{~m}^{3} \cdot \mathrm{mole}^{-1}\right]$} & $E_{C}$ & -0.449 & {$\left[\mathrm{~kJ} \cdot \mathrm{mole}^{-1}\right]$} \\
\hline$K_{H, \infty}$ & $1.97 \cdot 10^{-3}$ & {$\left[\mathrm{~m}^{1.5} \cdot \mathrm{mole}^{-0.5}\right]$} & $E_{H}$ & -47.1 & {$\left[\mathrm{~kJ} \cdot \mathrm{mole}^{-1}\right]$} \\
\hline$k_{R, \infty}$ & $3.55 \cdot 10^{8}$ & {$\left[\mathrm{~s}^{-1}\right]$} & $E_{R}$ & 186 & {$\left[\mathrm{~kJ} \cdot \mathrm{mole}^{-1}\right]$} \\
\hline$k_{C P, \infty}$ & $6.69 \cdot 10^{5}$ & {$\left[\mathrm{~s}^{-1}\right]$} & $E_{C P}$ & 147 & {$\left[\mathrm{~kJ} \cdot \mathrm{mole}^{-1}\right]$} \\
\hline$k_{C P, 1, \infty}$ & $1.65 \cdot 10^{0}$ & {$\left[\mathrm{~s}^{-1}\right]$} & $E_{C P, 1}$ & 46.8 & {$\left[\mathrm{~kJ} \cdot \mathrm{mole}^{-1}\right]$} \\
\hline$k_{C P, 2, \infty}$ & $3.32 \cdot 10^{5}$ & {$\left[\mathrm{~s}^{-1}\right]$} & $E_{C P, 2}$ & 156 & {$\left[\mathrm{~kJ} \cdot \mathrm{mole}^{-1}\right]$} \\
\hline$k_{C M, \infty}$ & $4.30 \cdot 10^{4}$ & $\begin{array}{c}{\left[\mathrm{m}^{3} \cdot \mathrm{mole}^{-1} \cdot \mathrm{s}^{-1} \cdot\right.} \\
\left.\mathrm{mg} \cdot \mathrm{mg}_{\text {cat }}{ }^{-1}\right]\end{array}$ & $E_{C M}$ & 200 & {$\left[\mathrm{~kJ} \cdot \mathrm{mole}^{-1}\right]$} \\
\hline$w$ & 0.12 & {$\left[\mathrm{mg} \cdot \mathrm{mg}_{\mathrm{cat}}\right]$} & & & \\
\hline
\end{tabular}



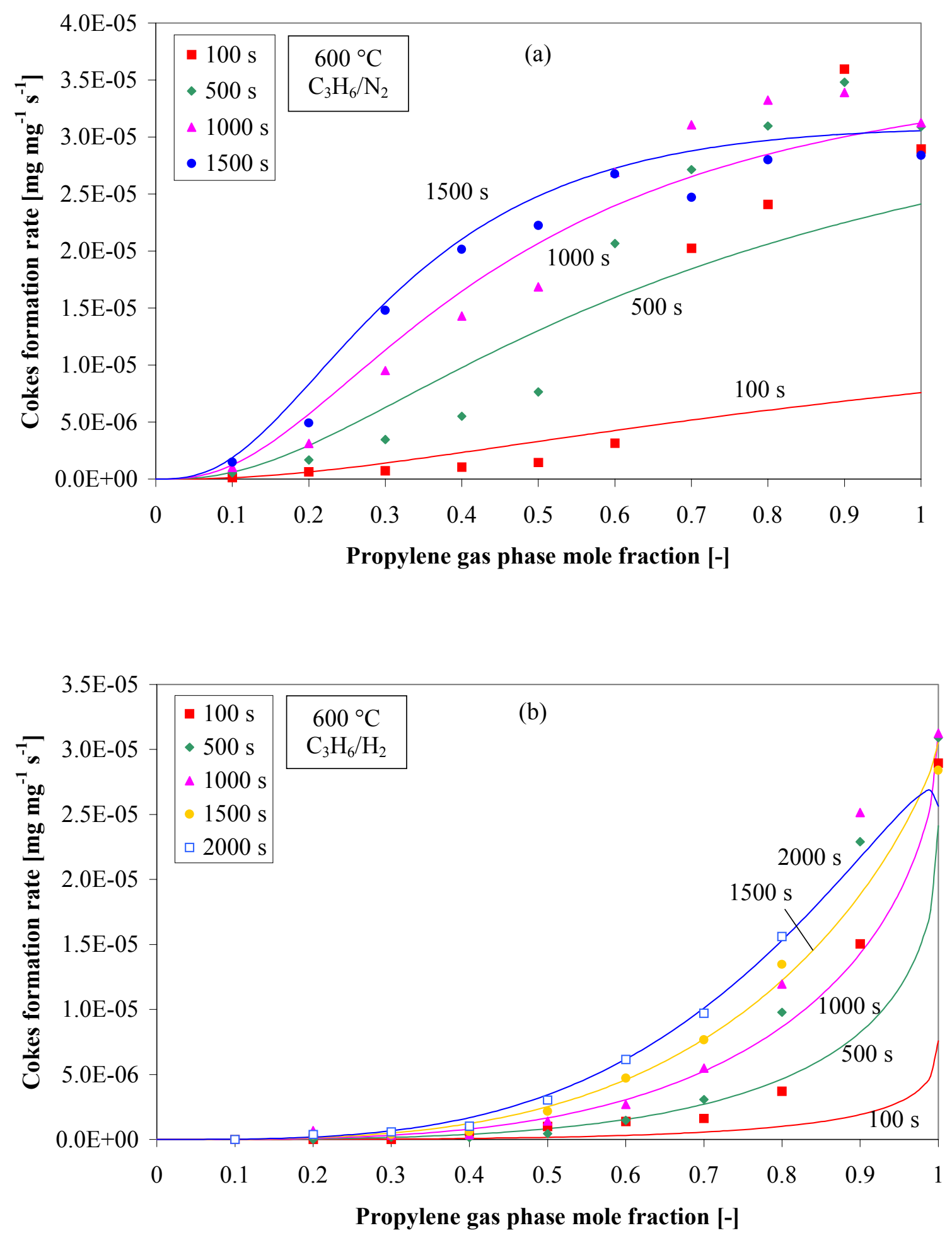

Figure 11. Comparison of experimentally determined (marks) and theoretically predicted (lines) coke formation rates as a function of the gas phase propylene mole fraction at different times on stream at $600{ }^{\circ} \mathrm{C}$ for propylene-nitrogen (a) and propylene-hydrogen (b) mixtures. 


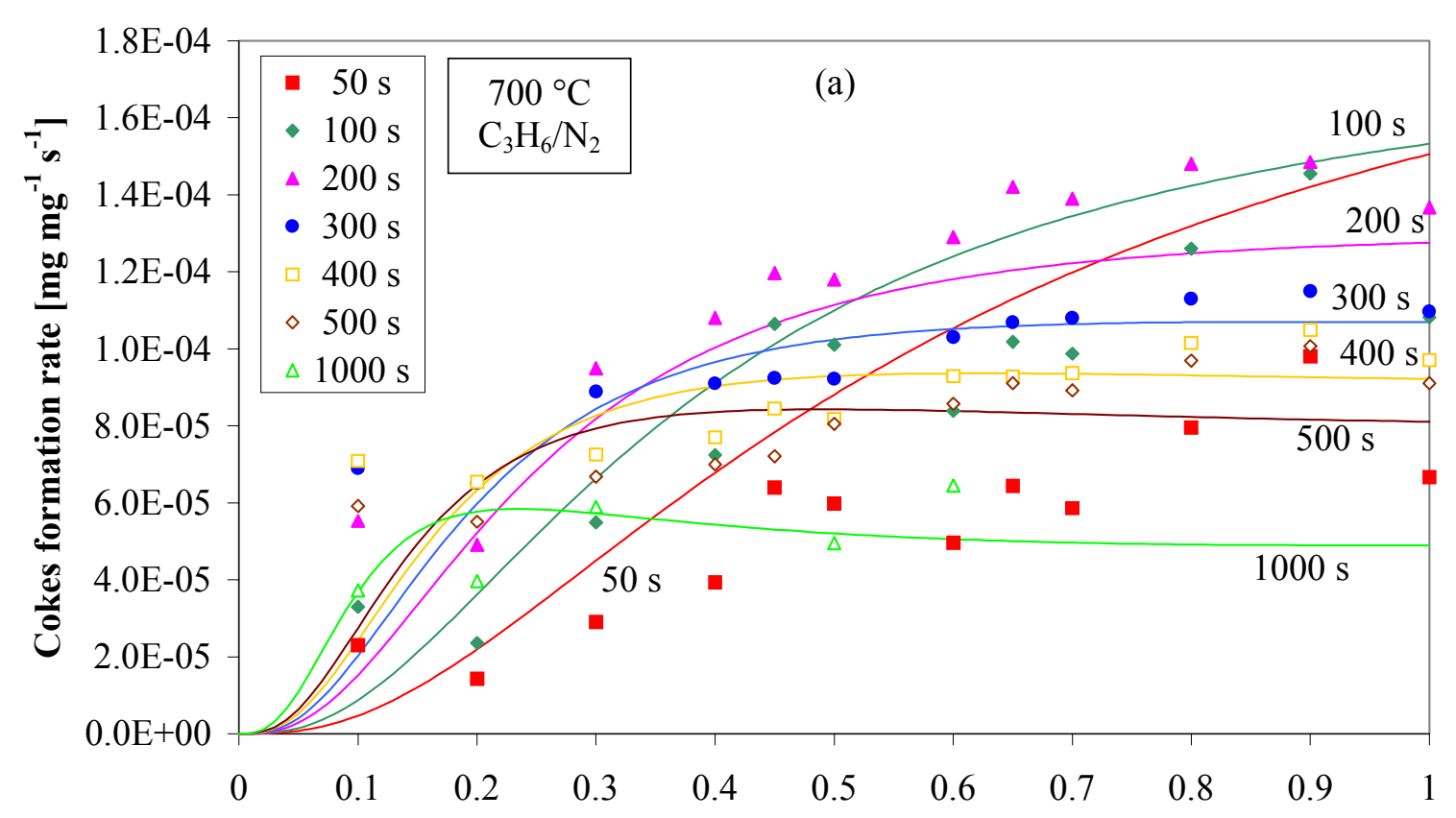

Propylene gas phase mole fraction [-]

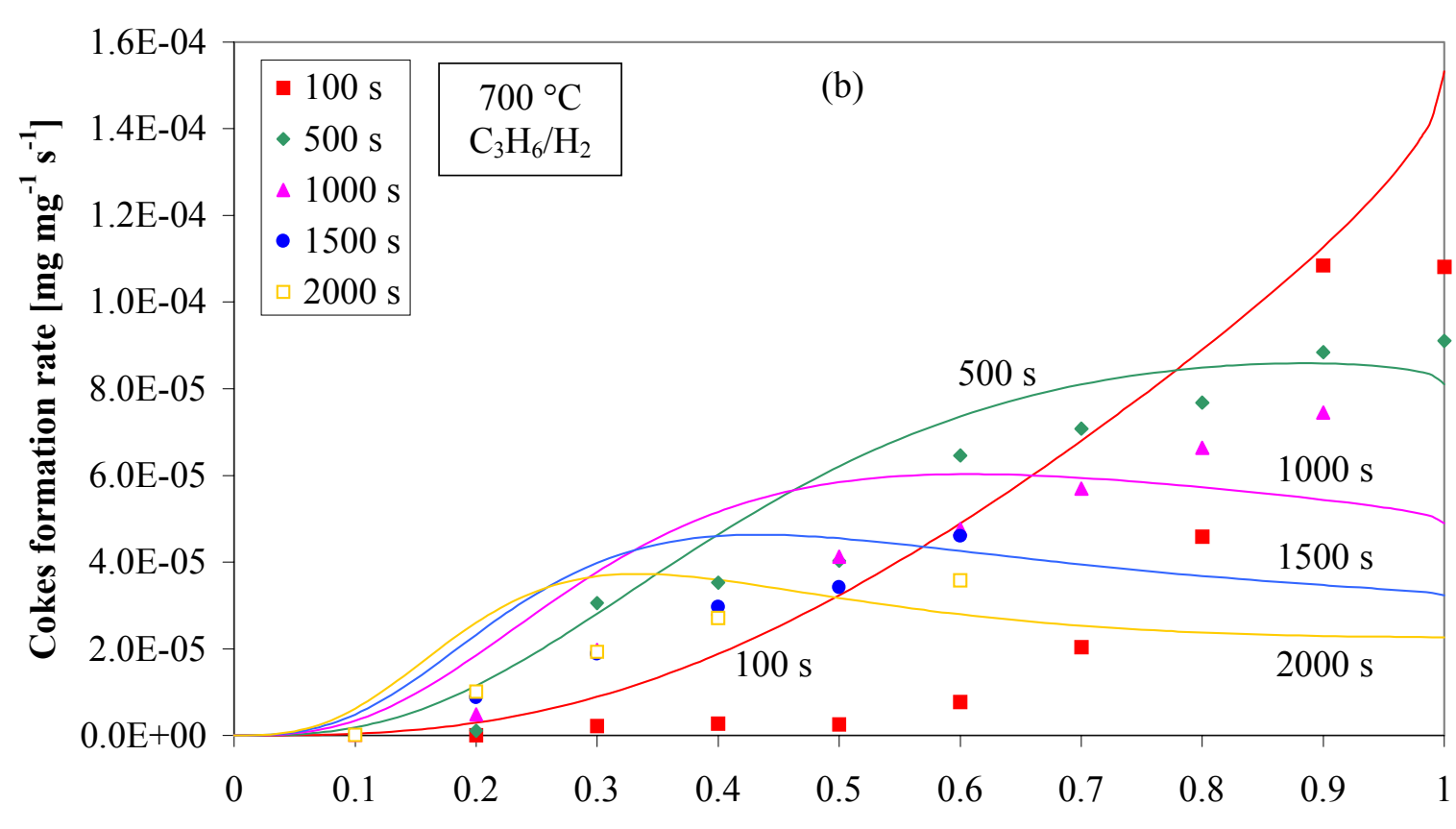

Propylene gas phase mole fraction [-]

Figure 12. Comparison of experimentally determined (marks) and theoretically predicted (lines) coke formation rates as a function of the gas phase propylene mole fraction at different times on stream at $700{ }^{\circ} \mathrm{C}$ for propylene-nitrogen (a) and propylene-hydrogen (b) mixtures. 

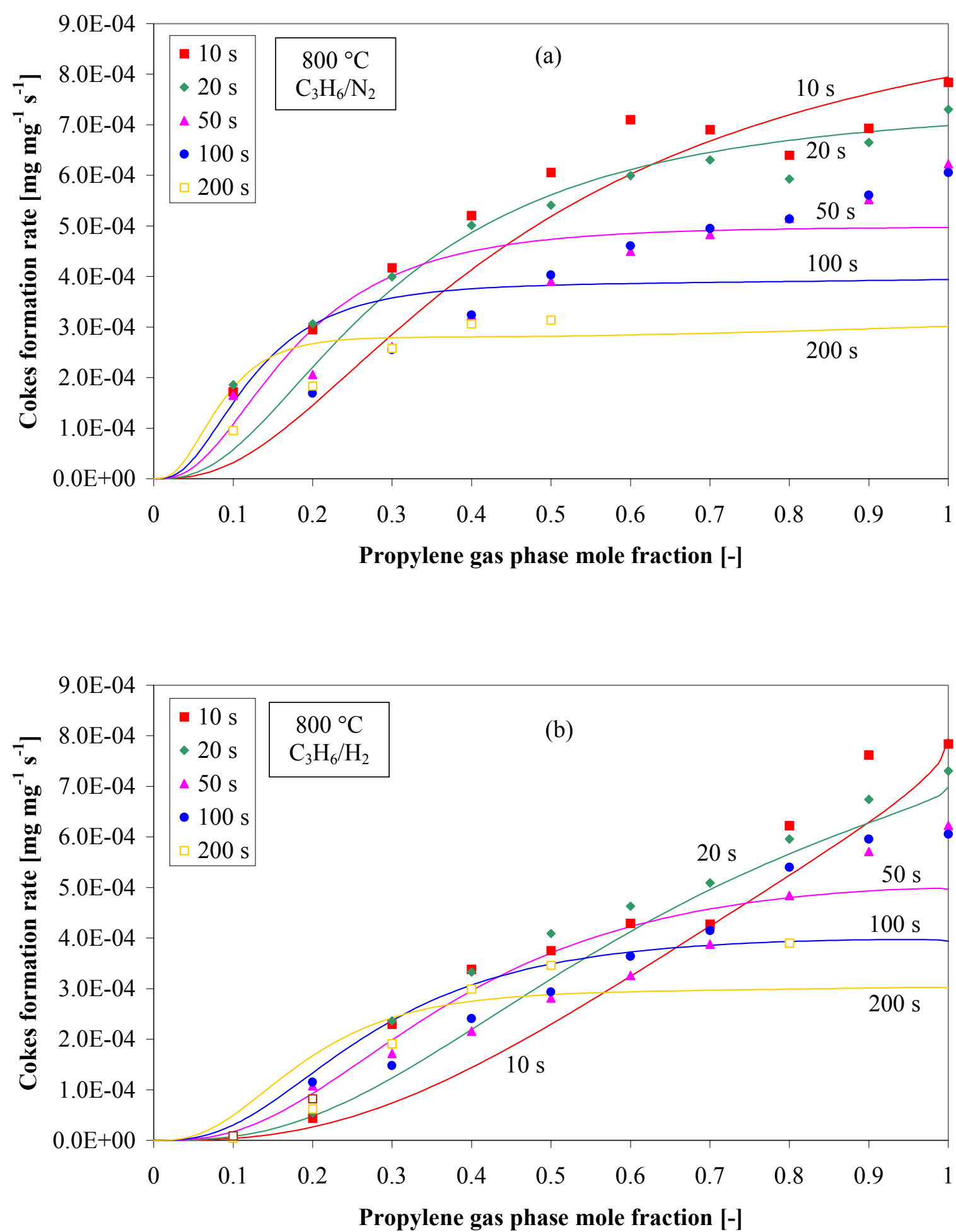

Figure 13. Comparison of experimentally determined (marks) and theoretically predicted (lines) coke formation rates as a function of the gas phase propylene mole fraction at different times on stream at $800{ }^{\circ} \mathrm{C}$ for propylene-nitrogen (a) and propylene-hydrogen (b) mixtures. 


\section{Discussion}

From Figures 11-13 it can be concluded that the derived kinetic coke formation model can describe the experimentally determined coke formation rates reasonably well. The model is capable of quantitatively describing the remarkable experimentally observed increase in coke formation rates in time over $1500 \mathrm{~s}$ at $600{ }^{\circ} \mathrm{C}$ for both propylene-nitrogen and propylenehydrogen gas mixtures and the observed decrease in coke formation rates as a function of time after only short times on stream at 700 and $800{ }^{\circ} \mathrm{C}$. Also, the observed very pronounced influence of the hydrogen concentration at $600{ }^{\circ} \mathrm{C}$ and its decreasing influence at higher temperatures is predicted by the derived model. Furthermore, the observed high apparent reaction order in the propylene concentration for propylene-hydrogen gas mixtures at low temperatures and its decrease to less than one at higher temperatures and longer times on stream is also quantitatively captured by the model.

Larger deviations between the experimentally determined coking rates and those predicted by the model are observed for high propylene concentrations for short times on stream, especially for low temperatures. This is also shown in Figure 14, giving the coke content as a function of time for propylene-nitrogen (a) and propylene-hydrogen (b) gas mixtures at $600{ }^{\circ} \mathrm{C}$. For propylene concentrations below $\mathrm{ca} .60-70 \%$ the model reasonably describes the coke content as a function of time. However, for propylene concentrations larger than $c a$. $70 \%$ relatively large discrepancies in the coke content predicted by the model and the experimentally observed coke content can be seen, notwithstanding the good agreement in the slopes of the curves for larger times on stream. Nevertheless, the derived kinetic model can be used very well to study effects of coke formation during propane dehydrogenation, since the propylene concentration will never exceed $50 \%$ in a commercial propane dehydrogenation reactor, while the hydrogen concentration is at least equal or larger than the propylene concentration.

The bias in coke-content caused at short times on stream for large propylene concentrations could be explained by either the neglect of a pore blocking mechanism in this model (coke deposits in the smallest pores no longer negligible) or the neglect of an additional contribution to coke formation at the platinum surface sites. This might also explain why Larsson et al. (1996) and Bariås et al. (1996) did not observe the initial increase in the coke formation rate 
on $\mathrm{Sn}-\mathrm{Pt} / \gamma-\mathrm{Al}_{2} \mathrm{O}_{3}$ catalysts. Firstly, they investigated coke formation rates over a fresh catalyst sample at relatively low temperatures of $c a$. 500-600 ${ }^{\circ} \mathrm{C}$ (see Figure 2). Secondly, they investigated the coke formation process on a platinum catalyst with tin as promotor. The addition of tin is believed to increase the transport of coke deposits from the metal surface to the support, thus increasing the contribution of the coke formation on the metal sites relative to the contribution of the acid sites, as reported by Lin et al. (1990).
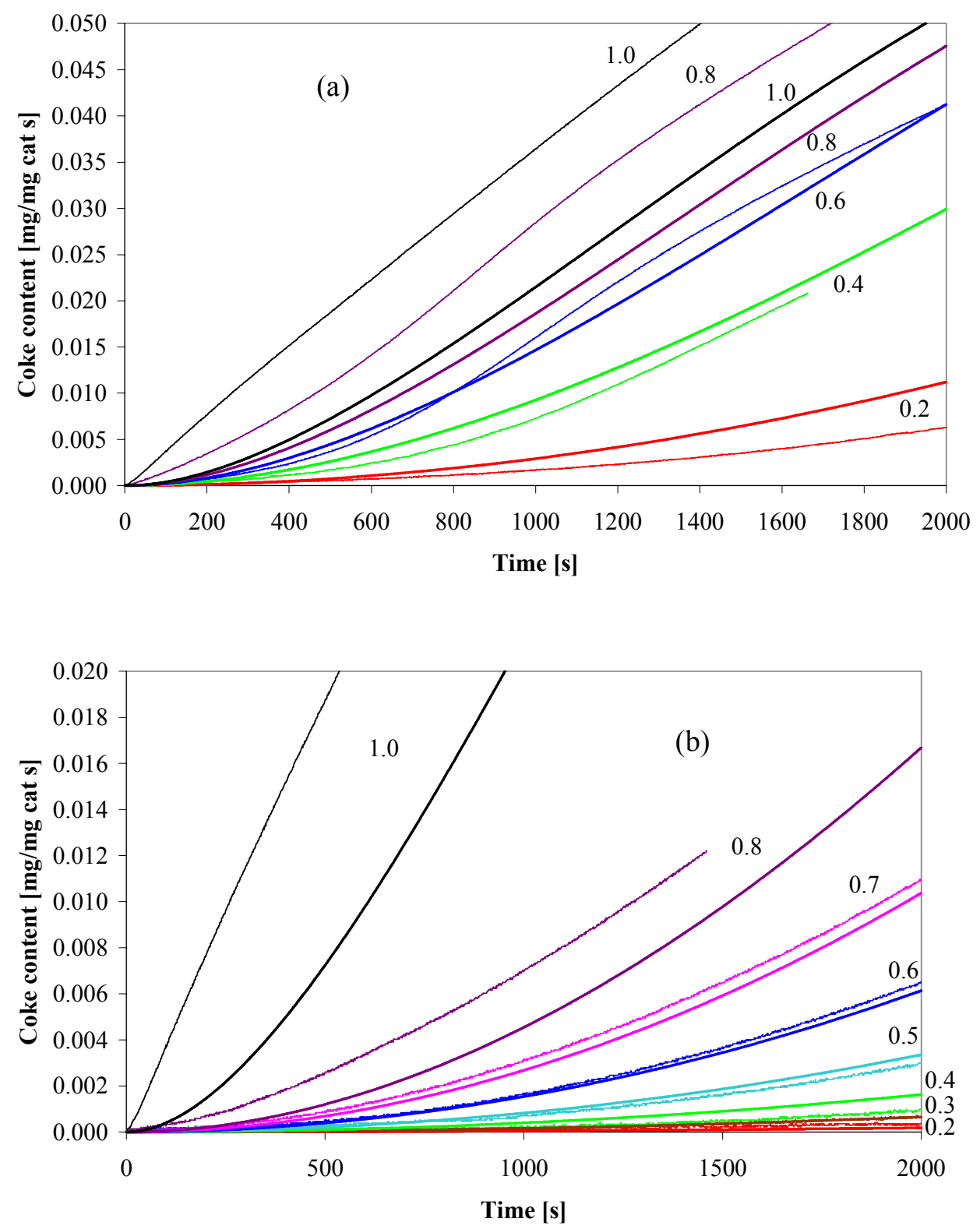

Figure 14. Comparison of the experimentally determined coke content (thin line) and the coke content predicted by the model (thick line) as a function of time for different propylene mole fractions in propylene-nitrogen (a) and propylene-hydrogen (b) gas mixtures at $600{ }^{\circ} \mathrm{C}$. 
Model results for the case of $50 \%$ propylene and $50 \%$ hydrogen gas mixture at $600{ }^{\circ} \mathrm{C}$ are represented in Figure 15. Initially the propylene dimer surface fraction $\theta_{\mathrm{PD}}$ increases causing an increase in the coke precursor and thus the monolayer coke formation rate, until a maximum is reached at $570 \mathrm{~s}$ because of the occupation of surface sites by the formed coke deposits. Initially coke precursor is formed via reaction of propylene dimer with adsorbed propylene, but for longer times on stream coke precursor originates primarily from monolayer cokes. The model predicts that after $2000 \mathrm{~s}$ about $80 \%$ of the surface sites has been covered with coke deposits. The contribution of multilayer coke formation for an equimolar propylene-hydrogen gas mixture at $600{ }^{\circ} \mathrm{C}$ is relatively small. After $5000 \mathrm{~s}$ the multilayer coke content is still less than $14 \%$ of the total coke content.
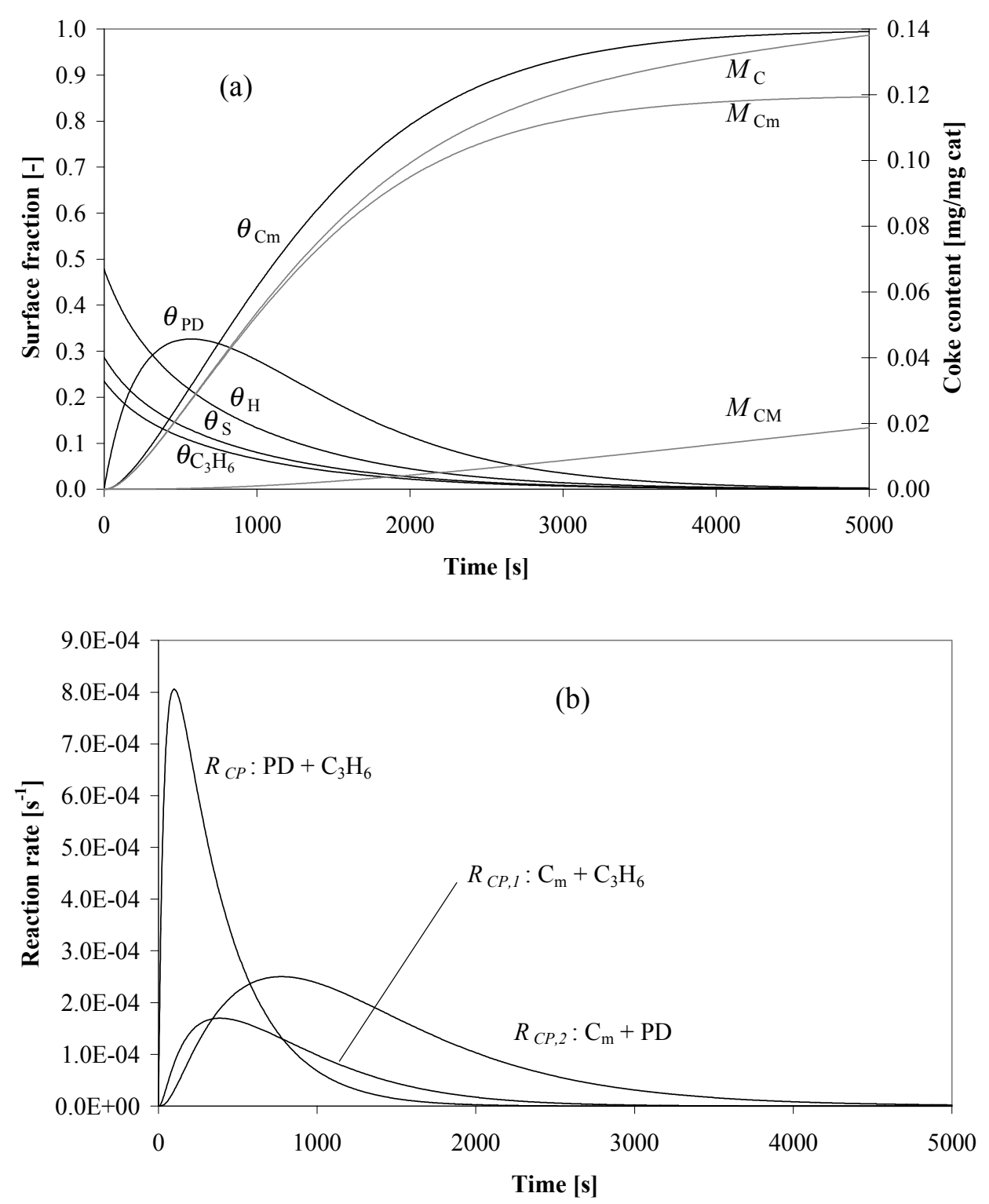

Figure 15. Model results for the surface fractions and coke content (a) and coke precursor reaction rates (b) for the case of $50 \%$ propylene and $50 \%$ hydrogen gas mixture at $600{ }^{\circ} \mathrm{C}$. 
Differences in the model assumptions make a direct comparison of the fitted adsorption and reaction rate constants and their activation energies with values from literature difficult. However, the fitted activation energies for coke precursor formation $\left(E_{C P}\right)$ and multilayer coke formation $\left(E_{C M}\right)$ given in Table 2,147 and $200 \mathrm{~kJ} \cdot \mathrm{mole}^{-1}$ respectively, compare very well with the (overall) activation energies fitted by Peña et al. (1993), 155 and $210 \mathrm{~kJ} \cdot \mathrm{mole}^{-1}$ for monolayer and multilayer coke formation and with the $135 \mathrm{~kJ} \cdot \mathrm{mole}^{-1}$ for the activation energy for coke precursor formation from 1-butene fitted by Marin et al. (1986). Furthermore, also the fitted adsorption coefficient for propylene on the used $\gamma-\mathrm{Al}_{2} \mathrm{O}_{3}$ monolithic catalyst at $600{ }^{\circ} \mathrm{C}\left(0.13 \mathrm{~m}^{3} \cdot \mathrm{mole}^{-1}\right)$ compare well with the adsorption coefficients for 1-butene and 1,3-butadiene on the $\gamma-\mathrm{Al}_{2} \mathrm{O}_{3} / \mathrm{Cr}_{2} \mathrm{O}_{3}$ catalyst fitted by Marin et al. (1986), 0.15 and 0.24 $\mathrm{m}^{3} \cdot \mathrm{mole}^{-1}$ respectively, and the adsorption coefficient for hydrogen is in the same order of magnitude. Besides, as in the work of Marin et al. (1986), it turned out not to be necessary to assume that hydrogen can reverse the coke precursor formation process in order to describe the coke formation rates with hydrogen present in the gas mixture. However, this cannot be excluded from this work.

Finally it is noted that in this work the kinetic rate expression for the time-dependent coke formation rate has been derived under steady state gas phase conditions, viz. the temperature and gas phase composition. The kinetic investigation could be extended by examining the coke formation rate under transient operating conditions. Transient kinetic experiments to determine coke formation rates under unsteady operating conditions have not been reported in the literature before. However, if the same reaction steps as in the steady state are rate determining (thus assuming that all other reaction steps are still instantaneous) and if mass accumulation effects of intermediary products not taken into account explicitly in the model are small, transient kinetic effects can be neglected. It is assumed that the derived 'steady state' kinetic expression for the time-dependent coke formation rate can be applied for unsteady conditions, as in the RCRFR.

\section{Summary and conclusions}

Experimentally determined coke formation rates as a function of time on stream for propylene-nitrogen and propylene-hydrogen gas mixtures in a thermogravimetric analyser 
over a used $\mathrm{Pt} / \gamma-\mathrm{Al}_{2} \mathrm{O}_{3}$ monolithic catalyst can be adequately described using a mechanistic dual coke growth model following Peña et al. (1993) and Marin et al. (1988).

Their model has been extended by assuming that the rate-determining coke precursor formation initially occurs via propylene oligomerisation process. Based on this mechanistic model (see Table 1) a kinetic rate expression has been derived (equation 1-7) and the adsorption and reaction rate constants and activation energies have been fitted using the Levenberg-Marquardt multivariable algorithm (see Table 2). The kinetic rate expression quantitatively describes the coke formation rates over a wide temperature range $\left(600-800{ }^{\circ} \mathrm{C}\right)$ and wide concentration range (at least 0-50\% propylene in nitrogen or hydrogen).

The model satisfactorily describes the remarkable experimentally observed initial quadratic increase in the coke formation rates versus time (auto-catalysis) with its high apparent propylene reaction order, and the decrease in coke formation rates after longer times on stream (auto-deactivation), with a constant residual coke formation rate when the coke content exceeds $12 \mathrm{wt} \%$. Also the observed very pronounced influence of the hydrogen concentration at low temperatures and its diminishing influence at higher temperatures is quantitatively captured by the model. The derived kinetic rate expression provides valuable information for the design and optimisation of propane dehydrogenation reactors.

\section{Acknowledgements}

The author wishes to thank H. bij de Vaate for her valuable contribution to the experimental work and W. Leppink for the construction and maintenance of the TGA. Furthermore, the financial support by the Netherlands Organization for Scientific Research (N.W.O.) is gratefully acknowledged.

\section{Notation}

C total coke

$C_{g} \quad$ gas phase concentration $\left[\mathrm{mole} \cdot \mathrm{m}^{-3}\right.$ ]

$C_{s} \quad$ surface concentration $\left[\mathrm{mole} \cdot \mathrm{m}^{-2}\right.$ ]

$\mathrm{C}_{\mathrm{m}} \quad$ monolayer coke

$\mathrm{C}_{\mathrm{M}} \quad$ multilayer coke 
$\mathrm{CP} \quad$ coke precursor

$E \quad$ activation energy $\left[\mathrm{kJ} \cdot \mathrm{mole}^{-1}\right]$

(g) gas phase

$k \quad$ reaction rate constant

$K \quad$ adsorption constant

$M \quad$ weight content $\left[\mathrm{mg} \cdot \mathrm{mg}_{\mathrm{cat}}{ }^{-1}\right]$

$n \quad$ apparent reaction order in the propylene concentration [-]

PD propylene dimer

$r^{2} \quad$ linear regression coefficient [-]

$R_{C} \quad$ coke formation rate $\left[\mathrm{mg} \cdot \mathrm{mg}_{\mathrm{cat}}{ }^{-1} \cdot \mathrm{s}^{-1}\right]$

(s) adsorbed

S free surface site

$t \quad$ time [s]

$x_{g} \quad$ gas phase molar fraction $\left[\right.$ mole $\cdot \mathrm{mole}^{-1}$ ]

$w \quad$ maximum monolayer coke content $\left[\mathrm{mg} \cdot \mathrm{mg}_{\mathrm{cat}}{ }^{-1}\right]$

Greek symbols

$\theta \quad$ surface fraction [-]

\section{Subscripts}

C propylene (adsorption equilibrium) / total coke

$\mathrm{CP} \quad$ coke precursor (formation reaction)

$\mathrm{Cm}$ monolayer coke (formation reaction)

CM multilayer coke (formation reaction)

g gas phase

$\mathrm{H}$ hydrogen (chemisorption equilibrium)

$\mathrm{R}$ propylene dimer (formation reaction)

s adsorbed

S free surface site

tot total

$0 \quad$ at initial conditions

$\infty \quad$ pre-exponential 


\section{References}

Barbier, J., Corro, G. and Zhang, Y. (1985). Coke formation on platinum-alumina catalyst of wide varying dispersion. Appl. Catal., 13, 245-255

Bariås, O.A., Holmen, A., and Blekkan, E.A. (1996). Propane dehydrogenation over supported Pt and Pt-Sn catalysts: catalyst preparation, characterization, and activity measurements. J. Catal., 158, 1-12

Beeckman, J.W. and Froment, G.F. (1979). Catalyst deactivation by active site coverage and pore blockage. Ind. Eng. Chem. Fundam., 18, 245-256

Beeckman, J.W. and Froment, G.F. (1980). Catalyst deactivation by site coverage and pore blockage. Chem. Eng. Sci., 35, 805-815

Cosyns, J., Chodorge, J., Commereuc, D. and Torck, B. (1998). Maximize propylene production. Hydrocarbon Process., March 1998, 61-66

Dumez, F.J. and Froment, G.F. (1976). Dehydrogenation of 1-butene into butadiene. Kinetics, catalyst coking, and reactor design. Ind. Eng. Chem. Process Des. Dev., 15, 291-301

Hamid, S.B.A. and Cerouane, E.G. (1994). Effect of temperature on propane aromatisation by $\mathrm{Ga}-\mathrm{H}-\mathrm{MFI}(\mathrm{Si}, \mathrm{Al})$ catalysts, Zeolites and related microporous materials: state of the art, 84, $2335-2344$

Larsson, M., Hultén, M., Blekkan, E.A. and Andersson, B. (1996). The effect of reaction conditions and time on stream on the coke formed during propane dehydrogenation, J. Catal., $164,44-53$

Lin, L., Zao, T., Zang, J. and Xu, Z. (1990). Dynamic process of carbon deposition on platinum and platinum-tin catalysts for alkane dehydrogenation. Appl. Catal., 67, 11-23 
Marin, G.B., Beeckman, J.W. and Froment G.F. (1986). Rigorous kinetic models for catalyst deactivation by coke deposition: application to butene dehydrogenation. J. Catal., 97, 416-426

Nam, I.S. and Kittrell, J.R. (1984). Use of catalyst coke content in deactivation modeling. Ind. Eng. Chem. Process Des. Dev., 23, 237-242

Peña, J.A., Monzón, A. and Santamaría, J. (1993). Deactivation by coke of a $\mathrm{Cr}_{2} \mathrm{O}_{3} / \mathrm{Al}_{2} \mathrm{O}_{3}$ catalyst during butene dehydrogenation. J. Catal., 142, 59-69

Reid, R.C., Prausnitz, J.M. and Poling, B.E. (1988). The properties of gases and liquids. McGraw-Hill Book Company, New York.

Resasco, D.E. and Haller, G.L. (1994). Catalytic dehydrogenation of lower alkanes. J. Catal., $11,379-411$

Taffe, P. (1996). Propping up the propylene supply. Eur. Chem. News, 21-27 October, 27-28 


\section{Appendix A - Derivation of the coke formation rate equation}

Assuming that the adsorption equilibria of propylene and hydrogen are established instantaneously, the hydrogen and propylene surface concentrations can be expressed explicitly as a function of the gas phase concentrations and the concentration free surface sites, denoted by $\mathrm{S}$, according to

$$
C_{s, \mathrm{H}}=K_{H} C_{g, \mathrm{H}_{2}}^{\frac{1}{2}} C_{s, \mathrm{~S}}, \quad C_{s, \mathrm{C}_{3} \mathrm{H}_{6}}=K_{C} C_{g, \mathrm{C}_{3} \mathrm{H}_{6}} C_{s, \mathrm{~S}}
$$

Since the surface sites are either unoccupied or adsorbed with propylene or dissociatively chemisorbed hydrogen, or covered with propylene-dimer or monolayer coke (since it is assumed that coke precursor instantaneously grows to monolayer coke), both assumed to occupy two surface sites,

$$
C_{s, t o t}=C_{s, \mathrm{~S}}+C_{s, \mathrm{H}}+C_{s, \mathrm{C}_{3} \mathrm{H}_{6}}+2\left(C_{s, \mathrm{PD}}+C_{s, \mathrm{C}_{\mathrm{m}}}\right)
$$

Substitution of the adsorption equilibria gives

$$
C_{s, \mathrm{~S}}=\frac{C_{s, t o t}-2\left(C_{s, \mathrm{PD}}+C_{s, \mathrm{C}_{\mathrm{m}}}\right)}{1+K_{H} C_{g, \mathrm{H}_{2}}^{\frac{1}{2}}+K_{C} C_{g, \mathrm{C}_{3} \mathrm{H}_{6}}}
$$

Defining surface fractions as

$$
\theta_{\mathrm{S}}=\frac{C_{s, \mathrm{~S}}}{C_{s, t o t}}, \quad \theta_{\mathrm{H}}=\frac{C_{s, \mathrm{H}}}{C_{s, t o t}}, \quad \theta_{\mathrm{C}_{3} \mathrm{H}_{6}}=\frac{C_{s, \mathrm{C}_{3} \mathrm{H}_{6}}}{C_{s, t o t}}, \quad \theta_{\mathrm{PD}}=\frac{2 C_{s, \mathrm{PD}}}{C_{s, t o t}}, \quad \theta_{\mathrm{Cm}}=\frac{2 C_{s, \mathrm{C}_{\mathrm{m}}}}{C_{s, t o t}}
$$

Rewriting the surface concentrations in terms of surface fractions results in

$$
\begin{aligned}
& \theta_{\mathrm{S}}+\theta_{\mathrm{H}}+\theta_{\mathrm{C}_{3} \mathrm{H}_{6}}+\theta_{\mathrm{PD}}+\theta_{\mathrm{Cm}}=1 \\
& \theta_{\mathrm{S}}=\frac{1}{1+K_{H} C_{g, \mathrm{H}_{2}}^{\frac{1}{2}}+K_{C} C_{g, \mathrm{C}_{3} \mathrm{H}_{6}}}\left(1-\theta_{\mathrm{PD}}-\theta_{\mathrm{Cm}}\right)
\end{aligned}
$$




$$
\begin{aligned}
& \theta_{\mathrm{H}}=\frac{K_{H} C_{g, \mathrm{H}_{2}}^{\frac{1}{2}}}{1+K_{H} C_{g, \mathrm{H}_{2}}^{\frac{1}{2}}+K_{C} C_{g, \mathrm{C}_{3} \mathrm{H}_{6}}}\left(1-\theta_{\mathrm{PD}}-\theta_{\mathrm{Cm}}\right) \\
& \theta_{\mathrm{C}_{3} \mathrm{H}_{6}}=\frac{K_{C} C_{g, \mathrm{C}_{3} \mathrm{H}_{6}}}{1+K_{H} C_{g, \mathrm{H}_{2}}^{\frac{1}{2}}+K_{C} C_{g, \mathrm{C}_{3} \mathrm{H}_{6}}}\left(1-\theta_{\mathrm{PD}}-\theta_{\mathrm{Cm}}\right)
\end{aligned}
$$

The number of surface sites occupied by propylene-dimer and monolayer coke is described as a function of time by the following balances (see Table 1):

$$
\begin{aligned}
& \frac{d \theta_{\mathrm{PD}}}{d t}=k_{R} \theta_{\mathrm{C}_{3} \mathrm{H}_{6}}^{2}-k_{C P} \theta_{\mathrm{C}_{3} \mathrm{H}_{6}} \theta_{\mathrm{PD}}-k_{C P, 2} \theta_{\mathrm{PD}} \theta_{\mathrm{Cm}} \\
& \frac{d \theta_{\mathrm{Cm}}}{d t}=k_{C P} \theta_{\mathrm{C}_{3} \mathrm{H}_{6}} \theta_{\mathrm{PD}}+k_{C P, 1} \theta_{\mathrm{C}_{3} \mathrm{H}_{6}} \theta_{\mathrm{Cm}}+k_{C P, 2} \theta_{\mathrm{PD}} \theta_{\mathrm{Cm}}
\end{aligned}
$$

The mass increase due to coke formation per unit mass of the catalyst, the coke content $M_{\mathrm{C}}$, is given by the sum of the monolayer and multilayer coke formation rates, represented by

$$
\frac{d M_{\mathrm{C}}}{d t}=w\left(k_{C P} \theta_{\mathrm{C}_{3} \mathrm{H}_{6}} \theta_{\mathrm{PD}}+k_{C P, 1} \theta_{\mathrm{C}_{3} \mathrm{H}_{6}} \theta_{\mathrm{Cm}}+k_{C P, 2} \theta_{\mathrm{PD}} \theta_{\mathrm{Cm}}\right)+k_{C M} C_{g, \mathrm{C}_{3} \mathrm{H}_{6}} \theta_{\mathrm{Cm}}
$$

where $w$ represents the maximum monolayer coke content.

Initially, the surface is free of any propylene-dimer and monolayer or multilayer coke,

$t=0: \quad \theta_{\mathrm{PD}}=\theta_{\mathrm{Cm}}=0 \quad$ and $\quad M_{\mathrm{C}}=M_{\mathrm{Cm}}=M_{\mathrm{CM}}=0$

which completes the model description by expressing the initial conditions for the differential equations. 


\section{Appendix B - Solution of the coke formation rate equation for short times on stream}

The equations describing the increase in coke content in time derived in Appendix A can be simplified for short times on stream allowing an analytical expression for the coke content. For short times on stream the monolayer coke fraction is still negligible, so that the equations reduce to:

$\frac{d M_{\mathrm{C}}}{d t} \approx w k_{C P} \theta_{\mathrm{C}_{3} \mathrm{H}_{6}} \theta_{\mathrm{PD}}$

$\frac{d \theta_{\mathrm{PD}}}{d t} \approx k_{R} \theta_{\mathrm{C}_{3} \mathrm{H}_{6}}^{2}-k_{C P} \theta_{\mathrm{C}_{3} \mathrm{H}_{6}} \theta_{\mathrm{PD}}$

$\frac{d \theta_{\mathrm{Cm}}}{d t} \approx k_{C P} \theta_{\mathrm{C}_{3} \mathrm{H}_{6}} \theta_{\mathrm{PD}}$

$\theta_{\mathrm{C}_{3} \mathrm{H}_{6}}=\theta_{\mathrm{C}_{3} \mathrm{H}_{6}, 0}\left(1-\theta_{P D}-\theta_{\mathrm{Cm}}\right), \quad$ with $\theta_{\mathrm{C}_{3} \mathrm{H}_{6}, 0}=\frac{K_{C} C_{g, \mathrm{C}_{3} \mathrm{H}_{6}}}{1+K_{H} C_{g, \mathrm{H}_{2}}^{\frac{1}{2}}+K_{C} C_{g, \mathrm{C}_{3} \mathrm{H}_{6}}}$

with $\theta_{\mathrm{PD}}=\theta_{\mathrm{Cm}}=0$ and $M_{\mathrm{C}}=0$

Summation of the balance equations for propylene dimer and monolayer coke results in

$\frac{d \theta_{\mathrm{PD}}}{d t}+\frac{d \theta_{\mathrm{Cm}}}{d t}=k_{R} \theta_{\mathrm{C}_{3} \mathrm{H}_{6}}^{2}$

which can be rewritten into

$\frac{d}{d t}\left(1-\theta_{\mathrm{PD}}-\theta_{\mathrm{Cm}}\right)=-k_{R} \theta_{\mathrm{C}_{3} \mathrm{H}_{6}, 0}^{2}\left(1-\theta_{\mathrm{PD}}-\theta_{\mathrm{Cm}}\right)^{2}$

Solution of this ordinary differential equation using the initial conditions (B.5) gives 
$\left(1-\theta_{\mathrm{PD}}-\theta_{\mathrm{Cm}}\right)(t)=\frac{1}{1+k_{R} \theta_{\mathrm{C}_{3} \mathrm{H}_{6}, 0}^{2} t}$

$\theta_{\mathrm{C}_{3} \mathrm{H}_{6}}(t)=\frac{\theta_{\mathrm{C}_{3} \mathrm{H}_{6}, 0}}{1+k_{R} \theta_{\mathrm{C}_{3} \mathrm{H}_{6}, 0}^{2} t}$

Substitution in the propylene dimer balance equation (B.2) gives:

$\frac{d \theta_{\mathrm{PD}}}{d t}=\frac{k_{R} \theta_{\mathrm{C}_{3} \mathrm{H}_{6}, 0}^{2}}{\left(1+k_{R} \theta_{\mathrm{C}_{3} \mathrm{H}_{6}, 0}^{2} t\right)^{2}}-\frac{k_{C P} \theta_{\mathrm{C}_{3} \mathrm{H}_{6}, 0}}{1+k_{R} \theta_{\mathrm{C}_{3} \mathrm{H}_{6}, 0}^{2} t} \theta_{\mathrm{PD}}$

The solution of this inhomogeneous ordinary differential equation is

$\theta_{\mathrm{PD}}(t)=\frac{1-\left(1+k_{R} \theta_{\mathrm{C}_{3} \mathrm{H}_{6}, 0}^{2} t\right)^{-\left(\frac{k_{C P}}{k_{R} \theta_{\mathrm{C}_{3} \mathrm{H}_{6}, 0}}-1\right)}}{\left(1+k_{R} \theta_{\mathrm{C}_{3} \mathrm{H}_{6}, 0}^{2} t\right)\left(\frac{k_{C P}}{k_{R} \theta_{\mathrm{C}_{3} \mathrm{H}_{6}, 0}}-1\right)}$

The monolayer coke surface fraction can then be written as

$\theta_{\mathrm{Cm}}(t)=\frac{k_{R} \theta_{\mathrm{C}_{3} \mathrm{H}_{6}, 0}^{2} t}{1+k_{R} \theta_{\mathrm{C}_{3} \mathrm{H}_{6}, 0}^{2} t}-\frac{1-\left(1+k_{R} \theta_{\mathrm{C}_{3} \mathrm{H}_{6}, 0}^{2} t\right)^{-\left(\frac{k_{C P}}{k_{R} \theta_{\mathrm{C}_{3} \mathrm{H}_{6}, 0}}-1\right)}}{\left(1+k_{R} \theta_{\mathrm{C}_{3} \mathrm{H}_{6}, 0}^{2} t\right)\left(\frac{k_{C P}}{k_{R} \theta_{\mathrm{C}_{3} \mathrm{H}_{6}, 0}}-1\right)}$

For relatively short times on stream the increase of the coke content in time is then given by

$M_{\mathrm{C}}(t)=w \theta_{\mathrm{Cm}}=w\left[\frac{k_{R} \theta_{\mathrm{C}_{3} \mathrm{H}_{6}, 0}^{2} t}{1+k_{R} \theta_{\mathrm{C}_{3} \mathrm{H}_{6}, 0}^{2} t}-\frac{1-\left(1+k_{R} \theta_{\mathrm{C}_{3} \mathrm{H}_{6}, 0}^{2} t\right)^{-\left(\frac{k_{C P}}{k_{R} \theta_{\mathrm{C}_{3},}, 0}-1\right)}}{\left(1+k_{R} \theta_{\mathrm{C}_{3} \mathrm{H}_{6}, 0}^{2} t\right)\left(\frac{k_{C P}}{k_{R} \theta_{\mathrm{C}_{3} \mathrm{H}_{6}, 0}}-1\right)}\right]$ 
CHAPTER 6

SAFETY ANALYSIS OF SWITCHING BETWEEN REDUCTIVE AND OXIDATIVE CONDITIONS 


\begin{abstract}
A new reverse flow reactor is developed where endothermic reactants (propane dehydrogenation) and exothermic reactants (fuel combustion) are fed sequentially to a monolithic catalyst, while periodically alternating the inlet and outlet positions. Upon switching from reductive to oxidative conditions hydrocarbons come into contact with air. Due to mixing in the monolith channels and in the inlet sections, combustible gas mixtures can be formed. In this chapter the effects during reaction phase switching are studied by detailed numerical simulations and some qualitative experiments. Due to the reverse flow concept and the use of a monolithic catalyst, switching between oxidative and reductive conditions can be carried out without intermediate flushing with inert gases, provided that proper precautions are taken.
\end{abstract}




\section{Introduction}

A new reactor concept is developed for the non-oxidative propane dehydrogenation to propylene and hydrogen over a platinum based monolithic catalyst. The highly endothermic propane dehydrogenation is carried out at high temperatures $\left(550-650{ }^{\circ} \mathrm{C}\right)$ because of thermodynamic constraints on the propane conversion. However, at these temperatures carbonaceous side-products, collectively termed coke, are formed at the catalyst surface, necessitating catalyst regeneration.

The reactor concept is based on, firstly, the indirect coupling between energy necessary for endothermic reactions and energy released by exothermic reactions, using a fixed catalyst as an energy repository. During the endothermic propane dehydrogenation reaction phase energy is withdrawn from the catalyst leading to a temperature drop of the catalyst and simultaneously coke deposition on the catalyst surface. During a consecutive exothermic fuel combustion reaction phase the catalyst is reheated and concurrently regenerated by burning off the coke. Secondly, recuperative heat exchange is integrated inside the reactor using the concept of reverse flow, i.e. periodic alternation of the gas flow direction while feeding the endothermic and exothermic reactants without any preheating. In this novel multifunctional reactor, called the Reaction Coupling Reverse Flow Reactor (RCRFR), the propane dehydrogenation reaction, energy supply at high temperatures, catalyst regeneration and recuperative heat exchange are all integrated in one apparatus.

Upon switching between the endothermic propane dehydrogenation reaction phase to the exothermic fuel combustion reaction phase and vice versa hydrocarbons and hydrogen come into contact with oxygen, at least for a short time. Thus, due to mixing a combustible gas mixture might be formed, possibly causing a temperature runaway (hot spot) or even an explosion. The effects resulting from switching between reductive and oxidative conditions in a monolithic catalyst have not been reported before in literature.

Mixing of oxygen and hydrocarbons can occur because of dispersion inside the monolith channels or mixing in the feed sections (present at both reactor sides because of the reverse flow concept), including the piping, valves and gas distribution sections.

Even if mixing induces an explosive gas mixture, heterogeneous deflagration or detonation is excluded in the monolith channels, if the channel diameter is smaller than the quenching diameter. Minimal quenching distances have been determined from spark ignition between 
parallel plates for propane, propylene and hydrogen combustion in air at 2.0, 1.5 and $0.64 \mathrm{~mm}$, respectively (Lewis and von Elbe, 1961). The quenching diameter is somewhat larger for tubes (Turns, 1996) and minimal at a fuel/air equivalence ratio of slightly exceeding unity and strongly increases for smaller or larger equivalence ratios (Kroschwitz and HoweGrant, 1993). Depending on the operating conditions and reactor design of the RCRFR, the duration of explosive gas mixtures entering the monolith is very short. Hence, in a monolithic catalyst with a channel diameter of $1 \mathrm{~mm}$ or smaller deflagrations can be excluded.

Because of the reverse flow concept the temperatures in the inlet section will - under normal operation - always be well below the auto-ignition temperatures for propane, propylene and hydrogen combustion, $723 \mathrm{~K}, 733 \mathrm{~K}$ and 823-873 K respectively (Lewis and von Elbe, 1961; Zabetakis, 1965), so that the danger of a homogeneous explosion in the inlet section is negligible. However, if due to mixing a hot spot is created at the monolith entrance, an explosive gas mixture in the inlet section might be ignited. These gas phase backdeflagrations to the gas inlet can occur if the monolith inlet temperature exceeds about $1000{ }^{\circ} \mathrm{C}$ (Lewis and von Elbe, 1961; Minkoff and Tipper, 1962).

Potential hazards can obviously be avoided by flushing the reactor with inert gases like nitrogen prior to reaction phase switching. However, if a flushing cycle could be prevented this would greatly enhance the feasibility of the RCRFR by avoiding additional complexity of a flushing cycle on the already very complex dynamic reactor behaviour, and by avoiding extra energy losses and nitrogen costs.

The aim of this work is the study of the phenomena occurring during reaction phase switching in a RCRFR by detailed numerical simulations backed up by some qualitative experiments. Having identified gas phase back-deflagration as the most dangerous hazard, this work focuses on the increase of the monolith entrance temperature in time due to combustion reactions in the monolith channels, where combustible gas mixtures are formed because of mixing in the monolith channels and the inlet section.

Firstly, effects occurring during reaction phase switching have been investigated by simulating three different scenarios. Before taking all mixing processes into account, two limiting cases are studied. In the first limiting case all pre-mixing effects are neglected and only dispersion in the monolith is taken into account. Upon reaction phase switching a step 
change in the inlet concentrations is assumed. In the second limiting case it is assumed that mixing in the inlet section is complete and lasts for an infinitely long time, resulting in a continuous feed of an explosive gas mixture. Finally, the case is simulated where explosive mixtures arise from premixing in an inlet section, resulting in time-dependent boundary conditions for the monolith inlet concentrations. The inlet section is represented as an ideally stirred vessel to consider a worst case scenario.

Secondly, qualitative effects discerned from the simulations are checked by some qualitative experiments.

Since more heat is released during propane combustion compared to propylene and hydrogen combustion under comparable operating conditions, only switching between propane and air feed and vice versa has been studied. Effects of additional coke combustion were ignored, since coke is only deposited in the centre of the reactor due to the low inlet and outlet temperatures in a RCRFR.

\section{Modelling}

The phenomena occurring in an adiabatic RCRFR upon reaction phase switching have been modelled with mass and energy balances for the gas and catalyst phase, using a one-dimensional plug flow model with superimposed axial dispersion. The model equations are summarised in Table 1. In Appendix A, the validity of the model approach is substantiated. Concluding from the theory for generalised Taylor dispersion for reactive systems, the effects of axial mixing due to a radial velocity profile arising from laminar flow are slightly overestimated when using Taylor's equation for the effective axial dispersion. By implementing Taylor's equation a worst case of axial mixing in the monolith channels is considered.

Furthermore, because of the very small pressure drop over a monolithic catalyst and since only relatively small catalyst lengths are considered in this work $(<25 \mathrm{~cm})$, the gas phase momentum balance could be ignored.

The gas phase physical properties have been modelled following Reid et al. (1988), using pure component properties as described by Dauber and Danner (1985). The solid phase is a cordierite monolith with rectangular channels having a hydraulic channel diameter of $0.96 \mathrm{~mm}$ and a gas phase porosity of 0.69 , where $1 \mathrm{wt} \% \mathrm{Pt}$ has been dispersed in the $\gamma-\mathrm{Al}_{2} \mathrm{O}_{3}$ 
washcoat. The catalyst phase was considered as an impermeable pseudo-homogeneous phase with constant physical properties (Eigenberger and Nieken, 1988).

Multi-component mass transfer between the gas bulk and the catalyst surface was described with the Maxwell-Stefan theory. For the mass and heat transfer coefficients the relation of Grigull and Tratz (1965) for circular tubes was implemented, because of the rounding of the channel due to the non-uniform distribution of the washcoat in the square support (Groppi and Tronconi, 1997). By solving the mass balances in the mass average reference frame, flux correction factors for the transport coefficients can be ignored (Bird et al., 1960).

Both homogeneous and heterogeneous reactions are included using simple one-step kinetics. The homogeneous propane combustion reaction kinetics was taken from Westbrook and Dryer (1981), despite the fact that this often used relation has been derived for (catalytic) afterburners where the propane concentration is very low and oxygen is present in large excess. The reaction kinetics for the heterogeneously catalysed propane combustion was taken from Bruno et al. (1983). However, this reaction rate expression does not take the influence of

Table 1. Model equations

Catalyst energy balance:

$$
(1-\varepsilon) \rho_{c} C_{p, c} \frac{\partial T_{c}}{\partial t}=(1-\varepsilon) \frac{\partial}{\partial z}\left(\lambda_{c} \frac{\partial T_{c}}{\partial z}\right)+\left[h a_{v}\left(T_{g}-T_{c}\right)+\sum_{i=1}^{n_{c}} C_{p, c, i} n_{i} a_{v}\right]+\sum_{i=1}^{n_{c}} r_{i}^{h e t} \bar{h}_{i} a_{v}
$$

Gas phase energy balance:

$$
\begin{aligned}
\varepsilon \rho_{g} C_{p, g} \frac{\partial T_{g}}{\partial t}=\varepsilon \frac{\partial}{\partial z}\left(\lambda_{g} \frac{\partial T_{g}}{\partial z}\right)-\varepsilon \rho_{g} v_{z, g} C_{p, g} & \frac{\partial T_{g}}{\partial z}+\varepsilon \rho_{g} D_{a x} \sum_{i=1}^{n_{c}} \frac{\partial \omega_{i, g}}{\partial z} C_{p, g, i} \frac{\partial T_{g}}{\partial z} \\
& -\left[h a_{v}\left(T_{g}-T_{c}\right)+\sum_{i=1}^{n_{c}} C_{p, c, i} n_{i} a_{v}\right]+\sum_{i=1}^{n_{c}} r_{i}^{h o m} \bar{h}_{i} \varepsilon
\end{aligned}
$$

Gas phase overall continuity equation:

$$
\varepsilon \frac{\partial \rho_{g}}{\partial t}=-\varepsilon \frac{\partial}{\partial z}\left(\rho_{g} v_{z, g}\right)
$$

Gas phase continuity equation for component $i\left(i=1,2, . . n_{c^{-}}-1\right)$ :

$$
\varepsilon \frac{\partial}{\partial t}\left(\rho_{g} \omega_{i, g}\right)=\varepsilon \frac{\partial}{\partial z}\left(\rho_{g} D_{a x} \frac{\partial \omega_{i, g}}{\partial z}\right)-\varepsilon \frac{\partial}{\partial z}\left(\rho_{g} \omega_{i, g} v_{z, g}\right)-n_{i} a_{v}+r_{i}^{h o m} \varepsilon
$$

Catalyst phase continuity equation for component $i\left(i=1,2, . . n_{c}-1\right)$ :

$n_{i}=\sum_{j=1}^{n_{c}} k_{x, i j} \rho_{g}\left(\omega_{i, g}-\omega_{i, c}\right)=r_{i}^{h e t}$ 
the oxygen concentration into account. Therefor, the reaction kinetics by Bruno et al. was adjusted to include a first order dependency with respect to the oxygen concentration. Furthermore, internal diffusion limitations were neglected compared to the external mass transfer limitations. Finally, radiative heat losses to the inlet section have been neglected to consider a worst case situation for the monolith entrance temperature.

Uniform initial profiles for gas and catalyst phase temperature and gas phase concentration profiles were taken (unless stated otherwise) and the usual Danckwerts-type boundary conditions were implemented. In case of flushing out propane with air including premixing in the inlet section, the propane mass fraction at the monolith entrance is given by

$$
\omega_{\mathrm{C}_{3} \mathrm{H}_{8}}(t)=\frac{\frac{M_{\mathrm{C}_{3} \mathrm{H}_{8}}}{M_{\mathrm{Air}}} e^{-\frac{t}{\tau_{\text {inlet }}}}}{1-\left(1-\frac{M_{\mathrm{C}_{3} \mathrm{H}_{8}}}{M_{\mathrm{Air}}}\right) e^{-\frac{t}{\tau_{\text {inlet }}}}}
$$

where $\tau_{\text {inlet }}$ represents the gas residence time in the inlet section.

The model equations were solved with a fully implicit finite difference technique using Barton's second order discretisation scheme for the convective terms (see e.g. Centrella and Wilson, 1984). A moving grid was implemented via updating of a transformation function for the axial coordinate. Superimposed on an equidistant grid, additional grid points were located at axial positions where the second order derivatives were largest, while keeping the total number of grid points constant. In the determination of a new grid spacing the minimum cell length was set by the Courant criterion in order to avoid numerical problems of overshoot and undershoot. Natural splines were used to interpolate the variable values from the old grid positions to the new grid positions. Furthermore, by extending the grid refinement zones slightly in the direction of the gas velocity the updating of the transformation function could be decreased to only once every 10 time steps. With this moving grid technique the required calculation time for negligible numerical diffusion compared to axial dispersion was strongly reduced (at least a factor of 10). In the calculations 100 equidistant grid points and 100 additional grid refinement points and a time step of $10^{-4} \mathrm{~s}$ were used for a monolith of $10 \mathrm{~cm}$ length. 


\section{Simulation results}

\subsection{No premixing}

Firstly, the situation has been studied where propane is superseded by air in the monolith, assuming a step change in the inlet concentrations when switching from propane to air as gas feed. Typical axial mass fraction and temperature profiles are shown in Figure 1.
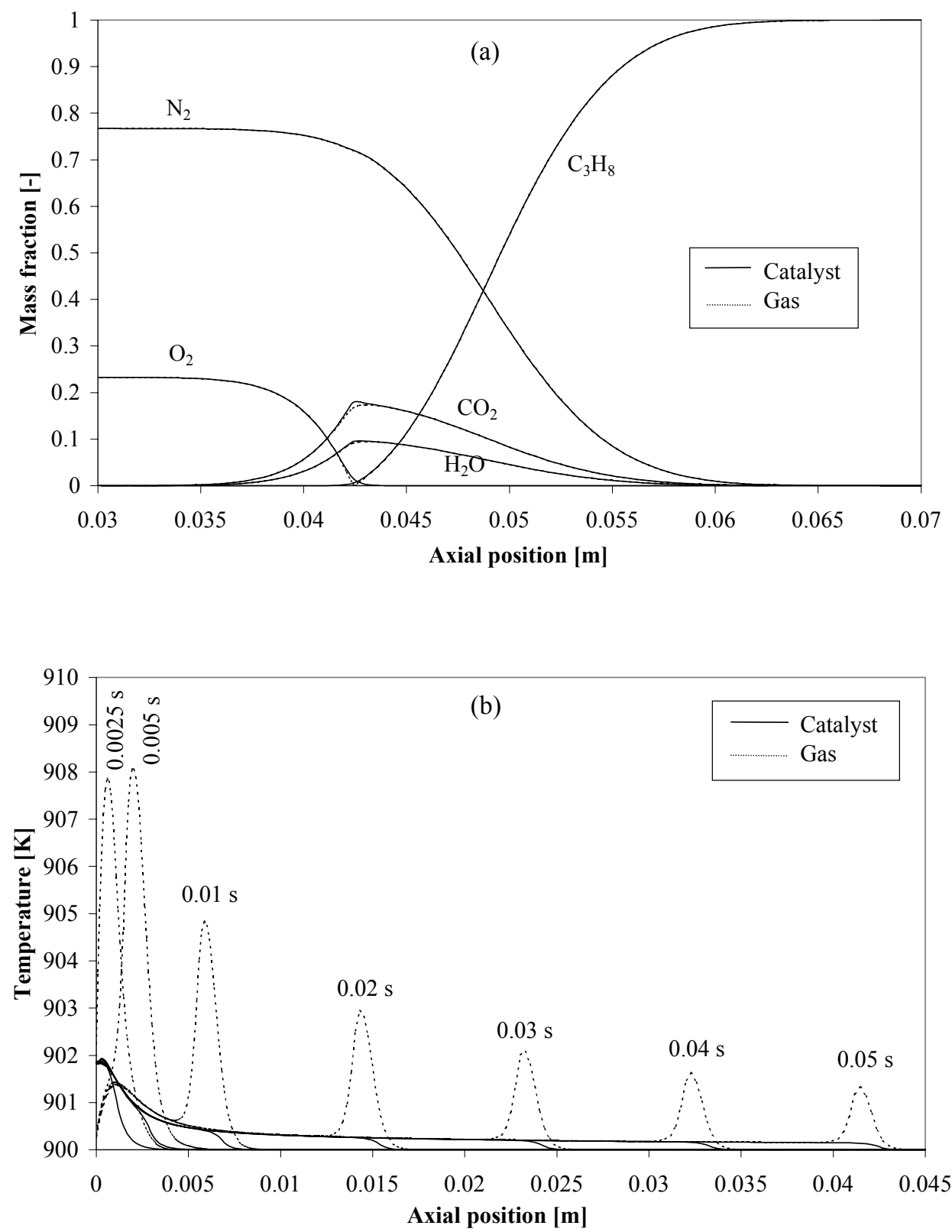

Figure 1. Axial mass fraction profiles after $0.05 \mathrm{~s}$ (a) and temperature profiles (b) for the catalyst and gas phase in case of propane superseded with air without premixing in the inlet section $\left(v_{z, g, \text { in }}=1 \mathrm{~m} \cdot \mathrm{s}^{-1}, T_{g, \text { in }}=T_{c, 0}=900 \mathrm{~K}\right)$. 
The propane combustion reaction products accumulate between the propane and oxygen reactants, thus creating a diffusive barrier. Already after very short times the propane combustion rate becomes limited by axial dispersion of propane and oxygen. In this case of very low concentrations of the reactants at the reaction front a Fickian description of the mass transfer from the gas bulk to the catalyst surface would have sufficed.

Although most of the propane combustion takes place at the catalyst surface, the gas phase temperature increases more than the catalyst temperature, due to the much smaller volumetric heat capacity of the gas phase. The influence of several important process parameters on the maximum temperature rise has been studied. The maximum temperature rise in the gas phase strongly increases with increasing rate of axial dispersion and increasing ratio of propane conversion by homogeneous reactions compared to heterogeneous reactions. Thus, the maximum temperature rise strongly increases for a monolith with a larger channel diameter (see Figure 2), due to the strongly increased axial dispersion and the increased ratio of the homogeneous to heterogeneous reaction rate, mainly because of the decrease in specific catalyst surface area. At higher gas inlet temperatures, the ratio of the homogeneous to heterogeneous reaction rate strongly increases, resulting in higher maximum temperature rises. Finally, the inlet gas velocity hardly effects the maximum temperature rise, because the increase in axial dispersion is counterbalanced by the increase in reaction zone length and relative overall conversion by heterogeneous combustion reactions.

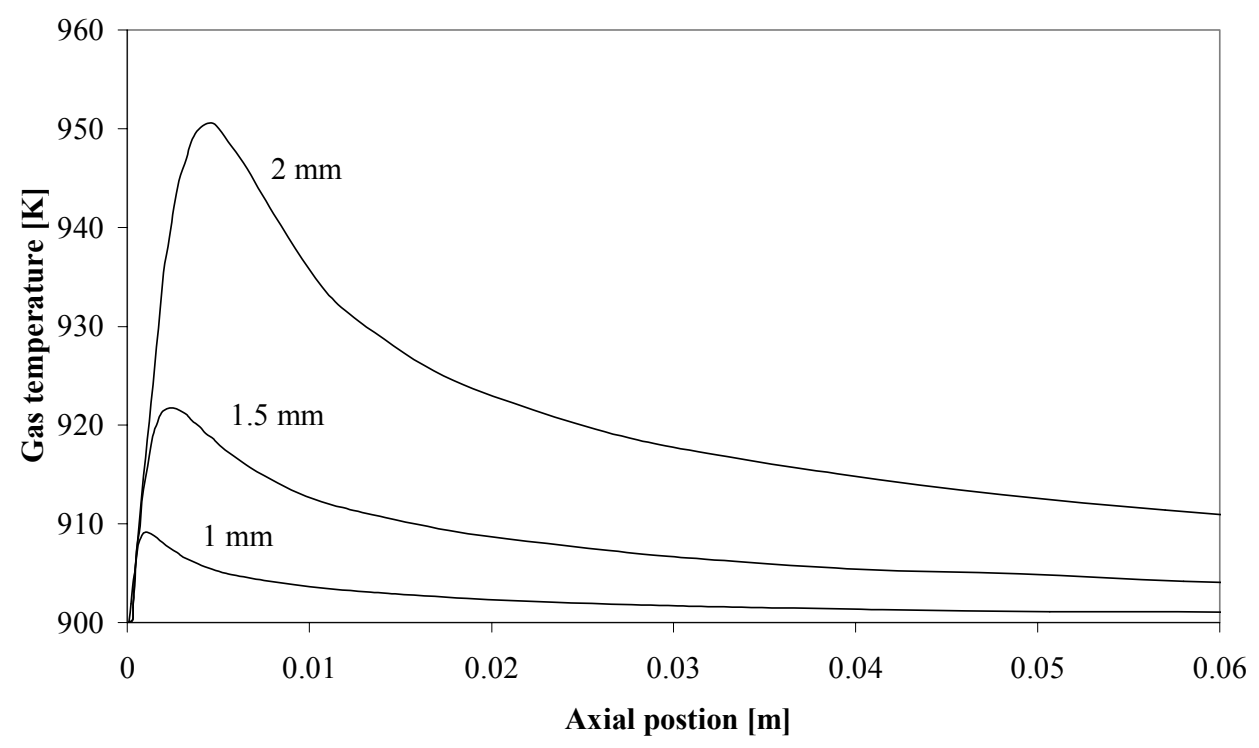

Figure 2. Effect of the channel diameter on the maximum gas temperature with no premixing in the inlet section $\left(v_{z, g, i n}=1 \mathrm{~m} \cdot \mathrm{s}^{-1}, T_{g, \text { in }}=T_{c, 0}=900 \mathrm{~K}\right)$. 


\subsection{Premixed feed}

Simulation results for the case of feeding a premixed propane/air mixture (with constant inlet composition) to a fully active monolith and a 5000 times less active monolith are presented in Figures 3 and 4.

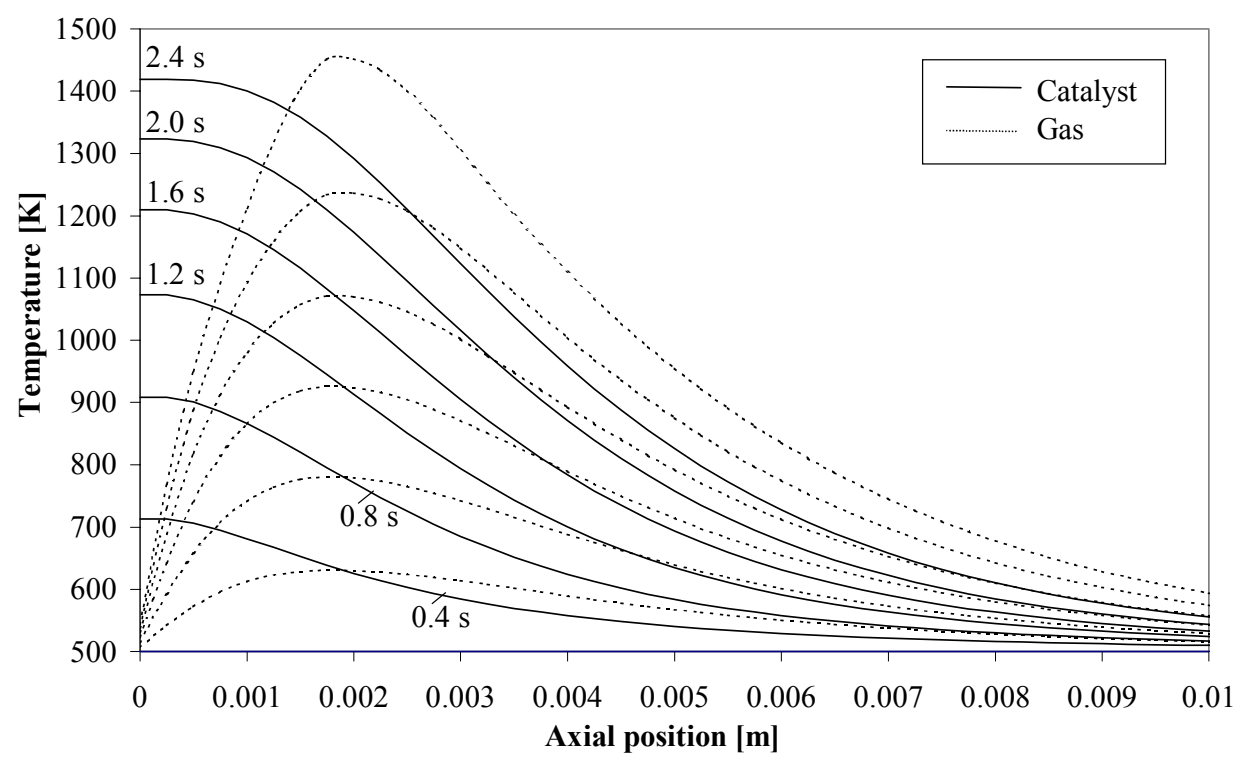

Figure 3. Catalyst and gas phase axial temperature profiles at every $0.4 \mathrm{~s}$ when feeding a premixed propane/air mixture to a catalytic monolith $\left(\omega_{\mathrm{C}_{3} \mathrm{H}_{8}, g, \text { in }}=0.05, v_{z, g, \text { in }}=1 \mathrm{~m} \cdot \mathrm{s}^{-1}, T_{g, \text { in }}=T_{c, 0}=\right.$ $500 \mathrm{~K})$.

When feeding a premixed gas mixture to a fully active monolith almost all propane conversion takes place at the catalyst surface very close to the monolith entrance, creating a hot spot in only a few seconds. When feeding the same mixture to a much less active monolith, the temperature initially increases much further inside the monolith to a very high temperature. Subsequently the temperature front moves back towards the monolith entrance opposite to the gas flow direction, creating a hot spot after a few minutes. Remarkably, the entrance temperature increases fastest for a propane/air mixture with an equivalence ratio of about 2 , regardless of the catalyst activity. Although the largest adiabatic temperature rise is generated for a stoichiometric mixture, the homogeneous reaction rate, dominant at these high temperatures, is largest for a mixture with an equivalence ratio of 3.3 (corresponding to $18 \mathrm{wt} \%$ propane in air). 


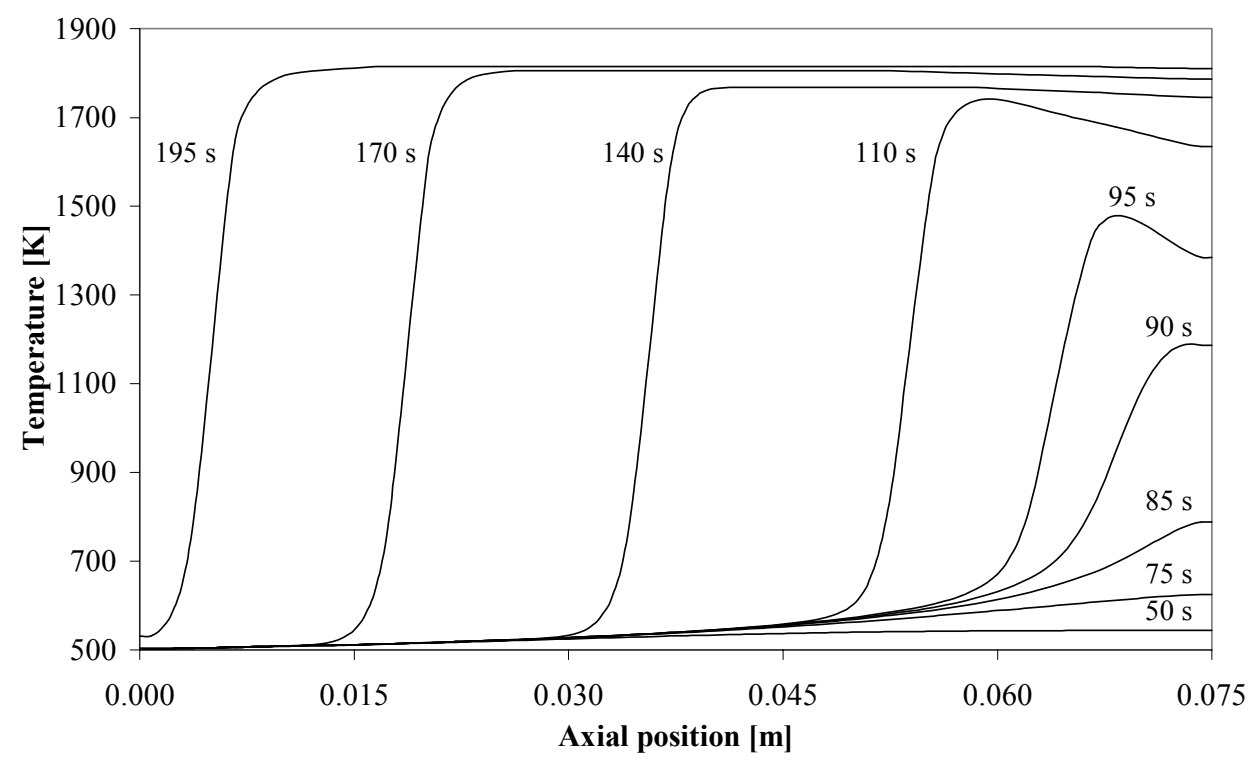

Figure 4. Catalyst phase axial temperature profiles at different times after starting feeding a premixed propane/air mixture to a 5000 times less active monolith $\left(\omega_{\mathrm{C}_{3} \mathrm{H}_{8}, g, \text { in }}=0.05\right.$, $\left.v_{z, g, i n}=1 \mathrm{~m} \cdot \mathrm{s}^{-1}, T_{g, i n}=T_{c, 0}=500 \mathrm{~K}, L=0.075 \mathrm{~m}\right)$.

\subsection{Premixing in the inlet section}

Finally, the effects of premixing in the inlet section have been simulated. The influence of premixing of propane and air in the gas-inlet section has been modelled by assuming an ideally stirred gas inlet section of equal cross-sectional area as the monolith (worst case scenario), so that the length of the inlet section $\left(L_{\text {inlet }}\right)$ represents a characteristic length for the premixed volume. The influence of premixing on the maximum temperature rise is very strong, as depicted in Figure 5.

Figure 5 also shows that the influence of premixing on the entrance temperature is less severe for a higher inlet gas velocity (because of a larger reaction zone in the monolith) and for the reverse case of air being replaced by propane (because of the reaction stoichiometry). An initial axial temperature profile with a low entrance temperature, as common in a reverse flow reactor, strongly decreases the maximum temperature rise. Due to the temperature profile the propane combustion takes place over a longer part of the monolith. 


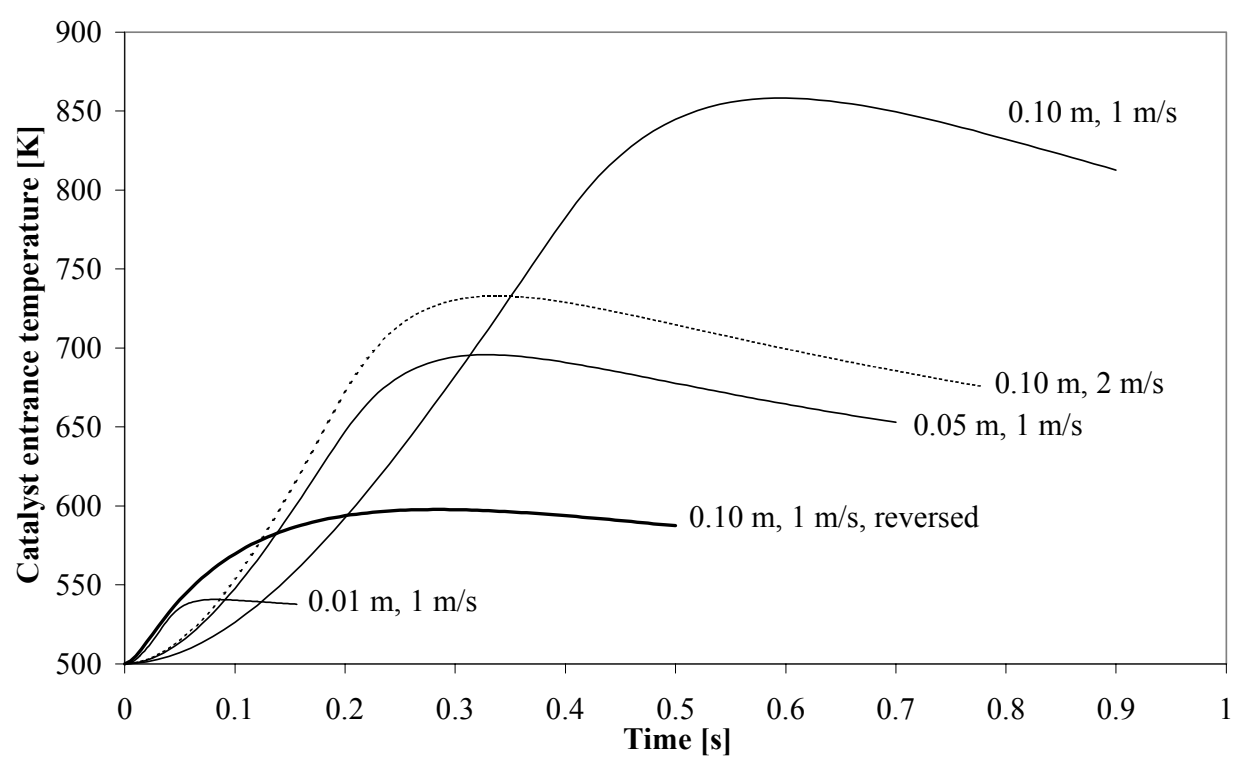

Figure 5. Effect of premixing when sweeping out propane by air on the catalyst entrance temperature as a function of time $\left(\omega_{\mathrm{C}_{3} \mathrm{H}_{8}, g, \text { in }}=0.05, T_{g, \text { in }}=T_{c, 0}=500 \mathrm{~K}, L_{\text {inlet }}\right.$ and $v_{z, g, \text { in }}$ indicated).

\section{Experimental}

To qualitatively verify the simulation results, experiments were carried out in a cylindrical quartz tube with an internal diameter of $19 \mathrm{~mm}$ placed in a tube oven (see Figure 6). In the 'open-ended' quartz tube a cylindrical shaped monolith piece, of equal diameter and $76 \mathrm{~mm}$ in length, was placed at a distance from a gas distribution plate to simulate premixing. The porous plate also acts as a flame quencher.

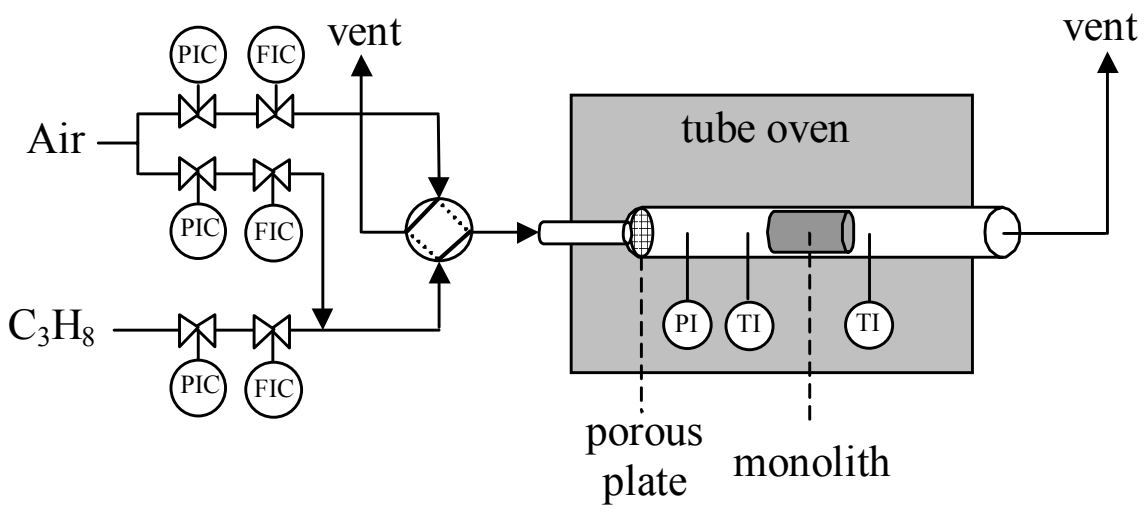

Figure 6. Experimental set-up. 
In the experiments two different types of cordierite monoliths were used (supplied by Engelhard), one with $1 \mathrm{wt} \% \mathrm{Pt}$ dispersed in the $\gamma-\mathrm{Al}_{2} \mathrm{O}_{3}$ washcoat and one without platinum, referred to as the active and inert monolith respectively. The hydraulic diameter of the square channels of both monoliths was $0.96 \mathrm{~mm}$. The gas phase temperature was measured just in front of and just behind the monolith. Using a pneumatic four-way valve the feed was switched from a propane/air mixture to air or vice versa.

\section{Experimental results}

\subsection{Premixed feed}

Typical experimental results for the case of a premixed propane/air feed to the inert monolith are given in Figure 7. The gas temperature $\left(T_{1}\right)$ just in front of the monolith initially decreases somewhat because of insufficient gas heating. The temperature of the gas $\left(T_{2}\right)$ flowing out of the monolith initially increases slowly due to heterogeneous reactions in the monolith. Suddenly, the temperature at the outlet rises very rapidly due to homogeneous combustion reactions, which could also well be observed visually as a bright yellow radiation.

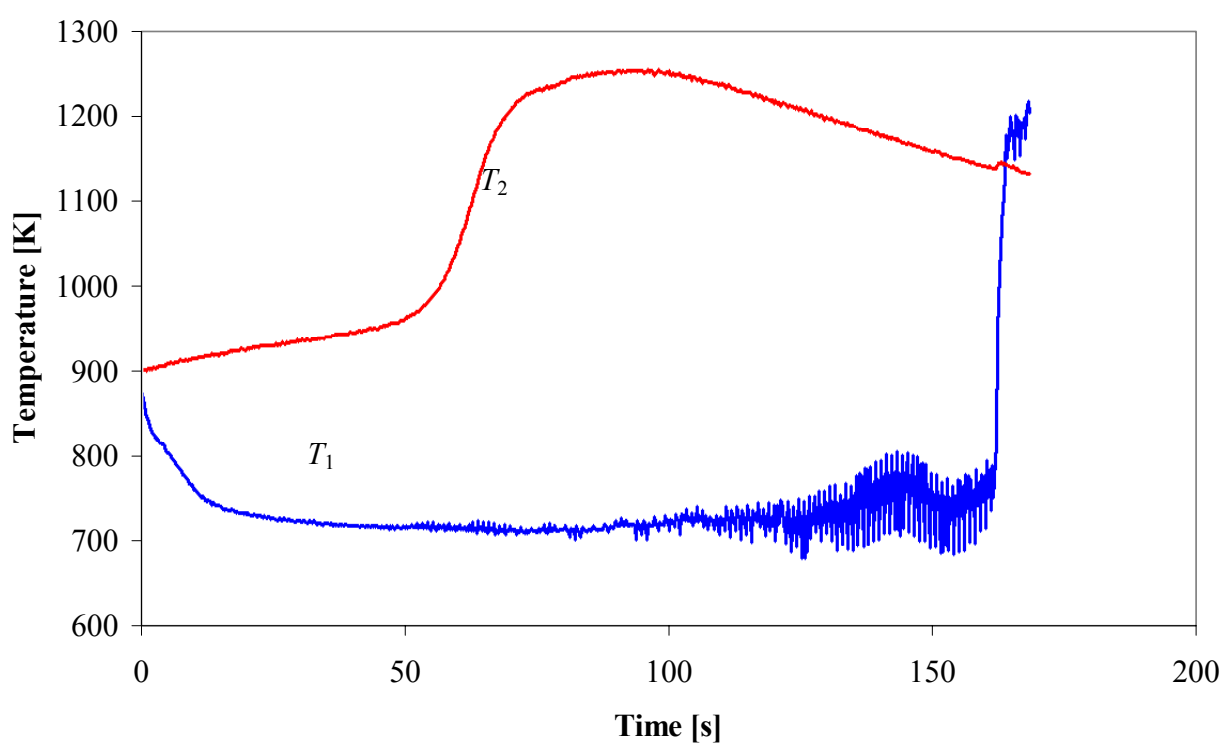

Figure 7. Evolution of the gas phase temperatures measured just in front of $\left(T_{1}\right)$ and just behind $\left(T_{2}\right)$ the monolith when feeding a premixed propane/air mixture over an inert monolith $\left(\omega_{\mathrm{C}_{3} \mathrm{H}_{8}, g, i n}=0.125, T_{c, 0}=900 \mathrm{~K}, v_{z, g, i n}=0.68 \mathrm{~m} \cdot \mathrm{s}^{-1}\right)$. 
Subsequently, this temperature front travels through the monolith in opposite direction relative to the gas flow direction. When the temperature front reaches the monolith inlet, the gas phase in front of the monolith is ignited, observed as an instantaneous temperature increase of about $500^{\circ} \mathrm{C}$.

It was found that the flashback-time decreases strongly with increasing initial and inlet temperatures (e.g. ca. $1 \mathrm{~min}$ at $700{ }^{\circ} \mathrm{C}$ and $4 \mathrm{~min}$ at $550{ }^{\circ} \mathrm{C}$ ) and was minimal for an equivalence ratio of about 2 (see Figure 8 ). These experimental observations correspond very well with the simulations.

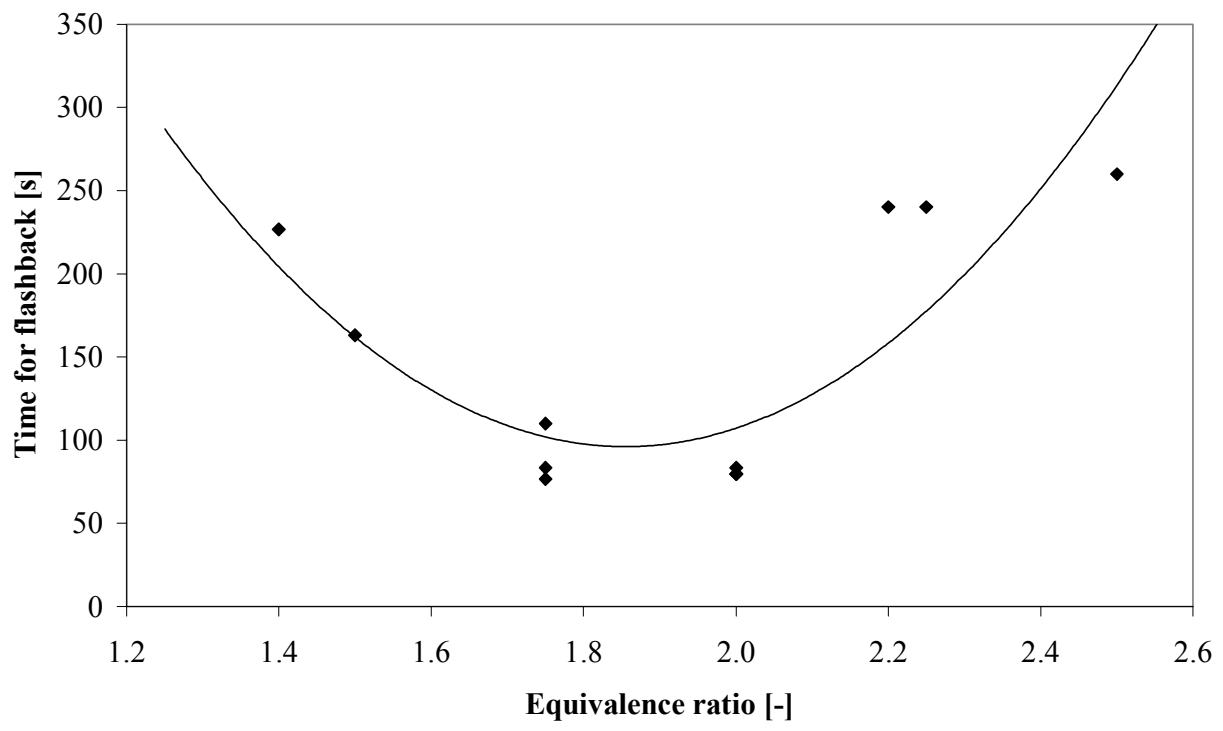

Figure 8. Time after which flashback-deflagration occurs in an inert monolith when feeding a premixed propane/air mixture as a function of the equivalence ratio $\left(T_{g, i n}=T_{c, 0}=823 \mathrm{~K}\right.$, $\left.v_{z, g, i n}=0.68 \mathrm{~m} \cdot \mathrm{s}^{-1}\right)$.

No temperature fronts were observed when feeding a premixed propane/air mixture to the active monolith. However, the entrance temperature increased quickly to approximately 500$600{ }^{\circ} \mathrm{C}$ within 5 to $20 \mathrm{~s}$ at 350 and $200{ }^{\circ} \mathrm{C}$, respectively. Again, the fastest temperature rise was found for a propane/air ratio equal to twice the stoichiometric ratio. 


\subsection{Switching between pure propane and air as feed}

In the experimental set-up no gas phase back-deflagrations were observed when switching from pure propane to air as feed or vice versa, not even if the active monolith was heated up to $1000{ }^{\circ} \mathrm{C}$ and placed almost at the end of the quartz tube. Presumably, the extent of mixing in the 'inlet-section' is much less severe than the ideal mixing assumed in the simulations.

\section{Conclusions}

Simulations have shown that flushing with inert gasses is not necessary for monoliths with a small channel diameter, if premixing in the gas inlet section is minimised and if the gas inlet and outlet temperatures are relatively low. The latter condition also excludes gas phase backdeflagrations. Due to the reverse flow concept and the high overall efficiency of the indirect energy transfer, inlet and outlet temperatures are low. The axial temperature profile further diminishes the temperature rise during reaction phase switching. To assure operation at low inlet and outlet temperatures, the monolith inlet and outlet temperatures should be measured continuously as a safety measure. The gas distribution plate acts as a flame-arresting device.

In order to use the whole monolith effectively and obtain maximum conversion, the Damköhler numbers of the endothermic and exothermic reaction phases need to be matched. Because the combustion reaction rate is much larger compared to the dehydrogenation reaction rate, the gas velocity during the fuel combustion cycle is relatively high, even further decreasing possible effects when switching from propane to air as gas feed. Temperature effects of switching from air to propane feed are less severe because of the reaction stoichiometry. Furthermore, switching from endothermic to exothermic reactants or vice versa could be carried out asynchronously with switching the gas flow direction. In this switching scheme the switching between the reaction phases is always carried out when the temperature front has moved somewhat further into the monolith, assuring a cold monolith inlet at a temperature equal to the gas inlet temperature (room temperature).

In a small set-up consisting of an open-ended quartz-tube containing a monolith and placed in a tube-oven, it has been experimentally confirmed that gas phase back-deflagrations do not occur during reaction phase switching, even with high initial uniform axial temperature 
profiles. Taking proper precautions, switching between oxidative and reductive conditions can be carried out without intermediate flushing with inert gases. Without flushing, the heat released by propane combustion during reaction phase switching can actually be used to reheat the catalyst.

\section{Acknowledgements}

The theoretical and experimental work by R. K. Drijfholt is greatly appreciated. Also the financial support by the Netherlands Organization for Scientific Research (N.W.O.) is gratefully acknowledged.

\section{Notation}

$a_{v} \quad$ specific external catalyst surface area $\left[\mathrm{m}^{2} \cdot \mathrm{m}^{-3}\right]$

$C_{p} \quad$ heat capacity $\left[\mathrm{J} \mathrm{kg}^{-1} \cdot \mathrm{K}^{-1}\right]$

$d_{h, c} \quad$ hydraulic channel diameter [m]

$D \quad$ diffusivity $\left[\mathrm{m}^{2} \cdot \mathrm{s}^{-1}\right]$

$D^{*} \quad$ dispersion dyadic $\left[\mathrm{m}^{2} \cdot \mathrm{s}^{-1}\right]$

$D_{a x} \quad$ axial dispersion coefficient $\left[\mathrm{m}^{2} \cdot \mathrm{s}^{-1}\right]$

$h \quad$ external heat transfer coefficient $\left[\mathrm{W} \cdot \mathrm{m}^{-2} \cdot \mathrm{K}^{-1}\right.$ ]

$\bar{h} \quad$ partial molar enthalpy $\left[\mathrm{J} \cdot \mathrm{kg}^{-1}\right]$

$k_{s} \quad$ heterogeneous conversion rate constant $\left[\mathrm{m} \cdot \mathrm{s}^{-1}\right]$

$k_{x} \quad$ external mass transfer coefficient $\left[\mathrm{m} \cdot \mathrm{s}^{-1}\right]$

$L \quad$ monolith length [m]

$L_{\text {inlet }} \quad$ length of inlet section [m]

$M \quad$ molecular weight $\left[\mathrm{kg} \cdot \mathrm{mole}^{-1}\right]$

$n \quad$ interfacial mass flux $\left[\mathrm{kg} \cdot \mathrm{m}^{-2} \cdot \mathrm{s}^{-1}\right]$

$n_{c} \quad$ total number of components

$\mathrm{Pe} \quad$ Peclet number for mass transport

$r^{\text {het }} \quad$ heterogeneous reaction rate $\left[\mathrm{kg} \cdot \mathrm{m}^{-2} \cdot \mathrm{s}^{-1}\right]$

$r^{\text {hom }}$ homogeneous reaction rate $\left[\mathrm{kg} \cdot \mathrm{m}^{-3} \cdot \mathrm{s}^{-1}\right]$

$R \quad$ gas constant $\left[\mathrm{J} \cdot \mathrm{mole}^{-1} \cdot \mathrm{K}^{-1}\right.$ ] 


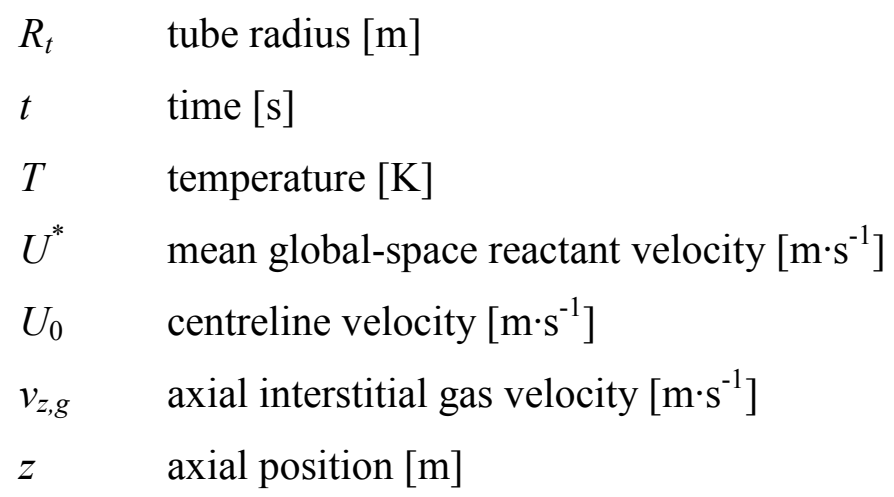

\section{Greek letters}

$\beta_{n} \quad$ positive roots of Bessel function equation: $\beta_{n} \mathrm{~J}_{1}\left(\beta_{n}\right)=\mu \mathrm{J}_{0}\left(\beta_{n}\right)(n=0,1,2, \ldots)$

$\varepsilon \quad$ gas phase porosity $\left[\mathrm{m}^{3} \cdot \mathrm{m}^{-3}\right]$

$\lambda \quad$ conductivity $\left[\mathrm{W} \cdot \mathrm{m}^{-1} \cdot \mathrm{K}^{-1}\right]$

$\mu \quad$ dimensionless reaction rate constant

$\rho \quad$ density $\left[\mathrm{kg} \cdot \mathrm{m}^{-3}\right]$

$\tau_{\text {inlet }} \quad$ gas residence time in inlet section $[\mathrm{s}]$

$\omega \quad$ mass fraction $\left[\mathrm{kg} \cdot \mathrm{kg}^{-1}\right]$

\section{Subscripts}

$\begin{array}{ll}\text { avg } & \text { average } \\ c & \text { catalyst phase } \\ g & \text { gas phase } \\ \text { in } & \text { at the inlet } \\ i, j & \text { component } i, j \\ 0 & \text { initial }\end{array}$

\section{References}

Bird, R.B. Stewart, W.E. and Lightfoot, E.N. (1960). Transport phenomena. John Wiley \& sons, New York, USA

Brenner, H., Edwards, D.A. (1993). Macrotransport processes, Butterworth-Heinemann, Stoneham, USA 
Bruno, C., Walsh, P.M., Santavicca, S.A., Sinha, N., Yaw, Y. and Bracco, F.V. (1983). Catalytic combustion of propane/air mixtures on platinum, Comb. Sci. and Techn., 31, 43-74

Centrella, J. and Wilson, J. (1984). Planar numerical cosmology. II. The difference equations and numerical tests, Astrophysical J. Suppl. Ser., 54, 229-249

Dauber, T.E. and Danner, R.P. (1985). Data compilation tables of properties of pure compounds, AIChE, New York, USA

Eigenberger,G. and Nieken, U. (1988). Catalytic combustion with periodic flow reversal. Chem. Engng Sci., 43, 2109-2115

Grigull, U. and Tratz, H. (1965). Thermischer Einlauf in ausgebildeter laminarer Rohrströmung, Int. J. Heat and Mass Transfer, 8, 669-678

Groppi, G. and Tronconi, E. (1997). Theoretical analysis of mass and heat transfer in monolith catalysts with triangular channels, Chem. Engng Sci., 52, 3521-3526

Kroshwitz, J.I. and Howe-Grant, M. (1993). Kirk-Othmer, Encyclopedia of chemical technology, $4^{\text {th }}$ ed., Vol. 6, John Wiley \& sons, New York, USA, 1056

Lewis, B. and von Elbe, G. (1961). Combustion, flames and explosions of gases, Academic Press, New York, USA

Minkoff, G.J. and Tipper, C.F.H. (1962). Chemistry of combustion reactions. Bulletworth \& Co. Ltd., Belfast, Northern Ireland

Reid, R.C., Prausnitz, J.M. and Poling, B.E. (1988). The properties of gases and liquids. McGraw-Hill, New York, USA

Sankasubramanian, R. and Gill, W.N. (1973). Unsteady convective diffusion with interphase mass transfer. Proc. R. Soc. Lond., A333, 115-132 
Shapiro, M. and Brenner, H. (1986). Taylor dispersion of chemically reactive species: Irreversible first-order reactions in bulk and on boundaries, Chem. Engng Sci., 41, 1417-1433

Turns, S.R. (1996). An introduction to combustion: concepts and applications, McGraw-Hill, New York, USA

Westbrook, C.K. and Dryer, F.L. (1981). Simplified reaction mechanisms for the oxidation of hydrocarbon fuels in flames. Comb. Sci. Techn., 27, 31-43

Zabetakis, M.K. (1965). Flammability characteristics of combustible gases and vapours, PhD. Thesis, Dept. of the Interior, Bureau of mines, Washington, USA 


\section{Appendix A - Validity of the one-dimensional plug flow model with superimposed axial dispersion}

The unsteady convective dispersion of a solute in fully developed isothermal laminar flow in a straight circular tube with an impermeable wall, where an irreversible first-order heterogeneously catalysed reaction takes place, was studied by Sankasubramanian and Gill (1973), and later more rigorously by Shapiro and Brenner (1986), extending the generalised Taylor dispersion phenomena to reactive systems. They showed that the mean reaction rate is independent of the flow rate and that the mean solute velocity and dispersivity depend on the rate of interphase transport.

The mean global-space reactant velocity $U^{*}$ and dispersion dyadic $D^{*}$, as defined by Brenner and Edwards (1993) in their notation, for the convective dispersion of a solute in Poiseuille flow with a centreline velocity $U_{0}$ in a circular tube of radius $R_{t}$ with a constant diffusivity $D$ and heterogeneous reaction rate constant $k_{s}$ is given by

$\frac{U^{*}}{U_{0}}=\frac{\mu^{2}+\left(\beta_{0}-2 \frac{\mu}{\beta_{0}}\right)}{6\left(\mu^{2}+\beta_{0}^{2}\right)}$

$\frac{D^{*}}{D}=1+16 P e^{2} \frac{\beta_{0}^{2}}{\mu^{2}+\beta_{0}^{2}} \sum_{k=1}^{\infty} \frac{\left(\mu^{2}+\beta_{k}^{2}+\beta_{0}^{2}\right)^{2}}{\left(\mu^{2}+\beta_{k}^{2}\right)\left(\beta_{k}^{2}-\beta_{0}^{2}\right)^{5}}$

where the dimensionless numbers $P e$ and $\mu$ are given by

$P e=\frac{U_{0} R_{t}}{D}, \quad \mu=\frac{k_{s} R_{t}}{D}$

and where $\beta_{n}$ are the positive roots of the following transcendental equation involving Bessel functions

$\beta_{n} \mathrm{~J}_{1}\left(\beta_{n}\right)=\mu \mathrm{J}_{0}\left(\beta_{n}\right) \quad(n=0,1,2, \ldots)$ 
In Figure A.1 and A.2 the reactant velocity, $U^{*}$, relative to the average gas velocity, $U_{\text {avg }}$, and the reactant dispersivity $D^{*}$, relative to the reactant dispersivity without reaction, $D_{k_{s}=0}^{*}$, are plotted as a function of the first order heterogeneous conversion rate constant, $k_{s}$, for a monolithic catalyst with circular channels of $1 \mathrm{~mm}$ in diameter and a reactant diffusion coefficient (relative to the gas mixture) of $1 \cdot 10^{-4} \mathrm{~m}^{2} \cdot \mathrm{s}^{-1}$.

These figures clearly show that a heterogeneous reaction increases the mean reactant velocity and decreases the reactant dispersivity. Moreover, it can be concluded that the effects of a parabolic velocity profile on the axial concentration profiles are within $25 \%$ at the most.

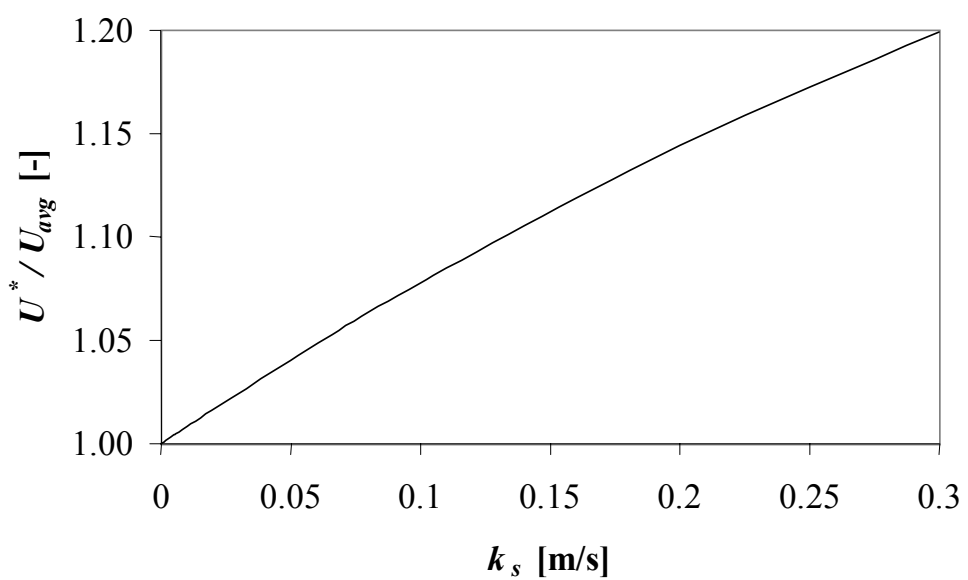

Figure A.1 The reactant velocity $U^{*}$ relative to the average velocity $U_{a v g}$ as a function of the heterogeneous reaction rate constant at the tube wall $k_{s}\left(R_{t}=0.5 \cdot 10^{-3} \mathrm{~m}, D=1 \cdot 10^{-4} \mathrm{~m}^{2} \cdot \mathrm{s}^{-1}\right)$.

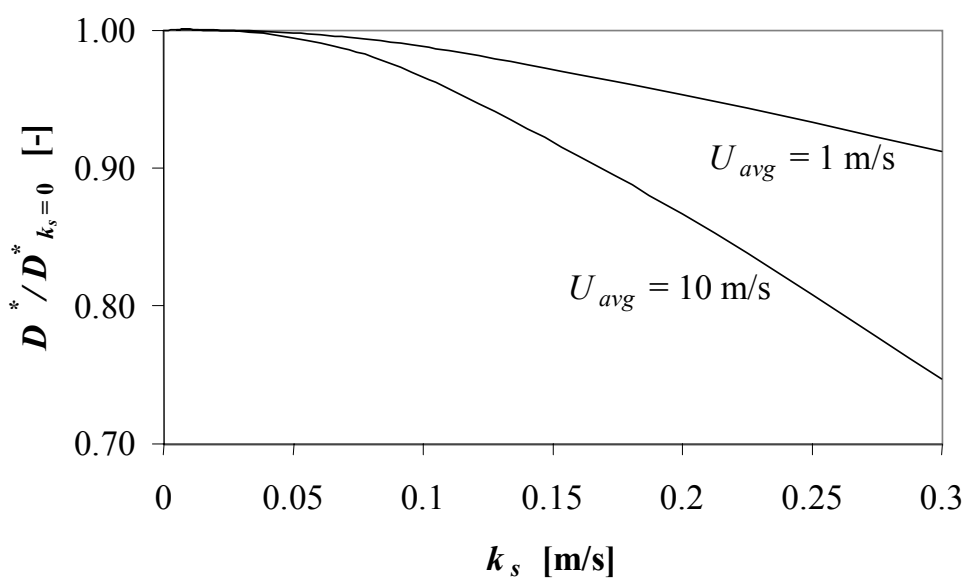

Figure A.2 The reactant dispersivity $D^{*}$ relative to the reactant dispersivity without reaction $D_{k_{s}=0}^{*}$ as a function of the heterogeneous reaction rate constant at the tube wall $k_{s}$ for different average gas velocities $U_{\text {avg }}\left(R_{t}=0.5 \cdot 10^{-3} \mathrm{~m}, D=1 \cdot 10^{-4} \mathrm{~m}^{2} \cdot \mathrm{s}^{-1}\right)$. The reactant dispersivity in absence of heterogeneous reactions, usually referred to as the Taylor dispersivity, is given by $\frac{D_{k_{s}=0}^{*}}{D}=1+\frac{P e^{2}}{192}$. 
CHAPTER 7

\author{
REACTION COUPLING \\ REVERSE FLOW REACTOR - \\ AN EXPERIMENTAL STUDY
}




\section{Abstract}

In a small laboratory scale reactor the concept of the Reaction Coupling Reverse Flow Reactor has been investigated experimentally for the propane dehydrogenation coupled with methane combustion over a monolithic catalyst in reverse flow aiming for a proof of principle.

Despite the inherently and inevitably large influences of radial heat losses on the axial temperature profiles in a laboratory scale reactor, as shown with some experiments with propane and methane combustion in reverse flow without propane dehydrogenation cycles, introductory experiments have shown that indeed endothermic and exothermic reactions can be integrated inside the reactor together with recuperative heat exchange. The cyclic steady state was easily obtained without any problems associated with process control. Furthermore, intermediate flushing with nitrogen between the propane dehydrogenation and methane combustion cycles could be safely omitted. However, the oxygen concentration during the methane combustion cycles needed to be reduced in order to avoid too high temperatures due to local combustion of carbonaceous products in the washcoat deposited during the preceding propane dehydrogenation cycle.

Propane dehydrogenation experiments in a reactor filled entirely with active catalyst demonstrated the seriousness of 'back-conversion', a term used to indicate the loss of propane conversion due to propylene hydrogenation because of the low exit temperatures. Experiments performed in a reactor with inactive sections flanking the active catalyst section at both ends showed that the back-conversion could be effectively counteracted. 


\section{Introduction}

For highly endothermic reactions at high temperatures with rapid but reversible catalyst deactivation a new multifunctional reactor is developed aiming for high energy-efficiency by integration of in situ energy supply, catalyst regeneration and recuperative heat exchange inside the reactor. The reactor concept effectuates an indirect coupling between energy necessary for the endothermic reactions and energy released by exothermic reactions using the catalyst material as an intermediary energy store. During the endothermic reaction cycle energy is withdrawn from the catalyst cooling down the catalyst, while simultaneously the catalyst is deactivated. During a consecutive exothermic reaction cycle the catalyst is reheated and concurrently regenerated. Furthermore, the direction of the gas flow through the fixed catalyst bed is periodically reversed while the reactants are fed without any preheating, which allows integration of recuperative heat exchange inside the reactor.

Application of this new reactor, called the 'Reaction Coupling Reverse Flow Reactor' (RCRFR), is especially interesting for the non-oxidative propane dehydrogenation indirectly coupled with fuel combustion over a platinum based monolithic catalyst. Due to the inherent fast switching between endothermic and exothermic reaction phases because of energy constraints, fast catalyst regeneration is assured, which allows operation at more severe operating conditions, viz. higher temperatures and lower hydrogen concentrations, with higher equilibrium conversions and olefin selectivities.

The reactor behaviour and energy constraints for the RCRFR coupling the propane dehydrogenation and fuel combustion have been studied in detail in Chapters 2 and 3 using numerical simulations. In this chapter the feasibility of the reactor concept is tested experimentally. The main purpose of this experimental work is to present a proof of principle, i.e. to show with experiments that endothermic and exothermic reactions can be integrated inside the reactor with recuperative heat exchange. Secondly, with a preparatory experimental study some features of the reactor behaviour can be investigated experimentally and possible technical problems inherent to the reactor concept can be identified. Especially the following questions are important in this respect:

1. Are dangerous gas phase back-deflagrations indeed excluded by the use of the reverse flow concept in a monolith, as studied in Chapter 6, so that intermediate flushing with nitrogen between the propane dehydrogenation and fuel combustion reaction cycles can be omitted? 
2. Can the cyclic steady state be obtained easily, or are there any difficulties associated with process control?

3. Is back-conversion (hydrogenation of propylene) at the end of the reactor due to the low exit-temperatures resulting from the reverse flow concept a serious problem? Can inactive sections or less active sections reduce this back-conversion, as studied in Chapter 3 ?

4. What are the effects of coke formation during the endothermic propane dehydrogenation cycle and coke combustion during the exothermic fuel combustion cycle? Are the carbonaceous products deposited uniformly along the axial coordinate? Can all the coke be combusted during the exothermic regeneration cycle? What are the temperature effects?

Because large scale industrial reverse flow reactors operate almost adiabatically, it would be ideal to closely approach adiabatic operating conditions also in our laboratory scale reactor. From experimental work on reverse flow reactors it is well known that even very small heat losses can influence the axial temperature profiles enormously. In most experimental studies insulation has been applied to suppress radial heat losses, sometimes with additional electrical compensatory heating (see Van de Beld, 1995). However, the insulation material acts as an additional heat buffer and also the compensatory heating influences the process dynamics. A better way of minimising radial heat losses and influences of the surroundings is the use of an evacuated jacked, as applied by Neophytides and Froment (1992) and Van de Beld (1995) and Van de Beld and Westerterp (1996). However, at higher temperatures the contribution of heat losses due to radiation might be considerable, even when radiation shields are used. The best way of approaching adiabatic operating conditions is by increasing the reactor diameter, as also recognised by Blanks et al. (1990).

In the RCRFR the Damköhler numbers of the endothermic and exothermic reaction cycles need to be matched in order to use the entire catalyst bed efficiently (see Chapter 2). For the propane dehydrogenation - fuel combustion reaction system this results in high gas velocities during the combustion reaction cycle compared to the gas velocity during the dehydrogenation cycle. Moreover, in order to minimise the influences of radial heat losses the throughput during the endothermic dehydrogenation phase should be chosen as high as possible, resulting in very high throughputs during the combustion reaction phase. Increasing the reactor diameter to suppress radial heat losses increases the throughput quadratically. Construction of a pilot scale RCRFR would, however, largely exceed the limited financial means of this project. For a laboratory scale RCRFR with a maximum air flow rate a compromise between the desired gas velocity during the endothermic reaction cycle and the 
desired reactor diameter need to be effected and relatively large influences of radial heat losses need to be accepted unfortunately. Nevertheless, a proof of principle and some important introductory experimental investigations can be conducted in a laboratory scale RCRFR. No optimisation of the reactor set-up, catalyst properties (e.g. platinum loading), operating conditions, reactant conversions and product selectivities and overall reaction coupling energy efficiencies are considered in this work.

Firstly, the experimental set-up and the reverse flow reactor are described. Then, some experimental results of only methane or propane combustion performed in reverse flow mode without dehydrogenation cycles are presented and discussed in order to investigate whether reported influences of operating conditions can be actually observed in the laboratory scale RCRFR in a qualitative sense. Finally, propane dehydrogenation experiments coupled with methane combustion are discussed.

\section{Experimental}

\subsection{Experimental set-up}

In Figure 1 a schematic drawing of the fully automated experimental set-up is given. With Brooks' mass flow controllers the composition of the reaction mixtures consisting of propane, hydrogen and nitrogen for the endothermic reaction cycle on the one hand and propane, methane, oxygen and nitrogen for the exothermic reaction cycle on the other hand can be set. With an electrical valve (EV1002) one of these reaction mixtures is fed to the reactor, while the other mixture is vented (optionally the mass flow controller set-points for the gasses that are vented can be set to zero). The direction of the gas flow through the reactor, placed in horizontal position, can be reversed by switching two three-way valves (EV1003), with the same pneumatic actuator to assure that the valves are switched simultaneously. Because of large differences in the flow rates between the endothermic and exothermic reaction cycles the reactor pressure is controlled by a back-pressure controller for small flows during the dehydrogenation cycles (PC1003) and by one for large flows during the combustion cycles (PC1004) via switching of an electrical valve (EV1005). The pressure at the reactor inlet (PI1001) and outlet (PI1002) were measured with electronic transducers. For safety reasons a pressure relieve valve was installed (with a maximum overpressure of 2 bar). Before an 


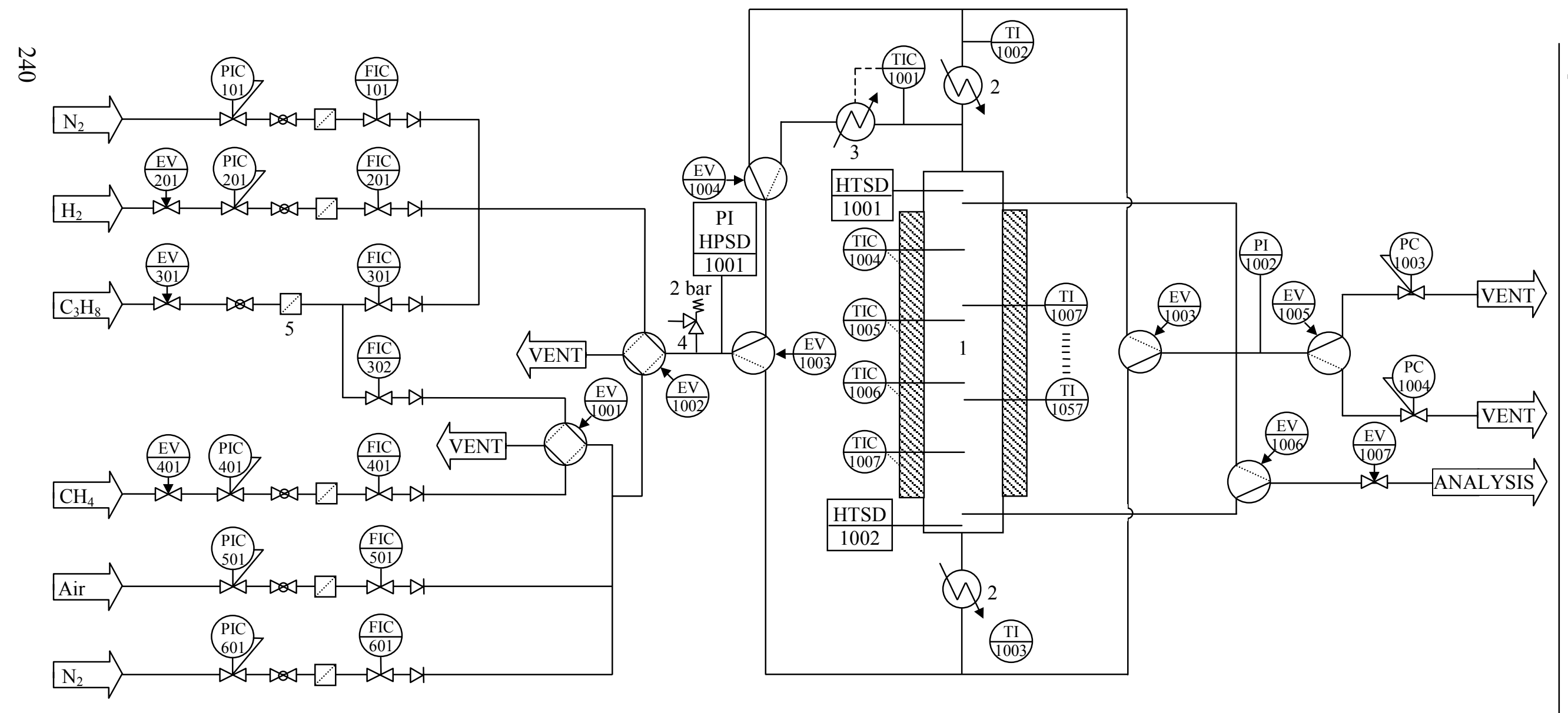

\begin{tabular}{|c|c|c|c|c|}
\hline Description & Abbreviation & Description & Abbreviation & Description \\
\hline 1 Reactor & $\mathrm{EV}$ & Emergency valve & PI & Pressure indicator \\
\hline 2 Cooler & FIC & Flow rate indicator and controller & PIC & Pressure indicator and controller \\
\hline 3 Preheater & HPSD & High pressure shut down & TI & Temperature indicator \\
\hline 4 Pressure relieve valve & HTSD & High temperature shut down & TIC & Temperature indicator and controller \\
\hline 5 Filter & & & VENT & Gas ventilation system \\
\hline
\end{tabular}

Figure 1. Flowsheet of the experimental set-up. 
experiment is started the reactor is preheated up to temperatures of $600{ }^{\circ} \mathrm{C}$ at maximum by feeding air preheated in an electrical gas heater (with a capacity of about $2 \mathrm{~kW}$ ) via switching of electrical valve EV1004. When an experiment is started the gas heater is taken off line and valve EV1004 is switched back. In order to protect downstream equipment, especially the valves, two water coolers (with a capacity of about $3 \mathrm{~kW}$ ) have been positioned at the reactor inlet and outlet. Part of the reactor effluent can be collected via valves EV1006 and EV1007 for analysis on a GC-TCD or infrared analysers for $\mathrm{CO}$ and $\mathrm{CO}_{2}$, described in Chapter 4.

The set-up is completely automated and controlled by a Mitsubishi PLC (Programmable Logic Controller). The PLC continuously checks several parameters against alarm values, like the reactor pressure (HPSD1001), temperatures in the reactor (TIC1004-TIC1007), the temperatures at the reactor inlet and outlet (HTSD1001 and HTSD1002) to avoid gas phase back-deflagrations (see Chapter 6), and concentrations of the propane and methane in air to avoid explosive gas mixtures. In case of an emergency the PLC shuts down the installation automatically and the electrical valves in the feed lines of hydrogen (EV201), propane (EV301) and methane (EV401) are closed and the set-up is purged with nitrogen. In the program environment 'CITECT' from Ci Technologies Pty. Limited an extensive interface for the PLC was programmed on a personal computer to monitor the set-up, to save important process values and to change operating conditions. The desired process conditions for an experiment (composition of reaction mixtures and the total flow rate, cycle time and flow direction per reaction cycle) can be changed in CITECT, which makes sure that the PLC takes care of the necessary actions.

The experimental procedure for a dehydrogenation experiment was as follows. Firstly, the reactor was preheated with air. Subsequently, an experiment with only methane or propane combustion in reverse flow was carried out in order to effectuate low temperatures at the reactor ends to avoid gas phase back deflagrations when switching to the dehydrogenation cycle. Furthermore, the centre of the reactor could be heated further to even higher temperatures, if desired, using the fuel inlet concentration to control the maximum temperature. When the reactor inlet and outlet was sufficiently cooled and the centre of the reactor sufficiently heated, the dehydrogenation experiment was started. At the end of the dehydrogenation experiment, again an experiment of fuel combustion in reverse flow was carried out with relatively long forward and backward flow cycle times, so that all possible accumulated coke deposits were removed. 


\subsection{Reverse Flow Reactor}

A rectangular reactor was constructed of high temperature stainless steel to contain rectangular blocks of a cordierite monolithic catalyst. In Figures 2 and 3 a picture and a schematic drawing of the reverse flow reactor are given. Monolith blocks with a cross-sectional area of $55 \times 55 \mathrm{~mm}^{2}$ (400 cpsi) and $75 \mathrm{~mm}$ in length were supplied by Engelhard and consisted of squared channels with a hydraulic channel diameter of $0.96 \mathrm{~mm}$, a channel wall thickness of $0.19 \mathrm{~mm}$ and an average washcoat thickness of $37 \mu \mathrm{m}(11-89 \mu \mathrm{m})$, determined from SEM-pictures. Two types of monoliths were used in the experiments, one with a platinum loading of $1.5 \mathrm{~g} / 1$ monolith dispersed in the $\gamma-\mathrm{Al}_{2} \mathrm{O}_{3}$ washcoat and one without platinum, referred to as the active and inactive monolith respectively. The total length of the catalyst blocks in the reactor was $0.555 \mathrm{~m}$.

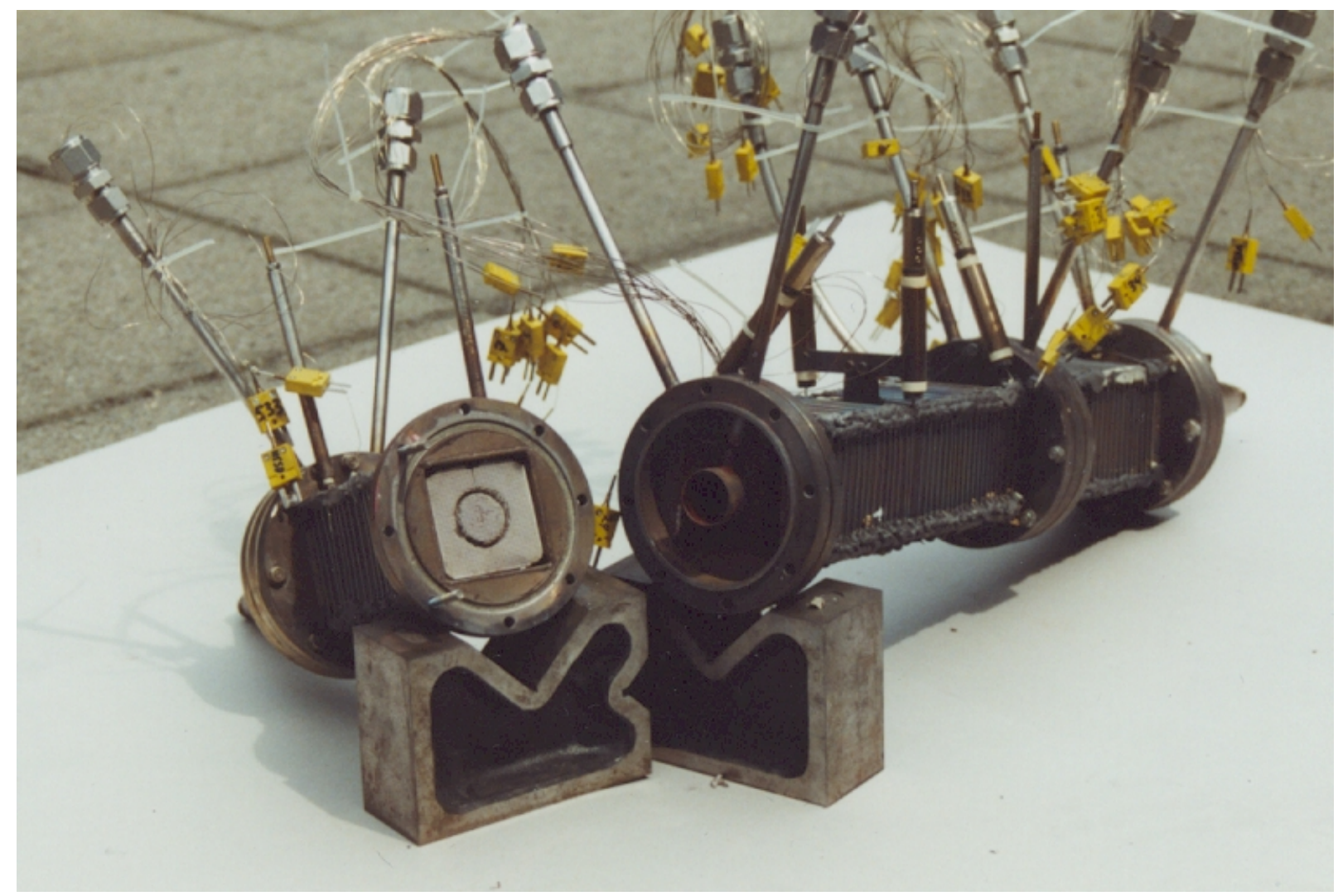

Figure 2. Picture of the reverse flow reactor.

In order to determine the axial and radial temperature profiles in the monolith the reactor was constructed out of five parts connected with flanges. Through the flanges K-type thermocouples of $0.5 \mathrm{~mm}$ diameter could be led to the monolith blocks (see Figure 4). The 
thermocouples were positioned at the desired position either parallel to the channels or perpendicular to the channels through small holes drilled in the monolith at different positions. About 45 thermocouples were used to determine the axial temperature profile in the innermost channels and 8 thermocouples were used to determine the 'radial' (i.e. perpendicular to the average gas flow direction) temperature profile at a fixed axial position (after $0.37 \mathrm{~m}$ catalyst length). Ten additional thermocouples were used for control and safety purposes. All temperature data was collected at least twice every second by a program developed in Borland Delphi, running on a separate personal computer with five Advantech data-acquisition cards. Through a link between the data-acquisition cards and the PLC the time on stream during an experiment was synchronised.

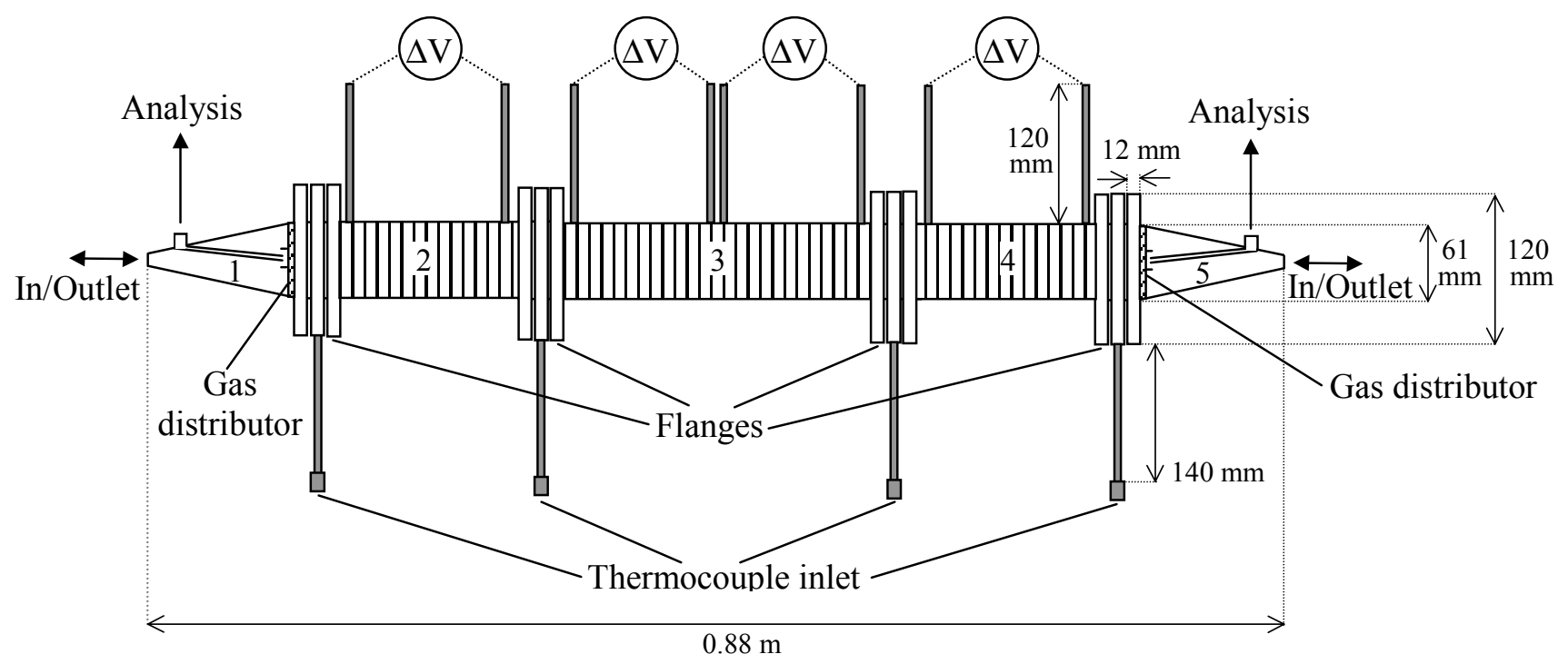

Figure 3. Schematic drawing of the reverse flow reactor.

Due to the absence of radial mixing of the gas in a monolith the influence of the surroundings are largest on the outermost channels, protecting the innermost channels from radial heat losses to some extent. With small rings in the flanges it was assured that also between different catalyst blocks gas flowing through the innermost channels was not mixed with gas flowing through the outermost channels. It was experimentally verified that the radial temperature profile for the innermost channels is practically uniform (see Appendix A). The axial temperature profiles were detected in the innermost channels.

At the base of the conical reactor ends, both periodically acting as inlet and outlet, a metal porous plate was installed to distribute the gas flow evenly over the channels. Part of the gas effluent from the innermost channels could be collected for analysis via a small conduit. 


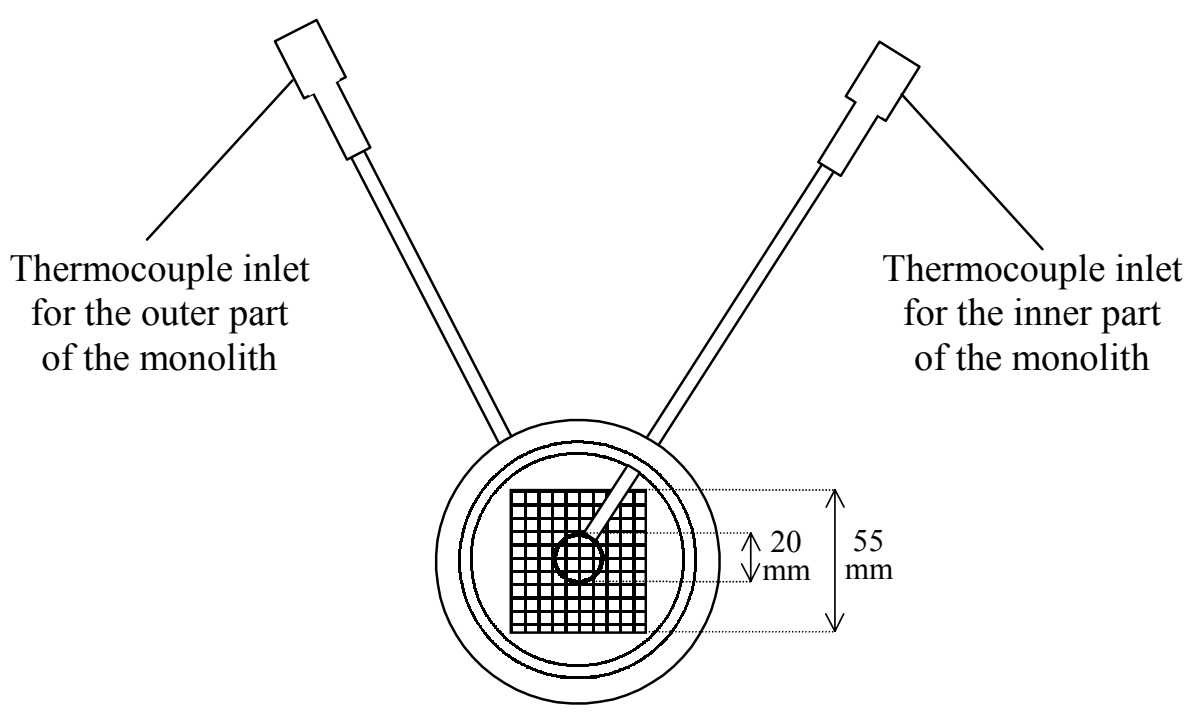

Figure 4. Schematic drawing of a flange with thermocouple inlets to measure temperatures in the inner and outer part of the monolithic catalyst.

For compensatory heating the reactor wall was wrapped with four separate electrical resistance wires placed under $48 \mathrm{~V}$, having a total heating capacity of about $1 \mathrm{~kW}$. For control of the electrical resistance heaters the reactor wall temperature was measured with a thermocouple at four different axial positions (in the middle of the different sections). The setpoints for the heaters could be set either to a constant value or to a temperature locally measured in the channels of the monolith. Finally, the reactor was insulated with a first layer of ceramic wool and a second layer of ceramic foam in a brick housing.

\section{Experimental results and discussion}

\subsection{Propane and methane combustion in reverse flow}

Some influences of the operating conditions, like the cycle time, inlet concentration and mass flow rate are shown in Figures 5-8 for propane combustion and in Figures 9-12 for methane combustion in reverse flow over a monolithic catalyst. The gas inlet temperature was about $20{ }^{\circ} \mathrm{C}$ and the inlet pressure depended on the flow rate (ca. 1.5 bar at $6.5 \mathrm{Nm}^{3} \cdot \mathrm{h}^{-1}$ and almost $2.5 \mathrm{bar}$ at $13 \mathrm{Nm}^{3} \cdot \mathrm{h}^{-1}$ ). The two electrical resistance heaters at the inlet and outlet were off line and the middle two heaters were set at $400{ }^{\circ} \mathrm{C}$ and $550{ }^{\circ} \mathrm{C}$ for the propane and methane combustion experiments, respectively. The heater temperatures were lower than the temperatures measured in the centre of the monolith, assuring net heat losses. The reproducibility of the experiments was very good (see Figure 12). 


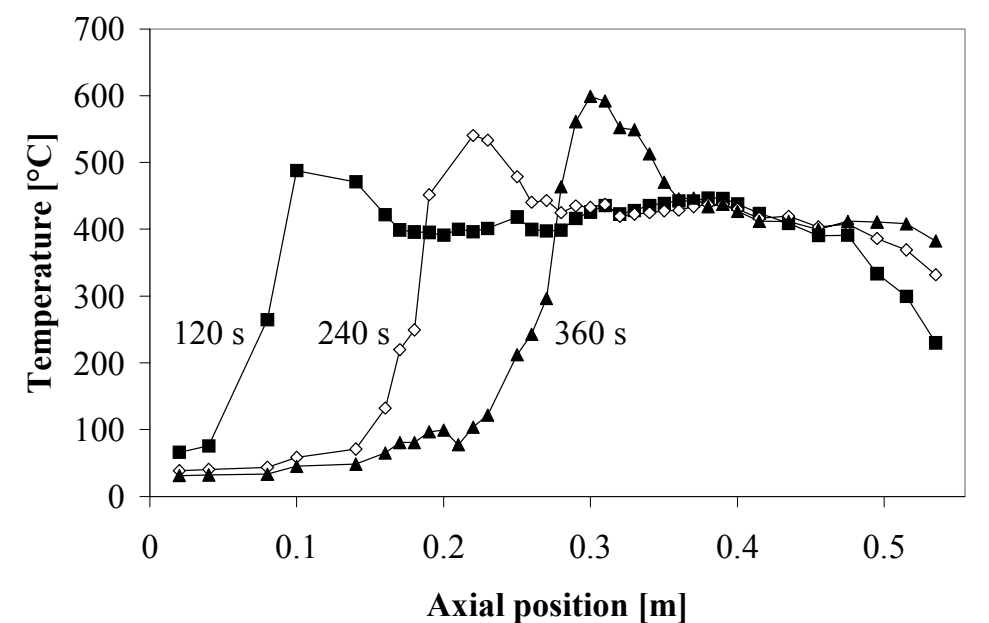

Figure 5. Influence of the cycle time on the axial temperature profile at the end of the forward cycle for propane combustion in reverse flow over a monolithic catalyst $\left(x_{g, \mathrm{C}_{3} \mathrm{H}_{8}, \text { in }}=0.2 \%, \Phi_{v, \text { in }}=6.5 \mathrm{Nm}^{3} \cdot \mathrm{h}^{-1}\right)$.

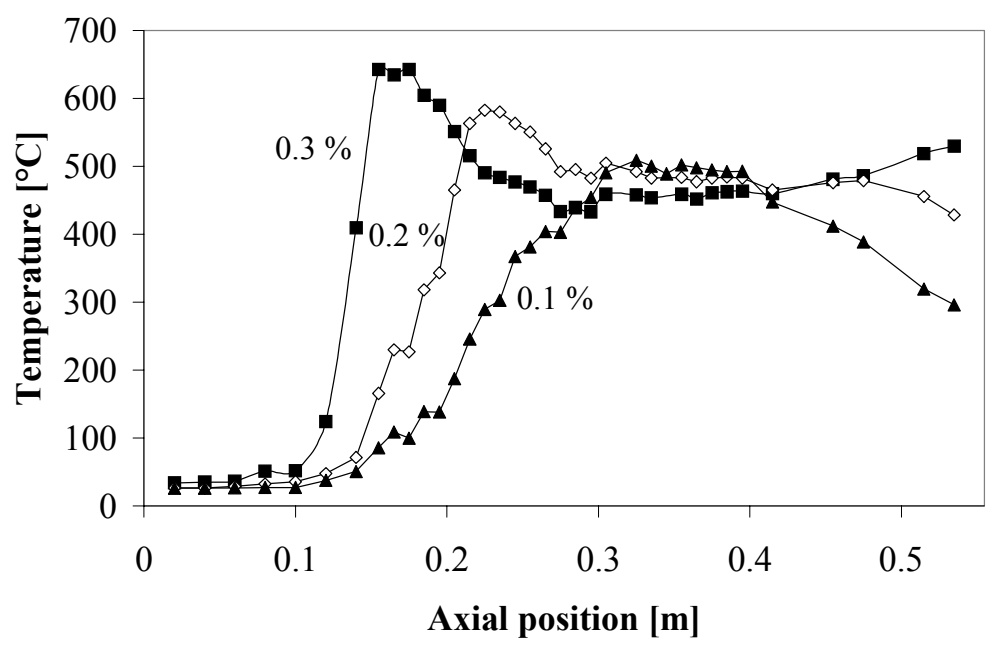

Figure 7. Influence of the propane inlet mole fraction on the axial temperature profile at the end of the forward cycle for propane combustion in reverse flow over a monolithic catalyst $\left(\Phi_{v, i n}=6.5 \mathrm{Nm}^{3} \cdot \mathrm{h}^{-1}, \Delta t=120 \mathrm{~s}\right)$.

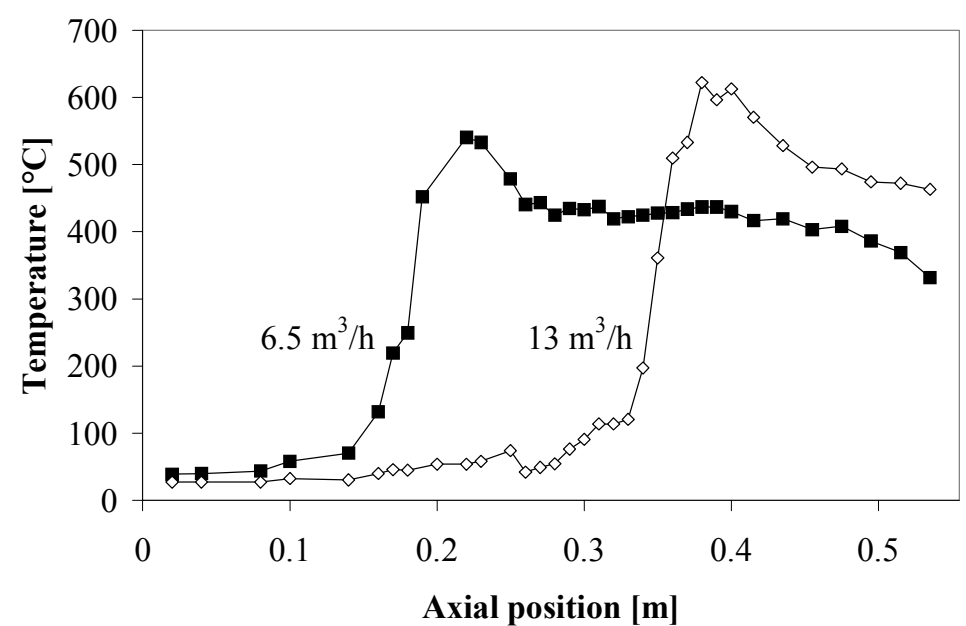

Figure 6. Influence of the flow rate on the axial temperature profile at the end of the forward cycle for propane combustion in reverse flow over a monolithic catalyst $\left(x_{g, \mathrm{C}_{3} \mathrm{H}_{8}, \text { in }}=0.2 \%, \Delta t=240 \mathrm{~s}\right)$.

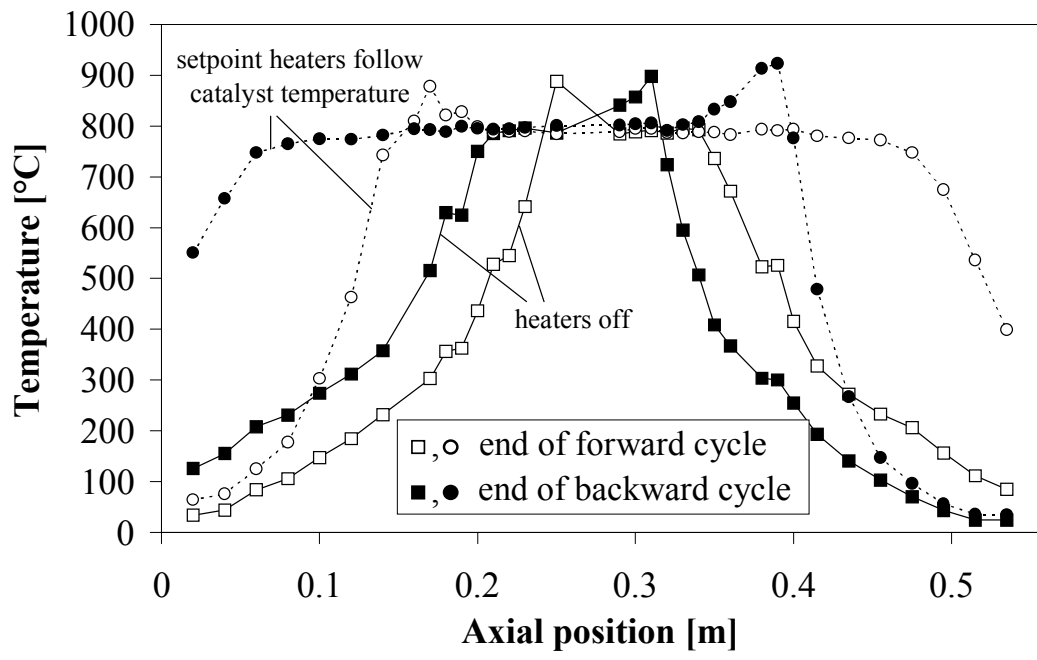

Figure 8. Influence of the heaters on the axial temperature profiles for propane combustion in reverse flow over an inactive monolith $\left(\Phi_{v, \text { in }}=\right.$ $5.9 \mathrm{Nm}^{3} \cdot \mathrm{h}^{-1}, x_{g, \mathrm{C}_{3} \mathrm{H}_{8}, i n}=0.26 \%, \Delta t=60 \mathrm{~s}$ ). 


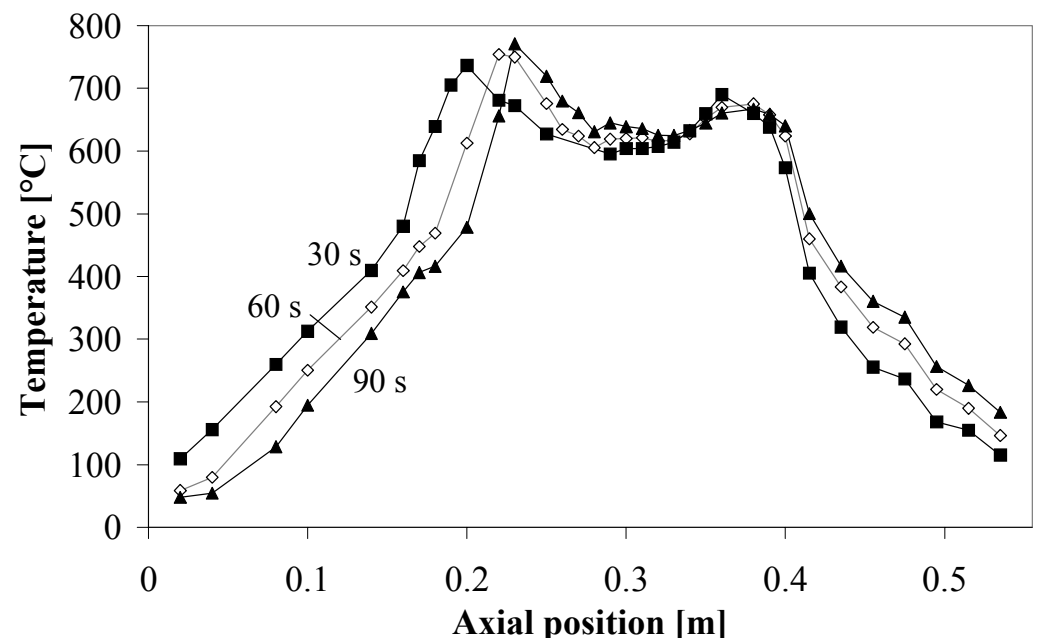

Figure 9. Influence of the cycle time on the axial temperature profiles for methane combustion in reverse flow over a monolithic catalyst $\left(x_{g, \mathrm{CH}_{4}, i n}=\right.$ $\left.0.5 \%, \Phi_{v, \text { in }}=6.5 \mathrm{Nm}^{3} \cdot \mathrm{h}^{-1}\right)$.

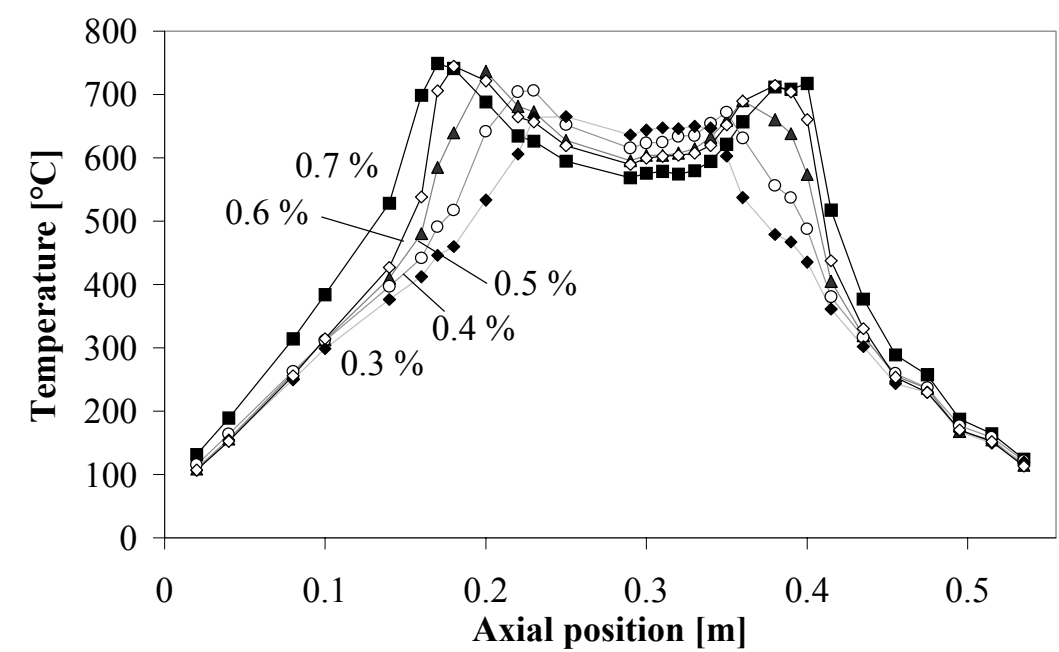

Figure 11. Influence of the methane inlet mole fraction on the axial temperature profile at the end of the forward cycle for methane combustion in reverse flow over a monolithic catalyst $\left(\Phi_{v, i n}=6.5 \mathrm{Nm}^{3} \cdot \mathrm{h}^{-1}, \Delta t=30 \mathrm{~s}\right)$.

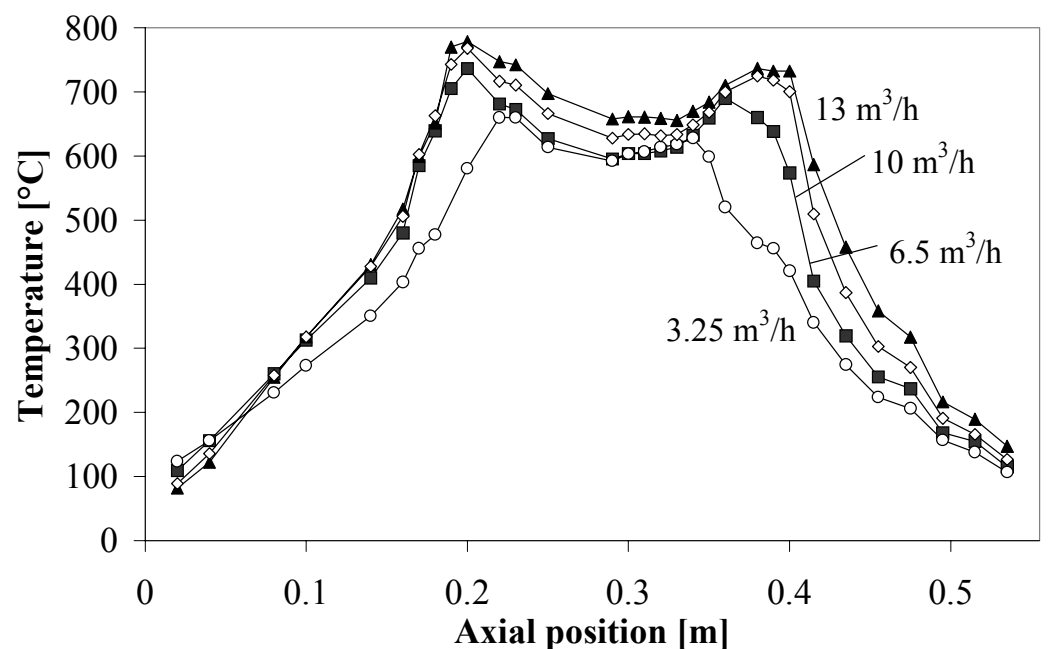

Figure 10. Influence of the flow rate on the axial temperature profile at the end of the forward cycle for methane combustion in reverse flow over a monolithic catalyst $\left(x_{g, \mathrm{CH}_{4}, \text { in }}=0.5 \%, \Delta t=30 \mathrm{~s}\right)$.

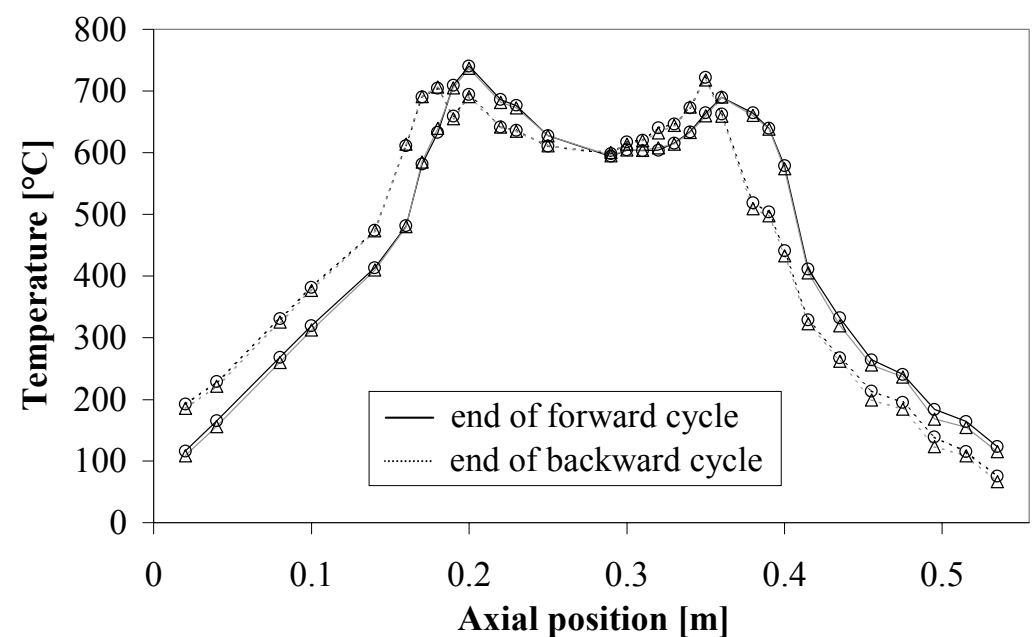

Figure 12. Reproducibility test: axial temperature profiles for methane combustion in reverse flow over a monolithic catalyst $\left(x_{g, \mathrm{CH}_{4}, \text { in }}=0.5 \%\right.$, $\left.\Phi_{v, \text { in }}=6.5 \mathrm{Nm}^{3} \cdot \mathrm{h}^{-1}, \Delta t=30 \mathrm{~s}\right)$. 
The large influence of the cycle times on the maximum temperatures (Figure 5 and 9) indicates the large influence of radial heat losses. In an adiabatic reactor the maximum temperature is independent of the cycle time, as easily confirmed with model simulations and also shown experimentally by e.g. Van de Beld (1995) for ethylene combustion in reverse flow with a low ethylene inlet concentration with a maximum temperature of only about $350{ }^{\circ} \mathrm{C}$, assuring relatively low radial heat losses.

Furthermore, the insulation material acts as an instationary additional heat buffer. When the temperatures in the catalyst material are high energy is transported to the insulation material, but before this energy is lost to the surroundings, it is partly returned to the catalyst when the heat front passes.

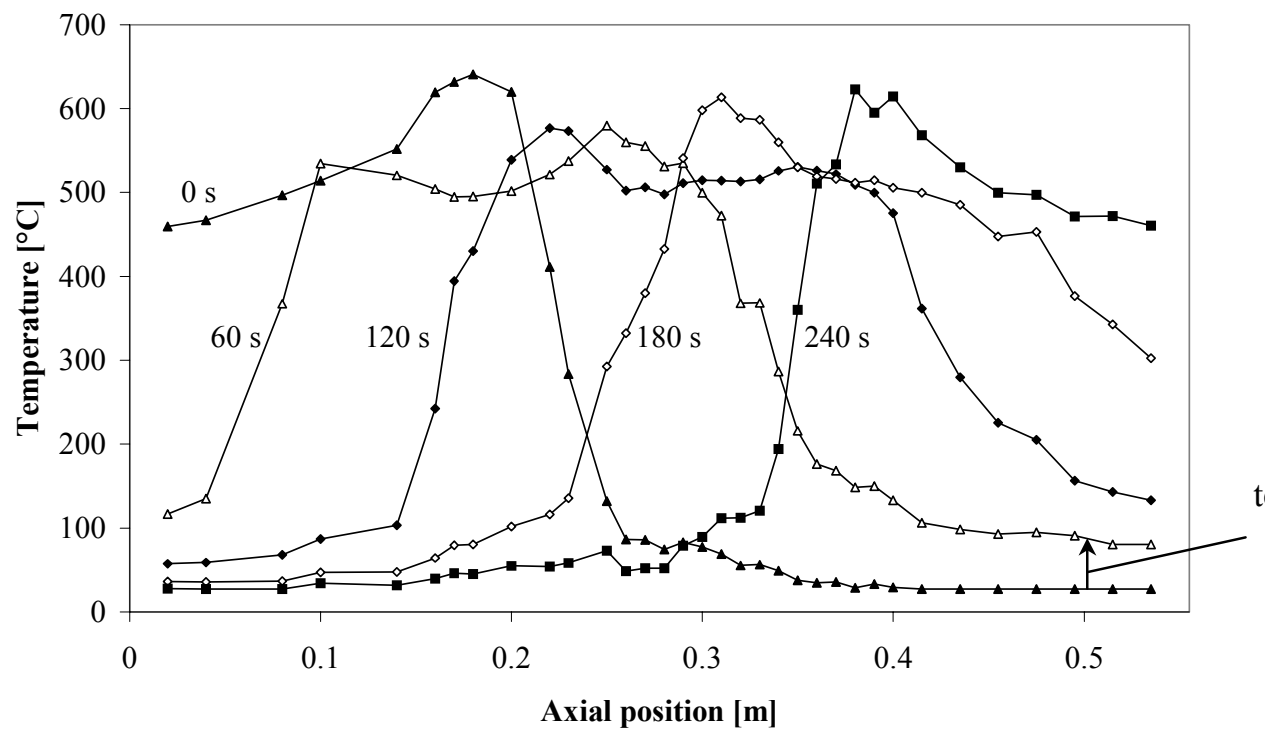

temperature increase due to energy transfer from the insulation material

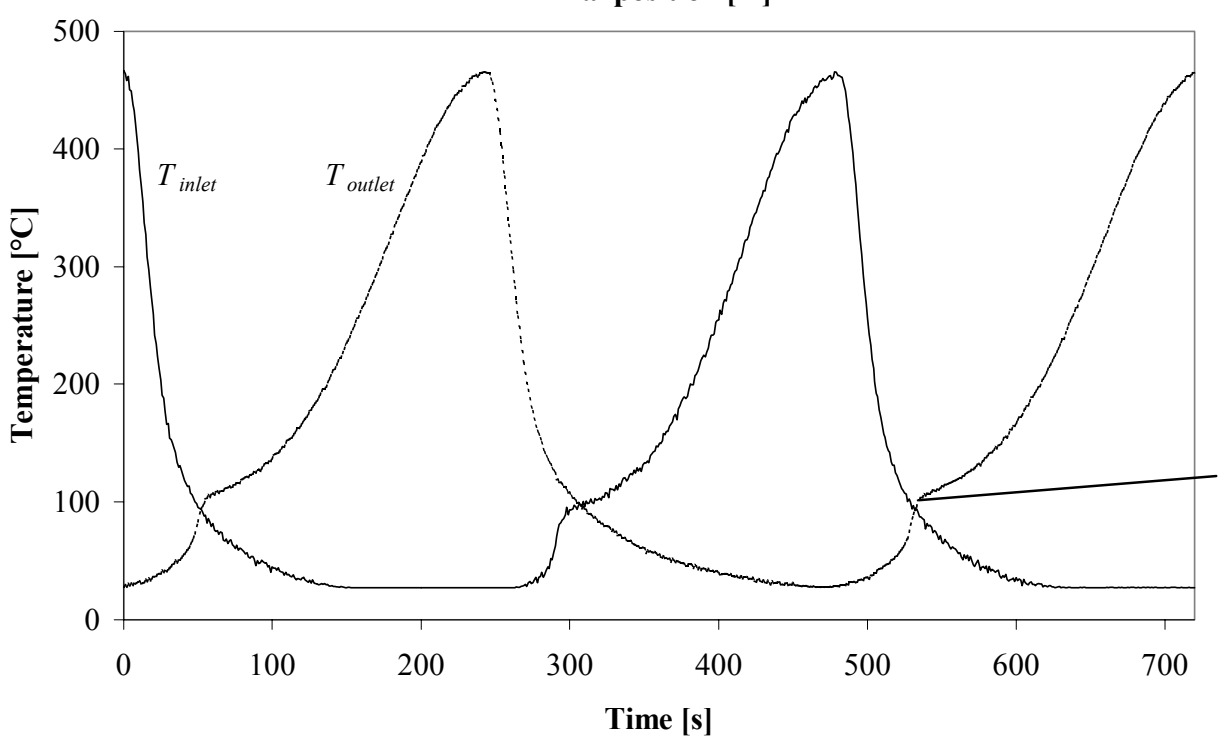

temperature increase due to energy transfer from the insulation material

Figure 13. Axial catalyst temperature profiles (a) and the temperatures at the inlet and outlet of the monolith (b) as a function of time for propane combustion over a monolithic catalyst. (Operating conditions: $x_{g, \mathrm{C}_{3} \mathrm{H}_{8}, \text { in }}=0.2 \%, \Phi_{v, \text { in }}=13.0 \mathrm{Nm}^{3} \cdot \mathrm{h}^{-1}, \Delta t=240 \mathrm{~s}$ ). 
The unsteady heat buffer effect of the insulation material can be clearly observed in Figure 13 from the temperature increase at the reactor outlet just after reversing the flow direction. This figure also shows that the monolith temperature at the reactor inlet does not decrease immediately to the gas inlet temperature, when the flow is reversed mainly due to the heat capacity of the inlet section.

The extent of radial heat losses in the steady state has been studied separately via interpretation of radial and axial temperature profiles from experiments with preheated air without methane of propane in the feed and without periodic flow reversals, shortly described in Appendix A. The temperature profiles could be described with a simplified twodimensional model approximating the rectangular monolith blocks as cylinders and using constant effective heat conductivities for the catalyst (with air flowing through the channels) and insulation material (consisting of the reactor wall and the different layers of insulation materials), about 0.5 and $0.2 \mathrm{~W} \cdot \mathrm{m}^{-1} \cdot \mathrm{K}^{-1}$ respectively. Using these estimates the overall heat transfer coefficient for the overall radial heat losses from the inner channels of the monolith ('inner ring') can then be estimated at about $6 \mathrm{~W} \cdot \mathrm{m}^{-2} \cdot \mathrm{K}^{-1}$.

To quantitatively compare the experimental results for propane and methane combustion in reverse flow with numerical simulations it is essential to describe the energy transport inside the monolith and the insulation materials with a two-dimensional model (or even a threedimensional model because of the rectangular geometry) as a consequence of the absence of radial gas mixing. However, we refrain from detailed two-dimensional modelling, since radial heat losses are of no practical relevance for large-scale reverse flow reactors and, additionally, very specific to a certain reactor. Furthermore, for the rectangular reactor used in this work the radial heat losses to the surroundings are not well defined especially due to the instationary heat buffering effect of the reactor wall and the different layers of insulation materials, which renders a rigorous modelling of the radial heat losses a difficult task.

Instead, the effect of radial heat losses on the axial temperature profiles during methane and propane combustion are explored using an approximate one-dimensional model, as described in detail in Chapter 2, but extended to include non-adiabatic conditions by adding a heat loss term in the catalyst phase energy balance. This model neglects radial temperature differences across the cross-section of the monolith, resembling the limit of infinite effective monolith conductivity, and assumes a constant overall heat transfer coefficient for the radial heat transport from the monolith through the insulation material to the surroundings. The effects of 
radial heat losses on the axial temperature profiles for propane and methane combustion in reverse flow over an active monolith are investigated by comparing simulation results for adiabatic conditions with the results for non-adiabatic conditions for several different overall heat transfer coefficients, see Figure 14. Due to the forced unsteady state operation the maximum temperature in reverse flow reactors is strongly influenced by the reaction rate in contrast to ordinary adiabatic reactors, where the maximum temperature is only determined by the inlet temperature and the adiabatic temperature rise. Hence, the kinetics of the heterogeneous combustion of methane and propane over the active monolithic catalyst were experimentally determined for low fuel concentrations in the experimental set-up described in Chapter 4. The kinetic results are briefly described in Appendix B.

From Figure 14 the large influence of the radial heat losses is clear. Due to the radial heat losses the temperature plateau is enormously indented. Even for a reactor with 3.2 larger diameter (increasing the mass flow rate tenfold) and a 5 times smaller radial heat transfer coefficient than for the small reverse flow reactor in this work (case with $U_{o v} \approx$ $0.1 \mathrm{~W} \cdot \mathrm{m}^{-1} \cdot \mathrm{K}^{-1}$ ), resembling the conditions of Van de Beld's (1995) reactor with a vacuum jacket, the drop of the temperature plateau still exceeds $150^{\circ} \mathrm{C}$. Furthermore, for the methane combustion simulations the maximum temperature of the temperature peaks are only slightly effected by the radial heat losses, but for the propane combustion simulations the maximum temperature of the temperature peaks have decreased considerably. Due to the much larger cycle times for the propane combustion the temperature peak at the back end of the temperature plateau has decreased much more due to the radial heat losses. Because of the much lower temperature of the temperature peak at the beginning of the cycle the energy is released over a larger reaction zone resulting in a slower formation of the temperature peak. As a consequence the temperature peak cannot reach its maximum value for the propane combustion within the cycle time, despite the larger cycle times.

When comparing the simulation results with the experimental results reported before, the temperature peaks in the experiments were located much further inwards towards the centre of the reactor, but the indentation of the temperature plateaux was much less pronounced. This is caused by a radial temperature profile over the monolith due to radial heat losses. Because of the lower temperatures in the outer channels the ignition of the combustion takes place further inside the reactor at larger distances from the reactor inlet in the outer channels compared to the inner channels, so that in the outer channels the temperature plateau is much smaller. 
(a)

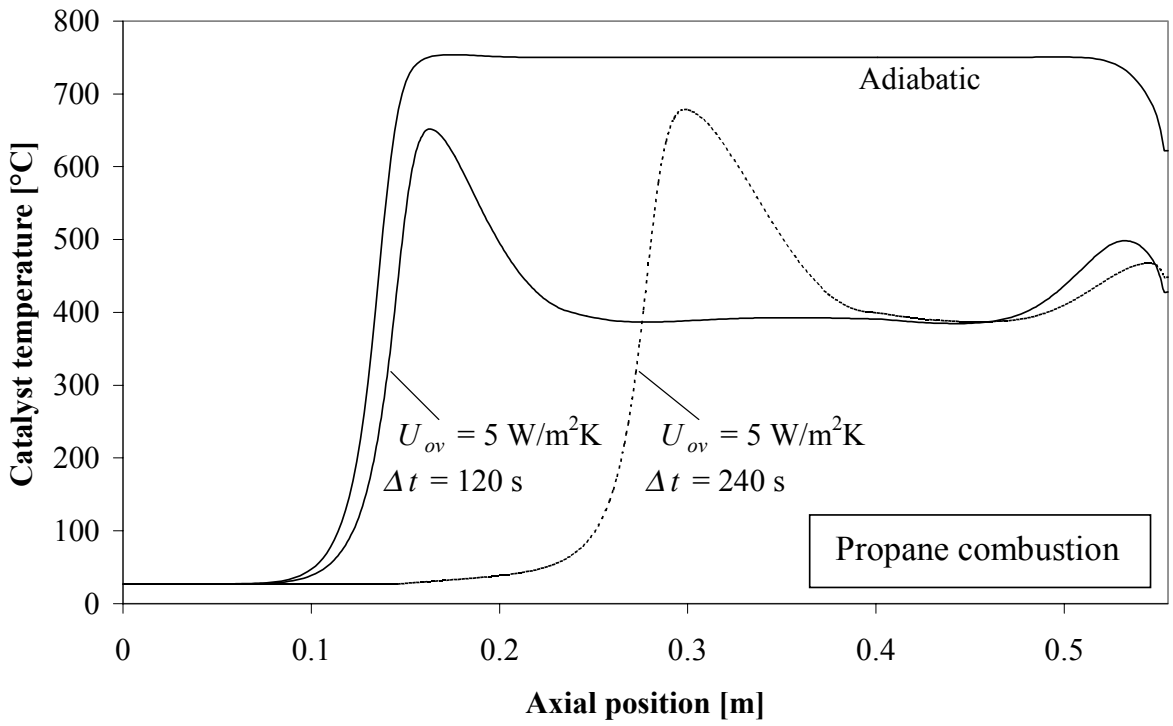

(b)

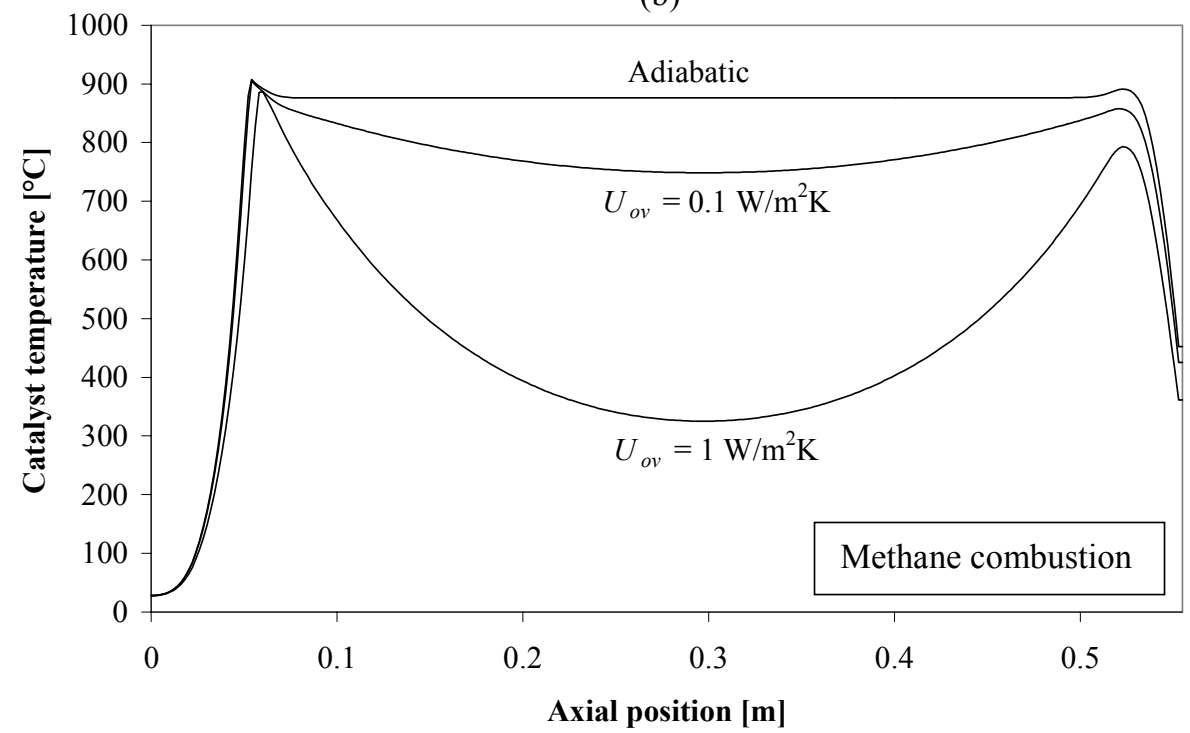

Figure 14. Computer simulations to investigate the influence of radial heat losses (characterised with an overall heat transfer coefficient $U_{o v}$ ) on the axial temperature profiles for propane (a) and methane (b) combustion in reverse flow in a reactor $(0.055 \mathrm{~m}$ in diameter and 0.555 $\mathrm{m}$ length) filled entirely with active monolithic catalyst. For the propane combustion simulations compensatory heating was taken into account (via $T_{\infty}=400{ }^{\circ} \mathrm{C}$, for $0.15 \leq z \leq$ $0.405 \mathrm{~m}$ ), as opposed to the methane combustion simulations were for comparison compensatory heating was left out of consideration. (Homogeneous combustion was modelled with the two-step mechanism by Westbrook and Dryer, 1981).

Conditions for the simulations:

Propane combustion: $x_{g, \mathrm{C}_{3} \mathrm{H}_{8}, \text { in }}=0.2 \%, \Phi_{v, \text { in }}=13.0 \mathrm{Nm}^{3} \cdot \mathrm{h}^{-1}, \Delta t=120,240 \mathrm{~s}$;

Methane combustion: $x_{g, \mathrm{CH}_{4}, \text { in }}=0.5 \%, \Phi_{v, \text { in }}=6.5 \mathrm{Nm}^{3} \cdot \mathrm{h}^{-1}, \Delta t=30 \mathrm{~s}$; 
Due to the delayed ignition in the outermost channels the heat losses from the inner channels are larger at the beginning of the heat front causing also the ignition in the inner channels to take place further inside the reactor compared to adiabatic conditions. However, at the end of the temperature front at the temperature plateau in the inner channels the radial heat losses are strongly reduced due to the delayed heat generation in the outer channels, resulting in a much smaller indentation of the temperature plateau. Because of the relatively high ignition temperatures the compensatory heating was necessary to assure ignition in the outer channels and to avoid complete extinction, at least for short cycle times.

The enormous impact of non-adiabatic conditions on the experimentally observed plateau temperature was also reported by Van de Beld (1995). Even in their reverse flow reactor with a three times larger diameter and an evacuated jacket to achieve a relatively low radial heat transfer coefficient the experimentally determined plateau temperature and the plateau temperature calculated for adiabatic conditions differed tremendously. When plateau temperatures for adiabatic conditions were calculated above $600{ }^{\circ} \mathrm{C}$, the experimentally determined temperatures were about $200{ }^{\circ} \mathrm{C}$ lower and these differences increased considerably at higher temperatures.

Concluding, the influence of the radial heat losses can only be considerably reduced by conducting experiments in a reactor with a much larger reactor diameter. By the use of a monolithic catalyst radial heat losses are somewhat reduced due to the absence of radial gas mixing in a monolithic catalyst avoiding levelling out of radial temperature differences.

Nevertheless, the influences of the mass flux and the inlet concentration on the maximum temperature correspond to the expected influences (see Figures 15 and 16). The maximum temperature increases at higher gas flow rates, but reaches a maximum and becomes independent of the gas flow rate when the effective pseudo-homogeneous axial conductivity is dominated by the contribution of effective axial heat transport in the gas phase (see Appendix A of Chapter 2). Thus, for industrial size reactors with high throughputs the maximum temperature is independent of the gas flow rate. The maximum temperature increases less than proportional with increasing methane inlet concentrations. The logarithmic increase of the maximum temperature for higher methane inlet concentrations is expected from Figure A.1 in Appendix A of Chapter 2, which shows that the dimensionless maximum 
temperature $\theta_{c, \max }$ (proportional to the inlet mss fraction) increases virtually linearly with the exponent of the maximum temperature number $\Theta$. Finally, from the experiments also the well-known 'wrong-way behaviour' of reverse flow reactors can be observed, i.e. lower maximum temperatures for faster reactions. The observed maximum temperature increases from $500-600{ }^{\circ} \mathrm{C}$ for propane combustion over an active monolith to $700-800{ }^{\circ} \mathrm{C}$ for methane combustion over an active monolith to over $900{ }^{\circ} \mathrm{C}$ for propane combustion over an inactive monolith for comparable adiabatic temperature increases.

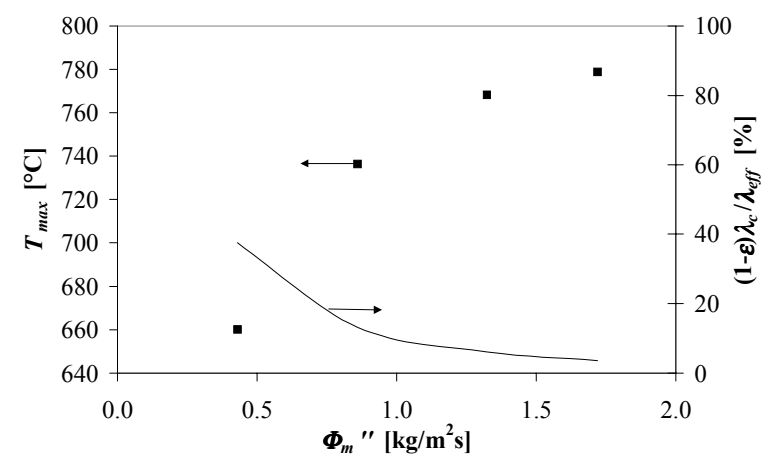

Figure 15. The maximum temperature and the relative contribution of conduction in the catalyst material to the total effective pseudohomogeneous axial conductivity as a function of the gas mass flux for methane combustion in reverse flow $\left(x_{g, \mathrm{CH}_{4}, \text { in }}=0.5 \%, \Delta t=30 \mathrm{~s}\right.$, corresponding axial temperature profiles in Figure 10).

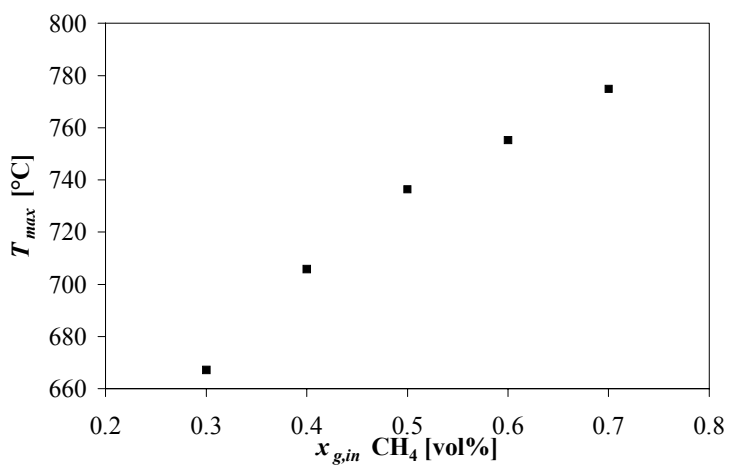

Figure 16. The maximum temperature as a function of the methane inlet mole fraction for methane combustion in reverse flow $\left(\Phi_{v, \text { in }}=\right.$ $6.5 \mathrm{Nm}^{3} \cdot \mathrm{h}^{-1}, \Delta t=30 \mathrm{~s}$, corresponding axial temperature profiles in Figure 11). 


\subsection{Propane dehydrogenation coupled with methane combustion in reverse flow}

Since radial heat losses determine to a large extent the shape of the axial temperature profiles in a small laboratory scale reverse flow reactor, it was not possible to experimentally validate the typical shape of axial temperature profiles occurring in a reverse flow reactor coupling endothermic and exothermic reactions for, for instance, different ratios of the endothermic and exothermic Damköhler numbers and for different switching schemes, as simulated in Chapters 2 and 3. For large Damköhler numbers of the exothermic reaction cycle compared to the Damköhler number of the endothermic reaction cycle simulations have shown that the plateau temperature strongly decreases and only two small high temperature peaks remain, rendering a large part of the reactor ineffective. Unfortunately, radial heat losses have a similar effect on the shape of the axial temperature profiles. Furthermore, for asymmetric switching schemes a slope in the plateau temperature was calculated, but this effect is completely overshadowed by the dominating effects of radial heat losses.

Nevertheless, from some introductory dehydrogenation experiments it could be concluded that a cyclic steady state could be easily obtained without any problems associated with process control, generally within about two hours after starting the dehydrogenation experiment. Furthermore, intermediate flushing with nitrogen between the propane dehydrogenation and fuel combustion reaction cycles could be safely omitted. However, to avoid too high temperatures during the fuel combustion reaction cycle it was necessary to dilute the methane/air mixture with nitrogen. In Figure 17 axial temperature profiles are shown for dehydrogenation experiments conducted with different oxygen inlet concentrations during the methane combustion cycle. Although the axial temperature profiles at the end of the endothermic and exothermic cycles in the cyclic steady state were hardly altered if the oxygen inlet concentration was decreased, very high temperatures were observed at the beginning of the combustion cycle, unless the oxygen concentration was less than about $5 \%$. Temperature increases well above $300{ }^{\circ} \mathrm{C}$ have been detected when air was used, severely damaging the catalyst. Since these high temperatures were also detected when the reactor was flushed with nitrogen between the dehydrogenation and combustion cycles, effects of mixing of the endothermic and exothermic reactants and products (or combustion of adsorbed components) can be excluded and the high temperatures can only be attributed to the combustion of carbonaceous products formed as a side product during the dehydrogenation cycle. As soon as the oxygen supply was stopped, the high temperatures rapidly disappeared. 


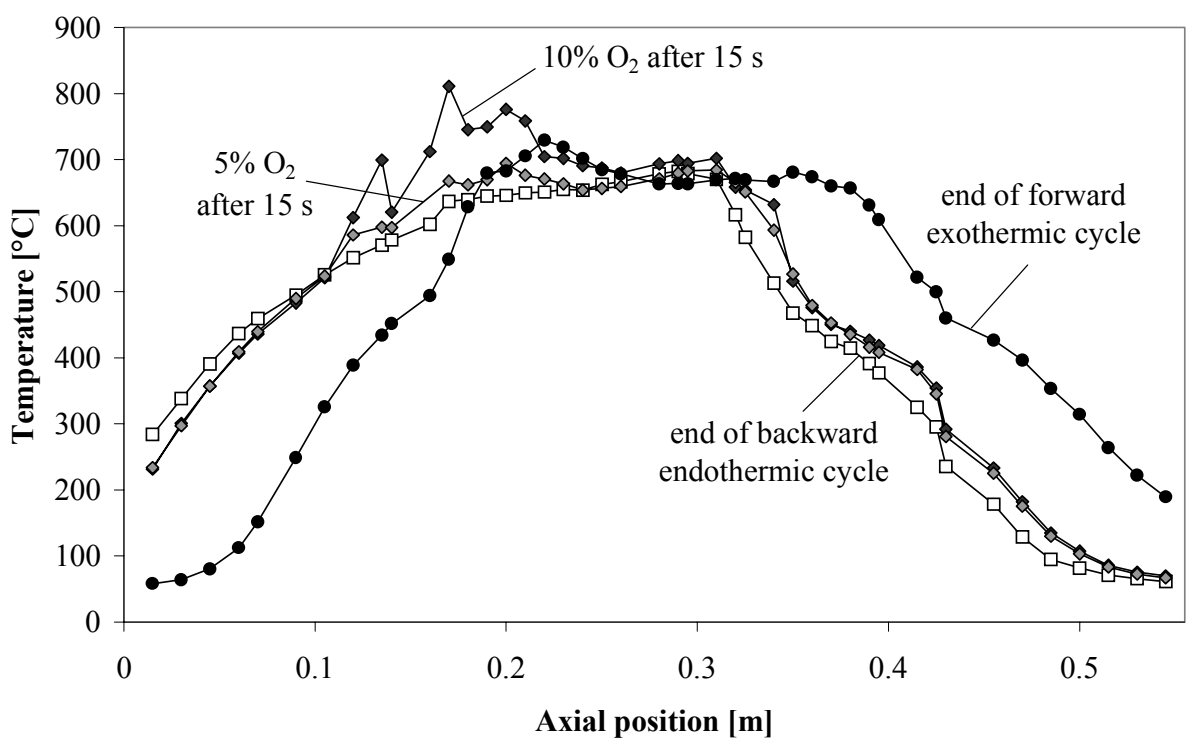

Figure 17. Effect of oxygen inlet concentration on the axial temperature profiles during the forward methane combustion cycle in the cyclic steady state for the operating conditions listed below.

Propane dehydrogenation cycle: $\Phi_{v, i n}=1.0 \mathrm{Nm}^{3} \cdot \mathrm{h}^{-1}, \Delta t=60 \mathrm{~s}, x_{g, \mathrm{C}_{3} \mathrm{H}_{8}, \text { in }}=50 \%, x_{g, \mathrm{H}_{2}, \text { in }}=50 \%$;

Methane combustion cycle: $\quad \Phi_{v, \text { in }}=6.5 \mathrm{Nm}^{3} \cdot \mathrm{h}^{-1}, \Delta t=90 \mathrm{~s}, x_{g, \mathrm{CH}_{4}, \text { in }}=0.4 \%$;

Switching scheme:

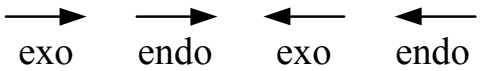

The rapid temperature response indicates that the coke combustion is a very local phenomenon. If the catalyst is heated uniformly, the total temperature increase due to combustion of the coke can be calculated with

$\Delta T_{C}=\frac{\left(-\Delta h_{C}\right) M_{C, 0}}{C_{p, c}}$

where $M_{C, 0}$ represents the coke content at the beginning of the exothermic cycle. From the coke formation model described in Chapter 5 it can be estimated that a 33\% propylene / 67\% hydrogen gas mixture at $650^{\circ} \mathrm{C}$ produces after $60 \mathrm{~s}$ only about $1.5 \cdot 10^{-5} \mathrm{mg}$ coke/mg monolith, which results in a temperature increase of the monolith of less than $1{ }^{\circ} \mathrm{C}$, assuming a catalyst heat capacity of $1160 \mathrm{~J} \cdot \mathrm{kg}^{-1} \cdot \mathrm{K}^{-1}$ (Hayes et al., 1996) and a reaction enthalpy for coke combustion of $-3.5 \cdot 10^{7} \mathrm{~J} \cdot \mathrm{kg}^{-1}$. For this experiment the contribution of coke combustion to the net heating of the catalyst during an entire methane combustion cycle can be neglected. However, the coke is formed and combusted locally in the washcoat of the monolith and if the 
conduction of energy from the washcoat to the monolith support is rate determining (despite the small washcoat thickness), temporarily much higher temperatures might exist in the washcoat. To avoid these local (very) high temperatures it is necessary to decrease the coke combustion rate by decreasing the oxygen concentration e.g. through nitrogen dilution.

It is important to realise that the contribution of coke combustion to the net heating of the catalyst during the methane combustion cycle strongly increases, if the endothermic propane dehydrogenation experiments are carried out with longer endothermic cycle times and at somewhat higher temperatures. The coke content increases quadratically with increasing propane dehydrogenation cycle times for the relatively small cycle times considered here. Furthermore, at higher temperatures the coke content increases very strongly especially because of the decreased influence of the hydrogen concentration (see Chapter 5).

Since large temperature increases can be avoided using oxygen concentrations still well above the desired fuel inlet concentrations, the necessary decrease in the oxygen concentration has no adverse effect on the specification of the endothermic and exothermic operating conditions. The only effect could be a possible advantageous decrease in the methane combustion reaction rate (Trimm and Lam, 1980). If not all the carbonaceous deposits can be removed during the methane combustion cycle because of the reduced oxygen supply, the oxygen concentration could be gradually increased during the combustion cycle.

In the next section the results of experiments of propane dehydrogenation in reverse flow coupled with methane combustion with reduced oxygen inlet concentrations are discussed focussing on the effect of back-conversion.

\subsubsection{Effect of back-conversion in a reactor entirely filled with active catalyst}

Firstly, the extent of back-conversion for propane dehydrogenation in reverse flow was investigated for a reactor entirely filled with active catalyst. In Figure 18 the results for the axial temperature profiles at the end of the reaction cycles in the cyclic steady state are shown for three cases with different operating conditions. Also the results of the product analysis (propane conversion and relative propylene selectivity) of samples taken at the end of the forward endothermic cycle just prior to switching to the methane combustion cycle are listed. 

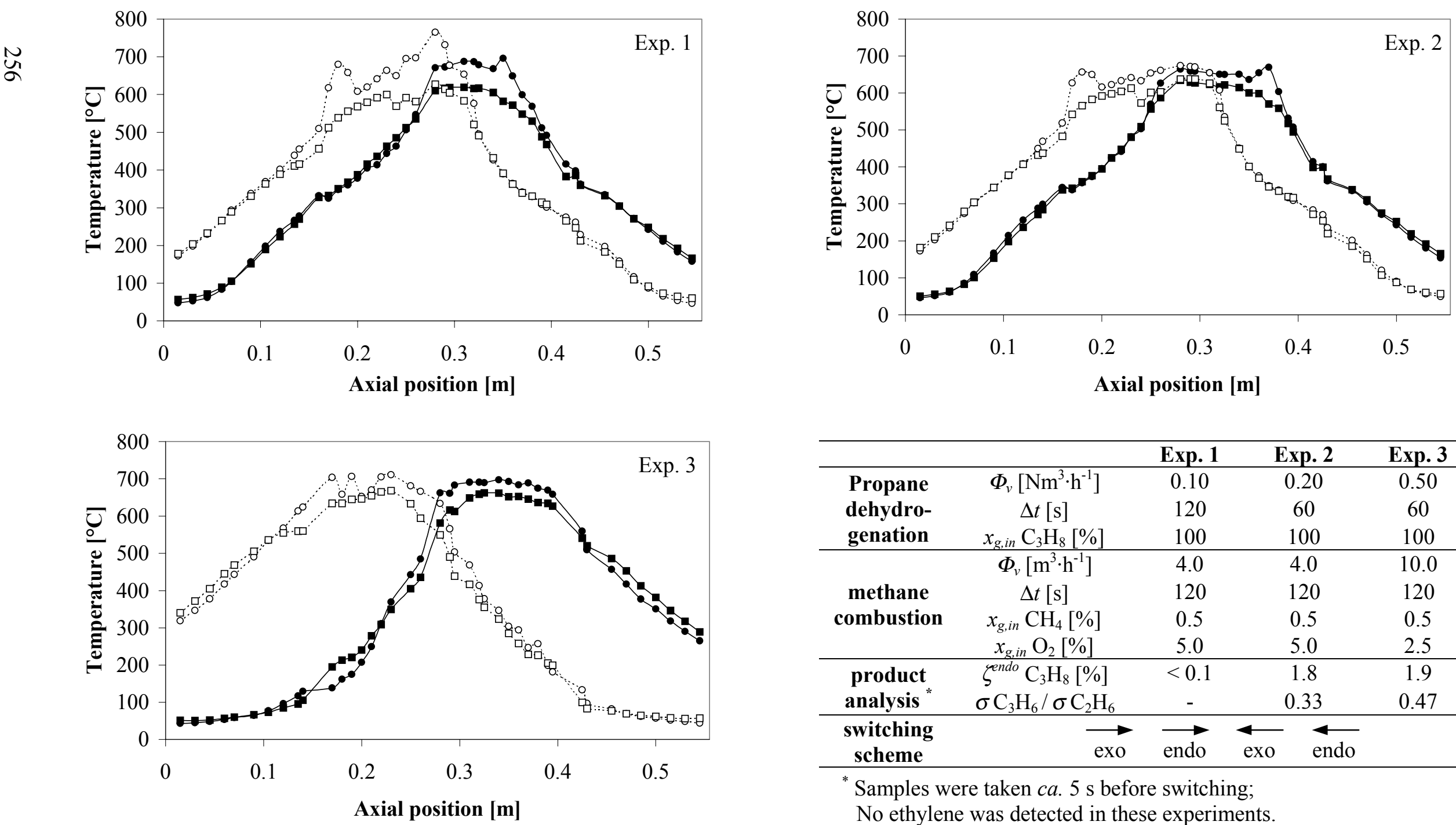

\begin{tabular}{|c|c|c|c|c|}
\hline & & Exp. 1 & Exp. 2 & Exp. 3 \\
\hline \multirow{3}{*}{$\begin{array}{l}\text { Propane } \\
\text { dehydro- } \\
\text { genation }\end{array}$} & $\Phi_{v}\left[\mathrm{Nm}^{3} \cdot \mathrm{h}^{-1}\right]$ & 0.10 & 0.20 & 0.50 \\
\hline & $\Delta t[\mathrm{~s}]$ & 120 & 60 & 60 \\
\hline & $x_{g, \text { in }} \mathrm{C}_{3} \mathrm{H}_{8}[\%]$ & 100 & 100 & 100 \\
\hline \multirow{4}{*}{$\begin{array}{l}\text { methane } \\
\text { combustion }\end{array}$} & $\Phi_{v}\left[\mathrm{~m}^{3} \cdot \mathrm{h}^{-1}\right]$ & 4.0 & 4.0 & 10.0 \\
\hline & $\Delta t[\mathrm{~s}]$ & 120 & 120 & 120 \\
\hline & $x_{g, i n} \mathrm{CH}_{4}[\%]$ & 0.5 & 0.5 & 0.5 \\
\hline & $x_{g, \text { in }} \mathrm{O}_{2}[\%]$ & 5.0 & 5.0 & 2.5 \\
\hline \multirow{2}{*}{$\begin{array}{l}\text { product } \\
\text { analysis * }\end{array}$} & $\zeta^{\text {endo }} \mathrm{C}_{3} \mathrm{H}_{8}[\%]$ & $<0.1$ & 1.8 & 1.9 \\
\hline & $\sigma \mathrm{C}_{3} \mathrm{H}_{6} / \sigma \mathrm{C}_{2} \mathrm{H}_{6}$ & - & 0.33 & 0.47 \\
\hline $\begin{array}{l}\text { switching } \\
\text { scheme }\end{array}$ & $\overrightarrow{\text { exo }}$ & $\overrightarrow{\text { endo }}$ & $\overleftarrow{\text { exo }} \quad \longleftarrow$ & \\
\hline
\end{tabular}

Figure 18. Propane dehydrogenation coupled with methane combustion over a monolithic catalyst: influence of the endothermic flow rate on the axial temperature profiles and the propane conversion and propylene selectivity during the propane dehydrogenation cycle (middle two heaters set at $550{ }^{\circ} \mathrm{C}$ ).

- end of forward exothermic cycle $\quad$ end of backward exothermic cycle

- end of forward endothermic cycle $\square$ end of backward endothermic cycle 
In view of the relatively large gas residence time compared to the cycle time for the endothermic cycle, only the concentration at the end of the endothermic cycle was determined. For all three experiments the differences between the axial temperature profiles at the end of the endothermic and exothermic cycle are relatively small and the temperature plateau increases and decreases more or less uniformly. The uniform increase and decrease of the temperature plateaux indicates relatively small conversions, as expected because of the short length of the temperature plateau. Therefore, experiments with different (asymmetric) switching schemes gave similar temperature profiles. The decrease in the temperature plateau during the propane dehydrogenation could not have been caused by merely radial heat losses. This was verified experimentally with an experiment where nitrogen was substituted for propane during the 'propane dehydrogenation' cycle, which showed a significantly smaller decrease of the temperature plateau during the 'endothermic' cycle. The temperature difference between the axial temperature profiles at the beginning and end of the propane dehydrogenation cycle is thus indicative for the average conversion during the propane dehydrogenation cycle.

The effect of increasing the endothermic gas velocity and simultaneously decreasing the endothermic cycle time while keeping the operating conditions of the exothermic cycle constant, so that the same amount of energy is supplied, can be seen by comparing experiments 1 and 2. For Experiment 1 with the lower endothermic gas velocity the temperature plateau is somewhat higher at the end of the exothermic cycles, probably because of more overlap of the methane combustion zones. The temperature difference between the beginning and the end of the endothermic cycle, and thus the propane conversion, is larger for the case with the lower endothermic gas velocity, as expected because of the longer gas residence time (note: the propane conversion is much smaller than the equilibrium conversion). However, the conversion determined from a sample taken at the reactor outlet was negligible for the low gas velocity experiment and remarkably larger for the experiment with a higher endothermic gas velocity. This can only be explained by the increased conversion and back-conversion for lower gas velocities during the dehydrogenation cycle. By shifting the plateau temperature towards the end of the reactor by increasing the cycle times for the forward endothermic and exothermic cycles compared to the backward cycles, a gas sample could be taken at the end of the temperature plateau and a propane conversion of about $10 \%$ was determined. These experiments show the enormous detrimental effect of the back-conversion on the overall propane conversion. Even if the endothermic gas velocity is 
increased again with a factor 2.5, increasing the exothermic gas velocity with the same factor to keep the total energy input constant, ( $c f$. experiments 2 and 3), the propane conversion is hardly effected. The plateau temperature at the end of the endothermic and exothermic cycle has increased only some $25{ }^{\circ} \mathrm{C}$ due to the larger gas velocity during the exothermic reaction cycle while the length of the temperature plateau is about the same. The decrease in the propane conversion by propane hydrogenation due to the smaller gas residence time is counteracted by an apparently equivalent decrease in the propane back-conversion by propylene hydrogenation, also because of the smaller gas residence time and the somewhat higher outlet temperatures.

Remarkably, only ethane and no ethylene was detected for these three experiments, although higher selectivities for ethylene compared to ethane are expected for a pure propane feed, based on the kinetic study reported in Chapter 4. Indeed, for the experiment where the temperature plateau was moved to the reactor outlet a high ethylene to ethane ratio was determined. The absence of ethylene in the dehydrogenation experiments is probably caused by hydrogenation of ethylene to ethane at the end of the reactor, just like the hydrogenation of propylene to propane. The equilibrium conversion of ethane to ethylene and hydrogen is even lower than the equilibrium conversion of propane to propylene at the same temperature and pressure. The back-conversion of ethylene is also very undesired, since ethylene is a valuable side-product in contrast to ethane.

The temperature peaks at the back end of the exothermic cycle are caused by local coke combustion in the washcoat. These temperature peaks disappear within a few seconds after switching to the dehydrogenation cycle. These temperature peaks indicate that not all the carbonaceous products have been removed from the catalyst surface at the end of the exothermic cycle. This is mainly caused by the movement of the temperature profiles, especially during the exothermic cycle because of the much higher gas velocities. At the end of the backward propane dehydrogenation cycle the temperature plateau is located most to the left. Upon switching to the forward methane combustion cycle the plateau moves to the right and before all the coke at the left end of the plateau can be combusted, the temperature front passes and the catalyst temperature decreases to too low temperatures for coke combustion. When the temperature plateau returns to the left during the backward methane combustion cycle part of these remaining carbonaceous deposits are combusted. During the propane dehydrogenation experiments carbonaceous deposits accumulated at the ends of the part of 
the reactor where high temperatures have been prevailing, i.e. at $0.15-0.2 \mathrm{~m}$ and at 0.35-0.40 $\mathrm{m}$. This was confirmed by relatively high temperature peaks at these axial positions during the methane combustion cycles with long cycle times to regenerate the catalyst after the dehydrogenation experiment.

\subsubsection{Effect of back-conversion in a reactor with inactive sections flanking the active catalyst}

It has been investigated whether two inactive sections of $0.15 \mathrm{~m}$ length flanking an active section of $0.255 \mathrm{~m}$ at the reactor ends can reduce the back-conversion observed for a reactor entirely filled with active catalyst. In Figure 19 the axial temperature profiles are shown for a propane dehydrogenation experiment with inactive sections for operating conditions comparable to those in Figure 18.

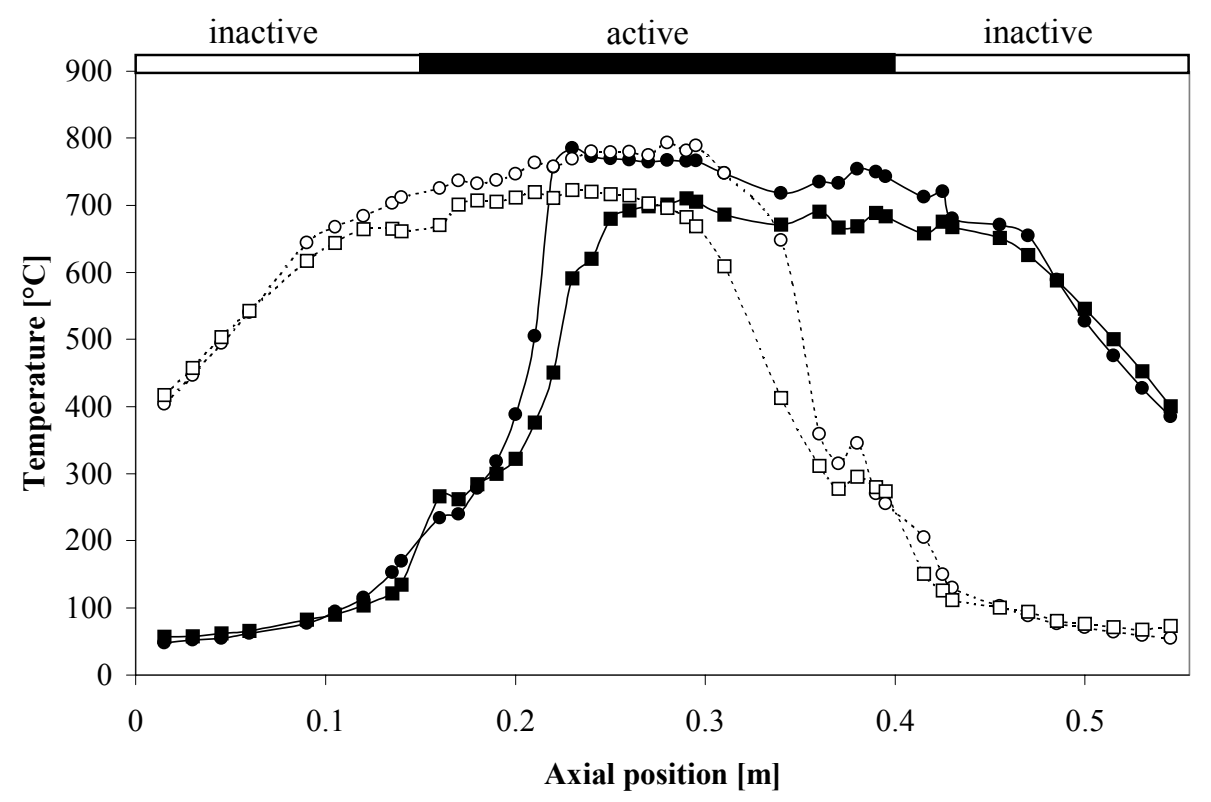

Figure 19. Axial temperature profiles at the end of each reaction cycle for propane dehydrogenation coupled with methane combustion in reverse flow in a reactor filled with $0.225 \mathrm{~m}$ active catalyst flanked with two inactive sections of $0.15 \mathrm{~m}$ at either end. Operating conditions listed below (middle two heaters set at $600{ }^{\circ} \mathrm{C}$ ). Product analysis $c a .5 \mathrm{~s}$ before switching: $\zeta^{\text {endo }} \mathrm{C}_{3} \mathrm{H}_{8}=14.6 \% ; \sigma \mathrm{C}_{3} \mathrm{H}_{6} / \sigma \mathrm{C}_{2}=5.4 ; \sigma \mathrm{C}_{2} \mathrm{H}_{4} / \sigma \mathrm{C}_{2} \mathrm{H}_{6}=5.4$;

Propane dehydrogenation cycle: $\Phi_{v, \text { in }}=0.5 \mathrm{Nm}^{3} \cdot \mathrm{h}^{-1}, \Delta t=60 \mathrm{~s}, x_{g, \mathrm{C}_{3} \mathrm{H}_{8}, \text { in }}=100 \%$;

Methane combustion cycle: $\quad \Phi_{v, \text { in }}=13.0 \mathrm{Nm}^{3} \cdot \mathrm{h}^{-1}, \Delta t=120 \mathrm{~s}, x_{g, \mathrm{CH}_{4}, \text { in }}=0.5 \%, x_{g, \mathrm{O}_{2}, \text { in }}=2.5 \%$;

Switching scheme:

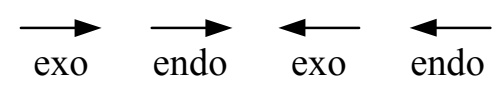

- end of forward exothermic cycle $\quad$ end of backward exothermic cycle

- end of forward endothermic cycle $\quad \square$ end of backward endothermic cycle 
Strikingly, due to the inactive sections the length of the temperature plateau has increased considerably and also the plateau temperatures are some $25-50{ }^{\circ} \mathrm{C}$ higher. From Figure 20, showing the evolution of the axial temperature profiles during the forward methane combustion cycle, it can be observed that at the transition between the inactive and active section the temperature strongly increases from 700 to $800{ }^{\circ} \mathrm{C}$ within $40 \mathrm{~s}$ after switching to the methane combustion cycle. When the temperature front passes the transition point, the maximum temperature decreases somewhat again.

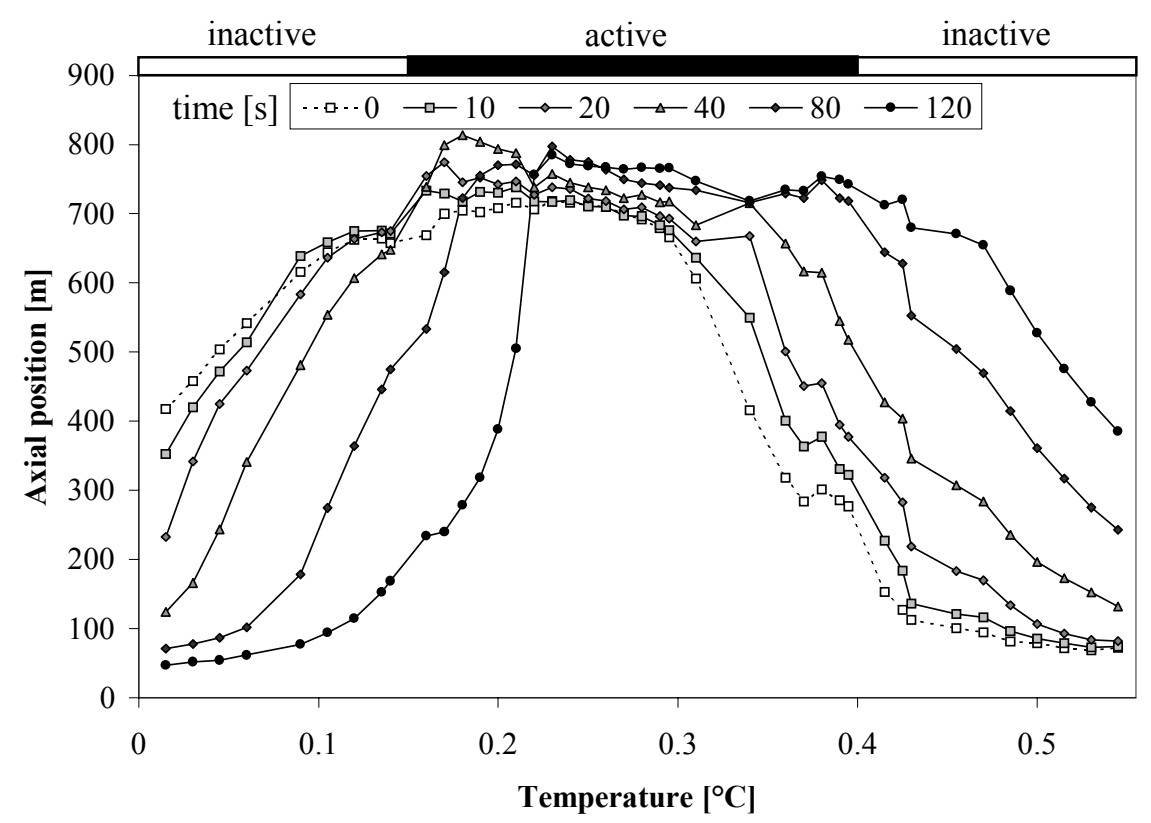

Figure 20. Axial temperature profiles at different times (in s) during the forward methane combustion cycle for the propane dehydrogenation experiment coupled with methane combustion in reverse flow in a reactor filled with $0.225 \mathrm{~m}$ active catalyst flanked with two inactive sections of $0.15 \mathrm{~m}$ at either end for the operating conditions listed in Figure 19.

Although the length of the temperature plateau in the active section at the end of the endothermic cycle has increased some $50 \%$ and the plateau temperature is some $25{ }^{\circ} \mathrm{C}$ higher due to the inactive sections ( $c f$. Figure 19 with Figure 18, experiment 3), the propane conversion has increased a factor 10 from $1.9 \%$ to $14.6 \%$. Since this conversion corresponds to the maximum conversion determined from the experiment where the temperature profile was moved to the reactor end, it can be concluded that the inactive sections reduce the propylene back-conversion almost completely in this experiment. Furthermore, also the ethylene back-conversion has been largely prevented by the inactive sections, as shown by the high ratio of the ethylene and ethane selectivities. 
Results of experiments performed with different inlet gas flow rates for the endothermic reaction cycle, ranging from $0.25 \mathrm{Nm}^{3} \cdot \mathrm{h}^{-1}$ to $1.50 \mathrm{Nm}^{3} \cdot \mathrm{h}^{-1}$, keeping all other operating conditions constant are shown in Figure 21. For these experiments the methane inlet concentration has been increased somewhat compared to the previous experiments to increase the propane conversion. The figures clearly show the formation of a temperature peak during the exothermic methane combustion cycle and the subsequent consumption of the temperature peak during the endothermic propane dehydrogenation cycle, while the temperature fronts move in the direction of the flow. Due to the higher temperatures of the temperature peaks resulting from the higher methane inlet concentration the greater part of the conversion of propane to propylene takes place at the temperature peaks at the beginning of the endothermic cycle. However, at the end of the endothermic cycle when the temperature peak has almost been consumed, the propane conversion takes place more uniformly over the temperature plateau.

The temperature profiles at the end of the methane combustion cycles are practically the same for the different experiments because of identical operating conditions during the exothermic reaction cycle. With the operating conditions chosen the temperature at the transition point between the active and inactive section at the back end of the temperature profile during the propane dehydrogenation cycle is always above $650{ }^{\circ} \mathrm{C}$, assuring high possible propane conversions. The equilibrium conversion of pure propane at $650{ }^{\circ} \mathrm{C}$ and atmospheric pressure is about $67 \%$.

When the endothermic gas flow rate was increased from 1.0 to $1.5 \mathrm{Nm}^{3} \cdot \mathrm{h}^{-1}$, experiments 3 and 4 respectively, the propane conversion decreased from 20.8 to $12.4 \%$. The plateau temperatures at the end of the propane dehydrogenation cycle remained about the same, but the length of the plateau temperature has decreased some $10 \%$ due to the higher heat front velocity during the endothermic cycle. The decrease in propane conversion corresponds well to the decrease in the gas residence time and the shorter temperature plateau. The propylene and olefin selectivities were very high for these high endothermic gas flow rates.

Decreasing the endothermic gas flow rate from 1.0 to $0.25 \mathrm{Nm}^{3} \cdot \mathrm{h}^{-1}$, experiments 3 and 1 respectively, the gas residence time increased with a factor 4 , but the conversion has hardly increased (only some $20 \%$ ), even though the length of the temperature plateau increased 

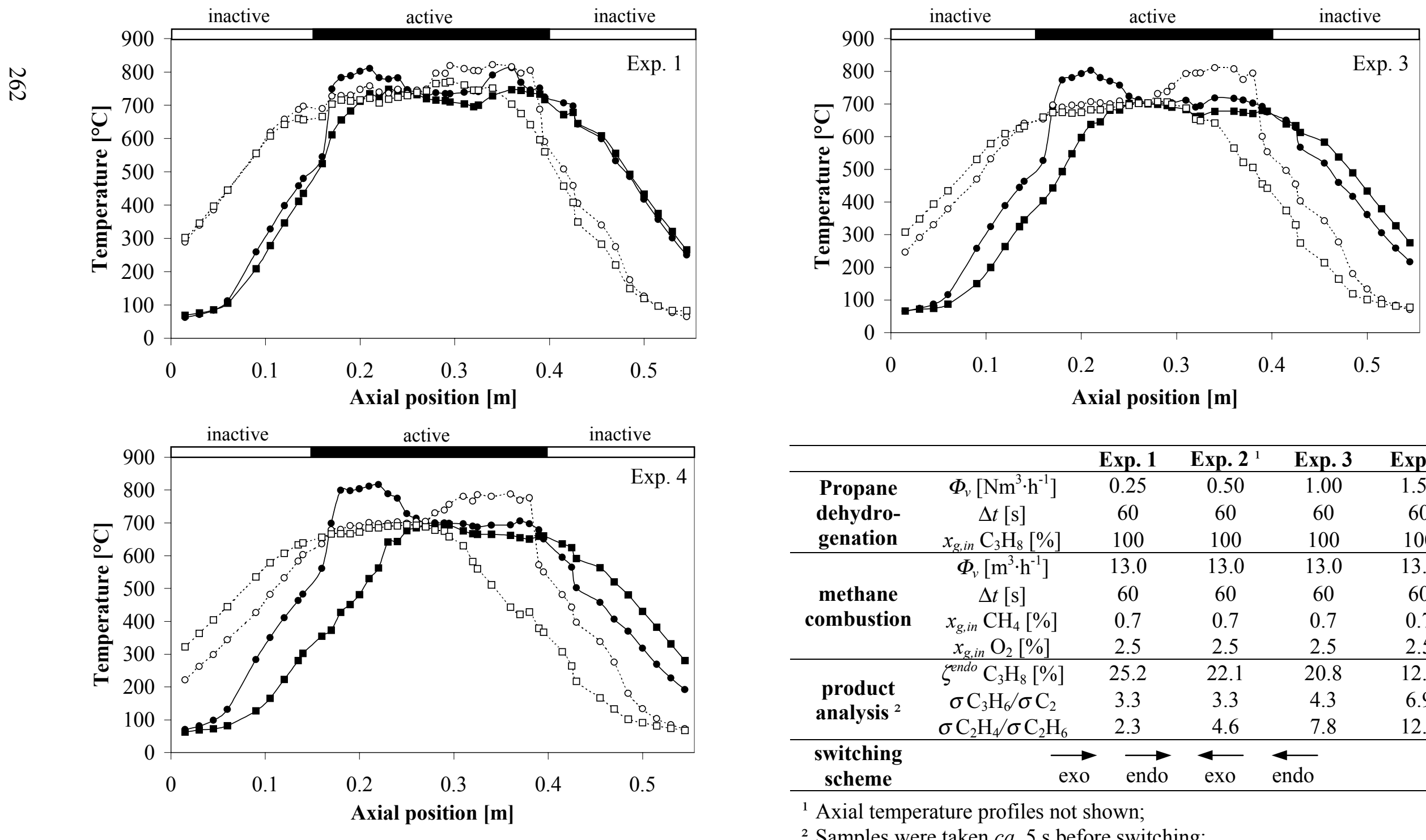

\begin{tabular}{|c|c|c|c|c|c|}
\hline & & Exp. 1 & Exp. $2^{1}$ & Exp. 3 & Exp. 4 \\
\hline \multirow{3}{*}{$\begin{array}{l}\text { Propane } \\
\text { dehydro- } \\
\text { genation }\end{array}$} & $\Phi_{v}\left[\mathrm{Nm}^{3} \cdot \mathrm{h}^{-1}\right]$ & 0.25 & 0.50 & 1.00 & 1.50 \\
\hline & $\Delta t[\mathrm{~s}]$ & 60 & 60 & 60 & 60 \\
\hline & $x_{g, i n} \mathrm{C}_{3} \mathrm{H}_{8}[\%]$ & 100 & 100 & 100 & 100 \\
\hline \multirow{4}{*}{$\begin{array}{l}\text { methane } \\
\text { combustion }\end{array}$} & $\Phi_{v}\left[\mathrm{~m}^{3} \cdot \mathrm{h}^{-1}\right]$ & 13.0 & 13.0 & 13.0 & 13.0 \\
\hline & $\Delta t[\mathrm{~s}]$ & 60 & 60 & 60 & 60 \\
\hline & $x_{g, i n} \mathrm{CH}_{4}[\%]$ & 0.7 & 0.7 & 0.7 & 0.7 \\
\hline & $x_{g, i n} \mathrm{O}_{2}[\%]$ & 2.5 & 2.5 & 2.5 & 2.5 \\
\hline \multirow{3}{*}{$\begin{array}{l}\text { product } \\
\text { analysis }^{2}\end{array}$} & $\zeta^{\text {endo }} \mathrm{C}_{3} \mathrm{H}_{8}[\%]$ & 25.2 & 22.1 & 20.8 & 12.4 \\
\hline & $\sigma \mathrm{C}_{3} \mathrm{H}_{6} / \sigma \mathrm{C}_{2}$ & 3.3 & 3.3 & 4.3 & 6.9 \\
\hline & $\sigma \mathrm{C}_{2} \mathrm{H}_{4} / \sigma \mathrm{C}_{2} \mathrm{H}_{6}$ & 2.3 & 4.6 & 7.8 & 12.4 \\
\hline $\begin{array}{c}\text { switching } \\
\text { scheme }\end{array}$ & $\longrightarrow \overrightarrow{\text { exo }}$ & $\overrightarrow{\text { endo }}$ & $\stackrel{4}{\text { exo }}$ & $\overline{\text { endo }}$ & \\
\hline
\end{tabular}

${ }^{1}$ Axial temperature profiles not shown;

${ }^{2}$ Samples were taken $c a$. $5 \mathrm{~s}$ before switching;

Figure 21. Propane dehydrogenation coupled with methane combustion over a monolithic catalyst of $0.155 \mathrm{~m}$ length in the centre of the reactor and two $0.15 \mathrm{~m}$ inactive sections at the reactor ends: Influence of the endothermic flow rate on the axial temperature profiles and the propane conversion and propylene selectivity during the propane dehydrogenation cycle (middle two heaters set at $600{ }^{\circ} \mathrm{C}$ ).

- end of forward exothermic cycle $\quad \circ$ end of backward exothermic cycle - end of forward endothermic cycle $\quad$ end of backward endothermic cycle 
somewhat and plateau temperature increased some $25-50^{\circ} \mathrm{C}$. An explanation for the absence of the increase in the propane conversion is the decrease of the catalyst activity caused by the accumulation of carbonaceous deposits. Due to the higher plateau temperature, longer temperature plateau and somewhat higher propylene concentrations during the propane dehydrogenation if the endothermic gas velocity is decreased, the coke formation rates are considerably increased. Due to the increased amount of coke deposited on the catalyst during the propane dehydrogenation cycle, probably not all the coke products can be combusted within the relatively short methane combustion cycle, causing accumulation of carbonaceous products also in the centre the active catalyst section. Accumulation of relatively large amounts of carbonaceous deposits also in the centre of the reactor was confirmed when the catalyst was regenerated after the propane dehydrogenation experiments.

\subsubsection{Qualitative comparison with model simulations}

The effects of back-conversion and coke accumulation were briefly investigated with model simulations. For the endothermic reaction phase the propane dehydrogenation and propylene hydrogenation reaction kinetics from Chapter 4 (ignoring gas phase side reactions) and the coke formation kinetic model from Chapter 5 were incorporated in the simulation model. For the exothermic regeneration phase the experimentally determined heterogeneous methane combustion kinetics was incorporated (see Appendix B), next to a coke combustion kinetic model, which was derived from coke combustion experiments over the monolithic catalyst carried out in the TGA set-up described in Chapter 5. The coke combustion model is briefly outlined in Appendix C.

In Figure 22 the calculated axial temperature and propane mass fraction profiles at the beginning and the end of the endothermic forward flow reaction cycle are shown for an adiabatic reactor filled entirely with active catalyst and for an adiabatic reactor filled with an active section in the centre of the reactor and two inactive sections at either reactor end. The simulations show that even for an adiabatic reactor back-conversion is quite considerable (especially at the beginning of the endothermic cycle) and that back-conversion can be effectively suppressed using inactive sections at the reactor ends, which qualitatively corresponds with experimental observations. 

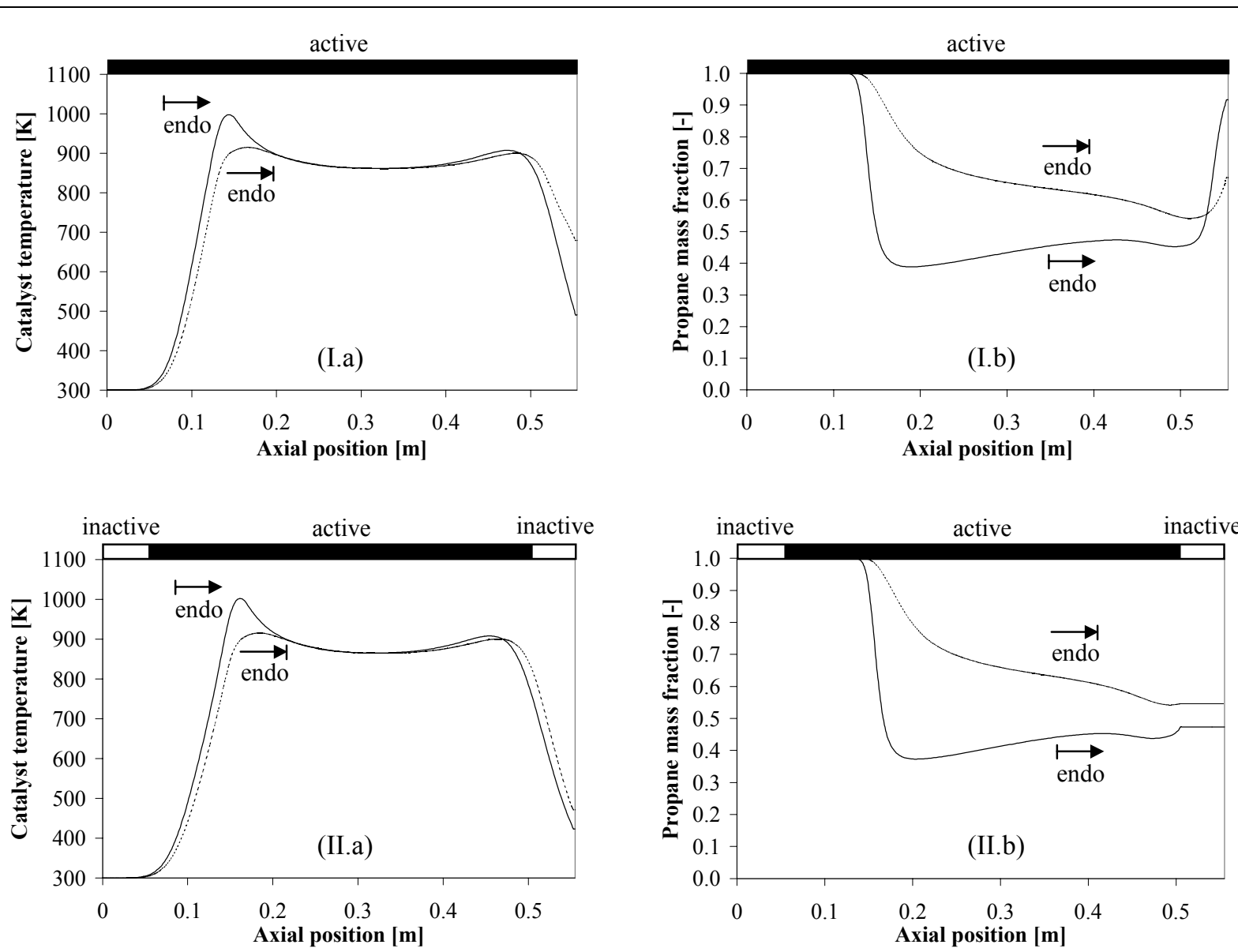

Figure 22. Simulation results for the propane dehydrogenation coupled with methane combustion in reverse flow over a monolithic catalyst, showing axial catalyst temperature (a) and propane mass fraction (b) profiles at the beginning $(\longmapsto$, solid lines) and end $(\longrightarrow$, dashed lines) of the endothermic forward flow cycle for an adiabatic reactor of $0.555 \mathrm{~m}$ length, either completely filled with active material (case I) or filled with an active section of $0.455 \mathrm{~m}$ length in the centre and two $0.050 \mathrm{~m}$ inactive sections at the reactor ends (case II). (Homogeneous methane combustion was modelled with the two-step mechanism by Westbrook and Dryer, 1981).

Propane dehydrogenation cycle: $\quad \Phi_{v, \text { in }}=0.5 \mathrm{Nm}^{3} \cdot \mathrm{h}^{-1}, \Delta t=30 \mathrm{~s}, x_{g, \mathrm{C}_{3} \mathrm{H}_{8}, \text { in }}=100 \%$;

Methane combustion cycle: $\quad \Phi_{v, \text { in }}=5.0 \mathrm{Nm}^{3} \cdot \mathrm{h}^{-1}, \Delta t=90 \mathrm{~s}, x_{g, \mathrm{CH}_{4}, \text { in }}=0.3 \%$ (in air);

Switching scheme:

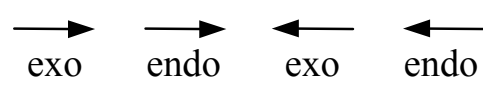

Furthermore, also for the coke content cyclic steady state profiles are obtained, shown in Figure 23, indicating that all the coke formed during the propane dehydrogenation is combusted during the combustion cycle. However, coke has been accumulated at the ends of the temperature plateau at the reactor ends and at the centre of the reactor, coinciding well with experimental observations. 


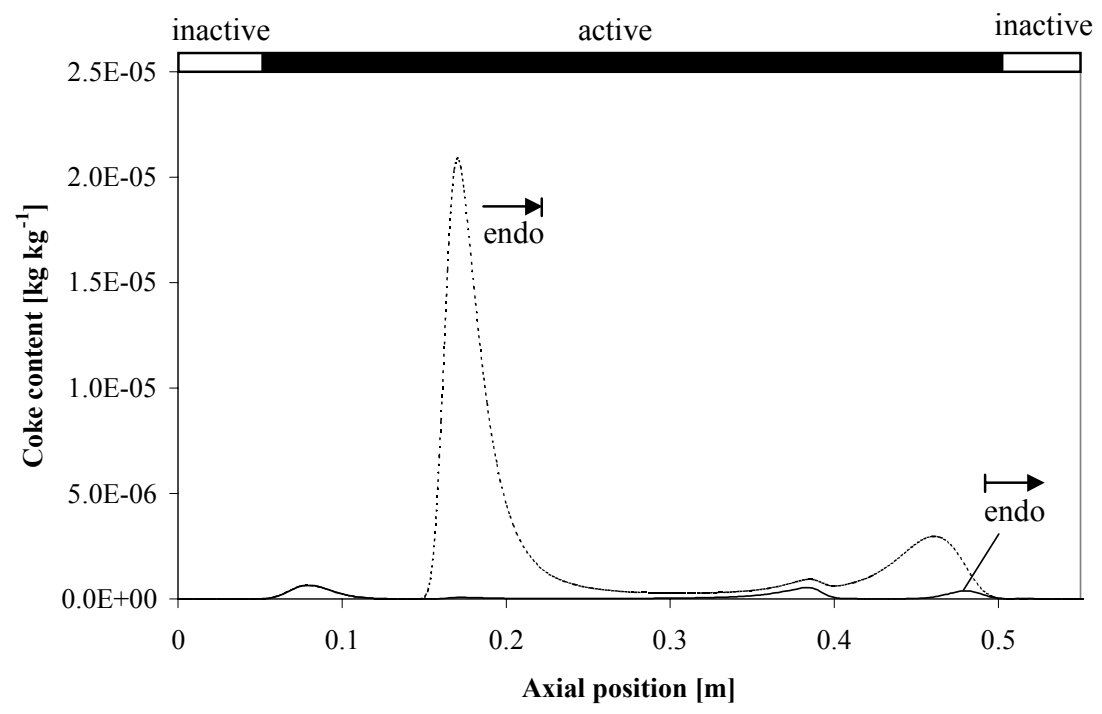

Figure 23. Simulation results for the propane dehydrogenation coupled with methane combustion in reverse flow over a monolithic catalyst for the axial coke content profiles at the beginning $(\longmapsto$, solid line) and end $(\longrightarrow$, dashed line) of the endothermic forward flow cycle for a reactor of $0.555 \mathrm{~m}$ length filled with an active section of $0.455 \mathrm{~m}$ length in the centre and two $0.050 \mathrm{~m}$ inactive sections at the reactor ends (case II). Operating conditions listed in Figure 22.

\section{Summary and conclusions}

Propane dehydrogenation coupled with methane combustion over a monolithic catalyst in reverse flow has been experimentally investigated. In a small laboratory scale monolith reactor, insulated and installed with compensatory heating, axial temperature profiles as a function of time and the product composition of the reactor effluent at the end of the endothermic propane dehydrogenation cycle were determined.

Despite the inevitably large influences of radial heat losses on the axial temperature profiles the experiments have shown that endothermic and exothermic reactions can be coupled in reverse flow, integrating in situ heat supply and catalyst regeneration with recuperative heat exchange. Although the influence of radial heat losses prevented from quantitative validation of the experiments with model simulations, the experiments showed that the cyclic steady state was easily obtained without any problems associated with process control and intermediate flushing with nitrogen between the propane dehydrogenation and fuel combustion reaction cycles could indeed be safely omitted. Too high temperatures in the catalyst during the methane combustion cycle due to local combustion of carbonaceous products deposited in the washcoat during the propane dehydrogenation cycle could be avoided by decreasing the oxygen concentration. 
Propane dehydrogenation experiments in a reactor entirely filled with active catalyst showed that almost all the propylene formed at the high temperature plateau was again hydrogenated at the reactor end, resulting in a low propane conversion. Remarkably, for higher endothermic gas velocities the propane conversion increased. The lower gas residence time decreased the conversion of propane by propane dehydrogenation at the high temperatures of the temperature plateau, but also decreased the back-conversion of propylene by propylene hydrogenation at the lower temperatures at the reactor end. Noteworthily, also the ethylene formed as a side-product was hydrogenated to ethane at the reactor ends. Experiments with two inactive sections at the reactor ends flanking an active catalyst section in the centre showed that the back-conversion of both propylene and ethylene could be effectively suppressed. The inactive sections also increased the length of the temperature plateau and the plateau temperature.

Furthermore, the propane dehydrogenation experiments have shown that carbonaceous deposits can accumulate at the ends of the temperature plateau most to the left and most to the right. Due to the much larger heat front velocity during the exothermic combustion cycle compared to the endothermic dehydrogenation cycle because of the much higher throughput, the duration of time that high temperatures prevailed at these positions was much larger during the endothermic cycle compared to the exothermic cycle. As a result, the time during the combustion cycle was insufficient to remove all the carbonaceous deposits formed during the endothermic cycle. Accumulation of coke deposits at these positions can be reduced, if the exothermic cycle is allowed to act in the same flow direction as the endothermic cycle for a little while before the flow direction is reversed, simultaneously purging the reactor and minimising the propylene losses. Additionally, accumulation of coke deposits can be counteracted by choosing the forward exothermic and endothermic cycle times somewhat larger than the backward cycles times, so that the temperature profiles move gradually over several complete cycles to the right, and subsequently smaller forward cycle times to move the temperatures back to the left, and so on, obviously at the expense of somewhat larger heat losses. Moreover, if necessary, once in a while two additional cycles can be included after the methane combustion cycle and before switching to the propane dehydrogenation cycle. During these two cycles (a forward and backward cycle) with mainly air as feed (possibly with methane added to maintain high temperatures and possibly diluted with nitrogen to avoid exceeding maximum temperature constraints) the temperature plateau can be moved through the entire reactor removing all the coke deposits and completely regenerate the catalyst. Furthermore, if the plateau temperature during the propane dehydrogenation cycle is very 
high the coke formation rate can be higher than the coke combustion rate (with the low oxygen concentration to avoid too high temperatures). In this case coke can also accumulate in the centre of the temperature plateau. At high operating temperatures the contribution of coke combustion to the net heating of the catalyst can be considerable. To avoid accumulation of coke the maximum allowable operating temperatures are restricted by the coke formation and coke combustion rates and, moreover, the ratio of the exothermic to endothermic cycle times needs to be large enough to combust all the coke.

\section{Acknowledgements}

The investigations were financially supported by the Netherlands Organization for Scientific Research (N.W.O.). The author wishes to thank in particular H.J. Moed for the construction and maintenance of the experimental set-up. Also the help of R. Meijer with the process control is greatly appreciated. Finally, the author is grateful to R.C. Nijssen for his valuable contribution to the experimental work.

\section{Notation}

$a_{v} \quad$ specific external catalyst surface area $\left[\mathrm{m}^{2} \cdot \mathrm{m}^{-3}\right]$

$C_{g} \quad$ gas phase concentration $\left[\mathrm{mole} \cdot \mathrm{m}^{-3}\right]$

$C_{p} \quad$ heat capacity $\left[\mathrm{J} \cdot \mathrm{mole}^{-1} \cdot \mathrm{kg}^{-1}\right]$

$d \quad$ reactor diameter or width $[\mathrm{m}]$

$d_{\text {ins }} \quad$ insulation thickness [m]

E activation energy $\left[\mathrm{kJ} \cdot \mathrm{mole}^{-1}\right]$

$\Delta h_{C} \quad$ reaction enthalpy of coke combustion $\left[{\left.\mathrm{J} \cdot \mathrm{kg}^{-1}\right]}^{-1}\right.$

$J_{i} \quad \mathrm{i}^{\text {th }}$ order Bessel function

$k \quad$ reaction rate constant

$k_{g} \quad$ external mass transfer coefficient $\left[\mathrm{m} \cdot \mathrm{s}^{-1}\right]$

$K^{*} \quad$ constant defined in coke combustion rate equation $\left[\mathrm{m}^{3} \cdot \mathrm{mole}^{-1} \cdot \mathrm{kg}_{\mathrm{C}} \cdot \mathrm{kg}_{\mathrm{cat}}{ }^{-1} \cdot \mathrm{s}^{-1}\right]$

$L \quad$ reactor length [m]

$M \quad$ molar mass $\left[\mathrm{kg} \cdot \mathrm{mole}^{-1}\right]$

$M_{C} \quad$ coke content $\left[\mathrm{mg}_{\text {coke }} \cdot \mathrm{mg}_{\text {cat }}{ }^{-1}\right]$ 


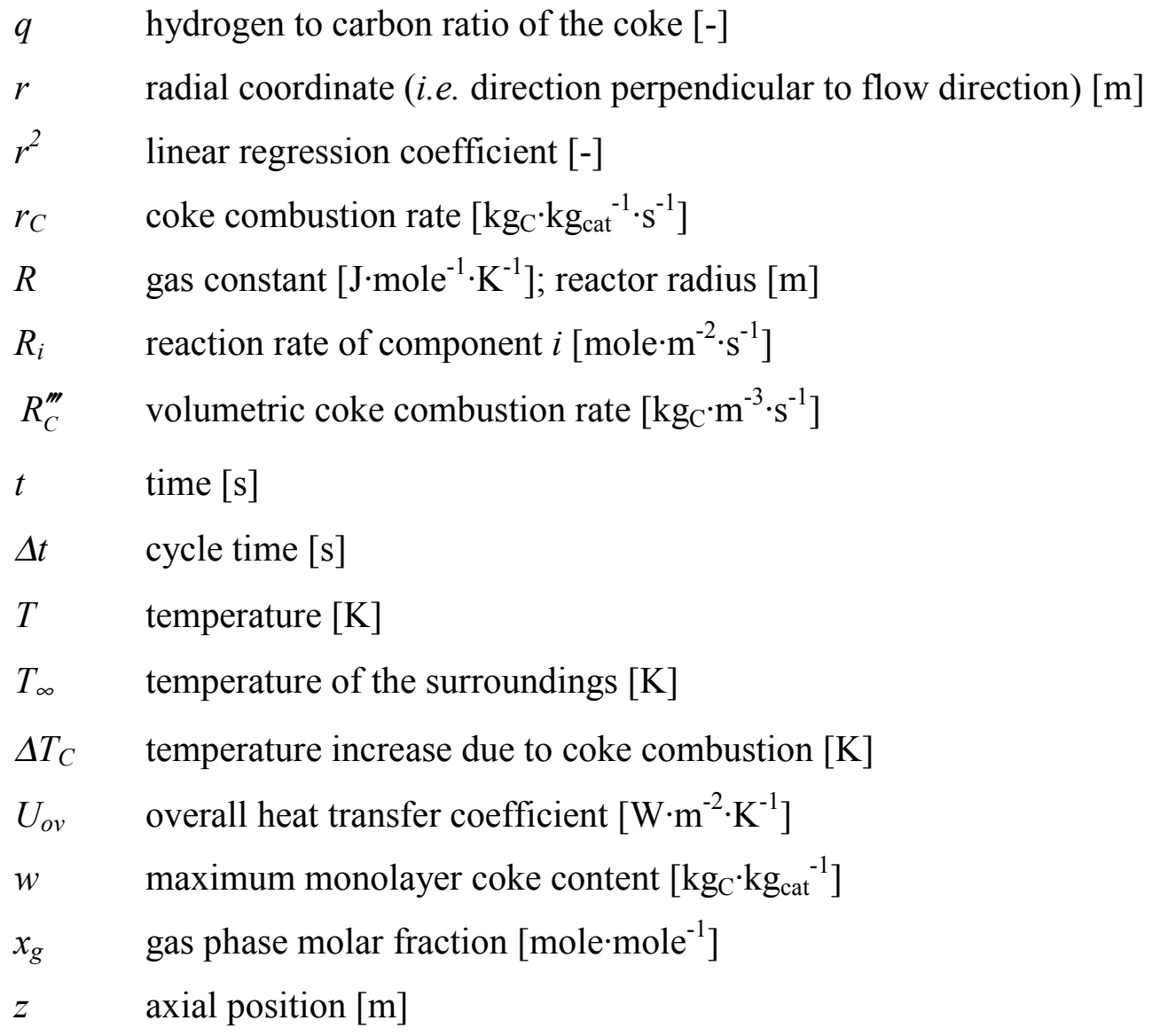

Greek symbols

$\varepsilon \quad$ monolith porosity $\left[\mathrm{m}^{3} \cdot \mathrm{m}^{-3}\right]$

$\theta_{c, \max }$ dimensionless maximum temperature [-] $\left(=\frac{R T_{\max }}{E}\right)$

$\theta_{C m} \quad$ monolayer coke surface fraction [-]

$\theta_{C M} \quad$ multilayer coke surface fraction [-]

$\zeta \quad$ conversion [-]

$\lambda \quad$ conductivity $\left[\mathrm{W} \cdot \mathrm{m}^{-1} \cdot \mathrm{K}^{-1}\right]$

$\xi \quad$ dimensionless radial coordinate $[-]\left(=\frac{r}{R}\right)$

$\rho \quad$ density $\left[\mathrm{kg} \cdot \mathrm{m}^{-3}\right]$

$\sigma \quad$ selectivity [-]

$\phi \quad$ dimensionless axial coordinate $[-]\left(=\frac{z}{L}\right)$

$\Phi_{v} \quad$ volumetric flow rate $\left[\mathrm{m}^{3} \cdot \mathrm{s}^{-1}\right.$ or $\left.\mathrm{Nm}^{3} \cdot \mathrm{h}^{-1}\right]$

$\Phi_{m}^{\prime \prime} \quad$ mass flux $\left[\mathrm{kg} \cdot \mathrm{m}^{-2} \cdot \mathrm{s}^{-1}\right]$ 


\section{Subscripts}

c catalyst phase

C coke

eff effective (i.e. considering the monolith as a pseudo-homogeneous medium)

g gas phase

in inlet

ins insulation material

max maximum

MC methane combustion

ov overall

PC propane combustion

$0 \quad$ initial

$\infty \quad$ pre-exponential; surroundings

\section{Superscripts}

endo endothermic reaction phase

exo exothermic reaction phase

het heterogeneous reactions

hom homogeneous reactions

\section{Dimensionless numbers}

$B i \quad$ Biot number $\left(=\frac{\lambda_{\text {ins }}}{\lambda_{c, e f f}} \frac{1}{\ln \left(1+\frac{d_{\text {ins }}}{R}\right)}\right)$

$G z \quad$ Graetz number $\left(=\frac{\lambda_{c, e f f} L}{\Phi_{m}^{\prime \prime} C_{p, g} R^{2}}\right)$

$Y \quad$ dimensionless temperature gradient $\left(=\frac{T-T_{\text {in }}}{T_{\infty}-T_{\text {in }}}\right)$

$\Theta \quad$ maximum temperature number (for definition see Chapter 2) 


\section{References}

Bernett, C.J., Kolaczkowski, S.T. and Thomas, W.J. (1991). Determination of heterogeneous reaction kinetics and reaction rates under mass transfer controlled conditions for a monolith reactor. Trans. I. Chem. E., 69, 209-220.

Blanks, R.F., Wittrig, T.S. and Peterson, D.A. (1990). Bidirectional adiabatic synthesis gas generator. Chem. Engng Sci., 45, 2407-2413.

Carlslaw, H.S. and Jaeger, J.C. (1959). Conduction of heat in solids. $2^{\text {nd }}$ ed., Clarendon Press, Oxford, United Kingdom.

Hayes, R.E., Kolaczkowski, S.T., Thomas, W.J. and Titiloye, J. (1996). Transient experiments and modeling of the catalytic combustion of methane in a monolith reactor. Ind. Eng. Chem. Res., 35, 406-414.

Neophytides, S.G. and Froment, G.F. (1992). A bench scale study of reversed flow methanol synthesis. Ind. Eng. Chem. Res., 31, 1583-1589.

Trimm, D.L. and Lam, C.-W. (1980). The combustion of methane on platinum-alumina fibre catalysts - I. Kinetics and mechanism. Chem. Engng Sci., 35, 1405-1413.

Van de Beld, L. (1995). Air purification by catalytic oxidation in an adiabatic packed bed reactor with periodic flow reversal. Ph.D. Thesis, Twente University, Enschede, The Netherlands.

Van de Beld, L. and Westerterp, K.R. (1996). Air purification in a reverse-flow reactor: model simulations vs. experiments. AIChE J., 42, 1139-1148.

Westbrook, C.K. and Dryer, F.L. (1981). Simplified reaction mechanisms for the oxidation of hydrocarbon fuels in flames. Combustion Science and Technology, 27, 31-43. 


\section{Appendix A - Estimation of heat losses in the experimental reverse flow reactor}

The extent of heat losses in the experimental reverse flow reactor can be assessed from experimentally determined steady state axial and radial temperature profiles for experiments using preheated air as feed at different gas flow rates and inlet temperatures. In these experiments the flow direction through the catalyst bed was not reversed and no fuels were added to the air feed. Based on a simple two-dimensional model effective heat conductivities for the monolith and the insulation materials could be estimated. The radial conductive energy transport through the reactor wall and the two different layers of insulation materials were lumped in one effective heat conductivity and, furthermore, small differences in the insulation thickness along the axial coordinate were ignored. Moreover, the effective heat conductivities of the monolith and the insulation material have both been assumed independent of the operating conditions, especially the temperature and gas velocity. With these parameters the effects of heat losses on the axial temperature profiles in the reverse flow reactor can be investigated.

To simplify the description of the energy transfer processes in the monolith and the insulation materials and to enable us to obtain an analytical solution for the temperature profiles, the rectangular monolith is approximated by a cylinder, as depicted in Figure A.1. Furthermore a uniform gas velocity profile over the channels is assumed.

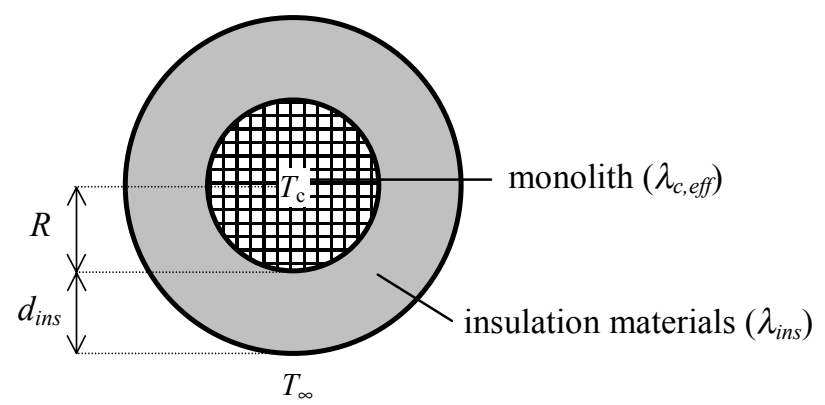

Figure A.1 Monolith approximated as a cylinder in the description of radial heat losses.

A differential steady-state energy balance over the monolith (gas and catalyst phase), neglecting axial conduction compared to axial convection, yields: 
$\Phi_{m}^{\prime \prime} C_{p, g} \frac{\partial T}{\partial z}=\lambda_{c, e f f} \frac{1}{r} \frac{\partial}{\partial r}\left(r \frac{\partial T}{\partial r}\right)$

with the following boundary conditions

$$
\begin{array}{lll}
z=0, & 0 \leq r \leq R: & T=T_{i n} \\
r=0, & 0 \leq z \leq L: & \frac{\partial T}{\partial r}=0 \\
r=R, & 0 \leq z \leq L: & -\lambda_{c, \text { eff }} \frac{\partial T}{\partial r}=\frac{\lambda_{\text {ins }}}{R} \frac{\left(T-T_{\infty}\right)}{\ln \left(1+\frac{d_{\text {ins }}}{R}\right)}
\end{array}
$$

In the last boundary condition the heat flux from the monolith is equated with the heat flux into the insulation material. Note that the heat transport through the reactor wall, a layer of ceramic wool and an additional layer of ceramic foam has been described with one overall effective heat conductivity. The solution of this partial differential equation with the above boundary conditions is given by Carlslaw and Jaeger (1959),

$$
Y=1-2 B i \sum_{n=1}^{\infty} \frac{e^{-\beta_{n}^{2} G z \phi}}{\left(\beta_{n}^{2}+B i^{2}\right)} \frac{J_{0}\left(\beta_{n} \xi\right)}{J_{0}\left(\beta_{n}\right)}
$$

where the dimensionless driving force and dimensionless radial and axial coordinates have been defined as

$Y=\frac{T-T_{\text {in }}}{T_{\infty}-T_{\text {in }}}, \quad \xi=\frac{r}{R}, \quad \phi=\frac{z}{L}$

and the Graetz-number and Biot-number as

$$
G z=\frac{\lambda_{c, \text { eff }} L}{\Phi_{m}^{\prime \prime} C_{p, g} R^{2}}, \quad B i=\frac{\lambda_{\text {ins }}}{\lambda_{c, \text { eff }}} \frac{1}{\ln \left(1+\frac{d_{\text {ins }}}{R}\right)}
$$

where $\beta_{n}$ is the $n^{\text {th }}$ root of $\beta J_{1}(\beta)=B i J_{0}(\beta)$. 

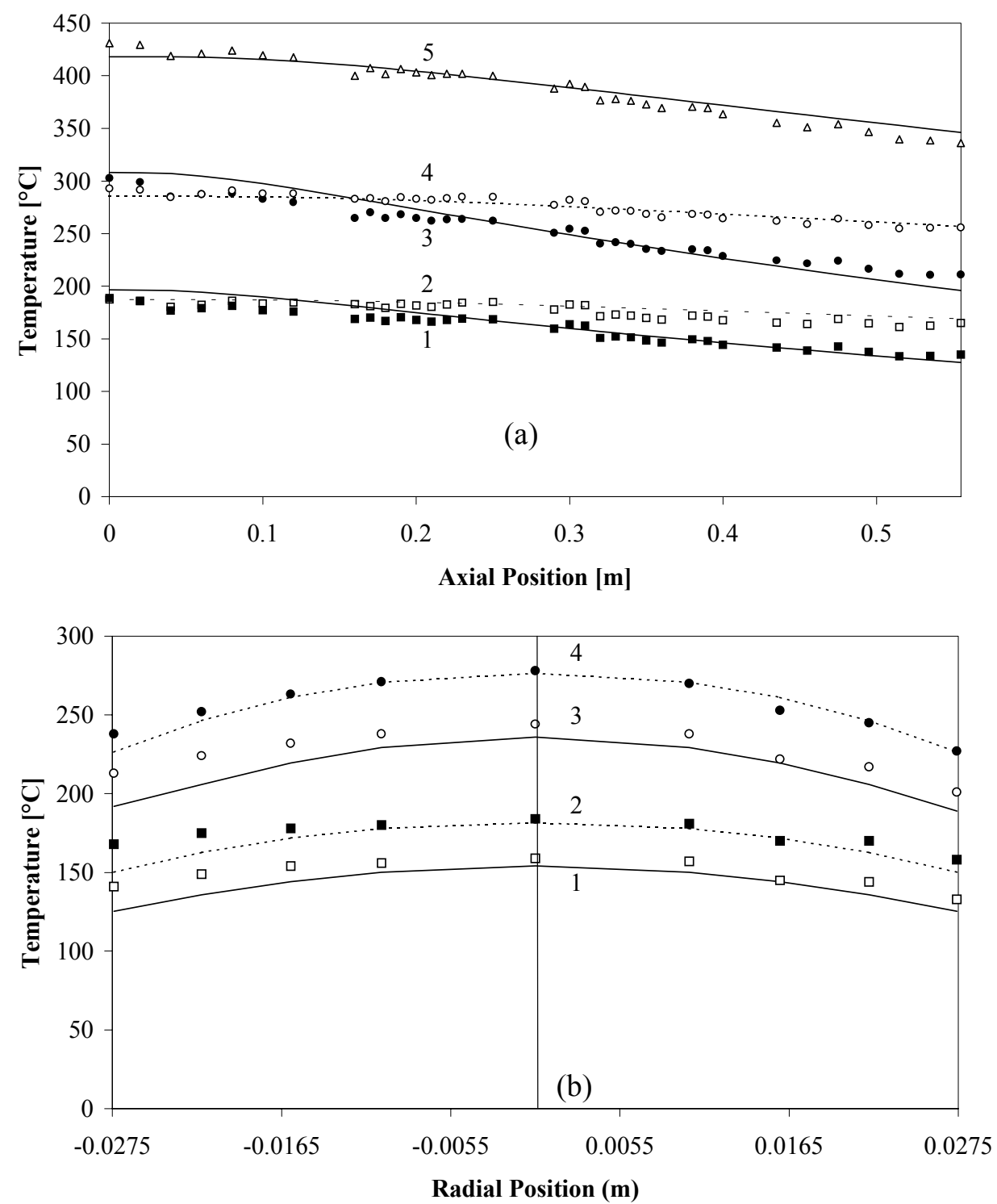

Figure A.2 Axial temperature profiles in the centre of the monolith (radial distance 0-0.01 m) (a) and radial temperature profiles at $0.37 \mathrm{~m}$ from the inlet (b) when feeding preheated air with different inlet temperatures and gas flow rates (volumetric flow rate for experiments 1-5: $3.6,10.8,3.7,10.8$ and $7.3 \mathrm{Nm}^{3} \cdot \mathrm{h}^{-1}$, respectively). The markers indicate the experimental values. The lines correspond to model calculations using an effective heat conductivity for the monolith of $0.5 \mathrm{~W} \cdot \mathrm{m}^{-1} \cdot \mathrm{K}^{-1}$ and $B i$ set equal to 0.54 .

Using experiments with preheated air feed with different inlet gas flow rates and inlet temperatures, the effective monolith heat conductivity and the $B i$-number are estimated at $0.5 \mathrm{~W} \cdot \mathrm{m}^{-1} \cdot \mathrm{K}^{-1}$ and 0.54 respectively. The results have been depicted in Figure A.2. With an average insulation thickness of $0.03 \mathrm{~m}$, the conductivity of the insulation is estimated at $0.2 \mathrm{~W} \cdot \mathrm{m}^{-1} \cdot \mathrm{K}^{-1}$. The estimates for the monolith and insulation conductivities compare reasonably well with typical values for cordierite monoliths and insulation materials. 
From these experiments it can be concluded that the temperature in the innermost channels is practically uniform in the direction perpendicular to the average flow direction (see Figure A.2b). Furthermore, ignoring radial temperature profiles overall radial heat transfer coefficients can be estimated from the experiments at $2-5 \mathrm{~W} \cdot \mathrm{m}^{-2} \cdot \mathrm{K}^{-1}$. This is only slightly higher than the heat transfer coefficient of about $1.6 \mathrm{~W} \cdot \mathrm{m}^{-2} \cdot \mathrm{K}^{-1}$ in the reverse flow reactor of Van de Beld (1995) equipped with an evacuated jacket. Especially because of the reactor dimensions (length and width $0.055 \mathrm{~m}$ in this work versus $0.145 \mathrm{~m}$ inner diameter of Van de Beld's reverse flow reactor) higher overall heat transfer coefficients were expected. 


\section{Appendix B - Kinetics of the heterogeneous combustion of methane and propane over a monolithic platinum alumina catalyst}

The kinetics of the complete combustion of methane and propane over a $\mathrm{Pt} / \gamma-\mathrm{Al}_{2} \mathrm{O}_{3}$ monolithic catalyst (with $1.5 \mathrm{~g}$ Pt per 1 monolith, corresponding to about $1.1 \mathrm{wt} \% \mathrm{Pt}$ in the washcoat) has been determined in the same kinetic set-up as described in Chapter 4. Again the kinetics-reactor was operated differentially, i.e. the reactant conversion was kept below $10 \%$ to avoid influences of back-mixing and axial temperature profiles caused by the released reaction energy during the combustion of methane and propane. In the combustion experiments no carbon monoxide was detected in the effluent. It was checked by calculations that the conversion rate was not influenced by internal or external mass transfer limitations in the investigated temperature range (overall efficiency factors exceed 98\%). Furthermore, at these relatively low temperatures the contribution of homogeneous reactions can be excluded (for propane combustion see e.g. Bernett et al., 1991). Finally, the kinetics was determined on a partially deactivated catalyst with a BET-area of approximately $15.3 \mathrm{~m}^{2} \cdot \mathrm{g}^{-1}$ monolith (see Chapter 4). The experimental results are shown in Table B.1 and Figures B.1-B.3.

\section{Methane combustion}

For the combustion of methane a first order dependency in the methane concentration was found (at 500 and $600{ }^{\circ} \mathrm{C}$ ) and an activation energy of $98.5 \mathrm{~kJ} \cdot \mathrm{mole}^{-1}$ was fitted. These results correspond very well with the experimental results by Trimm and Lam (1980) for methane combustion over a $\mathrm{Pt} / \gamma-\mathrm{Al}_{2} \mathrm{O}_{3}$ catalyst $(0.4 \mathrm{wt} \% \mathrm{Pt})$.

Table B.1 Experimentally determined reaction kinetics for the combustion of methane and propane over a $\mathrm{Pt} / \gamma-\mathrm{Al}_{2} \mathrm{O}_{3}$ monolithic catalyst (Pt-content: $1.5 \mathrm{~g} \cdot \mathrm{l}^{-1}$ monolith). The BET area was determined at $15.3 \mathrm{~m}^{2} \cdot \mathrm{g}^{-1}$ monolith, the sample weight $2.0 \mathrm{~g}$ and the total external surface area about $9.5 \cdot 10^{-3} \mathrm{~m}^{2}$. The reaction rates are given per unit external catalyst surface area.

$$
\begin{array}{cc}
\text { Heterogeneous methane combustion } & \text { Heterogeneous propane combustion } \\
R_{M C}^{\text {het }}=k_{M C, \infty}^{\text {het }} \exp \left(-\frac{E_{M C}^{\text {het }}}{R T}\right) C_{g, \mathrm{CH}_{4}} C_{g, \mathrm{O}_{2}} & R_{P C}^{\text {het }}=k_{P C, \infty}^{\text {het }} \exp \left(-\frac{E_{P C}^{\text {het }}}{R T}\right) C_{g, \mathrm{C}_{3} \mathrm{H}_{8}} C_{g, \mathrm{O}_{2}} \\
k_{M C, \infty}^{h e t}=5.18 \cdot 10^{2} \mathrm{~m}^{4} \cdot \mathrm{mole}^{-1} \cdot \mathrm{s}^{-1} & k_{P C, \infty}^{\text {het }}=4.68 \mathrm{~m}^{4} \cdot \mathrm{mole}^{-1} \cdot \mathrm{s}^{-1} \\
E_{M C}^{h e t}=98.5 \mathrm{~kJ} \cdot \mathrm{mole}^{-1} & E_{P C}^{\text {het }}=48.6 \mathrm{~kJ} \cdot \mathrm{mole}^{-1}
\end{array}
$$




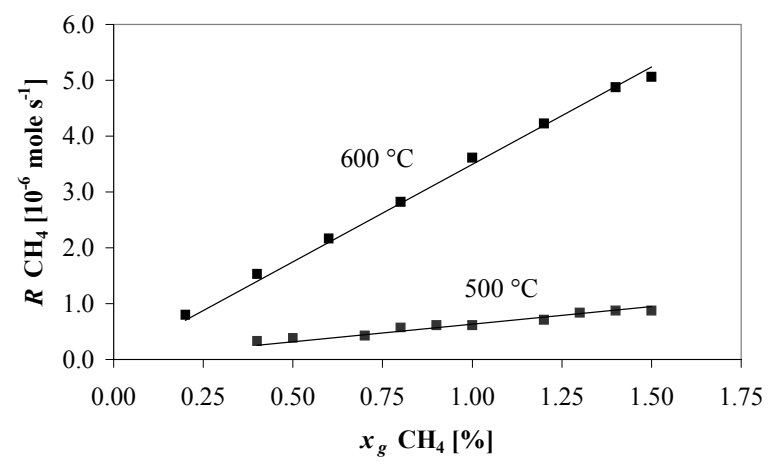

Figure B.1 Reaction rate of the heterogeneous methane combustion as a function of the methane inlet mole fraction at $500{ }^{\circ} \mathrm{C}$ and $600^{\circ} \mathrm{C}$.

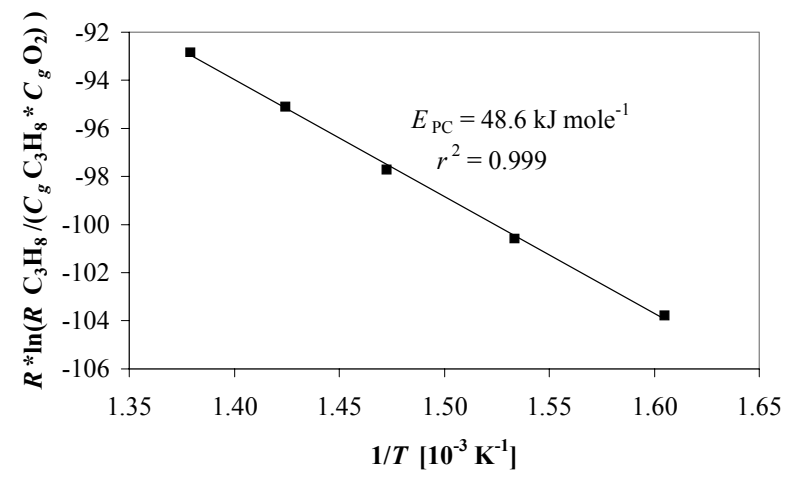

Figure B.3 Arrhenius-plot for the heterogeneous propane combustion for a mixture of $0.3 \mathrm{~mole} \%$ propane in air.

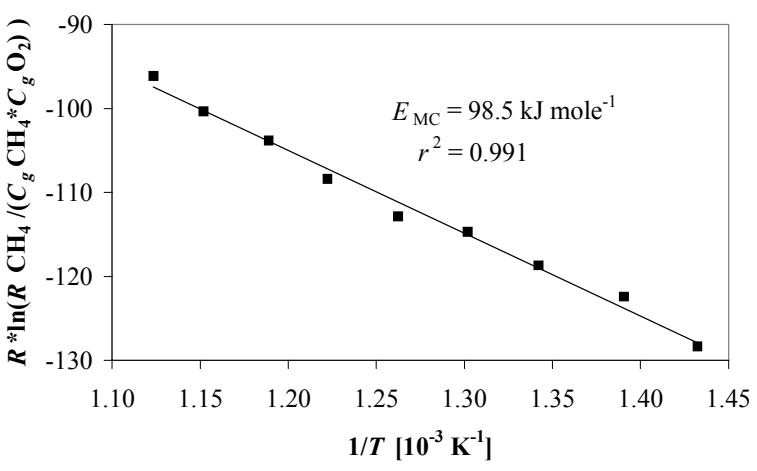

Figure B.2 Arrhenius plot for the heterogeneous methane combustion for a mixture of $0.5 \mathrm{~mole} \%$ methane in air.

Their reaction rate equations reduce to a first order dependency in the methane concentration at low methane concentrations as typically used in this work (methane inlet mole fractions below 0.015). Furthermore, Trimm et al. fitted an overall apparent activation energy of $86 \mathrm{~kJ} \cdot \mathrm{mole}^{-1}$ based on a reaction rate equation with mole fractions instead of molar concentrations. Reinterpreting the experimental results of this work with a reaction rate equation based on mole fractions an overall apparent activation energy of $85 \mathrm{~kJ} \cdot \mathrm{mole}^{-1}$ is found.

For a methane-air mixture with 0.5 vol\% methane at $850 \mathrm{~K}$ Trimm and Lam determined a methane combustion rate of $2.6 \cdot 10^{-8} \mathrm{~mole} \cdot \mathrm{m}^{-2} \cdot \mathrm{s}^{-1}$ (based on the internal catalyst surface area) for a fresh catalyst with $0.4 \mathrm{wt} \% \mathrm{Pt}$. Correcting linearly for a higher platinum loading assuming constant platinum dispersion - the reaction rate can be corrected to $7.4 \cdot 10^{-8}$ mole $\cdot \mathrm{m}^{-2} \cdot \mathrm{s}^{-1}$. In this work the methane combustion rate at the above conditions was 
determined at $1.2 \cdot 10^{-6}$ mole $\cdot \mathrm{s}^{-1}$ for a $1.1 \mathrm{wt} \% \mathrm{Pt}$ in the washcoat. The internal specific catalyst surface area was about $15 \mathrm{~m}^{2} \cdot \mathrm{g}^{-1}$ and the sample weight was $2.0 \mathrm{~g}$, so that the experimentally determined reaction rate based on the internal catalyst surface area is about $4 \cdot 10^{-8}$ mole $\cdot \mathrm{m}^{-2} \cdot \mathrm{s}^{-1}$, which also corresponds quite reasonably with the experimental results of Trimm et al. The influence of the oxygen concentration on the methane combustion rate was not determined in this work. A first order dependency was assumed (based on the rate equations given by Trimm and Lam, 1980).

\section{Propane combustion}

Because of the very high reaction enthalpy of the propane combustion, the propane combustion rates could only be determined for very low propane concentrations $(<0.5 \mathrm{vol} \%)$ at relatively low temperatures $\left(350-450{ }^{\circ} \mathrm{C}\right)$. For very low propane concentrations a first order dependency was found for the propane concentration and an activation energy of only $48.6 \mathrm{~kJ} \cdot \mathrm{mole}^{-1}$. For the propane combustion rate over a monolithic $\mathrm{Pt}-\mathrm{Rh} / \gamma-\mathrm{Al}_{2} \mathrm{O}_{3}$ catalyst (with $1.4 \mathrm{~g} \cdot \mathrm{l}^{-1}$ noble metal loading) Bernett et al. (1991) also found a first order dependency in the propane concentration with a much higher activation energy of $89.8 \mathrm{~kJ} \cdot \mathrm{mole}^{-1}$, also for very small propane concentrations $(<0.4 \mathrm{vol} \%)$ and at somewhat lower temperatures $(290-$ $375^{\circ} \mathrm{C}$ ). For a propane-air mixture with $0.3 \mathrm{vol} \%$ propane at $650 \mathrm{~K}$ Bernett et al. determined a propane disappearance rate of $8.1 \cdot 10^{-4} \mathrm{~mole} \cdot \mathrm{m}^{-2} \cdot \mathrm{s}^{-1}$ (based on the external catalyst surface area). With the experimental set-up in this work a propane combustion rate of $1.3 \cdot 10^{-6}$ mole $\cdot \mathrm{s}^{-1}$ was observed for the same conditions over a catalyst with approximately the same platinum loading. With a total external catalyst surface area in the monolith channels of about $9.5 \cdot 10^{-3} \mathrm{~m}^{2}$, the experimentally determined reaction rate is $1.4 \cdot 10^{-4}$ mole $\cdot \mathrm{m}^{-2} \cdot \mathrm{s}^{-1}$ (based on the external catalyst surface area). The lower propane combustion rate determined in this work is probably caused by differences in the catalyst properties, especially the specific catalyst surface area. The propane combustion rate in this work was determined over a catalyst, which had been operated at high temperatures $\left(600-700{ }^{\circ} \mathrm{C}\right)$ for significantly long periods of time (>24 h.), while Bernett et al. used a fresh catalyst, or at least a catalyst which has not been at high temperatures. As shown in Chapter 4 (Figure 7) the catalytic activity can decrease even up to a factor of 10 due to sintering and destruction of active sites (e.g. by decrease in platinum dispersion) at high temperatures. Finally, again a first order in the oxygen concentration was assumed. 


\section{Appendix C - Kinetics of the combustion of carbonaceous deposits formed during propane dehydrogenation on a monolithic platinum alumina catalyst}

In order to simulate possible coke accumulation effects during propane dehydrogenation coupled with methane combustion in reverse flow, a rate expression for the combustion of these carbonaceous deposits is required. In the literature no such relation has been found. Using the TGA (Thermogravimetric Analysis) experimental set-up described in detail in Chapter 5 some coke combustion experiments were carried out in order to derive a coke combustion rate equation as simple as possible, circumventing detailed study of the complex mechanism of the combustion of the coke, a term to indicate the hotchpotch of different types of carbonaceous products with different carbon-hydrogen ratios. For the experiments the same small piece of monolithic catalyst was used for many successive experiments (see Chapter 5).

In Figure C.1 the coke combustion rate, i.e. the slope of the coke content versus time, is given for a monolithic sample using air at different temperatures. The coke was formed under pure propylene atmosphere at $700{ }^{\circ} \mathrm{C}$ for 15 minutes at atmosphere pressure. This figure shows that the coke combustion is a complex process, which cannot be described with a simple rate expression. From the figure three phases in the coke combustion can be distinguished. Remarkably, at the beginning the coke is combusted very slowly, especially at relatively low combustion temperatures.

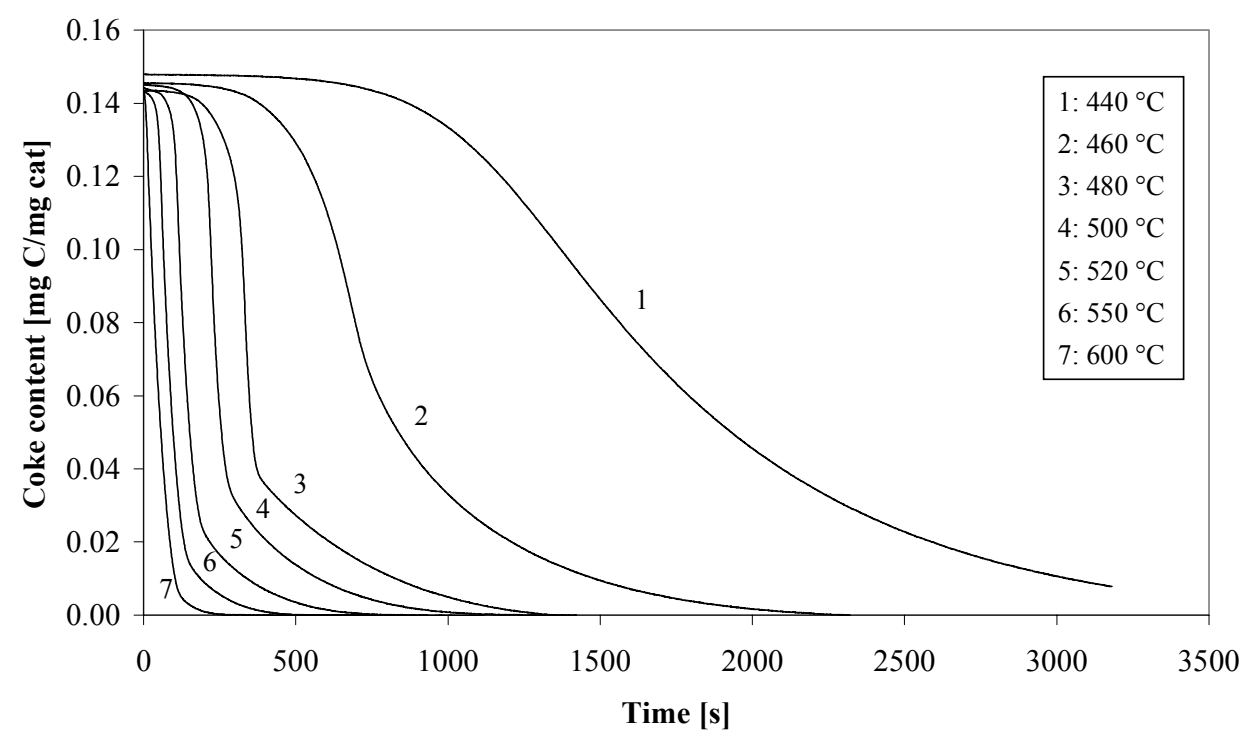

Figure C.1 Coke combustion rates using air at different combustion temperatures over a small sample of a monolithic $\mathrm{Pt} / \gamma-\mathrm{Al}_{2} \mathrm{O}_{3}$ catalyst. The coke was formed under pure propylene atmosphere at $700{ }^{\circ} \mathrm{C}$ for 15 minutes. 


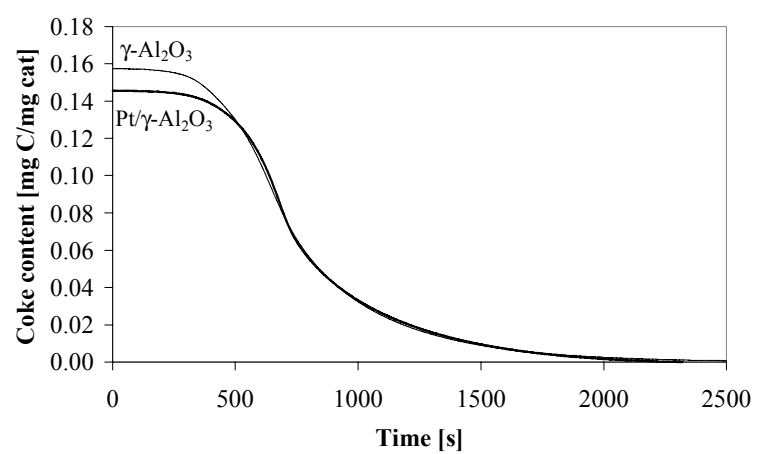

Figure C.2 Coke combustion rates using air at $460{ }^{\circ} \mathrm{C}$ for monolith samples with $\left(\mathrm{Pt} / \gamma-\mathrm{Al}_{2} \mathrm{O}_{3}\right)$ and without $\left(\boldsymbol{\gamma}-\mathrm{Al}_{2} \mathrm{O}_{3}\right)$ platinum dispersed in the washcoat. (Coke formation conditions: $100 \%$ propylene, $700{ }^{\circ} \mathrm{C}, 15 \mathrm{~min}$ ).

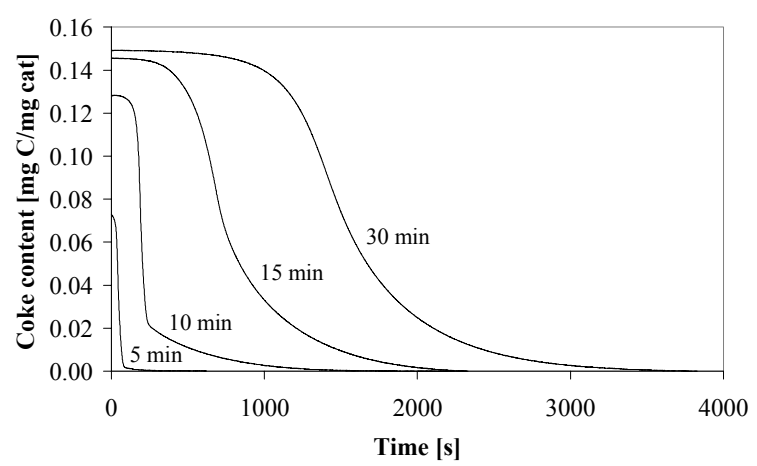

Figure C.4 Coke combustion rates using air at $460{ }^{\circ} \mathrm{C}$ of a sample where coke was formed with $100 \%$ propylene at $700{ }^{\circ} \mathrm{C}$ for the indicated period of time.

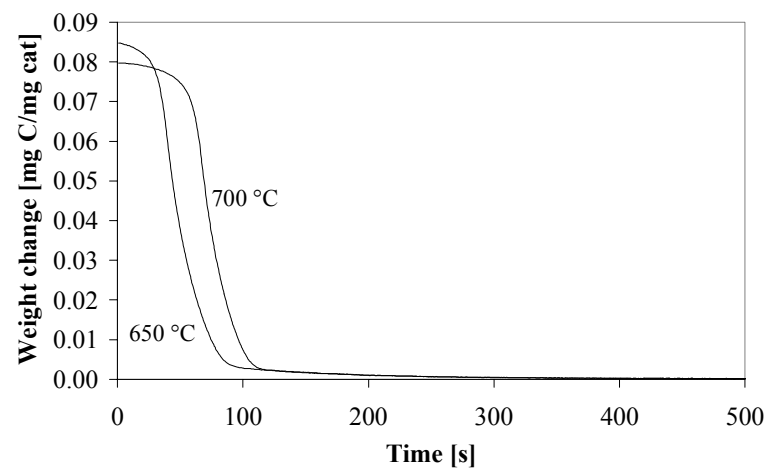

Figure C.6 Coke combustion rates using air at $460{ }^{\circ} \mathrm{C}$ of a sample where coke was formed with pure propylene at two different temperatures and periods of time but to the same coke content.

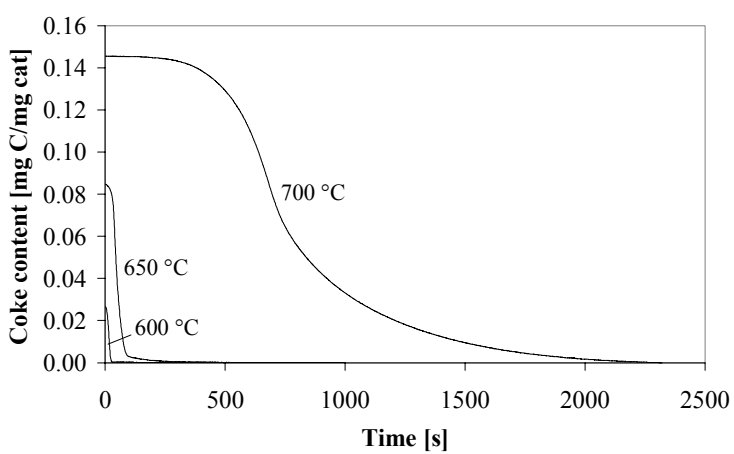

Figure C.3 Coke combustion rates using air at $460{ }^{\circ} \mathrm{C}$ of a sample where coke was formed with $100 \%$ propylene for $15 \mathrm{~min}$ at the indicated temperatures.

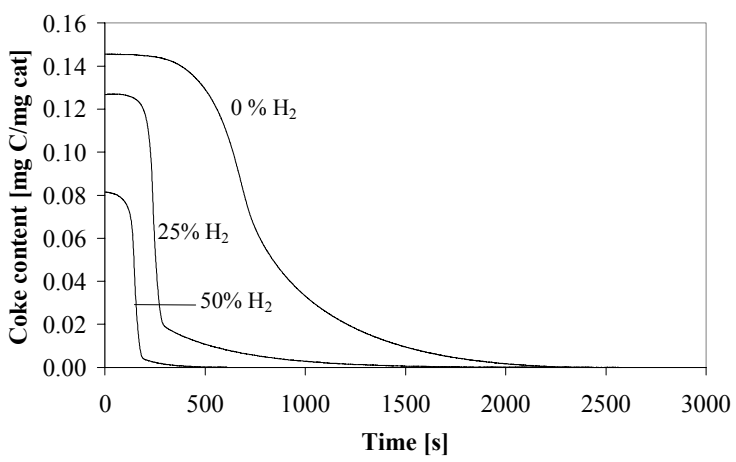

Figure C.5 Coke combustion rates using air at $460{ }^{\circ} \mathrm{C}$ of a sample where coke was formed at $700{ }^{\circ} \mathrm{C}$ for $15 \mathrm{~min}$. for the indicated propylene-hydrogen composition.

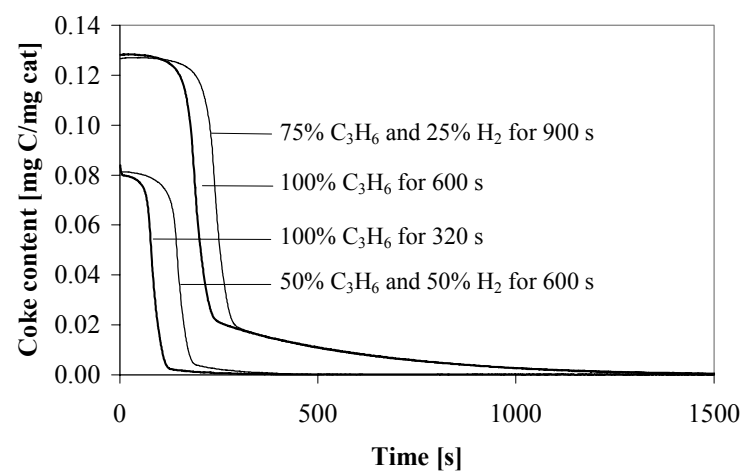

Figure C.7 Coke combustion rates using air at $460{ }^{\circ} \mathrm{C}$ of a sample where coke was formed at $700{ }^{\circ} \mathrm{C}$ for different propylene-hydrogen mixtures and different periods of time, but to the same coke content. 
With combustion temperatures below $420-430{ }^{\circ} \mathrm{C}$ the carbonaceous deposits could not be removed from the catalyst sample. Subsequently, the combustion rate becomes very high and for combustion temperatures exceeding $480{ }^{\circ} \mathrm{C}$ the coke combustion was actually limited by oxygen supply to the reactor. Then, suddenly the coke combustion rate decreases considerably again.

It was shown that the platinum dispersed in the washcoat had no influence on the coke combustion rate, as expected, since it was shown in Chapter 4 and 5 that for this catalyst most of the carbonaceous products were deposited on the $\gamma-\mathrm{Al}_{2} \mathrm{O}_{3}$ washcoat (see Figure C.2). In Figures C.3-C.5 it is shown that the conditions during the coke formation have a large impact on the total amount of coke deposited and thus on the coke combustion rates. In Figures C.6 and C.7 the effect of the total amount of coke on the coke combustion rates has been excluded by comparing coke formation rates of a sample on which the same amount of coke was deposited but at different operating conditions. These figures show that for samples with the same amount of coke deposits the coke combustion rates are similar, except for the duration of the first phase of slow coke combustion. Especially if the coke was formed at higher temperatures or for longer times on stream, the initial first phase was extended.

The three phases of coke combustion can be tentatively interpreted by the sequential combustion of multilayer and monolayer coke (see Figure C.8, see Chapter 5 for a more detailed description of monolayer and multilayer coke). In the first phase multilayer coke is combusted, which is relatively slow at low temperatures e.g. because of a low hydrogen to carbon ratio. Furthermore, relatively more multilayer coke is formed compared to the total amount of coke for higher temperatures or longer times on stream. Once most of the multilayer coke has been combusted the combustion of the monolayer coke commences. At a certain monolayer coke content the combustion rate of the coke decreases again, possibly because of internal diffusion limitations during the combustion process of the coke deposited in the smallest pores.

This model has been used as a basis to formulate rate expressions for the coke combustion, without any further proof. Furthermore, a zeroth order in the coke content for the multilayer and fast monolayer coke combustion is assumed. The slow monolayer coke combustion is assumed to be first order in the monolayer coke content. Moreover, all three combustion rates are assumed first order in the oxygen concentration. From the experiments it was found that 
the transition from fast to slow monolayer coke combustion occurred at a constant combustion rate.

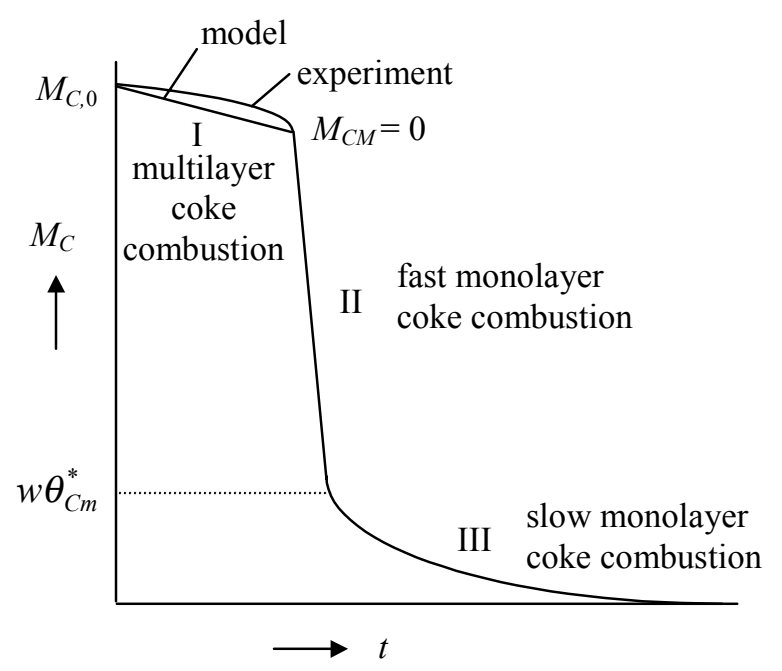

Figure C.8 Interpretation of the coke combustion process in terms of three successive phases: multilayer coke combustion and fast and slow monolayer coke combustion.

The coke combustion rate expressions are given in Table C.1. An Arrhenius-type temperature dependency is assumed for the coke combustion reaction rate constants. The Arrhenius plots to determine the activation energy of the coke combustion reaction rate constants are shown in Figures C.9-C.11.

Table C.1 Coke combustion rate equations

I. Multilayer coke combustion: $\quad r_{C}=-k_{C M} C_{\mathrm{O}_{2}, c} \quad \theta_{C M}>0$

II. Fast monolayer coke combustion: $\quad r_{C}=-k_{C m 1} C_{\mathrm{O}_{2}, c} \quad \theta_{C M}=0, \theta_{C m}^{*}<\theta_{C m} \leq 1$

III. Slow monolayer coke combustion: $r_{C}=-k_{C m 2} C_{\mathrm{O}_{2}, c} w \theta_{C m} \quad \theta_{C M}=0,0 \leq \theta_{C m} \leq \theta_{C m}^{*}$ where $\theta_{C m}^{*}=\frac{K^{*}}{k_{C m 2} w} \quad$ with $K^{*}=4.10 \cdot 10^{-5} \mathrm{~m}^{3} \cdot \mathrm{mole}^{-1} \cdot \mathrm{kg}_{\mathrm{C}} \cdot \mathrm{kg}_{\mathrm{cat}}{ }^{-1} \cdot \mathrm{s}^{-1}$ $\left(r_{C}\right.$ in $\left.\mathrm{kg}_{\mathrm{C}} \cdot \mathrm{kg}_{\mathrm{cat}}{ }^{-1} \cdot \mathrm{s}^{-1}\right)$.

\begin{tabular}{ccc}
\hline & pre-exponential constant & Activation energy \\
\hline $\begin{array}{c}\text { Multilayer } \\
\text { coke combustion }\end{array}$ & $k_{C M, 0}=1.60 \cdot 10^{5} \mathrm{~m}^{3} \cdot \mathrm{mole}^{-1} \cdot \mathrm{s}^{-1} \cdot \mathrm{kg}_{\mathrm{C}} \cdot \mathrm{kg}_{\mathrm{cat}}{ }^{-1}$ & $E_{C M}=145 \mathrm{~kJ} \cdot \mathrm{mole}^{-1}$ \\
$\begin{array}{c}\text { Fast monolayer } \\
\text { coke combustion }\end{array}$ & $k_{C m I, 0}=1.52 \cdot 10^{19} \mathrm{~m}^{3} \cdot \mathrm{mole}^{-1} \cdot \mathrm{s}^{-1} \cdot \mathrm{kg}_{\mathrm{C}} \cdot \mathrm{kg}_{\mathrm{cat}}{ }^{-1}$ & $E_{C m l}=324 \mathrm{~kJ} \cdot \mathrm{mole}^{-1}$ \\
$\begin{array}{c}\text { Slow monolayer } \\
\text { coke combustion }\end{array}$ & $k_{C m 2,0}=3.52 \cdot 10^{3} \mathrm{~m}^{3} \cdot \mathrm{mole}^{-1} \cdot \mathrm{s}^{-1}$ & $E_{C m 2}=95.1 \mathrm{~kJ} \cdot \mathrm{mole}^{-1}$ \\
\hline
\end{tabular}




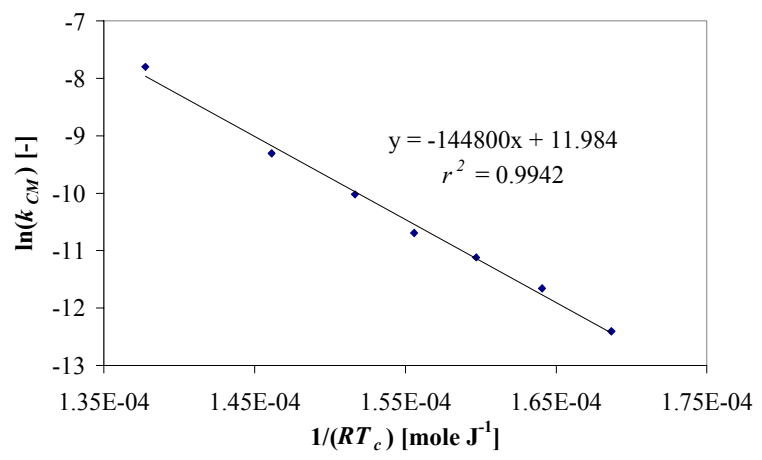

Figure C.9 Arrhenius plot for the multilayer coke combustion (phase I).

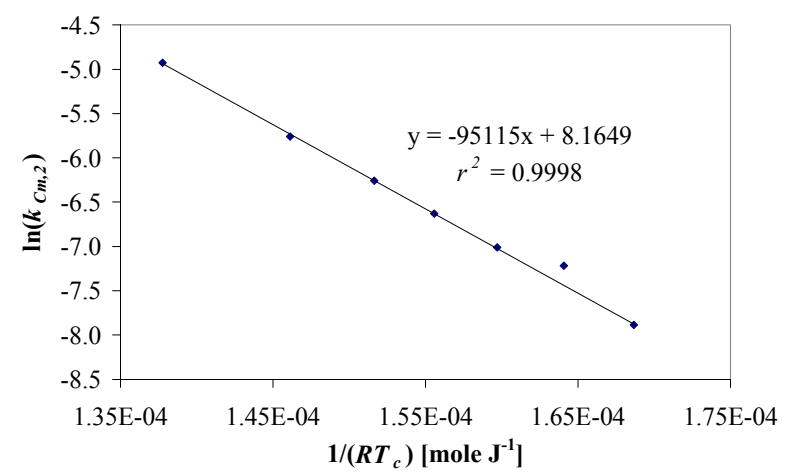

Figure C.11 Arrhenius plot for the slow monolayer coke combustion (phase III).

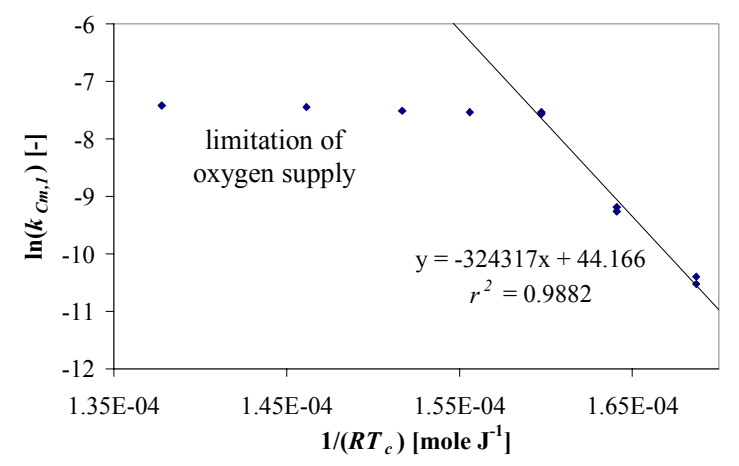

Figure C.10 Arrhenius plot for the fast monolayer coke combustion (phase II)

The reaction rate expressions are given in terms of weight of the carbonaceous deposits combusted per unit of catalyst weight per second. Considering coke as $\mathrm{CH}_{\mathrm{q}}$ units the coke combustion reaction can be represented by

$$
\mathrm{CH}_{\mathrm{q}}+(1+q / 4) \mathrm{O}_{2} \stackrel{R_{C}^{\prime \prime \prime}}{\longrightarrow} \mathrm{CO}_{2}+q / 2 \mathrm{H}_{2} \mathrm{O}
$$

The coke combustion rate in terms of moles $\mathrm{CH}_{\mathrm{q}}$ combusted per unit reactor volume per second is then given by

$R_{C}^{\prime \prime \prime}=r_{C} \frac{(1-\varepsilon) \rho_{c}}{M_{\mathrm{CH}_{\mathrm{q}}}}$

Since the coke combustion has been assumed to be first order in the oxygen concentration, external mass transfer limitations for oxygen transport from the gas bulk to the catalyst surface can easily be accounted for. 
Defining a general reaction rate constant $k_{C}$ by $r_{C}=k_{C} C_{\mathrm{O}_{2}, \mathrm{c}}$ for all three combustion phases the volumetric oxygen consumption rate by coke combustion $R_{C, \mathrm{O}_{2}}^{\prime \prime \prime}$ can be calculated with

$$
R_{C, \mathrm{O}_{2}}^{\prime \prime \prime}=-\frac{1}{\frac{1}{k_{C} \frac{(1-\varepsilon) \rho_{c}}{M_{\mathrm{CH}_{\mathrm{q}}}}\left(1+\frac{q}{4}\right)}+\frac{1}{k_{g} a_{v}}} C_{\mathrm{O}_{2}, g}
$$

Finally, the experiments showed the importance of removing all the coke deposits (see Figure C.12). If not all the coke is combusted during the exothermic regeneration cycles the time required to remove the coke deposits in subsequent cycles will strongly increase.

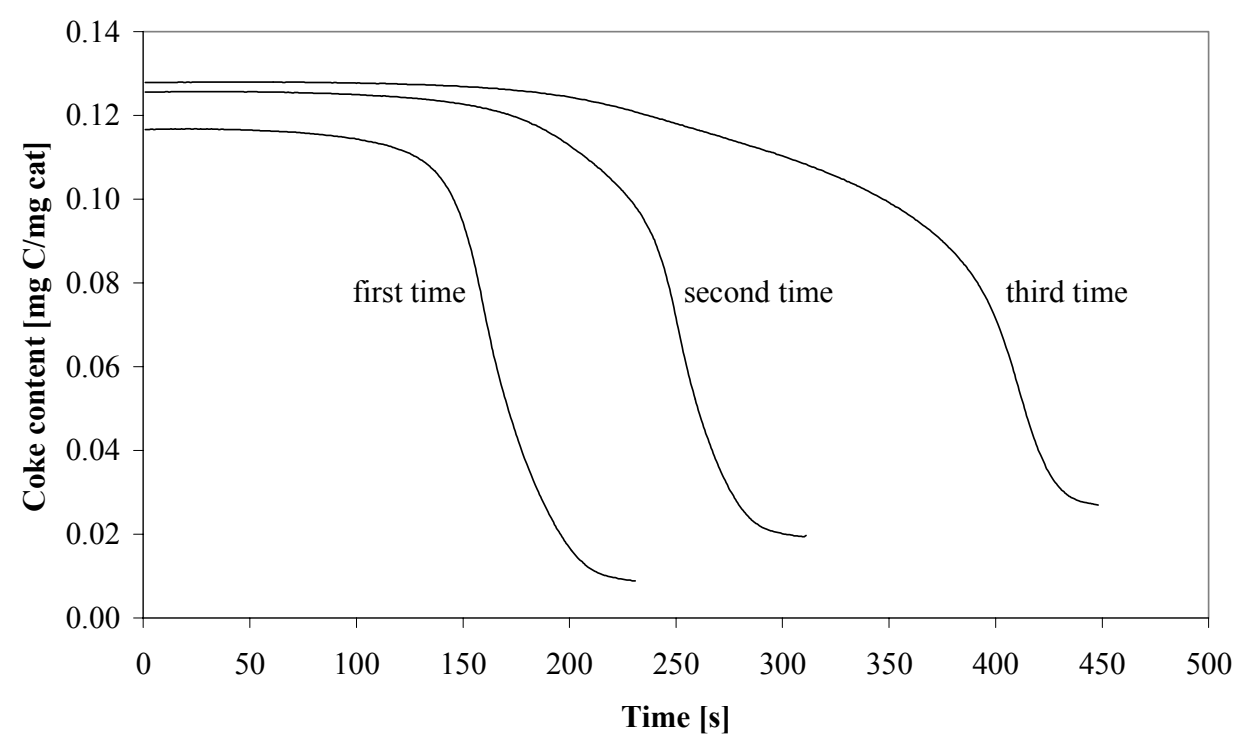

Figure C.12 Coke combustion rates using air at $460{ }^{\circ} \mathrm{C}$ for three successive experiments where each time coke was formed under pure propylene atmosphere at $700{ }^{\circ} \mathrm{C}$ for 15 minutes, but where not all of the carbonaceous deposits were removed during the combustion. 
CHAPTER 8

\section{OPTIMISATION OF PROCESS CONDITIONS AND COMPARISON WITH CONVENTIONAL PROCESSES}




\section{Abstract}

Based on the experimentally determined kinetics of the propane dehydrogenation and propylene hydrogenation over a monolithic $\mathrm{Pt} / \gamma-\mathrm{Al}_{2} \mathrm{O}_{3}$ catalyst and their most important sidereactions including coke formation (Chapters 4 and 5), it has been determined using Pontryagin's maximisation principle that for undiluted propane feeds at atmospheric pressure the propylene yield is optimal at high reactor temperatures $\left(675-725^{\circ} \mathrm{C}\right)$ and short cycle times. Maximum propylene yields (50-60\%) are thus attained at high propane conversion (75-90\%) and relatively low propylene selectivity (ca. 70\%) with significant amounts of coke formed as by-product. Due to the increase of the coke formation rate as a function of time the optimal axial temperature profile shifts from a strongly increasing temperature profile at the beginning of the dehydrogenation cycle to an almost uniform axial temperature profile after a few minutes on stream. The Reaction Coupling Reverse Flow Reactor (RCRFR) is very well suited for these 'high intensity' operating conditions.

Then, process characteristics of a process for propane dehydrogenation based on this new reactor concept are qualitatively compared with conventional commercial propane dehydrogenation processes in order to elucidate possible advantages and possibilities or disadvantages and difficulties and to evaluate the economic feasibility of the RCRFR process. The RCRFR process resembles the Houdry Catofin process. However, large savings on investments in expensive high-temperature heat exchange equipment in the reactor section can be achieved due to the incorporation of recuperative heat exchange inside the reactor by periodic flow reversals. Furthermore, the higher propane conversion reduces the propane recycle flow rate, decreasing compression costs (also because of higher reactor pressure) and reducing investments and operating costs in the gas separation units. However, it remains to be demonstrated experimentally that indeed high propane conversion and propylene (or olefin) yield can be achieved in the RCRFR with high energy efficiency without problems of coke accumulation for long times on stream. 


\section{Introduction}

In this thesis a new reactor concept has been developed aiming for high energy-efficiency through multi-functionality. Energy supply, catalyst regeneration and recuperative heat exchange are all integrated inside the reactor by carrying out consecutively endothermic and exothermic cycles in reverse flow. The applicability of the new reactor concept, termed 'Reaction Coupling Reverse Flow Reactor' (RCRFR), has been studied for the non-oxidative propane dehydrogenation over a $\mathrm{Pt} / \gamma-\mathrm{Al}_{2} \mathrm{O}_{3}$ monolithic catalyst.

In Chapters 2 and 3 it has been studied on the basis of detailed modelling how the operating conditions of the endothermic and exothermic reaction phases need to be matched in order to achieve a cyclic steady state. It has been shown that for a switching scheme with an inherently zero differential creep velocity the endothermic inlet concentration can be optimised independently of the gas velocities, while controlling the maximum temperature at high throughput and maximum energy efficiency. Furthermore, simulation results have demonstrated that by employing less active sections installed at either end of an active catalyst bed and completely inactive sections at the reactor ends and using combined propane and methane combustion for the exothermic reaction phase full equilibrium conversion and recuperative heat exchange can be achieved simultaneously even for reversible endothermic reactions, while controlling the maximum temperature and the plateau temperature. An experimental proof of principle of the reactor concept has been given in a small laboratory scale reverse flow reactor, as described in Chapter 7. Due to the low inlet and outlet temperatures resulting from the reverse flow concept and low axial dispersion of a monolithic catalyst purge-cycles with nitrogen between the endothermic and exothermic cycles could safely be omitted (see also Chapter 6).

The non-oxidative propane dehydrogenation over a monolithic catalyst was identified as a very interesting reaction system for operation in reverse flow coupled with fuel combustion, especially because the inherently short cycle times (as a consequence of the energy constraints) allows operation at more severe reaction conditions with higher equilibrium conversions. The reaction kinetics of the propane dehydrogenation - propylene hydrogenation and the most important side-reactions, including propane cracking, propane and propylene hydrogenolysis and coke formation, have been determined for wide temperature and concentration ranges (see Chapters 4 and 5). Based on the derived reaction kinetics optimal 
process conditions, particularly the optimal axial temperature profile, can be determined for the propane dehydrogenation. Obviously, a true optimisation of the operating conditions in a propane dehydrogenation reactor would involve an economic optimisation of an entire production facility minimising the investment and production costs for all process units including all gas separation units and compression and heat exchange equipment. However, because the operation and investment costs increase with decreasing propane conversions (per pass) due to an increased propane recycle and simultaneously the revenues decrease with decreasing propylene selectivities, the optimal process conditions can be approximated by the reaction conditions for maximum propylene yield. In this chapter optimal axial temperature profiles for maximum propylene yield are determined based on the experimentally derived reaction kinetics for the propane dehydrogenation reaction system. Based on these results possible benefits of operation at more severe reaction conditions with higher equilibrium conversions can be assessed.

Then, characteristics of a process for the propane dehydrogenation based on this new reactor concept are qualitatively compared with conventional processes for propane dehydrogenation in order to elucidate possible advantages and possibilities or disadvantages and difficulties and to evaluate the economic feasibility of the RCRFR.

\section{Optimal axial temperature profiles for the propane dehydrogenation}

Many authors have noted benefits of increasing temperatures along the axial coordinate for the propane dehydrogenation. Higher propane conversion and energy efficiency were reported by Ercan and Gartside (1996) for a recent modification of the commercial Houdry Catofin process for propane dehydrogenation due to an increasing temperature profile, achieved by feeding the regenerating gas in counter-current flow to the process gas. In the classical Houdry Catofin process the regeneration and process gasses are fed in the same direction, resulting in a decreasing temperature profile.

Stitt et al. (1999) compared the overall reactor performance for different forms of temperature profiles, viz. uniform, linear and exponential increase and decrease via numerical modelling. In their model they simply imposed selected forms of axial temperature profiles and compared the resulting overall propane conversion and propylene selectivity and coke content profiles, and found surprisingly little influence of the form of the axial temperature profile on the 
overall reactor performance. In their reactor model they assumed that all by-products are formed directly from propane according to a simple first order rate expression for the sidereactions. They did take the decrease in the catalyst activity due to coke formation into account using a first order deactivation model, however, they assumed that carbonaceous deposits originate from propane instead of propylene and ignored the important complex composition and time dependency of the coke formation rates. Especially the influence of the hydrogen concentration on the coke formation rates should be included in order to predict the coke formation rates correctly at the investigated temperature range (see Chapter 5). Finally, Stitt et al. only considered temperature profiles with the same average temperature of only $600{ }^{\circ} \mathrm{C}$ and assumed a constant GHSV of $4000 \mathrm{hr}^{-1}$ (resulting in calculated overall propylene yields of only $c a$. 25\%) without examining the important effect of different average temperatures and gas residence times.

Using the derived reaction kinetics for the propane dehydrogenation - propylene hydrogenation and their most important side reactions over a $\mathrm{Pt} / \gamma-\mathrm{Al}_{2} \mathrm{O}_{3}$ monolithic catalyst, optimal axial temperature profiles for maximum propylene yield for this catalyst can be calculated using Pontryagin's maximisation principle. Because the coke formation rates change as a function of time on stream also the optimal axial temperature profiles change with time. Especially the influences of the time on stream for very short operating times, the influence of the gas residence time and the effect of hydrogen dilution on the optimal axial temperature profile and propane conversion and propylene selectivity are investigated.

\subsection{Optimisation model}

The most important model assumptions are as follows:

1. The reactor is entirely filled with the same active monolithic catalyst (uniform platinum loading) with the same catalyst properties as for which the kinetics was determined. Due to the small washcoat thickness and high specific external catalyst surface area internal and external mass transfer limitations for the conversion rate of the propane dehydrogenation-propylene hydrogenation and their side reactions are absent. Furthermore, for a monolithic catalyst axial dispersion and the pressure drop can be neglected. The pressure was kept constant at atmospheric conditions. 
2. The time-dependency of the reaction rates of the propane dehydrogenation and its side reactions is neglected. The 'pseudo' steady state reaction kinetics over a coked catalyst have been taken for the optimisation. Without a hydrogen reduction cycle prior to the dehydrogenation cycle (as in the RCRFR) and especially for a pure propane feed the asymptotic steady state is approached quickly. Furthermore, the benefits of a higher catalyst activity at the 'initial' catalyst conditions might be lost due to lower propylene selectivity. Adsorption phenomena taking place at the beginning of the propane dehydrogenation cycle have been ignored.

3. At low propane dehydrogenation cycle times the formation of multilayer coke can be neglected. For the RCRFR the propane dehydrogenation cycle time should actually be chosen small enough to avoid the formation of multilayer coke, since multilayer coke considerably retards the regeneration of the catalyst, see Appendix $\mathrm{C}$ of Chapter 7 . With the coke model derived in Chapter 5 the coke formation rate for short times on stream can be represented by

$$
\dot{m}_{C}=w \rho_{C}(1-\varepsilon) k_{R} k_{C P} \theta_{\mathrm{C}_{3} \mathrm{H}_{6}, 0}^{3} t
$$

4. Hydrogen formation during coke formation is ignored. For the very short cycle times considered in this work high hydrogen to carbon ratio of the carbonaceous deposits are expected. The conversion rate of propylene to carbonaceous deposits is then given by

$$
r_{\mathrm{C}_{3} \mathrm{H}_{6}, C}=-\dot{m}_{C}
$$

The decrease in the total mass flux due to carbon deposition is, however, taken into account.

5. The maximum allowable temperature is specified at a high value of $750{ }^{\circ} \mathrm{C}$. At even higher temperatures the catalyst activity might deteriorate enormously by sintering of the washcoat and losses of platinum dispersion. It should be noted that the reaction kinetics was determined up to temperatures of $675^{\circ} \mathrm{C}$, so that some extrapolation is required. 
The relevant equations to determine the optimal axial temperature profile with Pontryagin's maximisation principle incorporating the above assumptions are shortly outlined in Table 1.

The optimal axial temperature profile is calculated by solving a boundary value problem for a system of 14 ordinary differential equations consisting of 7 process equations (describing the axial profiles of the propane, propylene, hydrogen, ethylene, ethane and methane mass fractions and the total mass flow rate) and 7 adjungated functions, where for each axial position the Hamilton function is optimised. For reasons of computational stability the control problem was not written in terms of Mayer's problem $\left(F=0, S=\Phi_{m, \text { out }}^{\prime \prime} \omega_{\mathrm{C}_{3} \mathrm{H}_{6}, \text { g,out }}\right)$ and very strong under-relaxation was used in the shooting method.

Taking account of the varying mass flux along the axial coordinate due to coke formation the overall propane conversion and propylene selectivity and yield have been defined as:

$$
\zeta_{\mathrm{C}_{3} \mathrm{H}_{8}}=1-\frac{\omega_{\mathrm{C}_{3} \mathrm{H}_{8}, g, \text { out }}}{\omega_{\mathrm{C}_{3} \mathrm{H}_{8}, g, \text { in }}} \frac{\Phi_{m, \text { out }}^{\prime \prime}}{\Phi_{m, \text { in }}^{\prime \prime}}
$$

$\sigma_{\mathrm{C}_{3} \mathrm{H}_{6}}=\frac{1-\frac{\omega_{\mathrm{C}_{3} \mathrm{H}_{6}, g, \text { out }}}{\omega_{\mathrm{C}_{3} \mathrm{H}_{8}, g, \text { in }}} \frac{\Phi_{m, \text { out }}^{\prime \prime}}{\Phi_{m, \text { in }}^{\prime \prime}}}{1-\frac{\omega_{\mathrm{C}_{3} \mathrm{H}_{8}, g, \text { out }}}{\omega_{\mathrm{C}_{3} \mathrm{H}_{8}, g, \text { in }}} \frac{\Phi_{m, \text { out }}^{\prime \prime}}{\Phi_{m, \text { in }}^{\prime \prime}}}$

$\eta_{\mathrm{C}_{3} \mathrm{H}_{6}}=\sigma_{\mathrm{C}_{3} \mathrm{H}_{6}} \zeta_{\mathrm{C}_{3} \mathrm{H}_{8}}$

and the gas residence time as

$$
\tau=\frac{L}{\Phi_{m, i n}^{\prime \prime}}\left[\mathrm{s} \cdot \mathrm{m}^{3} \cdot \mathrm{kg}^{-1}\right]
$$


Table 1. Equations to determine the optimal axial temperature profile for propane dehydrogenation for optimal propylene yield using Pontryagin's maximisation principle.

The goal is to determine the axial temperature profile $T(z)$ so that the functional

$S\left(\left.\mathbf{x}\right|_{z=L}\right)+\int_{z=0}^{L} F(\mathbf{x}, T, z) d z$

is maximised for a process described by a system of ordinary differential equations given by

$$
\frac{d}{d z} \mathbf{x}=\left.\mathbf{f}(\mathbf{x}, T, z) \quad \mathbf{x}\right|_{z=0}=\mathbf{x}_{\text {in }}
$$

Applying Pontryagin's maximisation principle the optimal axial temperature profile is determined via optimisation of the Hamilton function $H$ as a function of the temperature for all axial positions:

$$
\left.\frac{\partial H}{\partial T}\right|_{\forall z}=0 \quad\left(\text { and }\left.\frac{\partial^{2} H}{\partial T^{2}}\right|_{\forall z} \leq 0\right)
$$

where the Hamilton function $H$ and the adjungated functions are defined as

$H=F+\mathbf{p} \cdot \mathbf{f}$

$\frac{d}{d z} \mathbf{p}=-\left.\frac{\partial}{\partial \mathbf{x}} H \quad \mathbf{p}\right|_{z=L}=\frac{\partial}{\partial \mathbf{x}} S$

The process equations consist of differential mass balances describing the axial profiles of the mass fractions of propane, propylene, hydrogen, ethylene, ethane and methane and the total mass flow, defining the vectors $\mathbf{x}, \mathbf{x}_{\mathbf{i n}}$ and $\mathbf{f}$ as

$\mathbf{x}=\left[\begin{array}{c}\omega_{1, g} \\ \vdots \\ \omega_{n_{c}-1, g} \\ \Phi_{m}^{\prime \prime}\end{array}\right] \quad \mathbf{x}_{\text {in }}=\left[\begin{array}{c}\omega_{1, g, i n} \\ \vdots \\ \omega_{n_{c}-1, g, i n} \\ \Phi_{m, i n}^{\prime \prime}\end{array}\right] \quad \mathbf{f}=\left[\begin{array}{c}\frac{1}{\Phi_{m}^{\prime \prime}}\left(r_{1}+\omega_{1, g} \dot{m}_{C}\right) \\ \vdots \\ \frac{1}{\Phi_{m}^{\prime \prime}}\left(r_{n_{c}-1}+\omega_{n_{c}-1, g} \dot{m}_{C}\right) \\ -\dot{m}_{C}\end{array}\right]$

where $r_{i}=\sum_{j=1}^{n_{r}} v_{i, j} R_{j} M_{j}$ represents the total reaction rate of component $i$ by all reactions, viz. propane dehydrogenation, propylene hydrogenation, propane cracking, propane and propylene hydrogenolysis and coke formation.

(nitrogen mass fraction calculated from the summation equation: $\omega_{n_{c}, g}=1-\sum_{i=1}^{n_{c}-1} \omega_{i, g}$ )

With $F=\frac{d}{d z}\left(\Phi_{m}^{\prime \prime} \omega_{\mathrm{C}_{3} \mathrm{H}_{6}, g}\right)$ and $S=0$ the propylene yield is optimised. 


\subsection{Optimisation results}

In Figure 1 the optimisation results are shown for a pure propane feed in a reactor with a total gas residence time of $5 \mathrm{~s} \cdot \mathrm{m}^{3} \cdot \mathrm{kg}^{-1}\left(\mathrm{GHSV}=400 \mathrm{~h}^{-1}\right)$ after $120 \mathrm{~s}$ operation of the dehydrogenation cycle. From the figure it can be concluded that indeed an increasing temperature profile with a temperature increase of almost $50{ }^{\circ} \mathrm{C}$ is optimal for these conditions. Strikingly, the optimal temperatures are very high, starting from $664{ }^{\circ} \mathrm{C}$ up to $719^{\circ} \mathrm{C}$.

(a)

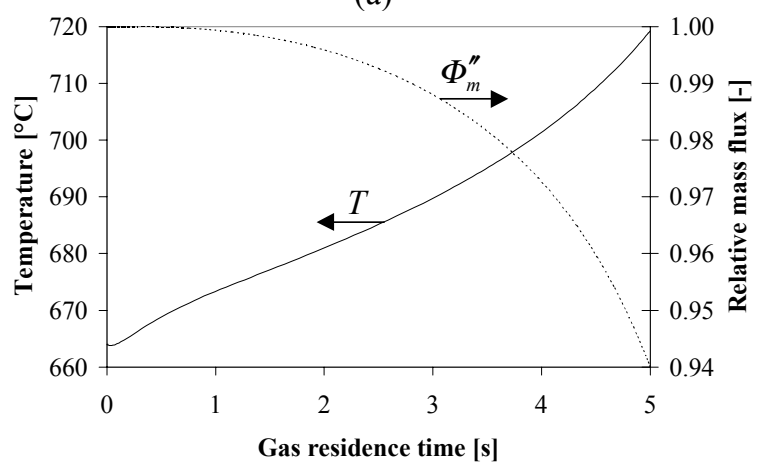

(b)

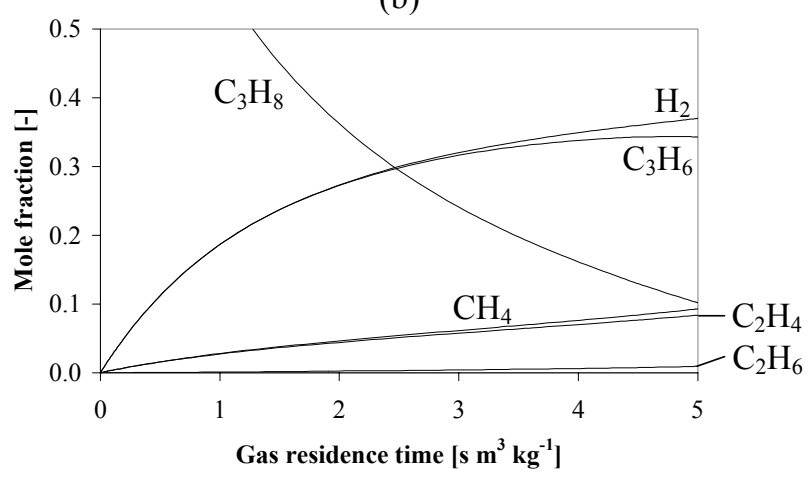

Figure 1. Optimal axial temperature profile and corresponding relative mass flux (a) and mole fraction profiles (b) for a pure propane feed after $120 \mathrm{~s}$ in the dehydrogenation cycle in a reactor at atmospheric pressure with a total residence time of $5 \mathrm{~s} \cdot \mathrm{m}^{3} \cdot \mathrm{kg}^{-1}$. $\left(\zeta_{\mathrm{C}_{3} \mathrm{H}_{8}}=0.823, \sigma_{\mathrm{C}_{3} \mathrm{H}_{6}}=0.694, \eta_{\mathrm{C}_{3} \mathrm{H}_{6}}=0.571\right)$

Apparently, the optimal propylene yield (57\%) is achieved at relatively high propane conversion (82\%) and low propylene selectivity (69\%). At high temperatures the propane dehydrogenation equilibrium is shifted towards product side at the cost of lower propylene selectivity due to side-reactions. The most important side-reactions are propane cracking (at the reactor inlet) and propylene hydrogenolysis (at the reactor outlet), resulting in the formation of mainly ethylene and methane as by-products, and also coke formation. From Figure 1 it can be concluded that most of the carbon deposition takes place at the end of the reactor because of the higher temperatures and higher propylene concentrations (despite the higher hydrogen concentration). 


\subsubsection{Influence of time on stream}

Since adsorption phenomena have been ignored, the coke formation rate is zero at the beginning of the propane dehydrogenation cycle, but the coke formation rate increases linearly with time for short times on stream (see Chapter 5). Due to the increase in the coke formation rate as a function of time the optimal axial temperature profile also changes with time. In Figure 2 the influence of time on stream on the optimal axial temperature profiles is shown for pure propane fed to a reactor with a total gas residence time of $5 \mathrm{~s} \cdot \mathrm{m}^{3} \cdot \mathrm{kg}^{-1}$. From the figure it is evident that a strongly increasing temperature profile is optimal for short times on stream, but for longer times on stream, where coke formation becomes very important, almost isothermal conditions become optimal.

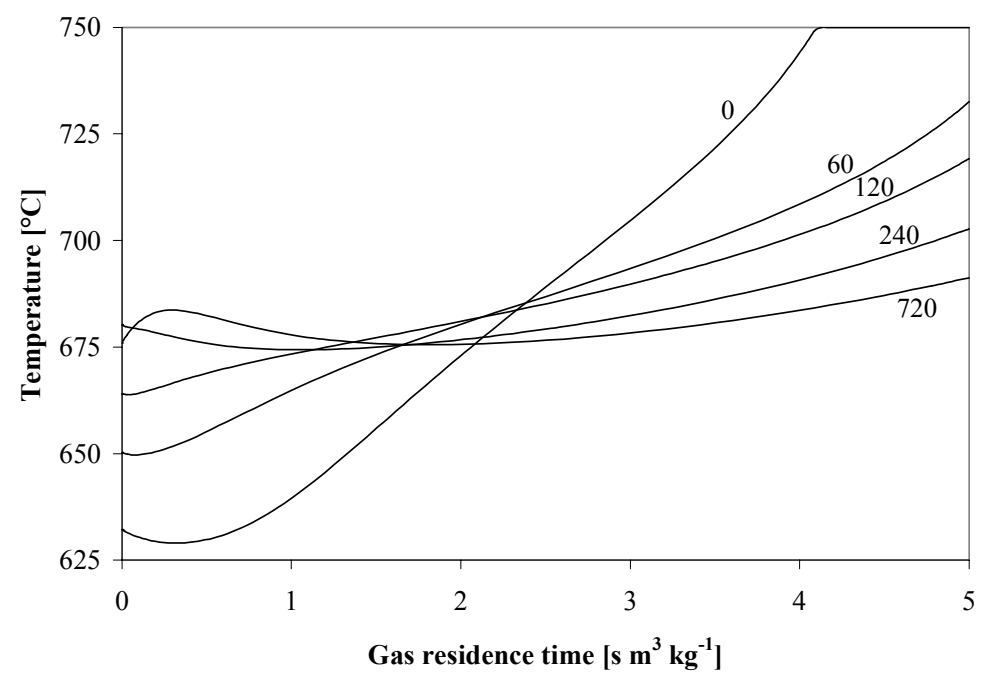

Figure 2. Optimal axial temperature profiles as a function of time on stream during the propane dehydrogenation cycle $\left(x_{g, \mathrm{C}_{3} \mathrm{H}_{8}, \text { in }}=1.0, \tau=5 \mathrm{~s} \cdot \mathrm{m}^{3} \cdot \mathrm{kg}^{-1}, T_{\max }=750{ }^{\circ} \mathrm{C}, P=1 \mathrm{~atm}\right)$.

In Figure 3 the propane conversion, propylene selectivity and propylene yield corresponding to the optimal axial temperature profiles for optimal propylene yield are shown as a function of the time on stream. In order to maintain propylene selectivity the temperature at the reactor outlet needs to be reduced for longer times on stream due to the increased coke formation rates. The lower exit temperatures strongly reduce the propane conversion and thus the propylene yield. The figure clearly shows that operation with short propane dehydrogenation cycle times can increase the average propylene yield quite considerably. 


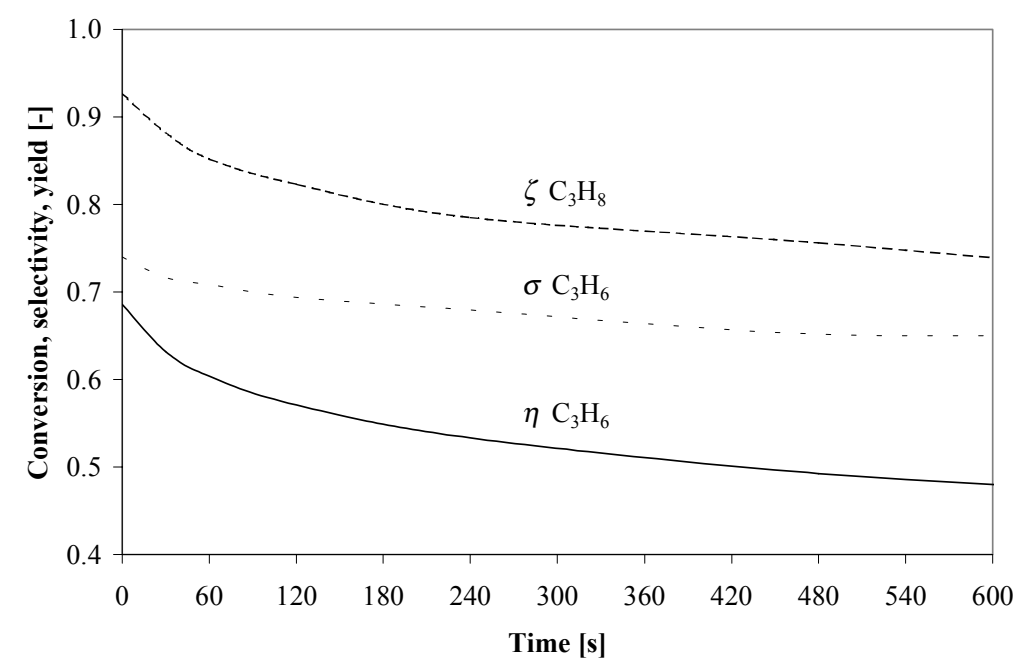

Figure 3. Influence of time on stream during the propane dehydrogenation cycle on the propane conversion and propylene selectivity and yield for optimal propylene yield $\left(x_{g, \mathrm{C}_{3} \mathrm{H}_{8}, \text { in }}=1.0, \tau=5 \mathrm{~s} \cdot \mathrm{m}^{3} \cdot \mathrm{kg}^{-1}, T_{\max }=750{ }^{\circ} \mathrm{C}, P=1 \mathrm{~atm}\right)$.

\subsubsection{Influence of gas residence time}

The influence of the total gas residence time on the optimal axial temperature profiles after $120 \mathrm{~s}$ on stream in the dehydrogenation cycle is depicted in Figure 4. Remarkably, increasing the total gas residence time does hardly influence the optimal temperature gradient at the end of the reactor.

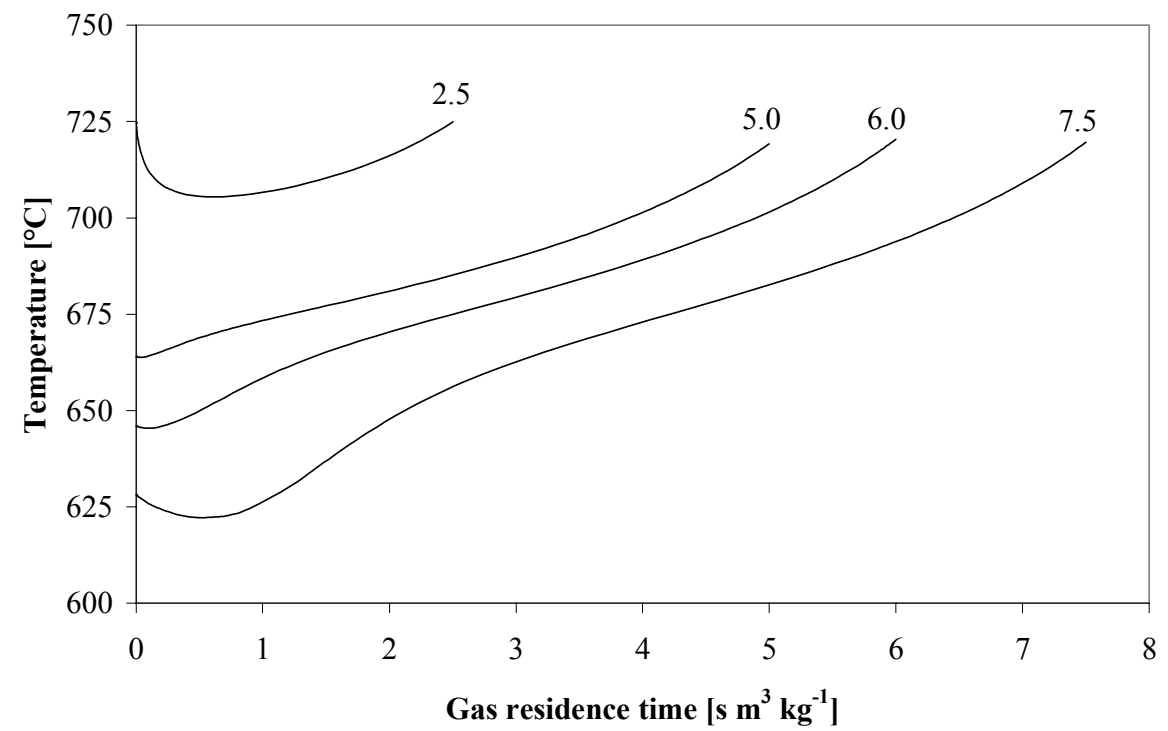

Figure 4. Optimal axial temperature profiles after $120 \mathrm{~s}$ on stream in the propane dehydrogenation cycle for different total gas residence times $\left(x_{g, \mathrm{C}_{3} \mathrm{H}_{8}, \text { in }}=1.0, T_{\max }=750^{\circ} \mathrm{C}, P=1 \mathrm{~atm}\right)$. 
For longer total gas residence times the optimal temperatures for the first part of the reactor strongly decrease, rendering this part of the reactor much less active. Hence, the optimal propane conversion, propylene selectivity and propylene yield hardly increase for longer total gas residence times (propylene yield increases from $57 \%$ at $5 \mathrm{~s} \cdot \mathrm{m}^{3} \cdot \mathrm{kg}^{-1}$ to $58 \%$ at $\left.20 \mathrm{~s} \cdot \mathrm{m}^{3} \cdot \mathrm{kg}^{-1}\right)$. It was found that both the temperature level and shape of optimal temperature profile at the reactor inlet were very sensitive for the particular set of kinetic rate constants fitted to the experimental data. However, different fits gave identical optimal temperature profiles for the end of the reactor.

\subsubsection{Influence of propane inlet mole fraction for propane-hydrogen mixtures}

It has been investigated whether higher propylene yields can be achieved, if the propane feed is diluted with hydrogen. A higher hydrogen concentration and especially lower propylene concentration decrease the coke formation rates considerably (see Chapter 5). Therefor, the optimal axial temperature profiles after $120 \mathrm{~s}$ on stream for propane-hydrogen mixtures as feed (see Figure 5) show higher temperature gradients at the end of the reactor, similar to the optimal axial temperature profiles at the beginning of the cycle with zero coke formation rate.

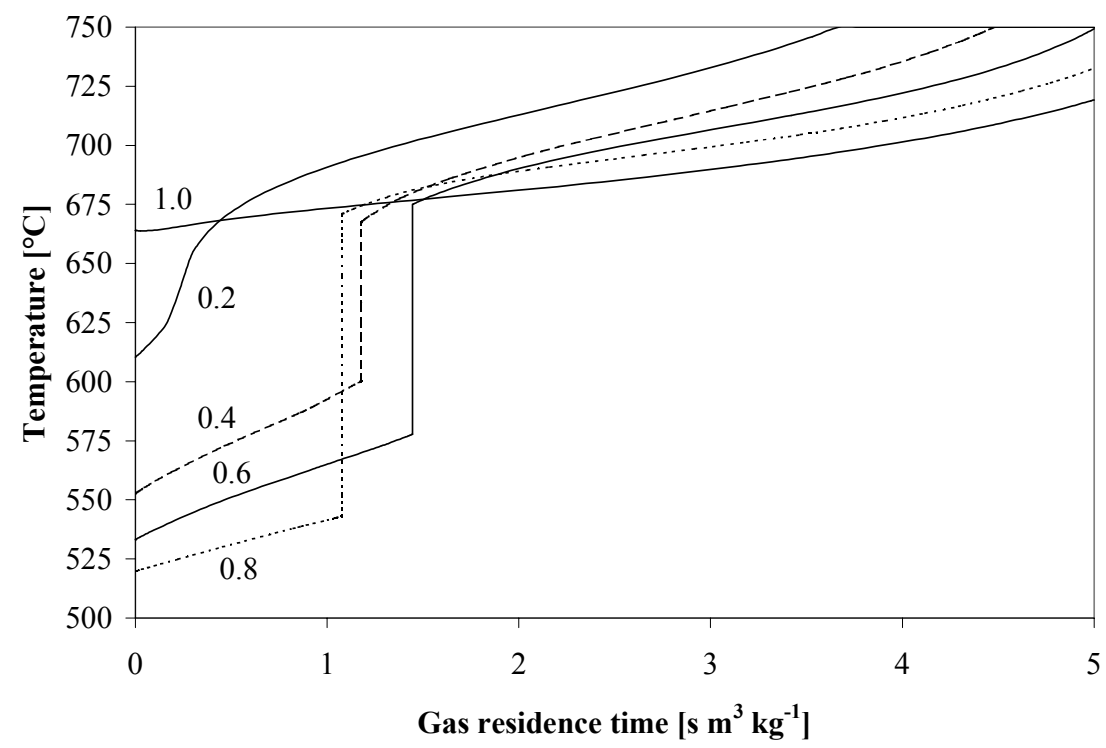

Figure 5. Optimal axial temperature profiles for different propane-hydrogen feeds (propane inlet mole fraction indicated) after $120 \mathrm{~s}$ on stream $\left(\tau=5 \mathrm{~s} \cdot \mathrm{m}^{3} \cdot \mathrm{kg}^{-1}, T_{\max }=750^{\circ} \mathrm{C}, P=1 \mathrm{~atm}\right)$. 
For propane-hydrogen feeds also propane hydrogenolysis play an important role because of the higher hydrogen concentration, which explains the lower optimal temperatures at the beginning of the reactor. The somewhat higher propane conversion due to the higher exit temperatures is completely counteracted by the decrease in the propylene selectivity by the increased importance of propane and propylene hydrogenolysis, resulting in even somewhat lower overall propylene yields. For a $20 \%$ propane - $80 \%$ hydrogen feed the optimal propylene yield is only $51 \%$ compared to $57 \%$ propylene yield for a pure propane feed (after $120 \mathrm{~s}$ on stream and with a maximum temperature of $750{ }^{\circ} \mathrm{C}$ ), so that the propylene production capacity decreases over a factor 5 for the $20 \%$ propane $-80 \%$ hydrogen feed. Besides, for propane-hydrogen feeds the ethane selectivities are of the same order as the ethylene selectivities, while for pure propane feeds the ethylene to ethane ratio was much higher.

\subsubsection{Comparison with isothermal conditions}

In Figure 6 the optimal propylene yield for isothermal reactor conditions is compared with the optimal propylene yield for optimal axial temperature profiles. From the figure it can be concluded that the benefits of an optimal axial temperature profile are marginal compared to isothermal reactor conditions for a reactor with a total gas residence time of $5 \mathrm{~s} \cdot \mathrm{m}^{3} \cdot \mathrm{kg}^{-1}$ with a pure propane feed for a few minutes times on stream.

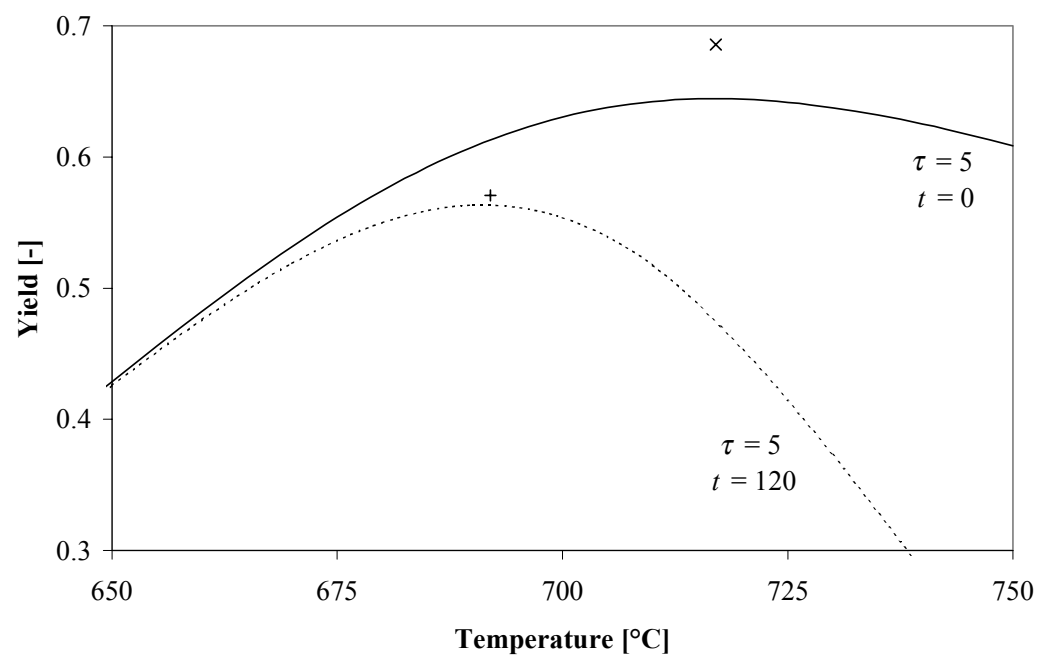

Figure 6. Propylene yield as a function of the reactor temperature for isothermal reactor conditions for a pure propane feed for a reactor with a total gas residence time $\tau$ of $5 \mathrm{~s} \cdot \mathrm{m}^{3} \cdot \mathrm{kg}^{-1}$ at the beginning of the propane dehydrogenation cycle $(t=0 \mathrm{~s})$ (solid line) and after $120 \mathrm{~s}$ on stream (dashed line) $\left(T_{\max }=750{ }^{\circ} \mathrm{C}, P=1 \mathrm{~atm}\right)$. The markers indicate the maximum propylene yield with an optimal axial temperature profile. 
However, significant increases in the propylene yield can be achieved with increasing temperature profiles if coke formation is strongly reduced, i.e. for very short times on stream and for propane feeds diluted with hydrogen, as expected from Figures 4 and 5.

\subsubsection{Conclusions}

From the optimisation results it can be concluded that for propane dehydrogenation over a $\mathrm{Pt} / \gamma-\mathrm{Al}_{2} \mathrm{O}_{3}$ monolithic catalyst, using the kinetics for the propane dehydrogenation-propylene hydrogenation reaction system and their side-reactions including coke formation from Chapters 4 and 5, maximal propylene yields can be achieved for relatively short total gas residence times $\left(c a .5 \mathrm{~s} \cdot \mathrm{m}^{3} \cdot \mathrm{kg}^{-1}\right)$ at relatively high temperatures $\left(675-725{ }^{\circ} \mathrm{C}\right)$ for a pure propane feed with very short propane dehydrogenation cycle times (smaller than a few minutes). In the optimisation process the reactor pressure was kept constant at atmospheric pressure. A lower reactor pressure can increase the propane equilibrium conversion, however, at the expense of a lower propylene production rate per unit reactor volume and a higher energy consumption of the compressor in the gas separation unit.

These optimal 'high intensity' operating conditions coincide very well with the operating conditions aimed for and achievable in the RCRFR. Furthermore, for these operating conditions only marginal benefits of a special temperature profile were calculated compared to isothermal conditions, corresponding to the findings of Stitt et al. (1999). In the adiabatic RCRFR the temperature profile is an outcome eventuating from the operating conditions chosen for the endothermic and exothermic reaction cycles. However, slightly decreasing temperatures at the beginning of the temperature plateau and slightly increasing temperatures at the end of the temperature plateau, resembling the optimal axial temperature profiles, are accidentally very typical for the RCRFR and can easily be obtained by adjusting the Damköhler numbers of the endothermic and exothermic cycles (see Figure 6, Chapter 2).

The relatively high temperatures also lead to high coke formation rates. In the RCRFR the energy released by the combustion of the coke can effectively be used for the propane dehydrogenation, requiring less additional fuels during the combustion/regeneration cycle. For complete autothermal operation of the RCRFR, i.e. the combustion of the coke supplies all the energy necessary for the endothermic propane dehydrogenation without addition of 
extra fuels during the exothermic regeneration cycle, the average coke formation rate $\left\langle\dot{m}_{C}\right\rangle$ should at least be higher than

$$
\left\langle\dot{m}_{C}\right\rangle=\frac{m_{C, \text { end }}^{\text {endo }}}{\Delta t^{\text {endo }}}>\frac{\omega_{\mathrm{C}_{3} \mathrm{H}_{8}, g, \text { in }} \eta_{\mathrm{C}_{3} \mathrm{H}_{6}}}{\rho_{C}(1-\varepsilon)} \frac{\Delta h_{P D}}{\left(-\Delta h_{C}\right)} \tau^{\text {endo }} .
$$

To achieve $50 \%$ propylene yield from a pure propane feed in a reactor with $5 \mathrm{~s} \cdot \mathrm{m}^{3} \cdot \mathrm{kg}^{-1}$ total gas residence time the average coke formation rate should be about $1 \cdot 10^{-5} \mathrm{~kg}_{\mathrm{C}} \cdot \mathrm{kg}_{\mathrm{cat}}{ }^{-1} \cdot \mathrm{s}^{-1}$, taking the catalyst density at $650 \mathrm{~kg} \cdot \mathrm{m}^{-3}$ reactor and the propane dehydrogenation and coke combustion reaction enthalpies at $2.3 \cdot 10^{6}$ and $-3.5 \cdot 10^{7} \mathrm{~J} \cdot \mathrm{kg}^{-1}$ (assuming complete combustion of the coke). At the end of the reactor the propylene and hydrogen concentrations are about $30 \%$ both and the temperature is about $725^{\circ} \mathrm{C}$ (see Figure 1). With the coke formation model from Chapter 5, the coke content after $60 \mathrm{~s}$ can then be estimated at $9.6 \cdot 10^{-4} \mathrm{~kg}_{\mathrm{C}} \cdot \mathrm{kg}_{\mathrm{cat}}{ }^{-1}$, so that the maximum coke formation rate averaged over 1 minute dehydrogenation time is about $1.6 \cdot 10^{-5} \mathrm{~kg}_{\mathrm{C}} \cdot \mathrm{kg}_{\mathrm{cat}}{ }^{-1} \cdot \mathrm{s}^{-1}$. However, in the major part of the reactor much lower temperatures and propylene concentrations prevail, resulting in much lower coke formation rates. Concluding, for optimal propylene yield the RCRFR cannot be operated completely autothermally, but the energy released in the catalyst regeneration can considerably contribute in heat supply for the propane dehydrogenation, saving on fuel costs.

In the above discussion only the total energy balance was considered. Obviously, not only the total amount of energy transferred, but also the zones of energy production and energy consumption need to be matched (see Chapter 2 and 3). From Figure 1 it was concluded that most of the carbon deposition takes place at the end of the reactor, while most of the propane conversion takes place in the first part of the reactor. Due to the flow reversals the energy released during the combustion of the coke can effectively be used for the propane dehydrogenation. Additionally, coke combustion in the centre of the reactor helps avoiding low plateau temperatures, just like the effect of methane addition to the propane-air feed in a RCRFR with less active sections at both reactor ends (see Chapter 3). Thus the coke formation and combustion alleviates the requirement of Damköhler matching of the endothermic and exothermic reaction phases, which is beneficial for a higher propylene production capacity. Finally, using the propane and methane concentrations the energy balance can be fulfilled and the maximum temperature of the temperature peaks and the temperature plateau can be controlled (also using the platinum loading of the less active 
sections as an optimisation parameter for the maximum temperature). Future work should extend the numerical simulations reported in Chapter 3 by including coke formation and coke combustion with simultaneous methane and propane combustion to demonstrate the feasibility of the above.

In the next paragraph a propane dehydrogenation process based on the RCRFR is compared with currently applied 'conventional' propane dehydrogenation processes.

\section{Comparison with conventional industrial processes}

Currently most of the world's propylene production is accounted for by steam cracking and fluid catalytic cracking (FCC), where propylene is produced as a by-product in the ethylene production and oil refinery respectively. In 1998 steam crackers produced about $75 \%$ of the total propylene demand, 24\% was produced by FCC units and only $1 \%$ of the total propylene production was by propane dehydrogenation (Baker, 1999b). The strong increase in the demand for propylene relative to ethylene during the last decade (e.g. Taffe, 1996; Cosyns et $a l ., 1998)$ has initiated the development of new alternative processes for selective propylene production in addition to the traditional petrochemical and refinery processes. The increased availability of lower alkanes resulting from more strict environmental legislation has made especially catalytic propane dehydrogenation economically attractive (Resasco and Haller, 1994). With minor adaptations conventional commercial processes originally designed for hydrocarbon dehydrogenation of higher alkanes $\left(\mathrm{C}_{3}-\mathrm{C}_{5}\right)$ could also be applied for the dehydrogenation of propane. Propylene was first commercially produced by catalytic propane dehydrogenation in 1986 using the Houdry Catofin process. Several processes have now been commercialised for the catalytic propane dehydrogenation, viz. the Houdry Catofin, UOP Oleflex, Phillips STAR, BASF/Linde and the Samprogetti-Yarsintez processes. These processes differ mainly in the manner of heat supply for the endothermic dehydrogenation (adiabatic or non-adiabatic reactor conditions) and catalyst regeneration (continuous or periodic catalyst regeneration). Some typical process features, process data and reactor operating conditions for these processes have been summarised in Tables 2 and 3. 
Table 2. Process data for the Houdry Catofin, UOP Oleflex, Phillips STAR, BASF/Linde and Snamprogetti-Yarsintez processes for propane dehydrogenation

\begin{tabular}{|c|c|c|c|c|c|c|}
\hline & $\begin{array}{l}\text { Type of reactors } \\
\text { and catalyst regeneration }\end{array}$ & $\begin{array}{l}\text { Number } \\
\text { of } \\
\text { reactors }\end{array}$ & Type of catalyst & Energy source & $\begin{array}{l}\text { First operational } \\
\text { plant (Reported } \\
\text { conversion costs) }\end{array}$ & Selected references \\
\hline $\begin{array}{c}\text { Houdry } \\
\text { Catofin } \\
\text { (ABB Lumus } \\
\text { Crest Inc.) }\end{array}$ & $\begin{array}{l}\text { Parallel fixed bed reactors with } \\
\text { periodic in situ catalyst regeneration } \\
\text { (total cycle time: } 15-30 \text { min.; } \\
\text { dehydrogenation: } 30-50 \% \text {; } \\
\text { heating: } 25-30 \% \text {; } \\
\text { purge, reduction, losses: balance) }\end{array}$ & $3-8$ & $\begin{array}{l}\text { Chromium oxide } \\
\text { on alumina support } \\
\text { Lifetime: } 1.5-3 \text { yrs. }\end{array}$ & $\begin{array}{l}\text { Preheating of } \\
\text { catalyst with } \\
\text { hot air, } \\
\text { recuperative } \\
\text { heat exchanger }\end{array}$ & $\begin{array}{c}1986, \\
\text { PEMEX, Mexico } \\
(0.062 ; 0.068 ; 0.08)\end{array}$ & $\begin{array}{l}\text { Ercan and Gartside, } 1996 \\
\text { Gussow et al., } 1980 \\
\text { Meyers, } 1983 \\
\text { Meyers, } 1997 \\
\text { Eisele and Killpack, } 1993\end{array}$ \\
\hline $\begin{array}{c}\text { UOP } \\
\text { Oleflex }\end{array}$ & $\begin{array}{l}\text { Moving bed reactors in series } \\
\text { with continuous catalyst regeneration } \\
\text { (catalyst residence time in reactors } \\
\text { before regeneration: } 2-7 \text { days) }\end{array}$ & 4 & $\begin{array}{l}\text { Platinum on } \\
\text { alumina support } \\
\text { Lifetime: } \sim 5 \text { yrs. }\end{array}$ & $\begin{array}{l}\text { Feed and } \\
\text { interstage heaters, } \\
\text { recuperative } \\
\text { heat exchanger }\end{array}$ & $\begin{array}{l}1990 \\
\text { NPPC, Thailand } \\
(0.097)\end{array}$ & $\begin{array}{c}\text { Atkins and Evans, } 1993 \\
\text { Gregor, } 1993 \\
\text { Meyers, } 1983 \\
\text { Meyers, } 1997 \\
\text { Pujado and Vora, } 1983 \\
\text { Pujado and Vora, } 1990 \\
\text { Resasco and Haller, } 1994 \\
\text { Eisele and Killpack, } 1993 \\
\text { Vora et al., } 1983\end{array}$ \\
\hline $\begin{array}{l}\text { Phillips } \\
\text { STAR }\end{array}$ & $\begin{array}{l}\text { Parallel fixed bed tube reactors } \\
\text { in fire-box furnace with } \\
\text { periodic in situ catalyst regeneration } \\
\text { ( } \sim 7 \mathrm{~h} \text {. dehydrogenation; } \\
\sim 1 \mathrm{~h} \text {. regeneration) }\end{array}$ & $2-8$ & $\begin{array}{l}\text { Platinum on zinc- } \\
\text { aluminate support } \\
\text { Lifetime: } 1-2 \text { yrs. }\end{array}$ & $\begin{array}{l}\text { Fire-box furnace, } \\
\text { preheating by steam, } \\
\text { recuperative heat } \\
\text { exchanger }\end{array}$ & $(0.055)$ & $\begin{array}{l}\text { Dunn et al., } 1992 \\
\text { Meyers, 1983, } \\
\text { Meyers, 1997, } \\
\text { Eisele and Killpack, } 1993\end{array}$ \\
\hline BASF/Linde & $\begin{array}{l}\text { Parallel fixed bed tube reactors } \\
\text { in fire-box furnace with } \\
\text { periodic in situ catalyst regeneration } \\
\text { ( } \sim 9 \text { h. dehydrogenation; } \\
\sim 3 \text { h. regeneration) }\end{array}$ & 3,6 & $\begin{array}{l}\text { Chromium oxide } \\
\text { on alumina support }\end{array}$ & Fire-box furnace & $\begin{array}{l}1993 \\
\text { Staoil/Himont jv. } \\
\text { Belgium }\end{array}$ & $\begin{array}{l}\text { Bölt et al., } 1993 \\
\text { Baker et al., 1999a }\end{array}$ \\
\hline $\begin{array}{l}\text { Snamprogetti } \\
\text {-Yarsintez }\end{array}$ & $\begin{array}{l}\text { Interconnected fluidised bed reactors } \\
\text { with continuous catalyst regeneration } \\
\text { (catalyst residence time in } \\
\text { dehydrogenation fluid bed: } 5-30 \mathrm{~min} \text {.) }\end{array}$ & 2 & $\begin{array}{l}\text { Chromium oxide } \\
\text { on alumina support }\end{array}$ & $\begin{array}{l}\text { Burning fuel and } \\
\text { decoking in } \\
\text { regenerator, } \\
\text { recuperative heat } \\
\text { exchanger }\end{array}$ & - & $\begin{array}{l}\text { Sanfilippo, } 1993 \\
\text { Rodolfo et al., } 1999\end{array}$ \\
\hline
\end{tabular}


Table 3. Reported operating conditions, conversion and selectivities for the Houdry Catofin, UOP Oleflex, Phillips STAR, BASF/Linde and Snamprogetti-Yarsintez processes for propane dehydrogenation.

\begin{tabular}{|c|c|c|c|c|c|}
\hline & Feed type & Temperature $\left[{ }^{\circ} \mathrm{C}\right]$ & $\begin{array}{c}\text { Total } \\
\text { pressure [atm] }\end{array}$ & Conversion $[w t \%]$ & Selectivity [mole\%] \\
\hline $\begin{array}{c}\text { Houdry } \\
\text { Catofin } \\
\text { (ABB Lumus } \\
\text { Crest Inc.) }\end{array}$ & $\begin{array}{l}\text { Undiluted propane } \\
\left(\sim 95 \mathrm{wt} \% \mathrm{C}_{3},\right. \\
\left.4 \mathrm{wt} \% \mathrm{iC}_{4}\right)\end{array}$ & $\begin{array}{l}525-675 \\
550-650\end{array}$ & $\begin{array}{c}0.13-0.66 \\
0.17-1.0 \\
0.50\end{array}$ & $\sim 68$ & $\begin{array}{l}\text { propylene: } 73,80 \\
\text { coke: } 0.5-1 \mathrm{wt} \%\end{array}$ \\
\hline $\begin{array}{l}\text { UOP } \\
\text { Oleflex }\end{array}$ & $\begin{array}{l}\text { Propane diluted } \\
\text { with hydrogen }\end{array}$ & $600-625$ & $\geq 1$ & $\sim 48$ & $\begin{array}{l}\text { propylene: } 89,90,89-91 \\
\text { coke: } \leq 0.01, \sim 0.02 \mathrm{wt} \%\end{array}$ \\
\hline $\begin{array}{l}\text { Phillips } \\
\text { STAR }\end{array}$ & $\begin{array}{l}\text { Propane diluted } \\
\text { with steam } \\
\text { (3-30 moles steam/ } \\
\text { mole feed) }\end{array}$ & $\begin{array}{c}480-620 \\
(\sim \text { isothermal })\end{array}$ & $\geq 1$ & $30-40$ & $80-90,84-88$ \\
\hline BASF/Linde & $\begin{array}{c}\text { Propane diluted } \\
\text { with hydrogen } \\
\text { (On-stream times: } \\
6-8 \mathrm{hr} \text {.) }\end{array}$ & ( isothermal) & $\geq 1$ & $\sim 30$ & 90,91 \\
\hline $\begin{array}{l}\text { Snamprogetti- } \\
\text { Yarsintez }\end{array}$ & & $\begin{array}{c}565-590 \\
\text { (temperature } \\
\text { increase in fluid } \\
\text { bed } \sim 20 \mathrm{~K} \text { ) }\end{array}$ & $1.2-1.5$ & $\sim 89$ & \\
\hline
\end{tabular}


Research and innovations for new propane dehydrogenation processes have, not surprisingly, centred on perturbing the equilibrium conversion by removal of the hydrogen, either via a catalytic membrane permselective for hydrogen (e.g. Reo et al., 1997; Zaika et al., 1993a, $1993 b)$ or via oxidation of the hydrogen to water by oxidative propane dehydrogenation (e.g. Cavani and Trifirò, 1995; Wan et al., 1999). Especially the low product of hydrogen permeability and separation factor and the high cost of the membranes and problems with sintering and deactivation by coke formation have prevented commercialisation of catalytic membrane reactors for propane dehydrogenation up until now. For the oxidative propane dehydrogenation further improvements on the catalyst's propylene (or olefin) selectivity (at high propane conversions) are required to make this process economically feasible.

In the Reaction Coupling Reverse Flow Reactor higher propane conversions are achieved by operation at higher reactor temperatures $\left(675-725^{\circ} \mathrm{C}\right)$ for undiluted propane feeds at atmospheric pressure. For pure propane feed at atmospheric pressure the equilibrium propane conversion increases from $67 \%$ at $650{ }^{\circ} \mathrm{C}$ to $90 \%$ at $750{ }^{\circ} \mathrm{C}$. At even higher temperatures the equilibrium propane conversion increases only very gradually. Although the increase in the propane conversion $(75-90 \%)$ is somewhat counterbalanced by a decrease in the propylene selectivity ( $\mathrm{ca} .70 \%)$ at these high operating temperatures, still relatively high propylene yields can be achieved (50-60\%) (see Figure 3), compared to $53-60 \%$ for the Houdry Catofin, $43 \%$ for the UOP Oleflex, $24-36 \%$ for the Phillips STAR and about $27 \%$ for the BASF/Linde processes. The optimal temperatures for the RCRFR are somewhat higher than the optimal temperatures for the Houdry Catofin process because of the higher reactor pressure in the RCRFR.

By using higher reactor temperatures also the coke formation rates are increased. The increase in the coke selectivities is, however, somewhat compensated for by smaller cycle times for the RCRFR, which also greatly facilitates the combustion of the coke (see Appendix C, Chapter 7). In the RCRFR the energy released by the combustion of the coke can very efficiently be used for the propane dehydrogenation, reducing the amounts of fuels required during the combustion/regeneration via decreasing the ratio of exothermic to endothermic cycle times. Furthermore, in the RCRFR the most important gas phase hydrocarbon byproducts are ethylene and methane. Higher temperatures at the surface of the (de)hydrogenation catalyst favours ethane dehydrogenation over ethylene hydrogenation, assuring higher olefin selectivities. To exemplify, the ethane dehydrogenation equilibrium 
conversion for a pure ethane feed at atmospheric pressure is doubled from $29 \%$ at $650{ }^{\circ} \mathrm{C}$ to $60 \%$ at $750{ }^{\circ} \mathrm{C}$.

The RCRFR process largely resembles the Houdry Catofin process, however, without heat exchange equipment in the reactor section (except for a small start-up heater and a cooler for protection of downstream valves) thanks to the incorporation of recuperative heat exchange in the reactor by periodic flow reversals. Also, the purge cycle with nitrogen can be omitted due to the reverse flow concept and the use of a monolithic catalyst. In Figure 7 a process scheme of the conventional Houdry Catofin process is depicted, where the equipment superfluous for the RCRFR process has been indicated.

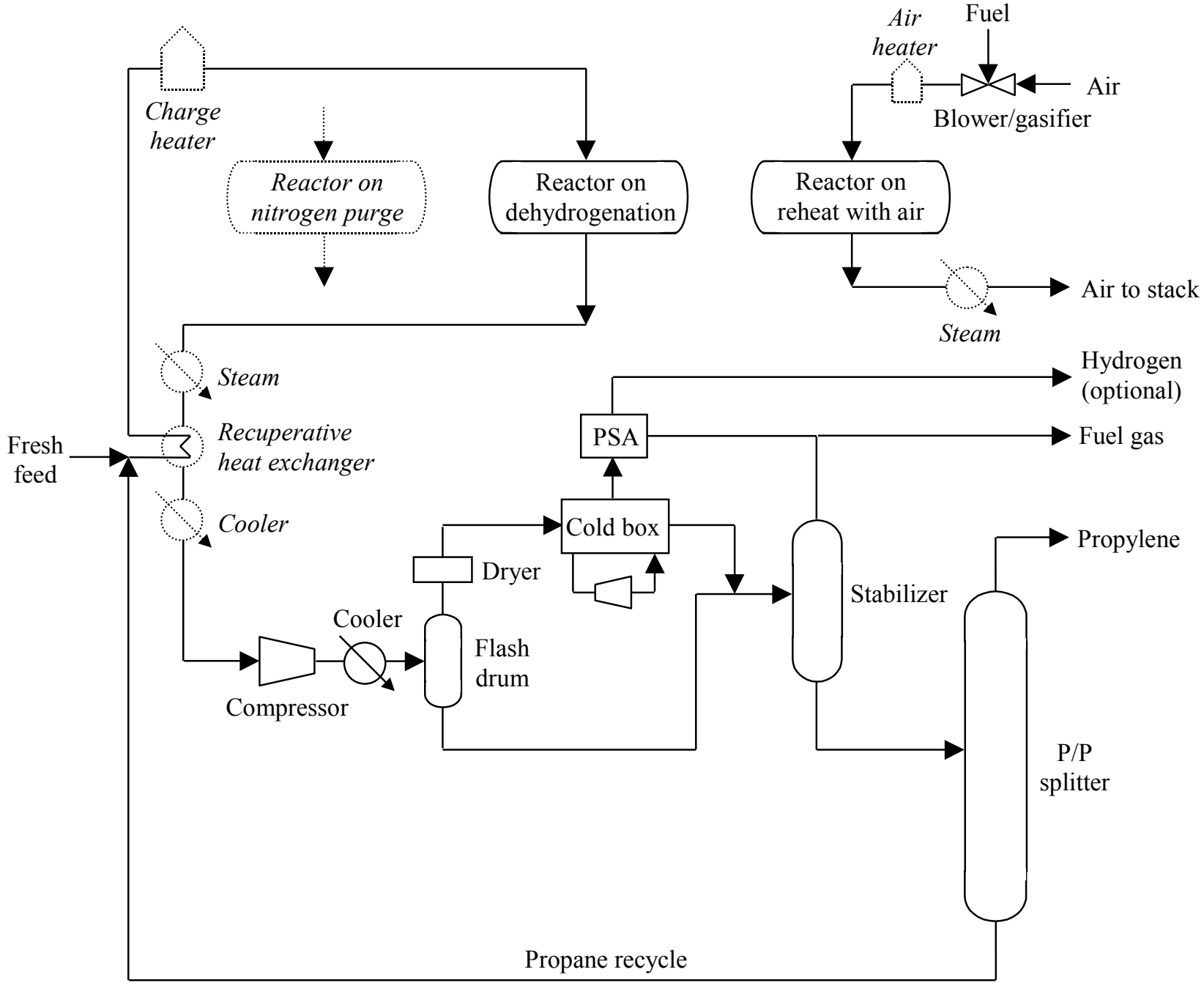

Figure 7. Process scheme for the Houdry Catofin process (adapted from Meyers, 1983). Equipment with dashed lines has become superfluous for the RCRFR process. 
Next to large savings on investments in expensive high temperature heat exchange equipment, also savings on investments and operating costs in the separation units might be achieved. Firstly, the RCRFR operates at about atmospheric conditions as opossed to the Houdry Catofin process which operates at slightly sub-atmospheric pressure (about $51 \mathrm{kPa}$; Ercan and Gartside, 1996), resulting in lower compression costs for the RCRFR-process. Secondly, the higher propane conversion in the RCRFR process strongly reduces the propane recycle, so that the flow rates through the reactor and separation units are reduced, enabling further savings on investments and operating costs. Optionally, an even higher propane conversion can be aimed for in order to produce chemical grade propylene (92-94\% propylene) without the need for a $\mathrm{P} / \mathrm{P}$ splitter and a propane recycle, obviously at the expensive of a somewhat lower propylene selectivity.

Moreover, the number of reactors put in parallel in the RCRFR-process depends primarily on the ratio of the endothermic and exothermic cycle times in order to achieve a constant propylene production rate, just like the Houdry Catofin process. The length of the RCRFRreactors strongly depends on the gas velocities and cycle times of both the endothermic and exothermic reaction phases. The length of the RCRFR-reactors will probably be longer than the length of the reactors in the Houdry Catofin process (at the same gas velocity), since recuperative heat exchange is integrated inside the reactor and the RCRFR-reactors accommodate two reaction zones, one for each flow direction. However, due to the increased production capacity per reactor volume thanks to higher operating pressures and temperatures, the length of a single reaction zone in the RCRFR-reactor is significantly smaller. With a monolithic catalyst very high intrinsic catalyst activities can be achieved without internal or external mass transfer limitations assuring high catalyst efficiency factors and maximal propylene selectivity. Furthermore, in a monolithic catalyst high throughputs can be realised with negligible pressure drop. Also, the construction of the monolithic RCRFR-reactors is relatively simple (ease of scale-up) and the reactors can be positioned horizontally, possibly facilitating catalyst replacement.

The major drawbacks of the RCRFR-process are the more complex reactor behaviour (process control) and the probable larger product losses due to the smaller cycle times despite the lower axial dispersion in the monoliths. 


\section{Conclusions}

Based on the derived kinetics of the propane dehydrogenation - propylene hydrogenation over a monolithic $\mathrm{Pt} / \gamma-\mathrm{Al}_{2} \mathrm{O}_{3}$ catalyst and their most important side reactions including coke formation, it was determined using Pontryagin's maximisation principle that the propylene yield is optimal $(50-60 \%)$ at high reactor temperatures $\left(675-725^{\circ} \mathrm{C}\right)$ for undiluted propane feeds at atmospheric pressure - with high propane conversion $(75-90 \%)$ and relatively low propylene selectivity ( $c$ a. 70\%) - and short cycle times. The RCRFR is very well suited for these 'high intensity' operating conditions.

Especially the integration of recuperative heat exchange by the reverse flow concept makes the RCRFR economically attractive because of possible large savings on investments in expensive high-temperature heat exchange equipment compared to the Houdry Catofin process. Furthermore, the relatively high propane conversion (even for pure propane feed at atmospheric pressure) can be exploited to decrease investments and operating costs for the gas separation units by the strong decrease of the propane recycle flow rate, however, at the expense of a lower propylene selectivity (but high ethylene to ethane selectivity). Although the economic potential of the RCRFR-process looks promising, its true technical and economic feasibility still remains to be proven. Further research is necessary to better assess the economic potential of the RCRFR-process.

Firstly, with extensive, detailed numerical simulations including coke formation and coke combustion the design of the RCRFR and the operating conditions of both reaction phases should be optimised, especially with respect to maximal propylene production capacity per unit reactor volume and reaction coupling energy efficiency. Special attention should be paid to the influence of coke formation and coke combustion on the reactor behaviour and the optimal process conditions. For example, can coke accumulation problems indeed be solved by choosing the proper operating conditions and switching schemes? Furthermore, what are the optimal methane, propane (or different fuels like LPG?) and oxygen inlet concentrations (as a function of time?) during the combustion/regeneration cycle, and what are the optimal platinum loadings, or catalyst properties in general, of the less active and active catalysts sections? Furthermore, in the optimisation of the cycle times the propylene losses due to switching - completely ignored in this work - should be quantified, which entails an 
economic optimisation between higher propylene yields but also higher propylene losses for smaller propane dehydrogenation cycle times. Moreover, in the optimisation of the reactor the whole process including the gas separation units need to be considered, where even different possibilities for the separation units and product specifications need to be evaluated.

Secondly, the catalyst properties should be optimised. Benefits of a monolithic catalyst have been discussed before, but the optimisation of the properties of the monolithic catalyst has been left entirely out of consideration in this work, despite its important influence on the reactor performance. Obviously, the concentration and type of active components and promotors, but also the type (acidity) and thickness of the washcoat need to be optimised for optimal use of the expensive catalyst (an overall efficiency factor just below 1 for the propane dehydrogenation) and for maximal propylene selectivity and minimal coke selectivity. Also the volumetric heat capacity of the support (channel diameter, support thickness, support material etc.) should be maximised in order to maximise the ratio of the cycle times to the gas residence time. Special attention should be paid to the long-term stability of the catalyst, especially in view of the high temperatures (sintering and platinum (dispersion) losses), temperature gradients (thermal stresses) and frequent alternations between reductive conditions (coke formation) and oxidative conditions (coke combustion), and the influence of small impurities in the feed on the catalyst performance. Since the catalyst is operated at forced unsteady state conditions at the catalyst surface, the catalyst properties should be optimised for these 'initial' conditions.

Finally and most importantly, it should be demonstrated in an experimental set-up that indeed high propane conversion and propylene (or olefin) yield can be achieved in the RCRFR with high energy efficiency without problems of coke accumulation for long times on stream. Obviously, due to the requirement of adiabaticity the scale of this reactor (especially with respect to the volumetric flow rates) is necessarily large.

\section{Acknowledgements}

The author wishes to thank E.J. Bergsma for his contribution to the economic evaluation of the processes and the Netherlands Organization for Scientific Research (N.W.O.) for their financial support. 


\section{Notation}

f functions describing the process in terms of process variables $\mathbf{x}$ (see Table 1)

$F \quad$ function integrated over reactor length to be optimised (see Table 1)

$H \quad$ Hamilton function

$\Delta h \quad$ reaction enthalpy $\left[\mathrm{J}_{\mathrm{kg}}{ }^{-1}\right]$

$k_{C P} \quad$ reaction rate constant of coke precursor formation (see Chapter 5) $\left[\mathrm{s}^{-1}\right]$

$k_{R} \quad$ reaction rate constant of propylene dimer formation (see Chapter 5 ) $\left[\mathrm{s}^{-1}\right]$

$L \quad$ reactor length [m]

$M \quad$ average molecular mass $\left[\mathrm{kg} \cdot \mathrm{mol}^{-1}\right]$

$m_{C} \quad$ coke content $\left[\mathrm{kg}_{\mathrm{C}} \cdot \mathrm{m}^{-3}\right]$

$\dot{m}_{C} \quad$ coke formation rate $\left[\mathrm{kg}_{\mathrm{C}} \cdot \mathrm{m}^{-3} \cdot \mathrm{s}^{-1}\right]$

$n_{c} \quad$ number of components

$n_{r} \quad$ number of reactions

p vector with adjungated functions (see Table 1)

$P \quad$ total pressure [atm]

$r_{i} \quad$ reaction rate of component $i\left[\mathrm{~kg} \cdot \mathrm{m}^{-3} \cdot \mathrm{s}^{-1}\right]$

$R_{j} \quad$ reaction rate of reaction $j\left[\right.$ mole $\cdot \mathrm{m}^{-3} \cdot \mathrm{s}^{-1}$ ]

$S \quad$ function to be optimised (see Table 1)

$t \quad$ time [s]

$\mathrm{T}$ temperature $\left[\mathrm{K},{ }^{\circ} \mathrm{C}\right]$

$\Delta t \quad$ cycle time $[\mathrm{s}]$

$w \quad$ monolayer coke concentration $\left[\mathrm{kg}_{\mathrm{C}} \cdot \mathrm{kg}_{\mathrm{cat}}{ }^{-1}\right]$

$\mathbf{x} \quad$ vector with process variables (see Table 1)

$x_{i, g} \quad$ gas phase mole fraction of component $i\left[\right.$ mole $\left.\cdot \mathrm{mole}^{-1}\right]$

$z \quad$ axial coordinate [m]

\section{Greek symbols}

$\varepsilon \quad$ monolith porosity $\left[\mathrm{m}^{3} \cdot \mathrm{m}^{-3}\right]$

$\zeta \quad$ conversion $\left[\mathrm{kg} \cdot \mathrm{kg}^{-1}\right]$

$\eta \quad$ yield $\left[\mathrm{kg} \cdot \mathrm{kg}^{-1}\right]$

$\theta_{i} \quad$ surface fraction of component $i[-]$ 


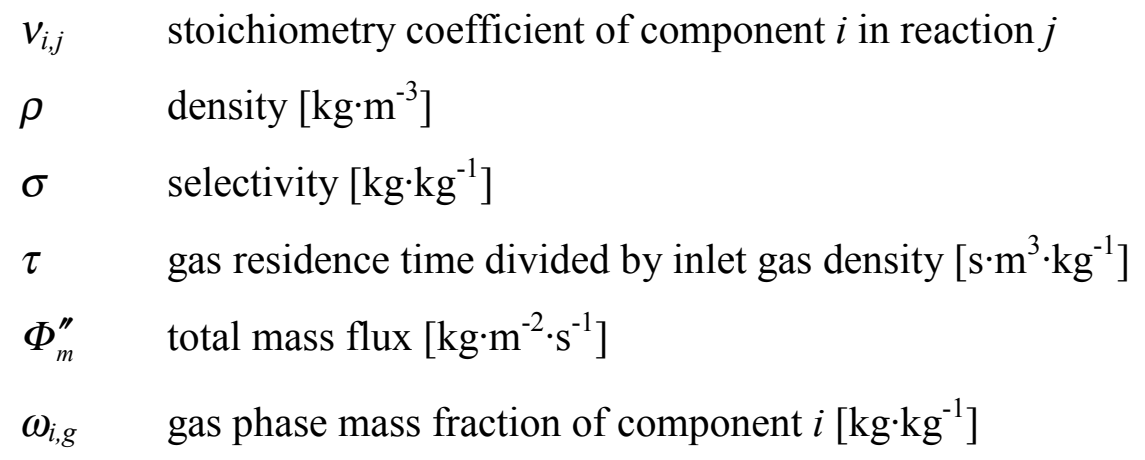

\section{Subscripts}

C coke, coke formation

end at the end of the cycle

$g \quad$ gas phase

in at the inlet

max maximum

out at the outlet

$P D$ propane dehydrogenation

$0 \quad$ at initial conditions (i.e. fresh catalyst)

\section{Superscripts}

endo endothermic cycle

\section{References}

Atkins, M.P. and Evans, G.R. (1993). Catalytic dehydrogenation: A review of current processes and innovations, presented at the DGMK-conference on Selective hydrogenations and dehydrogenations, November 11-12, 1993, Kassel, Germany, 200-210

Baker, J. (Ed.) (1999a). Linde set to license C3/C4 dehydrogenation process. European Chemical News, March 1992, 19

Baker, J. (Ed.) (1999b). Propylene. European Chemical News, July 1999, 18-19 
Bölt, H., Zimmerman, H. (1993). Dehydrogenation process for propane and isobutane, presented at the DGMK-conference on Selective hydrogenations and dehydrogenations, November 11-12, 1993, Kassel, Germany, 175-187

Cavani, F. and Trifirò, F. (1995). The oxidative dehydrogenation of ethane and propane as an alternative way for the production of light olefins. Catalysis Today, 24, 307-313

Cosyns, J., Chodorge, J., Commereuc, D. and Torck, B. (1998). Maximize propylene production. Hydrocarbon Processing, March 1998, 61-66

Dunn, R.O. and Shoemaker, L.W. (1992). The Phillips steam active reforming (STAR) process for the dehydrogenation of $\mathrm{C}_{3}, \mathrm{C}_{4}$ and $\mathrm{C}_{5}$ paraffins, presented at the Refining, $\mathrm{LNG}$ and PetrochemAsia 1992, Technology Conference and Exhibition, Singapore, December 1-4, 1992

Eisele, P. and Killpack, R. (1993) Ullmann's Encyclopedia of industrial chemistry, fifth completely revised ed., Vol. A22, Eds. Elvers, Hawkins, Russey and Schulz, VCH Verlagsgesellschaft mbH, Weinheim, Germany, 211-271

Ercan, C. and Gartside, R.J. (1996). Reactor performance and stability in an alternating reaction-reheat paraffin dehydrogenation system. Can. J. Chem. Engng, 75, 626-637

Gregor, J.H., Zimmerman, J.E. and Cottrell, P.R. (1993). The Oleflex process: evolution, commercialisation and optimization of a dehydrogenation technology, presented at the DGMK-conference on Selective hydrogenations and dehydrogenations, November 11-12, 1993, Kassel, Germany, 189-200

Gussow, S., Spence, D.C. and White, E. A. (1980). Dehydrogenation links LPG to more octanes, Oil and Gas J., Dec. 1980, 96-101

Meyers, R.A. (1983). Handbook of petroleum refining processes, first edition, McGraw-Hill Inc., USA 
Meyers, R.A. (1997). Handbook of petroleum refining processes, second edition, McGrawHill Inc., USA

Pujado, P.R. and Vora, B.V. (1983). Production of LPG olefins and derivatives. UOP Process Division Technology Seminar 1983, UOP inc., Des Plaines, Illinois, USA

Pujado, P.R. and Vora, B.V. (1990). Make $\mathrm{C}_{3}-\mathrm{C}_{4}$ olefins selectively. Hydrocarbon Processing, March 1990, 65-70

Reo, C.M., Bernstein, L.A. and Lund, C.R.F. (1997). Cocurrent membrane reactors vs. PFRs for shifting dehydrogenation equilibrium. AIChE J., 43, 495-504

Resasco, D.E. and Haller, G.L. (1994). Catalytic dehydrogenation of lower alkanes. J. Catal., $11,379-411$

Rodolfo, L., Bartolini, A., Buonomo, F., Kotelnikov, G.Y. and Bespalov, V.Y. (1999). Process for obtaining light olefins by the dehydrogenation of the corresponding paraffins. European Patent no. 0894781 A1

Sanfilippo, D. (1993). Dehydrogenation in a fluidized bed: an east-west collaboration. Chemtech August 1993, 35-39

Stitt, E.H., Jackson, S.D., Ahern, J. and King, F. (1999). Modelling for design of a deactivating non-isothermal propane dehydrogenation reactor. In Delmon, B. and Froment, G.F. (Eds). Catalyst Deactivation 1999, 137-144

Taffe, P. (1996) Propping up the propylene supply. Eur. Chem. News, 21-27 October, 27-28

Vora, B.V., Berg, R.C., Pujado, P.R. (1983). UOP Oleflex process for LPG-Paraffin dehydrogenation, UOP Process Division Technology Seminar 1983, UOP inc., Des Plaines, Illinois, USA 
Wan, H.L., Zhou, X.P., Weng, W.Z., Long, R.Q., Chao, Z.S., Zhang, W.D., Chen, M.S., Luo, J.Z. and Zhou, S.Q. (1999). Catalytic performance, structure, surface properties and active oxygen species of the fluoride-containing rate earth (alkaline earth)-based catalysts for the oxidative coupling of methane and oxidative dehydrogenation of light alkanes. Catalysis Today, 51, 161-175

Zaika, Z.D., Minet, R.G., Tsotsis, T.T. (1993a). A high temperature catalytic membrane reactor for propane dehydrogenation, J. membrane science, 77, 221-232

Zaika, Z.D., Minet, R.G., Tsotsis, T.T. (1993b). Propane dehydrogenation in a packed-bed membrane reactor, AIChE J., 39, 526-529 


\section{Dankwoord (Acknowledgements)}

Aan de totstandkoming van dit proefschrift hebben velen een belangrijke bijdrage geleverd en $\mathrm{ik}$ wil hen dan ook allen bedanken voor hun inzet. Een aantal presonen wil ik in het bijzonder bedanken voor hun bijdrage.

Allereerst wil mijn promotoren Hans Kuipers en Wim van Swaaij bedanken voor de mogelijkheid die zij mij hebben geboden om het in dit proefschrift beschreven onderzoek uit te voeren. Met name het grote vertrouwen dat zij in mij hebben gesteld om het onderzoek met grote vrijheid naar eigen inzicht in te vullen en uit te voeren, heb ik zeer gewaardeerd. Hierbij fungeerde Hans niet alleen als onmisbaar wetenschappelijk klankboord, maar vooral ook als een goede coach die op de juiste momenten het onderzoek een zet in de juiste richting wist te geven. Zijn efficiënte, doelgerichte en systematische werkwijze en zijn open en directe communicatie zijn een voorbeeld voor mij en hebben sterk bijgedragen aan de plezierige en stimulerende samenwerking. Wim, die het onderzoek op wat grotere afstand volgde, wil ik bedanken voor zijn oprechte interesse en aanstekelijke enthousiasme bij het ontwikkelen van nieuwe reactorconcepten. Daarnaast wil ik referent Maarten van der Burgt en de overige leden van de promotie-commissie bedanken. De Nederlandse Organisatie voor Wetenschappelijk Onderzoek (NWO) ben ik erkentelijk voor de beschikbaar gestelde financiële middelen voor dit onderzoek.

Acht studenten hebben in het kader van hun afstudeeropdracht een zeer belangrijke bijdrage geleverd aan dit promotie-onderzoek. Roelf Drijfholt bestudeerde de mogelijke gevolgen van het schakelen van propaan naar lucht als voeding aan de reactor. In zijn 'explosie-reactor' heeft gelukkig geen enkele explosie plaatsgevonden. Herman Bottenberg heeft een goed begin gemaakt van de bestudering van de invloed van schakelschema's en procesparameters op de axiale temperatuurprofielen in de reactor (zoals bijvoorbeeld de 'scheve temperatuurplateau's). Zijn opvolger Harold Scholts heeft dit verder uitgebreid met de bestudering van verschillende reactor-configuraties en de noodzakelijke modificaties om het reactorconcept geschikt te maken voor evenwichtsreacties. Wouter Vos en zijn opvolger Remco de Boer hebben de experimenten uitgevoerd waarmee de kinetiek van de propaandehydrogenering onderzocht is en Heleen bij de Vaate de experimenten waarmee de kinetiek van de cokesvorming tijdens de propaandehydrogenering bestudeerd is. Robert Nijssen heeft de experimenten in de 'echte' reverse flow reactor uitgevoerd, waarmee het principe van het 
reactorconcept experimenteel is aangetoond. Bertus Bergsma voerde een inventarisatie uit van de economische mogelijkheden van het reactorconcept. Ik wil hen allen hartelijk bedanken voor het vele werk dat zij hebben verzet, wat zijn weerslag heeft gevonden in de dikte van dit proefschrift, en ook voor de prettige en goede samenwerking waardoor we als een team aan dit promotie-onderzoek gewerkt hebben. Dit heeft de periode van mijn promotie-onderzoek tot een zeer leuke en gezellige tijd gemaakt.

Al het experimentele werk had niet uitgevoerd kunnen worden zonder technische ondersteuning van met name Henk-Jan Moed en Robert Meijer. Hun technische creativiteit en praktijkervaringen brachten zij in bij het ontwerp van de reactoren en was van doorslaggevend belang voor het welslagen van het experimentele onderzoek. Henk-Jan Moed heeft de opstellingen van de kinetiek-reactor en de reverse flow reactor zeer vakkundig en snel gemaakt. Robert Meijer zorgde adequaat voor de procesbesturing en procesregeling van de opstellingen en de on-line data-acquisitie systemen. Daarnaast wil ik Wim Leppink hartelijk bedanken voor het vervaardigen en onderhouden van de TGA-opstelling, alsmede Benno Knaken en Gerrit Schorfhaar, die altijd bereid waren te helpen bij de wat kleinere hand-enspan diensten.

Bert Kamp ben ik veel dank verschuldigd voor het bijna compleet reviseren en aanpassen van de GC. Ook kapotte IR's en ander electrische apparatuur werden altijd snel en goed gerepareerd. Harry Olde Veldhuis wil ik bedanken voor het ombouwen van de vele MFC's die binnen mijn project gebruikt zijn en Benny Hövels voor de aan- en afvoer van de vele gascylinders. Voor ondersteuning bij computer en netwerk-problemen kon ik altijd terecht bij Jan Heezen en Joachim Olde Bolhaar. De bestelling van gewenste artikelen werd verzorgd door Wim Platvoet, Nelly Vos en Jan Jagt.

De administratieve ondersteuning was in goede handen van Gery Stratingh, Nicole Haitjema, Ria Stegehuis-de Vegte, Brigitte Sanderink en Ria Hofs-Winkelman, terwijl Rik Akse zorgde voor een keurige afhandeling van de financiële aspecten van het onderzoek. Medewerkers, studenten en promovendi die tijdens mijn promotie-onderzoek in het Vlugterlaboratorium werkzaam waren, wil ik hartelijk bedanken voor de gezellige tijd en prettige werksfeer. Ook wil ik mijn paranimfen, mijn broer Peter van Sint Annaland en collega Wim Brilman, bedanken voor hun inzet en enthousiasme. 
Tenslotte, wil ik mijn ouders bedanken, die altijd voor mij klaar stonden, mij onvoorwaardelijk steunden en mij in mijn studie stimuleerden. Zo kon ik voor softwarevraagstukken altijd bij mijn vader aankloppen en voor meer huishoudelijke vraagstukken bij mijn moeder.

Bedankt allemaal!

Martin. 


\section{Levensloop}

Martin van Sint Annaland werd geboren op 2 juni 1971 in Apeldoorn, waar hij ook de openbare lagere school bezocht. In 1989 behaalde hij het VWO diploma aan het Stedelijk Gymnasium te Apeldoorn.

In september 1989 begon hij met de studie Chemische Technologie aan de Universiteit Twente te Enschede. In het kader van deze ingenieursopleiding liep hij van augustus tot oktober 1993 stage bij een raffinaderij van Shell in Clyde, gelegen in Sydney, Australië. In september 1994 studeerde hij cum laude af bij de vakgroep Proceskunde op de modellering van de hydrodynamica van circulerende fluïd bedden middels een twee-dimensionaal TwoFluid model met de kinetische theorie voor granulaire stroming.

$\mathrm{Na}$ het behalen van het ingenieursdiploma startte hij in oktober 1994 met de Ontwerpersopleiding Procestechnologie van de Universiteit Twente in samenwerking met de Rijksuniversiteit Groningen. De jaaropdracht van deze opleiding is uitgevoerd bij TNO in Apeldoorn op de zuivering van gasstromen die verontreinigd zijn met organische componenten in zeer lage concentraties middels fotokatalytische oxidatie.

In augustus 1996 begon hij als promovendus (OIO) via N.W.O. een promotie-onderzoek bij de vakgroep Proceskunde naar het ontwikkelen van een nieuw reactorconcept, waarbij de reactiewarmte van endotherme en exotherme reacties indirect gekoppeld wordt met gelijktijdige periodieke omkering van de gasstromingsrichting. De resultaten van dit onderzoek zijn in dit proefschrift beschreven.

In februari 2000 trad hij in dienst als Universitair Docent bij werkeenheid PK-FAP (Fundamentele Aspecten van de Proceskunde) van de faculteit Chemische Technologie van de Universiteit Twente. 


\section{STELLINGEN}

behorende bij het proefschrift

\section{A NOVEL REVERSE FLOW REACTOR COUPLING ENDOTHERMIC AND EXOTHERMIC REACTIONS}

van M. van Sint Annaland

oktober 2000

1. Koppeling van de reactie-enthalpiën van endotherme en exotherme reacties met geïntegreerde recuperatieve warmtewisseling via periodieke omkering van de stromingsrichting door een gepakt bed waarbij de temperatuur een maximum waarde niet mag overschrijden, kan het meest efficiënt worden uitgevoerd in de sequentiële reactorconfiguratie mits een geschikt schakelschema gekozen wordt.

(Dit proefschrift)

2. De maximum temperatuur in een reverse flow reactor waarbij de reactanten van de exotherme reactiefase volgens een eerste orde kinetiek worden omgezet, wordt bepaald door een enkel dimensieloos kental.

(Dit proefschrift)

3. Initieel neemt de cokesvormingssnelheid uit propeen op een $\gamma-\mathrm{Al}_{2} \mathrm{O}_{3}$ oppervlak lineair toe met de tijd, wat duidt op een autokatalytische reactie.

(Dit proefschrift)

4. CFD (Computational Fluid Dynamics) is niet geschikt voor ongeduldige mensen, aangezien - in tegenstelling tot wat men zou verwachten - de rekentijd niet zal afnemen met de komst van krachtigere computers.

5. De meeste wetenschappers rekenen ten onrechte de beweegredenen voor hun onderzoek niet tot hun wetenschappelijk onderzoek.

6. Door alleen tweede-geldstroom onderzoeksprojecten met een aanzienlijke financiële premie te belonen blijkt dat de 'ondernemende' Universiteit Twente een hogere prioriteit geeft aan onderzoek dat (indirect) door de overheid gefinancieerd wordt dan aan onderzoek dat mede door het bedrijfsleven gefinancieerd wordt.

7. Een doeltreffende maatregel om een onderdeel van een organisatie weg te 'saneren' is het invoeren van een intern verrekeningsmodel van de kosten.

8. Hoewel de IT-sector claimt het file-probleem te kunnen verminderen middels flexibele werktijden of tele-werken, bewerkstelligt zij echter tot dusver juist het tegenovergestelde door het werven van nieuw personeel met een 'auto van de zaak'. 